\title{
Auf dem Weg nach Europa
}

Deutungen, Visionen, Wirklichkeiten

Herausgegeben von Irene Dingel und Matthias Schnettger

\section{Vandenhoeck $\&$ Ruprecht}
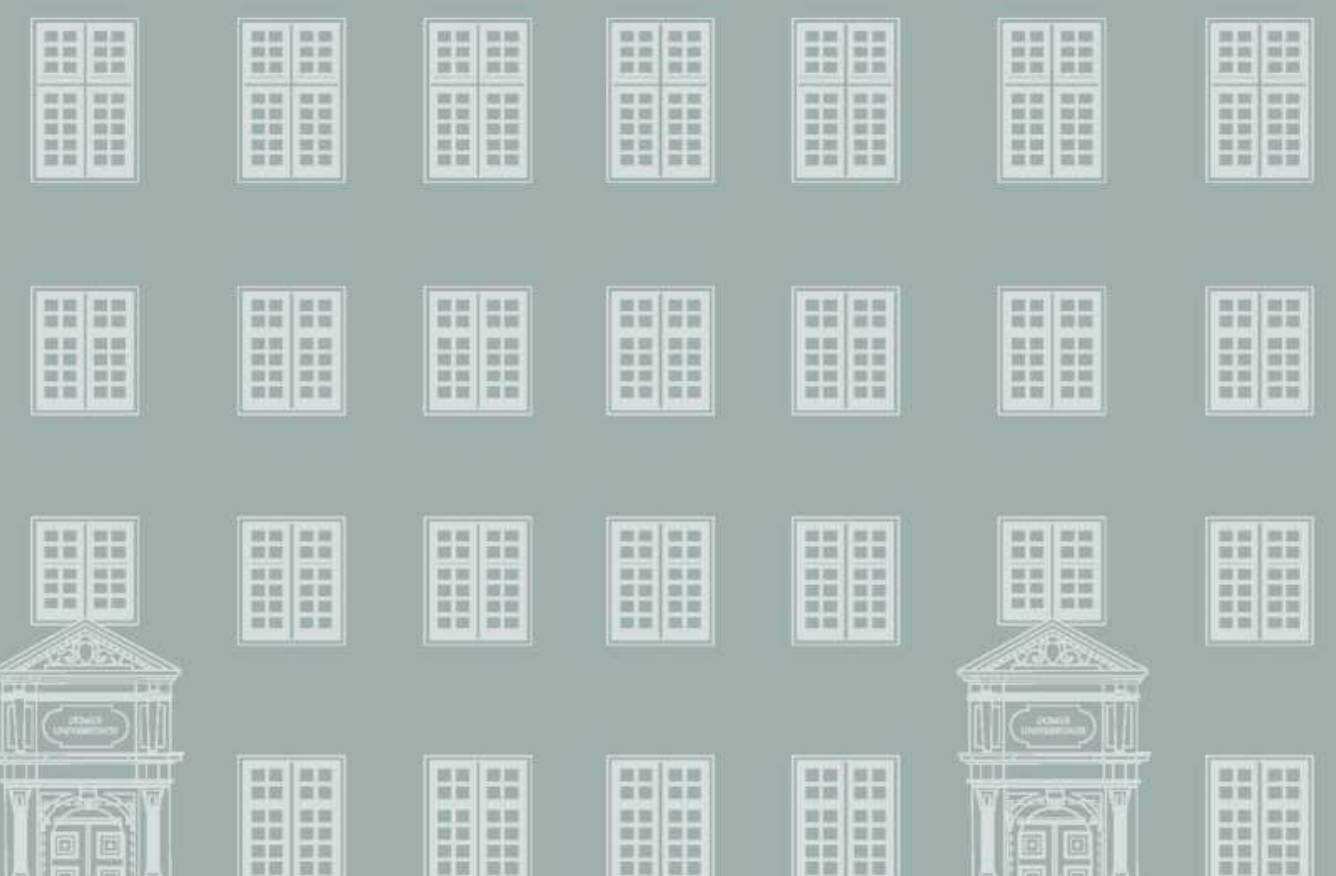


\section{V\&R}




\title{
Veröffentlichungen des Instituts für Europäische Geschichte Mainz
}

\author{
Abteilung für Abendländische Religionsgeschichte \\ Abteilung für Universalgeschichte \\ Herausgegeben von Irene Dingel und Heinz Duchhardt
}

Beiheft 82

Vandenhoeck \& Ruprecht 


\title{
Auf dem Weg nach Europa
}

\section{Deutungen, Visionen, Wirklichkeiten}

\author{
Herausgegeben von \\ Irene Dingel und Matthias Schnettger
}

Vandenhoeck \& Ruprecht 
Mit 15 Abbildungen

Bibliografische Information der Deutschen Nationalbibliothek: Die Deutsche Nationalbibliothek verzeichnet diese Publikation in der Deutschen Nationalbibliografie; detaillierte bibliografische Daten sind im Internet über https://dnb.de abrufbar.

(C) 2010, Vandenhoeck \& Ruprecht GmbH \& Co. KG, Theaterstraße 13, D-37073 Göttingen

Das Werk und seine Teile sind urheberrechtlich geschützt.

Die Beiträge sind als Open-Access-Publikation im Sinne der Creative-Commons-Linzenz BY-NC-ND International 4.0 (»Namensnennung - Nicht kommerziell - Keine Bearbeitung «) unter dem DOI 10.13109/9783666100956 abzurufen. Um eine Kopie dieser Lizenz zu sehen, besuchen Sie https://creativecommons.org/licenses/by-nc-nd/4.0/. Jede Verwendung in anderen als den durch diese Lizenz erlaubten Fällen bedarf der vorherigen schriftlichen Zustimmung des Verlages.

Satz und Redaktion: Vanessa Brabsche

Vandenhoeck \& Ruprecht Verlage | www.vandenhoeck-ruprecht-verlage.com

ISSN 2197-1056

ISBN 978-3-666-10095-6 


\section{Inhalt}

Vorwort

Statt einer Laudatio:

Matthias Schnettger

Auf dem Weg nach Europa?

Deutsche Historiker der 1940er Jahrgänge

Johannes Arndt

Die europäische Medienlandschaft im Barockzeitalter

Wolfgang Harms

Europa in der deutschen Bildpublizistik der Frühen Neuzeit

Martin Wrede

Der Kontinent der Erbfeinde. Deutsche und europäische Feindbilder der Frühen Neuzeit zwischen Säkularisierung und Sakralität

Joachim Berger

Herkules - Held zwischen Tugend und Hybris.

Ein europäischer Erinnerungsort der Frühen Neuzeit

Elisabeth Oy-Marra

Der Papst als neuer Aeneas. Rom als >caput mundi< und die

Herrschaftsansprüche der Päpste in der Frühen Neuzeit

Ivan Parvev

»Krieg der Welten« oder »Balance of Power«.

Europa und die Osmanen, 1300-1856

Ronald G. Asch

Der Adel Großbritanniens und Irlands zwischen insularer Isolation und europäischem Kosmopolitismus im späten

16. und frühen 17. Jahrhundert

Martin Peters

Europa im Blick der Geschichte und Statistik (1750-1815) 
Karl-Heinz Lingens

Europa in der Lehre des »praktischen Völkerrechts«

Kerstin Armborst-Weihs

Die zionistische Bewegung und ihr Verhältnis zu Europa.

Visionen, Entwürfe und Wirklichkeiten von den Anfängen

bis zur Zwischenkriegszeit

Małgorzata Morawiec

Europavisionen in Ostmitteleuropa in der ersten Hälfte

des 20. Jahrhunderts

Irene Dingel

Der Abendlandgedanke im konfessionellen Spannungsfeld.

Katholische und evangelische Verlautbarungen (um 1950/60)

Michael Stolleis

Europa als Vorstellung und Arbeitsgebiet der westdeutschen

Staatsrechtslehre nach 1945

Autorenverzeichnis

Register 


\section{Vorwort}

Europa ist in der öffentlichen Diskussion präsent wie nie zuvor. Kaum ein Tag vergeht, an dem in den Medien nicht über EU-Verordnungen, -Erweiterungsverhandlungen oder die -Beamtenschaft berichtet, räsoniert oder geklagt wird. Dabei schwingt, vielfach allerdings eher implizit, immer auch die Frage mit, was dieses Europa - jenseits eines lediglich geographischen Begriffs und über die Institutionen der Europäischen Union hinaus - denn eigentlich sei bzw. was es sein solle.

Auch die Geschichtswissenschaft hat sich des Themas Europa in den vergangenen Jahren verstärkt angenommen. Der deutsche Buchmarkt wird geradezu überschwemmt von Nationalgeschichten der einzelnen europäischen Länder, die dem offenbar erheblichen Bedürfnis nach einer mehr oder weniger intensiven Information über die Vergangenheit unserer Nachbarn Genüge tun. Geringer ist da schon die Zahl derjenigen Publikationen, die sich, sei es mit Handbuchcharakter, sei es für Einzelaspekte, mit dem gesamten Kontinent oder doch größeren europäischen Räumen beschäftigen. Insgesamt kann man sich nicht dem Eindruck entziehen, dass vielen Werken noch ein suchender und vorläufiger Charakter anhaftet. Zwar herrscht an methodischen Neuansätzen zur vergleichenden und transnationalen Geschichte kein Mangel, doch deren empirische Einlösung lässt noch zu wünschen übrig - die Forschung zu den einzelnen europäischen Ländern ist einer integrativen EuropaHistoriographie noch weit voraus. Mit diesem Befund sollen nicht der Wert der vorliegenden Forschungen geschmälert bzw. die Fortschritte in Richtung auf eine transnationale Geschichte Europas gering geredet, sondern darauf hingewiesen werden, dass die historische Forschung zu Europa noch in der Entwicklung ist. Man könnte auch sagen: Sie ist auf dem Weg nach Europa.

An die Bemühungen um die Konstituierung einer im vollen Wortsinne europäischen Geschichte und in der Diskussion über deren Inhalte und Methoden knüpfte ein Kolloquium an, das vom 13. bis zum 15. November 2008 am Institut für Europäische Geschichte in Mainz stattfand und dessen Referate den Kernbestand dieses Bandes bilden.

Ziel ist, den Untersuchungsgegenstand »Europa« genauer zu fassen. Dezidiert vermieden werden sollte nach unserer Auffassung, das Europabild bzw. die Europabilder, die am Beginn des 21. Jahrhunderts verbreitet sind, auf die Vergangenheit rückzuprojizieren, um nicht der Gefahr zu erliegen, eine teleologisch auf das heutige (EU-)Europa ausgerichtete Geschichte des Kontinents zu pflegen. Im Gegenteil: es sollten die Vielfalt und der Wandel der Europabilder in der Geschichte ausgelotet werden. Bei einem deutlich ge- 
schichtswissenschaftlichen Schwerpunkt ist der Band interdisziplinär angelegt, um so einen noch besseren Zugang zu der Vielfalt der Europa-Deutungen, -Visionen und -Realitäten zu erhalten. Selbstverständlich kann ein Sammelband keine Monographie ersetzen, und ein so weites thematisches Feld wie Europadeutungen, -visionen und -wirklichkeiten kann in einem Band schon gar nicht erschöpfend, sondern nur exemplarisch behandelt werden. Dennoch vermögen die hier versammelten Beiträge einige Hinweise darauf zu geben, wie die Erforschung der Geschichte Europas ertragreich weiterbetrieben werden könnte.

Dem Konzept der Mainzer Tagung folgend, konzentrieren sich die Beiträge des Bandes auf die Neuzeit, also auf die Zeit ab etwa 1500, und gehen für diese Epoche folgenden Fragenkomplexen nach:

1. Wie wurde Europa zu verschiedenen Zeiten von verschiedenen Personen bzw. Personengruppen gedeutet? Was machte Europa in den Augen der Zeitgenossen aus? Welche spezifischen Bedeutungen wurden dem Begriff unterlegt (etwa im Sinne eines christlich geprägten Abendlandes im Unterschied zu einem nicht oder andersartig religiös geprägten Außereuropa oder auch konkret zum »muselmanischen« Osmanischen Reich)? In welchen Zusammenhängen war »Europa« ein bloß geographischer Begriff? Wer sollte »dazu« gehören, wer wurde (unter Umständen bewusst oder sogar wider besseres Wissen) ausgeschlossen?

2. Mit dem ersten steht ein zweiter Fragenkomplex in engem Zusammenhang: Welche Visionen wurden für Europa entwickelt? Wer erarbeitete sie und aus welchen Motiven? Dabei ist an das »Grand Dessin« des Herzogs von Sully von 1632/36 im frühen 18. Jahrhundert ebenso zu denken wie an die Paneuropa-Pläne Coudenhove-Kalergis in den 1920er Jahren und an die europäischen Einigungspläne nach dem Zweiten Weltkrieg.

3. Schließlich: In welchem Verhältnis standen die Realitäten zu diesen Deutungen und Visionen? Reflektierten die Europa-Deutungen konkrete politische, soziale und kulturelle Situationen? Unter welchen Bedingungen konnten Europa-Visionen ganz oder teilweise umgesetzt werden, und wo stießen sie sich an der Realität Europas, die in der Neuzeit weitgehend eine Geschichte der Antagonismen und Konflikte war? Was kann aus der Retrospektive, womöglich unbeachtet von den Zeitgenossen und jenseits ihrer Perspektiven, als spezifisch Europäisches in der Vergangenheit des Kontinents ausgemacht werden?

Die angesprochenen Fragenkomplexe sind natürlich nicht hermetisch voneinander zu trennen, sondern sie durchdringen sich gegenseitig, etwa wenn nach den Trägern eines bestimmten Europabildes gefragt wird oder danach, inwiefern Europavisionen von realen Erfahrungen geprägt waren oder um- 
gekehrt auf diese zurückwirkten. Da in den meisten Beiträgen alle angesprochenen Fragenkomplexe mehr oder weniger intensiv berücksichtigt werden, haben wir davon abgesehen, in diesem Band Sektionen zu bilden, sondern uns für eine weitgehend chronologische Anordnung der Beiträge entschieden. Dies trägt nicht nur den zeitgebunden unterschiedlichen Akzentsetzungen Rechnung, sondern erlaubt zugleich, die Vielfalt der Ansätze und zeitgenössischen Reflexionen angemessen abzubilden. Deutliche zeitliche Akzente liegen dabei in der Frühen Neuzeit sowie in den ersten beiden Dritteln des 20. Jahrhunderts.

Eine ganze Reihe von Beiträgen ist der Thematisierung Europas in den frühneuzeitlichen Medien gewidmet. Johannes Arndt betont, dass das frühneuzeitliche Mediensystem »stets ein europäisches« war. Er versteht die europäische Öffentlichkeit als »Kommunikationszusammenhang«, der von den Regierenden nur begrenzt kontrolliert werden konnte. Gefördert wurde die Vielfalt der Berichterstattung durch die politische Konkurrenz - wenn der eine Machthaber eine Information zu unterdrücken wünschte, lag ihre Verbreitung mit hoher Wahrscheinlichkeit im Interesse eines anderen.

An Wolfgang Harms' Beitrag wird deutlich, wie wenig selbstverständlich und wie medienabhängig der Europadiskurs in der Frühen Neuzeit war. Harms zeigt auf, dass das Thema »Europa« in den illustrierten Flugblättern der Frühen Neuzeit kaum eine Rolle spielte. Er führt dies darauf zurück, dass das Zielpublikum der Flugblätter, der sogenannte »Gemeine Mann«, an diesem Gegenstand nicht vorrangig interessiert war, dass es also keinen Markt für Europa-Flugblätter gab. Der frühneuzeitliche Diskurs über Europa war im Wesentlichen ein Elitenphänomen und bediente sich daher anderer Medien.

Ein Diskurs, der zumindest auch in illustrierten Flugblättern geführt wurde, war dagegen der über politische Gegner und Feinde. Martin Wrede charakterisiert vor diesem Hintergrund das frühneuzeitliche Europa geradezu als den »Kontinent der Erbfeinde«. Doch gerade in den Kriegen und den Feindschaften sieht er einen wesentlichen Grund für die Herausbildung eines gemeinsamen Kulturraums: Um bei all den Gegensätzen überhaupt friedensfähig zu sein, war für die Feinde eine »gemeinsame kulturelle bzw. Vertrauensgrundlage « unabdingbar.

Den Kommunikationsraum Europa nimmt auch Joachim Berger in den Blick, wenn er danach fragt, ob Herkules in der Frühen Neuzeit als europäischer Erinnerungsort betrachtet werden könne. Anhand dieses Beispiels arbeitet er heraus, dass Erinnerungstopoi in der Vormoderne nur selten explizit mit Europa in Verbindung gebracht oder auf Europa bezogen wurden. Wesentlich verbreiteter waren dagegen europäische Erinnerungsorte im Sinne einer gemeineuropäischen Erfahrung, ohne dass deren europäische Verbreitung den Zeitgenossen freilich bewusst sein musste. Diese Erinnerungsorte waren in dem Sinne "geteilt«, dass der mit denselben oder mit ähnlichen 
Begriffen bezeichnete »Ort« in den verschiedenen europäischen Kulturen höchst unterschiedlich erinnert werden konnte, seine Kontextualisierung also nicht nur Gemeinsamkeiten, sondern auch kulturelle Differenzen auszuloten verspricht.

Ein solcher gemeineuropäischer Erinnerungsort steht im Zentrum des Beitrags von Elisabeth Oy-Marra. Sie beschäftigt sich mit dem Aeneas-Mythos, der überall in Europa bekannt war und von daher einen idealen Bezugspunkt für die päpstliche Repräsentation darstellte. Das Bildprogramm in den Familienpalästen der Barberini und Pamphilj brachte durch den Rekurs auf den mythologischen Stadtgründer den Weltherrschaftsanspruch der Päpste sinnfällig zum Ausdruck - trotz oder gerade wegen des im 17. Jahrhundert unverkennbaren Macht- und Einflussverlustes der Römischen Kurie.

Zumindest partiell außerhalb des gemeinsamen europäischen Kultur- und Kommunikationsraums stand das Osmanische Reich. Dennoch ist dessen Verhältnis zu Europa, so Ivan Parvev, allein unter dem Gesichtspunkt eines »Clash of Civilizations « nicht angemessen zu fassen, und daher fordert er $\mathrm{zu}$ einer differenzierten Betrachtung dieser Beziehungsgeschichte auf. Dafür legt er ein Periodisierungsmodell vor, das dem Wandel weg vom Fundamentaldissens hin zu einem pragmatischen Umgang mit dem Osmanischen Reich, ja zu seiner Integration in die europäische Staatenfamilie im 19. Jahrhundert Rechnung trägt.

Anders als das Osmanische Reich waren die britischen Inseln unzweifelhaft stets ein Teil des christlichen Europa. Gleichwohl hat die Forschung herausgearbeitet, dass die Wahrnehmung einer Differenz zum Kontinent schon in der Frühen Neuzeit verbreitet war. Dessen ungeachtet war, wie Ronald G. Asch zeigen kann, in der Aristokratie der britischen Inseln ein europäischer Kosmopolitismus durchaus verbreitet. Diese »nachhaltige Europäisierung « weniger des englischen als des irischen und schottischen Adels hatte erhebliche Rückwirkungen auf die britische Geschichte des 17. Jahrhunderts, verstärkte sie doch die zentrifugalen Tendenzen in der zusammengesetzten Monarchie der Stuarts und war damit ein Faktor, der den Ausbruch und Verlauf der Krise der 1640er Jahre beeinflusste.

An der Nahtstelle von der Frühen Neuzeit zur Moderne stehen die folgenden zwei Beiträge. Martin Peters legt dar, in welchem Maße Europa in der zweiten Hälfte des 18. Jahrhunderts ein Orientierungspunkt für die Geschichtswissenschaften und die neue Wissenschaft der Statistik war, die ihren Reiz und ihre Legitimation nicht zuletzt aus dem Vergleich verschiedener europäischer Länder schöpfte.

Karl-Heinz Lingens befasst sich mit dem »praktischen Völkerrecht« seit dem 18. Jahrhundert. Dieses zielte darauf ab, trotz aller konfessionellen und sonstigen Unterschiede für den geographischen Raum, Europa im Rahmen einer gemeinsamen rechtlichen Ordnung zu beschreiben. Das »europäische 
Völkerrecht« rekurrierte ausdrücklich auf gemeinsame christliche Wurzeln und verschwand erst am Ende des 19. Jahrhunderts.

In einem gespalteten Verhältnis zu Europa stand die zionistische Bewegung seit dem 19. Jahrhundert. Dezidiert auf Palästina ausgerichtet, war der Zionismus in erster Linie doch ein europäisches Phänomen, und dementsprechend war Europa für die Zionisten zugleich »Aktionsraum« und »Verhandlungspartner«, wie Kerstin Armborst-Weihs herausarbeitet. Auch wenn es Kräfte gab, die eine Vorreiterrolle des Judentums für den europäischen Frieden reklamierten, blieb die Einstellung der Zionisten zu Europa alles in allem doch ambivalent.

Dass Europavisionen vom Zuschnitt der Paneuropa-Pläne CoudenhoveKalergis im Polen der Zwischenkriegszeit mehr auf Misstrauen denn auf Begeisterung stießen, zeigt Małgorzata Morawiec. Vor dem Hintergrund der historischen Erfahrungen war das Projekt einer deutsch-französischen Aussöhnung eher geeignet, Zweifel an der Zuverlässigkeit des französischen Verbündeten und Ängste vor einem Pangermanismus zu wecken. Demgegenüber besaß das Argument, Europa als Bollwerk gegen den Kommunismus zu einigen, weniger Durchschlagskraft.

Es ist bekannt, dass die europäische Einigungsbewegung nach 1945 in nicht unerheblichem Maße christlich fundiert war und dass hier der Abendlandgedanke eine wichtige Rolle spielte. Irene Dingel macht jedoch deutlich, dass es diese Aussage zu differenzieren gilt. So standen die Protestanten dem katholisch überformten Abendlandbegriff tendenziell distanzierter gegenüber. Der Idee einer mit Europa verbundenen »unitas ecclesiae« setzten sie die historisch gewachsene religiöse Pluralität und die Säkularisierung als positiv konnotierte Werte entgegen.

Dem »Europarecht« nach 1945 widmet sich schließlich Michael Stolleis. Er zeigt, in welchem Maße auf die Entwicklung dieses Fachgebiets der Jurisprudenz neben den universitären Akteuren auch die Politik einwirkte. Unabhängig von den erforderlichen flexiblen Reaktionen des Europarechts auf die wachsende europäische Integration sieht Stolleis aber einen unantastbaren Kernbestand im Bereich des europäischen Rechtsstaates und Rechtsschutzes.

Als ein wichtiges Ergebnis der Mainzer Tagung und des Sammelbandes ist festzuhalten, dass es, um eine europäische Geschichte voranzutreiben, in der Regel zielführender ist, nach den unterschiedlichen Europakonstruktionen bzw. -wahrnehmungen als nach einem wie immer gearteten >realen` Europa zu fragen. Hier kann nicht zuletzt die Erforschung von Kommunikationsräumen und Medien sowie die in ihnen ausgebildeten bzw. durch sie propagierten Perspektiven weiterführend sein. Eine zentrale Frage an die Europahistoriographie wird sein, inwiefern sie »die Rekonstruktion eines jeweils zeitgenössischen Europabewusstseins mit dem gleichzeitigen Blick auf transkulturelle Verflechtungen und gemeineuropäische Strukturelemente in angemes- 
sener Weise verbinden kann« (Johannes Wischmeyer, Tagungsbericht Auf dem Weg nach Europa. Deutungen, Visionen, Wirklichkeiten. 13.11.200815.11.2008, Mainz, in: H-Soz-u-Kult, 06.01.2009, http://hsozkult.geschichte. hu-berlin.de/tagungsberichte/id=2444; Zugriff: 10.11. 2009). Erschwert wird ein solches Vorhaben allerdings durch eine nicht immer befriedigende Quellenlage. Die Beiträge zeigen, wie wir meinen, den Wert der interdisziplinären Kooperation für die Erforschung der europäischen Geschichte ebenso auf wie die Bedeutung einer epochenübergreifenden Betrachtungsweise. $\mathrm{Zu}$ gleich wird deutlich, dass neben der Beschäftigung mit den >großen Themen auch \Miniaturen $<$ und Fallstudien ihre Berechtigung haben, um den Gegenstand Europa schärfer zu konturieren. Wie der Bau des Hauses Europa nur gelingen kann, wenn viele daran mitarbeiten, so ist dies, unserer Überzeugung nach, für den Aufbau einer Europahistoriographie mindestens ebenso sehr der Fall.

Wir danken allen die zum Gelingen des Kolloquiums vom November 2008 und zu der Erstellung dieses Sammelbandes beigetragen haben sowie nicht zuletzt der Fritz Thyssen Stiftung, welche die Mainzer Tagung mit einem namhaften finanziellen Zuschuss unterstützt hat. Dieses Symposium war zugleich konzipiert als Festkolloquium zu Ehren des langjährigen Direktors des Instituts für Europäische Geschichte (Abteilung für Universalgeschichte), Heinz Duchhardt, anlässlich seines 65. Geburtstages. Die überwiegende Zahl der hier versammelten Beiträge konzentriert sich deshalb auf ein von ihm intensiv gepflegtes Forschungsfeld. Aus diesem Anlass erklärt sich zugleich der Beitrag von Matthias Schnettger, der seinerzeit als öffentlicher Festvortrag gehalten wurde und nun anstelle einer Laudatio auch diesem Sammelband eine persönliche und doch zugleich wissenschaftlich fundierte Note verleiht. Schnettgers Blick auf die »Dreiundvierziger-Generation « unter den Historikern wirft Licht auf jene »Alterskohorte«, deren Leben und wissenschaftliches Wirken durch Nachkriegserfahrung und Aufbruchstimmung geprägt ist und die vor diesem Hintergrund Offenheit und Sensibilität für vielfältige Europakonzeptionen in Geschichte und Gegenwart entwickeln konnte. Unter den Europa-Historikern aus den Reihen der $»$ Dreiundvierziger« nimmt der Jubilar Heinz Duchhardt fraglos eine herausragende Stelle ein. Ihm sei dieser Band als nachträgliche Festgabe gewidmet.

Mainz, im November 2009

Irene Dingel

Matthias Schnettger 


\section{Matthias Schnettger}

\section{Auf dem Weg nach Europa?}

\section{Deutsche Historiker der 1940er Jahrgänge}

Bei dem ersten Treffen einer Gruppe deutscher Historiker nach Kriegsende im Herbst 1946 in Göttingen gab der Kölner Mediävist Peter Rassow die Parole aus »Fort aus der deutschen und hinein in die europäische Geschichte«, und er fand damit große Zustimmung bei seinen Kollegen. Wenn die Parole Rassows tatsächlich in großem Maße umgesetzt worden wäre, dann wäre das Thema meines Vortrags verfehlt, denn dann hätten sich die Historikerinnen und Historiker der 1940er Jahrgänge, die zum Zeitpunkt des angesprochenen Treffens im Herbst 1946 entweder noch gar nicht geboren waren oder jedenfalls noch in den Kinderschuhen steckten und mit hoher Wahrscheinlichkeit keinen Gedanken an eine künftige Laufbahn als Geschichtsprofessor hegten, nicht erst auf den Weg nach Europa begeben müssen. Bekanntlich aber blieb, um mit Winfried Schulze zu sprechen, trotz verschiedener Initiativen wie der Gründung des Instituts für Europäische Geschichte $1950 »$ jene Hinwendung zu Europa letztlich ein intellektuelles Strohfeuer « ${ }^{2}$, und selbst heute sind wir historiographisch noch nicht wirklich in Europa angekommen, ringen wir darum, was europäische Geschichte denn eigentlich sei. Ich betrachte daher meine Themenwahl als legitim und möchte in den folgenden 45 Minuten untersuchen, welchen Beitrag die Historikerinnen und Historiker der 1940er Jahrgänge, die mehr oder weniger gleich alt sind mit der europäischen Nachkriegsbewegung, zur Entwicklung einer europäischen Geschichte geleistet haben. Dabei wird meine besondere Aufmerksamkeit einem hier im Raum anwesenden Historiker gelten. Denn mein Vortrag soll zugleich eine kleine Laudatio aus Anlass des 65. Geburtstages von Heinz Duchhardt sein - ich hoffe, dass Sie mir das nicht nur nachsehen, sondern dass dieses Vorgehen auch in Ihrem Sinne ist! - Und natürlich auch in Ihrem, lieber Herr Duch-

1 Der Text gibt den öffentlichen Vortrag / die Laudatio auf Heinz Duchhardt am 14. November 2008 wieder. Dementsprechend wurde auf einen ausführlichen Anmerkungsapparat verzichtet. Belegt sind lediglich die wörtlichen Zitate. Der Vortrag basiert zu einem erheblichen Teil auf den Internet-Recherchen der wissenschaftlichen Hilfskräfte Miriam Funk und Miriam Freiin von Stenglin, denen auch an dieser Stelle herzlich gedankt sei.

2 Winfried Schulze, Europa in der Frühen Neuzeit - begriffsgeschichtliche Befunde, in: Heinz DuchHARdt / Andreas Kunz (Hg.), Europäische Geschichte als historiographisches Problem, Mainz 1997, S. 35-65, hier: S. 35. 
hardt! Wesentlich erleichtert worden ist mir diese Aufgabe durch die Freundlichkeit von Barbara Stambolis, die vor wenigen Wochen ein Kolloquium mit den und über die Historiker des Jahrgangs 1943 veranstaltet und in diesem Zusammenhang ein Interview mit Heinz Duchhardt führte, das sie mir liebenswürdigerweise vor der Publikation zur Verfügung gestellt hat.

Wie können Historikerinnen und Historiker auf dem Weg nach Europa sein? Das ist auf ganz unterschiedliche Weise möglich: Zunächst einmal ganz banal so, wie alle Bürgerinnen und Bürger in EU-Europa auf dem Weg sind, indem sie die Folgen des europäischen Einigungsprozesses in ihrem Leben erfahren. Zum zweiten kann es persönliche Begegnungen mit Europa im privaten oder akademischen Leben geben. Diese können drittens die wissenschaftliche Beschäftigung mit einem oder mehreren europäischen Nachbarländern zur Folge haben. Schließlich - die vielleicht intensivste Form, sich auf Europa einzulassen - können Historikerinnen und Historiker den Kontinent als Ganzen in den Blick nehmen und untersuchen, was denn das Spezifische Europas und seiner Vergangenheit ausmacht, und nach methodischen Mitteln und Wegen suchen, diese Fragen zu beantworten.

Diese Aspekte werden im Folgenden für die »40er« zu untersuchen sein. Natürlich ist es in diesem begrenzten Umfang nicht möglich, jede einzelne Historikerin und jeden einzelnen Historiker der »Generation 40« ins Auge fassen; ganz ausgeklammert werden angesichts der besonderen Bedingungen der DDR-Geschichtswissenschaft die ostdeutschen Fachvertreterinnen und -vertreter. Alles in allem werden die Ergebnisse notwendigerweise einen impressionistischen Charakter haben. Gleichwohl werden abschließend einige Herausforderungen formuliert, die sich aus den Befunden ergeben und die sich nicht nur an die Historikerinnen und Historiker der »Generation 40« richten.

\section{Allgemeine politische und gesellschaftliche Hintergründe}

In diesem Teil werden in knapper Form die allgemeinen politischen und gesellschaftlichen Hintergründe skizziert, vor denen sich die mögliche wissenschaftliche Annäherung eines in den 1940er Jahren geborenen Historikers an Europa vollziehen konnte.

Zehn Jahre sind ein recht langer Zeitraum, in dem sich viel ereignen kann, und gerade im Deutschland der 1940er Jahre änderten sich die politischen, gesellschaftlichen und ökonomischen Verhältnisse mehrfach in sehr grundsätzlicher Weise. Stand Anfang der 1940er Jahre das »Dritte Reich« auf dem Höhepunkt seiner äußeren Macht, erlebte es wenige Jahre später seinen Zusammenbruch. Das Kriegsende war für die Deutschen nicht nur eine politische und wirtschaftliche Katastrophe, sondern machte auch das ganze 
Ausmaß der von den Nazis verübten Verbrechen und des moralischen Bankrotts deutlich, den Deutschland erlebt und verschuldet hatte. Am Ende des Jahrzehnts schließlich bereitete sich der nicht nur wirtschaftliche Aufstieg eines zumindest äußerlich demokratisch geläuterten Westdeutschland vor, freilich um den Preis eines Verzichts auf die deutsche Einheit, da sich im Zeichen des beginnenden Kalten Krieges in der Mitte des europäischen Kontinents der Eiserne Vorhang niedersenkte.

Die hier in Rede stehenden Historikerinnen und Historiker wurden also je nach Geburtsjahrgang in ein sehr unterschiedliches Deutschland geboren, doch auch diejenigen, die in den letzten Jahren des »Dritten Reichs« das Licht der Welt erblickten und womöglich eine Früherziehung im nationalsozialistischen Geist à la Johanna Haarer erlebten, durchliefen ihre eigentliche Sozialisations- und Formationsphase im Nachkriegsdeutschland. Selbst wenn man in Rechnung stellt, dass es auch im Erziehungssystem eine wirkliche Stunde Null nicht gegeben hat, besteht ein fundamentaler Unterschied zwischen den in der ersten Hälfte und den in der zweiten Hälfte der 1940er Jahre Geborenen: Im Gegensatz zu jenen erlebten die erstgenannten die Zerstörungen und die Not der Kriegs- und der ersten Nachkriegsjahre schon mehr oder weniger bewusst mit. Manche erlitten mit ihren Familien in früher Kindheit das Schicksal von Flucht und Vertreibung.

Auch Heinz Duchhardt berichtet im Gespräch mit Barbara Stambolis von solchen Erfahrungen: vom Einmarsch der Amerikaner in seinem wittgensteinschen Heimatdorf als erster bewusster Erinnerung und von den Verwerfungen, welche die Ankunft katholischer Flüchtlinge aus Schlesien in dem bis dahin rein protestantischen Ort mit sich brachte. Das volle Ausmaß der Kriegszerstörungen nahm er indes erst nach dem Umzug in einen Mainzer Vorort im Jahr 1949 wahr. Noch gravierender war, dass Heinz Duchhardt zu der großen Zahl von Kindern der frühen 1940er Jahre gehörte, die ihren Vater nie kennenlernten, da dieser 1944 in Russland gefallen war. Er selbst stellt in dem Interview einen Zusammenhang mit diesen frühen Erlebnissen und seiner späteren Beschäftigung mit der historischen Friedensforschung her.

Die frühe Kindheit der »Generation 40« wurde also von denselben Erfahrungen geprägt, die in jenen Jahren den europäischen Einigungsbewegungen Auftrieb verliehen. Zumindest die älteren »40er« dürften die Erfolge dieser Einigungspolitik wie den Schuman-Plan, die Gründung der EGKS 1952 und die Römischen Verträge von 1957 bereits bewusst registriert haben. Das Europa, das diese jungen Menschen kennen lernten, war notwendigerweise das Europa westlich des Eisernen Vorhangs, während »Sowjetrussland « und seine Vasallen in der Adenauerzeit als Bedrohung, Feind- und Gegenbild, nicht als Teil der eigenen Welt dargestellt und wahrgenommen wurden. Es war ein Europa, das sich als Teil des »Westens« der Schutzmacht jenseits des Atlantiks näher fühlte als den geographischen Nachbarn im Osten. Dieses 
Welt- und Europabild blieb bei den »40ern« nicht unhinterfragt, wie dies auch Heinz Duchhardt gegenüber Barbara Stambolis für sich konstatiert.

Der Schwerpunkt der akademischen Ausbildung der »40er« fiel in die 1960er und frühen 1970er Jahre. Es war dies bekanntlich eine Zeit, in welcher das soeben skizzierte dichotomische Europa- und Weltbild Risse bekam und schließlich massiv in Frage gestellt wurde. Nach einer Phase der deutschfranzösischen Annäherung, die im Élysée-Vertrag vom Januar 1963 gipfelte, stürzte die Europapolitik Charles de Gaulles die EWG um die Mitte der 60er Jahre in eine ernste Krise, als der französische Präsident 1965/66 durch eine Politik des leeren Stuhls die europäischen Ministerräte für sieben Monate lahmlegte. Nicht zuletzt erteilte de Gaulle durch den Rückzug Frankreichs aus der militärischen Organisation der NATO einer bedingungslosen Anlehnung Europas an die USA eine Absage und lehnte zugunsten seines Konzepts eines »Europas der Vaterländer « eine supranationale europäische Einigung strikt ab. Zugleich weitete er mit seiner Vision eines Europa von Brest bis Brest den Blick nach Osten.

Die älteren »40er« steuerten bereits auf ihr Examen oder ihre Promotion zu, als das Jahr 1968 nicht nur Deutschland und seine Universitäten, sondern zahlreiche Städte und Länder Europas aufwühlte - wie Heinz Duchhardt in seinem Interview mit Barbara Stambolis ausführt, machten die Berichte, die sein eben aus Paris nach Mainz gekommener akademischer Lehrer Hermann Weber mitbrachte, auf den Studenten großen Eindruck. Neben den Vorgängen in Frankreich besaßen vor allem der »Prager Frühling « und seine Unterdrückung europäische Bedeutung. Wenige Jahre später gab es mit der EGErweiterung von 1973, der neuen Ostpolitik und dem beginnenden KSZEProzess weitere wichtige europapolitische Impulse, zu einem Zeitpunkt, als einige »40er« bereits die Promotion oder gar die Habilitation in der Tasche hatten - wie unser Jubilar, der 1968 in Mainz promoviert und 1974 im jugendlichen Alter von 31 Jahren ebendort habilitiert wurde.

Es wird darauf verzichtet, die Hochs und Tiefs im europäischen Einigungsprozess im Einzelnen anzusprechen. Daher nur noch der Hinweis auf eine biographisch-europäische Koinzidenz: Als ab 1989 das sowjetische Imperium zusammenbrach und die 1990er Jahre, nicht nur aufgrund von Maastricht-Vertrag und Begründung der Europäischen Union sowie der beginnenden Ost-Erweiterung von EU und NATO, sondern auch infolge der Wiederbelebung von Nationalismus, Krieg und Völkermord auf dem Balkan ein Schlüsseljahrzehnt für Europa wurden, hatten die »40er«, wenn alles gut gegangen war, ihre ersten Lehrstühle bereits »erobert«. Heinz Duchhardt, um ein nicht gar so willkürlich gewähltes Beispiel herauszugreifen, war im Jahr der Wende nach einer vierjährigen Zeit in Bayreuth seit einem Jahr Professor für Neuere Geschichte an der Westfälischen Wilhelms-Universität Münster. 
Die erste Dekade des neuen Jahrtausends ist in europäischer Hinsicht neben den beiden großen Osterweiterungen der EU von 2004 und 2007 und der Einführung einer gemeinsamen Währung insbesondere durch die Diskussion über die geographischen wie institutionellen Grenzen Europas geprägt. Sie steht, unter dem Eindruck des 11. September, der Klimakrise und aktuell der Finanzmarktkrise, zugleich stärker als die vorangegangenen Jahrzehnte im Zeichen einer Globalisierung, die für Europa schicksalhaft werden dürfte: Werden es die Europäer schaffen, gemeinsam als maßgeblicher Akteur auf globaler Ebene aufzutreten, ohne in selbstzerfleischendem Beharren auf nationalstaatlichen Interessen, in Selbstgenügsamkeit, aber auch ohne eine Abschottung nach außen ihr Potential zu verspielen? Diese Fragen stellen sich zu einem Zeitpunkt, da die »40er« teils auf dem Höhepunkt ihrer Karriere stehen bzw. sich teils bereits angeschickt haben, ihre Lehrstühle zu räumen.

Die Biographie der »40er« - und nicht nur der Historikerinnen und Historiker dieser Generation - stand und steht also in einem nicht unerheblichen Maß im Zeichen Europas: Parallel zu ihrer schulischen und universitären Ausbildung vollzog sich die Umsetzung des Gedankens der europäischen Einigung, und in ihrer Zeit als Akademiker in Amt und Würden wurden sie immer wieder mit europäischen Entwicklungen und Problemen konfrontiert, die, wie Schengen und Euro, teils ganz praktische Auswirkungen auf ihr bürgerliches Leben hatten, denen sie sich aber auch als wache, politisch denkende Menschen - und davon ist bei Historikerinnen und Historikern auszugehen - nicht entziehen konnten.

\section{Persönliche Erfahrungen mit Europa - und die Folgen}

Lassen sich über allgemeine Entwicklungen hinaus europäische Akzente in den individuellen akademischen Lebensläufen ausmachen? Ein Studium im Ausland war für die »40er« eher die Ausnahme als die Norm. Wenn allerdings ein Auslandstudium stattfand, hatte das oft wissenschaftliche Folgen: So waren die Basler Studienjahre von Wolfgang Hardtwig (Jahrgang 1944) sicherlich nicht ohne Einfluss auf seine spätere Dissertation über Geschichtsschreibung zwischen Alteuropa und moderner Welt. Jakob Burckhardt in seiner Zeit (1972) und wohl auch für eine dauerhafte europäische Akzentuierung seiner Forschungen verantwortlich, wie sie beispielsweise in vergleichenden Sammelbänden zur 48er Revolution oder zu Utopie und politische Herrschaft im Europa der Zwischenkriegszeit zum Ausdruck kommt.

Häufiger führte ein Studienaufenthalt nicht direkt nach Europa, sondern zu einer Vorliebe für das jeweilige Gastland. So ist für Neithard Bulst (Jahrgang 1941), der unter anderem in Lyon studierte, Frankreich nicht nur ein wichtiges Forschungsgebiet geworden, sondern er ist diesem Land auch institutionell eng 
verbunden. So war er mehrfach Directeur d'Études associé am Centre de Recherches Historiques der École des Hautes Études en Sciences Sociales in Paris und 1994 sowie 2003 Gastprofessor an der Université Denis Diderot in Paris.

Auch bei Rainer Hudemann (Jahrgang 1948) lassen sich biographische Hintergründe seiner westeuropäischen Vorlieben ausmachen. Er studierte 1969/70 am Institut d'Études politiques in Paris und erwarb dort das entsprechende Certificat. Mit seinem Examen und seiner anschließenden Assistententätigkeit in Trier und seiner 1985 angetretenen Professur für Neuere und Neueste Geschichte in Saarbrücken blieb er wissenschaftlich und lebensweltlich in unmittelbarer Nachbarschaft zum romanischen Teil Europas. Diese räumliche Nähe fand ihren thematischen Ausdruck in zahlreichen Arbeiten mit dem Schwerpunkt auf der europäischen Region »Saar Lor Lux«. Hudemanns Band zu Frankreich wurde durch eine Reihe von Gastprofessuren und durch zahlreiche Ehrungen noch enger geknüpft. So wurde ihm 1998 von der Metzer Universität der Titel eines Dr. h.c. verliehen, 2002 wurde er vom französischen Premierminister zum Officier im Ordre des Palmes Académiques und 2005 durch den französischen Präsidenten zum Officier de l'ordre National du Mérite ernannt. Bereits 1998 erhielt er den Preis der Stiftung für die deutsch-luxemburgische Zusammenarbeit. Dass die Beschäftigung mit einer europäischen Region, man könnte auch formulieren: mit Europa vor Ort, zugleich eine gesamteuropäische Bedeutung hat, wurde schon 1987 durch seine Berufung in die Europäische Akademie Otzenhausen und 2007 in ihren Akademierat unterstrichen.

Eine ausgesprochen europäische Karriere hat Gisela Bock (Jahrgang 1942) aufzuweisen, die nicht nur in Paris und Rom studierte, sondern 1985 bis 1989 ihre erste Professur - und zwar für europäische Geschichte - am European University Institute in Florenz innehatte. Zudem nahm sie in verschiedenen Phasen ihrer Karriere Gastprofessuren in Basel, Bern sowie an der Central European University in Budapest wahr. Dieser biographischen Weite des Horizonts entspricht, dass sie ihr Hauptforschungsgebiet, die Frauen- und Geschlechtergeschichte, in einem dezidiert europäischen Zugriff bearbeitet.

Und unser Jubilar? In seinem Interview mit Barbara Stambolis erzählt Heinz Duchhardt, dass er seine »ersten Auslandsaufenthalte geradezu in sich hineingesogen « habe. Seinen ersten Frankreichbesuch als Austauschschüler im Jahr 1957 beschreibt er als »prägendes Erlebnis«, und das durchaus mit Bezug auf ein Europa, in dem man sich nun frei bewegen konnte und in dessen Wertegemeinschaft man sich integrieren wollte. Für die Erweiterung seines Welt-, und Europabildes war ein Studienaufenthalt in Wien von großer Bedeutung, obwohl oder gerade weil er seine Zeit nach eigenem Bekunden weniger in den Hörsälen als im Archiv und in den zahlreichen Kulturinstitutionen der Donaumetropole zubrachte. Wichtig war aber auch ein Stück Eu- 
ropa in Mainz, das in Heinz Duchhardts Leben noch eine entscheidende Rolle spielen sollte: das Institut für Europäische Geschichte, mit dessen Stipendiaten Heinz Duchhardt im Rahmen einer Historikergruppe in Kontakt kam, die regelmäßig den Rheingau erwanderte. In dieser Gruppe gewann Friedrich Hermann Schubert für ihn eine besondere Bedeutung, denn im Gespräch mit ihm erlebte er eine »Bewusstseinserweiterung nach Westeuropa«.

Nach seinem kurzen Ausflug in die Politik und den Professuren in Bayreuth und Münster kam Heinz Duchhardt 1994 erneut nach Europa in Mainzans Institut für Europäische Geschichte, wo ihm der Kontakt zu den Stipendiatinnen und Stipendiaten sehr wichtig war und ist. Einen mehrjährigen Auslandsaufenthalt hat Heinz Duchhardt also nicht aufzuweisen, aber wenn man die zahlreichen Vortrags- und Tagungsreisen der letzten Jahre aufaddierte, käme man auf eine stattliche Gesamtzeit, die er in verschiedenen europäischen und außereuropäischen Ländern - seit einiger Zeit vor allem in China - verbracht hat. Zudem ist er Mitglied in zwei außerdeutschen Akademien, der Österreichischen und der Finnischen Akademie der Wissenschaften, sowie der Commission Internationale pour la Publication des Sources de l'Histoire Européenne. Er gehört den Wissenschaftlichen Beiräten der Deutschen Historischen Institute in Paris und Moskau an und ist seit Neustem Vorsitzender des Stiftungsrates der Stiftung »Deutsche Geisteswissenschaftliche Institute im Ausland «. Last but not least zog in Gestalt seiner zweiten Frau Małgorzata Morawiec Europa sozusagen in sein privates Leben ein. $\mathrm{Zu}-$ gleich ist sie ihm eine wichtige Partnerin bei seinen Europaforschungen.

\section{Annäherungen an Europa}

Intensive biographische Erfahrungen sind einer Beschäftigung mit dem europäischen Ausland förderlich; sie stellen aber nicht eine notwendige Voraussetzung dafür dar. Hatten die sozusagen gleichzeitig mit Europa heranwachsenden »40er« eine besondere Affinität zu europäischen Themen, selbst wenn sie persönlich wenige oder keine Begegnungen mit dem europäischen Ausland hatten? Wirft man einen Blick auf das wissenschaftliche Euvre der »40er«, so ergibt sich ein heterogenes Bild, das gleichwohl einige Grundmuster erkennen lässt:

Eine Gruppe von Historikerinnen und Historikern, die regelmäßig über den Tellerrand der deutschen Geschichte hinauszublicken pflegt, sind die Mediävisten, bei denen dies schon ihr Forschungsgegenstand nahe legt, denn bekanntlich kann man für das Mittelalter wohl von »Nationes«, aber nicht im modernen Sinne von Nationalstaaten reden, und bekanntlich erstreckte sich das Reich der Ottonen, Salier und Staufer über Nord- und Mittelitalien, das Königreich Arelat und das alte Lotharingien und bezog im Osten Böhmen 
ein. Auch bei einer Beschäftigung mit dem Spannungsverhältnis zwischen Papst und Kaiser oder dem merowingischen und karolingischen Frankenreich weitet sich eo ipso der Blick über »Deutschland« hinaus.

Beispielhaft für einen Mediävisten, der im Wesentlichen von Deutschland ausgehende, jedoch dessen Nachbarn einbeziehende Forschung betreibt, sei Johannes Fried (Jahrgang 1942) genannt, der bereits mit seiner Dissertation über die italienischen Juristen im 12. Jahrhundert, später mit seinen Forschungen über Otto III. und Boleslaw Chrobry einen europäischen Horizont erkennen ließ und 1991 in der Reihe Oldenbourg Grundriss der Geschichte den Band Die Formierung Europas 840-1046 publizierte. Ähnlich deutlich sind die europäischen Bezüge bei seinem Frankfurter Kollegen Heribert Müller (Jahrgang 1946), der nicht nur Spezialist für das mittelalterliche Frankreich und Burgund ist, sondern auch in Frankreich vielfältig vernetzt ist. Dies gilt mutatis mutandis für einige »40er«, wie Heinrich Dormeier (Jahrgang 1947, mit einem starken Italien-Bezug), Alexander Patschovsky (Jahrgang 1949, mit einem Akzent vor allem auf Böhmen) den Karolingerspezialisten Rudolf Schieffer (Jahrgang 1947) und Franz Josef Felten (Jahrgang 1946, mit einem Frankreichschwerpunkt). Deutlich ist der Europabezug auch bei Karl-Heinz Spieß (Jahrgang 1948), der mit Gegenständen wie Fremdheit, Reisen, Kommunikation sowie vergleichender Hofforschung Themen von eminent europäischer Tragweite berührt, oder bei Stefan Weinfurter (Jahrgang 1945), der sich mit der Reichsgeschichte von der ottonischen bis zur staufischen Zeit beschäftigt, dieses Reich jedoch ausdrücklich in einem europäischen Bezugsrahmen sieht, wie in den zusammen mit Bernd Schneidmüller herausgegebenen Sammelbänden Heilig - Römisch - Deutsch. Das Reich im mittelalterlichen Europa (2006) und Salisches Kaisertum und neues Europa (2007) erkennbar ist. Selbst Landeshistoriker haben europäische Anknüpfungspunkte gesucht und gefunden, wie zum Beispiel Franz Irsigler, für etliche Jahre Sprecher des Trierer Sonderforschungsbereichs »Zwischen Maas und Rhein: Beziehungen, Begegnungen und Konflikte in einem europäischen Kernraum von der Spätantike bis ins 19. Jahrhundert«.

Selbstverständlich ist auch der Horizont der Neuzeithistoriker nicht auf die deutsche Geschichte beschränkt, die Einbeziehung des europäischen Auslands in ihre Forschungen scheint jedoch weniger zwingend zu sein als bei ihren mediävistischen Kollegen. Einen traditionellen Ansatz, sich mit dem europäischen Ausland zu beschäftigen, repräsentiert die klassische Diplomatiegeschichte, und sie ist selbstverständlich auch unter den »40ern « vertreten, wofür beispielhaft nur Klaus Hildebrand (Jahrgang 1941) genannt werden soll. Selbstverständlich finden sich in solchen Studien Europa-Bezüge; sie bleiben jedoch vielfach eher implizit. Das gilt auch für die meisten Arbeiten zu einzelnen europäischen Ländern, von denen, wie angedeutet, Frankreich bei den »40ern« ein besonderes Interesse gefunden hat. Als Frankreichspe- 
zialisten können neben den bereits erwähnten beispielsweise Hans-Ulrich Thamer, Heinz-Gerhard Haupt (beide Jahrgang 1943), Wilfried Loth (Jahrgang 1948) und Gerd Krumeich (Jahrgang 1945) genannt werden; bei den drei Letztgenannten haben sich aus und neben dem Forschungsschwerpunkt Frankreich starke europäische Interessen entwickelt.

Neben Frankreich hat bei den »40ern« Großbritannien beachtliche Aufmerksamkeit gefunden, wie beispielsweise bei Marie Luise Recker (Jahrgang 1945), Bernd Weisbrod (Jahrgang 1946) und Anselm Doering-Manteuffel (Jahrgang 1949). Auch hier ist der Schritt von der Beschäftigung mit einem europäischen Land zu einer im engeren Sinne europäischen Geschichte nicht weit, wenn etwa Doering-Manteuffel seine Habilitationsschrift 1986 zum Thema England, die deutsche Frage und das europäische Mächtesystem 1815-1866 verfasst hat und aktuell an einem vergleichenden Forschungsprojekt zu Voraussetzungen und Formen des Wandels europäischer Industriegesellschaften im letzten Drittel des 20. Jahrhunderts arbeitet. Auch bei Wolf D. Gruner (Jahrgang 1944) begann der Weg nach Europa bzw. auf seinen Rostocker Lehrstuhl für Europäische und Neueste Geschichte, der mit dem Jean Monnet Lehrstuhl für Europäische Integrationsgeschichte und Europastudien verbunden ist, in Großbritannien, konkret mit seiner Habilitationsschrift über Großbritannien, der Deutsche Bund und die Struktur des europäischen Friedens im frühen 19. Jahrhundert. Frankreich und Großbritannien sind mit einigem Abstand diejenigen europäischen Länder, die das größte Interesse bei den »40ern « gefunden haben. Italienspezialisten wie Christof Dipper (Jahrgang 1943) erscheinen schon mehr oder weniger als »Exoten«.

Sozusagen qua definitionem zu den Europa-Historikern gehören die Osteuropa-Historiker. Allerdings verstehen sich diese vielfach als Spezialisten für eines oder wenige osteuropäische Länder, ohne einen ausdrücklichen Bezug zu Gesamteuropa. Dies konnte lange Zeit auch für den Russlandspezialisten Helmut Altrichter (Jahrgang 1945) gelten, der aber 2004 zusammen mit dem Spanienhistoriker Walther Bernecker (Jahrgang 1947) eine Geschichte Europas im 20. Jahrhundert veröffentlichte - ein weiterführender Ansatz einer Kooperation von Spezialisten für unterschiedliche europäische Großregionen. Auch mit dem Sammelband Gegenerinnerung. Geschichte als politisches Argument im Transformationsprozess Ost-, Ostmittel- und Südosteuropas 2005 hat er einen Beitrag zu einer vergleichenden europäischen Geschichte geleistet. Stärker noch ist ein originärer Europabezug in den Arbeiten von Hans Henning Hahn (Jahrgang 1947) zu erkennen, der sich zwar ebenfalls auf zwei Länder, Polen und Tschechien, konzentriert, aber ausgesprochen europäische Forschungsschwerpunkte erkennen lässt, nicht nur bilateraler Art, wie die deutsch-tschechischen Beziehungen, sondern auch solche von gesamteuropäischer Bedeutung, wie nationale Stereotypen und Minderheiten oder politische Mythen. Ähnlich europäisch »vorbelastet« wie die 
Osteuropaspezialisten sind deren mittelalterliches Pendant, die Byzantinisten, für die hier beispielhaft Günther Prinzing (Jahrgang 1943) zu nennen ist.

\section{Auf dem Weg zu einer europäischen Historiographie?}

Die bisher angeführten Beispiele sollten nicht den Eindruck erwecken, dass Europa das zentrale Arbeitsfeld der »40er « wäre. Das ist nicht der Fall. Eine große Zahl von ihnen, die daher hier auch nicht genannt worden ist, hat sich nicht, wenig oder erst spät mit der Geschichte eines oder mehrerer europäischer Länder beschäftigt. Noch weniger zahlreich als die Länderspezialisten sind diejenigen, die sich dezidiert Europa bzw. der europäischen Geschichte widmen, deren $»$ Gesamtœuvre oder ein bestimmtes wissenschaftliches Werk « - um aus dem Vorwort des ersten Bandes der Europa-Historiker zu zitieren - »eine europäische Dimensionierung« im strengen Sinne hat ${ }^{3}$.

Unter den mediävistischen Europa-Historikern ist an erster Stelle Michael Borgolte (Jahrgang 1948) zu nennen, der sich nach seiner Dissertation über den Gesandtenaustausch der Karolinger mit den Abbasiden und mit den Patriarchen von Jerusalem (1976), einem Thema, dem man heute tendenziell globalgeschichtliche Qualitäten zusprechen würde, über zwei Jahrzehnte nicht oder jedenfalls nur in dem unter Mediävisten üblichen Rahmen mit europäischen Gegenständen beschäftigte, sich dann jedoch engagiert an die Aufarbeitung des europäischen Mittelalters machte, indem er den Hochmittelalterband des Handbuchs der Geschichte Europas (2002) und den Mittelalterband in der Siedler Geschichte Europas (2006) verfasste und bereits 1998 an der Berliner Humboldt-Universität das Institut für vergleichende Geschichte Europas im Mittelalter ins Leben rief. Dieser europageschichtliche Akzent wurde 2005 durch die Einrichtung des DFG-Schwerpunktprogramms »Integration und Desintegration der Kulturen im europäischen Mittelalter« in Kooperation mit Bernd Schneidmüller verstärkt.

Borgolte verbindet, und zwar durchaus in Anknüpfung an seine oben erwähnte Dissertation, seine Europaforschungen mit einer deutlich gegen den traditionellen Abendlandgedanken gerichteten Programmatik, denn - laut seiner Homepage - vertritt er ausdrücklich die These, »daß Europa im Mittelalter nie durch eine Einheitskultur geprägt war, etwa auf der Basis des römischen Christentums«, dass vielmehr »die Begegnung der verschiedenen europäischen Kulturen zu unaufhörlichen Prozessen der Integration und Desintegration geführt hat, die im weltgeschichtlichen Vergleich die beson-

3 Heinz Duchhhardt / Małgorzata Morawiec / Wolfgang Schmale / Winfried Schulze, Vorwort, in: Dies. (Hg.), Europa-Historiker. Ein biographisches Handbuch, Bd. 1, Göttingen 2006, S. VII-X, hier: S. VII. 
dere Dynamik der europäischen Geschichte entbunden haben « ${ }^{4}$. Der tageseuropapolitische Bezug dieser These ist offensichtlich.

Es finden sich bei den »40ern« auch Beispiele für eine europäisch vergleichende Sozialgeschichte, so bei Werner Rösener (Jahrgang 1944), der seine Forschungen zur mittelalterlichen Agrargeschichte dezidiert europäisch ausgerichtet hat. Insofern ist es kein Wunder, dass sein Buch über Die Bauern in der europäischen Geschichte von 1993 rasch in die europäischen Hauptsprachen Englisch, Französisch, Spanisch und Italienisch - und nebenbei noch ins Japanische - übersetzt worden ist. Noch ausgeprägter ist der Ansatz einer europäisch vergleichenden Gesellschaftsgeschichte bei Hartmut Kaelble (Jahrgang 1940). Geradezu programmatisch ist hier das 1987 erschienene Bändchen Auf dem Weg zu einer europäischen Gesellschaft. Eine Sozialgeschichte Westeuropas, 1880-1980, das innerhalb weniger Jahre ins Französische, Englische, Italienische und Japanische übersetzt wurde und dem eine ganze Reihe weiterer, in dieselbe Richtung zielender Publikationen folgte. Ähnlich wie bei Borgolte wird bei Kaelble deutlich, dass er die Begriffe »Europa« bzw. »europäische Geschichte« nicht wertneutral verwendet, sondern damit bestimmte Inhalte und Ziele verbindet. Prägnant kommt der teleologische Charakter seines Bildes einer europäischen Geschichte im Titel eines Sammelbandes zum Ausdruck, den er 2004 zusammen mit Günter Schmid herausgegeben hat: Das europäische Sozialmodell. Auf dem Weg zum transnationalen Sozialstaat. Kaelble gehört neben Jürgen Kocka, Holm Sundhaussen und Manfred Hildermeier (durch die Bank »40er«) auch zu den Gründungsdirektoren des 1998 gegründeten Berliner Zentrums für Vergleichende Geschichte Europas, das sich unter expliziter Berufung auf den Mauerfall und die Umbrüche seit 1989 das Zusammenführen der Ost- und Westeuropaspezialisten auf die Fahne schrieb. Das Zentrum wurde 2004 in das Kolleg für Vergleichende Geschichte Europas überführt, und dieses nennt auf seiner Homepage die »Prozesse[n] der Grenzüberschreitung und der Grenzziehung, vor allem im Hinblick auf die Entstehung, Verbreitung und Erosion zivilgesellschaftlicher Werte und Praktiken in Europa seit dem 18. Jahrhundert« als vornehmliches Forschungsinteresse und lässt damit nicht zuletzt die Handschrift Kaelbles erkennen ${ }^{5}$.

Für die Migrationsgeschichte ist Klaus J. Bade (Jahrgang 1944) einer der national wie international führenden Fachleute. Dieses Thema beschäftigte ihn bereits in seiner Habilitationsschrift und wird von ihm nun vom Mittelalter bis in die Gegenwart untersucht. Hinter seiner Beschäftigung mit diesem Gegenstand steht die Überzeugung, dass die transnationale Migration ein

URL: http://ivgem.geschichte.hu-berlin.de/site/lang_de-DE/3810/default.aspx (eingesehen am 16.10.2008).

5 URL: http://web.fu-berlin.de/bkvge/ (eingesehen am 16.10.2008). 
»normales«, ja konstitutives Phänomen der europäischen Geschichte sei auch hier sind die aktuellen gegenwartspolitischen Implikationen unübersehbar.

Ein Kernproblem der europäischen Geschichte bildet einen der Forschungsschwerpunkte Dieter Langewiesches: die europäischen Nationen, Nationalismen und Nationalstaaten im 19. und 20. Jahrhundert. Auch seine anderen Themen, wie Liberalismus, 1848er Revolution sowie Krieg und Gesellschaft behandelt er vielfach in einer europäischen Dimension. Daher kann Langewiesche heute zweifelsohne zu den ausgesprochenen Europa-Historikern unter den »40ern" gerechnet werden. Das war nicht immer so: Abgesehen von seiner Habilitation über Bildungsbestrebungen und Freizeitgestaltung österreichischer Arbeiter im Kaiserreich und in der ersten Republik (erschienen 1980) hat er zu europäischen Themen bis in die Mitte der 90er Jahre nur einen bedeutenden Beitrag geleistet: den 1985 erschienenen OldenbourgGrundriss-Band Europa zwischen Restauration und Revolution 1815-1849. Erst seit etwa 15 Jahren drängen die europäischen Bezüge in seinen Forschungen massiv nach vorn.

Ein weiterer ausgesprochener Europahistoriker mit globalgeschichtlichen Tendenzen ist Franz Knipping. Er ist insofern eine Ausnahme unter den »1940ern«, als bei ihm die Öffnung nach Europa sich von der Dissertation zum Thema Die amerikanische Rußlandpolitik in der Zeit des Hitler-Stalin-Pakts über die Habilitation zu Deutschland, Frankreich und das Ende der Locarno-Ära bis in die jüngeren Publikationen durchgehend verfolgen lässt. Bei Knipping stehen die internationalen, zumal die diplomatischen Beziehungen zwischen den politischen Akteuren im Vordergrund, wie auch in dem von ihm zusammen mit Heinz Duchhardt herausgegebenen Handbuch der Internationalen Beziehungen zum Ausdruck kommt. Nicht umsonst wurden Knippings europageschichtliche Forschungen 1994 mit einer Jean-Monnet-Professur honoriert.

$\mathrm{Zu}$ den Europahistorikern unter den Frühneuzeitlern zähle ich Heinz Schilling (Jahrgang 1942), weniger weil er schon in seiner Dissertation über Niederländische Exulanten im 16. Jahrhundert. Ihre Stellung im Sozialgefüge und im religiösen Leben deutscher und englischer Städte ein transnational-migrationsgeschichtliches Thema behandelt hat, sondern weil er, allerdings erst seit den 1990er Jahren, seine Konfessionalisierungsforschungen immer deutlicher auf eine europäisch vergleichende Ebene gehoben und sich außerdem verstärkt den internationalen Beziehungen im Europa der Frühen Neuzeit zugewandt hat. Ein Markstein war die federführende Mitwirkung an der Europaratsausstellung zum 350jährigen Jubiläum des Westfälischen Friedens 1998, aber auch der zweite Band des Handbuchs der Geschichte der internationalen Beziehungen (2007). Wie sehr Schilling in den letzten zehn Jahren im europäischen Ausland wahrgenommen wird, zeigt die Aufnahme 
in mehrere Akademien: die Koninklijke Nederlandse Academie van Wetenschappen, die British Academy sowie die Academia Europea.

Nicht unerwähnt bleiben kann Winfried Schulze (Jahrgang 1942), in dessen Arbeiten immer wieder europäische Horizonte aufscheinen, der sich aber insbesondere vergleichsweise früh um die historiographiegeschichtlichen Aspekte der Europathematik verdient gemacht hat, wie in seiner kleinen Studie zur Gründung des Instituts für Europäische Geschichte oder in seinem Aufsatz Europa in der Frühen Neuzeit - begriffsgeschichtliche Befunde.

Auch Heinz Duchhardt war, wie vielen seiner Jahrgangsgenossen, das Thema Europa nicht in die akademische Wiege gelegt. Sein Doktorvater Ludwig Petry war stärker landesgeschichtlich orientiert, und seine Qualifikationsschriften kreisten in guter Tradition deutscher Frühneuzeitforschung um das Alte Reich. Zwar ist das Reich bei Duchhardt erkennbar in Europa verortet wirklich im Fokus steht Europa in diesen frühen Arbeiten aber nicht. Das ändert sich jedoch bereits in den späten 1970er Jahren, und damit früher als bei den meisten anderen »40ern«, sehr deutlich und nachhaltig. Ohne dass sich Heinz Duchhardt allein auf dieses Arbeitsfeld festlegen ließe, hat das Themenfeld Europa seitdem in seinem reichen Euvre einen festen und privilegierten Platz, wobei unter seinen Mainzer akademischen Lehrern in dieser Hinsicht Hermann Weber den stärksten Einfluss ausübte.

Am Anfang stand sein Interesse an den internationalen Beziehungen und an der historischen Friedensforschung. An »europäischen « Publikationen jener Jahre ist der Band Gleichgewicht der Kräfte, Convenance, europäisches Konzert von 1976, die Studien zur Friedensvermittlung in der frühen Neuzeit von 1979 und der Quellenband Krieg und Frieden im Zeitalter Ludwigs XIV. von $1987 \mathrm{zu}$ nennen. Der Titel des 1990 in der Reihe Enzyklopädie deutscher Geschichte erschienenen Bands Altes Reich und europäische Staatenwelt 1648-1806 fasst diesen thematischen Schwerpunkt in Heinz Duchhardts Euvre jener Jahre prägnant zusammen.

Mit der Herrscherweihe und Königskrönung im frühneuzeitlichen Europa von 1983 und dem Exodus der Hugenotten von 1985 machte sich Heinz Duchhardt daran, auch andere Themenfelder europäisch vergleichend auszuleuchten, und auch der Oldenbourg Grundriss-Band, 1989 erstmals, noch unter dem Titel Das Zeitalter des Absolutismus erschienen, weist eine eindeutige europäische Ausrichtung auf. Ausflüge in die afrikanische Geschichte während seiner Bayreuther Zeit blieben hingegen dann doch eher eine Episode, und eine Überblicksvorlesung zur Geschichte Afrikas blieb nach der Berufung nach Münster in der Schublade. Europäische Themen waren in Heinz Duchhardts Münsteraner Lehre dagegen stets präsent.

In den 1990er Jahren verfolgte und vertiefte Heinz Duchhardt die Europa-Thematik in seinen Arbeiten zu den europäischen Staatenbeziehungen. Hierfür steht das Handbuch der Geschichte der Internationalen Beziehun- 
gen, das er nicht nur gemeinsam mit Franz Knipping herausgibt, sondern von dem er den vierten Band selbst verfasst hat. Schließlich sind die verschiedenen Publikationen im Umkreis des 350jährigen Jubiläums des Westfälischen Friedens zu nennen, die den Kulminationspunkt der Beschäftigung mit der historischen Friedensforschung bilden - wobei sich diesbezüglich angesichts Dutzender von Vortragsveranstaltungen zu diesem Thema nach 1998 doch eine offensichtliche Übersättigung einstellte.

Für einen zweiten europäischen Themenschwerpunkt, die vergleichende Untersuchung der frühneuzeitlichen Monarchien, stehen der große Sammelband European Monarchy von 1992 und die daran anknüpfende Zeitschrift Majestas, die Heinz Duchhardt mit großem persönlichen Engagement herausgab und die eine deutlich internationale Ausrichtung mit einem Schwerpunkt auf Europa hatte. 2003 legte Heinz Duchhardt zudem mit dem die zweite Hälfte des 17. und das 18. Jahrhundert umfassenden sechsten Band des Handbuchs der Geschichte Europas eine Synthese vor, die den Kontinent von der Algarve bis an den Ural, vom Nordkap an den Bosporus in die Darstellung einbezieht.

1994 wurde Heinz Duchhardt zum Direktor der Abteilung für Universalgeschichte des Instituts für Europäische Geschichte berufen. Und wer Heinz Duchhardt kannte, der wusste, dass ihm diese Berufung eine Verpflichtung sein würde, nicht nur in seinen bisherigen Forschungen fortzufahren, sondern seine europahistorischen Bemühungen noch zu intensivieren. Von dem Bestreben, die europäische Geschichte konzeptionell besser in den Griff zu bekommen, zeugen unter anderem die Sammelbände Europäische Geschichte als historiographisches Problem (1997), Europäer des 20. Jahrhunderts (2002), Vision Europa (2003) sowie die drei Bände der Europa-Historiker.

Den bedeutendsten Schritt in Richtung auf eine Neukonzeptionalisierung der europäischen Geschichte markiert aber das Jahrbuch für Europäische Geschichte, das Heinz Duchhardt im Jahr 2000 ins Leben gerufen hat und das er seitdem in Verbindung mit einem ausgesprochen europäischen Advisory Board federführend betreut. $\mathrm{Zu}$ den Zielen dieses Periodikums heißt es im Geleitwort des ersten Bandes, dass das neue Journal »seine Aufgabenstellung als dezidiert, >europäisch« «egreife.

Die Entwicklung der politischen Idee Europa wird ebenso eine Rolle spielen wie die Praxis der europäischen Integrationsprozesse. Dies schließt im Übrigen auch die desintegrativen Erscheinungen und Kräfte sowie die unausgereiften Anläufe von Europäisiserungsprozessen ein. [...] Grundsätzlich ist die Zeitschrift offen für das Gesamtspektrum der historischen `Subdisziplinen< [...] und für die Vielfalt der verschiedenen methodischen Zugriffe ${ }^{6}$.

6 Heinz DuchHARdt, Zum Geleit, in: Jahrbuch für Europäische Geschichte 1 (2000), S. VII-VIII, hier: S. VII. 
Dieses zugleich strenge und offene Programm hat Heinz Duchhardt durchgehalten. Streng war und ist er nicht nur hinsichtlich der Qualität der Beiträge, sondern auch in dem Sinne, dass beim Jahrbuch nicht nur Europa draufsteht, sondern auch Europa drin ist. Offen ist er nicht nur hinsichtlich einer thematischen und methodischen Vielfalt, sondern auch darin, dass er in seinen Europastudien keinen teleologischen Ansatz verfolgt.

Diese Offenheit ist in verschiedener Hinsicht ein Grundzug von Heinz Duchhardt, nicht nur in Hinsicht auf seine europageschichtlichen Positionen. Dies schließt die grundsätzliche Bereitschaft ein, immer wieder eigene Positionen zu überprüfen - und dann auch mal einen als unhaltbar erkannten Buchtitel in der vierten Auflage radikal zu ändern - sich selbst Neuem zu öffnen oder doch, wenn er nicht jeden »Turn« persönlich mitvollziehen mag, es gelten zu lassen oder auch wertzuschätzen, wenn es nach seinem Dafürhalten etwas taugt.

Dies zeigt sich nicht zuletzt in seinem mit großer Beharrlichkeit verfolgten Ziel, das Institut für Europäische Geschichte zu einem Zentrum europabezogener Grundlagenforschung zu machen. Dieser Begriff der Grundlagenforschung bringt zum Ausdruck, dass derzeit eben noch keine letztgültige Geschichte Europas zu schreiben ist, sondern dass es darum gehen muss, Mosaikstein um Mosaikstein hierfür zusammenzutragen. In diesem Sinne hat er nicht nur eine Fülle von Projekten bearbeitet oder angestoßen, sondern in Kooperation mit Irene Dingel die Strukturen des Instituts so verändert, dass dessen interdisziplinäres Potential nun viel effektiver zu nutzen ist und es seinen Platz in der ersten Reihe der deutschen und europäischen EuropaInstitute nicht nur behaupten, sondern ausbauen kann.

\section{Fazit}

Insgesamt kann man nicht behaupten, dass die »40er«, deren Biographien wie die ihrer ganzen Generation in gewisser Weise durchaus von europäischen Begleitakkorden geprägt waren, sich im Rahmen ihrer wissenschaftlichen Arbeit in ihrer Mehrzahl schnurstracks auf den Weg nach Europa gemacht hätten. Mit einzelnen europäischen Ländern beschäftigten sich durchaus einige von ihnen, und von da aus führte sie ihr Weg manchmal tatsächlich nach Europa. Andere brauchten diesen Umweg nicht, dennoch liegen die wissenschaftlichen Leistungen der »40er«, ungeachtet der unbestrittenen europäischen Verdienste Einzelner, weniger im Bereich der europäischen Geschichte.

Für diesen Befund lassen sich verschiedene Gründe anführen: Die Konzentration auf eine sozialgeschichtliche Forschung, die einherging mit einer partiellen Diskreditierung traditioneller politikgeschichtlicher Methoden, 
war einer Beschäftigung mit dem Phänomen Europa zunächst wenig förderlich. Selbstverständlich wandte man sich zunächst der eigenen, deutschen Gesellschaftsgeschichte $\mathrm{zu}$; eine transnationale Sozialgeschichte scheint zunächst undenkbar gewesen zu sein, wurde jedenfalls nicht gedacht, auch wenn der europäische Vergleich durchaus eine Rolle spielte, um deutsche Sonderentwicklungen deutlicher zu konturieren.

Die historische Forschung war in weiten Teilen lange Zeit aber nicht nur methodisch, sondern auch vom Gegenstand her Europa eher abgewandt. Es wäre für die »40er« in der Phase ihrer akademischen Ausbildung geradezu unklug gewesen, allzu sehr auf europäische, besser gesagt: nichtdeutsche Themen zu setzen, denn bis in die jüngste Zeit spielte bei der Berufungspraxis der Nachweis der Kompetenz für die deutsche Geschichte die entscheidende Rolle, sprich: der Bonus eines europäischen Horizonts fiel weniger ins Gewicht als der Malus einer vermeintlichen ungefestigten Basis in der nationalen Geschichte.

Das deckt sich mit der Beobachtung, dass auch die ausgesprochenen »Europäer« unter den »40ern« diese Berufung zumeist erst dann entdeckten, als sie bereits in Amt und Würden waren. Für das deutlich wachsende Interesse an europäischen Themen seit den 1990er Jahren lassen sich allerdings noch weitere strukturelle Ursachen ins Feld führen:

Die sich intensivierende öffentliche Diskussion zum Thema Europa, zu seinen Grenzen, zu europäischen Identitäten und dergleichen seit den 1990er Jahren verlieh diesem Gegenstand eine wachsende gegenwartsbezogene Relevanz und Attraktivität, und hier fühlten sich auch Historikerinnen und Historiker angesprochen, aus der Perspektive ihrer jeweiligen Arbeitsgebiete Antworten zu geben oder durch intensivierte Forschung nach Antworten zu suchen. Abgesehen davon, dass es nunmehr der eigenen Profilierung durchaus förderlich war, sich mit Europa zu beschäftigen, muss man bedenken, dass Historikerinnen und Historiker im Allgemeinen neugierige, wache und entwicklungsfähige Menschen sind, auf die die Ausweitung bisheriger Forschungsgebiete in einen größeren, europäischen Rahmen oder auch die Erarbeitung neuer, europäischer Themenfelder einen beträchtlichen Reiz ausüben konnte. Nunmehr boten sich Ansatzpunkte, alte Konzepte, die den kurzfristigen europahistorischen Boom nach dem Zweiten Weltkrieg geprägt hatten, wie der Abendlandgedanke oder in atlantischer Erweiterung »der Westen« kritisch zu überprüfen, sie zu modifizieren oder ihnen neue Interpretamente entgegenzustellen. Hier traf es sich gut, dass der »Cultural Turn«, den freilich nicht alle »40er« mitvollzogen, einer Beschäftigung mit Europa durchaus förderlich war. Forschungen zu Kommunikation, Identitäten und Feindbildern drängten sich im europäischen Bezugsrahmen geradezu auf.

Nicht nur die »40er«, die deutschsprachige historische Forschung insgesamt scheint erst teilweise in Europa angekommen zu sein. Was bedeutet das 
für die aktuelle historische Forschung? Bei allen Notwendigkeiten für die Geschichtswissenschaft, sich globalen Herausforderungen zu öffnen, bleibt es wichtig, die europäische Dimension nicht aus dem Blick zu verlieren.

Die europäische Geschichte sollte dabei nicht als ein erforderlicher Zwischenschritt auf dem Weg zu einer Globalgeschichte betrachtet werden, sondern sie behält wie auch National-, Landes- und Lokalgeschichten einen eigenen, bleibenden Stellenwert. Tatsächlich kann die europäische Geschichte im Rahmen eines Systems von im Idealfall miteinander korrespondierenden Historiographien ein erhebliches Gewicht als mögliche Schaltstelle zwischen Nationalgeschichte, vergleichender Landesgeschichte und auch Globalgeschichte beanspruchen. Sie kann dies umso mehr tun, wenn sie sich nicht für teleologische Geschichtsbilder vereinnahmen lässt, sondern eine Offenheit behält. Wenn dann auch nicht jeder Ansatz einer europäischen Geschichte sich als zielführend erweisen sollte, ist das vielleicht zu verschmerzen, denn manchmal ist auch in der Geschichtswissenschaft der Weg das Ziel. 


\section{Johannes Arndt \\ Die europäische Medienlandschaft im Barockzeitalter}

\section{Prolog und Fragestellung}

Die europäische Medienlandschaft im Sinne der Fragestellung soll begrifflich eingegrenzt werden auf das »europäische Mediensystem der (periodischen) politischen Druckpublizistik«. Das beinhaltet, dass es sich zum einen um ein System handelt, wobei Anleihen bei der Systemtheorie vorgenommen werden. Zum anderen steht Europa im Zentrum. Zum dritten soll es um die Beobachtung politischer Begebenheiten gehen, wobei Haupt- und Staatsaktionen von Krieg und Frieden, Machtgewinn und -verlust, dynastische und höfische Ereignisse sowie die daran beteiligten sozialen Gruppen im Vordergrund stehen. Zum vierten werden Druckwerke als Quellen ausgewertet, dabei soll das »making of « mit berücksichtigt werden. Als Zeitrahmen gilt die Barockepoche: Der Barockbegriff ${ }^{1}$ wird zeitlich bis in die 1740er Jahre reichen und auf diese Weise von der anschließenden Hochaufklärung abgegrenzt.

Europa war für die frühmoderne politische Berichterstattung kein Problem, sondern eine Chance. Daher sind auch ausführliche Reflexionen darüber, was Europa sei, selten - denn Europa war ihr Wahrnehmungsraum. Verleger und Herausgeber der Periodika, deren Zusammenwirken im Folgenden untersucht werden, hatten sich Europa in nationale Räume und innerhalb derselben in Medienzentren eingeteilt. Dabei gehörten die drei Ebenen Europa-Nationen-Regionalzentren zusammen, die Einteilung diente nur organisatorischen, rechtlichen und logistischen Gründen. Zahlreiche Periodika führten den Europa-Begriff in ihrem Namen: Das Diarium Europaeum ${ }^{2}$ und das Theatrum Europaeum ${ }^{3}$ werden bis heute als wichtige Serienwerke ge-

1 Die Verwendung des Barockbegriffs als Epochensignatur resultiert aus dem Unbehagen mit dem früheren Epochenbegriff »Absolutismus« im Sinne, wie es Heinz Duchhardt in der vierten Auflage seines Grundrisses zur europäischen Geschichte zum Ausdruck gebracht hat: Heinz DuchHardt, Barock und Aufklärung, München ${ }^{4} 2007$, Einleitung.

2 [Martin Meyer u.a. (Hg.)], Diarium Europaeum, Philemeri Irenici Elisii Diarium Europaeum insertis actis electoriis Oder Kurtze Beschreibung denkwürdigster Sachen/ So sich in Frieds= und Kriegs= Geschäfften in Europa [...] vom Jahre 1657 [...] begeben haben, 45 Bde., Frankfurt/ Main 1659-1683. Vgl. dazu: Sonja Schultheiss, Das »Diarium Europaeum« (1659-1683). Verleger und Autoren, Aufbau und Inhalt, in: Archiv für Geschichte des Buchwesens 48 (1997), S. 315-346.

3 Johann Philipp Abelein u.a. (Hg.), Theatrum Europaeum, Oder Außführliche und Warhafftige Beschreibung aller und jeder denckwürdiger Geschichten/ so sich hin und wieder in der Welt [...] zugetragen haben, 21 Bde., Frankfurt/Main 1643-1738. Vgl. zum »Theatrum Europaeum« 
nutzt und als Quellen im Basismodul des Geschichtsstudiums gelehrt. Nicht weniger interessant, aber weniger bekannt sind die Europäische Zeitung ${ }^{4}$, die ab 1680 in Hanau herausgegeben wurde, oder die Europäische Fama, welche den gegenwärtigen Zustand der vornehmsten Höfe entdecket ${ }^{5}$, eine Zeitschrift, die zusammen mit ihren Nachfolgeserien von 1702 bis 1756 in Leipzig erschien. Eine historisch-politische Zeitschrift in London, von 1691 bis 1733 erschienen, führte den Namen The Present State of Europe $e^{6}$, ein ebenso ausgerichtetes Journal in den Niederlanden hieß Europische Mercurius ${ }^{7}$.

Während das Diarium und das Theatrum Europaeum langfristig ausgerichtete und chronologisch aufgebaute Historienwerke waren, gliederten sich die meisten Zeitungen nach den Korrespondenten-Orten. So standen bei ihnen die weitest entfernten Nachrichten vorn, ihr Datum lag auch wegen der Länge der Kommunikationswege am längsten zurück. Die später eingetroffenen und damit aktuelleren Berichte standen hinten. Die meisten historisch-politischen Zeitschriften hingegen gliederten sich nach Berichtsnationen. Der niederländische Mercure historique et politique ${ }^{8}$, der hier eine

immer noch die ältere Studie von Hermann BingeL, Das Theatrum Europaeum. Ein Beitrag zur Publizistik des 17. und 18. Jahrhunderts, Lübeck 1922 (ND Wiesbaden 1969). Eine neue bibliographische und kunsthistorische Bestandsaufnahme im Rahmen der Merian-Ausgaben: Lucas Heinrich Wüthrich (Hg.), Das druckgraphische Werk von Matthaeus Merian d. Älteren, Bd. 3: Die großen Buchpublikationen, Hamburg 1993, S. 113-272.

4 Die Europäische Zeitung wurde ab 1680 bei Justus Böff in Hanau herausgegeben, die Zeitung hatte auch den Namen Hanauischer Mercurius. Im 17. Jahrhundert erschien sie zweimal wöchentlich mit vier Seiten Umfang. Eine »Extraordinari-Ausgabe« von zwei Seiten Umfang konnte dazwischengeschoben werden, wenn genügend Nachrichten verfügbar waren.

5 [Philipp Balthasar SinOLD vON SCHÜTZ (Hg.)], Die europäische Fama, welche den gegenwärtigen Zustand der vornehmsten Höfe entdecket, Leipzig 1702-1735. Vgl. dazu Joachim KirchNER, Das deutsche Zeitschriftenwesen. Seine Geschichte und seine Probleme, Bd. 1, Wiesbaden 1958, S. 33; Susanne Friedrich, Drehscheibe Regensburg. Das Informations- und Kommunikationssystem des Immerwährenden Reichstags um 1700, Berlin 2007, bes. S. 453-455. - Zu Sinold von Schütz und den anderen Herausgebern: Astrid Blome, Das deutsche Rußlandbild im frühen 18. Jahrhundert. Untersuchungen zur zeitgenössischen Presseberichterstattung über Rußland unter Peter I., Wiesbaden 2000, S. 22 Anm. 71.

6 [Anonym], The Present State of Europe: Or, the Historical and Political Monthly Mercury. Containing all the Public and Private Occurrences, Civil, Ecclesiastical, and Military, that are most Considerable in every Court: The Various Interests of Princes, their Pretensions, Disputes, and Intrigues etc. [...], London 1691-1733.

7 »Europische Mercurius, Behelzende Al het voornaamste, $\mathrm{t}$ geen, zo omtrent de zaaken van Staat als Oorlog, in alle de Koningryken en Landen van Europa, en ook zelfs in verscheidene Gewesten van d'andere Deelen der Wereld, is vorgevallen «, 50 Bde., Amsterdam 1690-1739; vgl. dazu Joop W. Koopmans, De presentatie van het nieuws in de Europische Mercurius (16901756), in: Mededelingen van de Stichting Jacob Campo Weyerman 23 (2000), S. 117-133.

8 Mercure historique et politique (gegründet 1685 von Gatien COURTILS DE SANDRAS; seit 1724 redigiert von Jean Rousset DE Missy), Den Haag 1686-1782; vgl. zum Periodikum auch Jean LomBARD, Art. »Mercure historique et politique 1«, in: Jean SGARD (Hg.), Dictionnaire des journaux (1600-1789), Bd. 2, Paris 1991, S. 870-878; Christiane Berkvens-Stevelinck, L'information politique dans les journaux de Rousset de Missy, in: Henri Duranton / Pierre Rétat (Hg.), Gazette et information politique sous l'Ancien Régime, St. Etienne 1999, S. 97-106; Hans Bots, 
Vorbildfunktion ausübte, begann mit Italien, dann folgte das Alte Reich, anschließend Frankreich, Spanien, die Niederlande, England, Skandinavien sowie Ost- und Südosteuropa. Variationen konnten immer vorkommen, vor allem, wenn das Reich auf dem Balkan gegen das Osmanische Reich kämpfte, dann standen »Reich und Hungarien« zusammen in einem Nationenblock. Auch einzelne Zeitungen, z.B. die Gazette d'Amsterdam ${ }^{9}$, folgten dieser Einteilung. Erst dahinter rangierten, im Kopf jeder Einzelmeldung, die Ortsangaben, aus denen die Mitteilung korrespondiert worden war. Dieser Korrespondenzverweis konnte auf einen Briefmitteiler verweisen, aber auch auf ein anderes Periodikum, das als Referenztitel diente. Zwar hielt man das »Ausschreiben «, d.h. Abschreiben anderer Zeitungen im großen Stil, für unprofessionell, doch gegen die Übernahme von Einzelangaben hatte niemand etwas einzuwenden. Das galt vor allem, wenn es sich um die Auswertung fremdsprachiger Zeitungen handelte, denn dann wurde immerhin die Übersetzung in die jeweilige Nationalsprache »geleistet«.

Der Medienraum, der im Folgenden untersucht werden soll, umfasst nicht ganz Europa, sondern einen Zentralabschnitt. Dabei handelt es sich um das Gebiet, in dem während der Frühmoderne die größte Handelsverdichtung nachgewiesen wurde: das »Blue-Banana«-Gebiet. Dieser Begriff stammt von einer Tagung von Wirtschaftsgeographen und Stadthistorikern in den 1980er Jahren, als der fragliche Zentralabschnitt auf der Graphik einer Europakarte durch eine Blaufärbung in Form einer Banane gekennzeichnet wurde, die von Mittelitalien in einem nach Nordwesten geneigten Bogen bis nach Mittelengland reichte ${ }^{10}$. Auch im frühneuzeitlichen »World-System « von Immanuel Wallerstein spielten diese Gebiete Italien, Schweiz, Oberdeutschland, Nordfrankreich, die Niederlande und England die Hauptrolle für den ökonomischen Aufstieg Europas ${ }^{11}$. Fernand Braudel hat die Verlagerung der frühmodernen Welthandelsmetropolen von Genua über Antwerpen, Amsterdam nach London beschrieben, alles Städte, die sich innerhalb des Blue-Ba-

Quelques gazettes de Hollande en langue française et le »Mercure historique et politique«: une analyse comparative, in: DuRANTON / RÉTAT, Gazette et information politique sous l'Ancien Régime, S. 159-168.

9 Pierre Rétat / Pascale Ferrand / Daniel Roux (Hg.), Gazette d'Amsterdam, 1691-1796. Niederländische Zeitung in französischer Sprache. CD-ROM-Ausgabe, 12 CD-ROMs, Oxford, Paris 2000-2002. Zur Bedeutung der Zeitung: Pierre RÉTAT, La Gazette d'Amsterdam, miroir de l'Europe au 18e siècle, Oxford 2001.

10 Roger Brunet, Les villes Européennes, Paris 1989, Karte S. 79; zur Bedeutung der Niederlande in diesem System: Karel Davids / Jan Lucassen (Hg.), A Miracle mirrored. The Dutch Republic in European Perspective, Cambridge 1995, S. 25. - Brunet hat inzwischen, mit Bezug auf das 20. Jahrhundert, dem »Blue-Banana-Konzept« weitere Elemente und Karten hinzugefügt: Roger BRunet, Lignes de force de l'espace européen, in: Mappe Monde 66 (2002), S. 14-19.

11 Immanuel Wallerstein, The Modern World System. Capitalist Agriculture and the Origins of the European World-Economy in the Sixteenth Century, New York 1974. 
nana-Gebietes befanden ${ }^{12}$. Es verwundert nicht, dass die frühen Hauptverbindungen des europäischen Postwesens, wie Wolfgang Behringer nachgewiesen hat, denselben Raum kommunikativ erschlossen und von dort aus später ihre Außenverbindungen, etwa nach Wien und noch später nach Berlin, andockten ${ }^{13}$. Die europäischen Pressezentren lagen demnach ebenfalls in diesen Ländern, von denen man Deutschland, die Niederlande, Frankreich und England in ein Verhältnis zueinander setzen kann - Italien hingegen wird ausgelassen, da die italienischen Periodika noch nicht ausreichend ausgewertet wurden.

Im Folgenden geht es um die vier nationalen Medienkulturen, sogenannte »mediale Tetraeder«: Altes Reich, Frankreich, England und mittendrin die niederländische Republik. Dabei wurden die Aspekte betont, die für den internationalen Zusammenhang besonders wichtig sind. Zum Schluss folgen einige Überlegungen darüber, was dieser Medienverbund für die europäische politische Öffentlichkeit bedeutete.

\section{Die Niederlande}

Begonnen werden soll mit der Republik am Unterlauf von Rhein und Maas, wobei das Pendant, die Spanischen und später Österreichischen Niederlande, ebenfalls an der Druckmedienentwicklung intensiv teilnahmen und durch die Spaltung keinesfalls zur Mediensteppe wurden. Der Schwerpunkt der Überlegungen liegt allerdings auf der Republik. In manchen Studien der Vergangenheit wurden Flugschriften-, Zeitungs- oder Zeitschriftenpublizistik zwischen Großbritannien, Frankreich und dem Reich verglichen. Die Niederlande wurden meist weggelassen, sehr zu Unrecht: Für das 17. und die erste Hälfte des 18. Jahrhunderts waren die Vereinigten Provinzen nicht nur eine politische Großmacht, sondern auch eine Mediengroßmacht. Zum einen war die Republik eine urbanisierte Handelsgesellschaft. Der Anteil der Bevölkerung, der Medieninformationen für seine alltägliche Arbeit benötigte, war viel größer als in allen anderen europäischen Staaten. Dies begünstigte einen großen Markt für Druckwerke. Zweitens war auch die Lesefähigkeit weiter entwickelt als im sonstigen europäischen Durchschnitt, bedingt sowohl durch Wirtschaftserfordernisse als auch durch unermüdliche Förderung von Seiten der protestantischen Kirchen. Drittens war das politische System durch seine Konzertanz zwischen Statthaltern und »Staaten«, d.h. Stände-

12 Vgl. die Verlagerung vom Süden nach Nordwesten beispielsweise bei Innovationen im Bankwesen: Fernand BRAudel, Sozialgeschichte des 15.-18. Jahrhunderts, 3 Bde., hier: Bd. 1: Der Handel, München 1985, S. 429-431.

13 Raumschwerpunkte des Postwesens: Wolfgang BeHRInger, Im Zeichen des Merkur. Reichspost und Kommunikationsrevolution in der Frühen Neuzeit, Göttingen 2003, S. 95. 
versammlungen auf den oberen Ebenen, sowie dem städtischen Republikanismus - eine Diskurskultur, die der medialen Vermittlung von politischen Inhalten bedurfte und sie ständig neu generierte ${ }^{14}$. Dies wirkte dem Herrschaftsarkanum entgegen, und daher hatten Medienproduzenten es schwerer, ein wirkliches Geheimnis zu verraten und sich damit strafbar zu machen. Auf städtischer Ebene kam hinzu, dass gerade die bedeutenden Verleger als Großkaufleute, die mit Texten handelten, vielfach als Magistratsmitglieder politischen Einfluss besaßen, was sie ebenfalls schützte.

Medienproduktion hatte in den Niederlanden eine lange Tradition. Schon unter Philipp II. entstand der Antwerpener Medienkonzern Plantin ${ }^{15}$. In der jungen Republik des beginnenden 17. Jahrhundert etablierten sich große Druckhäuser wie Blaeu und Elsevier ${ }^{16}$. In und neben diesen großen Konzernen entwickelte sich bereits in der zweiten Dekade des 17. Jahrhunderts, und damit etwa zeitgleich mit Deutschland, ein leistungsstarkes Zeitungswesen $^{17}$. Zudem widerstrebte es den Eliten in der Republik, die sich gegen Denk- und Gewissenszwang von Spanien emanzipiert hatten, nun ihrerseits Denk- und Gewissenszwang auf dem Medienmarkt auszuüben. Zwar waren die Drucker und Verleger nicht völlig frei in ihrem Handeln - so hatte sich jeder zu hüten, das Verfassungsverhältnis zwischen Provinzen und Oranierhaus oder die fragile Religionsordnung kritisch zu hinterfragen -, doch viel freier als irgendwo sonst in Europa ${ }^{18}$. Die Herrschenden, sowohl die Oranier als auch die Regenten, hatten sich an die öffentliche »Begleitmusik» ihres

14 Vgl. zu diesem Spannungsverhältnis Olaf MöRKE, `Stadtholder` oder `Staetholder`. Die Funktion des Hauses Oranien und seines Hofes in der politischen Kultur der Republik der Vereinigten Niederlande im 17. Jahrhundert, Münster / Hamburg 1997.

15 Colin Clair, Christopher Plantin, London 1960; Francine DE NAve, Eine Druckerei von Weltrang im Antwerpen des 16. Jahrhunderts. Christophe Plantins »Gulden Passer«, in: Paul RAABE (Hg.), Gutenberg. 550 Jahre Buchdruck in Europa Weinheim 1990, S. 65-74; Leon Voet, The Golden Compasses. A History and Evaluation of the Printing and Publishing Activities of the Officina Plantiniana at Antwerp, 2 Bde., Amsterdam u.a. 1969-1972.

16 Johan Keuning / Marijke Donkersloot-De Vrij (Hg.), Willem Jansz. Blaeu. A Biography and History of his Work, Amsterdam 1973; David W. DAvies, The World of the Elseviers 15801712, Den Haag 1954 (ND 1960); Berry P. Dongelmans / Paul G. HoftiJzer / Otto S. Lankhorst $(\mathrm{Hg})$, Boekverkopers van Europa. Het 17de-eeuwse Nederlandse uitgevershuis Elzevier, Zutphen 2000.

17 Zur niederländischen Frühpresse: Folke DAHL, Amsterdem - Earliest Newspaper Centre of Western Europe. New Constributions to the History of the First Dutch and French Corantos, in: Het Boek 25 (1939), S. 161-197; Maarten SchneIder, De Nederlandse krant, 1618-1978. Van »nieuwstydinghe« tot dagblad, Amsterdam 1943 (hg. von Joan Hemels, Baarn ${ }^{4} 1979$ ).

18 Forschungsentwicklung zur Zensur in der Niederländischen Republik: Willem Pieter Cornelis KNutTel (Hg.), Verboden boeken in de republiek der Vereenigde Nederlanden, Den Haag 1914; H. A. Enno van Gelder, Vrijheid en onvrijheid in de Republiek. Geschiednis der vrijheid van drukpers en godsdienst van 1572 tot 1798, Haarlem 1948; Alastair C. Duke / Coenraad A. TAmse (Hg.), Too mighty to be free: Censorship and the press in Britain and the Netherlands, Zutphen 1987, S. 63-86; Ingrid Marlies Weeknout, Boekencensuur in de noordelijke Nederlanden. De vrijheid van drukpers in de zeventiende eeuw, Den Haag 1998. 
Regierungshandelns gewöhnt und reagierten selten so gereizt auf kritische Kommentare und Anspielungen wie hochadlige Potentaten in den benachbarten Monarchien.

Hinzu kam, dass die Niederländer ein polyglottes Volk waren. Der Hofadel sprach seit der Burgunderzeit französisch, und seit den Vertreibungen der 1580 er Jahre waren wallonische Gemeinden in mehreren großen Städten fest etabliert. Auch für die Kaufmannschaft waren französische Sprachkenntnisse nützlich, selbst wenn kein wallonischer Hintergrund bestand ${ }^{19}$. Im letzten Drittel des 17. Jahrhundert folgte ein neuer Strom frankophoner Flüchtlinge, diesmal Hugenotten, die in die französischen Gemeinden der niederländischen Städte aufgenommen wurden. Hatten sich die Flüchtlinge des späten 16. Jahrhunderts durch eine besondere Abneigung gegen Spanien ausgezeichnet, so distanzierten sich ihre Glaubensgeschwister ein Jahrhundert später deutlich von Frankreich.

Für die Medienmacher bestand darin ein doppelter Nutzen: Zum einen war Französisch die »Lingua franca« Europas im 17. und 18. Jahrhundert, der Markt für französischsprachige Texte war viel größer als der für niederländischsprachige. Zum anderen kamen mit den Glaubensflüchtlingen überdurchschnittlich viele medienerfahrene Personen in die holländischen Städte, die als Verleger oder Zeitschriftenredakteure reüssierten. Sie nutzten verbliebene Kontakte nach Frankreich, um Nachrichten zu akquirieren und eigene Periodika zu vertreiben, sie handelten aber auch mit Interessenten im gesamten sonstigen Europa. Dies klappte gut, obwohl viele von ihnen offen gegen die Regierung Ludwigs XIV. schrieben. Diese Grundhaltung ging mit den Interessen der einheimischen politischen Publizisten einher, seit die Republik 1672 unter fragwürdigen Begründungen von französischen Armeen besetzt worden war. Einige Jahre lang dominierte noch die Vorsicht, doch ab ca. 1690 konnte man in der Republik unter dem Schutz der englisch-oranischen Personalunion alles schreiben, was die französische Regierung ärgerte. Eine französischsprachige Spitzenpresse aus Zeitungen und Zeitschriften etablierte sich in Amsterdam, Den Haag, Leiden oder Haarlem, die ganz Europa mit Nachrichten versorgte, und das bis in die Französische Revolutionszeit hinein ${ }^{20}$.

19 Zur wallonischen Gemeinde in Amsterdam: Willem Frijhoff / Maarten PraK (Hg.), Geschiedenis van Amsterdam. Centrum van de Wereld, 1578-1650, Amsterdam 2004, S. 414f.

20 Vgl. beispielsweise zur »Gazette d'Amsterdam«: Pierre RÉTAT, La Gazette d'Amsterdam, miroir de l'Europe au 18e siècle, Oxford 2001; zur »Gazette de Leyde«: SchNEIDER, De Nederlandse krant, S. 80. 


\section{Das Alte Reich}

Das klassische Bild der politischen Publizistik im Alten Reich ist geprägt von strengen Presseedikten, der Überhöhung des Herrschaftsarkanums als politische Realität, von zahlreichen überlieferten Zensurprozessen und vom Theorem der »repräsentativen Öffentlichkeit«, das Jürgen Habermas vor fast einem halben Jahrhundert in die Welt gesetzt hat ${ }^{21}$. Mit der Wirklichkeit hatte all dies nur begrenzt zu tun. Das Alte Reich besaß, wie die Niederlande, eine ausgeprägte Föderalstruktur: Es konkurrierten zum einen der Kaiser als Reichsoberhaupt mit der Gesamtheit der Reichsstände, die Sitz und Stimme im Reichstag hatten (vertikale Konkurrenz), auf der nächstniedrigeren Ebene auch die Reichsfürsten mit ihren Landständen, wobei diese Konflikte auf die Ebene der Reichsgerichte emporgehoben werden konnten. Zum anderen konkurrierten aber auch unterschiedliche Reichsstände miteinander (horizontale Konkurrenz), z.B. um Gebietsbesitz und Herrschaftsrechte, aber auch um symbolische Kapitalien wie die Positionierung in den Kurien des Reichstags (Rangstreit) oder um die Prozeduren bei Belehnungen (Zeremoniellstreit). All dies ist vielfach untersucht worden, nicht zuletzt im Mainzer Institut für Europäische Geschichte, wobei das Reichssystem aus staatstheoretischer ${ }^{22}$ sowie verfassungs- und sozialhistorischer Sicht ${ }^{23}$ ebenso monographisch behandelt wurde wie unter den Paradigmata des »komplementären Reichsstaats $\ll^{24}$ oder der verfassungsgeschichtlichen Symbolsprache ${ }^{25}$.

Daraus folgte, dass Medienproduzenten relativ leicht an Informationen kamen, weil die politischen Potenzen, indem sie miteinander konkurrierten, gern Nachrichten durchließen, die ihnen selbst nutzten oder dem Gegner schaden konnten. Die großen Editionswerke seit Goldast von Haiminsfeld und Lundorp waren zum Teil Selbstdarstellung der Fürsten in ihren symbolischen Kapitalien, den innegehabten und den beanspruchten ${ }^{26}$. Am Im-

21 Jürgen Habermas, Strukturwandel der Öffentlichkeit. Untersuchungen zu einer Kategorie der bürgerlichen Gesellschaft, Neuwied 1962 (ND Frankfurt/Main 1990).

22 Bernd Roeck, Reichssystem und Reichsherkommen. Die Diskussion über die Staatlichkeit des Reiches in der politischen Publizistik des 17. und 18. Jahrhunderts, Stuttgart 1984.

23 Besonders Karl Otmar Freiherr von Aretin, Das Alte Reich 1648-1806, 3 Bde., Stuttgart 19931997.

24 Georg Sснміdт, Geschichte des Alten Reiches. Staat und Nation in der Frühen Neuzeit, 14951806, München 1999.

25 Barbara Stollberg-Rilinger, Des Kaisers alte Kleider. Verfassungsgeschichte und Symbolsprache des Alten Reiches, München 2008.

26 Melchior Goldast von HAiminsfeld, Copeylicher Begriff verschiedener Reichs=Satzungen/ und anderer des Heil. Römischen Reichs/ Keyser/ König/ Churfürsten und Gemeiner Stände/ Constitutionen/ Ordnungen [...], 2 Bde., Hanau 1609 (ND Frankfurt/Main 1712); Michael Caspar Lundorp, Der Römischen Keyserlichen [...] Mayestat [...] und deß heiligen Römischen Reichs/ Geistlicher und Weltlicher Chur und Fürsten und anderer Reichsständ Acta Publica [...], 10 Bücher in 4 Bden., Frankfurt/Main 1621-1624; ders., Der Römischen Keÿserlichen [...] 
merwährenden Reichstag gelang es nie, den Strom der Informationen trockenzulegen, der von der subalternen Ebene an die »Novellanten« verkauft wurde $^{27}$. Die Tätigkeit der Obersten Reichsgerichte war ohnehin öffentlich, so dass jeder Interessent aus dem In- oder Ausland sich problemlos auf dem aktuellen Stand halten konnte, wenn er regelmäßig gute Periodika bezog und eventuell noch eine geschriebene Zeitung aus Regensburg abonnierte. Aber auch die breitere Bevölkerung las Zeitung oder ließ sie sich auf dem Markt oder im Gasthaus vorlesen ${ }^{28}$. Im Laufe einiger Jahrzehnte wurden nicht nur die politischen, wirtschaftlichen und akademischen Eliten flächendeckend versorgt, sondern auch das Kleinbürgertum, während die Tagespresse den Bauernstand nach gegenwärtigem Forschungsstand erst in der zweiten Hälfte des 18. Jahrhunderts erreichte ${ }^{29}$. Die Mehrzahl der periodischen Presseorgane war in Reichsstädten beheimatet, wobei Hamburg, Köln, Frankfurt/Main, Augsburg und Nürnberg herausgehobene Rollen spielten. Daneben übte das kursächsische Leipzig als Messeplatz für den Buchhandel, insbesondere für historisch-politische Zeitschriften und Editionen von Staatsrechtsquellen (Lünig), eine Zentralfunktion aus.

In den anderen Reichsterritorien standen periodische Druckmedien unter einer stärkeren Kontrolle. Insbesondere die Innenpolitik des Landesherren war aus der Berichterstattung ausgenommen, und auch sonst wurde auf die drei Hauptbereiche der Zensur geachtet: 1. Respekt vor dem Landesvater und anderen Standespersonen, 2. Vermeidung von Kritik an anderen Konfessionen und ihren Praktiken, 3. Beachtung der guten Sitten. Diese Kriterien waren allgemein bekannt und von den Medienmachern akzeptiert. In der großen Mehrzahl der Fälle verlief das Nachrichtenwesen in gewohnten Bahnen, ohne dass Anstoß erregt wurde.

Mayestät [...] auch deß heiligen Römischen Reichs Geistlicher und Weltlicher Ständ/ Chur und Fürsten [...] Acta Publica [...], 10 Bücher in 7 Bden., Frankfurt/Main 1627-1641.

27 Zur Kommunikation am Immerwährenden Reichstag: Susanne Friedrich, Drehscheibe Regensburg. Das Informations- und Kommunikationssystem des Immerwährenden Reichstags um 1700, Berlin 2007. Eine Fallstudie: Johannes ARNDT, »Pflicht=mässiger Bericht«. Ein medialer Angriff auf die Geheimnisse des Reichstags aus dem Jahr 1713, in: Jahrbuch für Kommunikationsgeschichte 4 (2002), S. 1-31.

$28 \mathrm{Vgl}$. die Episode einer Wirtshausschlägerei in Frankfurt/Main 1656 nach öffentlicher Zeitungslektüre, vermittelt durch eine geschriebene Zeitung: Elger BLÜHM / Rolf ENGELSING (Hg.), Die Zeitung. Deutsche Urteile und Dokumente von den Anfängen bis zur Gegenwart, Bremen 1967, S. 36f.

29 Martin Welke, Zeitung und Öffentlichkeit im 18. Jahrhundert, in: Elger BlÜHm / Hartwig GeBHARDT (Hg.), Presse und Geschichte I. Beiträge zur historischen Kommunikationsforschung, München 1977, S. 71-99; Martin WelKe, Das Publikum der frühen periodischen Tagespresse in Deutschland, in: Dittmar Dahlmann (Hg.), Die Kenntnis Rußlands im deutschsprachigen Raum im 18. Jahrhundert. Wissenschaft und Publizistik über das russische Reich, Göttingen 2006, S. 11-24. - Vgl. zur Leserschaft in Hamburg: Holger BönIng, Welteroberung durch ein neues Publikum. Die deutsche Presse und der Weg zur Aufklärung. Hamburg und Altona als Beispiel, Bremen 2002, S. 128f. 


\section{Frankreich}

Aus der Perspektive der Aufklärer und vieler ihrer Erforscher war Frankreich das Land der obrigkeitlichen Medienmonotonie: Kardinal Richelieu hatte 1631 dem Arzt Theophraste Renaudot gestattet, die Gazette, später Gazette de France zu betreiben, und dieses offiziöse Periodikum druckte demnach nichts als die Meinung der Regierung in Paris ${ }^{30}$. Bis 1789 wurde das Entstehen alternativer Nachrichtenblätter mit allen Mitteln behindert oder verhindert, wobei zahllose Untertanen, die etwas mehr über Europa und vor allem das eigene Land wissen und schreiben wollten, ihr Leben in der Bastille fristen mussten. Erst nach 1750 wurden Aufklärer Zensoren und Zensoren Aufklärer, spielten die Untergrundschriftsteller mit ihnen Katz und Maus, und die staatliche Kulturhegemonie erodierte, lange bevor der König 1793 seinen Kopf verlor ${ }^{31}$. Soweit die herrschende Meinung.

Es ist richtig, dass die offizielle Hauptversorgung mit Nachrichten in Frankreich staatlich gelenkt, kontrolliert und monopolisiert war. Das bedeutete aber nicht, dass man nicht an andere Informationen hätte kommen können. Insbesondere die politischen und wirtschaftlichen Eliten in Paris wussten von der Existenz der französischsprachigen Blätter aus den Niederlanden, die Gazettes périphériques. Viele ihrer Mitglieder waren im Verborgenen die Informanten gewesen, die geholfen hatten, die Blätter zu füllen. Auch war der Handel mit den Auslandszeitungen lizensiert und nur selten verboten. Allerdings waren sie mit hohen Zöllen belegt, was ihre Massenverbreitung behinderte. Gilles Feyel hat diesen Umstand mit dem Begriff »double marché de l'information « bezeichnet ${ }^{32}$.

Trotz der staatsnahen Haltung folgte die Gazette den Usancen des europäischen Mediensystems. Es wurden die internationalen Nachrichten gebracht, die gerade umliefen und auch in den anderen Periodika in Europa erschienen. So fand der Ständestreit in Mecklenburg in der zweiten Dekade des 18. Jahrhunderts, der 1719 zu einer Reichsexekution führte, detaillierte Berichterstattung: Fast jede Woche wurde eine neue Meldung aus Hamburg angefügt. Es ist kaum wahrscheinlich, dass ein französischer Regierungszensor auf diese regelmäßige Einrückung bestanden hat. Die Tendenz zeigt sich daher am

30 Lexikalischer Überblick: Gilles Feyel, Art. »Gazette de France«, in: Jean SGard (Hg.), Dictionnaire des journaux (1600-1789), Bd. 1, Paris 1991, S. 443-449.

31 Gudrun Gersmann, Im Schatten der Bastille. Die Welt der Schriftsteller, Kolporteure und Buchhändler am Vorabend der Französischen Revolution, Stuttgart 1993; Robert DARNTON, Literaten im Untergrund. Lesen, Schreiben und Publizieren im vorrevolutionären Frankreich, Frankfurt/Main 1988 (engl. 1982); ders., Poesie und Polizei. Öffentliche Meinung und Kommunikationsnetzwerke im Paris des 18. Jahrhunderts, Frankfurt/Main 2002 (engl. 2000); ders. (Hg.), Revolution in Print. The Press in France 1775-1800, Berkeley / London 1989.

32 Gilles FEYEL, L'annonce et la nouvelle: la presse d'information en France sous l'Ancien Régime (1630-1788), Oxford 2000, S. 435-546; zu den »Gazettes périphériques«: ebd., S. 436. 
ehesten in den Weglassungen: So wurde die Introduktion des Kurfürsten von Hannover in den Kurfürstenrat im September 1708 nicht erwähnt, weil die Kurerhebung von Frankreich bis dahin noch nicht anerkannt worden warnoch im Juni 1711 hieß Kurfürst Georg Ludwig nur »Duc de Hanover « ${ }^{33}$. Auch das Reichsvikariat der Kurpfalz 1711 fehlt völlig, denn Frankreich erkannte den geächteten Max Emanuel von Bayern als den korrekten Reichsvikar an, was die Zeitung aber nicht als Kontroverse ausführen mochte. Das kursächsische Reichsvikariat wurde übrigens erwähnt ${ }^{34}$.

Im ausgehenden 17. Jahrhundert traten zwei wichtige Zeitschriften hinzu, die ebenfalls einen staatsnahen Charakter hatten: das 1665 gegründete Journal des Sçavants ${ }^{35}$ als zentrales Organ für die Vermittlung wissenschaftlicher Erkenntnisse an alle Gebildeten und der ab 1672 erscheinende Mercure Galant $^{36}$ als das zentrale Hof-, Kultur- und Literaturblatt. 1707/1716 wurde diese Trias zum Quartett durch die Suite de la Clef ou Journal Historique, eine historisch-politische Zeitschrift, die nach ihrem Herkunftsort auch Journal de Verdun genannt wurde. Maßvolles Räsonnement war hier erlaubt ${ }^{37}$.

Frankreich war daher zwischen 1648 und 1750 mit den gängigen politischhistorischen Informationen versorgt, die auf dem Kontinent umliefen. Die Regierung nutzte ihre Gazette zur offiziösen Meinungsmultiplikation, die Herrschaftseliten gelangten in den Besitz auch erweiterter Informationen, die Mehrzahl der Untertanen schien mit dem Zustand nicht unzufrieden zu sein. Zugespitzte Herrschaftskritik war bis zu dieser Zeit noch nicht das Ziel größerer Kreise innerhalb der Autoren- und Verlegerschaft.

33 Gazette de France, 13. Juni 1711.

34 Ebd., 23. Mai 1711.

35 Zum Selbstverständnis des Herausgebers Dennis de Sallo: »Journal de sçavants« 1 (1665): »Avis de l'imprimeur au lecteur«, zitiert nach: Joachim KIRCHNER, Das deutsche Zeitschriftenwesen. Seine Geschichte und seine Probleme, Bd. 1, Wiesbaden 1958, S. 16.

36 Zum Periodikum und seinem Gründer: Monique Vincent, Donneau de Visé et le Mercure Galant, Paris 1986; dies., Anthologie des nouvelles du Mercure Galant (1672-1710), Paris 1996; dies., Mercure Galant: extraordinaire, affaires du temps, table analytique contenant l'inventaire de tous les articles publiés 1672-1710, Paris 1998; dies., Le Mercure Galant: présentation de la première revue féminine d'information et de culture, 1672-1710, Paris 2005. - Hans Mattauch spricht von einem »Salonblatt«: Hans Matтauch, Situation und Typologie der französischen Zeitschriftenpresse in der Frühzeit (1665-1730), in: Publizistik. Vierteljahreshefte für Kommunikationsforschung 10 (1965), S. 538-551.

37 [Claude Jourdan (Hg.)], Suite de la Clef ou Journal historique sur les matières du temps, contenant aussi quelques nouvelles de littérature, et autres remarques curieuses, in: Journal de Verdun, 120 Bde., 1717-1776. Hintergrundinformationen: Philip STEwarT, Art. »Suite de la Clef ou Journal historique (1717-1776)«, in: Jean SGARD (Hg.), Dictionnaire des journaux (1600-1789), Bd. 2, Paris 1991, S. 1105f. Vgl. auch die Überlegungen zur französischen Medienlandschaft um 1740 von Sebastian KüsTER, Vier Monarchien - Vier Öffentlichkeiten. Kommunikation um die Schlacht bei Dettingen, Münster 2004, S. 226-229. 


\section{England}

England gilt Medieninteressenten als das Musterland der Pressefreiheit. Dabei hatte sich die Geschichte des Zusammenwirkens der Medienproduzenten und der Staatsgewalt bis zum Ende des 17. Jahrhunderts nicht sehr von Frankreich unterschieden: War die Zentralgewalt temporär schwach, wie 1640 bis 1649,1679 bis 1683 oder 1688/89, dann blühte die Innovation auf dem Bücher- und Flugschriftenmarkt, um nach der anschließenden Restauration der Staatsgewalt wieder in engere Bahnen gelenkt zu werden ${ }^{38}$. »Frei $«$ wurde die Presse erst 1695, als es dem Parlament nicht gelang, ein neues Zensurgesetz zu verabschieden, nachdem das alte ausgelaufen war. So blieb der gewachsene Zustand bestehen, nachdem die konkurrierenden Positionen der Parlamentsgruppen Gegenstand der Berichterstattung sein konnten, ohne dass dies ein Verstoß gegen das Herrschaftsarkanum darstellte. Die üblichen Vorsichtsmaßnahmen - Respekt vor der Krone, Verzicht auf Beleidigung von Standespersonen, Vermeidung von Angriffen auf religiöse Empfindungen sollten allerdings weiter beachtet werden, das geboten Anstand und Sitte, und das war auch weiterhin einklagbar. Der Presseinnovation kam zugute, dass König Wilhelm III. aus den Niederlanden stammte und dort die freie Presse gewohnt war. Er war darin geübt, eine eigene Pressearbeit zu leisten, um sich in ein vorteilhaftes Licht zu setzen. Schnell setzte er durch, dass seine Parteigänger im Parlament wirkungsvoller in den Zeitungen erschienen als die Gegner ${ }^{39}$.

Nach früheren »Newsbooks« und anderen kurzlebigen Periodika wurde 1665 die London Gazette als offiziöses Regierungsblatt lizensiert ${ }^{40}$. Die Informationen des Blattes stammten teilweise aus der offiziellen Korrespondenz der englischen Regierung, anderenteils aus Zeitungen des Festlands, die ausgewertet wurden. Dazu gehörten die Gazette aus Paris, die Relations Veritables aus Brüssel, die Gazette d'Amsterdam und der Oprechte Haerlemse Courant $^{41}$. Auch gab es ein System aus professionellen Avisenschreibern, von denen viele Informationen europaweit vermittelt wurden. Die London

38 Zur frühen englischen Pressegeschichte: Jeremy BLACK, The English Press, 1621-1861, Stroud 2001.

39 Black, The English Press, 1621-1861, S. 8. Zur englischen Presse unter Wilhelm III.: Robin B. WaLKER, The Newspaper Press in the Reign of William III, in: The Historical Journal 17 (1974), S. 691-709.

40 Immer noch grundlegend: Phyllis Margaret Handover, A History of the London Gazette, 1665-1965, London 1965. Zu den Entstehungsumständen: Daniel Woolf, News, History and the Construction of the Present in Early Modern England, in: Brendan Dooley / Sabrina A. BARON (Hg.), The Politics of Information in Early Modern Europe, London / New York 2001, S. $80-118$, bes. S. $97 f$.

41 Schultheiss-Heinz, Politik in der europäischen Publizistik, S. 68. 
Gazette bezog durch sie Informationen aus dem Reich ebenso wie aus Italien (Rom und Venedig) ${ }^{42}$. Umgekehrt werteten auch kontinentale Druckmedien die Londoner Zeitung als Quelle aus.

Die Zeitung überstand auch das Jahr 1695 und wurde zum Vorbild für zahlreiche Neugründungen. Der Verzicht auf staatliche Vorzensur hatte eine Medienblüte zur Folge, die nicht mehr durch Restriktionen, sondern nur noch durch das Fassungsvermögen des Marktes beschränkt wurde. Zwar wurden 1697, 1698, 1702, 1704 und 1712 nochmals Initiativen für ein Zensurgesetz unternommen, bis Krone und Parlament einsahen, dass die öffentliche Ordnung trotz der Eigendynamik am Medienmarkt keineswegs beeinträchtigt wurde ${ }^{43}$. Im Gegenteil wuchsen dem Staat ab 1712 durch die »Stamp Tax« erhebliche Steuereinkünfte $\mathrm{zu}^{44}$.

Die Staatsnähe der London Gazette blieb auch über 1695 hinaus erhalten. Nach dem Sieg des Herzogs von Marlborough und des Prinzen Eugen über die vereinigten Bayern und Franzosen bei Höchstädt 1704 druckte die Gazette nicht nur die Siegesmeldungen, sondern ein halbes Jahr lang Glückwunschadressen zahlreicher Persönlichkeiten und Korporationen des öffentlichen Lebens in Großbritannien an die Königin wegen dieses Sieges ${ }^{45}$. Ansonsten bildete auch die London Gazette das übliche Spektrum europaweiter Politikberichterstattung ab, wobei kleine Ungenauigkeiten nicht ausbleiben konnten, sondern für die Eigenständigkeit der Redaktionsarbeit sprachen. Beispielsweise wurde der Kurfürst von Mainz während des Interregnums von 1711 als »Vicar of the Empire« bezeichnet, die Reichsvikariate von Kursachsen und Kurpfalz konnten bei diesem Kenntnisstand daher nur fehlen ${ }^{46}$.

Es erstaunt angesichts der Vielfalt der Zeitungen und späteren moralischen Zeitschriften, dass historisch-politische Zeitschriften offenbar in England keine Blüte erlebten. Die schon erwähnte Zeitschrift The Present State of Europe hing organisatorisch auf eine Weise, die nicht restlos geklärt ist, mit dem niederländischen Mercure historique et politique zusammen, aus dem viele Artikel übernommen wurden. Nur den England-Teil hatte man entfernt ${ }^{47}$. Naheliegender Weise kritisierte das Periodikum die französische Kriegführung, in respektloser Weise wurde Ludwig XIV. im Zusammen-

42 Peter Fraser, The Intelligence of the Secretaries of State and their Monopoly of Licensed News, Cambridge 1956, S. 53.

$43 \mathrm{Vgl}$. zu den Einzelheiten: BLack, The English Press, 1621-1861, S. 8. Zu den Auswirkungen: Hannah BARKER, Newspapers, Politics and English Society, 1695-1855, Harlow 2000.

44 Vgl. zur Entwicklung der Besteuerung: Barker, Newspapers, Politics and English Society, S. 39.

45 Die London Gazette wurde von September 1704 bis Anfang April 1705 durchgesehen, und es wurden über den ganzen Zeitraum hinweg Glückwunschadressen gefunden, wenn auch mit abnehmender Tendenz.

46 London Gazette, 5. Mai 1711 st.vet. (aus Köln vom 5. Mai 1711 st.n.).

47 WaLKer, The Newspaper Press in the Reign of William III, S. 697. 
hang mit seinen Bündnissen mit Kurbayern 1702 »the most Christian Defender of Infidelity« tituliert, und die Freude über den Sieg von Blenheim/ Höchstädt 1704 fand offenen Ausdruck ${ }^{48}$.

\section{Die europäische Öffentlichkeit}

Europa war für die Nachrichtenproduzenten von Anfang an keine Fiktion, sondern eine Realität. Das frühmoderne Mediensystem war stets ein europäisches, in das nach und nach außereuropäische Informationen eingeflochten wurden. Es verdankte seine Entstehung und die Systematik seines Prozessierens weder einem politischen Anstoß noch der dauerhaften politischen Förderung oder Finanzierung. Allerdings entnahm es seinen Gegenstand und seine Inhalte der politischen Entwicklung und den politischen Konflikten seiner jeweiligen Zeit. Die europäische Öffentlichkeit wird hier nicht als eine soziale Gruppe verstanden, sondern als ein Kommunikationszusammenhang: Wer an der Nachrichtenproduktion bzw. -rezeption teilhatte, wirkte an dieser Öffentlichkeit mit. Informationen wurden in der jeweiligen Landessprache oder auf französisch erhoben. Für das jeweilige Sprachsegment wurden die periodischen Endprodukte wiederum in die Landessprache übersetzt. Die Übersetzungsleistung gehört zu den wichtigsten Schritten des Informationskreislaufes, ist allerdings bislang noch kaum erforscht.

Genauso wenig, wie die Politik dieses System geschaffen hatte, konnte sie es wieder verschwinden lassen: Nachdem das Flugschriftenwesen im 16. und das Zeitungswesen im 17. Jahrhundert einmal etabliert waren, hätte der Ausstieg eines verärgerten Potentaten nicht sein Land medienfrei und damit leichter kontrollierbar gemacht, sondern er wäre der Lächerlichkeit anheim gefallen: Der einzige große Fürst in Europa, der auf ein geordnetes Medienwesen in seinem Land dauerhaft verzichtete, war der Papst. Doch auch im Kirchenstaat gab es genügend Avisenschreiber, um alle europäischen Interessenten, politische, wirtschaftliche und medienkulturelle, stets mit aktuellen Nachrichten zu versorgen. Das Mediensystem profitierte damit von der politischen Konkurrenz: Wenn schon eine politische Macht der jeweils anderen Schlimmes zutraute und wenig Gutes wünschte, so förderte sie auch aktiv oder durch Unterlassen die Nachrichtenübermittlung zu deren Ungunsten. In einigen Fällen wurde dies offensichtlich geduldet, etwa bei der breiten Berichterstattung in den Niederlanden in französischer Sprache, in ande-

48 Zum Zitat: »Present State of Europe« 1702, Bd. 2, November, S. 420f.; zur Schlacht vom 13. August 1804: »Present State of Europe« 1704, Bd. 2, August, S. 321-330 mit mehreren Briefen hochgestellter Militärs und einer Aufstellung über die Anzahl und den Rang der Kriegsgefangenen. 
ren wurde es ausdrücklich gefördert, etwa bei der Unterstützung der »Société typographique« in Neuchâtel durch König Friedrich den Großen von Preußen $^{49}$.

49 Vgl. zu Neuchâtel und zum französischem Untergrundbuchdruck vor allem die Studien von Robert DaRnton, Das große Katzenmassaker. Streifzüge durch die französische Kultur vor der Revolution, München / Wien 1989; ders., Forbidden Best-Sellers of Prerevolutionary France, New York / London 1995; ders., Literaten im Untergrund; ders., Poesie und Polizei. 


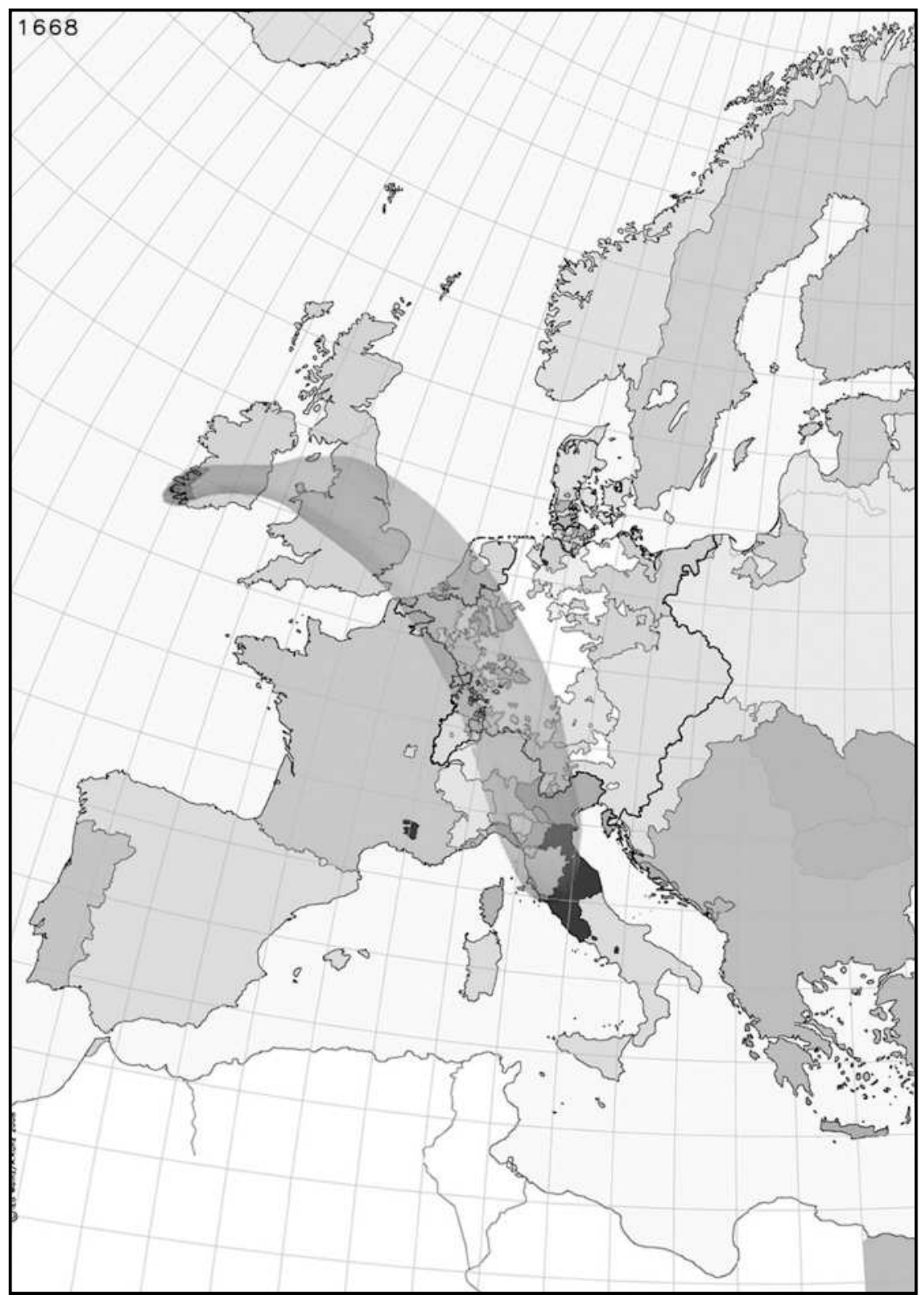

Abbildung 1: Das »Blue-Banana«-Gebiet 


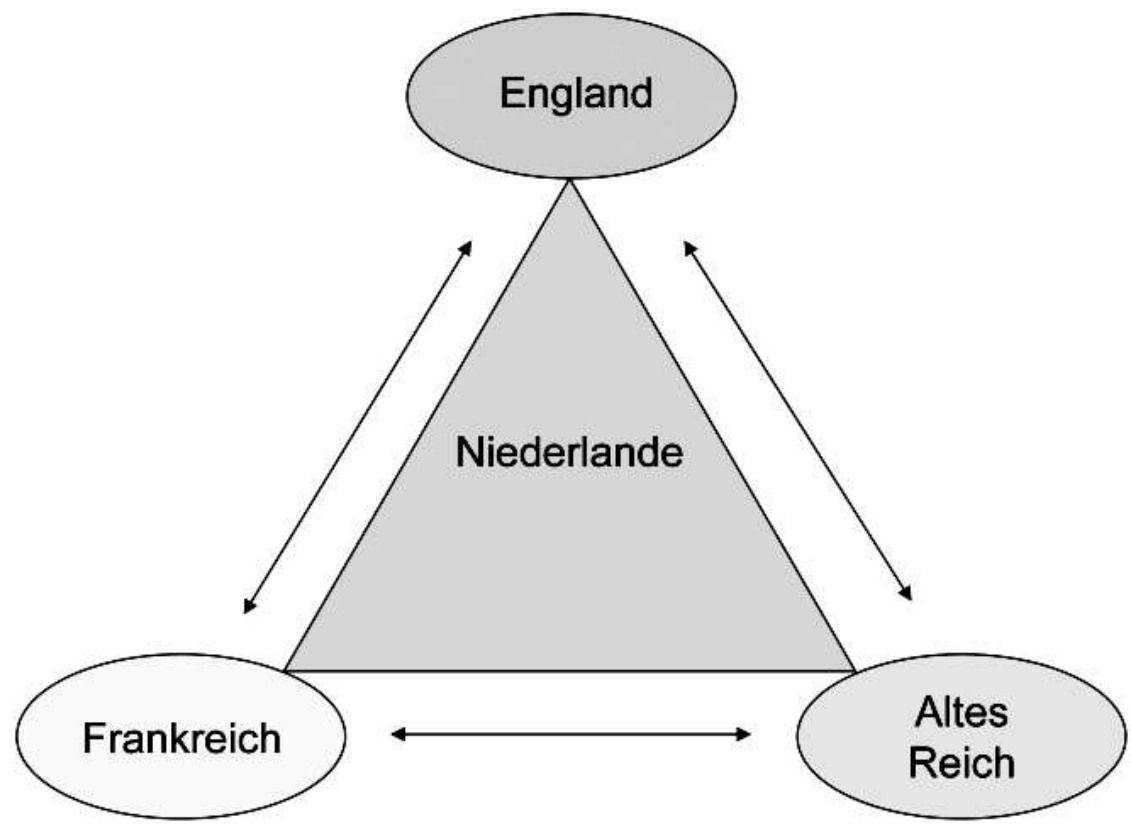

Abbildung 2: Medialer Tetraeder: Beziehungsgeflecht der nationalen Druckmedienkulturen in der Frühmoderne 


\section{Wolfgang Harms}

\section{Europa in der deutschen Bildpublizistik der Frühen Neuzeit}

Der nachfolgende Beitrag versucht, aus der Geringfügigkeit der Befunde einige Besonderheiten des untersuchten Gegenstandsbereichs zu erklären, der Bildpublizistik innerhalb ihres Medienverbunds mit Zeitung und Flugschrift $^{1}$, und zwar hinsichtlich eines generellen Interesses an Europa und der speziellen Interessenlage beim nicht randscharf zu rekonstruierenden Publikum des illustrierten Flugblatts. Dieses ist über seinen persuasiv gewichtigen Bildanteil besonders mit den Bilderfahrungen verknüpft, die auch in anderen Bereichen der bildenden Künste, nicht zuletzt in der Titelgraphik zeitgenössischer Buchproduktion entstanden sind. Das illustrierte Flugblatt ist stets auf historische Situationen bezogen, auf die es oft appellativ meinungsbildend reagiert. Innerhalb des durch die Praxis, nicht aber durch festgelegte Regelungen hergestellten Medienverbunds lieferte das Flugblatt bis zum Auftreten periodisch erscheinender Zeitungen Anfang des 17. Jahrhunderts Verbindungen von primärer Information und daran anknüpfender Deutung oder Meinungslenkung. In Konkurrenz mit der Zeitung konzentrierte sich das Flugblatt im 17. Jahrhundert stärker auf das weite Spektrum der Meinungserzeugung, Orientierung, Perspektivierung und Meinungslenkung.

Was besagt es, wenn es auffällig wenig illustrierte Flugblätter gibt, die diese Aufgabe gegenüber allem, was mit dem Wort `Europa zu verbinden wäre, übernehmen? In der zeitgenössischen mehrblättrigen Flugschrift entfalten sich, wie Georg Schmidt gezeigt hat ${ }^{2}$, lebhafte Diskurse über die Machtverhältnisse und sozialen Zustände in Europa, Erwägungen über die Herausbildung neuer Argumentationsmuster und Formen der Meinungsbildung in Flugschriften, zu denen auch narrativ-fiktionale Schilderungen der europäischen Gegenwart gehören. Die informativen und vor allem argumentativ und trak-

1 Zum Medienverbund siehe Michael SchilLing, Bildpublizistik der frühen Neuzeit. Aufgaben und Leistungen des illustrierten Flugblatts in Deutschland bis um 1700, Tübingen 1990, S. 115; Wolfgang HaRms, Das illustrierte Flugblatt in Verständigungsprozessen innerhalb der frühneuzeitlichen Kultur (zuerst 2000), wiederabgedruckt in: Wolfgang HaRms / Michael SchiLLing (Hg.), Das illustrierte Flugblatt der frühen Neuzeit. Traditionen - Wirkungen - Kontexte, Stuttgart 2008, S. 63-71.

2 Georg SснміDт, Das Reich und Europa in deutschsprachigen Flugschriften. Überlegungen zur räsonnierenden Öffentlichkeit und politischen Kultur im 17. Jahrhundert, in: Klaus BussmanN / Elke Anna Werner (Hg.), Europa im 17. Jahrhundert. Ein politischer Mythos und seine Bilder, Wiesbaden / Stuttgart 2004, S. 119-148. 
tathaft erörternden Behandlungen des Europathemas in der Flugschrift haben fließende Übergänge zu Behandlungen im Buch, in annalistischen Werken wie dem Theatrum Europaeum und im knapper zuspitzenden, oft besser memorierbaren Flugblatt und wohl auch in den Gesprächen von Politikern und Juristen, aber Letzteres ist nur eine Vermutung. In der erzählenden deutschen Literatur fehlt das mit dem Begriff `Europa erfassbare Thema einer überstaatlichen Einheit lange Zeit, bis es dann im Werk Grimmelshausens, besonders in seiner Continuatio des Simplicissimus, im Rahmen einer Betrachtung Europas vom außereuropäischen Raum her gehäuft dargestellt und perspektiviert wird ${ }^{3}$. Nicht nur im Hinblick auf das Thema `Europa $<$ verfolgt das illustrierte Flugblatt in seinem Bezug auf die von Situation zu Situation, Region zu Region, Konfession zu Konfession variierenden Erwartungen, Hoffnungen, Befürchtungen und Verwirrungen des intendierten Publikums nur selten den Einblick in länger andauernde Zusammenhänge; es konnte dann von einer modernen Geschichtsschreibung, die teleologisch geordnete Hauptstränge von Herrschaftsgeschichte ins Zentrum rückte, vorrangig als vermeintliche Illustration bekannter Hauptereignisse instrumentalisiert werden. Des illustrierten Flugblatts tatsächlich ganz anders gelagerte wirkliche Besonderheit, in seiner Zeit etwas aussprechbar und anschaulich zu machen, was sonst kaum dokumentierbares Element oder Hintergrund zu Ereignissen geblieben wäre, wurde erst von neuerer Forschung wahrgenommen, die sich für latente Motivationen, auch für unterschwellig sich entwickelnde oder schließlich doch ins Leere laufende Hoffnungen und Ziele interessiert und nicht jede Thematisierung eines Flugblatts lediglich auf eine schon erwiesene Tatsächlichkeit hin befragt. Das weite Spektrum seiner Schwierigkeitsgrade machte es möglich, dass über das Flugblatt sämtliche Bildungsschichten seiner Zeit erreicht wurden. Es gab kein Thema, keine Interessenlage, auf die es sich nicht hätte einstellen können. Doch musste vorausgesetzt werden können, dass irgendwo im Publikum ein Interesse schon latent vorhanden war und weiter gelenkt werden oder aber wenigstens erstmals erregt werden konnte. Hätte ich hier die Stellung Kursachsens zwischen Kaiser und Schweden im Zeitraum 1628 bis 1648 zu behandeln, wäre die Menge der FlugblattBelege groß, die ihre Wirkung sowohl im engeren sächsischen Herrschaftsbereich wie in der gesamten Bevölkerung Norddeutschlands angesichts drohender militärischer Entwicklungen suchten. Unterschiedliche Arten von Unruhe, Neugierde und Sorge sind die Voraussetzungen anderer Ballungen

3 Peter Hanenberg, Die Entdeckung Europas in der deutschen Literatur, in: Jan Papiór (Hg.), Eurovisionen III. Europa Vorstellungen im kulturhistorischen Schrifttum der frühen Neuzeit (16. bis 18. Jahrhundert), Posen 2001, S. 357-366; illustrierte Flugblätter bleiben unbeachtet. Zur schärferen Wahrnehmung Europas mithilfe des Vordringens in die außereuropäische Welt siehe auch Heinz Duchнardt, Europa am Vorabend der Moderne 1650-1800, Stuttgart 2003, S. 36f. 
von Bildpublizistik, etwa zu den ersten drei Jahrzehnten der Reformation, zum Erscheinen des Kometen 1618 zu Kriegsbeginn, zum Auftreten des angeblichen Messias Sabbatai Zwi (um 1675), zum Bauernaufstand ob der Enns (um 1625) oder zu der Frage der Bewahrung deutscher kultureller Identität in der Abgrenzung von allem >Welschen ( (besonders um 1625/1640).

Im Folgenden soll zunächst eine Randerscheinung des illustrierten Flugblatts herangezogen werden. Es ist ein folioformatiges illustriertes Blatt, das um 1667 an der Universität Altdorf auch als Lehrtafel benutzt worden ist ${ }^{4}$. Es stellt graphisch und mit lateinischen Inschriften die Statue aus Nebukadnezars Traum dar, die, getragen durch die fortschreitende Daniel-Exegese, ein Gerüst christlich-heilsgeschichtlicher Strukturierung des Ablaufs der vier Weltalter bieten konnte, wobei auf dem Blatt der Stein, der in Nebukadnezars Traum die Statue zerstört, in Form eines Torsos gegenwärtig ist, der das sich ausbreitende Christentum verkörpert. Die Zerstörung meint spiritualiter, dass das Reich Christi alle älteren Reiche dieser Welt zerstört und ersetzt ${ }^{5}$. Vom Kopf abwärts werden im alten Schema die Weltreiche der Chaldäer und Assyrer, dann der Meder und Perser, danach der Griechen chronologisch und zugleich räumlich gereiht, bis dann das vierte, sich bis in die europäische Gegenwart erstreckende Weltalter und Weltreich sich, dem Bildelement der Beine folgend, in zwei Teile teilt, das christlich-abendländische bis zu Kaiser Rudolf II., das mohammedanisch-morgenländische bis zu Sultan Selim II. Das Wort >Europa fällt hier nicht, doch ist das vierte Weltreich eindeutig vorwiegend in diesem Erdteil lokalisiert. Das Wissen eines chronologischen Schemas eröffnet die Einbindung Europas in die geographische Ordnung. Hier wird am Rande der Flugblattform eine Leistung der Enzyklopädien vermittelt, die das Wissen der Epoche sammeln und verfügbar halten und im 17. Jahrhundert den drei Erdteilen Asien, Afrika und Europa bereits Amerika als vierten Erdteil hinzufügen, so in Johann Jacob Hoffmanns Lexicon universale, das ab 1677 in Basel erscheint. Europa wird auf den geographischen Raum vom Nordkap bis zum Kap Maleas auf der Peloponnes, und vom portugiesischen Kap Sao Vicente bis zum Don und dem Marmara-Meer im Osten ${ }^{6}$ festgelegt,

4 Colossus vel Statua Regis Babylonici Nobogdonosoris, (Altdorf oder Nürnberg) 1667, abgebildet und von Andreas Wang kommentiert in: Wolfgang Harms (Hg.), Deutsche illustrierte Flugblätter des 16. und 17. Jahrhunderts, Bd. 2, Tübingen ${ }^{2} 1997$, Nr. II, 1. Diese bildgetragene Geschichtssystematik ist vielfach variiert worden, in ähnlicher Nähe zum illustrierten Flugblatt z.B. in: Colossus Monarchicus Statua Danielis Dan. II, 21, Augsburg (1765 oder später), Exemplar München, Bayrische Staatsbibliothek: Einbl. XI,7.

5 Eine gute Übersicht über die Beachtung von Kommentaren auf katholischer Seite bietet Cornelius a Lapide, Commentarius in Danielem prophetam, in: Joseph M. PÉronne (Hg.), Commentaria in Scripturam Sacram, Bd. 13, Paris 1860, S. 1-194, hier: S. 32f.

6 So retrospektiv zusammengefasst in Zedlers Universallexikon und zuvor bei Johann Jacob Hoffmann, Lexikon universale, historico - geographico - chronologico - poetico - philologicum, Bd. 1, Basel 1677, S. 693. 
so dass auch Teile des Osmanischen Reichs zu Europa gehören. Es ist aufs Flugblatt zu übertragen, was Kaspar Stieler 1695 über die Zeitung gesagt hat: Ihr Leser muss über die zeitgenössischen Herrscher und ihre Territorien Bescheid wissen und »muß der Europäischen Geschichte kundig seyn «" wenn er die vorgelegten Informationen bzw. Ereignisdeutungen verfolgen und beurteilen will, aber die primäre Quelle seines Wissens ist das Flugblatt in der Regel nicht, abgesehen von der Darstellung soeben eingetretener naturwissenschaftlicher, medizinischer, astronomischer oder meteorologischer Casus.

Das illustrierte Flugblatt bzw. seine Urheber, die Verleger, Drucker, Graphiker, Textautoren bis zum auswählenden Händler vermögen aufkommende oder schon länger akute Erwägungen des Publikums aufzugreifen, besonders auch erregende Aporien, auf die sonst keine Antwort überzeugt. Bis dahin unausgesprochene Fragen nach Hintergründen - etwa woher eine Hungersnot oder die Geldentwertung der Jahre 1620/25 herrührte - vermag es zum handhabbaren Gesprächsgegenstand zu machen, kann dabei Wertvorstellungen festigen oder aber spiegeln, wie und warum Werte fragwürdig zu werden drohen. Die gesamte Welt der Affekte, ihrer Bedingungen, Wirkungen und Bändigungen, die ja in Urkunden oder in der Zeitung nur selten greifbar werden, aber die ersten Wahrnehmungen der Zeitereignisse begleiten, kann hier in Bild und Text zu Bezugspunkten privater und öffentlicher Erörterung gemacht werden. Urheber der illustrierten Flugblätter sind oft Verleger oder Drucker, die zu erkennen meinen, welches Thema eine Resonanz finden könne, die dann den Verkauf erleichtert. Es ist aber auch möglich, dass Organe der Obrigkeit ein Flugblatt lancieren, die ein aufkommendes Thema beizeiten in ihrem Sinne besetzen wollen, etwa wenn derzeit ausgebliebene Machtkonstellationen als angeblich bereits dauerhaft vollzogenes Ereignis suggestiv vorgestellt werden, so die dauerhafte Unterstützung des Schwedenkönigs durch den sächsischen Kurfürsten ${ }^{8}$. Für eine spezielle Dimension an Hintergründen, die wohl eher in den Bereich der >arcana imperii fallen, steht das illustrierte Flugblatt nie unmittelbar, allenfalls über metapherngestützte Andeutungen zur Verfügung. An der Diskussion über den Prozess, der »zur Autonomie und Säkularität des modernen Politikbegriffes führte « ${ }^{9}$, beteiligten sich illustrierte Flugblätter ebensowenig wie an der Entwicklung von Konzepten für ein politisch zusammengehöriges Europa.

7 Kaspar Stieler, Zeitungs Lust und Nutz (1695), hg. v. Gert Hagelweide, Bremen 1969, S. 243.

8 Triga Heroum Invictissimorum pro veritate, o. O. 1632, abgebildet und von Michael SchILLING kommentiert in: Deutsche illustrierte Flugblätter, Bd. 2, Nr. II, 271.

9 Heinz Schilling, Krieg und Frieden in der werdenden Neuzeit - Europa zwischen Staatenbellizität, Glaubenskrieg und Friedensbereitschaft, in: Klaus Bussmann / Heinz Schilling (Hg.), 1648 Krieg und Frieden in Europa, Textband 1, Münster 1998, S. 13-22, hier: S. 20. 
Unter den vielen Blättern, die im Dreißigjährigen Krieg die Not der Zeit und die Friedenshoffnung behandeln, sind nur sehr wenige, die dabei auch von Europa sprechen. Zuerst als Beilage zu einer Frankfurter Messrelation erschien 1645 ein anonymes Blatt, das Groß Europisch Kriegs=Balet / getantzet durch die Könige vnd Potentaten / Fürsten vnd Respublicken / auf dem Saal der betrübten Christenheit ${ }^{10}$. Dass ein geographischer Raum als architektonischer Raum dargestellt wird, findet sich auf Flugblättern öfter; so betreten etwa Gustav Adolf von Schweden und Tilly als Heerführer den großen Saal eines Hauses, der als »römisches Reich« identifiziert wird. Dass es bei dem vorliegenden Blatt der Saal der »Christenheit« ist, darf als Umschreibung von Europa angesehen werden, wogegen die Anwesenheit des »Türckischen Kaisers« (am Rand rechts) kein Widerspruch ist. In der ersten der drei vorausgegangenen niederländischen Fassungen des Blatts war noch ohne Bezug auf Europa vom \Saal des Christenreiches` die Rede gewesen ${ }^{11}$. Die Tanzenden und ihre Zuschauer sind im Titel korrekt als Mächte Europas im Vorfeld der Friedensverhandlungen von Münster und Osnabrück angegeben, sie werden einzeln mit Hilfe einer Bildlegende identifiziert. Die später mit Bezug auf den Wiener Kongress bekannt gewordene Metapher `Der Kongreß tanzt< lässt sich nicht einfach zur Beschreibung dieses Blattes nutzen. Zuerst in einem Gedicht von Friedrich Rückert wird 1814 der Gegensatz gesehen, dass der (Wiener) Kongress nicht (voran-)gehe, sondern tanze, womit getadelt wird, dass die am Kongress beteiligten Fürsten und Diplomaten Lustbarkeiten dem Fortgang diplomatischer Arbeit vorziehen. Zwischen dem vorliegenden Blatt und dem Tadel von 1814 steht ein Augsburger Blatt von 1758 ${ }^{12}$ : Der Neu eröffnete Politische Masquirte Ball der Kriegenden Pouissancen in Germania, wo die Mächte auf einem mit einer Europakarte bedeckten Tanzboden galant tanzen.

Im Blatt von 1645 aber ist das Tanzen zunächst noch als Metapher fürs Kämpfen zu verstehen, so wie das Wort »Tantz« im Text selbst mehrfach für »Kampf« gebraucht wird. Der schwedische General Torstenson »springt noch wol den Böhmischen Tantz« (Strophe 5), womit die unter seinem Oberbefehl gewonnene Schlacht bei Jankau (1645) gemeint sein dürfte. Der Kon-

10 Groß Europisch Kriegs=Balet (Frankfurt/Main 1645), abgebildet und von Beate RATTAY kommentiert in: Wolfgang Harms (Hg.), Illustrierte Flugblätter aus den Jahrhunderten der Reformation und der Glaubenskämpfe, Ausstellungskatalog, bearbeitet von Beate RATTAY, Coburg 1983, Nr. 100; dazu Gerd Dethlefs, Schauplatz Europa. Das `Theatrum Europaeum des Mathaeus Merian als Medium kritischer Öffentlichkeit, in: Europa im 17. Jahrhundert, S. 149179, hier: S. 161-163.

11 Abbildungen der drei Varianten des niederländischen Blatts bei John Roger PAAS, The German Political Broadsheet 1600-1700, Bd. 7, Wiesbaden 2002, Nr. PA 377-379, dort auch die deutschen P 2174f.

12 Manfred Sсновт, Politik und Propaganda. Der siebenjährige Krieg in den zeitgenössischen Flugschriften, Frankfurt/Main 2006, S. 286 und Abbildung 1. 
tre-Tanz dieses Blattes nimmt insgesamt Bezug auf militärische Ereignisse der Jahre von 1632 bis 1645. Gustav Adolf von Schweden (gefallen 1632) ist beim Tanz tot zu Boden gesunken (rechts), Kurfürst Johann Georg I. von Sachsen (vorn links) versucht, »Such zu tretten auß dem Tantz O weh / ich seh darzu kein Schantz«: Zwischen den widerstrebenden Verpflichtungen gegenüber dem Kaiser und der lutherischen Konfession will er sich der Beteiligung am »Tantz« entziehen, vermag es aber nicht. Der soeben (1643) im Alter von fünf Jahren zum König gekrönte Ludwig XIV. von Frankreich ist sich dagegen sicher, gut mittanzen zu können. Eine Vorstellung vom Handlungsraum Europa, das dem Blick einer politisch nicht definierten Öffentlichkeit ausgesetzt ist, vermitteln die identifizierten Akteure. Diese sind in der Regel nicht namentlich, sondern mit ihren Titeln genannt, unter ihnen der Kaiser, die Könige von Portugal, Spanien, Kastilien, England, Schweden und Dänemark, jeweils in einer Person zusammengefasst die italienischen Fürsten und die Schweizer Kantone, dann der Papst, die Kardinäle und die Erzbischöfe von Mainz, Köln und Trier, der Prinz von Oranien, die Kurfürsten von Sachsen und Brandenburg, der Herzog (nicht Kurfürst) von Bayern sowie im Osten der türkische Sultan und Fürst Rakoczy, dieser wohl identifizierbar mit Fürst Georg I. von Siebenbürgen, der sich 1643 mit Schweden und 1645 mit Frankreich verbündete und vielleicht als einer der Indikatoren für eine eher frankreichfreundliche und zugleich antipäpstliche Position des Blattes gelten dürfte. Keine der dargestellten Personen bietet sich einem Betrachter als Identifikationsfigur an. Die Metapher des Tanzens als Kämpfens könnte sich für ihn beim längeren Betrachten schließlich doch zu einer Metapher des Versäumens vordringlicher Aufgaben wandeln, etwa der Unterlassung diplomatischer Friedensvorbereitungen.

Bei der knappen Andeutung der Beweggründe, wegen denen die einzelnen Potentaten sich am Krieg beteiligen, fällt vor allem aber das Vorherrschen von Kritik gegenüber den meisten Herrschern auf. Inwiefern am unterschiedlichen Verhalten der Personen Europa als politischer Raum dargestellt wird, wäre an den einzelnen Gruppierungen näher abzulesen: den aktiv Tanzenden, den interessiert Zuschauenden und den zum Tanz aufspielenden Kardinälen unter Leitung des Papstes. In zeittypischer Weise wird als Ursprung allen Übels das dominante Wirken eines Lasters, hier des Neides, genannt: Die Invidia-Personifikation schwebt hoch oben links »außwerffend seine Zanckäpffel«; der Neid hat das Ballett eingesetzt, in dem »Christen Potentaten / Einander hassen / verrahten / Land vnd Leut alles drauff geht Vmb zu tantzen diß Balet«. Und der neben ihnen schwebende Straf- und Racheengel mit dem Schwert droht den Mächtigen für den Fall, dass sie diese Art des Tanzens nicht beenden, Hunger, Pest und Tod an. Am Ende steht seine Aufforderung, statt des Tanzens zum Frieden zurückzukehren. Und durch den Bildteil, der das Tanzen nicht als Kampf, sondern 
als geselliges Vergnügen vor Augen führt, verstärkt sich ein Unbehagen am Verhalten der Potentaten, die die Aufgabe der Friedensstiftung ignorieren. Hier wird nicht viel mit dem Begriff Europa operiert, es wird auch nicht das Konzept eines politischen Europas entworfen; es wird aber davon ausgegangen, dass die gegenwärtige, vom Kriegsgeschehen erzeugte desolate Lage in ganz Europa ein Problem eben Gesamteuropas ist, das nicht von dem einen oder dem anderen Teil Europas gesondert gelöst werden kann, sondern nur durch eine gemeinsame, von gleichen Wertvorstellungen geleitete Annäherung an den Frieden. Angesichts dieser gemeinsamen Not und der gemeinsamen Aufgabe, zum Frieden zu finden, unterbleibt jede Frage »nach dem nationalen oder regionalen Sonder- und Einzelfall $\aleph^{13}$. Dass die Vorstellung von Europa territoriale oder nationale Identitäten überschreiten kann oder dass Europa ein nicht notwendig national strukturierter Handlungsraum ist, konnte offenbar - wenn auch selten - vom Flugblatt in Ansätzen verständlich gemacht werden. Dieses Blatt traf thematisch und in seiner kritischen Perspektivierung die Situation weiter Teile des Publikums. Es hatte mit jeweils mehreren Auflagen großen Erfolg in deutschen und niederländischen Fassungen, blieb aber in der Darstellung des Handlungsraumes Europa ein Sonderfall. Die im Publikum vorgefundene oder hervorrufbare Erregung betraf eine in Europa weitverbreitete Not, nicht aber eine Europakonzeption.

Die ersten periodisch erscheinenden Zeitungen der Welt, die Straßburger Relation (ab 1605) und der Wolfenbütteler Aviso (spätestens ab 1609) ${ }^{14}$, ignorieren von Anfang an eine nationale Ordnung ihrer Informationen und verteilen ihre Korrespondenten (und damit unterschiedliche Wissensstände und Perspektiven) auf viele Orte Europas: auf Augsburg, Köln, Antwerpen, Den Haag, London, Wien, Prag, Lyon, Rom. Die Berichte einiger weniger Orte (besonders Venedig und Antwerpen) öffnen den Blick regelmäßiger auch auf außereuropäische Ereignisse, wodurch eine Profilierung des europäischen Raums nahegelegt wird. In der Zeitung wird Europa regelmäßig als »gemeinsamer Bezugsrahmen« vorausgesetzt und als ein Raum, »in dem man voreinander Kenntnis nahm $\ll^{15}$.

Eine vergleichbare Sicht auf Europa als einen ungeteilten politischen Handlungsraum gilt für die Titelmetaphorik; die reichen Titelei-Illustrationen und das Darstellungskonzept des schon genannten, von 1635 bis 1738 publizierten annalistischen Geschichtswerks Theatrum Europaeum, das den Wortlaut und den Bildteil vieler historisch-politischer Flugblätter und Flug-

13 Duchhardt, Europa, S. 10 und vgl. S. 73.

14 Johannes Weber, Deutsche Presse im Zeitalter des Barock. Zur Vorgeschichte öffentlichen politischen Räsonnements, in: Hans-Wolf JäGER (Hg.), `Öffentlichkeit` im 18. Jahrhundert, S. 137-149, hier: S. 137-139.

15 Dethlefs, Schauplatz Europa, S. 160f. 
schriften integriert und Europa als einen Raum vieler widerstreitender Staaten (einschließlich des Osmanischen Reichs) zeigt. Fast noch konsequenter im Verzicht auf die Beachtung nationaler Raumeinteilungen verfährt das Diarium Europaeum (ab 1659). Dass es daneben auch ein Bewusstsein von der Vielgestaltigkeit europäischer Staaten, europäischer Bündnisse und Streitfälle, europäischer Kultur und europäischer Religiosität gab, ist damit nicht bestritten; in den deutschen illustrierten Flugblättern lässt sich eher eine solche Pluralität als ein Streben nach Einheit finden. Hierzu gehört auch die Tatsache, dass illustrierte Flugblätter ihre Themen vorzugsweise am Beispiel einzelner Persönlichkeiten (Herrscher, Heerführer, Theologen) konkretisieren oder anhand von Themen, die auf größere Bevölkerungsgruppen bezogen sind (Bedrohung oder Hoffnung für Einwohner einer Stadt oder eines Territoriums, für Anhänger einer Konfession), nicht aber Institutionen als solche (Kabinett, Hofrat, Domkapitel, Gericht, Universität) zum Gegenstand oder zum erklärten Adressatenkreis machen ${ }^{16}$.

Die Bildersprache, der sich die Graphiker der illustrierten Flugblätter bedienen oder die sie mit der verbal vorgegebenen Metaphernsprache mischen, hat für einige der Inhalte, für die `Europar stehen kann, keine Bildformeln erprobt oder bereitgehalten ${ }^{17}$. Cesare Ripa brachte seine Iconologia zuerst 1593, illustriert 1603 heraus. In ihr sind wirkungsreich gewordene Personifikationen der Erdteile enthalten. Europa wird mit Zeichen des Anspruches ausgestattet, der überlegene der vier Erdteile zu sein: er erscheint als prächtig gekleidete Königin auf zwei Füllhörnern, den Zeichen von Reichtum oder Überfluss. In der Rechten hält sie ein Kirchenmodell, mit dem meist auf die Grabeskirche in Jerusalem und in jedem Fall auf ihre Überlegenheit hingewiesen wird, die sie gegenüber heidnischen Erdteilen durch ihr Christentum gewonnen hat. Ihre weiteren Attribute betonen andere Bereiche ihres höheren Ranges, und zwar das Pferd und Waffen für die Kriegskunst und Eule, Buch, Musikinstrumente und Malgeräte für die Künste und Wissenschaften. In der Kunst werden durch Variationen unterschiedliche Akzente gesetzt, zum Beispiel in Jan van Kessels Erdteilzyklus (1664/1666), der die jeweilige Personifikation durch die Veranschaulichung von tatsächlichen oder vermeintlichen Spezifika der Landschaften, der Fauna und der Flora eines Erdteils ausstattet. Bei der Europa-Darstellung werden wie bei Ripa die Verankerung im Christentum (unter anderem Ausblick auf Rom mit der Engelsburg) und die Überlegenheit im Bereich der Künste und Wissenschaften sowie der Kriegskunst betont. Eingängiges Europa-Bildvokabular aus der engeren oder weiteren Ripa-Nachfolge oder aus Darstellungen des Europa-Mythos ist nicht in Flug-

16 Duchhardt, Europa, S. 47.

17 Sabine Poeschel, Studien zur Ikonographie der Erdteile in der Kunst des 16.-18. Jahrhunderts, München 1985, S. 99-101. 
blättern thematisiert worden, wohl aber in der Tafelmalerei, in Kupferstichen und in (vorwiegend historiographischer und geographischer) Titelblattgraphik. Durch den Titel des Flugblatts, nicht durch graphisch beigegebene Attribute, ist im Mittelpunkt des Bildteils eines Blattes von $1631^{18}$ eine `Europa identifizierbar: eine klagende und verwundete Europa zwischen einer finsteren, von kriegerischem Geschehen angefüllten Seite zu ihrer Linken und einer von hellem, friedlichem Geschehen markierten Seite zu ihrer Rechten. Der Graphiker des Blattes, der bekannte lutherische Flugblattillustrator Andreas Bretschneider aus Leipzig, gibt seinem Bild eine inhaltliche Ausrichtung, die in weiten Teilen nicht mit den verbalen Aussagen konform ist, die von dem ebenfalls als Flugblattautor bekannten Leipziger Gelehrten und später in Sachsen geadelten und zum Dresdner Hofpoeten aufgestiegenen Elias Rudel $^{19}$ stammen, dessen Name nur in einer der drei Auflagen des Blattes genannt wird. Alle drei sind im Jahr 1631 erschienen, etwa zu der Zeit, als der sächsische Kurfürst Johann Georg I. die protestantischen Reichsstände zum Leipziger Konvent geladen hatte, um eine Koalition mit dem Schwedenkönig zu verhindern und Friedensverhandlungen mit dem Kaiser voranzutreiben. Das offenbar erfolgreiche Blatt dürfte etwa zwischen dem 12. April 1631, dem Tag des Konventsbeschlusses, und dem 20. Mai 1631, dem Tag der Zerstörung Magdeburgs, erschienen sein.

Das Bild zeigt eine klagende, von Pfeilen durchbohrte barfüßige Europa mit aufgelösten Haaren, Klagegebärden, aufgerissenem, beflecktem Gewand. Sie wendet sich ab von gerüsteten Kriegern und Pfeilschützen, deren Fahne den Teufel zeigt. Unter den Soldaten befindet sich ein Jesuit, so dass sie als Vertreter der katholisch-kaiserlichen Partei zu identifizieren sind. Die Haltung der Europa ist der hellen Seite zugewandt, wo im Freien eine kleine Gruppe sitzt, zu der ein Stehender spricht. Die Gruppe ist nicht genauer identifizierbar, nimmt aber die Bildformel eines Blattes von 1630 und $1631^{20}$ auf, wo in einer solchen Gruppe »die wahre Lehr« des Luthertums verkörpert wird. Sie steht hier wie dort im Kontrast zum feindseligen Verhalten ihrer konfessionellen Gegner. Vom Bild her, dem traditionell zuerst

18 Europa querula et vulnerata, Das ist / Klage der Europen, (Leipzig) 1631, abgebildet und von Beate RATTAY kommentiert in: Illustrierte Flugblätter Coburg, Nr. 93; Abbildungen auch beider Varianten bei PAAs, Political Broadsheet, Bd. 5, Nr. P 1306-1308; dazu Silvia Serena TschopP, Gegenwärtige Abwesenheit. Europa als politisches Denkmodell im 17. Jahrhundert?, in: Europa im 17. Jahrhundert, S. 25-36, hier: S. 33-36.

19 Zu Elias Rudel siehe Marian R. SPerberg-McqueEn, Ein Vorspiel zum Westfälischen Frieden. Paul Flemings >Schreiben vertriebener Frau Germanien Simpliciana 6/7 (1985), S. 150-183, hier: S. 159-161 und 171.

20 Zustand der Christlichen Kirchen Anno 1630, abgebildet und von Michael SchiLling kommentiert in: Deutsche illustrierte Flugblätter, Bd. 2, Nr. II, 217 (vgl. auch II, 218). Eine Übersicht über die Vielzahl der Variationen auf das Thema dieser Blätter geben die Abbildungen bei PAAs, Political Broadsheet, Bd. 5, Nr. P 1370-1374, auch 1269-1271 und 1294f. 
rezipierten Teil eines Flugblatts, wird der Verdacht nahegelegt, es handele sich hier 1631 um ein weiteres jener Blätter, die über die Jesuiten die kaiserliche Politik angreifen und verteufeln. Warum es Europa ist, die als Opfer erscheint, bleibt im Bild rätselhaft.

Der Text setzt andere Akzente. Er greift auf, dass die Europa-Personifikation des Bildes am ehesten Darstellungen der Armut aufnimmt. In Verbindung mit dem elenden Aussehen und dem Klagegestus könnte der Kranz, der der Europa vom Himmel her aufs Haupt gelegt wird, an die Verleihung der >corona vitae` nach einem von >patientia geprägten Märtyrerleben erinnern. Dieses alles erhielte dann in Rudels Versen eine Entfaltung, während das Geschehen im Bild rechts und links der Europa nirgendwo erwähnt wird. Damit wird verbal auf eine Anklage gegen eine politische konfessionelle Partei verzichtet. Der Text, der sich mit seinen Alexandrinern auf hoher Stilebene bewegt und damit einem wenig gebildeten Publikum schwer zugänglich ist, ist eine Wechselrede zwischen dem Ich im kurzen ersten und im dritten Viertel sowie der Europa im kurzen zweiten und im langen vierten Viertel. Zunächst stimmen beide in der Klage über das Leid überein, in das Europa unverschuldet geraten ist, danach baut das Ich Möglichkeiten des Trostes auf, die von Europa als Beendigung ihres Leids verstanden werden. In ihrer verbalen Selbstdarstellung steigern die Worte Europas gegenüber dem Bild die Details des Leids erheblich: »Sih an wie die gestalt / die schönheit meiner Wangen Nun gantz verblasset ist / die Zung am gaumn bleibt hangen / Es bebet mein Gesang / die Harff im staube ligt / Mein Mund verstummen will / wo er nicht hülffe krigt«.

Europa wird durch keine Andeutung mit einzelnen europäischen Territorien identifiziert. Sie kann als Bildformel für die Gesamtheit derer, die in Europa unter den Folgen des anhaltenden Krieges leiden, verstanden werden, und dabei greift der Text die antithetische Unterscheidung von Kriegsgegnern des Bildteils weder zustimmend noch widersprechend auf. Diese Europa ähnelt zeitgenössischen Bildformeln der leidenden Germania, so in einer anonymen emblematischen Kommentierung aus pfälzisch-calvinistischer Sicht um 1620/1625, ähnlich wie dort auch auf dem Titelblatt von Johann Rists 1649 erschienenem Drama Das Friede wünschende Teutschland ${ }^{21}$, deren räumliche Gültigkeit hier durch den Bezug auf Europa ausgeweitet wird. Diese Hinweise sollen keine Abhängigkeiten suggerieren, können aber den Gedanken nahelegen, dass eine ähnliche Thematik in vergleichbarer Situation - die Bedrohung eines Raumes und seiner Bevölkerung - immer wieder zu ähnlichen Gestaltungen führen kann, ohne eine Raumspezifik zu beabsichtigen.

21 Johann Rist, Das Friede wünschende Teutschland (zuerst Hamburg 1647), hg. v. Eberhard MANNACK, Berlin u.a. 1972. 
Die klagende Personifikation steht für einen räumlich großen, nicht unterteilten Bereich des Leids und der Klagenden. Dass das Blatt nicht eine Germania, sondern eine Europa als Klagende wählt, obwohl im Leipziger Konvent nur die deutschen protestantischen Reichsstände und Schweden unmittelbar involviert sind, dürfte als ein Mittel zu verstehen sein, die unbegrenzte Weite der Kriegsnot und des Wunsches nach Frieden zu unterstreichen. Der Weg bis zum Westfälischen Frieden ist noch lang, aber die hier eingesetzte europäische Dimension jeder Bemühung um die Beendigung des Krieges steht im Vorfeld der publizistisch variationsreich geförderten Einsicht in die Notwendigkeit der Beendigung des Krieges, nicht nur im jeweiligen Territorium - hier Sachsen beziehungsweise Deutschland -, sondern in Europa insgesamt ohne nähere territoriale Akzentuierungen. In den Worten der Europa dieses Blattes lautet der Appell kurz und bündig: »Den Frieden wollen wir / der Krieg kein Heyl hat bracht «. Er ist an die gerichtet, die jetzt oder später an Verhandlungen denken könnten und diese vorbereiten sollten, und darf damit rechnen, unter den übrigen Zeitgenossen Zustimmung zu finden. Hier wird kein Blick in einen spezifisch europäischen Handlungsraum oder auf Handlungen europäischer Mächte insgesamt geworfen. Das Blatt bezieht sich auf Vorgänge im Reich ${ }^{22}$.

Beide Blätter, die hier thematisiert wurden, gehen davon aus, dass ihre Adressaten unter einem Erschöpfungskrieg leiden und einen Frieden dringend wünschen. Beide Blätter stehen diplomatischen Aktionen oder juristischen Argumentationen für den Frieden fern, bleiben im Bereich derer, die die Notwendigkeit des Friedens spüren, aber nicht selbst artikulieren, sondern eine Artikulierung ihres Leids und ihrer Hoffnungen benötigen und in diesem durch nichts autorisierten Medium erhalten. Im Vorfeld einer Vorstellung von Europa als politischer Größe könnte von einem solchen Blatt eine frühe Diskussion erzeugt worden sein, die in enger Bindung an Friedenshoffnungen einer strikt argumentierenden zielgerichteten diplomatischen Erörterung vorgegriffen hätte. Diese illustrierten Flugblätter konnten rechtliche Probleme eines Friedensschlusses, der das Selbstverständnis von Konfessionen berührte, übergehen und aus der Perspektive der nicht an Jurisprudenz, Kirche und Herrschaft beteiligten Bevölkerungsmehrheit die Beendigung von Not in den Vordergrund rücken. Im Blatt zum Leipziger Konvent wird die Europa-Vorstellung eingesetzt, um die Grenzenlosigkeit des vom Krieg in Deutschland bewirkten Leids hyperbolisch zu betonen, ohne dass eine gegliederte Raumvorstellung mit Europa verbunden wäre. Das Blatt des Europisch Kriegs Balet vermittelt eine Vorstellung von einem Mächte-Raum Europa, in dem und für den ein Friedenswerk erstellt werden muss; die emotionale Erreichbarkeit des intendierten Publikums gründet sich auf dem ge-

22 Tschopp, Abwesenheit, S. 35f. 
meinsamen Leiden am Krieg und dem Ausbleiben eines Friedensvertrags in ganz Europa. Aber nicht der Frage einer jetzigen oder künftigen politischen oder kulturellen Ganzheit Europas gilt die Erregung, sondern dem gegenwärtigen Zustand seiner Teile.

Die illustrierten Flugblätter der Frühen Neuzeit haben ein sehr unterschiedlich geschichtetes oder gruppiertes Publikum. In Fürsten- und Ratsbibliotheken wurden vorwiegend Blätter zu politisch-militärischen Ereignissen, auch zu konfessionellen Auseinandersetzungen, aber nur in Ausnahmefällen zur religiösen oder moralischen Unterweisung gesammelt; exakte astronomische, biologische und medizinische Fallbeschreibungen waren als Träger wissenschaftlichen Fortschritts vorwiegend für Gelehrte bestimmt; satirisch-moralische Blätter einfacheren rhetorischen Niveaus gelangten an Gasthauswände, jedoch auch in die Hände von Betrachtern aller Stände. Je nach der sprachlichen Aufbereitung und der Wissensvoraussetzungen des einzelnen Blattes vermag es unterschiedlich Gebildete und unterschiedlich Interessierte zu erreichen, durch billigen Preis, Schnelligkeit der Herstellung und eine gewisse Ubiquität des Angebots dem Buch überlegen ${ }^{23}$. Aber ein einzelnes Blatt erlaubt noch nicht Rückschlüsse auf die generelle Befindlichkeit und die Bedürftigkeit der gesamten Zeitgenossen. Die beiden hier in den Mittelpunkt gerückten Blätter sind durch ihr höheres Sprach- und Versniveau oder ihre inhaltliche Vielfalt nicht auf populäre Eingängigkeit angelegt, könnten eher in einer allgemeineren Nähe zum Hof und zu städtischer Obrigkeit auf Interesse für ihre Angebote zum Nachdenken und Handeln gestoßen sein, wobei die Verse des Leipziger Blatts für das Verstehen des Texts höhere Hürden aufbauen als die des Frankfurter Blatts. Beide kokettieren nicht damit, völlig Neues vorzutragen, zeigen den ernsthaften Versuch, Unterschätztes als Dringliches ins allgemeine Bewusstsein zu rücken, zum Gesprächsgegenstand zu machen, und ihre Inhalte haben zumindest auf Seiten des Verlegers und des Händlers das Zutrauen geweckt, hier handele es sich um einen Gedankenkomplex, der in der gegenwärtigen aktuellen Situation Interesse finde oder Interesse zu entzünden vermöchte. In diesen Grenzen lassen diese Blätter Schlüsse zu auf eine mögliche Befindlichkeit innerhalb rekonstruierbarer Adressatenkreise ihrer Zeit. Es dürften lesefähige, vorwiegend städtisch gebildete Teile der Bevölkerung sein, die durchaus auch in der Lektüre von Büchern erfahren sein können, sich hier aber innerhalb der Erreichbarkeit auch derer befinden, die auf die Hilfe des Vorlesens angewiesen sein oder zum Kauf teurer Flugschriften und Bücher nicht imstande sein könnten. Wieweit sie mittelbar oder unmittelbar an politischem

23 Wolfgang Harms, Historische Kontextualisierungen des illustrierten Flugblatts (zuerst 1985), bibliographisch ergänzt wiederabgedruckt in: HARMs / Schilling, Das illustrierte Flugblatt, S. 21-61. 
Handeln beteiligt sein können, ist schwer zu belegen. In jedem Fall sind die von illustrierten Flugblättern erreichbaren Käufer- und Leserschichten an den als aktuell empfundenen ${ }^{24}$, gedanklich und mit anderen Zeitgenossen räsonnierend behandelten Themen und Ereignissen interessiert und wohl meistens emotional angerührt ${ }^{25}$. Die Ergebnisse solcher Überlegungen sind wohl eher außerhalb der etablierten linearen Vorstellungen von Abläufen der Geschichte anzusetzen, die sich dem Anschein nach strikt teleologisch darstellen ließen. In den Flugblättern werden eher Akzentuierungen von Möglichkeiten sichtbar, etwa auch später durchgesetzte oder bald wieder vergessene Gedanken-, Affekt- oder Konzeptionspotenziale, die manchmal schnell, manchmal nie und vielleicht öfter verzögert als unterschwellig mitwirkende Faktoren in den Komplexität gewinnenden Willensbildungen oder Erwartungen Virulenz erlangen.

In diesem Sinne begegnet man in den Flugblättern der Frühen Neuzeit nicht dem klaren Ziel, ein irgendwie einheitliches, politisch oder kulturell strukturiertes Europa zu konzipieren oder als erkannte Größe vorstellbar zu machen oder näher um seiner selbst willen zu erörtern. Ein solches Ziel hat diese Leserschichten, die in der Frühen Neuzeit oft mit dem unscharfen Begriff 〉Gemeiner Mann « gefasst werden können, offenbar wenig umgetrieben. Bei intendierten Lesern von Buch und Flugschrift oder anders definiert: bei Lesern in deutlicherer Herrschaftsnähe sah es anders aus. Das illustrierte Flugblatt - bzw. seine Verleger und Autoren - hat gegenüber dem Gegenstand $`$ Europa $<$ in seinem Bereich des Publikums wenig Anlass vorgefunden, sein Potential der Meinungsbildung sowie Erregungserzeugung und -steuerung einzusetzen. Der Kern der Diskussion über Europavorstellungen und -konzeptionen fand in der Frühen Neuzeit in anderen Teilen der Kommunikationsmöglichkeiten statt.

24 Zur Aktualität des illustrierten Flugblatts wird außer den unmittelbar in der räumlichen und zeitlichen Nähe stattfindenden gegenwärtigen militärischen, politischen oder natürlichen Ereignissen auch die jederzeit ohne Bindung an eine kalendarische zeitliche Nähe vordringlich bedeutsamen Botschaften oder Abhandlungen der Gegenwart oder auch der Vergangenheit (besonders im religiösen Bereich wie der Gnadenlehre oder der praxis pietatis) mitgerechnet. Vgl. den Gedanken von Rainer WoHLfEIL, `Reformatorische Öffentlichkeit‘, in: Ludger GRENZMANN / Karl Stackmann (Hg.), Literatur und Laienbildung im Spätmittelalter und in der Reformationszeit. Symposion Wolfenbüttel 1981, Stuttgart 1984, S. 41-52, hier: S. 42f.

$25 \mathrm{Zu}$ den erreichbaren Publikumsschichten siehe Schilling, Bildpublizistik, S. 40-53; Christian OGgolder / Karl Vocelka, Flugblätter, Flugschriften und periodische Zeitungen, in: Josef Pauser / Martin Scheutz / Thomas Winkelbauer (Hg.), Quellenkunde der Habsburgermonarchie (16.-18. Jahrhundert). Ein exemplarisches Handbuch, Wien u.a. 2004, S. 860-874, hier: S. $862-864$. 


\title{
Martin Wrede
}

\section{Der Kontinent der Erbfeinde}

\author{
Deutsche und europäische Feindbilder der Frühen \\ Neuzeit zwischen Säkularisierung und Sakralität
}

\section{Ein Kontinent der Feinde}

Aus Anlass des 350-jährigen Jubiläums des Westfälischen Friedens fand 1998 an der Universität Osnabrück ein großangelegter »europäischer« Kongress statt, der, das war das geringere seiner Anliegen, zunächst an den Westfälischen Frieden selbst erinnern sollte, der aber zugleich und darüber ins Unendliche weit hinaus, »den Frieden« schlechthin zeichnen wollte, als eine »europäische Vision« und Kulturleistung ${ }^{1}$.

Europa wurde dort also an den positiven Wert »Frieden« geknüpft. Das war nicht nur politisch korrekt, sondern auch sachlich keineswegs falsch. Es drohte auf der so ausgewiesenen ideengeschichtlichen Höhenwanderung freilich aus dem Blick zu geraten, dass der 1648er Kongress durchaus kein ähnlich idealistisches Unternehmen gewesen war, wie jener von 1998, dass eigentlich auch alle anderen europäischen Friedensschlüsse der Neuzeit alles andere gewesen waren als idealistische Unternehmen, und dass das moderne Europa letztlich und aufs Ganze gesehen eher von seiner spezifischen Bellizität und Kriegspraxis konturiert oder auch konstituiert wurde als vom Friedensgedanken ${ }^{2}$. Darauf wiesen auch einige realhistorische Stimmen jener Osnabrücker Tagung hin. Wolfgang Reinhard etwa betonte, dass es sich bei den Verträgen von Münster und Osnabrück letztlich um reine Erschöpfungsfrieden gehandelt hatte. Heinz Duchhardt legte dar, was Alteuropa im Grundsätzlichen »in friedens- und ordnungspolitischer Hinsicht gewesen war: defizitär, phantasielos, nicht über den Tellerrand [...] hinausblickend « ${ }^{3}$.

1 Vgl. Klaus Graber, Der Frieden. Umrisse eines Kongresses. Rede zur Eröffnung, in: Ders. u.a. (Hg.), Erfahrung und Deutung von Krieg und Frieden. Religion - Geschlechter - Natur und Kultur, München 2001, S. 17-26.

2 Vgl. etwa Johannes Burkhardt, Die Friedlosigkeit der Frühen Neuzeit. Grundlegung einer Theorie der Bellizität Europas, in: Zeitschrift für historische Forschung 24 (1997), S. 509-574.

3 Heinz Duchhardt, Zwischenstaatliche Friedens- und Ordnungskonzepte im Ancien Régime. Idee und Realität, in: Ronald G. Asch / Wulf E. Voss / Martin Wrede (Hg.), Frieden und Krieg in der Frühen Neuzeit. Die europäische Staatenordnung und die außereuropäische Welt, München 2001, S. 37-45, hier: 44 (Zitat); Wolfgang Reinhard, Kriegsstaat und Friedensschluß, in: Asch, Frieden und Krieg, S. 47-57. 
Auch auf diesem Wege hat Europa sicherlich vielfach und sogar einigermaßen effektiv Frieden gemacht oder gehalten. Es gehört ganz zweifellos zu den Grundsignaturen des Kontinents, dass Feindverhältnisse durch Interessenausgleich beendet oder jedenfalls ausgesetzt werden konnten ${ }^{4}$. Europa aber wurde eben doch vom Krieg gemacht, es war »geboren aus dem Geist der Gewalt « ${ }^{5}$. Diese Gewalt wurde bis ins 16. Jahrhundert keineswegs vornehmlich und auch danach alles andere als ausschließlich nach außen gerichtet - dies war bekanntermaßen das Ziel, auf das sich die Phantasien der Europa-Idealisten des 17. und 18. Jahrhunderts richteten ${ }^{6}$. Die Gewalt fand bereits innerhalb der Grenzen Europas statt - in einem Ausmaß, das die Frage provozieren musste, ob und wenn ja, warum man es hier mit einer Einheit, einem Kulturraum zu tun habe ${ }^{7}$. Das frühneuzeitliche Europa war keine »Welt«, aber eben ein »Kontinent von Feinden« - oder, noch etwas pointierter gesagt - ein Kontinent von Erbfeinden. Europa war zerrissen von politischen Gegensätzen und ins Religiöse gesteigerten »Erbfeindschaften«. - Es wurde von diesen Feindschaften allerdings auch zusammengehalten. Über den scheinbaren Widerspruch wird abschließend zu sprechen sein.

Im Folgenden soll es nun vordringlich darum gehen, diesen Stellenwert des Religiösen zu bestimmen und den Wandel eines sakralen zu einem säkularen und damit durchaus ein gutes Stück entschärften Erbfeindbegriff nachzuzeichnen. Zunächst ist jedoch zu umreißen, wozu ein Feind gut ist, und aus welchem Holz er sein muss, wenn er denn eine Chance haben soll, auch zum Erbfeind »aufsteigen« zu können.

\section{Feindbilder}

Tatsächlich waren die tiefgreifenderen der politischen Auseinandersetzungen in den drei Jahrhunderten zwischen Luther und Napoleon jeweils davon gezeichnet, dass eine Partei versuchte, die andere propagandistisch aus dem

4 Randall Lesaffer, War, Peace and Interdstate Friendship and the Emergence of the Ius Publicum Europaeum, in: Asch, Frieden und Krieg, S. 87-113; Heinhard SteIGER, Ius bändigt Mars. Das klassische Völkerrecht und seine Wissenschaft als frühneuzeitliche Kulturerscheinung, in: Asch, Frieden und Krieg, S. 59-85.

5 Robert Bartlett, Die Geburt Europas aus dem Geist der Gewalt. Eroberung, Kolonisierung und kultureller Wandel von 950 bis 1350, München 1998 (engl. Orig.: The Making of Europe Conquest, Colonization and Cultural Change, 950-1350, London 1993).

6 Kurt von Raumer, Ewiger Friede. Friedensrufe und Friedenspläne seit der Renaissance, Freiburg/Brsg. u.a. 1953.

7 Wim Blockmans, Europe? Which Europe?, in: Marie Louise von Plessen (Hg.), Idee Europa. Entwürfe zum Ewigen Frieden. Ordnungen und Utopien für die Geschichte Europas von der pax romana zur Europäischen Union. Eine Ausstellung als historische Topographie, Berlin 2003, S. 17-22. Vgl. ders., Geschichte der Macht in Europa. Völker, Staaten, Märkte, Frankfurt/Main u.a. 1998, S. 15-33. 
Binnenraum der »christlich « und das hieß hier: der gemäßigt regierten Nationen auszuschließen. Es diente ebenso der Beleidigung und Herabsetzung des Gegners wie der Selbstermunterung, wenn Franzosen in Spanien, Engländer in Frankreich, Dänen in Schweden, Polen in Russland unchristliche, unredliche »viehische Despotien « und Willkürherrschaften ausmachten ${ }^{8}$.

Die »Beleidigungen«, die Feindbilder transportierten, kamen freilich selten beim Gegner an. Da gab es gewiss Ausnahmen; der Bouclier d'estat et de justice des Freiherrn Franz Paul von Lisola, die erste, Maßstäbe, Themen wie Motive setzende antifranzösische Flugschrift der Epoche Ludwigs XIV., wurde in Paris sehr wohl rezipiert, ihre Verbreitung verfolgt und ihr Besitz bestraft ${ }^{9}$. Die französischsprachige Presse niederländischer Provenienz wurde von Paris aufmerksam beobachtet, ihre Verbreitung zwar behindert, aber nicht verhindert. Für die Masse der antifranzösischen deutsch- oder niederländischsprachigen Flugschriften freilich galt anderes und die französische Politik verzichtete seit den 1680er Jahren bewusst auf Beeinflussung wie Berücksichtigung der »öffentlichen Meinung« in den Nachbarländern und gab dieses Spiel verloren ${ }^{10}$. Nicht anders hatte Madrid auf die Attacken im Geiste der »Schwarzen Legende« reagiert bzw. auf Reaktion verzichtet ${ }^{11}$.

Dies konnten beide angegriffenen Parteien insofern leicht tun, als Meinungsbeeinflussung in Frankreich oder in Spanien selbst außerhalb der Reichweite antifranzösischer oder antispanischer Pamphletisten lag und von ihnen auch nicht angestrebt wurde. Die von Flugschriften in Zeiten von Krieg und Krise erzeugten und unterhaltenen Feindbilder dienten vor allem anderen der Selbstermunterung bzw. der Selbstvergewisserung durch Abgrenzung im Herkunftsland von Autor, Auftraggeber und Publikum, also der »negativen Integration «.

Im Anfang war der Feind - und wenn nicht ausschließlich, so doch maßgeblich. So ließe es sich zugespitzt wohl für die allermeisten historischen Prozesse von Identitätsbildung und -bewahrung formulieren. Abgrenzungsmechanismen waren für die Genese von Identitäten stets von entscheidender

8 Martin Wrede, Art. »Feindbild«, in: Enzyklopädie der Neuzeit 3 (2006), S. 878-890. Vgl. Herfried MünKLER, Nation als politische Idee im frühneuzeitlichen Europa, in: Klaus L. GARBER (Hg.), Nation und Literatur im Europa der Frühen Neuzeit. Akten des 1. Internationalen Osnabrücker Kongresses zur Kulturgeschichte der Frühen Neuzeit, Tübingen 1989, S. 56-86, hier: S. $63 f$.

9 Markus Baumanns, Das publizistische Werk des kaiserlichen Diplomaten Franz Paul Freiherr von Lisola (1613-1674). Ein Beitrag zum Verhältnis von Absolutistischem Staat, Öffentlichkeit und Mächtepolitik in der frühen Neuzeit, Berlin 1994, S. 325-334.

10 Joseph Klaits, Printed Propaganda under Louis XIV. Absolute Monarchy and Public Opinion, Princeton, N.J. 1976, S. 86f.

11 Peer Schmid, Spanische Universalmonarchie oder >teutsche Libertet . Das spanische Imperium in der Propaganda des Dreißigjährigen Krieges, Stuttgart 2001, S. 444. 
Bedeutung, und das Fremde bzw. die Feinde, von denen es sich abzugrenzen galt, wurden notwendig gebannt in Feindbilder als Konstrukte von Polemik, Vorurteil, Selbsterbauung ${ }^{12}$.

Diese Bilder konnten recht unterschiedlich ausfallen: Der Feind konnte als bedrohlicher Wüstling entworfen werden oder aber, war er denn einmal besiegt, als ridiküler Schwächling, er konnte ebenso kulturloser Barbar sein wie überfeinerter Betrüger - und im Übrigen sehr wohl auch ehrenwerter Gegner. Grundlegend war in allen Varianten das Prinzip der Selbsterhöhung, grundlegend war jedoch zumindest in den erstgenannten Fällen vor allem ein Moment des Religiösen: Der Feind wurde, in Reformationswie Napoleonzeit, gezeichnet als Feind des wahren Christentums und im Extremfall - der war keineswegs selten - erklärt zum »Erbfeind« bzw. zum $»$ Antichrist $\ll^{13}$.

\section{Erbfeinde und Antichristen}

Solche »Ehre« widerfuhr natürlich nur einem Gegner, mit dem es wirklich »ernst« wurde. Um 1690 wurden aus den welfischen Landen ein Dutzend gegen Dänemark gerichteter Flugschriften lanciert, in denen es um die Annexion Lauenburgs durch den »Heideherzog « Georg Wilhelm von Celle ging bzw. um deren Orchestrierung, also um eine in der deutschen Geschichte und für den Bestand des Reiches eher marginale Frage. Natürlich schuf dergleichen im Alten Reich noch kein dänisches Feindbild. Und die gleiche »NichtKarriere« widerfuhr letztlich, trotz deutlich größerer, deutlich länger anhaltender Anstrengungen der Konfliktparteien, auch den zwar unbeliebten, aber eben als Macht und Nation nach 1648 nie mehr wirklich ernstgenommenen, nie mehr wirklich als bedrohlich empfundenen Schweden. Allein durch obrigkeitliche Flugschriftenkampagnen ließ sich kein Feindbild, kein Erbfeind erzeugen ${ }^{14}$.

Ein echter »Erbfeind« musste aus anderem Material sein als die »armen« und »gierigen« Leute aus dem Norden, die nach einigem Plündern wieder in »Dorn- und Distel-Paradiß« entschwunden schienen - mochten sie auch weiter im Besitz bedeutender deutscher Territorien geblieben $\operatorname{sein}^{15}$. Das sagte schon der Begriff. Der mittelhochdeutsche serbevint zeichnet. Und der frühneuzeitliche »Erbfeind« ließ sich auf zweierlei Weise

12 WredE, Feindbild, S. 878f.

13 Ders., Art. »Erbfeind«, in: Enzyklopädie der Neuzeit 3 (2006), Sp. 396-400; MünKLER, Nation als politische Idee, $\mathrm{S}$. $63 \mathrm{f}$.

14 Martin Wrede, Das Reich und seine Feinde. Politische Feindbilder in der reichspatriotischen Publizistik zwischen Westfälischem Frieden und Siebenjährigem Krieg, Mainz 2004, S. 288-290, $322 f$ u. $548 f$. 
verstehen: Er war entweder der >eingeschworene`, grundsätzliche Feind der Christenheit mit eschatologischer Qualität oder aber der dauerhafte, >ererbte Feind als historisches Phänomen. Beide Aspekte waren nah verwandt, denn eine lang andauernde, gleichsam ewige Feindschaft war vorstellbar und konnte legitim sein ursprünglich nur gegenüber einer Macht, die nicht auf der Basis christlicher Werte und europäischer rechtlicher Normen stand oder zu stehen schien. Beide waren allerdings nicht identisch ${ }^{16}$.

Der Erbfeind-Begriff in seiner weiten, propagandistischen Verbreitung ist zumindest in der Frühen Neuzeit spezifisch deutsch. Die sprachlichen Gegenstücke - »ennemi héréditaire «, »old «, »common« oder »hereditary enemy« etc. entbehrten der im Deutschen gegenwärtigen religiösen Dimension. Die Sache aber, eine stark religiös aufgeladene dauerhafte politische Feindschaft, war auch anderwärts bekannt, sei es zwischen (katholischen) Polen einerseits und (orthodoxen) Russen oder (lutherischen) Schweden andererseits, sei es zwischen den rivalisierenden Mächten Westeuropas, und hier notfalls auch auf der Basis einer gemeinsamen konfessionellen Identität, wie zwischen Frankreich und Spanien ${ }^{17}$. In allen Fällen ließen sich diese Feindverhältnisse als endzeitliche Konfrontation mit der Macht des Bösen lesen, die zu bezeichnen man gerne direkt auf den Begriff des Antichrists zugriff. So gab es um 1600 verschiedene französische Stimmen, die den Katholischen König zum »Antichrist« ausriefen und die zu einem regelrechten, aus gegebenem Anlass die »Reconquista« wiederholenden Heiligen Krieg, einem Kreuzzug nach Madrid, aufforderten ${ }^{18}$.

Grundsätzlich aber lag wohl der Antichrist-Begriff bei der Denunziation politischer Gegner protestantischen Milieus näher. Verbreitet war die Verwendung besonders in England - als notwendige Folge der Selbststilisierung zur »auserwählten Nation« und zum »neuen Israel«. Die nationale Identität zunächst Englands, dann Britanniens gründete sich fest auf einen zwar unklar definierten, dafür aber umso entschiedeneren Protestantismus und infolgedessen ließ sich die Übertragung des von der Reformation ursprünglich auf den Papst bezogenen Motivs auf die kontinentalen katholischen Großmächten Spanien und Frankreich problemlos bewerkstelligen; im Bedarfsfall galt dies aber auch für innenpolitische Gegner - etwa den eigenen König - oder

15 Manifest Oder Declaration Deß Krieges der Holländer Wider die Schweden/ Wobey angefügt [...] Eines Melancholischen Meditation / und ein Gespräch / Unterschiedener Personen / über den gefährlichen Einfall der Schweden in Pommern [...], s'Graven Hage 1675, S. 26 u. 29 (Zitat). Vgl. Wrede, Das Reich und seine Feinde, S. 249-253 u. 265-269. Siehe dort auch weitere Quellenverweise.

16 Wrede, Erbfeind, S. 396f.

17 Ders., Feindbild. Zum letztgenannten Beispiel siehe Alexandre Yali Haran, Le lys et le globe. Messianisme dynastique et rêve impérial en France aux XVI ${ }^{\mathrm{e}}$ et XVII ${ }^{\mathrm{e}}$ siècles, Seyssel 2000.

18 Haran, Le lys et le globe, S. 223-228. 
benachbarte protestantische Abweichler - etwa die Niederländer ${ }^{19}$. »Popery« und »englishness « - bzw. »britishness « - waren unvereinbar, ja »antipopery« machte »britishness « überhaupt erst möglich. Ein besonders populärer Agent des Papstes war aus englischer Sicht nach Philipp II. natürlich Ludwig XIV. Unter dem Einfluss nicht zuletzt von calvinistischen französischen Exulanten nahm der Sonnenkönig in der englischen, der niederländischen und auch der deutschen Öffentlichkeit Züge des Antichrists an. Im 18. Jahrhundert wurde das englisch-französische Feindverhältnis dann zwar, wie Jeremy Black gezeigt hat, eher als »natural and necessary « und damit rational bedingt angesehen. Wie lange darunter ein religiöses Moment mitschwang, wäre jedoch zu fragen ${ }^{20}$.

\section{Deutsche Beispiele: Osmanen und Franzosen}

Im Folgenden soll nun von zwei Beispielen aus deutscher Perspektive ausführlicher die Rede sein: Dem deutschen Blick - und den Veränderungen dieses Blicks - auf Osmanen und Franzosen sowie auf das Wechselspiel, das zwischen jenen beiden »Erbfeinden« »imagologisch" stattfand. Die Osmanen als traditioneller, »eingeschworener « »Erbfeind Christlichen Namens«, die Franzosen als langjähriger Kriegsgegner nicht nur der Deutschen, sondern auch von Engländern, Niederländern, Spaniern. Zumindest bei den englischen und niederländischen Nachbarn sollten die Folgen der Konfrontation mit denen im Reich übereinstimmen. »Die Franzosen« wurden zum »anderen Erbfeind $\ll^{21}$.

Nicht eigens betrachtet wird der deutsche oder auch europäische Blick auf Russland. Das Zarenreich war gewiss der »Erbfeind« der Krone Polen bzw. der polnischen Nation, deren Selbststilisierung zur »antemurale christia-

19 Siehe bes. Christopher HiLl, Antichrist in Seventeenth-Century England, Revised Ed., London 1990.

20 Jeremy Black, Natural and Necessary Ennemies. Anglo-French Relations in the Eighteenth Century, London 1986. Vgl. ders., The Catholic Threat and the British Press in the 1720s and 1730s, in: Journal of Religious History 12 (1983), S. 364-381; Colin Haydon, I love my King and my Country, but a Roman Catholic I hate: Anti-catholicism, Xenophobia and National Identity in Eighteenth-century England, in: Tony Claydon (Hg.), Protestantism and national Identity. Britain and Ireland c. 1650-c. 1850, Cambridge 1998, S. 33-52 sowie (anders akzentuiert) Steven C.A. Pincus, To protect English liberties. The English Nationalist Revolution of 1688-1689, in: Claydon (Hg.), Protestantism, S. 75-104. Zur englisch-britischen Natiogenese und dem dabei wirksamen »Feindbild Frankreich" vgl. sonst neben Linda Colley, Britons, Forging the Nation, 1707-1837, London ${ }^{2} 1994$, bes. Steven C.A. Pincus, From butterboxes to wooden shoes. The shift in English popular sentiment from anti-Dutch to anti-French in the 1670s, in: Historisches Jahrbuch 38 (1995), S. 331-361. Zur entsprechenden Rolle Spaniens: Martina MitTag, Nationale Identitätsbestrebungen und antispanische Polemik im englischen Pamphlet, 1558-1630, Frankfurt/Main 1993.

21 Wrede, Das Reich und seine Feinde, S. 324-545. 
nitatis« sich ebensosehr auf die Gegnerschaft zu den muslimischen Osmanen bezog wie zu den orthodoxen Russen ${ }^{22}$. Weiter im Westen Europas besaßen Russland und die Russen bis ins 18. Jahrhundert hinein gleichfalls kaum Sympathien - bekanntermaßen war das Gegenteil der Fall -, allerdings besaßen sie bis auf weiteres auch kein Bedrohungspotential. Russen galten als »Barbaren«, einem »Tyrannen« untertan, mit den großen Ausnahmen Polens und Schwedens galten sie indes nicht unbedingt als Feinde. Es gab religiöses Misstrauen und kulturelle Ablehnung; politischer Feindschaft hingegen fehlte der konkrete Anknüpfungspunkt ${ }^{23}$.

\section{IV.1 Der Erbfeind Christlichen Namens: Die Osmanen}

Im Falle der türkischen Osmanen war der Antagonismus hingegen nicht nur seit langem politische Realität geworden - für das Alte Reich spätestens seit der ersten Türkenbelagerung Wiens 1529 -, sondern dieser war in einer Weise religiös und kulturell verfestigt bzw. mental internalisiert wie es sich nachhaltiger kaum denken lässt. Religion, Gesellschaftsstruktur, Rechtstraditionen und Lebensformen »der Türken « wurden in allem als vollkommenes Gegenbild zur göttlichen und christlich-abendländischen Weltordnung wahrgenommen bzw. gezeichnet: Das Reich des Sultans galt als schrankenlose Despotie, die ihre unendlichen Ressourcen aus erbarmungsloser Unterdrückung der Untertanen schöpfte - d.h. der Christen. Regiert werde mit Willkür und Gewalt; Eigentum sei unbekannt, sexuelle Libertinage Prinzip; der »Türke« galt im Felde wie anderwärts als brutales, triebgesteuertes »Un-

22 Janusz TAzBIR, Poland as the Rampart of Christian Europe. Myths and Historical Reality, Warschau 1987.

23 Vgl. Francine-Dominique Liechtenhan, Le Russe, ennemi héréditaire de la chrétienté? La diffusion de l'image de la Moscovie en Europe occidentale aux XVIe et XVIIe siècles, in: Revue Historique. Paris 115 (1991), S. 77-103. Hier sei zum europäischen Russlandbild nur verwiesen auf Marshall T. PoE, A People Born to Slavery. Russia in Early Modern European Ethnography, 1476-1748, New York 2000; Gabriele ScheidEgGER, Perverses Abendland - barbarisches Russland. Begegnungen des 16. und 17. Jahrhunderts im Schatten kultureller Missverständnisse, Zürich ${ }^{2} 1993$ sowie Dieter GroH, Rußland im Blick Europas. 300 Jahre historische Perspektiven, Frankfurt/Main 1988. Speziell zu Deutschland vgl. Mechthild KeLLER / Lew Kopelew (Hg.), West-östliche Spiegelungen. Russen und Rußland aus deutscher Sicht und Deutsche und Deutschland aus russischer Sicht von den Anfängen bis zum 20. Jahrhundert. Wuppertaler Projekt zur Erforschung der Geschichte deutsch-russischer Fremdenbilder, München ${ }^{2} 1988$. Zur positiveren Wahrnehmung des 18. Jahrhunderts: Eckhard MATthes, Das veränderte Rußland. Studien zum deutschen Rußlandverständnis im 18. Jahrhundert zwischen 1725 und 1762, Frankfurt/Main 1981; Astrid BLome, Das deutsche Rußlandbild im frühen 18. Jahrhundert. Untersuchungen zur zeitgenössischen Presseberichterstattung über Rußland und Peter I., Wiesbaden 2000 sowie jetzt Dittmar Dahlmann (Hg.), Die Kenntnis Rußlands im deutschsprachigen Raum im 18. Jahrhundert. Wissenschaft und Publizistik über das Russische Reich, Göttingen 2006. 
tier« - durchaus im Sinne der Apokalypse. Dabei galt die Regel, dass die Autoren die Osmanen umso furchtbarer zeichneten, umso weniger sie von ihnen wussten - und etwa lutherische Pastoren im deutschen Norden wussten sehr wenig ${ }^{24}$.

Rezipiert wurde dieses Bild in ganz Europa. Sogar auf Island wurde wider die Türken gepredigt ${ }^{25}$. Wenn es ein genuin »europäisches Feindbild« gab, war es der »Großtürke«, der »Bluthund Mahomet«, der »verfluchte türkische Alcoran ${ }^{26}{ }^{2}$. - Allerdings gab es dabei eben doch entscheidende Unterschiede. Die französische Krone hatte aus bekannten, traditionellen machtpolitischen Gründen kein besonderes Interesse an einer Perhorreszierung des Osmanenreiches und der französische, ebenso wie der englische und niederländische Levantehandel brachte zumindest Momente von Austausch und Vorurteilsabbau nach Westeuropa. Polen und Venedig wiederum führten mit den Türken zwar oft Krieg - sehr viel öfter als das Reich - waren aber ebenso oft in der Lage, Frieden zu schließen, Handel zu treiben und kulturellen Austausch zu pflegen. Es sei nur an die stark von exotischer Ästhetik beeinflusste polnische Adelskultur des $»$ Sarmatismus « erinnert ${ }^{27}$. Nordeuropa wiederum lag letztlich doch recht weit entfernt von den Kriegsschauplätzen an Donau, Dnjepr oder im östlichen Mittelmeer. Türkenfeindschaft und Türkenfurcht waren

24 Wrede, Das Reich und seine Feinde, S. 72-159.

25 Bernard LEwIS, Die Welt der Ungläubigen. Wie der Islam Europa entdeckte. Frankfurt/Main / Berlin 1983, S. 31.

26 Der Türckische Mahomet/ Und seinem Buch Alcoran, Dessen Herkommen/ und was für Ehre die Türcken/ ihren Mahomet/ erzeigen/ Beneben auch/ wie schrecklich und jämmerlich die Christen gemartert/ und gepeiniget werden/ wenn sie von den Türcken gefangen werden, Hannover 1683, S. 8. Vgl. Wrede, Das Reich und seine Feinde, S. 66-216. Siehe dort auch weitere Quellenverweise.

27 Zum Sarmatismus siehe Norbert Kersken, Geschichtsbild und Adelsrepublik. Zur Sarmatentheorie in der polnischen Geschichtsschreibung der frühen Neuzeit, in: Jahrbücher für die Geschichte Osteuropas 52 (2004), S. 235-260; Janusz TAZBIR, Sarmatismus als Ideologie und Kulturströmung, in: Walther Leitsch u.a. (Hg.), Polen und Österreich im 17. Jahrhundert, Wien u.a. 1999, S. 9-36; Anke Heynoldt, Die Bedeutung des Sarmatismus für das Nationalbewußtsein und die Kultur des polnischen Adels zwischen dem 16. und 18. Jahrhundert, in: Kultursoziologie 7/1 (1998), S. 6-57; Maria BogucKA, La noblesse polonaise face à l'Orient: entre fascination et l'effroi $\left(\mathrm{XVI}^{\mathrm{e}}-\mathrm{XVIII}{ }^{\mathrm{e}}\right.$ siècles), in: Histoire à Nice. Actes du colloque Franco-Polonais d'Histoire, Nice-Antibes, 6-9 novembre 1980, Nizza 1983, S. 17-28. - Zum osmanisch-venezianischen Austausch: Maria Pia PedAni, In nome del Gran Signore. Inviati ottomani a Venezia dalla caduta die Constantinopoli alla guerra di Candia, Venedig 1994, bes. S. $23-48$ u. 196-198. Die für die Handelsrepublik im Gegensatz zu ihrem nördlichen Nachbarn immerhin gegebene »Möglichkeit« normaler Beziehungen zu den Osmanen unterstreicht Paolo Preto, Venezia e i Turchi nel Seicento, in: Ruggero Simonato (Hg.), Marco d'Aviano e il suo tempo. Un cappucino del Seicento, gli Ottomani e l'Impero. Atti del convento storico internazionale Pordenone 12-13 novembre 1993, Pordenone 1993, S. 44-58. Am weitesten in dieser Richtung geht die Interpretation von Daniel Goffman, The Ottoman Empire and Early Modern Europe, Cambridge 2002, S. 137, der von einer »Ottoman-Venetian association« spricht. Siehe dort auch zum englisch-niederländischen Handel mit den Osmanen. Zu Frankreich: Michael HocHEDLINGER, Die französisch-osmanische >Freundschaft< 1525-1792, in: Mitteilungen des Instituts für österreichische Geschichtsforschung 102 (1994), S. 108-164. 
daher in Deutschland durch eine spezifische Mischung aus Nähe und Ferne in besonderer Weise ausgeprägt. Hier waren die Türken zu nah, als dass man es bei wohligem Schaudern belassen oder sie sogar mehr oder weniger entspannt hätte ignorieren können, und sie waren zu fern, als dass ein wirkliches tägliches Arrangement nötig oder möglich geworden wäre ${ }^{28}$.

Dieses gemeinchristliche türkische Feindbild trug denn auch durchaus »nationale« Züge, wenn sich die Deutschen als »Vormauer und Schutzwehr der Christenheit« entwarfen. Es galt die Türkenabwehr als nationale Aufgabe sowie, dies dann vor allem, der Türkensieg als nationaler Triumph. Denn die deutsche Nation war vielleicht infolge der Konfessionsspaltung keine uneingeschränkt »erwählte Nation« bzw., richtiger gesagt, keine Nation, die sich selber in rechtgläubiger Emphase »Erwähltheit« attestierte, wie dies in England, den Niederlanden aber etwa auch in Portugal tendenziell der Fall war. Die deutsche Nation war jedoch, und dies verringert die Differenz wohl ein wenig, uneingeschränkt »ausgezeichnet«. Ausgezeichnet vor allen anderen zunächst durch den Besitz der Kaiserwürde und sodann durch den besonderen Auftrag der Türkenabwehr bzw., nach 1683, durch den besonderen Erfolg des Türkensieges ${ }^{29}$. Dass auch andere Nationen daran beteiligt gewesen waren, ließ sich in nationaler Autosuggestion problemlos übersehen - doch das war keine deutsche Besonderheit, das vermochten Polen oder Franzosen wenigstens ebensogut. - Auch für Polen war der Sieg vom Kahlenberg ein nationaler Triumph, geradezu eine »finest hour«, der die Rolle des Landes als eigentliche »Vormauer der Christenheit« eindrucksvoll bestätigt hatte ${ }^{30}$. Und die Große Galerie in Versailles fasste ins Bild, wie die Türkensiege nicht nur von 1664, sondern selbst 1683 eigentlich Siege des Großen Königs waren ${ }^{31}$.

Der türkische Erbfeind hatte für die Deutschen jedoch zunächst keine politisch-historische, sondern eine heilsgeschichtliche Funktion, wie sich mit Blick auf den »kurzen« Türkenkrieg von 1663/64 gut erkennen lässt. Das in diesen Jahren von den verschiedenen Türkenbüchlein oder Türkenglocken, den Weckrufen oder Warnschriften transportierte Feindbild unterscheidet sich kaum von dem des Reformationsjahrhunderts. Die entsprechenden Schriften sind durch und durch theologisch apokalyptisch geprägt, das aktuelle politische Geschehen wird - vorwiegend auf protestantischer Seite heilsgeschichtlich gedeutet: Die Türken galten als »flagellum Dei«, mit dem

28 Martin Wrede, Der Kaiser, das Reich, die deutsche Nation - und ihre Feinde. Natiogenese, Reichsidee und der Durchbruch des Politischen im Jahrhundert nach dem Westfälischen Frieden, in: Historische Zeitschrift 280 (2005), S. 83-116, hier: S. 97.

29 Wrede, Der Kaiser, das Reich, die deutsche Nation, S. 100.

30 Jan Wimmer, Der Entsatz von Wien 1683, Warschau 1983.

31 Martin Wrede, Türkenkrieger - Türkensieger. Leopold I. und Ludwig XIV. als Ritter und Retter der Christenheit, in: Christoph Kampmann u.a. (Hg.), Bourbon, Habsburg, Oranien. Konkurrierende Modelle im dynastischen Europa um 1700, Köln u.a. 2008, S. 149-156, hier: S. 161. 
Gott die Christenheit für ihre Sünden strafen wolle bzw. strafen müsse. Auch die bereits in der Reformation aufgeworfene Frage, ob die Christen der strafenden Hand des Herrn überhaupt Widerstand leisten dürften, wurde weiterhin diskutiert, und Brisanz gewann das Thema noch immer gerade aus seinem Stellenwert für die konfessionelle Kontroverse ${ }^{32}$.

Etliche dieser Schriften sind auch getränkt von eschatologischer Naherwartung des Weltendes ${ }^{33}$. Alle »wohlgegründeten « Prophezeiungen, so heißt es etwa 1663, würden erkennen lassen, dass ihr neuerlicher und nun so bedrohlicher Ansturm der letzte sein werde, den das Gottesvolk noch zu ertragen habe. Der Jüngste Tag stehe bevor und dies nun sei des Türken »letztes Gekretze und Gereuffe $\ll^{34}$.

Das allerdings war bekanntlich nicht der Fall und auch der Jüngste Tag ließ auf sich warten. Dem »kurzen« Türkenkrieg von 1663 folgte 1683 der "große«, und das hieß die zweite Türkenbelagerung Wiens. Zunächst interpretierte man nun auch diesen Krieg wieder im Lichte von Himmelszeichen und trug eschatologische Deutungen $v^{35}{ }^{35}$. Doch Mahnungen und Prophezeiungen, Gottes Zorn und Weltende sollten die Türkenpublizistik nach 1683 nicht mehr prägen. Die spektakuläre und schon bald als irreversibel erkannte Niederlage des Erbfeindes, die Rückeroberung von Ungarn, entzog dem deutschen Bedrohungsgefühl die Grundlage. Der erfolgreiche Fortgang der Auseinandersetzungen ließ das eschatologische Deutungsmuster obsolet werden. Das Jüngste Gericht stand nicht mehr auf einer nun politisch verstandenen Tagesordnung ${ }^{36}$.

32 Wrede, Das Reich und seine Feinde, S. 72-87, mit Diskussion von Quellen und Literatur.

33 Z.B.: Türcken Trutz und Gottes Schutz. In Betrachtung/ Deß im vergangenen 1660. Jahrs im Monat December zu Scharsbodack in Ober-Ungarn am Himmel erscheinenen Wunderzeichens gezeiget [...], o.O. 1661. - Vgl. Hartmut LehmanN, Die Kometenflugschriften des 17. Jahrhunderts als historische Quelle, in: Wolfgang BRÜCKNER u.a. (Hg.), Literatur und Volk im 17. Jahrhundert. Probleme populärer Kultur in Deutschland, 2 Bde., Wiesbaden 1985, Bd. 2, S. 683700; Alfred Messerli, Angst und Wunderzeichen in Einblattdrucken. Überlegungen zu einem Bild/Text-Medium aus der zweiten Hälfte des 16. Jahrhunderts, in: Rolf-Wilhelm BREDNICH / Andreas Hartmann (Hg.), Populäre Bildmedien, Göttingen 1989, S. 131-150; Thomas KLingeBIEL, Einführung: Apokalyptik, Prodigienglaube und Prophetismus im Alten Reich, in: Hartmut Lehmann / Anne-Charlott Trepp (Hg.), Im Zeichen der Krise. Religiosität im Europa des 17. Jahrhunderts, Göttingen 1999, S. 17-32; Susanne Homeyer, »... das ende mus verhanden sein«. Studien zur eschatologischen Bildlichkeit auf illustrierten Flugblättern der frühen Neuzeit, phil. Diss. Magdeburg 2002.

34 Etzliche $\mathrm{Zu}$ fernerem Nachdencken movirte Politische und Historische Discursen/ Was von des Tyrannischen Türckens ietzigem Einbruch und wieteren Progressen in künfftigen Jahren/ muthmaßlich zu halten sey? [...], Wittenberg 1663, S. 45.

35 Der Ottomannische Welt-Hammer/ abgebildet Erstlich/ Durch eine Beschreibung der heutigen Türckischen Militz [...]/ Zweytens/ Durch einen Unterredungs-Discurs von dem vorigen Türcken-Kriege [...]/ Drittens/ Durch ein vorgedrucktes Antwort-Schreiben/ [...] darinn die Fragen kürtzlich erörtert werden/ Ob die drey jüngste Kometen diesen Türckenkrieg bedeutet haben? Ob die Prophezeyung vom Gog und Magog auf den Türcken gehe? Ob deß Tekli jetzige Actiones sich/ mit der Religion/ entschuldigen lassen?, o.O. 1683, Bl. B 1r-B 2r. 
Ebenso wie der Türkenkrieg veränderten nach dem »Kahlenberg« auch die den Krieg begleitende Publizistik und damit das Bild des Feindes ihre Konturen. Es wurden nicht nur der Sieg und die Sieger glorifiziert, sondern der Gegner in zahlreichen, auf weite Verbreitung zielenden Schriften der Verachtung preisgegeben. Statt »Türcken Trutz« zu beschwören, teilte man nun »Türcken Spott« aus und stimmte kräftiges Triumphgeschrei an ${ }^{37}$.

In der weitberühmte[n]/ Und Wohl ausgebauete[n] ... Bad-Stube heizen etwa die Fürsten aus der ganzen, als Einheit auftretenden Christenheit dem Sultan und seinem Großwesir so kräftig ein, dass beide Blut schwitzen ${ }^{38}$, und in der Türckische[n] Prügel-Suppe beklagt ein kleinmütiger, gedemütigter Kara Mustafa sein Schicksal, das ihm bald die »Seidene Schnur« bringen werde ${ }^{39}$.

Dieser und viele andere etliche andere Schriften symbolisieren augenfällig den Paradigmenwechsel im Umgang mit dem türkischen Erbfeind, der nun nicht mehr Furcht erregte, sondern Spott herausforderte. Sie machen allerdings auch das Ausmaß der Erleichterung deutlich, die sich an den Entsatz von Wien knüpfte, demonstrieren, wie groß das Bedrohungsgefühl gewesen war und wieviel Selbstvergewisserung noch immer erforderlich blieb ${ }^{40}$.

Dennoch reicht das Bild vom mächtigen und bedrohlichen türkischen Erbfeind bis weit ins 18. Jahrhundert hinein. Noch der entsprechende Artikel des Zedler ist essentiell auf der Grundlage der Türkenbücher des 17. Jahrhunderts verfasst und entsprechend geprägt ${ }^{41}$. Datieren lässt sich die Auflösung des Schreckbildes also nicht. Es handelte sich, wie immer, wenn uns nichts Genaueres einfällt, um einen Prozess der »langen Dauer«, der zeigt, wie fest jenes Bild im kollektiven Gedächtnis verankert war. Die entscheidenden Wegmarken sind aber sicherlich die Jahre zwischen 1683 und 1699.

36 Wrede, Das Reich und seine Feinde, S. 211-213. Vgl. zum Kontext demnächst Matthias PohLig, »The greatest of all Events«. Zur Säkularisierung des Weltendes um 1700, in: Ders. u.a. (Hg.), Säkularisierungen in der Frühen Neuzeit. Methodische Probleme und empirische Fallstudien, Berlin 2008.

37 Türcken-Noth und Türcken-Spott In dreyerley Kupffer-Gemählden nachdencklich vorgestellet [...], o.O. 1687.

38 Die weitberühmte/ Und Wohl ausgebauete Türckische Bad-Stube [...], o.O. 1683. Vgl. als graphische Variante das Flugblatt »Türckisches Schweiß-Bad«, das 1686 nach dem Fall von Ofen gedruckt wurde und das entsprechende Szenario abbildet: Türcken-Noth und Türcken-Spott, 2. Kupfer. Das Blatt ist ediert in Wolfgang Harms (Hg.), Illustrierte Flugblätter des Barock. Eine Auswahl, Tübingen 1983, Nr. 69.

39 Türckische Prügel-Suppe dem verlogenen Gott Mahomet/ Welche ihme der Tyrannische GroßVezier/ wegen empfangener Teutscher tichter Ohrfeigen/ seines Bernheuterischen Großsprechers/ und flüchtigen Verlusts hat kochen und anrichten lassen [...]. Allen tapffern und großmüthigen Teutschen vorgestellet/ $\mathrm{Zu}$ einem Gelächter/ einer so armseligen und ohnmächtigen Gottheit, o.O. 1683.

40 Wrede, Das Reich und seine Feinde, S. 144f.

41 Zedler, Universal-Lexikon, Bd. 45, Leipzig 1754, Sp. 1629-1700. 
Der Zedler-Artikel gehört weniger in den Bereich der politischen als vielmehr in den der Erinnerungskultur des 18. Jahrhunderts ${ }^{42}$.

Der Ausfall der »Geißel Gottes« leistete damit einen essentiellen Beitrag zur Veränderung des barocken, durchaus noch nahe am Mittelalter stehenden Weltbildes. Als »der Türke« als endzeitliche Bedrohung nicht mehr zur Verfügung stand, begann das eschatologische Konzept insgesamt zurückzutreten. Wenn zum Ende des 17. Jahrhunderts im Reich die theologisch-biblizistische Geschichtskonzeption durch eine politisch-säkulare ersetzt wurde, und wenn die Aufklärung mit den Vorurteilen auch die eschatologischen Ängste zurückdrängen konnte, so war dies also nicht zuletzt Folge der siegreichen Bewältigung der Türkengefahr ${ }^{43}$. Das apokalyptische Zeitalter endete nicht mit Luther, sondern mit dem Prinzen Eugen - bzw., richtiger gesagt, es endete mit Kara Mustafa, als diesen am 25. Dezember 1683 der Hinrichtungsbefehl des Sultans tatsächlich erreichte.

Anders als die Türkenkriege des 17. Jahrhunderts wurden, als Ergebnis dieses Prozesses, die im 18. Jahrhundert stattfindenden »Kriege gegen die Türken« weithin als politische Ereignisse dargestellt und wahrgenommen. Eine metaphysische Qualität reichte ihnen nicht mehr. Der Türkenkrieg Karls VI. mochte dabei in den Augen des Publikums eine andere Wertigkeit besitzen als der Polnische Thronfolgekrieg; er zog wohl auch noch einmal Freiwillige in die kaiserliche Armee, war aber von seiner Natur her, in Ursprung und Verlauf, nur mehr ein reiner Kabinettskrieg. Seine Wendungen wurden aufmerksam verfolgt, doch das Echo blieb verhalten. Auch die Türkenfurcht scheint mit den begrenzten türkischen Erfolgen dieses Krieges keine Neuauflage erlebt zu haben. Und als in den 1780er Jahren Joseph II. gen Belgrad zog, sah man im Reich zwar noch mit einem Auge hin, aber es rangierte nun eher unter »Vermischtes«, wenn »hinten weit in der Türkei die Völker aufeinanderschlugen « ${ }^{44}$.

42 Wrede, Das Reich und seine Feinde, S. 211-213.

43 Will-Erich Peuckert, Die große Wende. Das apokalyptische Saeculum und Luther. Geistesgeschichte und Volkskunde, Hamburg 1948, hier: S. 167-171; Adalbert KLEMPT, Die Säkularisierung der universalhistorischen Auffassung. Zum Wandel des Geschichtsdenkens im 16. und 17. Jahrhundert, Göttingen u.a. 1960, S. 59; Jean Delumeau, Angst im Abendland. Die Geschichte kollektiver Ängste im Europa des 14. bis 18. Jahrhunderts, Bde. 1-2, Reinbek b. Hamburg 1985, hier: Bd. 2, S. 353-357 u. 397-411; Arno SeIfERT, Der Rückzug der biblischen Prophetie von der neueren Geschichte. Studien zur Geschichte der Reichstheologie des frühneuzeitlichen deutschen Protestantismus, Köln u.a. 1990, S. 137f; Erich Trunz, Weltbild und Dichtung im deutschen Barock, München 1992, S. 37 u. 168-176.

44 Vgl. Ivan PARvev, Land in Sicht. Südosteuropa in den deutschen politischen Zeitschriften des 18. Jahrhunderts, Mainz 2008. - Zitat: Johann Wolfgang von GoETHE, Faust, 1. Teil, »Vor dem Tor« (Erstaufl. Tübingen 1808). - Zum 1807/08 beginnenden Austausch Goethes mit Joseph von Hammer-Purgstall siehe Ingeborg H. SolBRIG, Hammer-Purgstall und Goethe. >Dem Zaubermeister das Werkzeug‘, Bern u.a. 1973, S. 62-69. 
Die Osmanen waren nicht mehr »ungezügelte« Feinde, sondern unzivilisierte Barbaren, das Osmanische Reich wurde zum Gegenstand einer europäischen »mission civilisatrice«. Pointiert gesagt: Der Erbfeind war zum Barbar, zum Wilden, zurückgestuft worden; und gegen Barbaren führte man wohl zivilisatorische, aber keine »heiligen Kriege « ${ }^{45}$. Erwägungen, die angestellt wurden, die europäische Türkei zu erobern und dabei über das reine Konvenienzdenken hinausgehen, zielten weder auf die Vernichtung »des Türken« noch auf Ausbreitung des »Christlichen Namens«, sondern - säkularisiert - auf Kultur bzw. Zivilisation. Russland, Österreich oder auch »Deutschland « wurde eine kolonialpolitische »mission civilisatrice« für den Balkan attestiert, die die unterworfenen Völker befreien und die Barbaren zu europäischer Gesittung führen sollte. Das zeitgenössische Deutungsmuster der zivilisatorischen Mission Europas in »Asien« wurde also auf den Balkan und den gewesenen Erbfeind angewandt ${ }^{46}$. Der Opernkarriere des Buffo-Türken stand damit nichts mehr im Wege.

\section{2 Der »andere« Erbfeind: Das Frankreich Ludwigs XIV.}

Die Karriere des okzidentalischen Erbfeinds verlief bekanntlich zunächst entgegengesetzt zu der des orientalischen, d.h., sie führte von geringen Anfängen auf erstaunliche Höhen. Noch 1662 lobt eine profranzösische Flugschrift die friedliche Politik des Allerchristlichsten Königs und seine Verdienste um das Reich. Ludwig sei »Befästiger der Christenheit/ der stätige Feind des Mahometischen Reichs/ der tägliche Erhalter des Teutschen Friedens « ${ }^{47}$. Das war natürlich von interessierter Seite lanciert worden, doch kontrovers war es zu diesem Zeitpunkt keineswegs. - Schon zehn Jahre später allerdings sah das anders aus. Frankreich war offiziell zum »Reichsfeind« erklärt, inoffiziell zum »Erbfeind« ausgerufen ${ }^{48}$.

45 Zum Gegensatz der Konzepte von Barbar und Erbfeind siehe zugespitzt Pierre BéHar, Türkenbilder, Italienerbilder: Antithesen des Deutschen, in: Lili 94 (1994), S. 92-107, hier: S. 92. Vgl. Wrede, Das Reich und seine Feinde, S. 209; Wilson, Humanität und Kreuzzugsideologie, S. 17. - Zur Unterscheidung von `zivilisatorischen` und `Heiligen Kriegen`vgl. Dieter JANSSEN, Gerechte, heilige und zivilisatorische Kriege. Legitimation des Krieges und Bedeutung von Feindbildern in der angelsächsichen Welt der frühen Neuzeit, ca. 1550-1650, Hamburg 2004.

$46 \mathrm{Zu}$ den neueren Teilungsplänen, die sich auf die europäische Türkei bezogen, siehe Trandafir G. Duuvara, Cent projets de partage de la Turquie (1281-1913), Paris 1914, Karten VI-VIII. - Zum Kontext: Jürgen Osterhammel, Die Entzauberung Asiens. Europa und die asiatischen Reiche im 18. Jahrhundert, München 1998, S. 46-51 u. 375-403, bes. 390f.

47 Deß Aller Christlichsten Königs Friedhaltendes Gemüth mit den Ständen deß Teutschen Reichs [...], o.O. 1662, S. 6.

48 Wrede, Das Reich und seine Feinde, S. 330-483; Christoph Kampmann, Reichstag und Reichskriegserklärung im Zeitalter Ludwigs XIV, in: Historisches Jahrbuch 113 (1993), S. 41-59. 
Frankreich, oder richtiger Ludwig XIV., sollte nun der zweite »Türke« sein, ebenso wie der erste als Inkarnation des Antichrist anzusehen und auch zu behandel $n^{49}$. Die einschlägigen Schriften boten hierfür zwei, miteinander verschränkte Argumente: Einesteils wurden die Franzosen mit den Türken erst verglichen, dann identifiziert, andernteils ihre heilsgeschichtliche Qualität behauptet bzw. nachgewiesen. In dieser letzteren Perspektive war Ludwig schließlich der Antichrist nicht als Handlanger »des Türken«, sondern aus sich selbst heraus.

Propagandistisch instrumentalisieren ließ sich dabei besonders der zur Ironisierung geeignete Titel des »Roi-très-Chrétien«, auf den das französische Königtum seinen Anspruch auf Vorrang vor allen anderen Kronen gründete $^{50}$. Man ernannte den Allerchristlichsten König kurzum zum »Allerunchristlichsten«, da seine »türkische« Politik und Kriegführung nur diese Titulierung zuließen ${ }^{51}$. Zusätzliche Tiefe erhielt der polemische »Türkenvergleich« durch die sehr früh einsetzende Interpretation der französischen Staatsverfassung als »türkisch« und durch die Diskussion der angeblich tief verwurzelten, den Türken ähnlichen französischen Sittenlosigkeit; beides verstanden als Ausweis vollständiger Verworfenheit einer Nation und eines Staatswesens ${ }^{52}$. »Sex and crime « herrschten an der Seine genauso wie am Bosporus.

Dies waren scharfe Angriffe, doch ein eschatologisches Deutungsmuster lag ihnen nur eingeschränkt zu Grunde ${ }^{53}$. Der Rekurs auf den Erbfeind und der »Türkenvergleich« waren nicht zuletzt ein probates rhetorisches Manö$v \mathrm{ve}^{54}$. Als Oberflächenphänomen ist dieses jedoch nicht anzusehen: Die Diffamierung des Feindes als türkisch, als außerhalb der Christenheit stehend, entsprach offenkundig einer verbreiteten Auffassung bzw. Auffassungsbereitschaft und war nicht nur Interpretation, sondern zugleich Interpretament.

49 Wrede, Das Reich und seine Feinde, S. 364-374 u. 474-484.

50 Jacques Krynen, L'empire du roi. Idées et croyances politiques en France XIII ${ }^{e}-\mathrm{XV}^{\mathrm{e}}$ siècle, Paris 1993, S. 345-383.

51 Frühes Beispiel: Machiavellus Galdicus, Das ist: Verwandlung und Versetzung der Seele Des Maciavelli in Ludovicum XIV [...]/ Beschrieben Durch einen Ehrlichen Teutschen [...], o.O. 1675, Bl. A 2r.

52 Das Thema setzt die in zahlreichen Varianten erschienen Schrift: Die Frantzöische [!] Türckey/ angerichtet durch Die großen Staats-Männer/ Ariante und Polidor; oder Kurtze Erzehlung Der vornehmsten Thaten Des Königs in Franckreich/ und Was er ferner vor hat/ sein Reich in solchen Zustand zu setzen/als das Ottomannische Kayserthum/ umb/ Zur Monarchie und allgemeinen Beherrschung zu gedeyen. Gantz kürtzlich entdeckt durch Alexander Christian de Metre, »Roterdam《 1673 . Johannes HALler, Die deutsche Publizistik in den Jahren 1668-1674. Ein Beitrag zur Geschichte der Raubkriege Ludwigs XIV., Heidelberg 1892, S. 75 zu den weiteren Ausgaben, sowie Wrede, Das Reich und seine Feinde, S. 364-374, zum Motiv selbst.

53 Ebd., S. 474-480; Rudolf Meyer, Die Flugschriften der Epoche Ludwigs XIV. Eine Untersuchung der in schweizerischen Bibliotheken enthaltenen Broschüren (1661-1679), Basel u.a. 1955 , S. $69 f$.

54 Vgl. MÜNKLER, Nation als politische Idee, S. 63f. 
Die Formulierung politischer Feindschaft bedurfte nach wie vor essentiell der religiösen Dimension ${ }^{55}$.

Dass Ludwig ein »flagellum Dei« sei, war schon im Holländischen Krieg erörtert worden ${ }^{56}$; im Pfälzer Krieg gelangten weitere Elemente in die offenkundig wiederum vorzugsweise von Protestanten geführte Diskussion. Ludwig erreichte nun heilsgeschichtliche Qualität als der theologisch »erwiesene« Antichrist. Eine Prophezeiung wagt nicht nur, einschlägigen Stücken aus der Türkenpublizistik vergleichbar, den Ausblick darauf, bis zu welchem Punkt im Reich die Franzosen noch gelangen müssten, bevor Gott sie zurückschlagen werde, sondern führt dabei auch aus, dass Ludwig XIV. das zweite in der Johannesoffenbarung genannte Untier sei ${ }^{57}$. Anderwärts kann man eine Lösung für die Doppelgestalt des »Gog und Magog« finden: Der erste bezeichnet die französischen Lilien, der zweite den türkischen Halbmond $^{58}$.

Mit dem Sieg am Kahlenberg, der Aufhebung des Edikts von Nantes, vor allem aber mit dem Beginn des Pfälzer Krieges, erhielten die verbalen Attacken auf den »occidentalischen Türken« zusätzliche Schärfe und neue Impulse. Der »Allerunchristlichste« erschien jetzt endgültig als Verwandter des Erbfeindes enttarnt. In mehr als einer Beziehung übertraf er ihn sogar $^{59}$. Die Flugschriften sprachen nicht mehr nur von der $»$ Frantzösischen Türckey«, sondern vom »Occidentalischen Erb-Feindt«, vom »Primogenitus Satanae« oder von der »Monarchie des Anti-Christ ${ }^{60}$. Ludwig XIV. galt

55 Ebd., S. 63. Vgl. Reinhart Koselleck, Zur historisch-politischen Semantik asymmetrischer Gegenbegriffe, in: Ders., Vergangene Zukunft. Zur Semantik geschichtlicher Zeiten, Frankfurt/ Main ${ }^{4} 2000$, S. 211-259, hier: $229 \mathrm{ff}$.

56 Wrede, Das Reich und seine Feinde, S. 357-374.

57 Johann Lichtenbergers/ eines Einsiedlers Weissagungen/ So er Von Verfolgung der Kirchen/ Verwüstung deß gantzen Rhein-Strohmes Durch die Franzosen/ Wie auch zuvor Vom Abfall und Reformation der Römischen Kirchen geschrieben/ Genommen Aus seinem Prognostico, so er Anno 1488 und also vor 201 Jahren über der grossen Conjunction Saturni und Jovis Lateinisch geschrieben Und Zu Cöln am Rhein 1526 gedruckt worden. Anitzo wegen vielfältigen Nachfragens nebst dem Lateinischen ins Hoch-Teutsche vertirt und gedruckt, [Leipzig] 1689.

58 Glaube und Gedult Der Heiligen In dem Babylonischen Franckreich/Oder: Gespräch Zwischen einem Frantzössichen Freyherrn/ Ungarischen Prediger/ Und Schottischen Edelmann/ Darinnen erwiesen wird/ Daß Franckreich Ein zweytes Babel/ Und der jetzt herrschende König Das Thier sey Davon in der Offenbahrung Johannis Cap. XIII Meldung geschehen. Aus dem Holländischen ins Teutsche übersetzet, o.O. [ca. 1690], bes. S. 100f., 125f. u. 136f.

59 Unvorgreiffliches Bedencken/ Ob die zween grosse Kriege mit dem Türcken und Franzosen zugleich fortzuführen: $\mathrm{Oder} / \mathrm{Ob}$ mit einem und mit welchem am ersten Friede zu machen?, o.O. 1691, S. $12 \mathrm{f}$.

60 Der Occidentalische Erb-Feindt/ Das ist: Die Frantzösische heut zu Tag übliche underschidliche Staats-Maximen und Regierung [...]/ Dabey auch Uber die heutige annoch weit aussehende Frantzösische Proceduren [...]/ Und Bißhero verübter Frantzösisch-Barbarischer Grausamkeiten/ einige Reflexiones [...], o.O. 1690; Der Frantzösische und das Heil. Röm. Reich verderbende grausame Greuel und Abgott Ludewig der Vierzehende König in Frankreich an den sich Teutschland hat so lange Zeit vergaffet/ allein durch denselben nunmehr so hefftiglich gestraffet/ Nach seinen Eigenschaften abgemahlet auff dem Probierstein des Gesetzes 
jetzt als »allgemeine[r] Teutschen Feind, Feind der Christenheit, Feind des Menschlichen Geschlechts $~^{61}$. Man schloss Überlegungen über einen »ad exterminationem « zu verfolgenden »Franzosenzug« an. - Die religiöse Formel jedoch, das ist recht beachtlich, war durch ausgeweiteten Gebrauch nationalisiert worden: Man sprach vom »Christen-Feind« aber auch vom »TeutschenFeind «!

Diese Dämonisierung des westlichen Kriegsgegners war kein Einzelfall, und sie bildet auch kein deutsches Spezifikum. Die Heiligen im babylonischen Frankreich - so der Titel einer weitverbreiteten Schrift - waren die verfolgten, vertriebenen Hugenotten und das zitierte Werk aus dem Niederländischen übersetz ${ }^{62}$. In der Republik wie auch in England war das religiöse Motiv in der publizistischen Auseinandersetzung mit Frankreich fest verankert - sicherlich ebenso fest wie im Reich und möglicherweise noch mehr ${ }^{63}$. Transportiert wurde es wesentlich durch die Autoren des Refuge. In großem Umfang kursierten unter den der Verfolgung entkommenen Hugenotten apo-

des Herrn falsch befunden und nach dem gerechten Gericht Gottes dem Untergang und seiner Feinde billigmäßigen Rache/ sehr nahe kommende eingebildete Gerne-Monarch, o.O. 1689, B1. C 2v; Grund-Riß des in einen Französischen Staats-Modell umgegossennen Türkischen Alcorans. [...] in Druck gegeben Zu Constantinopel den 12. Augusti 1687. Aus dem Türkischen ins Teutsche übersetzt [...], »in Teutschland« 1688, S. 3f.

61 Grund-Riß des [...] Türckischen Alcorans, S. 100; Der in Plutonis Reich und Rachen eine Zeit lang gesteckte [...] Grausame Mordbrenner De La Brosse Oder [...] Ludovici XIV. [...] Unchristliche Proceduren [...], »Cölln« 1689, S. 1; Teutsche wehrt Euch Wider Franckreich. Das ist/ kurtzes Tractat Warinn [!] außführlich [...] enthalten/ was das Herrschsüchtige/ neidige/ Fridstöhrende Franckreich Für Boßheiten/ Gewalt und Vntrew verübt habe/ wider das Aller Durchleuchtigste Ertz-Hauß Oesterreich [...] Wie auch/ Daß alle Teutschen/ Catholische und Vncatholische/ gröste Ursach haben mit vereinigten Gemüthern [...] dem Frantzosen als einem gemeinen Teutschen Feind/ sich zu widersetzen, o.O. 1689.

62 Glaube und Gedult der Heyligen in dem Babylonischen Franckreich. Vgl. das niederl. Orig.: »Audax Philalethes« [i.e. Andries Pietersz ?], De Lydsaamheid en het Gelove der Heiligen. Onder so vele sware en Bittere Vervolgingen, Die Gods Kerke nun alomme moet uitstaan, en wel meest in Vrankryk, [Amsterdam] 1688. Vgl. auch die dte. Kurzfassung aus dem Spanischen Erbfolgekrieg: Franckreich Zweytes Babel/ worinnen dargethan wird/ daß der jetzt herrschende König Ludwig der XIV. Das Thier sey/ darvon in der Offenbahrung Joannis Cap. 13 Meldung geschehen, o.O. 1707. Die niederl. Ausg. zeigt als Titelkupfer Ludwig XIV. als apokalyptisches Untier. - Zur Kongruenz deutscher, niederländischer und englischer Flugschriften siehe Hubert GILlot, Le règne de Louis XIV et l'opinion publique en Allemagne, Paris 1914, S. 19; Wrede, Das Reich und seine Feinde, S. 480.

63 Vgl. Wolfgang Cillessen (Hg.), Krieg der Bilder. Druckgraphik als Medium politischer Auseinandersetzung im Europa des Absolutismus (Ausstellung Deutsches Historisches Museum 18.12.1997-3.3.1998), Berlin 1997, S. 216-224, sowie in der älteren Literatur MEYER, Flugschriften, S. 71; Pieter J.W. van MaLsSEN, Louis XIV d'après les pamphlets répandues en Hollande, Paris u.a. 1936, S. 76. - Zum niederländischen Selbstbild als »neues Israel«: Gerrit Groenhuis, Calvinism and National Consciousness: The Dutch Republic as the New Israel, in: Alastair C. Duke / Coenrad A. TAmse (Hg.), Britain and the Netherlands, Bd. 7: Church and State since the Reformation, Den Haag 1981, S. 118-133; Cornelis Huisman, Neerlands Israel. Het Natiebesef der traditioneel-gereformeerden in die achttiende eeuw, Dordrecht 1983, S. 56, 83 u. 136. - Zu England die in Anm. 20 genannte Literatur. 
kalyptische Interpretationen des Geschehens in Frankreich. Sie erkannten den Antichrist weiterhin im Papst, jedoch gleichfalls in dessen »erstgeborenem Sohn $\aleph^{64}$. Schon das Motiv der »Französischen Türkei« entstammte im Übrigen calvinistischen Schriften der Religionskriege - also einer innerfranzösischen Debatte mit nicht zuletzt antiabsolutistischer Stoßrichtung ${ }^{65}$.

Inwieweit allerdings auch in England oder den Niederlanden der Gedanke, Ludwig XIV. sei der Antichrist, tatsächlich rezipiert und internalisiert worden war, mag dahingestellt bleiben, Antichriste bzw. religiös überhöhte Erbfeinde aber gab es in Europa offenkundig mehrere ${ }^{66}$. Im Reich konnte von einer wirklichen Substitution des türkischen durch den französischen Erbfeind nur eingeschränkt die Rede sein; über eine, immerhin recht weitgehende Assimilation des französischen Feindbildes an das türkische ging die Entwicklung nicht hinaus. Das Bewusstsein, wer der »eigentliche« Erbfeind christlichen Namens sei, war auch am Ende des 17. Jahrhunderts noch hinreichend verfestigt - und man »wusste« eben auch, dass Frankreich ein bedrohlicher Nachbar, aber keineswegs das »Untier« der Johannes-Offenbarung war. »Der Türke« besaß als Schreck- und Feindbild eine größere Tiefendimension als »Ludovicus impius«. Im westlichen Europa mochte das anders gewesen $\operatorname{sein}^{67}$.

In den antitürkischen Schriften war der Erbfeindbegriff daher geläufig, etabliert und, bei aller Schärfe, unspektakulär; in den antifranzösischen Schriften hingegen war er von äußerster Polemik und zielte auf massive Verunglimpfung. Ebenso war das eschatologische Deutungsmuster in der Auseinandersetzung mit den Türken noch 1663/64 die Regel, 1683 immerhin noch spürbar, im Konflikt mit Frankreich blieb es letzten Endes die Ausnahme. Fest etablieren ließ sich diese Deutung des Feindverhältnisses nicht. Das schloss schon die kulturelle Dominanz Frankreichs ganz und gar aus. Politisch war das Konzept des französischen Erbfeinds zwischen 1670 und 1715 mehr als erfolgreich. Kulturell war es von jeder Aussicht auf Erfolg weit entfernt.

64 Barbara DE NÉGRONI, Intolérances. Catholiques et protestants en France, 1560-1787, Paris 1996, S. 111f.

65 La France-Tvrquie, C'est à dire, Conseils et Moyens tenus par les ennemis de la Couronne de France, Povr redvire le Royavme en tel estat que la Tyrannie Turquesque, »Orléans: Thibaut des Murs« 1576.

66 Jean Delumeau, Le péché et la peur. La culpabilisation en Occident, XIII $-\mathrm{XVIII}^{\mathrm{e}}$ siècles, Paris 1983, S. 597-600.

67 Wrede, Das Reich und seine Feinde, S. 474-484 (mit Quellenverweisen auch zum Folgenden). 
IV.3 Der »neue« Erbfeind: Frankreich im 18. Jahrhundert

Nach 1740 war der französische »Erbfeind « jedoch immerhin erinnerungsfähig und debattenwürdig. Mit den universalen Ambitionen Frankreichs und besonders Ludwigs XIV. wurde ebenso der Türkenkriege und der französischen Verwicklung darin gedach ${ }^{68}$. Und die Debatte kannte auch einige recht heftige Worte. So erinnert eine Schrift an den Pfälzer und den Holländischen Krieg, die Verwüstungen und Greuel jener Jahre, und fordert mit Blick darauf dann so schlicht wie radikal: »Diese gottlose Nation, ich meine die Franzosen, sollte von allen andern Völckern gäntzlich aus der Menschlichen Gemeinschaft ausgeschlossen werden ${ }^{69}$.

Die Kriege Ludwigs XIV. hatten im Reich und in Europa eindeutige Spuren hinterlassen, denn aus britischer Perspektive sah das nicht viel anders aus als aus deutscher ${ }^{70}$. Durch die neuerliche Ausrufung der Erbfeindschaft wurde jedoch konkret das deutsch-französische Feindverhältnis wiederum in besonderer Weise aufgeladen. Allerdings: Der (französische) Erbfeind von 1745 war ein ganz anderer als der (türkische) von 1664 oder 1683, und er war auch ein anderer als der (französische) von 1674 oder 1688. Bestimmung und Begründung des Sachverhalts waren nunmehr rein historisch. Eine Ableitung vom »eigentlichen« türkischen Erbfeind christlichen Namens war zwar weiterhin möglich und wurde auch vorgenommen ${ }^{71}$, doch es war dies weder zwingend noch die Regel. Der Begriff war säkularisiert worden und seiner metaphysischen Dimension weitgehend entkleidet; eschatologische Momente kamen nicht mehr zum Tragen. Der französische »Erbfeind« des Österreichischen Erbfolgekrieges war der Feind, den man aus dem Pfälzer oder dem Spanischen Erbfolgekrieg »ererbt« hatte.

Bezeichnend ist eine Passage in einem Universal-Geist der Crone Franckreich, die referiert, dass Ludwig XIV. einst als »flagellum Germaniae [!]《

68 [Gottfried Ernst Fritsch], Politische Betrugs-Historie von Franckreich Oder Die wenig auffrichtige Aufführung Des Französischen Hofes bey Kriegs- und Friedens-Geschäfften [...] so seit etlichen hundert Jahren die Crone Franckreich mit den Machten von Europa/ vornehmlich aber Mit dem gesammten Teutschen Reich [...] und insonderheit Mit den Durchläuchtigsten Häusern Oesterreich und Lothringen gepflogen [...], o.O. 1745, S. 71; La France d'après Nature Ouvrage très utile pour bien se mettre au fait des Intrigues des Ministres de la Cour de Versailles contre l'Auguste Maison d'Autriche, »Cologne« 1747, S. 70.

69 Drey Ehrliche Teutsche, Wahrlieb, Freymund, Und Guthertz Reden miteinander Lustig/ verträulich/ nachdencklich [...] Von der Vergangenen/ gegenwärtigen Und zukünfftigen Zeit. Zu Paris aus einem Manuscript gedruckt, so sich unter denen sub Hasta verkaufften Mobilien der gestorbenen Frantzösischen Reputation befunden [...], o.O. [ca. 1743], S. 63.

70 BLACK, Natural and Necessary Ennemies, S. 207 u. 210. Vgl. auch die übrige in Anm. 20 genannte Literatur.

71 Vgl. ein Gutachten Johann Jacob Mosers von 1745 für die kurhannoversche Regierung, in: Reflexiones über die dermalige hohe Candidaten der Römischen Kayser-Würde. Reinhard Rürup (Hg.), Johann Jacob Moser. Pietismus und Reform, Wiesbaden 1965, S. 215-233, hier: S. 218. 
bezeichnet worden sei. Ludwig XIV. wolle nun, wie der Verfasser erklärt, »ein Zucht-Meister der Deutschen« sein. Diese scheinbare Übersetzung bedeutete nichts anderes als eine vollständige Umwertung ins Nationale und ins Säkulare: Für eine göttliche Strafe nahm man Ludwig XIV. umso weniger, als man seinem angeblichen Ansinnen mit einigem Selbstbewusstsein gegenüberstand $\mathrm{d}^{72}$.

Noch bezeichnender für die »neue«, rein historische und säkulare deutschfranzösische Erbfeindschaft des mittleren 18. Jahrhunderts ist aber vielleicht eine im wörtlichen Sinn akademische Diskussion, die sich 1744 entsponn, als ein Parteigänger des mit Frankreich verbündeten Kaisers Karl VII. eine nur sehr mäßig reißerisch aufgemacht Schrift publizierte, die Historisch-politische Erörterung der Frage, Ob die Crone Franckreich vor einen Erb-Feind deß Heiligen Römischen Reiches zu achten seye ${ }^{73}$ ?

Der Autor versucht den Nachweis, dass jene Krone - natürlich - kein Feind des Reiches, dass sie - natürlich - kein »Erbfeind« der Deutschen sei. Nie habe Frankreich einen Angriffskrieg gegen das Reich geführt, bei den Kriegen der Epoche Ludwigs XIV. habe es sich um reine »Privatangelegenheiten des Hauses Österreich « gehandelt. Und Erbfeind des Reiches könne Frankreich schon deswegen nicht sein, weil man, wie jeder wisse, gelegentlich auch Frieden miteinander gemacht, sich - wie jetzt - gar verbündet habe ${ }^{74}$.

Die Erwiderung ließ nicht lange auf sich warten. Sie war von dem Göttinger Historiker Franz Dominikus Häberlin verfasst, und dessen Landesherr, Georg II. von England, stand bekanntlich auf der Seite der Gegner Karls VII. Auch seine Schrift kam freilich nur mäßig reißerisch daher, nämlich als $A n-$ merkungen Ueber die [...] Erörterung der Frage/ Ob die Crone Franckreich vor einen Erbfeind des Heil. Röm. Reichs zu achten seye? Häberlin weist die Beweisführung seines Kontrahenten Punkt für Punkt und mit viel Schulmeisterei zurück und kommt so zu dem nicht sehr überraschenden Ergebnis, dass nämlich »die Krone Franckreich allerdings den Nahmen eines Erb-Feindes des Teutschen Reiches verdiene ${ }^{75}$.

Nun können auch nicht überraschende Ergebnisse durchaus bemerkenswert sein. Für die Feststellung Häberlins gilt das in doppelter Hinsicht: Bemerkenswert ist zunächst, dass vor dem Hintergrund der Kriege Ludwigs XIV. und ihrer publizistischen Begleiterscheinungen die Bestätigung des »Erb-

72 Der Universal-Geist Der Crone Franckreich Als die Mißgeburth der Politic, o.O. 1745. Vgl. Wrede, Das Reich und seine Feinde, S. 494-511.

73 Historisch-politische Erörterung der Frage, Ob die Crone Franckreich vor einen Erb-Feind deß Heiligen Römischen Reiches zu achten seye? Nebst unpartheyischen Reflectionen Uber das unter dem Deckmantel einer besonderen Gemüths-Mäßigung uber den Hauffen zu werffen suchende Gleichgewicht von Europa, Frankfurt/Main 1744.

74 Ebd., passim.

75 Franz Dominikus HäBerlin, Anmerkungen Ueber die [...] Erörterung der Frage/ Ob die Crone Franckreich vor einen Erbfeind des Heil. Röm. Reichs zu achten seye?, o.O. 1745, S. 119. 
feindcharakters« überhaupt nötig erschien bzw. dass er sich, in der Hoffnung auf Glaubwürdigkeit, überhaupt in Zweifel ziehen ließ. Bemerkenswert ist sodann der ruhige bzw. einigermaßen umständliche Ton der Debatte. Mit den auf die Türkenkriege gerichteten Endzeitvorstellungen, mit der überbordenden, religiös aufgeladenen antifranzösischen Hysterie der 1690er Jahre hatte das alles nichts zu tun.

Zwar klagte man auch nach 1740 weiterhin über französische Besatzungstruppen, stellte ihren Mangel an Disziplin und Ordnung heraus und berichtete von ihren Ausschreitungen ${ }^{76}$. Dies weckte indes nicht nur Schrecken, sondern auch amüsierte Genugtuung. Die Soldaten Ludwigs XIV. waren sichtlich keine "gestiefelten Teufelsgestalten«. Man fand wohl Beweise für Zuchtlosigkeit, Willkür und Grausamkeit, aber ebenso für Wankelmut, Nachgiebigkeit und Feigheit. Die Franzosen wüssten »wohl zu Gasconiren «, nicht aber zu exerzieren ${ }^{77}$. - Der Verlauf des Österreichischen Erbfolgekrieges reduzierte die Reputation und damit auch die Bedrohlichkeit Frankreichs empfindlich. Der Siebenjährige Krieg sollte dem weiteren Raum geben ${ }^{78}$.

\section{Zusammenfassung und Ausblick}

Ein »Erbfeind« brauchte »lange Dauer«, nachhaltiges Bedrohungspotenzial und eine kulturelle Differenz, in der Regel Religions- bzw. Konfessionsverschiedenheit. Zur Not ging es allerdings auch ohne die, denn der »wahre Glauben « wird dem Erbfeind immer abgesprochen, besonders, wenn er mit dem des Gegners übereinstimmen sollte. Ausschließlich durch Propaganda oder »Diskurs« ließen sich weder Feindbild noch »Erbfeind « erzeugen.

Der türkische Erbfeind wurde mit erwiesener Ungefährlichkeit ausrangiert und mit ihm die sakrale, eschatologische Deutung des Weltgeschehens. Die »Geißel Gottes « fand sich zum »Buffo-Türken« ridikülisiert, und dessen Reich nicht mehr, theologisch, im Lande Gog und Magog verortet, sondern, geographisch, in Asien.

76 Vgl. etwa die Berichterstattung der Neue[n] Europäische[n] Fama, Bd. 7 (1741), 76 . Theil, zum guten Eindruck der französischen Armee, die den Verfasser indes an das Heer des Xerxes gemahnt, das gleichfalls einen imponierenden Anblick geboten habe, aber dennoch geschlagen worden sei. In der Folge werden die Besatzungslasten im Hinblick auf Quartiergestellung, Requisitionen und Fourage illustriert: 77. Theil, S. 366f.; 78. Theil, S. 482. Zum Geschehen in und um Prag: Bd. 8 (1742/43), 87. Theil, S. 214ff.; 91. Theil, S. 580-583. Zum weiteren Kriegsverlauf: Bd. $10(1744 / 45), 115$. Theil, S. 608f.; 116. Theil, S. $652 \mathrm{ff}$.

77 Der Mit seinem entlehnten Cörper sich noch in dem Kriege befindliche Simplicissimus Redivivus, Schreibet von Straßburg an einen vertrauten Caffée-Sieder nach Prag, o.O. 1744, bes. S. 16-20, Zitat S. 18.

78 Wrede, Das Reich und seine Feinde, S. 512-537. 
Frankophobie erreichte in den 1680er und 1690er Jahren im Reich nahezu den Status einer Ersatzreligion. Frankreich wurde zum Erbfeind ausgerufen, das Feindverhältnis sakralisiert. Das war in den Niederlanden und in England nicht anders und nicht zuletzt von Autoren des hugenottischen Refuge geprägt. Zu einer vollständigen Gleichordnung des »occidentalischen Erbfeinds « mit dem »orientalischen « kam es dennoch nicht, und eine kulturelle Differenz zur kulturellen Vormacht des Zeitalters konnte nie auch nur ansatzweise aufgebaut werden.

Frankreich aus Europa ausgrenzen zu wollen, war polemisch probat, politisch, gar kulturell absurd. Auch ein ins äußerste gesteigerter Konflikt hob das Verbindende nicht auf. Als Leopold I. starb, trug Ludwig XIV. zwar nicht schwarz, aber violett ${ }^{79}$. Und die Deutschen, zum Kummer mancher Pamphletisten, entschlugen sich weder französischer Weine noch Manieren ${ }^{80}$. Dass auch der Krieg selbst nicht nur Kulturkontakt, sondern auch -transfer brachte, lässt sich vielleicht am besten mit Blick auf das 18. Jahrhundert und die französischen Feld- und Besatzungstruppen des Siebenjährigen Krieges illustrieren - »die besten Feinde, die man sich nur wünschen kann $\aleph^{81}-$, doch schon die Kriege Ludwigs XIV. zwangen zur Auseinandersetzung mit Frankreich und den von ihm gesetzten Maßstäben, zum nicht geringen Teil auch zur Anpassung daran ${ }^{82}$. Auch sie verbanden die »Feinde « - intensiver als ihnen lieb war.

Die Osmanen hingegen, dies war augenfällig, gehörten nicht »dazu« weder im Krieg noch im Frieden. Türkenkriege behielten bis Passarowitz die Gefallenenzahlen unterstreichen dies eindringlich - eine besondere Qualität, für Friedens- bzw., richtiger gesagt, Waffenstillstandsschlüsse galt das gleiche $^{83}$. Die kriegerischen Konflikte rückten die Türken zwar in einen Wirkungszusammenhang mit Europa, sie öffneten ihnen aber nicht den Weg nach Europa. Diese Perspektive gab es erst im 18. Jahrhundert, als »der Türke«, nunmehr »gezähmt«, vom Erbfeind allmählich zum politisch-diplomatischen Gegner oder selbst Partner wurde. Freilich wurde er auch zum Objekt von Zivilisations- und Kolonisationsbestrebungen - und diese, wiederum, verorteten das Osmanenreich durchaus nicht in Europa ${ }^{84}$.

Die zunehmend als politisch erkannten Feindverhältnisse zu Franzosen wie Osmanen einigten zwar nicht den Kontinent, aber immerhin das Reich

79 Louis de Rouvroy, Duc de Saint-Simon, Mémoires, hg. von Yves Coirault, Bd. 2, Paris 1983, S. 600 .

80 WreDE, Das Reich und seine Feinde, S. 407-415.

81 Horst CARL, Okkupation und Regionalismus. Die preußischen Westprovinzen im Siebenjährigen Krieg, Mainz 1993, S. 238-243.

82 WreDE, Der Kaiser, Das Reich, die deutsche Nation, S. 106-115.

83 Ebd., S. 179-185.

84 Vgl., z.T. anders akzentuiert, den Beitrag von Ivan Parvev in diesem Band, sowie ders., Land in Sicht, S. 27-30. 
und zwar über die Konfessionsgrenze hinweg; sie trugen zur Säkularisierung seiner politischen Kultur bei. In den Nachbarstaaten ließ sich ähnliches beobachten. Zwischen 1670 und 1740 bewirkte dies eine Stabilisierung des Reiches. In der Folge, nach »Ausfall« der Feinde, war die Fragilisierung umso drastischer.

Der französische »Erbfeind « des Österreichischen Erbfolgekrieges war kein Antichrist mehr, sondern »nur« noch ein aus - jüngerer - Vergangenheit ererbter Feind. Er war einer, der kaum mehr Furcht einflößte, dessen Feindcharakter sich geradezu wissenschaftlich diskutieren ließ. Im Siebenjährigen Krieg wurde das Erbfeind-Motiv dann nur noch verhalten angespielt. Nationales Vorurteil war verpönt - weil es unangebracht erschien und unnötig blieb. Auch diesem Erbfeind war das Bedrohungspotenzial ausgegangen.

Russland als »potentieller Erbfeind« besaß im frühneuzeitlichen Europa bis ins 18. Jahrhundert hinein ein deutlich negativ konnotiertes Fremdbild, es war jedoch kein konkretes Feindbild. Die polnische, gegen Russland gewandte Propaganda der Zeit Sigismund Wasas blieb nicht ohne Widerhall, aber das Bedrohungspotenzial Russlands reichte über Polen, später Schweden nicht hinaus. Schwedische Versuche, in der letzten Phase des Nordischen Krieges auch im Reich ein russisches Feindbild aufzubauen, blieben Episode; die französischen Eindämmungsversuche der »Régence« und der Frühzeit Ludwigs XV. im »arcanum« der Kabinette ${ }^{85}$. Russland als Thema der Öffentlichkeiten war im Jahrhundert der Aufklärung Objekt europäischer Zivilisationsmission. Die preußische Propaganda des Siebenjährigen Krieges, die erstmals ein konkretes russisches Feindbild auch in die Mitte Europas beförderte, konnte jedoch auf längst gelegte Grundlagen aufbauen. Sie erreichte freilich so eine neue Qualität, die auf die Russophobie des 19. Jahrhunderts als Massenphänomen verwies ${ }^{86}$.

Die Sakralisierung der Feindverhältnisse zu Franzosen und Osmanen säkularisierte den Tatbestand fortan zu politisch zu verstehender Feindschaft. Wenn man drei »Erbfeinde« bzw. Antichristen bei der Hand hatte, wie die deutschen Protestanten des späten 17. Jahrhunderts - den Papst, »den Türken « und Ludwig XIV. -, verbrauchte sich das Motiv nicht wenig, zumal weitere Versuche, Erbfeinde aufzubauen, misslangen.

Dennoch bleibt die andere Seite der Medaille: Krieg und politische Feindschaft konnten der religiösen Aufladung nicht entbehren. Gerd Krumeich hat mit einigen guten Argumenten den Ersten Weltkrieg als Religionskrieg in-

85 Wrede, Das Reich und seine Feinde, S. 186f.; Heinz Duchrardt, Balance of Power und Pentarchie. Internationale Beziehungen 1700-1785, Paderborn 1997, S. 299.

86 Wolfgang BURGDORF, Reichskonstitution und Nation. Verfassungsreformprojekte für das Heilige Römische Reich Deutscher Nation im politischen Schrifttum von 1648 bis 1806, Mainz 1998, S. 155f. 
terpretiert - allerdings auf französischer Seite ${ }^{87}$. Friedrich Wilhelm Graf hat jüngst die These vorgebracht, es seien die Kriege des 19. Jahrhunderts generell und also auch in Deutschland auf mehr oder weniger die gleiche Weise religiös aufgeladen gewesen wie die des 16. oder 17. Jahrhunderts. Manches hätte sich also geändert, zwischen Luther und Clemenceau, um doch das Gleiche zu bleiben ${ }^{88}$.

Darüber lässt sich nachdenken. Doch wird man für die Frühe Neuzeit auf den Differenzen insistieren müssen: Im 16. und auch noch im 17. Jahrhundert werden das Politische, das Nationale dem Religiösen eingeschrieben und gewinnen ihre konzeptuelle Lebensfähigkeit eigentlich erst durch die religiöse Imprägnierung. »Letztwert« ist die Religion bzw. die Konfession. Nicht zuletzt die konfessionell motivierten Migrationsbewegungen legen davon ein eindringliches Zeugnis ab. Im 19. Jahrhundert, dem Jahrhundert der Nation, ist dies sicher nicht mehr der Fall ${ }^{89}$. Im 20. Jahrhundert - dem Jahrhundert der Ideologie - wird das Religiöse dann zum weihespendenden Ausstattungsgut jedweder politischen Bewegung und auch noch der Religionsfeindschaft. Befreiungskriege, Deutsche Einigungskriege und Erster Weltkrieg besaßen zweifellos auch ausgeprägt sakrale Aspekte, doch war dies eine Sakralität zweiter Ordnung. Und die Sakralisierung des Politischen besorgte im Übrigen zugleich die Säkularisierung des ehedem Heiligen ${ }^{90}$.

Die Zerrissenheit des frühneuzeitlichen Europa als eines Kontinents der Kriege und der religiös aufgeladenen Feindschaften stellte, in letzter Konsequenz, den »Wirkungszusammenhang« und Kulturraum gerade her. Schiller hat dies für den Dreißigjährigen Krieg ausdrücklich so formuliert, ihn gleichsam als einen europäischen Einigungskrieg skizziert, der als Ergebnis der Auseinandersetzung die »zusammenhängende Teilnehmung der Staaten aneinander « erbracht habe ${ }^{91}$. In einem solchen Sinne, Krieg verstanden als Kulturkontakt, würde dann auch das Osmanische Reich im 17. Jahrhundert

87 Gerd Krumeich, >Gott mit uns`? Der Erste Weltkrieg als Religionskrieg, in: Ders. / Hartmut Lehmann (Hg.), >Gott mit uns‘. Nation, Religion und Gewalt im 19. und frühen 20. Jahrhundert, Göttingen 2000, S. 273-283. Vgl. Michael Jeismann, Das Vaterland der Feinde. Studien zum nationalen Feindbegriff und Selbstverständnis in Deutschland und Frankreich 1792-1918, Stuttgart 1992; Annette BECKER, La guerre et la foi. De la mort à la mémoire, 1914-1930, Paris 1994.

88 Friedrich-Wilhelm Graf, Sakralisierung von Kriegen. Begriffs- und problemgeschichtliche Erwägungen, in: Klaus SchreIner (Hg.), Heilige Kriege. Religiöse Begründungen militärischer Gewaltanwendung: Judentum, Christentum und Islam im Vergleich, München 2008, S. 1-30.

89 Dieter Langewiesche, Nation, Nationalismus, Nationalstaat in Deutschland und Europa, München 2000, S. 16. Vgl. Heinz-Gerhard Haupt / Dieter Langewiesche (Hg.), Nation und Religion in der deutschen Geschichte, Frankfurt/Main u.a. 2001.

90 Vgl. - durchaus in diesem Sinne - Graf, Sakralisierung, S. 30.

91 Friedrich Schiller, Geschichte des Dreißigjährigen Krieges. Mit den Illustrationen der Erstausgabe und der Vorrede von Christoph Martin Wieland von 1791, Zürich 1988, S. 30f. 
sehr viel stärker zu »Europa« gehört haben als im 18. bzw. gar im 19. Jahrhundert - oder als, zeitgleich, das Reich des Zaren. Angesichts der klaren kulturellen Grenze mag das allerdings eine Überstrapazierung des Arguments sein.

Die Friedensfähigkeit der Feinde benötigte eine allen gemeinsame kulturelle bzw. Vertrauensgrundlage. Die lag in der Einordnung in eine mehr vom Aushandeln als vom Erzwingen geprägte politische Kultur sowie in der Berufung auf ein zwar geteiltes, aber in der Wurzel gemeinsames religiöses Erbe und Grundverständnis, das Ernsthaftigkeit und Verlässlichkeit zu verbürgen schien. Und hier wäre man dann auch wieder beim Westfälischen Frieden angelangt und etwa seiner konfessionell durchaus differenzierten, aber dennoch gemeinsamen Beschwörung durch Spanier und Niederländer ${ }^{92}$. Mit den Feindbildern wurden im 18. Jahrhundert allerdings auch die Friedensschlüsse säkularisiert; feierliche Vertragsbeschwörungen wie auf dem großen Staatsgemälde Gerard ter Borchs sollten fortan der Vergangenheit angehören ${ }^{93}$.

Der säkularisierte, national akzentuierte Erbfeind sollte sich in der Moderne freilich noch als hinreichend kriegerisch bzw. mobilisierend erweisen; der »aufgeklärte« Verzicht auf glaubensgestützte Beschwörung als verbindendes sakrales Element machte hingegen den Friedensschluss zwar unbedingt zeitgemäßer, allerdings nicht unbedingt wirksamer.

92 Klaus Bussmann / Heinz Schilling (Hg.), 1648. Krieg und Frieden in Europa. 26. Europaratsausstellung. Ausstellungskatalog, Münster 1998, S. 216f u. 221f. Vgl. Winfried Schulze, Pluralisierung als Bedrohung, Toleranz als Lösung. Überlegungen zur Entstehung der Toleranz in der Frühen Neuzeit, in: Heinz Duchnardt (Hg.), Der Westfälische Friede. Diplomatie, politische Zäsur, kulturelles Umfeld, Rezeptionsgeschichte, München 1998, S. 115-140.

93 Vgl. Lucien BéLy u.a. (Hg.), Guerre et paix dans l'Europe du XVIIe siècle, Paris ${ }^{2} 1991$, S. 65. $\mathrm{Zu}$ ter Borchs Darstellung des spanisch-niederländischen Friedensschlusses von 1648 siehe Alison M. KetTering, Gerard ter Borchs Beschwörung der Ratifikation des Friedens von Münster als Historienbild, in: Klaus Bussmann / Heinz Schilling, 1648. Krieg und Frieden in Europa, Textband 2: Kunst und Kultur, Münster 1998, S. 605-614. 


\title{
Joachim Berger \\ Herkules - Held zwischen Tugend und Hybris
}

\author{
Ein europäischer Erinnerungsort \\ der Frühen Neuzeit'?
}

Zwischen 1600 und 1773 entstanden in ganz Europa, von Madrid bis Petersburg, von London bis Neapel, gut 215 Bearbeitungen des Herakles-/Herkules-Mythos für Oper, Singspiel, Operette, Kantate, Lied, Tanz und Ballett. Hinzu treten tausende Adaptionen des Stoffs in den bildenden Künsten seit dem 15. Jahrhundert ${ }^{2}$. In allen künstlerischen Gattungen besonders populär war das Motiv der Wahl des jungen Halbgottes zwischen dem Weg der Tugend und des Lasters, das auf den antiken Autor Prodikos von Keos (um 470/460-nach 399 v. Chr.) zurückgeht.

Dieser Beitrag will in groben Strichen einige der Kontexte und der Medien nachzeichnen, in denen Herakles-Herkules als Held zwischen Tugend und Hybris in den europäischen Gesellschaften seit Ausgang des Mittelalters präsent war. Dabei ist zu fragen, ob man dieses Beispiel frühneuzeitlicher Antikenrezeption, -aneignung und -umformung als einen europäischen »lieu de mémoire« begreifen kann. Dieses Forschungsfeld beschäftigt nicht zuletzt Heinz Duchhardt seit mehreren Jahren. Nun soll es in einem eigenen Projekt im Forschungsbereich »Europa als Herausforderung für Politik, Gesellschaft und Kirche« des Instituts für Europäische Geschichte bestellt werden.

Im Folgenden soll diskutiert werden, inwieweit das Konzept der »lieux de mémoire« (bzw. Erinnerungsorte) für die Erforschung eines bestimmten Gegenstands (hier des Herakles- / Herkules-Mythos) einen spezifischen Erkenntnisgewinn bringen kann und welche allgemeineren Anfragen vor diesem Hintergrund an das ambitioniertere Vorhaben, >die europäischen Erinnerungsorte umfassend zu beschreiben, zu richten wären.

1 Ich danke den Diskutanten der Tagung für ihre Hinweise, zudem Małgorzata Morawiec und Thomas Weller für Literaturhinweise und Anregungen zu den »lieux de mémoire« sowie ganz besonders Julia Schmidt-Funke für ihre konstruktive »Fundamentalkritik«, die ich nur ansatzweise umsetzen konnte.

2 Ralph Kray / Stephan Oettermann, Herakles, Herkules, Bd. 2: Medienhistorischer Aufriß: Repertorium zur intermedialen Stoff- und Motivgeschichte, Basel u.a. 1994, S. 593-619. 


\section{»Lieux de mémoire« als Erinnerungstopoi}

Die Explikationen oder gar Definitionen, was ein europäischer »lieu de mémoire « sein könnte, sind zahlreich ${ }^{3}$. Ohne sie zusammenzufassen oder ihnen eine weitere an die Seite stellen zu wollen, soll eines der vorliegenden Angebote - und zwar bewusst ein relativ offenes - als heuristischer Ausgangspunkt dienen: Heinz Duchhardt und Małgorzata Morawiec verstehen unter europäischen »lieux de mémoire«

solche Referenzpunkte [...], die in einer sich je anders definierenden Vielzahl von europäischen Staaten diskutiert und verbreitet sind, dabei jedoch zugleich auf die spezifischen Identifikationsbedürfnisse partikularer (nationaler, regionaler, konfessioneller) Erinnerungskulturen zugeschnitten sind. [...] Als solche Referenzpunkte werden nicht nur [...] symbolische Orte wie Versailles oder Rom verstanden, sondern auch reale Persönlichkeiten und mythische Figuren, Abstrakta wie Ordnungsmodelle oder Friedensschlüsse von kontinentaler Bedeutung, aber auch kulturelle Phänomene $[\ldots]^{4}$.

In einer früheren Definition hatte Duchhardt betont, »daß die Qualität eines europäischen Gedächtnisortes ${ }^{5}$ sich danach bemisst, ob er zumindest die

3 Vgl. z.B. Henry Rousso, Das Dilemma eines europäischen Gedächtnisses, in: Zeithistorische Forschungen/Studies in Contemporary History, Online Ausgabe 1 (2004) 3, URL: http://www. zeithistorische-forschungen.de/16126041-Rousso-3-2004 (eingesehen am 06.04.2008); Aleida Assmann, Nation, Gedächtnis, Identität - Europa als Erinnerungsgemeinschaft?, in: Simon Donig / Tobias Meyer / Christiane Winkler (Hg.), Europäische Identitäten - eine europäische Identität?, Baden-Baden 2005, S. 24-32; Etienne Françors, Auf der Suche nach dem europäischen Gedächtnis, in: Themenportal Europäische Geschichte (2006), URL: http://www. europa.clio-online.de/2006/Article=82 (eingesehen am 24.01.2009); ders., Europäische lieux de mémoire, in: Gunilla-Friederike Budde / Sebastian ConRad / Oliver JANZ (Hg.), Transnationale Geschichte. Themen, Tendenzen und Theorien, Göttingen 2006, S. 290-303; ders., Auf der Suche nach den europäischen Erinnerungsorten, in: Helmut KöNIG / Julia SchмidT / Manfred Sicking (Hg.), Europas Gedächtnis. Das neue Europa zwischen nationalen Erinnerungen und gemeinsamer Identität, Bielefeld 2008, S. 85-103; Arnold Esch, Rom als europäischer Erinnerungsort [2005], in: Pforzheimer Reuchlinpreis 1955-2005. Die Reden der Preisträger, Heidelberg ${ }^{3} 2007$, S. 376-390; sowie die Beiträge im Jahrbuch für Europäische Geschichte 3 (2002) und den Konferenzbericht von Benedikt Stuchtey, European »Lieux de Mémoire«. German Historical Institute London Conference, held at Cumberland Lodge, Windsor Great Park, 5.-7. Juli 2002, in: German Historical Institute London - Bulletin 24 (2002), S. 121-125.

4 [Heinz DuchHardt / Małgorzata Moraviec]: »Europäische« Lieux de Mémoire, in: Institut für Europäische Geschichte, Mainz: Forschungsbereiche, URL: http://www.ieg-mainz.de/likecms/ index.php?site $=$ site.htm\&dir $=\&$ nav $=168$ (eingesehen am 10.11.2008).

5 Auf die semantischen Differenzen zwischen Erinnerung und Gedächtnis, die sich durch alle deutschen Explikationsversuche europäischer »lieux de mémoire« ziehen, sei hier nicht eingegangen. Vgl. dazu u.a. Marcus SANDL, Historizität der Erinnerung / Reflexivität des Historischen. Die Herausforderung der Geschichtssschreibung durch die kulturwissenschaftliche Gedächtnisforschung, in: Günter OesterLE (Hg.), Erinnerung, Gedächtnis, Wissen. Studien zur kulturwissenschaftlichen Gedächtnisforschung, Göttingen 2005, S. 89-119; Malte THIEssen, Gedächtnisgeschichte. Neue Forschungen zur Entstehung und Tradierung von Erinnerungen, in: Archiv für Sozialgeschichte 48 (2008), S. 607-634. 
meisten Mitlebenden berührte und ob die große Masse der Europäer heute mit ihm etwas anfangen kann « ${ }^{6}$. Das Kriterium gegenwärtiger Relevanz bzw. Präsenz sei zunächst zurückgestellt. Abschließend ist darauf zurückzukommen.

Für diese und andere Definitionen ist eine individuelle Erinnerung der Erinnernden an das Erinnerte - die sich in eine kollektive Erinnerung an gemeinsame Erfahrungen einbringen lässt - nicht notwendig. Anders als etwa die Studien zur kollektiven Erinnerung an Erlebnisse der jüngsten Zeitgeschichte - Stichwort: Auschwitz als »negativer« europäischer Erinnerungsort bzw. »negatives Geschichtszeichen « ${ }^{7}$-, verstehen diese Explikationen »mémoire« nicht im Sinn von >sich an etwas persönlich Erfahrenes erinnern sondern schlicht als >an etwas erinnern, eines Gegenstands gedenken den Blick gerät häufig ein gelenktes, nicht selten verordnetes Gedenken, das einen Gegenstand zu einem Erinnerungsort macht. Erinnerung wäre als eine »Technik des Umgangs mit Erfahrungen« zu verstehen, die »um Authentizität bemüht « sind, wenn sie auch fiktiv sein mögen ${ }^{8}$. Nur unter dieser Voraussetzung lässt sich das Beispiel aus der Sphäre der Mythen versuchsweise als Erinnerungsort begreifen.

Bei der Annäherung an den Gegenstand Herakles-Herkules als mutmaßlichen Erinnerungsort ist Aleida Assmanns und Patrick Schmidts Unterscheidung zwischen Topoi und Medien der Erinnerung hilfreich ${ }^{9}$. Insbesondere Schmidt weist darauf hin, dass Pierre Noras Sammlung der »lieux de mémoire« Frankreichs (und in deren Folge die »Deutschen Erinnerungsorte «) die Funktion der Medien in dem Prozess, der ein kollektives Gedächtnis forme, zu wenig beachte. Daraus sei auch die »verwirrende Vielfalt des Konzeptes der >lieux de mémoire« « maßgeblich zu erklären: Nora ${ }^{10}$ rechne ihnen sowohl »die Topoi und Mythen des kollektiven Gedächtnisses« zu, als auch »die Medien, durch die sie konstruiert und tradiert werden«. Beide Begriffsinhalte seien nicht deckungsgleich, aber auch nicht völlig konträr.

6 Heinz Duchhardt, Der Westfälische Friede - ein europäischer lieu de mémoire?, in: Westfälische Zeitschrift 154 (2004), S. 399-406, Zitat S. 403; ähnlich Esch, Rom, S. 380f.

7 FrançoIs, Lieux, S. 295; ders., Suche, S. 89.

8 Günter LotтEs, Europäische Erinnerung und Europäische Erinnerungsorte?, in: Jahrbuch für Europäische Geschichte 3 (2002), S. 81-92, Zitat S. 84.

9 Aleida Assmann, Im Zwischenraum zwischen Geschichte und Gedächtnis. Bemerkungen zu Pierre Nora. Lieux de mémoire, in: Etienne François (Hg.), Lieux de mémoire, Erinnerungsorte: d'un modèle français à un projet allemand, Berlin 1996, S. 19-27, hier: S. 23; Patrick Schмid, Zwischen Medien und Topoi: Die Lieux de memoire und die Medialität des kulturellen Gedächtnisses, in: Astrid ErLl / Ansgar Nünning (Hg.), Medien des kollektiven Gedächtnisses. Konstruktivität - Historizität - Kulturspezifität, Berlin u.a. 2004, S. 25-43, hier: S. 33 .

10 Vgl. seinen Rückblick: Pierre NorA, Das Abenteuer der »lieux de mémoire«, in: Etienne FrANÇOIS (Hg.), Nation und Emotion. Deutschland und Frankreich im Vergleich. 19. und 20. Jahrhundert, Göttingen 1995, S. 83-92. 
Manche »lieux« umfassten beides. Präziser wäre es, so Schmidt, die »lieux de mémoire « »auf einer Skala zwischen den Polen `Medium` und \Topos` zu verorten $\aleph^{11}$. Mit dieser Präzisierung lasse sich die $»$ Medialität des kollektiven Gedächtnisses « stärker reflektieren und herausarbeiten, »wie die behandelten >lieux de mémoire eine Wirksamkeit im öffentlichen Bewusstsein entfalten und über lange Zeiträume hinweg tradiert werden konnten $\aleph^{12}$.

Topoi wären von realhistorischen bzw. autochthonen Orten abzugrenzen. Letztere gingen zwar primär aufgrund ihrer symbolischen Funktion in die französischen »lieux de mémoire« und die deutschen »Erinnerungsorte« ein. Doch die Konnotationen der wörtlichen Bedeutungsebene vermengten sich nur zu oft mit denen der symbolischen. So waren es eben diese materiellen Orte, deren Aufnahme den Vorwurf der Beliebigkeit nach sich zog, der sowohl die französische als auch die deutsche Auswahl traf. Konsequent wäre es, jene Elemente aus dem Konstrukt europäischer »lieux de mémoire« auszuschließen oder gesondert zu behandeln, die sich keinem der beiden Kategorien Topoi bzw. Erinnerungsmedien zuordnen lassen, z.B. »kulturelle, politische und soziale Prozesse (die Sprache, die Orte der Herrschaft, die räumliche Ordnung des Territoriums etc.) $\ll^{13}$, oder allgemeiner: Institutionen, Landschaften, Grenzen oder soziale Gruppen.

Das Bild von Herakles/Herkules als Held zwischen Tugend und Hybris wäre deshalb (zunächst versuchsweise) als Erinnerungstopos ${ }^{14}$ in der Frühen Neuzeit zu verstehen - ein bestimmter Aspekt des antiken Heldenmythos, der als häufig evozierter Gemeinplatz in einem sozialen System als Referenzpunkt für bestimmte, geschichtlich verstandene Wertvorstellungen fungierte. Auf diesen Referenzpunkt waren bestimmte Erinnerungsmedien oder »Gedächtnisstützen« bezogen, die als »Träger« der Vergangenheitskonzeptionen ${ }^{15}$ fungierten, welche bestimmte soziale Akteure in gegenwartsbezogener Absicht aktivieren wollten bzw. konnten. Die Ausdrucksmodi dieser Wertvorstellungen waren auf europäischer Ebene transferierbar.

Die Frage, ob »Herkules« ein Erinnerungstopos (in) der Frühen Neuzeit gewesen sein könnte, stellt sich nur dann, wenn man das Konzept »Erinnerungsorte « auf die Vormoderne anwenden will16, also auf die Gemeinwe-

11 Schmidt, Lieux, S. 35.

12 Ebd., S. 28. Vgl. Heidi HeIN-KIRCHER, Überlegungen zum Verhältnis von »Erinnerungsorten« und politischen Mythen. Eine Annäherung an zwei Modebegriffe, in: Heidi HeIN-KIRCHER / Jarosław Suchoples / Hans-Henning Hahn (Hg.), Erinnerungsorte, Mythen und Stereotypen in Europa | Miejsca pamięci, mity i stereotypy w Europie, Wrocław 2008, S. 11-25, hier: S. 19.

13 Rousso, Dilemma, Ab. 5.

14 Vgl. ähnlich Еsch, Rom, S. 379.

15 Vgl. auch Rousso, Dilemma, Ab. 5.

16 Dafür plädiert u.a. Bernd SCHNEIDMÜLlER, Erinnerungsorte aus dem europäischen Mittelalter, in: Ruperto Carola. Forschungsmagazin der Universität Heidelberg 3 (2006), S. 4-10. 
sen vor den nationalen Anstaltsstaaten (des 19. Jahrhunderts) ${ }^{17}$, die zwar den Glauben an die eigene Nation noch nicht zum Letztwert erhoben, in denen aber durchaus schon überständische Identifikationsangebote formuliert wurden.

\section{Herkules - Held zwischen Tugend und Hybris Transformationen seit der Antike}

Der Halbgott Herakles (röm. Herkules), Sohn des Zeus und der Alkmene, ist der Archetyp des antiken, mythischen Helden. Seine zehn, schließlich zwölf sprichwörtlichen »Heldentaten«, die er als Auflage des tyrannischen Königs Eurystheus verrichtet, tauchen seit dem 7. Jahrhundert vor Christus in der Vasenmalerei auf. Die frühe bildliche Überlieferung betont die Stärke und Tapferkeit des Helden und unterscheidet sich so kaum von der Darstellung anderer archaischer Helden. Sie wird durch literarische, philosophische und historische Texte unterfüttert, differenziert und zum Teil auch konterkariert. Bis zum 5. Jahrhundert vor Christus arbeiten antike Autoren (u.a. Pindar, Bacchylides, Euripides und Prodikos) Herakles' Vorbildhaftigkeit heraus ${ }^{18}$ : Der Halbgott vollbringt seine Taten zum Wohle der Menschheit mit einem »zivilisatorische[n] Auftrag $«^{19}$. Dadurch erlangt er Unsterblichkeit im Olymp, wo ihn Zeus mit Hebe, der ewigen Jugend, vermählt. Herakles, der sein menschliches Schicksal annimmt und trotz aller Mühen und Leiden meistert, zeigt eine menschliche Seite, die zur Empathie einlädt.

Unter und neben diesem Idealbild eines humanen Halbgottes leben, insbesondere in bildlichen Darstellungen, archaische Konnotationen des Heldenmythos weiter: Herakles erscheint als stark, grausam, leidenschaftlich und anfechtbar ${ }^{20}$. Seine Taten, unter anderem der Mord an seiner ersten Frau Megara und den gemeinsamen Kindern, atmen eine den meisten antiken Helden eigene Hybris: Maßlosigkeit, Vermessenheit und Selbstvergessenheit. Der Ruhmesdrang des Helden, dessen Gewalttätigkeit die Kategorien

17 Die meisten snationalen Adaptionen des Nora'schen Konzepts beziehen sich auf die Moderne, allen voran Pim Den Boer / Willem Frijhoff (Hg.), Lieux de mémoire et identités nationales, Amsterdam 1993.

18 Zum Folgenden v.a. Rainer Vollkommer, Herakles. Die Geburt eines Vorbildes und sein Fortbestehen bis in die Neuzeit, in: Idea 6 (1987), S. 7-29, hier: S. 7-10; Wanda Löwe, Herkules Die Biographie eines Helden, in: Christiane Lukatis / Hans Otтомeyer (Hg.), Herkules. Tugendheld und Herrscherideal. Das Herkules-Monument in Kassel-Wilhelmshöhe, Eurasburg 1997, S. 9-22, hier: S. 20.

19 Fritz Graf, Art. Herakles, in: Hubert Cancik / Helmuth Schneider (Hg.), Der neue Pauly. Enzyklopädie der Antike 5 (1998), Sp. 387-392, Zitat Sp. 389.

20 Thalia PApadopoulou, Herakles and Hercules: The hero's ambivalence in Euripides and Seneca, in: Mnemosyne 57 (2004), S. 257-283. 
von Gut und Böse vermengt, zieht immer auch Leid nach sich - für andere, aber auch für den Heros selbst. Bei Euripides drückt Herakles' Wahnsinn zugleich seine Verletzlichkeit aus. Im römischen Kaiserreich werden dann die zur Empathie einladenden Tugenden akzentuiert. Seneca etwa verleiht dem Herakles-Herkules, der seinen eigenen Tod ohne Angst überwindet, die Tugend der Constantia. Die Sophisten des 5. Jahrhunderts laden die zwölf kanonisierten Taten mit einer moralischen Qualität auf: Herkules geht den steinigen Pfad der Tugend aus freien Stücken. Die ambivalenten Züge des Heros, seit der Antike ein Charakteristikum jeder Heldenverehrung ${ }^{21}$, bleiben jedoch präsent.

Schon früh wurde der Heros auf Monarchen bezogen. So forderte Isokrates (436-338 v. Chr.) König Philipp von Makedonien (um 382-336 v. Chr.) auf, dem Halbgott nachzueifern und damit selbst zum Vorbild zu werden. Alexander der Große erschien auf Münzen in Gestalt des Herakles. Die römischen Kaiser nahmen diese Identifikation auf; Galerius Valerius Maximianus (um 250/260-311) gab sich sogar den Beinamen »Herculius $\ll^{22}$. Parallelen zwischen Monarch und Halbgott waren leicht zu ziehen: Beide sind von göttlicher Abstammung bzw. Sendung, wirken in der Welt als Menschen und werden nach ihrem heldenhaften Tod unter die Götter aufgenommen.

An die tugendhaften Züge des Helden in der antiken Philosophie konnten christliche Aneignungen des Mythos in der Spätantike anknüpfen, und so überdauerte der Herakles-/Herkules-Stoff ${ }^{23}$ das Mittelalter. Es $»$ moralisierte $«$ und »christianisierte« die antiken Mythen gleichermaßen, wobei die antiken Formen und Attribute zunehmend überformt wurden ${ }^{24}$. Seit dem 10. Jahrhundert wurde der Halbgott des öfteren mit dem biblischen Samson (Simson) verglichen oder - bei Dante - mit David. Der Ovide Moralisé, im 14. und 15. Jahrhundert in zahlreichen, auch illustrierten Varianten überliefert, stellt den antiken Held nicht nur als Allegorie der »virtus« vor, sondern setzt ihn auch direkt mit Christus gleich. Mit den Eigenschaften Stärke, Mut und - christlich gewendeter - Tugendhaftigkeit konnte Herkules seit dem 13. Jahrhundert zum Vorbild des Ritters erkoren werden, am wirkungsvollsten in Raoul le Fèvres Recueil des histoires de Troye (1464), die, am burgundischen Hof entstanden, sowohl im französischen Original als auch in englischer Übersetzung jeweils über 20 Auflagen im neuen Medium des Buchdrucks erreichten. Mit dieser christlich-ritterlichen Aneignung war eine Brücke zur antiken

21 Vgl. statt vieler den Ausstellungskatalog: Odile FALIU / Marc Tourret (Hg.), Héros: d'Achille à Zidane, Paris 2007.

22 Vollkommer, Herakles, S. 16.

23 Aus sprachlichen Gründen wird im Folgenden nur die lateinische Form »Herkules« verwendet.

24 Jean SEznec, Das Fortleben der antiken Götter. Die mythologische Tradition im Humanismus und in der Kunst der Renaissance, München 1990 (Übers. d. überarb. frz. Ausgabe Paris 1980, eng. Orig. London 1940), S. 84 (Originalzitat im Präsens). 
Herrscherikonographie geschlagen - der Fürst als erster Ritter seines Landes war prädestiniert dafür, sich die Haut des christianisierten und moralischcharakterlich >eindeutig` gemachten Helden anzuziehen. So war der Titelheld in Pietro Andrea di Bassis Le fatiche d'Ercole (1475) gleichermaßen in Philosophie, Grammatik und Astronomie beschlagen, wie er körperlich stark, kultiviert und galant war - das Gegenbild des maßlosen, brutalen und erdverbundenen Kraftprotzes mit der Löwenhaut ${ }^{25}$. Bekanntlich blieb die aus dem 2. Jahrhundert stammende Überzeugung (»Nachäffungstheorie« des Märtyrers Iustinus) bis ins 18. Jahrhundert verbreitet, antike Mythen seien lediglich eine entstellte Form der biblischen Überlieferung ${ }^{26}$. Diese Überzeugung war eine wesentliche Voraussetzung, dass Heldenvorstellungen, über viele Transformationsstufen hinweg, bis in die Frühe Neuzeit überleben konnten.

\section{Aktualisierungen in der Renaissance}

Den Humanisten blieb die Ambivalenz des Heros in den antiken Schriften nicht verborgen. Sie waren bemüht, Widersprüche aufzulösen und in eine schlüssige allegorische Deutung zu bringen. Bei Francesco Petrarca (13041374) wurde »der Heros zum perfekten Fürstenideal, das Bildung und Weisheit mit Tatkraft und militärischem Erfolg verknüpft « ${ }^{27}$. Der Florentiner Stadtschreiber Coluccio Salutati (1331-1406) versuchte, die Tugenden des Helden mit seiner Maßlosigkeit oder gar seiner blinden Raserei in Einklang zu bringen, indem er die Wahl zwischen Tugend und Laster als Metapher für das gesamte Leben des Herkules - Läuterung durch Anfechtung - interpretierte $^{28}$. Die schwachen Momente des Helden - zum Beispiel seine Knechtschaft bei der lydischen Königin Omphale, der Herakles in Frauenkleidern Mägdedienste leisten musste - werden nun in Klugheit und Maßhaltung umgewertet.

Ähnliche formale und motivische Ausgleichsbestrebungen zwischen Stärke, Tugend und Hybris zeigen sich in den bildenden Künsten. Seit der zweiten Hälfte des 15. Jahrhunderts gewannen die antiken Götter ihre antiken Formen zurück ${ }^{29}$; griechische oder römische Vorlagen dienten Künstlern in kör-

25 Vollkommer, Herakles, S. 20.

26 Ralph KRAY, Wider >eine engbrüstige Imagination<. Studien zur medien-, stoff- und motivgeschichtlichen Typogenese des Herakles/Herkules-Mythos, in: Kray / Oettermann, Herakles, Bd. 2, S. 9-129, hier: S. 47.

27 Dieter Blume, Mythos und Widerspruch. 1. Herkules oder die Ambivalenz des Helden, in: Herbert BeCK (Hg.), Natur und Antike in der Renaissance, Frankfurt/Main 1985, S. 131-139, 166-168, Zitat S. 133.

28 Ronald G. Wiтt, Hercules at the crossroads. The life, works, and thought of Coluccio Salutati, Durham/NC 1983, S. 213-219.

29 SeZnec, Fortleben, S. 272. 
perlich-ästhetischer Hinsicht als Projektionsfläche auf der Suche nach dem ideal proportionierten Menschen. 1546 hatte man den ursprünglich in den römischen Caracallathermen aufgestellten »Hercules Farnese« wieder aufgefunden. Seitdem wurde motivisch besonders der Gestus der Nachdenklichkeit betont, als Gegengewicht zur körperlichen Kraft des Halbgottes. »Furor und Kontemplation« sind denn auch die maßgeblichen Pole der Darstellungmodi in den Bildwerken des 15. und 16. Jahrhunderts ${ }^{30}$.

Herkules eignete sich, im Zuge der Wiederaneignung antiker Formen für antike Mythen, als Blaupause für das Herrscherideal eines tugendhaften, weisen und starken Fürsten als christlicher Held. Diese Möglichkeit, bei einem antiken Stoff auf eine als `klassisch zugreifen, die Darstellungsmodi für die verschiedenen Haltungen des Helden zwischen Furor und Kontemplation bot, ließ Herkules möglicherweise geeigneter für zeitgenössische Adaptionen erscheinen als genuin christliche >Helden (wie etwa den Heiligen Georg). Entscheidend war, dass sich aus der Antike das herrscherkritische Komplement zu den positiven Tugenden erhalten hatte: Der unberechenbare Furor des Halbgottes, der stets an der Schwelle zur Bestialität stand, sein maßloser Ehrgeiz und seine Ignoranz irdischer Gesetze - diese Hybris erinnerte und mahnte den Fürsten, seine von Gott verliehene Macht nicht zu missbrauchen. In seinem irdischen Tun war der Held bzw. Fürst trotz seiner Bestimmung noch Mensch und stand noch nicht auf der selben Stufe wie die Götter. Seine Vergötterung konnte erst die Nachwelt bewirken; sie war kein Automatismus. Herkules' Stärke konnte sich sowohl wohltätig als auch grausam auswirken. Es oblag dem Fürsten, der tugendhaften der beiden Naturen des Heros Ausdruck zu verleihen und sich seine eigene Apotheose zu sichern ${ }^{31}$. Deshalb war das Motiv des Herkules Prodikos so populär ${ }^{32}$. Als Held zwischen Tugend und Hybris stellte Herkules ein selbstreflexives Moment, eine Art internalisierte Instanz der (Selbst-) Kritik innerhalb der höfischen Sphäre dar, die durch das Strukturmerkmal der »unaufrichtige[n] Kommunikation« geprägt war, da sich der Herrscher durch die Mechanismen von Gunsterweis und Huldentzug gegen Kritik immunisierte ${ }^{33}$.

30 Blume, Mythos, S. 133-138; Peter Gerlach, Herkules - ein somatischer Mythos, in: Ralph Kray / Stephan Oettermann (Hg.), Herakles, Herkules, Bd. 1: Metamorphosen des Heros in ihrer medialen Vielfalt, Basel u.a. 1994, S. 73-92, hier: S. 74.

31 Vgl. auch Stephen Orgel, The Example of Hercules, in: Walther Killy (Hg.), Mythographie der frühen Neuzeit. Ihre Anwendung in den Künsten, Wiesbaden 1984, S. 25-47.

32 Grundlegend Erwin Panofsky, Hercules am Scheidewege und andere antike Bildstoffe in der neueren Kunst, Leipzig / Berlin 1930 (ND Berlin 1997), S. 68-196.

33 Aloys Winterling, »Hof«. Versuch einer idealtypischen Bestimmung anhand der mittelalterlichen und frühneuzeitlichen Geschichte, in: Ders. (Hg.), Zwischen »Haus« und »Staat«. Antike Höfe im Vergleich, München 1997, S. 11-25, Zitat S. 17f. 
Wahrscheinlich nahm ein Teil der Fürsten, die Herkules-Darstellungen in Verbindung mit ihrer Person entweder beauftragten oder diese wohlwollend entgegennahmen, die Ambivalenz des Helden und das hortative Moment des Topos nicht wahr. Funktional gesehen stellte aber der kanonisierte ikonographische Fundus samt der antik-klassischen Formsprache den Rezipienten zumindest die Möglichkeit bereit, dieses kritische Potenzial, das alle zeitgenössischen Herkulesaneignungen bargen, zu aktivieren. Das auf antike Mythen Bezug nehmende Herrscherbild ${ }^{34}$ wurde von Räten, Gelehrten und Künstlern konstruiert. Es sollte Mitgliedern anderer Hofgesellschaften, aber auch den Untertanen des eigenen Territoriums vermittelt werden. Die Gleichsetzung oder Parallelisierung von Fürsten mit dem antiken Halbgott Herkules erfolgte in bildlichen Darstellungen in mehreren Varianten, die bereits in der Antike nachweisbar waren:

1. Bestimmte Attribute des Herkules werden in Darstellungen des Fürsten, in seinem Wappen oder in seinen Gebäuden und Gärten zitiert oder angedeutet.

2. Herkules tritt (anstelle des Fürsten) als Personifikation fürstlicher Herrschaft auf.

3. Herkules gesellt sich dem Fürsten als Begleiter zu, berät ihn oder leiht ihm seine Stärke und Tugenden.

4. (am eindeutigsten) Herkules erscheint im Gewande des Fürsten, zum Teil mit dessen Gesichtszügen.

In diesen Varianten wurde Herkules im Verlauf der Frühen Neuzeit zu einem europaweit verbreiteten Topos. Als »Erinnerungstopos« konnte der Held auf zwei Ebenen der Erinnerung bzw. des Gedenkens fungieren: Erstens ließ sich durch ihn eine personalisierte Vorgeschichte des landeseigenen Herrschergeschlechts konstruieren. Schon in der griechischen Antike war Herakles »[i]n zahlreichen lokalen Mythen [...] als Begründer einer königl. Genealogie« erschienen ${ }^{35}$. Seit dem späten Mittelalter leiteten sich ganze Dynastien vom »Geschlecht« des Herkules ab. Auf Annius' von Viterbo (Giovanni Nanni da Viterbo) Serie von Unveröffentlichten antiken Schriftstellern (1498) gingen zwei Zweige dieser Ableitung zurück: Der »Libysche Hercules« war der zehnte gallische König, damit der Vorfahre der Herrscher Frankreichs, Spaniens und Italiens, während der »Alemannische Hercules« der elfte König Deutschlands und damit Ahnherr der deutschen Monarchen war. Der jeweils regierende Monarch konnte in die Gestalt des

34 Grundlegend: Peter Burke, Le Roi Comme Heros Populaire: Seizieme a Dix-Huitieme Siecles, in: History of European Ideas 3 (1982), S. 267-271, hier: S. 268.

35 Graf, Herakles, Sp. 390. 
antiken Helden schlüpfen und die Tugend und Stärke seines Vorfahren aufnehmen. Herkules war also nicht nur ein Referenzpunkt, der »diskutiert und verbreitet « wurde ${ }^{36}$, sondern dessen Anrufung an eine ’heroische< Vergangenheit erinnern sollte, die allen Adressaten gemeinsam sei. Die zweite Ebene bestand just in dem hortativen Moment des Topos, der mahnenden Erinnerung an die (Gefahr der) Hybris - der Herrscher möge gedenken, dass er die Anlage zum willkürlichen Urteil, ja zur blinden Raserei in sich trage. Sein antiker Vorfahr erinnerte den aktuellen Herrscher an seine Fallhöhe.

\section{Dynastische und >nationaleく Aneignungen}

Von Italien aus setzte ein europaweiter Prozess der Adaption und Umformungkurz des Transfers - des Herkules-Mythos und seiner topischen Verwendung ein $^{37}$. Während dessen Transformationen in stoff- und motivgeschichtlicher Hinsicht gut erschlossen $\operatorname{sind}^{38}$, sind die Medien und Träger der Transfers noch nicht systematisch aufgearbeitet worden. Das kann dieser Beitrag nicht leisten. Hier interessieren vor allem die - zunächst primär dynastischen Kontexte, in denen der Topos von Herkules als Held zwischen Tugend und Hybris aufgenommen wurde, sodann die Medien seiner Verbreitung, Popularisierung und Speicherung. Im Folgenden kann weder auf die Vernetzungen unterschiedlicher künstlerischer Gattungen eingegangen, noch können ihre ästhetischen Eigenlogiken berücksichtigt werden. Der Überblick beansprucht keine Vollständigkeit; die Frage, wo Europa ende oder anfange, wird nicht einmal gestellt. Es geht darum, die topische Verwendung des HerkulesMythos in verschiedenen Kontexten und Medien zu umreißen.

Nicht Fürsten waren es, die sich antike Heroen zuerst auf ihre Fahnen schrieben, sondern die italienischen Stadtstaaten. In zahlreichen Kommunen ist seit dem 13. Jahrhundert ein Bedürfnis nach historisch-mythologischer Legitimierung ihrer korporativen Rechte zu greifen.

Zunächst wurde der Halbgott also von einem kollektiven Herrscher in Anspruch genommen - von der Stadt Florenz, die Herkules als denjenigen, der Tyrannen tötet und die (kommunalen) Freiheiten sichert, im 14. Jahrhundert zu ihrem Patron erhob. Die Medici, unterstützt von den Florentiner Neupla-

36 Vgl. das Zitat bei Anm. 4.

37 Vgl. z.B. Árpád Мıкó, Divinus Hercules and Attila Secundus. King Matthias as patron of art, in: New Hungarian Quarterly 31 (1990), S. 90-96; Herfried MüNKLER, Nationale Mythen im Europa der frühen Neuzeit. Zur Relevanz mythischer Narrationen bei der Nationalisierung Europas, in: Vorträge aus dem Warburg-Haus 1 (1997), S. 107-143; Horst BREDEKAMP, Herrscher und Künstler in der Renaissance Ostmitteleuropas, in: Johannes Helmrath / Ulrich MuHLACK / Gerrit Walther (Hg.), Diffusion des Humanismus. Studien zur nationalen Geschichtsschreibung europäischer Humanisten, Göttingen 2002, S. 250-280.

38 Vgl. die materialreiche, wenngleich sprachlich verkomplizierte Arbeit von KraY, Imagination. 
tonikern um Marsilio Ficino (1433-1499), konnten sich diese Tradition dann mühelos aneignen und auf ihre Dynastie übertragen. Cosimos I. Siegel (um 1540) zeigt Herkules mit Keule und Löwenfell. Auch Papst Leo X. (Giovanni de' Medici, 1475-1521) machte sich diesen >Hausmythos zu eigen. Konkurrierend bezogen sich unter anderem die Este-Herzöge von Ferrara auf den Helden. Unter Ercole I. (1431-1505) und dessen Neffen Ercole II. (1508-1559) trugen sie sogar seinen Namen ${ }^{39}$.

Außerhalb Italiens setzte sich der Bezug auf Herkules und sein Geschlecht in Burgund (bei Karl I. dem »Kühnen«, 1433-1477) sowie in Ungarn unter Matthias Corvinus (1443-1490) fort. Auch in England wurde er unter Heinrich VII. (1457-1509) aufgenommen und später auf Heinrich VIII. (14911547) übertragen. Frankreich folgte in der ersten Hälfte des 16. Jahrhunderts mit Franz I., Heinrich II. und Heinrich III.; ihren jüngsten Sohn, den Duc d'Alençon, nannte Katharina von Medici sogar Hercule(-François, 1555$1584)^{40}$. Die Valois waren noch in eher allgemeiner Form mit dem Halbgott in Verbindung gebracht worden. Am Ende des 16. Jahrhunderts wurde Heinrich IV. (1553-1610), der letzte französische König, der sein Heer selbst im Felde führte, konsequent als »Gallischer Hercules«, als stoischer Held, gefeiert. Beim Einzug in Lyon 1595 erscheint Herkules, das zentrale Thema des Entrée, als Ahnherr des Hauses Navarra, um eine Verbindung zum »Hércule Gaulois« zu konstruieren ${ }^{41}$. Heinrichs Sohn Ludwig XIII. (1601-1643) konnte auf diesen - auf Lukian zurückgehenden - Gestus aufbauen, der nicht nur mit Stärke, Ausdauer und Gerechtigkeit, sondern auch mit einer weiteren barocken Tugend verbunden war: Herkules überwindet die feindlichen Völker nicht mit Gewalt, sondern fesselt sie durch seine Beredsamkeit ${ }^{42}$.

Die Habsburger bezogen einen Aspekt des Mythos auf ihr gesamtes Reich, das über die traditionell mit den »Säulen des Herkules« bei Gibraltar

39 Marlis V. Hessert, Zum Bedeutungswandel der Herkules-Figur in Florenz. Von den Anfängen der Republik bis zum Prinzipat Cosimos I, Köln u.a. 1991, bes. S. 48-50; Randolph StarN, Reinventing Heroes in Renaissance Italy, in: Journal of Interdisciplinary History 17 (1986), S. 67-84.

40 William C. Mcdonald, Maximilian I of Habsburg and the veneration of Hercules: on the revival of myth and the German Renaissance, in: Journal of Medieval and Renaissance Studies 6 (1976), S. 139-154, hier: S. 151; Vollkommer, Herakles, S. 21; Mıkó, Hercules, S. 95; MarcRené Jung, Hercule dans la littérature française du XVIe siècle. De l'Hercule courtois à l'Hercule baroque, Genf 1966.

41 Léonard Gaultier, Henri IV. als herrschender Herkules, Druck, 16. Jh. Paris, Bibliothèque nationale de France.

42 J.-B. Gaignebet, Essai sur le cheminement d'Hercule au cours de l'histoire de France, in: Provence historique 25 (1975), S. 111-124; Corrado Vivanti, Henry IV, the Gallic Hercules, in: Journal of the Warburg and Courtauld Institutes 30 (1967), S. 176-197; Edmund H. DiCKERMAN / Anita M. Walker, The Choice of Hercules: Henry IV as Hero, in: Historical Journal 39 (1996), S. 315-337; Carl GoldsteIn, Mixed messages: interpreting Bosse's »Louis XIII as the Hercules Gallicus«, in: Source: notes in the history of art 26 (2007), S. 9-15. 
bzw. Cádiz begrenzte Welt hinausgehen sollte (»plus ultra« als Wahlspruch Karls V., 1500-1558). Im Heiligen Römischen Reich war der Ehrenname bereits dem Wittelsbacher Friedrich I. von der Pfalz (1425-1476) durch den Gelehrten Peter Luder verliehen worden, der seinen Kurfürsten als »Hercules« für die Kandidatur zum römischen König in Stellung bringen sollte, 1474 aber von Kaiser Friedrich III. in die Reichsacht erklärt wurde ${ }^{43}$. An diese Strategie knüpfte dann (noch vor seinem Enkel Karl V.) Kaiser Maximilian I. (1459-1519) an, der sich als »Hercules Germanicus« bezeichnen lie $\beta^{44}$. Die Gleichsetzung mit dem antiken Helden folgte auch bei ihm nicht allein dem Zeitgeist oder einer antikisierenden Mode, sondern drückte jeweils konkrete politische Ansprüche aus. Die Erneuerung des Ritterideals ist unter Maximilian durch den Bezug auf den edlen, starken und unwiderstehlichen Herkules wesentlich befördert worden.

Reichsfürsten griffen in ihren Territorialstaaten den Herkules-Mythos topisch auf. Vom 16. bis ins frühe 18. Jahrhundert ist im Alten Reich eine regelrechte »ideologische Konkurrenz« zwischen den Fürstenhöfen festzustellen, die Herkules für ihre Dynastie vereinnehmen »und ihn mit dem entsprechenden snationalen $<$ Beinamen versehen $\aleph^{45}$. Die bayerischen Wittelsbacher standen ihren Pfälzer Vettern nicht nach: Die Herzöge von Bayern beauftragten Johannes Turmair (Aventinus), in seiner Geschichte des bayerischen Herzogtums (1521) Herkules zum ersten Fürsten Bayerns zu erheben. Das Bildprogramm der Landshuter Residenz aus den 1540er Jahren unterstrich diesen Anspruch. Die Pfälzer Linie zog ab 1556 mit dem Figurenzyklus am Heidelberger Schloss nach, der Kurfürst Ottheinrich zum »Hercules Palatinus« erhob. In Kursachsen führte Christian II. (reg. 1591-1611) den Titel »Hercules Saxonicus«. Das Haus Württemberg folgte ein Jahrhundert später; 1689 feierte Ulrich Preziger Herzog Friedrich Karl als »Hercules Wirtembergicus « ${ }^{46}$.

Die Hochzeit, in der sich Fürsten mit Herkules gleichsetzten, liegt im letzten Drittel des 17. und im ersten Drittel des 18. Jahrhunderts. Die Selbstdarstellung der deutschen Höfe in ihrem jeweiligen regionalen Herkules-Gewand bewegte sich im Gravitationsfeld der Pole Wien und Paris/Versailles. Unter Kaiser Karl VI. (reg. 1711-1740) erreichte die Herkules-Herrscheriko-

43 Hanns Hubach, Kurfürst Ottheinrich als Hercules Palatinus. Vorbemerkungen zur Ikonographie des Figurenzyklus' an der Fassade des Ottheinrichbaus im Heidelberger Schloss, in: Barbara Zeitelhack (Hg.), Pfalzgraf Ottheinrich: Politik, Kunst und Wissenschaft im 16. Jahrhundert, Regensburg 2002, S. 231-248.

44 Zum Folgenden: McDonald, Maximilian, S. 140f., 143f., 146, 152.

45 Uta Deppe, Die Festkultur am Dresdner Hofe Johann Georgs II. von Sachsen (1660-1679), Kiel 2006, S. 328.

46 Vollkommer, Herakles, S. 22; Kray, Imagination, S. 106; Hubach, Hercules, S. 238f.; Johannes ZaHLTEN, Hercules Wirtembergicus. Überlegungen zur barocken Herrscherikonographie, München u.a. 1981. 
nographie im Reich einen letzten Höhepunkt ${ }^{47}$. Die europäischen Nachbarn reagierten auf das habsburgische Selbstbewusstsein nach dem Westfälischen Frieden. Ludwig XIV. von Frankreich (reg. 1643-1715) ließ sich wie seine Vorfahren zum »Hercules Gallicus« stilisieren; Charles Le Bruns Projekt für die »Grande Galerie« in Versailles (1678) sah ein Deckengemälde mit den Arbeiten des Herkules (mit Zügen Ludwigs XIV.) vor, das in der Apotheose des Helden, seiner Aufnahme in den Olymp, gipfeln sollte. Die Version, die schließlich realisiert wurde, zeigt Herkules nur als Begleiter des Königs im Krieg, der unter anderem den Flussgott Rhein überwindet ${ }^{48}$. Die Personifikation wird zurückgenommen, doch der Halbgott bleibt präsent. Noch unter Ludwig XV. (reg. 1715/23-1774) schuf François Lemoyne (1733-1736) in Versailles die großflächige Apothéose d'Hercule ${ }^{49}$. Schließlich sei Karl XII. von Schweden (reg. 1697-1718) genannt, der sich - nach Gustav Adolf und Christina - den Mythos ebenfalls aneignete bzw. zuschreiben lie $3^{50}$.

Ein neues inhaltliches Element der Herkulesikonographie ist die seit dem 17. Jahrhundert häufiger auftretende Verbindung des Halbgotts mit seiner Mentorin Athene bzw. Minerva, der Göttin der Weisheit, des Krieges und der Künste. Der Halbgott erscheint, vor allem in Frankreich, im Kontext mit Minerva als »Hercules Musagetes«, der nach erfolgreichem Kampf ausruht und sich auf die Förderung von Künsten und Wissenschaften konzentrieren kann $^{51}$. Christina von Schweden (1626-1689, reg. 1632-1654) wird in Huldigungsgedichten sowohl mit Herkules als auch mit Minerva identifiziert ${ }^{52}$. Von den Tugenden des antiken Halbgotts werden neben der obligatorischen Streitbarkeit auch die dem »Hercules Gallicus« entlehnte weise Beredsamkeit auf die Königin übertragen. Wird sie in der Literatur gelegentlich direkt mit Herkules gleichgesetzt, so tritt in bildlichen Darstellungen der (männliche) Löwe an die Stelle des Helden; es hätte die ästhetischen, ikonographischen und schicklichen Konventionen gesprengt, die Königin in das Löwenfell des Herkules einzukleiden.

47 Franz Matsche, Die Kunst im Dienst der Staatsidee Kaiser Karls VI. Ikonographie, Ikonologie und Programmatik des »Kaiserstils«, Berlin u.a. 1981, S. 343-371.

48 Klaus Irle, Herkules im Spiegel der Herrscher, in: Lukatis / OtтомeYer, Herkules, S. 61-77, hier: S. 71-73; KRAY, Imagination, S. 106.

49 Emmanuel Ducamp (Hg.), »L'Apothéose d'Hercule« de François Lemoyne au château de Versailles. Histoire et restauration d'un chef-d'oeuvre, Paris 2001; Vollkommer, Herakles, S. 24.

50 Flugblatt (Schlacht bei Pinczow am 19. Juli 1702), Augsburg 1702 (Kupferstich/Radierung). Nürnberg, Germanisches Nationalmuseum, Graphische Sammlung, HB 29543, Pacetti-Nr. 1348.

51 Stefanie Heraeus, »Die Wiedergeburt des guten Geschmacks in Hessen«. Landgraf Karl als Kriegsheld und Kunstmäzen, in: Lukatis / OTtomeyer, Herkules, S. 79-98.

52 Zum Folgenden: Jochen BECKER, »Deas supereminet omneis«: zu Vondels Gedichten auf Christina von Schweden und der bildenden Kunst, in: Simiolus, Netherlands Quarterly for the History of Art 6 (1972-1973), S. 177-208. Auf die geschlechtsspezifischen Attribute geht Becker (1972!) nicht näher ein. 
Herkules war als einziger der archaischen Heroen nicht lokal gebunden, sondern galt bereits in der Antike als panhellenischer Held, der für Frieden und Freiheit aller Griechen gekämpft habe ${ }^{53}$. Dieses einigende Potenzial des Helden ließ sich in der Frühen Neuzeit aktivieren, insbesondere in Krisenzeiten, wenn die Zeitgenossen nationale oder konfessionelle Spaltungen fürchteten bzw. beklagten: Maximilian I. versuchte um 1500, dem Reich durch einen allgemeinen Landfrieden und eine Reform seiner Institutionen zu Rechtssicherheit, klareren Entscheidungsprozessen und einer effektiveren Türkenabwehr zu verhelfen. Heinrich IV. wurde nicht zuletzt deshalb zum »Hercules Gallicus« stilisiert, da er das von Religionskriegen zerrissene Königreich beruhigen sollte. Gustav II. Adolf von Schweden (reg. 16111632) erschien 1630 auf einem Flugblatt der protestantischen Kriegspartei als »Schwedischer Hercules, Das ist: Trost und Frewde der Frommen | und getroste zuversicht der Göttlichen instehender Errettung«. Der König tritt als Knecht Gottes und »miles christianus« auf, der mit der Kraft des Halbgotts die Christenheit von der Tyrannei befreit ${ }^{54}$.

Der Anspruch der allgemeingültigen Vorbildhaftigkeit des Herkules ließ sich auf das kirchlich-religiöse Feld übertragen. So wurde das Bild eines nationalen Helden, der sein Vaterland von innerer Zerrissenheit und Fremdbestimmung befreit, auf die Reformatoren Martin Luther (»Hercules Germanicus «, Holzschnitt Hans Holbeins d. J., 1520) und Huldrych Zwingli (»Hercules Helveticus«) appliziert ${ }^{55}$. Die Gegenseite schwieg nicht: Während Bischof Franz Wilhelm von Osnabrück 1630 konfessionsneutral als »Christianus Hercules « gefeiert wurde, siegte der Gründer des Jesuitenordens Ignatius von Loyola in einem Huldigungsgedicht (1654) als Herkules über die Hydra (die Reformation) $^{56}$. Neu waren an diesen Darstellungen, dass sie nicht nur ein Identifikationspotenzial für Fürsten innerhalb der höfischen Sphäre abriefen, sondern einer weiteren Verbreitung des Mythos zuarbeiteten. Bevor etwas näher die Medien der Erinnerung thematisiert werden, gilt es einen Blick auf einen Quellenfundus zu werfen, auf den diese Medialisierungen zurückgreifen konnten.

53 Vollkommer, Herakles, S. 11.

54 Flugblatt (»Schwedischer Hercules«), um 1630. Nürnberg, Germanisches Nationalmuseum, Graphische Sammlung, HB 13602. Vgl. dazu Bernhard R. Kroener, Gustav II. Adolf. Vom »Löwen aus Mitternacht« zum »schwedischen Herkules«, in: Andreas HartmanN / Michael Neumann (Hg.), Mythen Europas. Schlüsselfiguren der Imagination. Vom Barock zur Aufklärung, Regensburg 2007, S. 14-35, hier: S. 22.

55 Vgl. dazu Walter Sparn, Hercules Christianus. Mythographie und Theologie in der frühen Neuzeit, in: KILLY, Mythographie, S. 73-107, hier: S. 76f.

56 Vollkommer, Herakles, S. 19; KraY, Imagination, S. 48. 


\section{Blaupausen: Die enzyklopädische Tradition}

Giovanni Boccaccios Genealogia Deorum (entstanden 1347-1360) ${ }^{57}$ gilt als »wichtigste[s] Glied in der Kette, welche die Mythologie der Renaissance mit der des Mittelalters verbindet $\kappa^{58}$. Sie verbindet die sammelnde und ordnende Mythographie mit spekulativ-interpretativer Mythologie; diese beiden Zugrif$\mathrm{fe}$ in der Mythenaneignung sind in der Folgezeit kaum mehr zu trennen. Zunächst als Manuskript kursierend und seit 1472 in vielen Auflagen gedruckt, blieb die Göttergenealogie für zwei Jahrhunderte ein Reservoir, aus dem Dichter, Historiker und bildende Künstler beim Studium der antiken Mythen schöpften. Sie unterscheidet mehrere Herkules-Figuren und führt insgesamt 31 Taten des Helden auf. Diese bildeten die literarische Grundlage für verschiedene Herkules-Zyklen der ersten Hälfte des 16. Jahrhunderts. Deren Behandlung des Stoffes zeigt noch kaum snationale Schulen, sondern nur graduell-individuelle Abweichungen von Boccaccios literarischer Vorlage. Auf den Herkules der Genealogia bezogen sich unter anderem der um 1500/1510 entstandene Holzschnittzyklus von Giovanni Andrea Valvassori (gen. Guadagnino, 16. Jahrhundert) ${ }^{59}$, der wiederum Loy (Thoman) Hering (gestorben 1549) als Vorlage für die Kalksteinreliefs mit den Taten des Helden in der Landshuter Stadtresidenz (um 1543) diente, sowie Albrecht Dürer (1471-1528) ${ }^{60}$ und Heinrich Aldegrever (1502-1561) ${ }^{61}$, schließlich auch der durch Nachstiche weitverbreitete Gemäldezyklus des Flamen Frans Floris (1516-1570) ${ }^{62}$. Boccaccios Göttergenealogie begleitete und unterfütterte also in der ersten Hälfte des 16. Jahrhunderts eine Welle von Herkules-Adaptionen ${ }^{63}$.

Erneuert und in ihrer Breitenwirkung abgelöst wurde die Genealogia Deorum um die Mitte des 16. Jahrhunderts durch verschiedene mythographische Handbücher ${ }^{64}$. Am bekanntesten waren Giglio Gregorio Giraldis

57 Erstausgabe: Johannes Boccacius de Certaldo, Genealogiae Deorum gentilium libri XV, Venedig 1472.

58 Seznec, Fortleben, Zitat S. 164; Kray, Imagination, S. 35f.

59 Verzeichnet bei Kray / Oettermann, Herakles, Bd. 2, Nr. $2215 f$.

60 Albrecht DürER, Taten des Herkules, Zyklus von 12 runden Zeichnungen, o.O. 1511. Verzeichnet bei Kray / Oettermann, Herakles, Bd. 2, Nr. 1713.

61 Heinrich Aldegrever, Taten des Herkules, Serie von 13 kleinformatigen Kupfern, jeweils mit lateinischen Distichen, datiert 1550. Verzeichnet bei Kray / Oettermann, Herakles, Bd. 2, Nr. 1483.

62 Frans Floris, Die Taten des Herkules, Folge von 10 (oder 12) Gemälden, um 1555 (seit 1768 verschollen), nachgestochen von Cornelis CoRT, Die Arbeiten des Herkules, 10 Kupfer, um 1555. Verzeichnet bei Kray / Oettermann, Herakles, Bd. 2, Nr. 1739f.

63 Inwieweit diese Abhängigkeit von Boccaccio auch auf die Kupferstichfolgen zu Leben und Taten des Herkules von Albrecht Altdorfer (um 1480-1538) und Hans Sebald Beham (1500-1550) sowie die Gemälde und Zeichnungen von Hans Baldung (gen. Grien, 1480-1545) und Lucas Cranach d.Ä. (1472-1553) zutrifft (verzeichnet bei Kray / Oettermann, Herakles, Bd. 2, Nr. 1492-1494, 1549, 1518-1521, 1670-1676), wäre form- und motivgeschichtlich noch zu überprüfen.

64 SEZneC, Fortleben, S. 172-245 (grundlegend). 
Göttergeschichte (erstmals 1548, lateinisch) ${ }^{65}$, Natale Contis Mythologie (1551, lateinisch, bis 1700 mehr als 30 Ausgaben) ${ }^{66}$ und Vincenzo Cartaris Götterbilder (1556, italienisch, bis 169918 Ausgaben) ${ }^{67}$. Diese drei Handbücher popularisierten antike Heldenmythen, indem sie synkretistisch-enzyklopädisch alle verfügbaren literarischen Darstellungen aneinanderreihten und durch Register und Indizes erschlossen. Sie erfassten den antiken Mythenschatz und übersetzen eine Vielzahl von Bedeutungsaspekten in griffige allegorische Deutungen, ohne die Überlieferungen zeitlich zu klassifizieren. Die (Cartari) beigegebenen Stiche gehen selten auf archäologische Studien der antiken Originale zurück, sondern illustrieren die literarischen Schilderungen. Die Handbücher greifen also weder die Wiederaneignung antiker Formsprache in den bildenden Künsten des Quattro- und frühen Cinquecento auf, noch hält ihr Quellenstudium den gelehrten Ansprüchen der Humanisten stand. Dennoch oder gerade deshalb wurden sie von italienischen Künstlern in der zweiten Hälfte des 16. Jahrhunderts häufig und ausgiebig konsultiert. Ihr enzyklopädischer Charakter ersparte den Rückgriff auf die antiken Quellen. Die Ambivalenz der antiken Heroen, die die Humanisten des 14. und 15. Jahrhunderts noch positiv aufzulösen gesucht hatten, schliff sich in diesem Aneignungsprozess $\mathrm{ab}^{68}$.

Giraldi, Conti und Cartari enthalten ausführliche Darstellungen des Herkules und seiner Taten, wobei sie wiederum neue mythische Zusammenhänge konstruieren. So zeigt eine spätere Cartari-Ausgabe den Halbgott mit den Attributen des Merkur. Die Iconologia des Cesare Ripa ${ }^{69}$ ergänzte kongenial das Mythenreservoir der drei Handbücher. Ripas Werk, 1593 erstmals erschienen, wurde ins Französische (1644), Niederländische (1644), Deutsche (1669-1670) und Englische (1709) übersetzt und bis weit ins 18. Jahrhundert vielfach (in Rom, Paris, Amsterdam, Hamburg, Frankfurt/Main und London) neu aufgelegt. Ripa ging auf dieselben Quellen wie die drei Handbücher zurück (mittelalterliche Mythographien, Hieroglyphen, Numismatik) und transformierte die Eigenexistenz der Götterfiguren in philosophisch-moralische »Bilderrätsel«. Die Iconologia wurde »das einflußreichste Handbuch für Personifikationen abstrakter Begriffe« in Europa und transportierte damit auch den Herkules-Mythos in einer moralisch ver-

65 Erstausgabe: Giglio Gregorio GIRALDI, De deis gentium varia et multiplex historia, Basel 1548.

66 Erstausgabe: Natale ConTI, Mythologiae sive explicationis fabularum libri decem, Venedig 1551.

67 Erstausgabe: Vincenzo CARTARI, Le imagini con la spositione de i dei degli antichi, Venedig 1556.

68 Blume, Mythos, S. 139.

69 Erstausgabe: Cesare RIPA, Iconologia, overo Descrittione dell' imagini universali cavate dall' antiquità et da altri luoghi, Rom 1593. 
eindeutigten Variante: Herkules, Musterbild der »heroischen Tugend«, ist großmütig, standhaft und weiß, seine Lust durch Vernunft zu bändigen ${ }^{70}$.

\section{Medien der Erinnerung}

Wie die Heldenfiguren der Handbücher in bildliche Darstellungen eingingen, kann hier nicht verfolgt werden. An dieser Stelle sei nur darauf hingewiesen, dass die Adaptionen des Herkules-Mythos in den bildenden Künsten der Frühen Neuzeit in die Tausende gehen. Von fast allen heute als bedeutend geltenden Künstlern des 16. bis 18. Jahrhunderts ist wenigstens ein »Herkules« überliefert. Dies gilt nicht nur für Malerei und Skulptur, sondern auch für das Kunstgewerbe ${ }^{71}$. Wenden wir uns weiteren Medien zu, die den Herkules-Mythos aus dem innerhöfischen Kontext heraus in breiteren Rezipientenschichten verfügbar machten.

Im 16. Jahrhundert tauchen an den Fürstenhöfen Frankreichs, Englands und im Reich in den Festen, Turnieren und Einzügen sowie den zu diesen Anlässen entstandenen ephemeren Kunstwerken zunehmend mythologische Anspielungen oder gar Personifikationen antiker Gottheiten auf. Ihren Ausgang nahm diese Adaption antiker Mythen in den italienischen Fürstentümern Mailand, Ferrara oder Mantua. Die meisten Höfe nördlich der Alpen behielten ihre ritterlichen Festformen des Spätmittelalters (Turnier, Einzug, Divertissements) bei, banden sie jedoch in eine Rahmenhandlung ein, in denen sich antikisierende Elemente mit lokalen oder nationalen Formen vermischten. Bei den höfischen Turnieren (u.a. Ringelrennen, Stechen zu Pferd, Fußkampf), die im 16. Jahrhundert meist mit einer »Mummerei« (einem Maskenball) abschlossen, kamen, zumindest an den Hofhaltungen der Habsburger, Prunkrüstungen »all'antica« bzw. »alla romana« in Mode. Bei den Einzügen und Divertissements trat zunehmend mythologisches >Personal< auf.

In Frankreich bestand gegenüber anderen Höfen eine besondere Ausgangslage für den Transfer italienischer Kunst und damit vermittelt auch santikerく Mythen. Denn unter der Regentin und Königinmutter Katharina von Medici hatte sich die schon unter Franz I. begonnene »Italianisierung« des französischen Hofs fortgesetzt. Zahlreiche Schlüsselpositionen in der Hof-und Staatsverwaltung waren in italienischer Hand; Kleidermode, Innenausstattung und Festkultur waren geprägt von den vielen Römern, Florentinern und Neapolita-

70 Seznec, Fortleben, S. 212f.; IrLe, Herkules, Zitat S. 65.

71 Vgl. z.B. Hans R. Weinrauch, Italienische Bronzen als Vorbilder der deutschen Goldschmiedekunst, in: Kurt Martin (Hg.), Studien zur Geschichte der europäischen Plastik, München 1965, S. 263-280, Abb. S. $268 f$. 
nern, die auf der königlichen Besoldungsliste standen ${ }^{72}$. Der französische Königshof entwickelte folglich eine besonders ausgeprägte und anhaltende Tradition der Herkulesikonographie ${ }^{73}$. Besonders bei den Einzügen der Monarchen in den Städten des Königreichs war Herkules eine feste Größe im mythologischen Personal. Fürstliche Entrées als Überbleibsel des Reisekönigtums blieben im 16. Jahrhundert, als sich die königliche Bürokratie zu zentralisieren begann, ein (primär symbolisch eingesetztes) Herrschaftsinstrument. Sie wirkten in die Breite, da sie im Gegensatz zu den zugangsbeschränkten höfischen Turnieren alle Stände als Zuschauer einbanden. Bereits 1486, als Anne de Bretagne, die später Karl VIII. heiraten sollte, in Paris einzog, zeigte ein Schaugerüst Herkules' Kampf mit der Hydra. 1517 in Rouen erwiesen Atlas und Herkules König Franz I. die Ehre. Beim Entrée in Rouen 1550 zog Heinrich II. durch ein Triumphtor in Form eines Felsengebirges, in dem Herkules wiederum gegen die Hydra, als Sinnbild des Krieges, kämpft. Noch beim Einzug Marias von Medici 1600 in Avignon war Herkules das zentrale Thema des Festzugs.

$\mathrm{Ab}$ der Jahrhundertmitte verkleideten sich die Fürsten zunehmend selbst als antike Götter. Beim Einzug Heinrichs II. in Paris (1549) trat der junge König als »le nouvel Hercule« auf, während sein 1547 verstorbener Vater als »Hercule gaulois« vergöttert wurde. In seiner Regierungszeit spielte sogar der gesamte französische Hof eine »Komödie des Olymp« nach. Etwas zeitversetzt schlossen die Habsburger zu den Valois auf. Als Ferdinand I. nach seiner Kaiserkrönung 1558 in Prag einzog, bildete ein »Kampf der Giganten gegen Jupiter« (dem sein Sohn Herkules selbstverständlich beistand) den Höhepunkt. Als Kaiser Maximilian II. 1575 Dresden besuchte, trat Herkules als Feuerwerksfigur zusammen mit den »Wilden Männern« auf. Anlässlich der Vermählung Erzherzog Ferdinands II. von Österreich mit Anna Caterina Gonzaga (1582) band ein Ephitalamium Heroicum die Schilderung des Festanlasses in eine Rahmenhandlung ein, in der Apollo als Gott der Künste, die Musen und der Hochzeitsgott Hymnaeus auftraten ${ }^{74}$.

Die höfischen Feste inszenierten ein ereignishaftes Gedenken an die ruhmvolle Vergangenheit und die Reinkarnation des mythischen Heros in Gestalt des aktuellen Monarchen. Zu dem performativen Akt und ephemeren Denkmal trat die Dokumentation für die Mit- und Nachwelt: Die Feste wurden häufig in aufwendigen Kupferstichwerken beschrieben, um anderen Höfen diese Statusmanifestationen mitzuteilen. Dass die Beschreibung oft aufwän-

72 Anka Muhlstein, Königinnen auf Zeit: Katharina von Medici, Maria von Medici, Anna von Österreich, Frankfurt/Main u.a. 2003, S. 27f.

73 Vgl. zum Folgenden die Übersicht bei Jung, Hercule, S. 203.

74 Seznec, Fortleben, S. 29; Veronika SAndBichler, Habsburgische Feste in der Renaissance, in: Wilfried SeIPEL (Hg.), Wir sind Helden. Habsburgische Feste in der Renaissance, Wien 2005, S. 1-15, 25-29; KRAY, Imagination, S. 43. 
diger ausfiel als das >eigentliche< Fest, war vermutlich allen Rezipienten bewusst. So ist fraglich, ob die ephemere Herkulesstatue, wie sie Pieter van der Borchts Kupferstich darstellt, tatsächlich in derart gigantischen Ausmaßen den Antwerper Marktplatz beim Einzug Albrechts VII. und Isabellas (1599) schmückte. Als Inszenierung einer Inszenierung machte der Stich diesen Koloss in römischer Rüstung, dem Putten eine überlange Lanze reichen, zur repräsentierten $>$ Realität ${ }^{75}$.

Ein Solitär unter den Herkules-Darstellungen mit überregionaler Wirkung war das Monument, das Landgraf Karl von Hessen-Kassel 1717 auf dem Karlsberg errichten lie $\beta^{76}$. Die riesige Skulptur war eine Nachschöpfung des »Hercules Farnese«, den Karl 1699 in Rom persönlich in Augenschein genommen hatte. Der Koloss war nicht nur weithin sichtbar und entwickelte sich zum Wahrzeichen von Stadt und Residenz, sondern wurde auch durch zahlreiche Druckschriften verbreitet ${ }^{77}$. Die meisten anderen Dynastien nutzten ein breiteres Medienspektrum. Schon Kaiser Maximilian I. war in einer Vielzahl panegyrischer Formen als (»teutscher«) Herkules gefeiert worden, um seinem Programm einer Erneuerung des Rittertums die größtmögliche Streuung zu verleihen: Gedichte, Epicedien, Economien, Widmungen in Prosa, Dramen ${ }^{78}$. Die Albertiner untermauerten ihren Anspruch, den »Hercules Saxonicus« zu verkörpern, mit einer ausgefeilten Festkultur. Der antike Halbgott (ergo: der Kurfürst) trat seit dem 17. Jahrhundert in Schießfesten und »Pyrotheatern« (Feuerwerken) auf. Friedrich August I. (reg. 1694-1733) nahm das Motiv u.a. in der Architektur (Dresdner Zwinger) und auf Münzen auf ${ }^{79}$.

\section{Redundanzen und Übergänge}

Herkules wurde bis zum frühen 18. Jahrhundert, ausgehend vom höfischen Kontext, zu einem in den vielfältigsten Kontexten und Medien verbreiteten Topos, der emblematisch mit Geschichte und gegenwärtigem Ruhm von Land und Dynastie verschmolz. Dabei veränderte und verdünnte sich die Aussagekraft. Dies zeigt sich zum einen in den Fortsetzungen der mythologischen Handbücher des 16. Jahrhunderts. Joachim von Sandrarts großangelegte Ico-

75 Pieter VAN DER Borcht, Herkulesstatute für den Einzug Albrechts VII. und Isabellas in Antwerpen, Kupferstich, 1599. Innsbruck, Universitätsbibliothek. Abb. 2 bei SEIPEL, Helden, S. 13.

76 Gerd Fenner, Der »Grottenbau« auf dem Karlsberg. Zur Baugeschichte des Oktogons und der Wasserkünste, in: LuKatis / OтTOMEYER, Herkules, S. 99-119.

77 Christiane Lukatis, Der Herkules Farnese. »Ein schönes Muster der starken männlichen Natur«, in: Lukatis / OtTOMEYer, Herkules, S. 35-60.

78 McDonald, Maximilian, S. 140f., 143f., 146, 152.

79 Depre, Festkultur, S. 314-328. 
nologia Deorum (1680) bezog sich ausdrücklich auf Boccaccio und Ripa; den Attributen und Eigenschaften des Herkules fügte sie nichts Wesentliches hinzu ${ }^{80}$. Zugleich fächerte sich der den höfischen Aneignungen zu Grunde liegende ikonographische Katalog auf. Herkules vermochte nicht mehr alle Tugenden, die in das Herrscherideal eingingen, in sich zu vereinen ${ }^{81}$.

Im frühen 18. Jahrhundert wird das Herkules-Motiv noch einmal an einem zentralen Ort fürstlicher Selbstdarstellung greifbar - in den fürstlichen Gärten, die in beinahe allen europäischen Residenzen entstanden. Seit dem 17. Jahrhundert waren Villen und Lustschlösser mit ihren Gärten ein bevorzugter Anlagerungsort für den Herkules-Mythos. So zeigte der Brunnen im Hof des Palazzo Pitti in Florenz den Kampf des Herkules mit dem Riesen Antaeus. Im Herkulesteich des sogenannten zweiten Gartens von Schloss Gottorf (ab 1637 errichtet) kämpfte Herkules mit der Hydra. Innerhalb der Gärten erhielt der Halbgott einen eigenen Reservatbezirk: Zur standesgemäßen Ausstattung einer Residenz gehörte ab dem späten 17. Jahrhundert eine Orangerie. Die Zitrusfrüchte ließen sich mit den goldenen Äpfeln der Hesperiden gleichsetzen, die Herkules als eine seiner Arbeiten entwenden muss. Mit dem von seinen Taten ausruhenden »Hercules Farnese«, der hinter seinem Rücken drei Äpfel in der Hand hält, war das Motiv in der europäischen Herkulestradition präsent. Die Äpfel galten sowohl als "Zaubermittel zur Erlangung realer Unsterblichkeit« als auch als »Symbol des dem Hercules gebührenden Tugendlohns « ${ }^{82}$. Dem Fürsten bot sich eine höfische Bühne, auf der er sich symbolisch in den allmächtigen Halbgott verwandeln und über die Natur bzw. den Kosmos herrschen konnte; »die Inbesitznahme der Goldenen Äpfel durch Herkules [gilt] als Anbruch des Goldenen Zeitalters ${ }^{83}$. Der Herkules-Mythos gehörte zum selbstverständlichen, ideellen Arsenal der höfischen Bauaufgabe Orangerie, so dass deren bloße Existenz noch keine Rückschlüsse auf das Selbstverständnis des Herrschers erlaubt, in dem die Figur »Herkules« eine bestimmte Funktion eingenommen hätte. Auch im Bereich der Gartenkunst und Architektur war das Motiv, weil es überall anzutreffen war, in der ersten Hälfte des 18. Jahrhunderts redundant geworden $^{84}$

80 Joachim VON SANDRART AUF STOCKAU, Iconologia Deorum, Oder Abbildung der Götter Welche von den Alten verehret worden, Nürnberg 1680, zu Herkules: S. 120-125. Vgl. SEZNEC, Fortleben, S. 244.

81 Ebd., S. 213.

82 Panofsky, Scheideweg, S. 145.

83 Claudia Gröschel, Die goldenen Äpfel. Zitrusfrüchte zwischen antikem Mythos, Herrschaftssymbol und bildender Kunst, in: Staatliche Schlösser und Gärten Baden-Württemberg (Hg.), Der Süden im Norden: Orangerien - ein fürstliches Vergnügen, Regensburg 1999, S. 6-13; Helmut-Eberhard PAulus, Orangerie - der realisierte Traum von der Antike als Paradies, in: Stiftung Thüringer Schlösser und Gärten (Hg.), Orangerieträume in Thüringen. Orangerieanlagen der Stiftung Thüringer Schlösser und Gärten, Regensburg 2005, S. 11-40, Zitat S. 23.

84 Diese Hinweise verdanke ich Sibylle Hoiman (Zürich), im Vorgriff auf ihre noch unpublizierte Dissertation (TU Berlin 2008). Vgl. Sibylle Holman, Die Orangerie in Belvedere bei Weimar. 
Mit der vielfältigen dynastischen und nationalen Aneignung wurden kaum mehr spezifische Werte verbunden. Zwar hatten sich die Medien, die Herkules eine Bühne boten, im 17. Jahrhundert mit der Aufnahme neuer Festformen (Feuerwerk, Schießen) und künstlerischer Gattungen (Oper und Ballett) noch erweitert. Doch der Variantenreichtum der Herkulesdarstellungen nahm insgesamt ab. Ähnliche Abnutzungserscheinungen wie in der Malerei und Gartenkunst zeigen sich in der Prosa des Spätbarocks. Auf den Hoftheatern war der Herkules-Stoff zwar weiterhin populär. Stoff- und motivgeschichtlich wird der Mythos allerdings kaum weiterentwickelt; Wirkung entfaltet er nun vor allem durch die neuen sinnlichen Angebote der Theaterund Opernmaschinerie, der aufwendigen Kostüme, dramatischen Interludien und der zahlreichen Nebenfiguren. Permanente Evozierung führte also zur Abnutzung. Ausnahmen bestätigen diese Entwicklung. Christoph Martin Wielands Singspiel Die Wahl des Herkules, 1773 zum 16. Geburtstag des Weimarer Erbprinzen auf dem dortigen Hoftheater aufgeführt, versuchte die Ambivalenz des Helden in einem dramatischen Fürstenspiegel zu erneuern. Gegen die auf äußerliche Effekte zielende Barockoper setzte er die »Aktion«, das heißt den inneren Kampf des zwischen Tugend und Wollust hin- und hergerissenen Helden ${ }^{85}$. Nachhaltige Wirkung entfaltete diese Adaption des Stoffs freilich nicht.

Die »europäische« Karriere des Herkules war - unter anderem - durch ein >gefühltes` Legitimitätsdefizit in den politischen Körperschaften ermöglicht worden, die seit dem 16. Jahrhundert verstaateten und für die Identifikation zwischen Herrscher und Staat auf einen Mythenvorrat zurückgriffen. Dieser war einerseits auf die eigene Dynastie zuzuschneiden, andererseits musste er europaweit verständlich und >verfügbar`sein. Im Verlauf der Frühen Neuzeit verselbständigte sich die Aneignung der Heldenmythen in den Künsten in dem Maße, wie sich die Medien (Buchdruck, Kupferstich, Holzschnitt) und Formen (Flugblätter, höfische Festbeschreibungen, Musiktheater / Oper, Turnier, Festaufzug / Entrée, Feuerwerke, Ballette etc.) diversifizierten. In der französischen Revolution zeigte sich, dass die politischen Eliten auch dann noch exklusive Aneignungsrechte beanspruchten, nachdem der Herkules-Stoff (seit dem späten 18. Jahrhundert) »vollends zum frei flottierenden, durch keine ernsthaften politischen, religiösen, ethischen etc. Realismus-Vorgaben mehr bestimmten und daher auch frei kombinierbaren Stoff geworden war ${ }^{86}$. Herkules mit seiner jahrhundertelangen dynastischen Aneignungsgeschichte wurde eben nicht als Symbol des Ancien Regime ent-

Eine höfische Bauaufgabe zwischen Schaulust und Botanik, in: Reinhard WEGNER (Hg.), Kunst die andere Natur, Göttingen 2004, S. 100-124.

85 Vgl. KraY, Imagination, S. 61.

86 Ebd., S. 65. 
sorgt ${ }^{87}$. Der Mythos öffnete sich vielmehr überständischen Identifikationen: Jacques Louis David schlug 1793 dem Nationalkonvent vor, eine Kolossalstatue zu errichten, die das französische Volk repräsentieren sollte - mit den Attributen des Herkules. Der Held verkörperte nun wieder, wie zu Beginn unseres Zeitraums, die florentinische Stadtrepublik, ein Kollektiv. Davids Entwurf eignete darüber hinaus ein herrschaftskritisches Moment: Es war das Volk selbst, das die Republik vor Uneinigkeit und Parteiengeist schützen sollte. David sah die Spannung zwischen Tugend und Hybris nicht mehr im Helden selbst verankert, sondern setzte das tugendhafte Volk (Herkules) den maßlosen zentrifugalen Kräften in den Provinzen und im Nationalkonvent gegenüber. Der Held verlor dabei ein zentrales Merkmal des bisherigen Erinnerungstopos: Herkules wurde weder eindeutig auf einen antiken Halbgott bezogen noch mit einer (elitär angeeigneten) französischen Geschichte verbunden, sondern stand als Gigant des Volkes allein in der Gegenwart.

\section{Herkules als europäischer Erinnerungstopos?}

Ist Herkules, der Held zwischen Tugend und Hybris, also ein europäischer Erinnerungstopos der Frühen Neuzeit? Die Antwort fällt erwartungsgemäß nicht eindeutig aus. Zunächst - ja, in dieser inhaltlichen Zuspitzung und im Bezug auf ein Herrscherideal ist der Erinnerungstopos Herkules in der Frühen Neuzeit erfunden und tradiert worden. Das Konzept des »Erinnerungsortes « ist zwar nicht notwendig, um die Transformationen und Transfers antiker Heldenmythen in der Frühen Neuzeit zu beschreiben. Es kann jedoch hilfreich sein, um den topischen Charakter bestimmter Bedeutungsgehalte schärfer zu erkennen, um die ästhetischen Eigenlogiken der jeweiligen Ausdrucksmodi einzubeziehen und um generell das Aushandeln von Deutungshoheiten über (imaginiert-konstruierte) gemeinsame Vergangenheiten als sozialen Prozess präziser als in einer Stoff-, Motiv- und Formgeschichte beschreiben zu können.

Herkules - als Held zwischen Tugend und Hybris - könnte also als ein europäischer Erinnerungstopos in (bestimmten Phasen, Regionen und Schichten) der Frühen Neuzeit aufgefasst werden, sofern man die Abnutzungserscheinungen als Teil des Phänomens mit einbezieht: Das herrscherkritische Moment der Hybris ging mehr und mehr verloren; Tugendhaftigkeit wurde auf körperliche Stärke reduziert. Wie Herkules gegenüber anderen Topoi in-

87 Lynn A. Hunt, Hercules and the radical image in the French Revolution, in: Representations 1 (1983), S. 95-117; Viktoria Schmidt-Linsenhoff, Herkules und Madame Sansculotte: Zur A1legorie des Volkes in der Franzöischen Revolution zwischen Mutters Rockzipfel und männlicher Souveränität, in: Journal Geschichte 1 (1990), S. 32-41. 
haltlich und bezüglich der ästhetischen Eigenlogiken in den Erinnerungsmedien einzustufen wäre, müssten weitere Fallstudien zeigen. Die Forschungspraxis beschränkt sich bisher größtenteils auf die jüngere Neuzeit und die Zeitgeschichte.

Sofort möchte man das Gesagte wieder einschränken. Wenn man genauer nach den Medien fragt, »die Topoi tradieren, aktualisieren und popularisieren«, erkennt man, dass manche Erinnerungsorte »nur für kleine politische oder intellektuelle Eliten relevant waren $\aleph^{88}$. Um von einem Erinnerungsort zu sprechen, sollte dieser jedoch nicht nur horizontal-geographisch, sondern auch vertikal-sozial breit verankert sein, wenn auch nicht zwingend im Sinne einer $>$ nationalen $<$ Massenmobilisierung des 19. Jahrhunderts ${ }^{89}$. Der $>$ Verdacht auf Elitenphänomen trifft Herkules als Held zwischen Tugend und Hybris sicherlich nicht bezüglich der Rezeptionsstrategien, mit denen die Eliten der Frühen Neuzeit die hier vorgestellten Ikonographien in verschiedenen Medien einsetzten. Um ihn gänzlich zu entkräften, wären jedoch detaillierte Untersuchungen zur tatsächlichen Wahrnehmung der Herrschersymbolik in Schichten außerhalb der höfisch-staatlichen und der gelehrten Eliten nötig.

\section{Europäische Erinnerungsorte - wann, für wen, wozu?}

In der spezifischen Konnotation der (ersten Hälfte der) Frühen Neuzeit, als Held zwischen Tugend und Hybris, ist Herkules vermutlich kein Topos, mit dem »die große Masse der Europäer heute [...] etwas anfangen kann«, wie es Heinz Duchhardt als Kriterium für einen europäischen Erinnerungsort formuliert hat ${ }^{90}$. Oder - wie es Aleida Assmann ausdrücken würde - der antike Heros in seiner Ambivalenz ist nicht im »Funktionsgedächtnis« der heutigen europäischen Gesellschaften gespeichert, hat keine Relevanz für »lebendige Gedächtnisse«, macht keine »Identitätsangebote« und besitzt keine »Orientierungsfunktion ${ }^{91}$. Zwar ist Herkules wahrscheinlich auch im frühen 21. Jahrhundert in verschiedenen europäischen Gesellschaften als Synonym für Kraft, Stärke und Ausdauer präsent (man vergleiche die zahlreichen maschinellen Erzeugnisse mit diesem Etikett) ${ }^{92}$. Und die »Herkules-Aufgabe $«$ dient, gerade in der Sphäre der Politik, immer noch dazu, eine schier über-

88 Schmidt, Lieux, 43.

89 Dies fordert auch Esch, Rom, S. 380 f.

90 DuchHardt, Westfälischer Friede, S. 403 (Hervorhebung durch den Verf.).

91 Aleida Assmann, Zur Mediengeschichte des kulturellen Gedächtnisses, in: Astrid ErLl / Ansgar NÜNNING (Hg.), Medien des kollektiven Gedächtnisses. Konstruktivität - Historizität Kulturspezifität, Berlin u.a. 2004, S. 45-60, Zitate S. 54.

92 Ohne dies als empirisch-statischen Beleg anzuführen, sei darauf hingewiesen, dass »Herkules / Herakles« in der Online-Enzyklopedie »Wikipedia« in über 25 europäischen Sprachen porträtiert wird. 
menschliche Herausforderung zu kennzeichnen ${ }^{93}$. Doch weder die Ambivalenz noch die Ubiquität und schon gar nicht die herrscherkritische Funktion des Topos reichen bis in die Moderne hinein.

Ist dieses Kriterium, die Präsenz im heutigen Funktionsgedächtnis, aber ein notwendiges, um von einem europäischen Erinnerungsort sprechen zu können? Ist das Ziel bei der Ermittlung europäischer Erinnerungsorte, für das gegenwärtige oder zukünftige Europa eine gemeinsame Tradition zu erfinden ${ }^{94}$ ? Wenn ja, dann könnte man in der Tat nur solche Topoi behandeln, die heute noch in den europäischen Gesellschaften lebendig sind. Dann stellt sich die Frage nach der normativen Grundlage der Auswahl, wer die Auswahl treffen (»nur die happy few Ideen-Fachhistoriker « ${ }^{95}$ ?) und ob diese einen gelehrt-elitären Bildungskanon abbilden soll etc. Zu Beginn müssten umfangreiche empirische Erhebungen (Befragungen) auf dem ganzen Kontinent stehen, die alle gesellschaftlichen Schichten - eben nicht nur die Residuen eines Bildungsbürgertums - erfassen, um zu ergründen, wer denn was genau mit den fraglichen Topoi anfangen kann. Historiker würden sich also systematisch-gegenwartsbezogen als Soziologen, Politologen oder Sozialpsychologen betätigen. Dabei wäre unter anderem zu fragen, welches $»$ heute $\iota^{96}$ eigentlich abgebildet werden soll, da sich >die Gegenwart - bei aller >Trägheit 〈 der Mentalitäten - nicht einfrieren lässt, und ob der solchermaßen konstruierte Kanon von Erinnerungsorten unbegrenzte Gültigkeit beansprucht (woran sich also >die Europäer in 50 oder 100 Jahren erinnern werden). Eine Alternative, die den Kompetenzen der historisch arbeitenden Wissenschaften ein wenig näher läge, wäre, an solche Orte zu erinnern, an die sich einst Erfahrungen angelagert hatten, die dann aber verschüttet ${ }^{97}$ oder verdrängt wurden und die nun möglicherweise für Europa integrative Wirkung entfalten könnten - also einen Ort aus dem Speichergedächtnis ins Funktionsgedächtnis zurückzuholen ${ }^{98}$. Beide Varianten dieser memorialpolitischen Stoßrichtung hätten zum Ziel, ein europäisches / europaweites Geschichtsbewusstsein in einer versuchsweise stillgestellten Gegenwart abzubilden bzw. zu konstruieren.

93 Vgl. z.B. (statt vieler) Reymer KLÜVER, Obama: Schwieriger Start. Präsident der kleinen Leute, in: Süddeutsche Zeitung, 16.02.2009, S. 2.

94 Im Sinne dieser gegenwartsbezogen-geschichtspolitische Stoßrichtung - die EU durch Markierung positiv konnotierter gemeinsamer Erinnerungsorte mit einem Geschichtsbewusstsein zu suntermauern < - argumentiert Heinz DuchHARdt, La Paix de Westphalie: de l'événement européen au lieu européen de mémoire?, Sigmaringen 1999, S. 25-27.

95 Dagegen wendet sich Esch, Rom, S. 380.

96 Vgl. das Zitat bei Anm. 89.

97 Vgl. Hein-Kircher, Erinnerungsorte, S. 17.

98 Vgl. François' Unterscheidung zwischen einem (historischen) Verständnis Europas als »Erbe« und einem Verständnis Europas als »Projekt« (François, Lieux, S. 292f.). 
Aus Sicht einer historischen Kulturwissenschaft, die ihr Orientierungswissen in der Hinterfragung scheinbar identitätsstiftender Mythen und Traditionen zu gewinnen sucht, wäre es hingegen kein notwendiges Kriterium, ob die Mehrheit der Europäer mit einem Erinnerungsort der Vergangenheit in einer jeweils neu zu bestimmenden Gegenwart etwas anfangen kann. In einem solchen Erkenntnisinteresse sind Erinnerungsorte vergangener Epochen gerade dann untersuchenswert, wenn sie verschüttete Traditionen bergen, die heute nicht mehr aktualisiert werden können und sollen. Eine Fragerichtung zum Herkules-Mythos, die historisches Orientierungswissen vermitteln könnte, wäre vielmehr der hier nur angedeutete $»$ Verschlei $\beta{ }^{99}$ in der zweiten Hälfte der Frühen Neuzeit und seine Trivialisierung im 19. und 20. Jahrhundert.

Das Kriterium der heutigen Präsenz von Erinnerungsorten beiseite zu lassen, entspräche einem Verständnis historischer Wissenschaften, die »nicht mehr historischen Sinn produzieren, sondern vergangenheitsbezogene Sinnbildungsprozesse zu ihrem Thema machen $\aleph^{100}$. Unter europäischen Erinnerungsorten gälte es dann solche Referenzpunkte aufzuspüren, die in der Tat über einen längeren Zeitraum »von den Kulturen der überwiegenden Mehrheit der europäischen Gemeinwesen diskutiert, rezipiert und weiterverarbeitet « wurden ${ }^{101}$. Die Akzeptanz- und Bedeutungsgeschichte eines solchen Ortes könnte durchaus bis an die jeweilige Gegenwart des/der Untersuchenden herangeholt werden. Entscheidend wäre, diese Gegenwart selbst zu historisieren und in Relation zu vorhergehenden Gegenwarten zu setzen. Da es nicht darum ginge, a priori in der Frühen oder Späten Neuzeit eine kollektive Identität über kulturelle Grenzen hinweg festzustellen, wäre es besonders interessant, wie sich die Konnotationen als Ergebnis europaweiter Transferprozesse verschoben und wie die in die Transfers eingebetteten gesellschaftlichen Aushandlungsprozesse verliefen, in denen sich entschied, ob und wie ein Element aus dem »Fundus gesellschaftlicher Erinnerungsanlässe $«^{102} \mathrm{zu}$ einem Erinnerungsort werden konnte. Wie lange man den Zeitraum ansetzt, in dem diese Orte in verschiedenen Sprachen identisch (oder sehr ähnlich) benannt und in den jeweiligen Kulturen mit ähnlichen oder verschiedenen ${ }^{103}$ Grundkonnotationen belegt wurden, wäre zu diskutieren ${ }^{104}$. Auf diesem Wege lie-

99 Sparn, Herkules, S. 82, 91 .

100 SANDL, Erinnerung, S. 113 (Originalzitat im Singular).

101 Duchhardt, Westfälischer Friede, S. 403.

102 Eine Formulierung von Martin Zierold (Gießen) auf einem Workshop des Instituts für Europäische Geschichte zum Thema »Europäische Erinnerungsräume«, Mainz 08./09.01.2009.

103 Laut Esch gibt es kaum Erinnerungsorte, in denen »die nationale und die europäische Perspektive weitgehend zur Deckung kommen können. Das schafft nur Rom.« Esch, Rom, S. 384.

104 Alaida Assmann argumentiert, dass $»[i] m$ Medium symbolischer Kommemoration [...] Erinnerungen über die Generationenschwelle hinweg stabilisiert werden können«, so dass sich mehrere Generationen auf gemeinsame Erinnerungen »verpflichten« können. Assmann, Europa, S. 26. 
ßen sich nicht $>$ die< europäischen Erinnerungsorte ermitteln, sondern lediglich eine Auswahl, die in einem bestimmten Zeitraum die Funktion von Erinnerungsorten einnahm, sie dann verlor und bisweilen später wiedergewann - in den verschiedenen Gesellschaften Europas mit ihren Teilöffentlichkeiten und (v.a. ästhetischen) Eigenlogiken jeweils zu verschiedenen Zeitpunkten und meist aus unterschiedlichen Gründen. Gegenstand wäre der Blick vieler >historischer Gegenwarten` auf ihre jeweilige(n) Vergangenheit(en). Aus diesen erfundenen, neu konstruierten, verblassenden, verschwundenen, wiederentdeckten oder aktualisierten Topoi wäre ebenso eine Auswahl zu treffen, und auch hier nicht nur forschungspragmatisch, sondern nach normativen Kriterien, die offenzulegen wären. Eine solche Auswahl würde jedoch keinen über Zeit und Raum allgemeingültigen Anspruch stellen und ließe sich daher geschichtspolitisch schwerer instrumentalisieren.

\section{»Lieux de mémoire« und europäische Identität(en)}

Die unterschiedlichen Aneignungen des Herkules-Mythos in der Frühen Neuzeit sind ein Beispiel für »Einheit und Vielfalt« in Europa. Dazu könnte man wahrscheinlich jedes Phänomen der europäischen Geschichte rechnen. Was trägt die Fragestellung dieses Beitrags darüber hinaus zu einer Sozial- und Kulturgeschichte der auf Europa bezogenen Ideen bei, also der Geschichte der Europa-Vorstellungen und Europa-Bilder? Kann oder soll die Erforschung europäischer »lieux de mémoire « »Reaktionen auf den angedachten bzw. sich faktisch vollziehenden Europäisierungsprozess « nachvollziehen helfen? In anderen Worten: Reflektiert die Präsenz derselben Erinnerungstopoi in verschiedenen europäischen Kulturen, dass sich die Zeitgenossen der jeweiligen innereuropäischen Verflechtungen bewusst waren und sich Wertvorstellungen verpflichtet fühlten, die sie gemeinsam und/oder als spezifisch >europäisch $<$ verstanden ${ }^{105}$ ?

In der Frühen und Späten Neuzeit waren in allen europäischen Kulturen bestimmte Denkfiguren als Erinnerungstopoi präsent. Als Belege für ein Europabewusstsein oder gar eine kollektive europäische Identität können sie jedoch nur bedingt herangezogen werden, aus zwei Gründen:

105 Diesen Anspruch erhebt z.B. Heinz Duchhardt mit der Einbindung des Projekts »Europäische lieux de mémoire« in den Forschungsbereich »Europa als Herausforderung für Politik, Gesellschaft und Kirche« des Instituts für Europäische Geschichte. Zitat: [Heinz Duchhardt / Małgorzata MoRAwIEC / Rainer VINKE]: Forschungsbereich »Europa als Herausforderung für Politik, Gesellschaft und Kirche«, in: Institut für Europäische Geschichte, Mainz: Forschungsbereiche, URL: http://www.ieg-mainz.de/likecms/index.php?site=site.htm\&dir=\&nav=168 (eingesehen am 08.02.2009). 
1. Die Zeitgenossen, also die jeweiligen Erinnerungsakteure und Erinnerungsträger, setzten diese Topoi selten mit »Europa« in Verbindung - also mit dem Kontinent als kulturell konstruierter Kategorie, die sich in politischen, religiösen, geographischen, künstlerisch-wissenschaftlichen, gesellschaftlichen Zusammenhängen manifestierte. Beispiel Herkules: Als Held zwischen Tugend und Hybris war er in der Frühen Neuzeit zwar insofern ein »europäischer« Erinnerungstopos, als er in ganz Europa präsent war. Er wurde jedoch in den meisten Adaptionen nicht mit Europa als kultureller Kategorie verbunden ${ }^{106}$ - wer von Herkules sprach (oder ihn in künstlerischen Medien auftreten ließ), hatte weder automatisch ein bestimmtes Europabild im Kopf noch formulierte er ein solches explizit. Eine Ausnahme bilden möglicherweise die »Säulen des Herkules « ${ }^{107}$. Wohl die wenigsten europäischen Erinnerungstopoi waren direkt auf Gestalt, Grenzen, >Wesen` Europas oder sonstige Repräsentationen des Kontinents bezogen. Auf diesen Fundus wird man sich wohl nicht beschränken wollen.

2. Europäische Erinnerungsorte können eine gemeineuropäische Erfahrung ausdrücken, derer sich die europäischen Gesellschaften in der Regel in ganz unterschiedlichen Ausprägungen erinnern. Diejenigen, die eine in ganz Europa verbreitete Denkfigur evozierten, thematisierten selten, dass diese Figur eine gemeineuropäische war und diese Verbreitung war der Mehrzahl von ihnen auch nicht bewusst. Diese These ließe sich durch systematische Quellenstudien an Ego-Dokumenten der Frühen und Späten Neuzeit falsifizieren. Solange diese nicht vorliegen, sei sie zumindest für jene Milieus und Stände aufrechterhalten, die nicht den gebildeten bzw. gelehrten Eliten angehörten.

Aufschlussreich für die Geschichte Europas als Kommunikationsraum sind weniger die gemeinsamen als vielmehr die »geteilten Erinnerungsorte«:

Orte des Konflikts und der Wechselwirkung, die durch trennende Identifikationsangebote und unterschiedliche Aneignungen gekennzeichnet sind und an denen sich die europäischen Gedächtniskulturen scheiden und gegenseitig bestimmen ${ }^{108}$.

106 »Eine Gedächtniskultur, die sich an Wort oder Idee Europa festmachte, existierte allenfalls temporär, situations- und ortsbezogen, nie durchgehend oder mit integrativer Kraft «. Bernd SCHNEIDMÜLLER, Europäische Erinnerungsorte im Mittelalter, in: Jahrbuch für Europäische Geschichte 3 (2002), S. 39-58, Zitat S. 45.

107 Sie finden sich im spanischen Staatswappen, im Wappen Andalusiens (seit 1918) und zuvor bereits im Stadtwappen von Cádiz, wo Herkules mit zwei Löwen erscheint, die die Berge Abyla (in Afrika) und Calpa (auf der iberischen Halbinsel) respräsentieren. Für diese Hinweise danke ich Thomas Weller (Mainz).

108 FrançoIs, Lieux, S. 295. 
Nach diesen Wechselwirkungen zu fragen, entspräche einem Erkenntnisinteresse, die Erfahrungen kultureller Differenzen sichtbar zu machen, die die Geschichte Europas seit dem Spätmittelalter nicht weniger prägten als die Erfahrungen von Gemeinsamkeiten ${ }^{109}$. Europäische Erinnerungsorte wären demnach Ausdrucksformen nicht des »gedachten Europa« oder des »vereinbarten Europa «, sondern des »gelebten Europa $« " 110$.

109 LotTes, Erinnerungsorte, S. 86: »[D]ie einzige gesamteuropäische Erfahrung [ist] diejenige der Nicht-Einheit, diejenige des Gegeneinanders und des Konfliks, diejenige der Differenzierung«.

110 Jost DüLFFER, Europäische Zeitgeschichte - Narrative und historiographische Perspektiven, in: Zeithistorische Forschungen/Studies in Contemporary History, Online Ausgabe 1 (2004) 3, URL: http://www.zeithistorische-forschungen.de/16126041-Duelffer-1-2004 (eingesehen am 06.04.2008), hier: Abb. 4; Klaus SchÖNHоven, Europa als Erinnerungsgemeinschaft. Abschiedsvorlesung an der Sozialwissenschaftlichen Fakultät der Universität Mannheim am 13. September 2007, Bonn 2007, S. 5. 


\title{
Elisabeth Oy-Marra
}

\section{Der Papst als neuer Aeneas}

\author{
Rom als >caput mundi und die Herrschaftsansprüche \\ der Päpste in der Frühen Neuzeit
}

Der Prozess der Zentrenbildung im frühneuzeitlichen Europa ist bekanntlich komplex - ganz gleich aus welcher Perspektive er betrachtet wird. Dabei konvergierten politische, wirtschaftliche und künstlerische Zentren nur selten. Vielmehr bildete die Politik eine andere Topografie heraus als die Wirtschaft. Selbst die Zentrenbildung in der Kunst folgte häufig einer eigenen Logik, auch wenn Zentren der Kunst auf jene der Wirtschaft und Politik wechselseitig angewiesen waren. Rom stellte in diesem Prozess in vieler Hinsicht eine Ausnahme dar. Als Zentrum der katholischen Kirche und des Kirchenstaates hatte es eine fast überzeitlich zu nennende, herausgehobene Stellung inne, die der Stadt eine Anziehungskraft verlieh, welche in Europa ihresgleichen suchte. Diese ließ sich vor allem auf die antike Autorität des Ortes zurückführen: als Stadt der Kaiser und Apostel war sie Kulminationspunkt der heidnischen und christlichen Geschichte und stand im Fluchtpunkt Europas, weil sie sich als politischer und kultureller Ursprung des modernen Europa und Mittelpunkt der Christenheit verstand und damit den Anspruch verband, auch in nachantiker Zeit >caput mundi< zu sein. Von Padua bis Bamberg legitimierten sich mittelalterliche Städte frei nach dem Vorbild Konstantinopels als zweites Rom, als Ableger und Kopie, ein Unterfangen, das dem »Original am Tiber« nur noch größere Autorität verlieh, und dies gerade nicht aufgrund der Macht einzelner Päpste, sondern trotz deren Ohnmacht. Zwar war die Autorität des Papstes als Oberhaupt der christlichen Kirche von besonderer Strahlkraft, doch würde man es sich zu einfach machen zu glauben, Rom verdanke seine Anziehungskraft bis ins 18. Jahrhundert hinein allein der Verbindung von antiker und katholischer Autorität.

Gérard Labrot hat die Mechanismen untersucht, die das Bild vom Rom als >caput mundi< über eine so lange Zeit haben wirksam sein lassen, und hat zeigen können, von welch großer Bedeutung hierfür die Zeit der katholischen Reform und ihrer Konsolidierung im Zeitraum zwischen der Wahl Pauls III. Farnese im Jahr 1534 und dem Tod Alexanders VII. Chigi 1667 gewesen ist. In dieser Zeit wandelte sich die vom Sacco di Roma 1527 in ihren Grundfesten erschütterte Stadt, stieg wie ein Phönix aus der Asche und wurde zu einem neuen Zentrum der Christenheit, das Menschen aus allen 
Nationen Europas wie ein Magnet anzog' ${ }^{1}$ Dieser Prozess war nicht zuletzt an die Neuinszenierung geschichtsträchtiger und heiliger Orte innerhalb der Stadt gebunden, von denen Rom besonders viele vorzuweisen hatte und hat ${ }^{2}$. Die auf diese Weise erfahrbar gemachte Autorität dieser Orte begünstigte die besondere Anziehungskraft der Stadt in Europa und verschaffte ihr eine Sonderstellung, die sie wiederum zu einem Modell auch für andere Zentren wie allen voran Paris und Wien werden ließ $3^{3}$.

Die Betonung der geschichtsträchtigen Orte mag in Rom als eine naheliegende, vielleicht sogar selbstverständliche Strategie erscheinen. In der Tat zeugten in kaum einer anderen Stadt die materiellen Reste von Antike und Christentum von der antiken Geschichte, deren Bedeutung für den translatio imperii-Gedanken der Päpste wie der Kaiser nicht hoch genug eingeschätzt werden kann ${ }^{4}$. Doch es wäre ein Trugschluss zu glauben, die materielle Präsenz allein habe genügt, die Legitimation der Päpste und der römisch-katholischen Kirche über die Jahrhunderte zu sichern. Hatten die Päpste der Renaissance noch vornehmlich ihre antike Autorität zur Schau gestellt, erinnert sei in diesem Zusammenhang an den Hof des Belvedere mit seinen antiken Statuen, den Julius II. im Vatikan errichten lie $\beta^{5}$, so mussten die Päpste der katholischen Reform und die neu gegründeten Orden ein verändertes Begründungsmodell ersinnen, denn der Verweis auf die heidnische Antike allein konnte ihre Autorität nicht mehr länger untermauern ${ }^{6}$. Im Gegenteil liefen sie vielmehr Gefahr, diese sogar zu verlieren. Gleichwohl wäre es viel zu kurz gegriffen zu glauben, die Päpste hätten sich allein auf ihre Glaubensautorität und auf die Restaurierungen von frühchristlichen Kirchenbauten beschränkt. Obgleich die weltliche Autorität des Papstes als Fürst des Kirchenstaates seit Paul III. von dem eigens hierfür ernannten Kardinalnepoten ausgeübt wurde, ein - wie Wolfgang Reinhard gezeigt hat - geschickter Schachzug,

1 Gérard Laвrot, Roma caput mundi. L'immagine barocca della città santa 1534-1677, Napoli 1997.

2 Vgl. hierzu vor allem die zahlreichen Restaurierungscampagnen frühchristlicher Kirchen und die hierbei hervorgehobenen Kultstätten.

3 Vgl. hierzu zuletzt: Dietrich Erben, Paris und Rom. Die staatlich gelenkten Kunstbeziehungen unter Ludwig XIV., Berlin 2004; zur Stadtplanung vgl. Peter StePhan, Rom unter Sixtus V. Stadtplanung als Vergegenwärtigung von Heilsgeschichte, in: Zeitschrift für Kunstgeschichte 72 (2009), S. 165-214; Dorothy Metzger Habel; The urban development of Rome in the age of Alexander VII, Cambridge 2002.

4 Gérard Labrot, Roma caput mundi. L'immagine barocca della città santa 1534-1677, Napoli 1997.

5 Vgl. z.B. Hans Henrik Brummer, On the Julian program of the Cortile delle Statue in the Vatican Belvedere, in: Matthias Winner (Hg.), Il Cortile delle Statue - der Statuenhof des Belvedere im Vatikan, Mainz 1998, S. 67-76.

6 Vgl. hierzu z.B.: Volker Reinhardt, Moses und der Gekreuzigte. Zur Funktion päpstlicher Kunstbeauftragung und Selbstdarstellung unter Julius II. und Urban VIII., in: August BuCK (Hg.), Höfischer Humanismus, Weinheim 1989, S. 133-160. 
um das Bild des Papstes als Oberhaupt der katholischen Kirche und »padre comune« der katholischen Fürsten nicht zu gefährden ${ }^{7}$, war der Anspruch der Päpste, auch als weltliche Fürsten wahrgenommen zu werden, keineswegs erloschen. Hierzu bedurfte es jedoch neuer Bilder. Nicht der Rekurs auf die antiken Kaiser stand nunmehr im Vordergrund, sondern die Rückbesinnung auf eine der bedeutendsten Gründungslegenden Europas: der Aeneis des römischen Dichters Vergil. Es würde an dieser Stelle zu weit führen, die komplexe und in ganz Europa weit verbreitete Rezeption der Aeneis auch nur andeutend zu referieren. Sie war das wichtigste Modell sowohl mittelalterlicher als auch frühneuzeitlicher Epen, ihr Held Aeneas diente unzähligen Kriegern als Exemplum ${ }^{8}$. Dennoch gehört der Bezug auf den Helden und dessen Irrfahrten nicht so sehr zum Standardrepertoire europäischer Fürsten, wie es vielleicht zu vermuten wäre. In Rom lag der Rekurs auf Aeneas naturgemäß nahe, doch seine direkte Inanspruchnahme lässt sich in den monumentalen Bildprogrammen Roms erst seit der Mitte der Renaissance beobachten. Wie im Folgenden gezeigt wird, avancierte die Aeneis insbesondere in der bildlichen Repräsentation der Päpste zu einem Modell, mithilfe dessen sie ihren weltlichen Herrschaftsanspruch zum Ausdruck brachten. Dabei lag der Tenor nur noch zum Teil auf dem vorbildlichen Helden Aeneas, nicht selten wurde Aeneas auch als Gründerfigur verstanden und mit einem aus der Geschichte des Ortes abgeleiteten Herrschaftsanspruch Roms als zweites Troja verwoben. Der Anspruch allein hätte wohl kaum eine Wirkung gezeigt. Erst seine entsprechende Umsetzung in die Malerei und Plastik und die mit diesen Künsten verbundenen ästhetischen Konzepte haben es vermocht, Aufmerksamkeit auch in anderen Machtzentren, wie in Wien und Paris, zu erregen und den Mythos zu aktualisieren.

Bereits in der Renaissance lässt sich eine, wenn auch stark assoziative Parallelisierung der römischen Kirche mit dem Mythos Roms als neuem Troja beobachten. In Raffaels Fresko des Borgobrandes in der Stanza dell'Incendio des Vatikans (vgl. Abb. 1) wird dem Brand im Vordergrund der segnende

7 Wolfgang ReinHard, Nepotismus. Zum Funktionswandel einer papstgeschichtlichen Konstante, in: Zeitschrift für Kirchengeschichte 86 (1975), S. 145-185.

$8 \mathrm{Zu}$ den Vergildeutungen vgl. Craig Kallendorf, In Praise of Aeneas. Virgil and Epideictic Rhetoric in the Early Renaissance, Hanover / London 1989; ders., Vergil and the myth of Venice. Books and Readers in the Italian Renaissance, Oxford 1999 und ders., Virgil's post-classical legacy, in: The Virgilian tradition: book history and the history of reading in early modern Europe, Aldershot u.a. 2007, S. IV, 574-587. In der Malerei vgl. beispielsweise: Keith CHRIStiansen, Dosso Dossi's Aeneas frieze for Alfonso d'Este's »camerino«, in: Apollo 151 (2000), S. 36-45; Michael JAFFÉ, Rubens's Aeneas cartoons at Cardiff, in: The Burlington magazine 125 (1983), S. 136-151; grundsätzlich: Gerhard BINDER, Der brauchbare Held: Aeneas: Stationen der Funktionalisierung eines Ursprungsmythos, in: Hans-Jürgen HoRN / Hermann WaLTeR (Hg.), Die Allegorese des antiken Mythos, Wiesbaden 1997, S. 311-330. 
Papst Leo IV. in der Benediktionsloggia von Sankt Peter gegenübergestellt ${ }^{9}$. Nun bezieht sich die Darstellung des Borgobrandes nicht eigentlich auf den Brand Trojas, doch die von Raffael am linken Bildrand dargestellte Figurengruppe, ein junger kräftiger Mann, der einen alten auf seinen Schultern trägt, und ein Kind, das die beiden begleitet, stellt unmissverständlich den Bezug zum brennenden Troja her, aus dem der vom Sohn begleitete Aeneas, seinen Vater Anchises auf den Schultern, gerettet haben soll. Schon hier lässt sich der in der Benediktionsloggia stehende Leo IV. als zweiter Aeneas, die römische Kirche als neues Troja deuten. Zu berücksichtigen ist dabei, dass die Parallelisierung des Papstes mit Aeneas nicht Leo IV., sondern dem Auftraggeber des Freskos, dem Medicipapst Leo X. (1513-1521), galt.

Anknüpfend an dieses traditionsstiftende Fresko verstand sich auch Paul III. (1534-1549) Farnese als Nachfahre des Vergilschen Helden. In der von Francesco Salviati ausgemalten >Sala dei fasti farnesiani< des Palazzo Farnese werden in der Mitte der beiden Längswände Aeneas und Paul III. als zentrale Figuren hervorgehoben und einander gegenübergestellt (vgl. Abb. 2 und 3). Hintergrund für diese besondere Hervorhebung des antiken Helden ist hier seine post festum konstruierte Wahl zum mythischen Gründervater der Farnese, der in den Bildern in zweifacher Hinsicht betont wird. Zum einen dient er hier als Exemplum für die bedeutenden Feldherren der Dynastie, Ranuccio und Pietro Farnese, die bei der Investitur bzw. im Kampf gezeigt werden. Zum anderen wird seine Stellung als Gründerfigur und historische Parallele, auf die sich Paul III. ganz offenbar als Papst beruft, durch die in der Gegenüberstellung zum Papst angedeuteten Parallelisierung zum Ausdruck gebracht $t^{10}$.

Erst der Kardinalnepot Pauls V., Scipione Borghese, griff wieder auf die Figur des Aeneas zurück, und beauftragte 1619 Bernini mit einer Statue des seinen Vater Anchises auf den Schultern tragenden Aeneas für seine »Galleria« der Villa Borghese auf dem Pincio (Abb. 4) ${ }^{11}$. Wie Rudolf Preimesberger gezeigt hat, handelt es sich bei dieser Skulpturengruppe jedoch nicht so sehr um einen allegorischen Bezug auf Papst Paul V., sondern um eines der Sinnbilder für den Kardinalnepoten Scipione Borghese ${ }^{12}$. Die Figur des Aeneas

9 Hierzu vgl. Rolf Quednau, Päpstliches Geschichtsdenken und seine Verbildlichung in der Stanza dell'Incendio, in: Münchner Jahrbuch der bildenden Kunst 3.F. 35 (1984), S. 83-128; und zuletzt: Michael Rohlmann, Gemalte Prophetie: Papstpolitik und Familienpropaganda im Bildsystem von Raffael's »Stanza dell'Incendio«, in: Götz-Rüdiger Tewes / Michael RohlmanN (Hg.), Der Medici-Papst Leo X. und Frankreich: Politik, Kultur und Familiengeschichte in der europäischen Renaissance, Tübingen 2002, S. 241-371.

10 Julian Kliemann, Gesta dipinte. La grande decorazione nelle dimore italiane dal Quattrocento al Seicento, Mailand 1993; Catherine Monbeig-Goguel, Palazzo Farnese: Sala dei Fasti Farnesiani, in: Anna Coliva (Hg.), Francesco Salviati: affreschi romani, Mailand 1998, S. 76-87.

11 Rudolf Preimesberger, Pignus imperii: ein Beitrag zu Berninis Aeneasgruppe, in: Friedrich Piel / Jörg Träger (Hg.), Festschrift Wolfgang Braunfels, Tübingen 1977, S. 315-325. 
eignete sich insofern hierfür, als Aeneas eine große Pietas zugeschrieben wurde, denn er hatte Vater und Sohn, Anchises und Ascanius, nicht im brennenden Troja zurückgelassen, sondern sie aus der brennenden Stadt uneigennützig gerettet. Der symbolische Bezug wurde also über die Pietät und Stärke des Helden hergestellt, so dass eine Parallele gezogen werden konnte zum Selbstverständnis des Kardinalnepoten, der seine Stellung ganz aus der tatkräftigen Unterstützung des Papstes legitimierte ${ }^{13}$. Genau diesen Aspekt der Unterstützung hob Bernini in seiner Skulptur besonders hervor, indem er den alternden Körper Anchises, dem der muskulöse Körper des Aeneas eine sichere Stütze bietet, auf eindrucksvolle Weise darstellte.

Schon kurz darauf rekurrierte auch Urban VIII. auf das Vergilsche Epos. Doch wird in den häufig impliziten Anspielungen auf die Aeneis in den umfangreichen panegyrischen Schriften und Impresen weniger auf die Figur des Helden Aeneas Bezug genommen. Vielmehr steht schon zu Beginn seines Pontifikats in der mit den Wappenzeichen der Bienen kombinierten Lorbeerimprese die Gründungslegende selbst im Vordergrund. In all seinen Anspielungen nachweisbar ist dieser Rekurs zum ersten Mal in den von Giovanni Ferro im Wahljahr des Papstes 1623 prachtvoll publizierten Impresen.

Urban VIII. Barberini war vielleicht der erste und einzige Papst in der Zeitspanne von 1534 bis 1667, dessen mäzenatische Aktivitäten auf eine neue Synthese des frühchristlich geprägten antiken und des modernen profanen Rom zielten. Er bemühte sich sowohl um die Restaurierung frühchristlicher Kirchen, als auch um die Integration der weltlichen Repräsentation in das sich allmählich formierende Bild des neuen, magnifizenten Rom ${ }^{14}$. Bereits zu Beginn seines Pontifikates ließ er sowohl die alte Märtyrerkirche der heiligen Bibiana von Bernini restaurieren ${ }^{15}$, als auch den Baldachin über dem Petrusgrabmal in Sankt Peter vom gleichen Bildhauer errichten ${ }^{16}$. Hierin folgte er noch dem Beispiel seiner Vorgänger, die sich ebenso um den Neubau von Sankt Peter und die Restaurierung frühchristlicher Kirchen verdient gemacht

12 Aeneas war nicht das einzige Sinnbild für die Bedeutung des Kardinalnepoten. Hierzu zählte auch Herkules und Atlas. Vgl. hierzu Cesare D'OnOFrio, La villa Aldobrandini di Frascati, Rom 1963, S. 120f.

13 Zum Selbstverständnis des Kardnialnepoten vgl. Reinhard, Nepotismus.

$14 \mathrm{Zu}$ Urban VIII. vgl. allgemein Ludwig von PASTOR, Geschichte der Päpste seit dem Ausgang des Mittelalters, Bd. 13, I, Freiburg 1960, S. 882-980; Francis Haskell, Maler und Auftraggeber. Kultur und Gesellschaft im italienischen Barock, Köln 1996, S. 73-76; Georg Lutz, Urban VIII., in: Enciclopedia dei papi, 3 Bde., Rom 2000, hier: Bd. 2, S. 298-321; zur Familie zuletzt: Lorenza Mocchi OnORI / Sebastian SchüTZE / Francesco Solinas, I Barberini e la cultura europea del Seicento, Rom 2007.

15 Jörg Martin Merz, Pietro da Cortona, Der Aufstieg zum führenden Maler im barocken Rom, Tübingen 1991, S. 113-139.

16 Sebastian SchÜtze, Urbano inalza Pietro, e Pietro Urbano. Beobachtungen zu Idee und Gestalt der Ausstattung von Neu-Skt. Peter unter Urban VIII., in: Römisches Jahrbuch der Bibliotheca Hertziana 29 (1994), S. 213-288. 
hatten. Anders als diese lag ihm jedoch an einer neuen und deutlichen Visualisierung des zweigestaltigen Regiments des Papstes. Der Ankauf des alten Palazzo Sforza, der durch die Architekten Maderno, Bernini und Borromini in kurzer Zeit zu einem neuen Familienpalast der Barberini restauriert und erweitert werden sollte, hob den Familiensitz nicht nur gegenüber anderen besonders hervor ${ }^{17}$. Zwei große aufsehenerregende Deckenfresken von Andrea Sacchi (vgl. Abb. 5) und Pietro da Cortona (vgl. Abb. 6) verliehen dem Palast nicht nur vielbeachtete Attraktionen, vielmehr werden in ihren Bildprogrammen Zusammenhänge dargestellt, die auf die Legitimität des Papstes als weltlicher Herrscher zielen ${ }^{18}$. Mit diesen Monumenten, dem Baldachin von Sankt Peter auf der einen und den Deckenfresken des Palazzo Barberini auf der anderen Seite war daher ein visuelles Netz auf die Stadt gelegt, das die sakrale und weltliche Herrschaft des Barberini-Papstes als eine Verbindung der zweigestaltigen Herrschaft des Papstes als Oberhaupt der katholischen Kirche und Oberhaupt einer Familie zum Ausdruck brachte und eines mit dem anderen zu verbinden suchte.

Die visuelle Kraft dieser Werke ist dabei weniger neuen Einsichten geschuldet als vielmehr einer bisher noch nie so gestalteten Synthese von sacro e profano, die den Papst sowohl in seiner Rolle als "padre comune« als auch in jener des solaren Herrschers inszeniert, auch wenn er nicht der eigentliche Akteur und »spiritus rector« gewesen sein dürfte, sondern der Kardinalnepot Francesco Barberini, der seine Person der Repräsentation des Papstbildes konsequent unterordnete ${ }^{19}$. In den Fresken Andrea Sacchis und Pietro da Cortonas kommen interessanterweise jedoch keine genuin profanen Themen zum Zuge, sondern eine christliche Geschichtsauffassung, die mit antiken Vorstellungen verquickt wird. Dabei wird vor allem der historische Ort Rom und pars pro toto der Palast in die visuelle Argumentation mit einbezogen.

Wie ein Paukenschlag überrascht das Fresko der »Göttlichen Weisheit« von Andrea Sacchi (vgl. Abb. 5) von 1629/30 seine Betrachter, indem es die Göttliche Weisheit in einen direkten Zusammenhang mit Europa und dem Palast als Wirkungsstätten stellt ${ }^{20}$. Nicht das traditionell bekannte Haus der Weisheit mit seinen sieben Säulen ist hier zu sehen ${ }^{21}$, sondern die majestätisch

17 Zum Palast vgl. Patricia WAdDy, Seventeenth Century roman Palaces: Use and the Art of the Plan, Cambridge Mass. / London 1990.

$18 \mathrm{Zu}$ den Fresken vgl. Merz, Pietro da Cortona; John Beldon Scott, Images of Nepotism. The Painted Ceilings of Palazzo Barberini, Princeton 1991 und Elisabeth Oy-MARra, Profane Repräsentationskunst in Rom von Clemens VIII. Aldobrandini bis Alexander VII. Chigi. Studien zu Funktion und Semantik römischer Deckenfresken im höfischen Kontext, Berlin 2005, S. 199-202 und 211-273.

19 Zu Francesco Barberini vgl. Birgit Eмich, Kardinal Francesco Barberini. Ein Papstneffe zwischen Kunst und Politik, in: Mochi Onori / Schütze / Solinas, Barberini, S. 111-116.

20 Scott, Nepotism, S. 38-67; Oy-Marra, Repräsentationskunst, S. 211-229. 
von ihren Tugenden umgebene, vor der aufgehenden Sonne über Europa thronende Weisheit, die ihre Strahlen auf Rom und den Palast selbst richtet.

Damit wird ein himmlisch-kosmischer Zusammenhang von göttlicher Weisheit und dem Wirken Urbans VIII. im Zentrum Europas hergestellt ${ }^{22}$, der im benachbarten Deckenfresko von Pietro da Cortona noch eine Vertiefung erfährt. Hier ist es die personifizierte »Göttliche Vorsehung« (vgl. Abb. 6), die in der von Chronos und den Parzen personifizierten Geschichte wirkt und ihren Lauf als Regentin vorherbestimmt ${ }^{23}$. Ihr Wille erfüllt sich, wie könnte es anders sein, den Bildern zufolge im historischen Moment der Wahl Maffeo Barberinis zu Papst Urbans VIII., der jedoch nicht eigentlich dargestellt ist. Dass seine Wahl bereits erfolgt sein muss, das können wir an seinem Wappen allerdings unmissverständlich erkennen, denn es wird durch die päpstlichen Schlüsselinsignien bekrönt ${ }^{24}$. Die Gegenüberstellung von göttlicher Vorsehung und päpstlichem Wappen stellt damit eine Verbindung von göttlicher Ratio und faktischer Ereignisgeschichte her, die sich im Bild wie in einem visionären Augenblick dem Betrachter erschließt. Über diese Bedeutungsebene hinaus spielt das Wappen bekanntlich jedoch noch auf eine weitere Geschichtskonstruktion an, die die göttliche Vorsehung mit einer der mächtigsten historischen Gründungslegenden Roms überblendet: die Gründung Roms durch den trojanischen Helden Aeneas, von der Vergil in der Aeneis erzählt. Nun ist der Held im Fresko nicht eigens dargestellt, vielmehr lässt sich dieser Bezug nur über ein leicht zu übersehendes Detail erkennen. Die von den Kardinaltugenden in der Schwebe gehaltene Lorbeerumkränzung des päpstlichen Wappens spielt nämlich auf eine Imprese des Papstes aus Giovanni Ferros: »Il teatro delle Imprese« an, in der Bienen in einem Lorbeerbaum dargestellt sind und die die Beischrift: »Hic Domus « trägt (vgl. Abb. 7) ${ }^{25}$. Ferro rekurriert in dieser Imprese auf die Erzählung des VII.

21 Zur Bildtradition der biblischen Vorstellung eines Hauses der Weisheit vgl. Katharina BAHLMANn / Mechthild Dreyer, Wissensarchitekturen, in: Katharina Bahlmann / Elisabeth OYMarra / Cornelia Schneider, Gewußt wo! Wissen schafft Räume. Die Verortung des Denkens im Spiegel der Druckgraphik, Berlin 2008, S. 150-155.

22 In der 1642 publizierten Palastbeschreibung der Aedes Barberinae von Girolamo Teti wird ein direkter Bezug zwischen der göttlichen Weisheit und Urban VIII. hergestellt, indem beschrieben wird, wie Urban VIII. unter dem Fresko die entsprechende Bibelstelle liest. Hierzu vgl. Hieronymus Tetius, Aedes Barberinae ad Quirinalem descriptae. Descrizione di Palazzo Barberini al Quirinale, hg. v. Lucia Faedo / Thomas Frangenderg, Pisa 2005, S. 323-341; OyMARRA, Repräsentationskunst, S. 211-220.

23 Hubert Locher, Das Staunen des Betrachters. Pietro da Cortonas Deckenfresko im Palazzo Barberini, in: Hans-Joachim Kunst (Hg.), Werners Kunstgeschichte, Worms 1990, S. 1-46; Merz, Pietro da Cortona, S. 235-270; Scott, Nepotism, S. 135-179; Oy-MARra, Repräsentationskunst, S. 229-273.

24 Zur Deutung des Wappens vgl. Walter Viтzтнuм, A comment on the Iconography of Pietro's da Cortona's Barberini Ceiling, in: The Burlington Magazine 102 (1960), S. 75f. 
Buches der Aeneis, in dem König Latinus einen Bienenschwarm im heiligen Lorbeerbaum beobachtet und ihn als Zeichnen der Vorsehung erkennt. Dieses Bild kombiniert Ferro mit der Inschrift `Hic Domus`, aus Aeneis VII, 122-123, wo es heißt: >Hic Domus, hoc patria est $\iota$, dem Ausspruch also, den Vergil Aeneas bei seiner Landung an der italischen Küste in den Mund legt und damit anzeigt, dass der Held Italien als neue Heimat erkannt hat. Schon in dieser Imprese wird Urban VIII. mit dem Helden Aeneas, dem mythischen Gründervater Roms, als ein von der göttlichen Vorsehung erwählter Akteur der Geschichte verglichen. Aber erst im Fresko wird ein Bezug zu Maffeo Barberini als Papst hergestellt, denn die Wappenzeichen werden nicht nur von einem Lorbeerkranz umgeben, sondern auch von den päpstlichen Insignien gekrönt. Die Lorbeerumkränzung des zentral im Deckenfresko Cortonas dargestellte Wappen spielt dagegen auf die Imprese und den damit verbundenen Bezug auf Aeneas an und obgleich die Beischrift »Hic Domus« im Fresko nicht dargestellt ist, so ist sie im Ort des Geschehens, im Palast selbst, implizit. Die Bienen im Lorbeer erschienen im Palast der Barberini, wodurch der Palast selbst zum »Hic Domus«, zum Ort der sich erfüllenden Weissagung, wird. In dieser Überblendung von Wappenzeichen und Imprese, kommt sozusagen die Ereignisgeschichte, die Urban VIII. auf den Thron Petri gebracht hat, nach dem Muster des Vergilschen Epos an ihr Ziel. Über das Bild des Papstes als zweiter Aeneas wird daher ein Bezug zur Gründungslegende Roms hergestellt und damit ein Geltungsanspruch vorgetragen, der auf nichts weniger als auf die Legitimation der päpstlichen Hoheit über das weltliche Rom als Ursprungsort Europas zielt.

Aeneas wird den Gründerfiguren der Kirche hinzugesellt, nicht um Petrus zu schwächen oder gar zu relativieren, sondern um dem Herrschaftsauftrag des Papstes eine historische Parallele zu verleihen, die gleichsam aktualisiert wird. Gleichwohl wird durch diese Art des Rekurses auf die Gründung Roms der Held Aeneas dem kirchlichen Gründervater Petrus gegenübergestellt.

Dieser im Fresko Cortonas im Palazzo Barberini angedeutete Bezug auf das Gründungsepos der Aeneis kommt ganz ohne Bezug auf die Darstellung der Figur des Helden Aeneas aus ${ }^{26}$. Tatsächlich steht in der Panegyrik und den hieraus entwickelten Bildern Urbans VIII. nicht der antike Held selbst im Vordergrund, sondern allein das ihm symbolisch zur Kenntnis gebrachte Ende seiner Irrfahrt und damit die bevorstehende Gründung Roms als neues Troja. Der in der Imprese über die Wappenzeichen der Bienen und den Lorbeer hergestellte, hoch gelehrte allegorische Bezug, tritt dem Betrachter im

25 Giovanni Ferro, Il Teatro delle Imprese, Venezia 1623, S. 72.

26 Die Lorbeerimprese ist nicht der einzige Bezug auf die Aeneis im Fresko. Auf den Längsseiten der Wölbung ist sowohl die Schmiede des Vulkan, vor allem aber die Schließung des Janustempels zu sehen, die auf die Jupiterprophetie des ersten Buches (I, 291-296) Bezug nimmt. Hierzu vgl. Oy-MARRA, Repräsentationskunst, S. 239. 
Zentrum des großen Saals im Palazzo Barberini in dem lorbeerumkränzten, von Cortona schwebend dargestellten Wappen bildmächtig entgegen. Erst diese Umsetzung, deren ästhetisches Kalkül ganz auf die plötzliche Vergegenwärtigung von bereits bekannten Zusammenhängen angelegt ist, verlieh dem Concetto seine Überzeugungskraft. Die gleichsam sich vor den Augen des Betrachters im Haus der Barberini erfüllende Geschichte beschwört die »hic et nunc« sich ereignende Aktualisierung des antiken Gründungsmythos.

Trotz des tiefgreifenden Misstrauens, das der Nachfolger Urbans VIII. auf dem päpstlichen Stuhl, Innozenz X. (1644-1655), seinem Vorgänger entgegenbrachte, beauftragte auch dieser Papst den gleichen Maler 1651 für die Ausmalung der Galerie in seinem Familienpalast an der Piazza Navona ${ }^{27}$. Interessanterweise fiel seine Wahl bei der Suche nach einem geeigneten Stoff auf die Aeneis. Anders jedoch als im Palazzo Barberini stellen die Fresken Cortonas kein allein auf Impresen und Personifikationen basierendes Bildprogramm dar, sondern zeigen für jeden leicht nachvollziehbar die Irrfahrten des Aeneas und dessen glückliche Landung an der italischen Küste (vgl. Abb. $8)^{28}$. Doch auch Innozenz X. versäumte es nicht, durch seine Wappenzeichen, den Olivenzweig und die Taube, einen engen Bezug zwischen dem antiken Helden und seinem Pontifikat herzustellen. Dieser Bezug wird besonders deutlich an den seitlichen Fresken über der Bogenlaibung, auf denen der Abstieg Aeneas' in die Unterwelt zu sehen ist (vgl. Abb. 9). Mit großen goldenen Lettern steht nicht nur das Motto Innozenz' X.: »Sub umbra alarum tuarum « darunter, die Stirnseite wird darüber hinaus durch das plastisch dargestellte päpstliche Wappen, das passend zur Inschrift geflügelt ist, gekrönt. Auf dem schmalen Wandstreifen ist der Abstieg in die Unterwelt des Helden zu sehen. Hier wird er seinen verstorbenen Vater treffen, der ihm die Weltherrschaft Roms prophezeit ${ }^{29}$. Auf diese Weise ist auch hier die Gründung Roms, der die Irrfahrt des Helden vorausgeht, den Bildern implizit. Das Bildprogramm endet zwar mit der Ermordung des Turnus (vgl. Abb. 11), sie weist aber über sich hinaus und muss als Voraussetzung für die nicht dargestellte Gründung und zukünftige Weltherrschaft Roms verstanden werden.

Wie wirkungsvoll gerade der Aeneaszyklus der Galleria Pamphilj war, lässt sich nicht nur an den Nachstichen zeigen, die trotz des schlechten Verhältnisses des Innozenz X. zum französischen Königshof in Paris großes Aufsehen

27 Ebd., S. 274-306.

28 Rudolf Preimesberger, Pontifex Romanus per Aeneam Praesignatus. Die Galleria Pamphilj und ihre Fresken, in: Römisches Jahrbuch für Kunstgeschichte 16 (1976), S. 223-287; OYMARra, Repräsentationskunst, S. 284-306.

29 Vergil, Aeneis VI, S. 417-425. Vgl. hierzu Preimesberger, Pontifex Romanus, S. 265f.; OyMarra, Repräsentationskunst, S. 288-291. 
erregten $^{30}$, sondern ebenso anhand aktiver Umdeutungen. Aus Wien stammen zwei Thesenblätter ungarischer Doktoranden, die ganz offensichtlich an Cortonas Deckenfresken der Galerie Innozenz' X. orientiert sind ${ }^{31}$. Die von Nicolaus Hoy gezeichneten und von Bartholomäus Kilian gestochenen Szenen stellen $>$ Die Ermordung des feindlichen Turnus durch Aeneas an der Küste Italiens` aus dem Jahr 1675 (vgl. Abb. 10) dar sowie ein Jahr später ১Quos ego « aus dem Jahr 1676 (vgl. Abb. 11). Leicht erkennt man die Abhängigkeit dieser Entwürfe von den beiden thematisch verwandten Szenen der Galeriefresken, die `Ermordung des Turnus` und `Quos ego<, das der Ermordung natürlich in der Abfolge des Bildprogramms vorausgeht (vgl. Abb. 11 und 13). Zwar kopierte der Zeichner Cortonas Fresken nicht genau, doch springen anhand von Details, wie der Haltung des besiegten Turnus und Neptuns, die große Nähe zu den Bilderfindungen Pietro da Cortonas ins Auge. Nicht jedoch die motivisch-kompositionelle Abhängigkeit der Kupferstiche von den Fresken Cortonas ist interessant, als vielmehr die unmissverständliche Identifikation des Kaisers mit dem antiken Helden Aeneas. In der Wiener Interpretation der Szene geht es zwar mehr um die besondere Hervorhebung der kriegerischen Macht des Kaisers und nicht um ihn als mythischen Gründer eines neuen Rom. Dennoch lässt sich hier schlussfolgern, dass die wenn auch nicht im direkten Auftrag entstandenen Wiener Thesenblätter das Lob des Kaisers als neuer Aeneas verkünden. Doch nicht erst das Thesenblatt reklamiert den Aeneasmythos für den habsburgischen Kaiser. Hierfür stand eine lange Tradition zu Verfügung ${ }^{32}$. Umso erstaunlicher ist jedoch der Rekurs auf die von Pietro da Cortona in Rom erstmals dargestellte Episode der `Ermordung des Turnus`, an die sich der Zeichner auch kompositorisch eng anlehnte. Die motivisch-stilistische Abhängigkeit der Thesenblätter von den römischen Fresken verrät dabei sicher mehr als nur eine Wertschätzung in künstlerischer Hinsicht. Ganz offenbar hat es Cortona vermocht, den mythischen Helden so überzeugend darzustellen, dass sein Bild die Imagination seiner Zeitgenossen alsbald prägte. Nicht zuletzt behauptete sich Rom in

30 Gérard Audran nach Pietro DA CoRtona, Galeria dipinta nel Palazzo del Prencipe Panfilio da Pietro Berettini da Cortona [1668]; vgl. hierzu Thomas KirchNer, Der epische Held. Historienmalerei und Kunstpolitik im Frankreich des 17. Jahrhunderts, München 2001, S. 255, der auf das Interesse an den Fresken des Palazzo Pamphilj von Pietro da Cortona in den späten 60er Jahren in Paris verweist.

31 Sibylle Appunn-Radtke, Das Thesenblatt im Hochbarock. Studien zu einer graphischen Gattung am Beispiel der Werke Bartholomäus Kilians, Weißenhorn 1988, Kt. 11, 12; Géza GaLAvics, Thesenblätter ungarischer Studenten in Wien des 17. Jahrhundert. Künstlerische und pädagogische Strategien, in: Herbert KARNER / Werner TeLESKo (Hg.), Die Jesuiten in Wien. Zur Kunst- und Kulturgeschichte der österreichischen Ordensprovinz der »Gesellschaft Jesu« im 17. und 18. Jahrhundert, Wien 2003, S. 113-130.

32 Marie TAnner, The last descendant of Aeneas: the Hapsburgs and the mythic image of the emperor, New Haven [u.a.] 1993. 
Europa auch dank seiner Bilder, die mit der Stadt am Tiber verbunden waren und immer neue Facetten präsentierten.

Die Beispiele haben gezeigt, dass Aeneas nicht erst für Urban VIII. und Innozenz X. neben dem heiligen Petrus zu einer wichtigen Identifikationsfigur geworden war. Vielmehr findet sich der Rekurs und stolze Bezug auf den mythischen Gründervater Roms seit Leo X. in den Bildprogrammen der Päpste. Gleichwohl lässt sich im 17. Jahrhundert ein besonderes Interesse vermerken, denn die Botschaft der Aeneis rückt stärker als zuvor in den Mittelpunkt päpstlicher Repräsentation. In den Bildprogrammen der päpstlichen Familienpaläste der Barberini und Pamphilj wird Aeneas nicht allein als großer Krieger evoziert, vielmehr wird die von ihm vollbrachte Gründung Roms in den Vordergrund gerückt, und damit der einst von Vergil geschaffene Mythos der schon Augustus prophezeihten Weltherrschaft der Stadt am Tiber, den die Bilder zu aktualisieren versuchen. Dabei stehen sie in einem immer größer werdenden Kontrast zu dem im Pontifikat Urbans VIII. schon spürbaren und 1648 durch den Frieden von Münster und Osnabrück (während des Pontifikates Innozenz' X.) festgeschriebenen Machtverlust der Päpste. Die Bilder behaupten also eine mythische Bedeutung, die die Realität längst überholt hatte. Doch die europäische Bedeutung der Stadt am Tiber war nicht auf die Macht der Päpste angewiesen. Sie schöpfte sie vielmehr immer mehr aus ihrer (Kunst-)Geschichte, die in der Zwischenzeit zum Gegenstand historischer Wissenschaften geworden $\mathrm{war}^{33}$.

33 Ingo Herklotz, Cassiano dal Pozzo und die Archäologie des 17. Jahrhunderts, München 1999; ders.: Die Accademia Basiliana. Griechische Philologie, Kirchengeschichte und Unionsbemühungen im Rom der Barberini, Rom 2008; Gabriele Bickendorf, Die Historisierung der italienischen Kunstbetrachtung im 17. und 18. Jahrhundert, Berlin 1998; Christoph Frank (Hg.), Rome and European Heritage, Internationaler Kongreß, Rom 2005. 


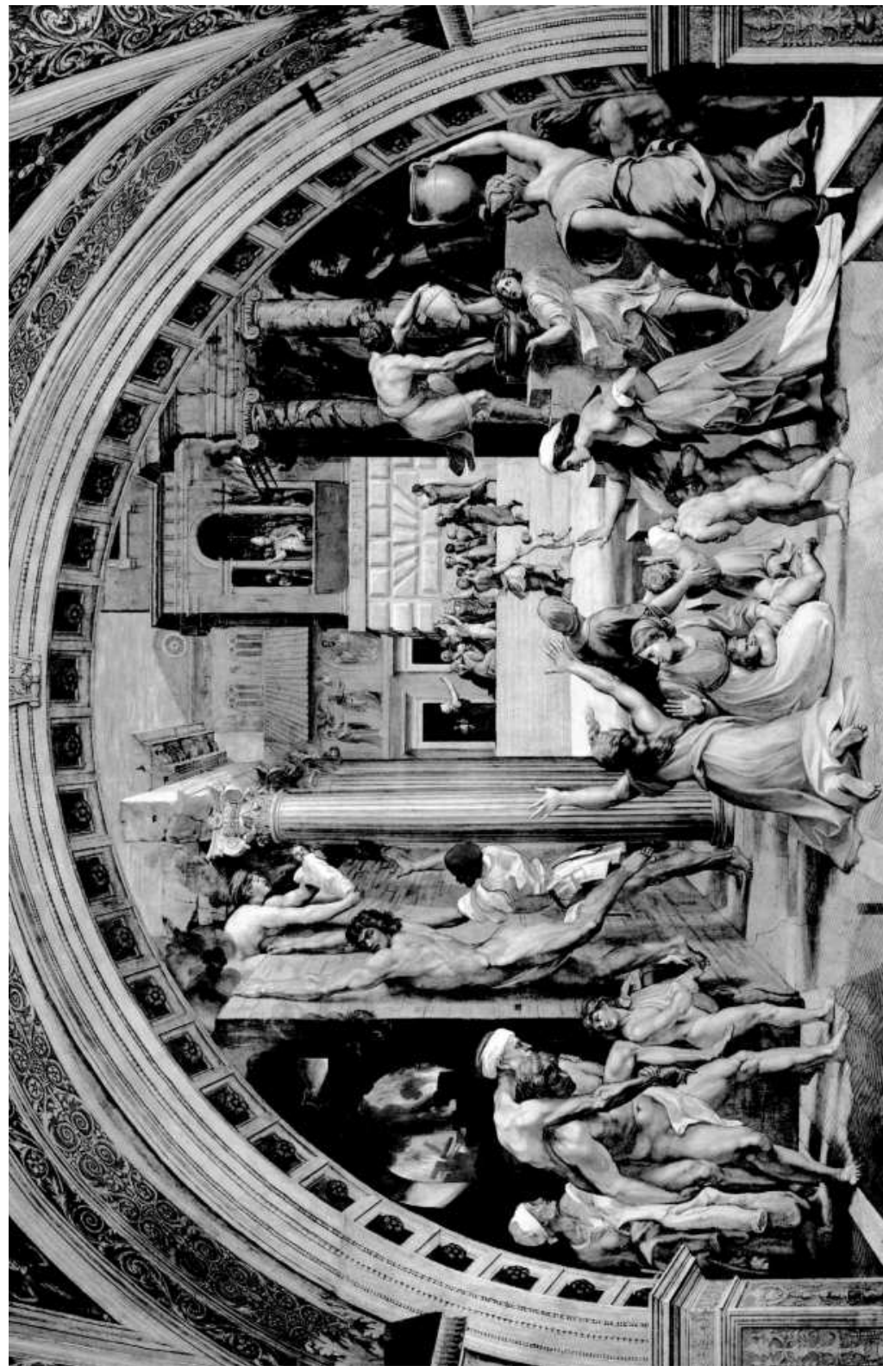




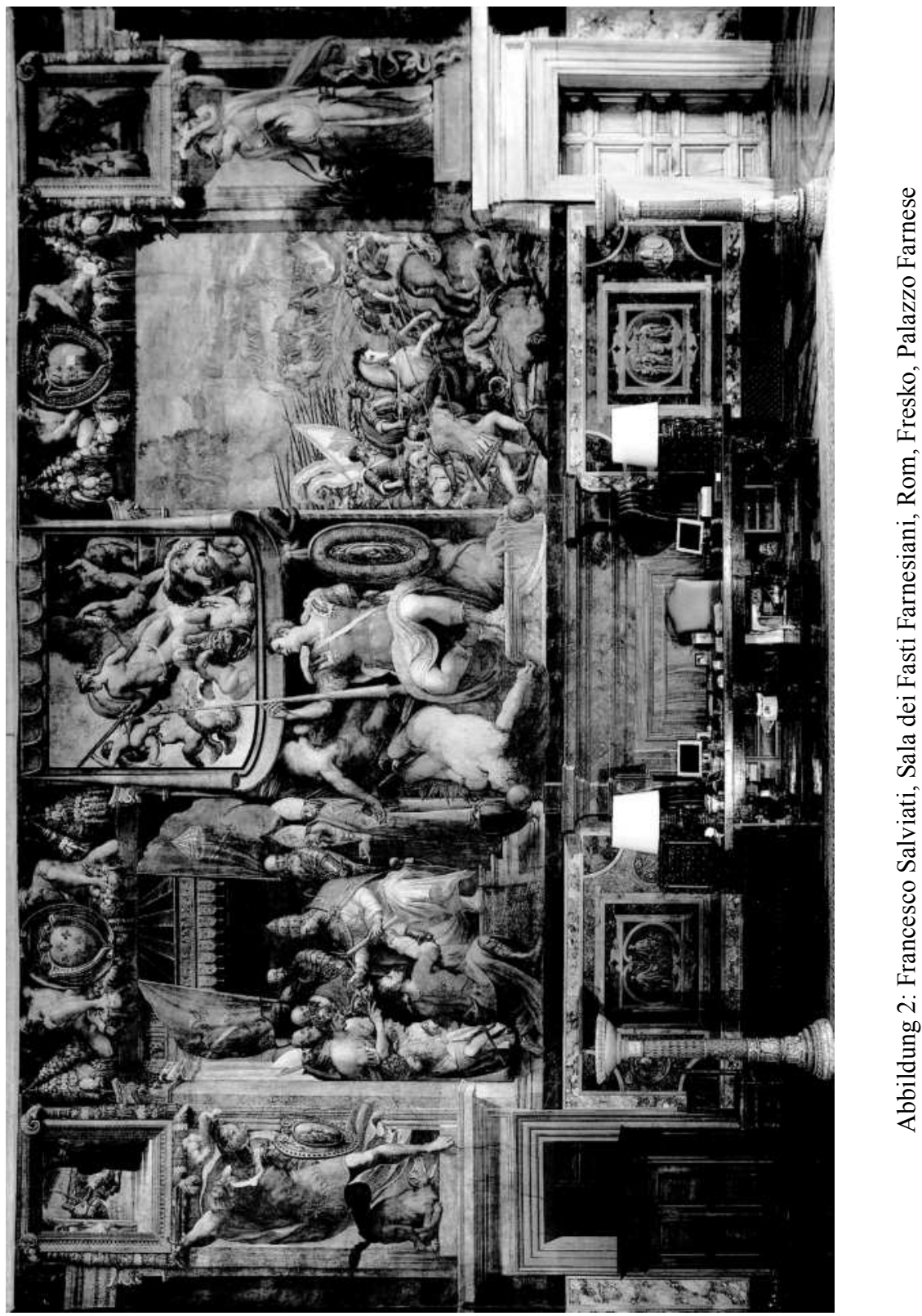




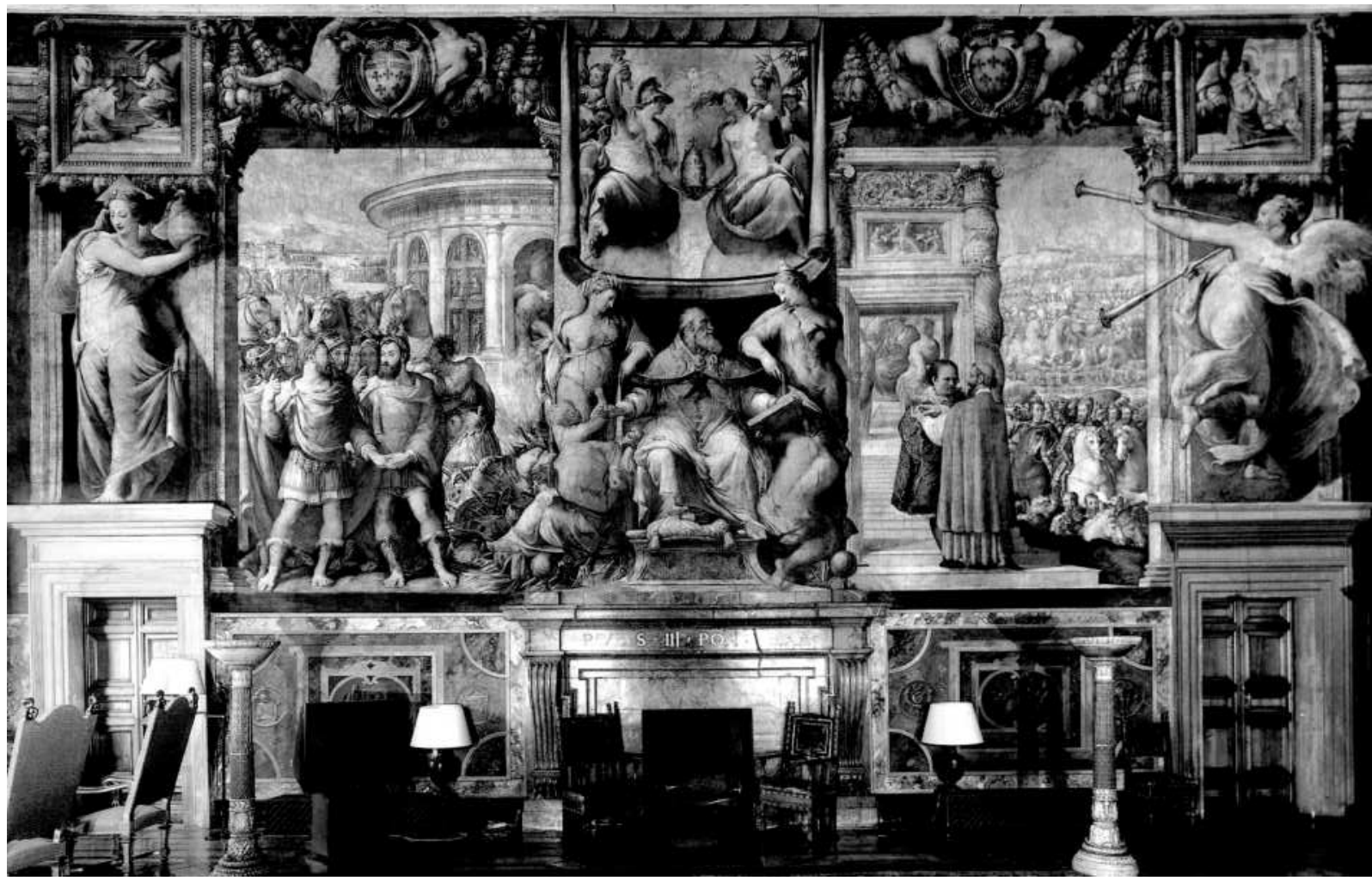




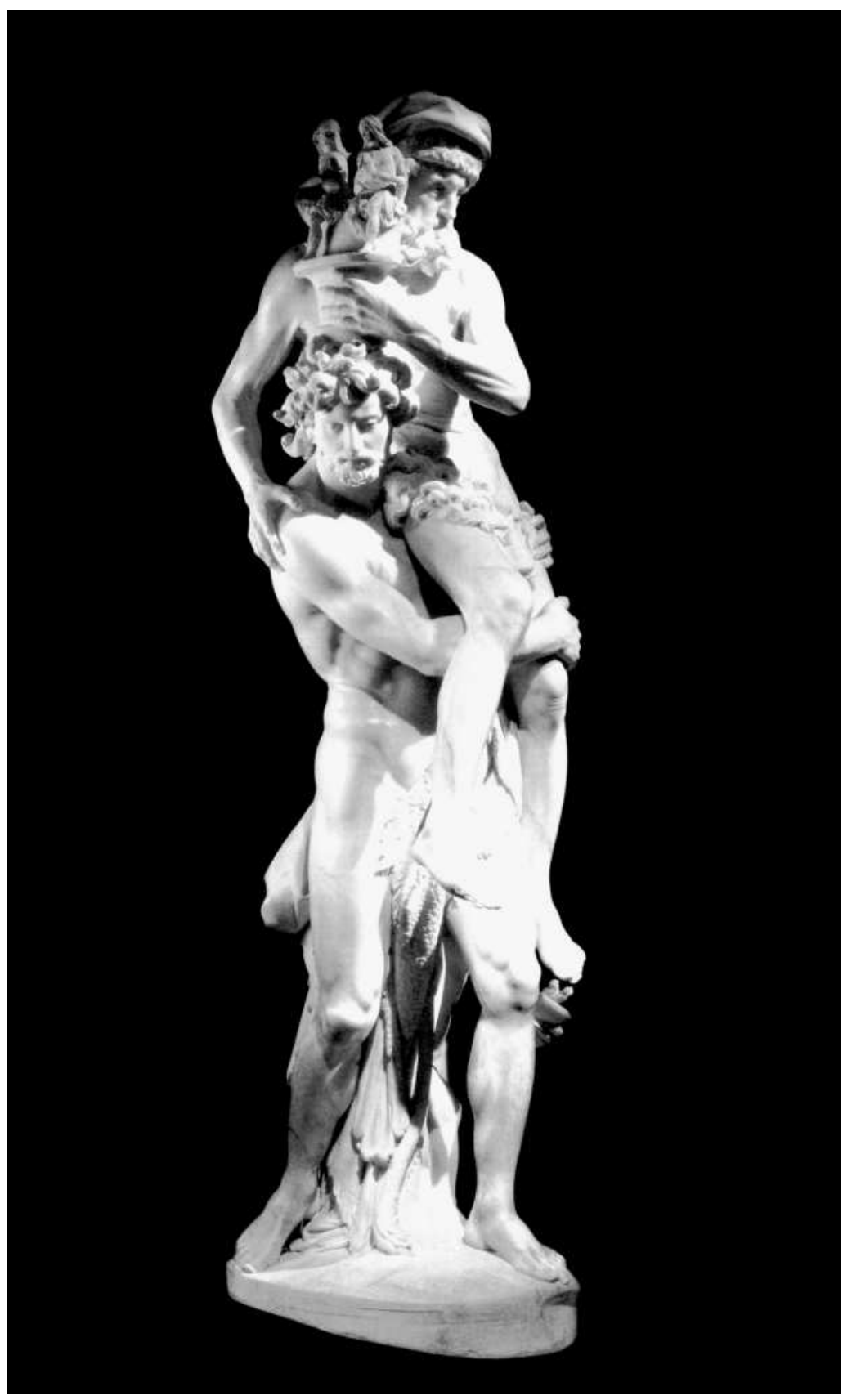

Abbildung 4: Gian Lorenzo Bernini, Aeneas und Anchises, Rom, Galleria Borghese 


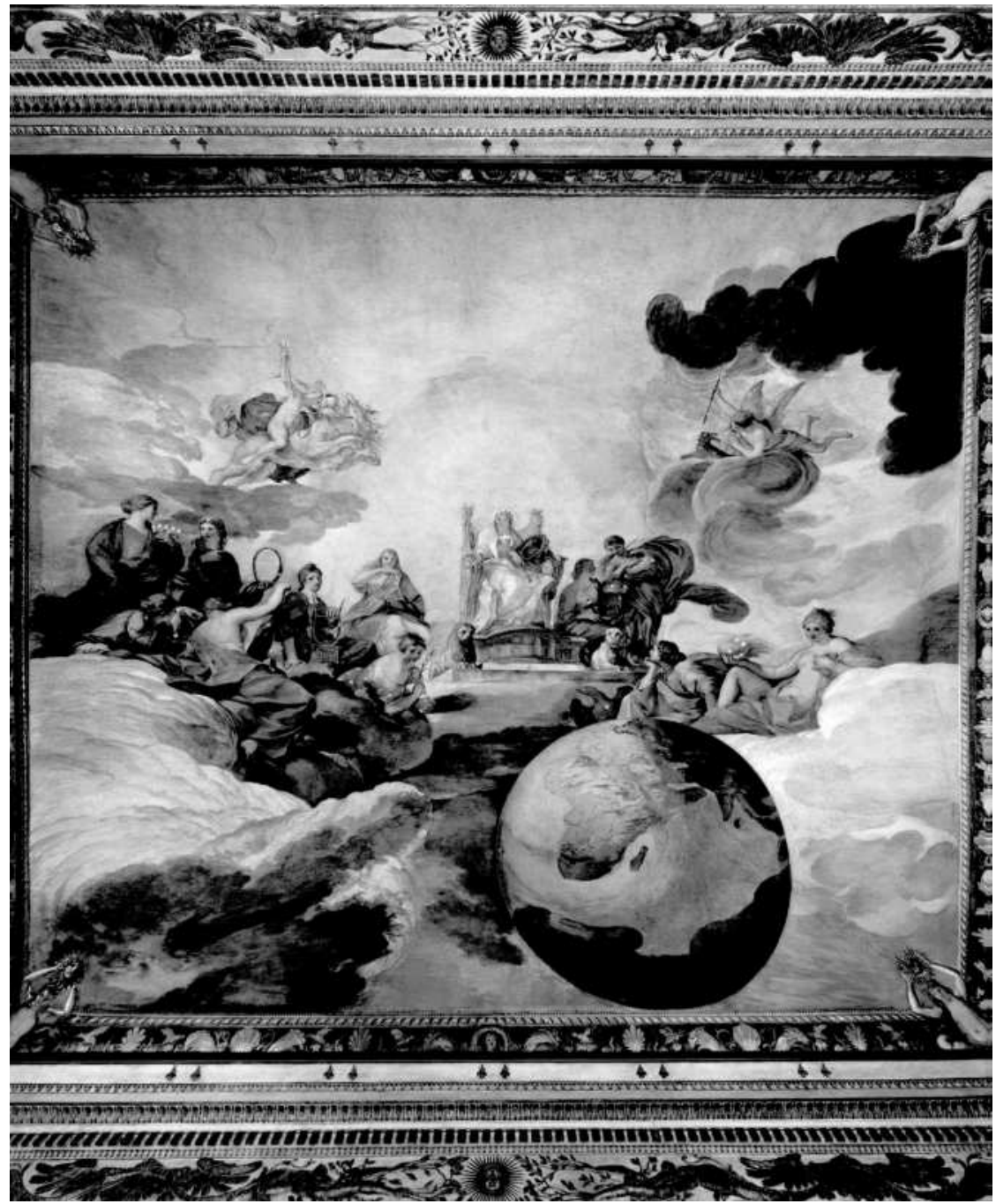

Abbildung 5: Andrea Sacchi, Die göttliche Weisheit, Deckenfresko, Rom, Palazzo Barberini 


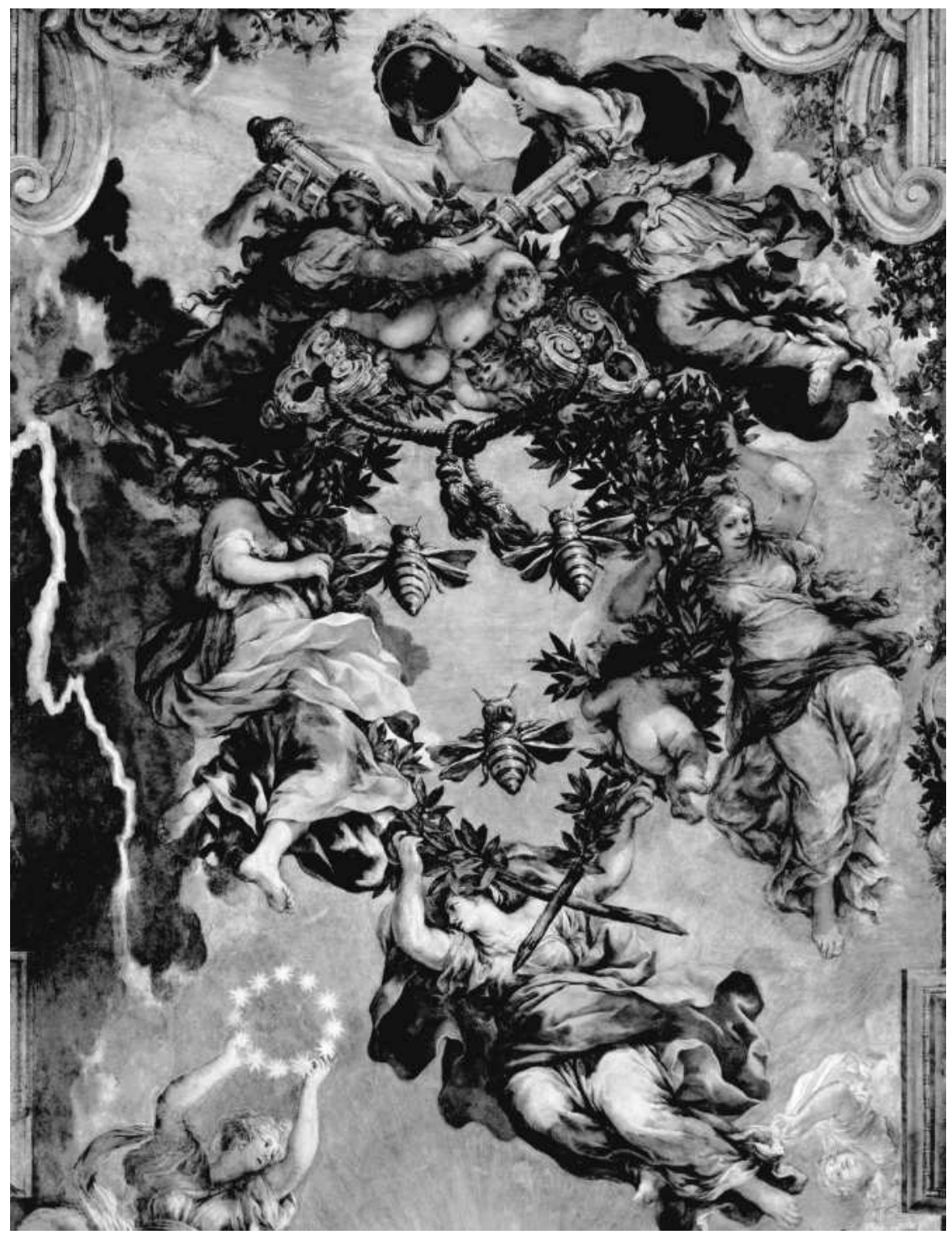

Abbildung 6: Pietro da Cortona, Die göttliche Vorsehung, Deckenfresko, Rom, Palazzo Barberini 
Teatro d'Imprefe,

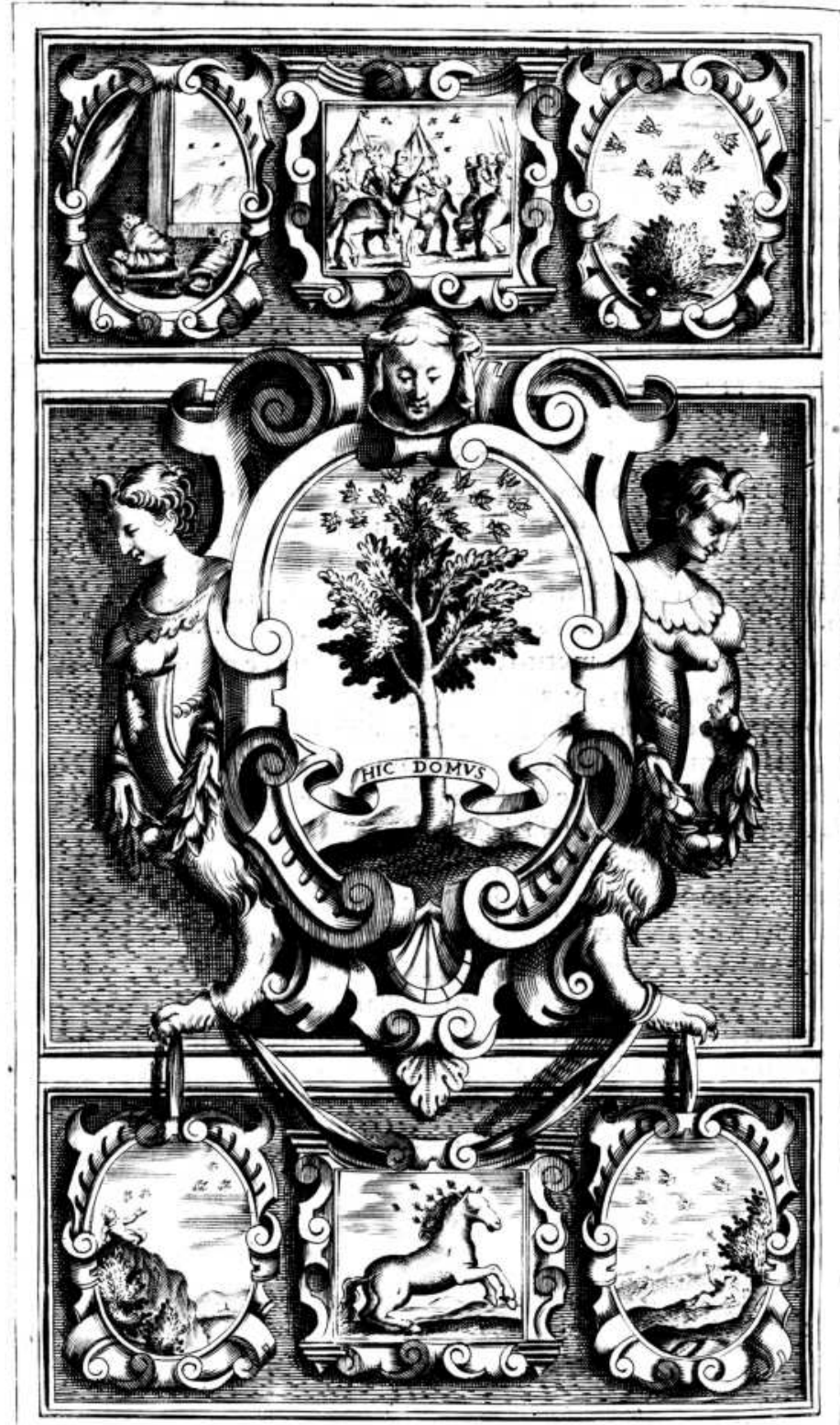

Abbildung 7: Giovanni Ferro, Hic domus, aus: Giovanni Ferro, Teatro d'Imprese, Venedig 1623 


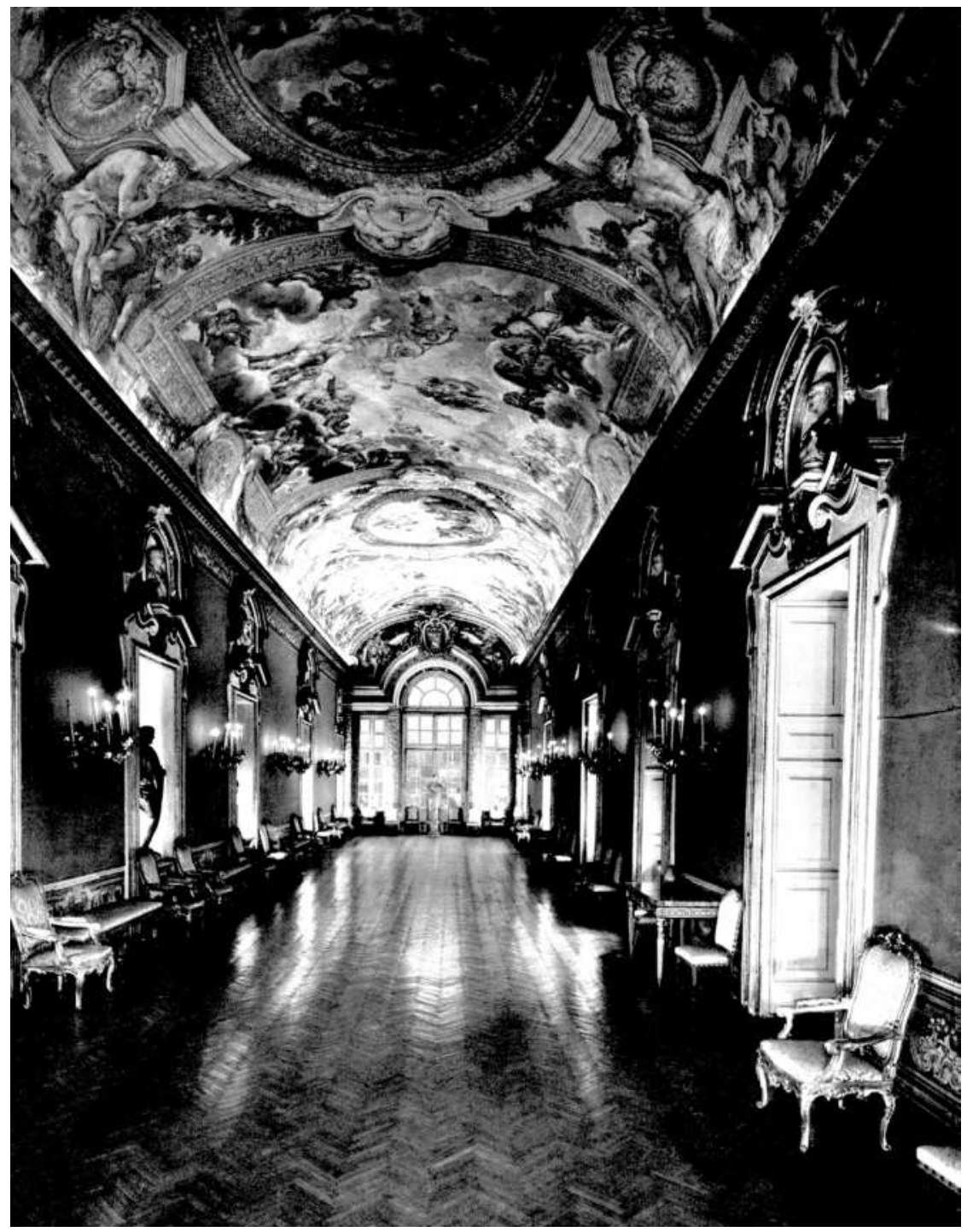

Abbildung 8: Blick in die Galleria Pamphilj, Rom, Palazzo Pamphilj 


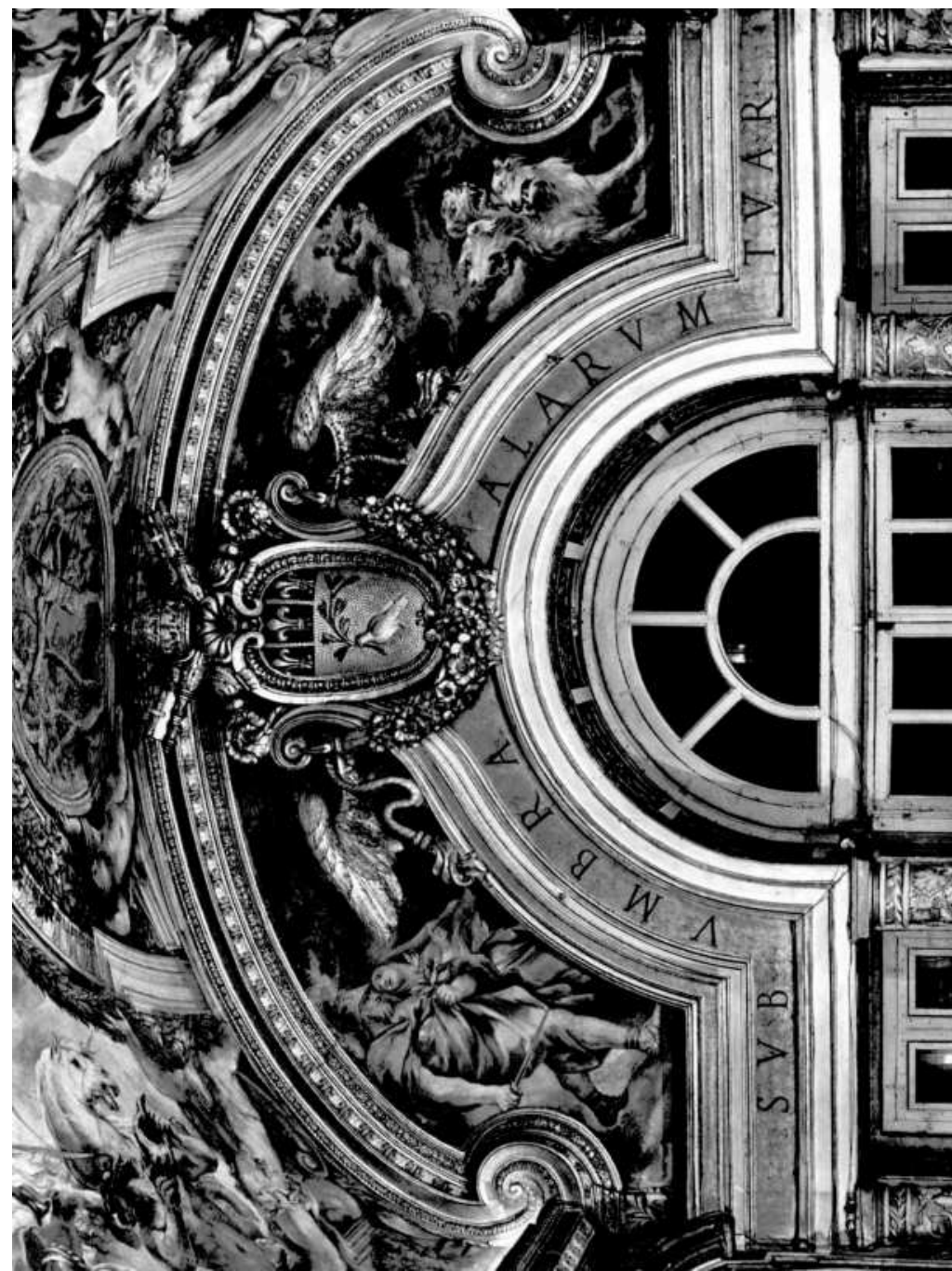

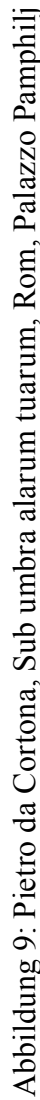




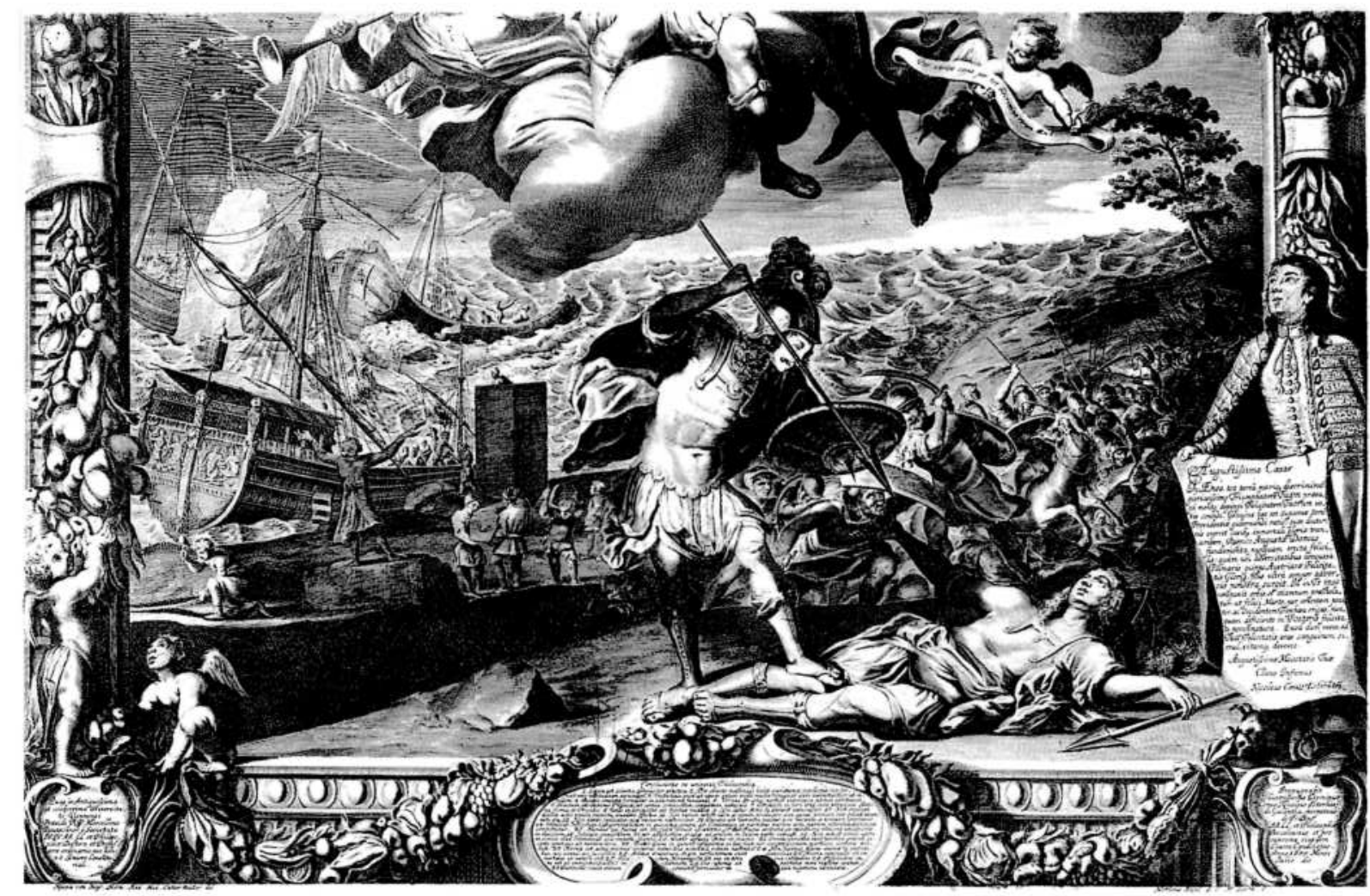




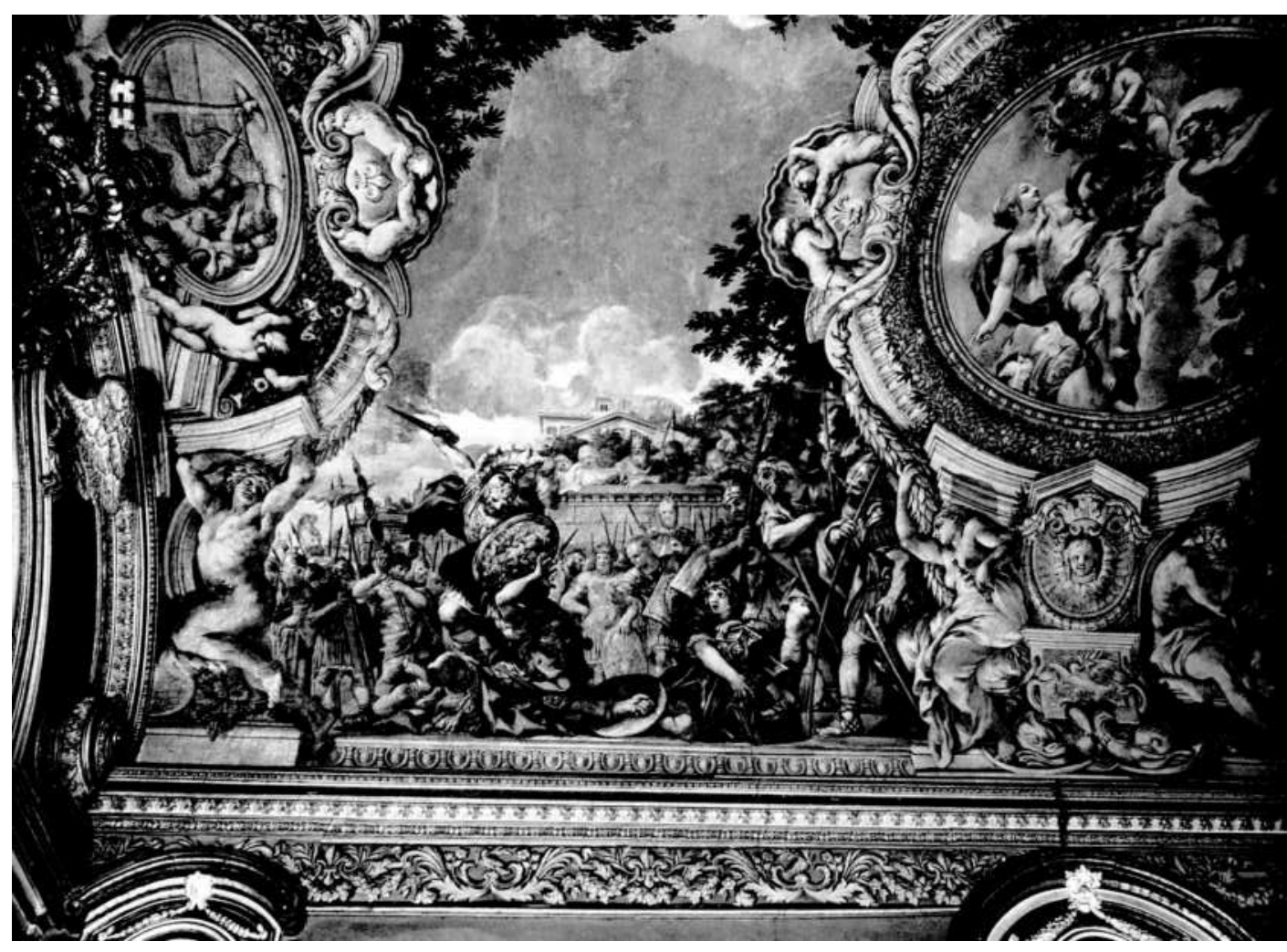

Abbildung 11: Pietro da Cortona, Die Ermordung des Turnus, Fresko, Rom, Galleria Pamphilj 


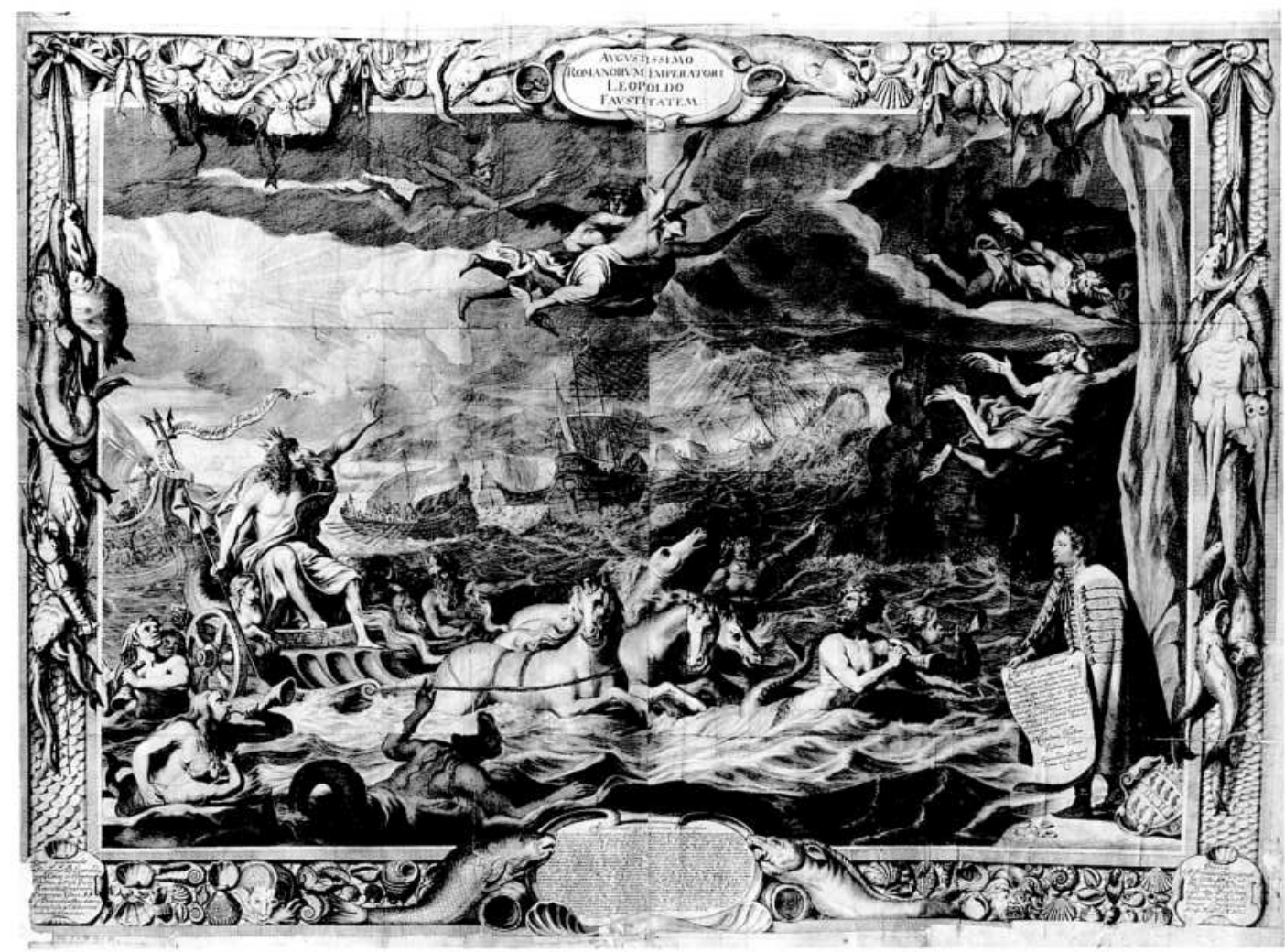

$\square$
9
0
0
0
0
2
0
0
0
0
0
0
0
0
0
0
0

Abbildung 12: Nicolaus Hoy und Bartolomäus Kilian, Quos ego, Thesenblatt, Kupferstich 1676 


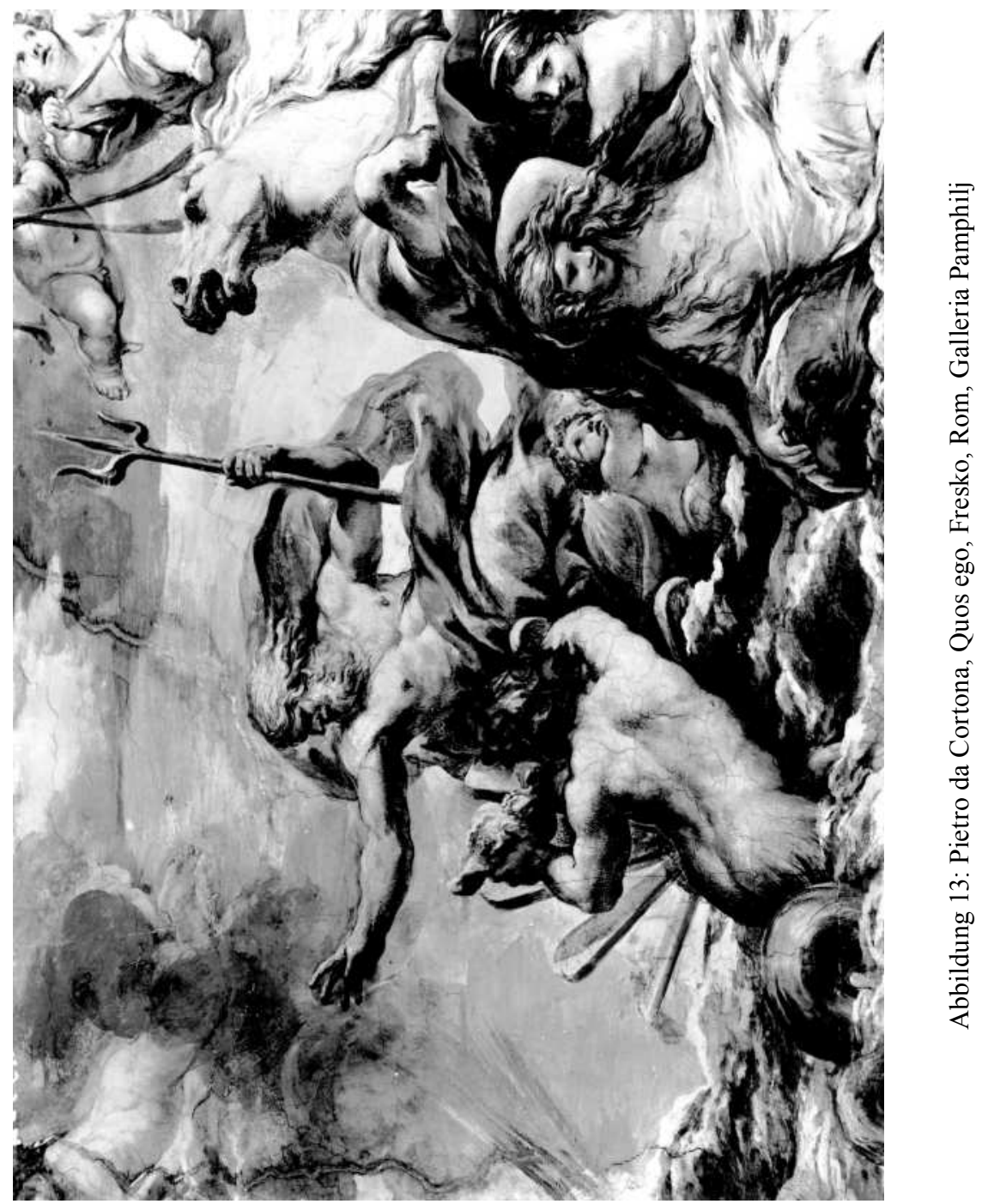




\title{
Ivan Parvev
}

\section{$»$ Krieg der Welten« oder »Balance of Power»}

\author{
Europa und die Osmanen, 1300-1856
}

\section{Einführung}

Die Geschichte Europas im späten Mittelalter und in der Frühen Neuzeit hätte sicherlich einen anderen Entwicklungsweg genommen, wäre der osmanische Staat nur eine regionale, lediglich in Kleinasien agierende Macht geblieben. Das Ausgreifen nach Südosteuropa, der durch den Islam bedingte und über den für das Türkentum typischen Herrschaftsanspruch und das Weltmachtstreben verstärkte Expansionsdrang haben jedoch dazu geführt, dass schon in der zweiten Hälfte des 15. Jahrhunderts die Dynastie der Osmanen ein Imperium aufgebaut hat, das die damaligen Europäer, so wie sie etwa Papst Pius II. verstanden hat, mit Unbehagen und berechtigter Sorge erfüllte. Über das Mittelmeer bedrängt und langsam aus diesem Gewässer von der Levante durch die Flotte des Sultans Richtung Gibraltar verdrängt, musste die »Res publica christiana« in Richtung Übersee vorstoßen - vorbei die Zeiten, als das Abendland sich ernsthaft anschickte, Palästina von den »muslimischen Ungläubigen« $z u » b e f r e i e n «$. Jetzt musste man froh sein, dass es dem Eroberer von Konstantinopel, Mehmed II., nicht vergönnt war, auch Rom unter seine Herrschaft zu bringen. Der »Terror Turcorum«, die »Türkenangst«, wurde zu einem Commonplace der europäischen Frühen Neuzeit ${ }^{1}$.

Die menschliche Natur ist so geschaffen, dass man Angstzustände zu verdrängen sucht, um sie nicht als Traumata immer wieder erleben zu müssen. Ähnlich verhalten sich Historiker, wenn es darum geht, die Vergangenheit ihres eigenen Vaterlandes und den Lebensweg eines seiner großen Herrscher $\mathrm{zu}$ schildern und zugleich über weniger glorreiche Momente zu berichten etwa, wenn es zuzugeben gilt, dass ein Kaiser vom Schlage eines Karl V. sich vor den Osmanen (den Türken) ganz einfach gefürchtet haben könnte. Ob ein Monarch, der sich mit keinem Angstgegner auseinandergesetzt hat, in einem besseren Licht steht als jemand, der ständig vom »Erbfeind-Syndrom«

1 Vgl. Richard Ebermann, Die Türkenfurcht. Ein Beitrag zur Geschichte der öffentlichen Meinung in Deutschland während der Reformationszeit, Halle/Saale 1904; Hans Joachim KissLING, Türkenfurcht und Türkenhoffnung im 15./16. Jahrhundert. Zur Geschichte eines »Komplexes«, in: Südost-Forschungen 23 (1964), S. 1-18; allgemein zum Problem »Angst« Jean Delumeau, Angst im Abendland. Die Geschichte kollektiver Ängste im Europa des 14. bis 18. Jahrhunderts, Reinbek bei Hamburg 1985. 
heimgesucht wird, ist schwer zu beurteilen. Eins steht jedenfalls fest: Das Osmanische Reich ist über lange Zeit hin ein gefährlicher, unberechenbarer Gegner des christlichen Europa geblieben.

In den letzten zwanzig Jahren hat sich nicht nur die Welt verändert, sondern auch bereits in der Geschichte vergraben geglaubte Themen sind quasi aus der Asche emporgestiegen. Wer würde schon während des Kalten Krieges glauben, dass die Beziehungen zwischen dem Westen und dem Islam einmal so militante Dimensionen annehmen würden wie etwa im Mittelalter oder der Frühen Neuzeit? Man war gewöhnt, vom »Krieg der Ideologien« zu sprechen, vom »Reich des Bösen« und von der »kapitalistischen Ausbeutung der Werktätigen«, doch wer konnte schon voraussehen, dass sehr bald Begriffe wie »Clash of Civilizations«, »Krieg gegen den Terror« die oben genannten Schlagwörter ins Reich der historischen Dinosaurier verbannen würden?

Gerade angesichts dieser bemerkenswerten Transformation ist es sicherlich lohnenswert, die Beziehungen zwischen Europa und dem Osmanischen Reich noch einmal zu hinterfragen, um festzustellen, ob die neuen Commonplaces ins europäisch-osmanische Raster passen oder ob es möglich wäre, gewisse Schlüsse aus der Vergangenheit zu ziehen, die eine Art »Richtschnur« für das Verständnis der Gegenwart sein könnten. Im Übrigen hat jede Historikergeneration das Recht, die Geschichte mit eigenen Augen zu betrachten - und das sollte sicherlich auch für das Problemfeld »Europa-Osmanisches Reich« gelten.

\section{Die europäisch-osmanischen politischen Beziehungen} (1300-1856) als »Clash of Civilizations «?

Es wäre natürlich keine bahnbrechende Einsicht, wenn man behaupten würde, dass die Osmanen als Eroberer in Südost- und Mitteleuropa aufgetreten sind und nicht als Friedensprediger, die ihre Sache mit der Kraft des Wortes und nicht durch die Kraft des Schwertes befördert haben. Ist es dennoch angebracht, die fast 600-jährigen europäisch-osmanischen Beziehungen durchwegs als »Clash of Civilization« oder die Grenze zwischen Europa und dem Reich des Sultans als »Bloody border« (vgl. Huntington) zu betrachten? Vieles spräche ja dafür - nicht zuletzt die Tatsache, dass der Jihad, der Heilige Krieg der Muslime, die eigentliche ideologische Grundlage der osmanischen Politik in Europa ausgemacht hat. Oder aber der Umstand, dass auch die Europäer sehr oft ihre Konflikte mit den Osmanen ebenfalls unter dem Zeichen der Opposition »Kreuz gegen Halbmond « gesehen haben. Wäre diese Annahme richtig, müssten sich jedoch sowohl die Osmanen als auch die Europäer von staatsideologischen Überlegungen bei der Gestaltung der bilateralen Be- 
ziehungen leiten lassen und nicht etwa von Gedanken, die von der Staatsräson oder dem Gleichgewicht der Kräfte herrühren.

Die Jahrhunderte der europäisch-osmanischen Beziehungen in ihrer Ganzheit entsprechen dieser vereinfachten Vorstellung jedoch keinesfalls. Nicht zuletzt deshalb, weil der Staat der Osmanen nicht über Nacht zu einem mächtigen Kontinentalreich wurde, sondern sich dieser Prozess über viele Jahrzehnte hinzog. Aus diesem Grund sollte man auch die europäischosmanischen Beziehungen der besagten Epoche nicht »en bloc« betrachten, sondern sie stattdessen periodisieren. Erst danach sollte man der Frage nachgehen, wie sich die Osmanen den Europäern gegenüber verhalten haben, und natürlich auch umgekehrt.

\subsection{Periodisierung der europäisch-osmanischen Beziehungen}

Die Festlegung innerer Grenzen im Rahmen eines historischen Phänomens ist schon immer etwas Kontroverses gewesen. Nicht zuletzt deshalb, weil die einzelnen historischen Phasen, die man kenntlich machen will, nicht wie mit einem Skalpell scharf und millimetergenau von einander getrennt werden können. Ein Ausweg wäre, stattdessen die dabei gedachten »Grenzen« nicht als enge Furchen, sondern eher als verhältnismäßig breite »Streifen des Übergangs « aufzufassen, in denen die konkreten Jahreszahlen als Orientierungen und nicht als »Schlagbäume« dienen.

Indem man die These aufstellt, dass historische Perioden ganz selten mit abrupten Brüchen markiert werden, während sie viel öfter durch chronologisch längere Übergangsphasen an ihren Enden gekennzeichnet sind, lassen sich die Beziehungen der Osmanen zu den europäischen Staaten des 14.-19. Jahrhunderts in folgende vier Perioden aufteilen:

1. »Formative Periode «, 1300-1453

2. »Klassische Periode «, 1453-1688

3. »Transformative Periode «, 1688-1798

4. »Integrative Periode «, 1798-1856

\subsubsection{Formative Periode, 1300-1453}

Die formative Periode beginnt mit der Gründung des osmanischen Reiches um 1300 in Kleinasien und endet mit der Eroberung Konstantinopels im Jahr 1453. Während dieser Zeit ist die Europa-Politik der Osmanen regional angelegt und umfasst geographisch den südöstlichen Teil des Alten Kontinents. Das Interessante dabei ist, dass die orthodoxen christlichen Staaten der Halbinsel (Byzanz, Bulgarien, Serbien, die Walachei etc.) die Osmanen keines- 
falls als ideologische Widersacher und Glaubensfeinde ansahen, sondern sie in ihrem »regionalen Staatensystem « als gleichberechtigte Partner aufnahmen. Die Belege dafür sind vielfältig - das Abschließen politischer Bündnisse, die sich gegen andere christliche bzw. nichtchristliche Staaten richteten, die Existenz von Vasallitätsverhältnissen, wobei primär die Osmanen die Souveräne waren ${ }^{2}$, sowie von dynastischen Eheverbindungen ${ }^{3}$. Gemeinsame Waffengänge gab es sowohl gegen Christen als auch gegen Nichtchristen. Es scheint, dass während der formativen Periode der europäisch-osmanischen Beziehungen die Religion bzw. die Staatsideologie für die Außenpolitik nicht ausschlaggebend war - weder für die Osmanen noch für die orthodoxen Fürsten.

Dass es diesen »Clash of Civilizations « im 14. und bis weit in das 15. Jahrhundert in Südosteuropa wider Erwarten nicht durchweg gegeben hat, mag zwar überraschend klingen, ist aber aus der eigentlichen Geschichte der Region durchaus zu erklären. Byzanz war traditionell ein Bollwerk des Christentums gegen den Islam seit dem 7. Jahrhundert, hat sich aber an den Kreuzzügen für die Befreiung der Heiligen Stätten in Palästina nur bedingt beteiligt - dieses Unternehmen war und blieb eigentlich eine Initiative des von Rom her bestimmten christlichen Abendlandes. Konstantinopel wurde zwar von den Arabern belagert, doch in Kleinasien haben sich die Byzantiner mit den türkischstämmigen Muslimen letztendlich arrangieren können. Anders ausgedrückt - die orthodoxen Fürsten in Südosteuropa kannten den Islam, sie wussten auch viel über seine expansive Ideologie, haben aber mit der Zeit festgestellt, dass man mit den Muslimen als Nachbarn auch in Frieden leben konnte, zumal die Vertreter dieser Glaubensgemeinschaft bis Mitte des 14. Jahrhunderts keine Anstalten machten, Südosteuropa selbst zu erobern. Wenn man sich noch dazu vergegenwärtigt, dass in dieser Region nomadische Streifzüge seit Jahrhunderten zum politischen Alltag gehörten, wird man unschwer verstehen können, warum man die Osmanen als (fast) gleichberechtigten Akteur im südosteuropäischen Staatensystem angesehen hat ${ }^{4}$.

2 Gegenbeispiele gab es jedoch auch. Im Vertrag von Gallipoli 1403 willigte der Osmanenherrscher Süleyman ein, nicht nur einen Allianzvertrag mit Byzanz und Venedig zu unterzeichnen, sondern auch im Briefverkehr den Kaiser von Ostrom als seinen »Vater« zu bezeichnen und sich selbst als seinen »Sohn«. Noch dazu erklärte er sich bereit, einen seiner Verwandten als eine Art Pfand für die Erfüllung des Traktats nach Konstantinopel zu entsenden. Vgl. George T. Dennis, The Byzantine-Turkish Treaty of 1403, in: Orientalia Christiana periodica XXXIII (1967), S. 72-88.

3 Allerdings verbot der Islam, dass muslimische Frauen Christen heirateten, so dass unter den Osmanen nur Männer solche Verbindungen eingehen konnten.

4 Vielleicht wurde dieser Prozess durch den Umstand gefördert, dass ein Teil der damaligen osmanischen Führungselite aus ehemaligen orthodoxen Christen bestand. Mit anderen Worten man kannte sich und sprach auch mitunter dieselbe Sprache, was wahrscheinlich eine gewisse Vertrautheit vermittelte. 
Da jedoch mit der Zeit der osmanische Staat sein Machtpotential deutlich vergrößerte, wurde den orthodoxen Herrschern in der Region klar, dass man die Osmanen nicht ganz richtig eingeschätzt hatte. Insbesondere um die Mitte des 15. Jahrhunderts begann sich langsam eine Tendenz abzuzeichnen, die während der klassischen Periode der europäisch-osmanischen Beziehungen ihre volle Entfaltung erlebte - nämlich die allmähliche »Abstoßungsreaktion « in Bezug auf den osmanischen Staat, gepaart mit der Überzeugung, dass dieser expandierenden Macht nur durch ein »Zusammenrücken aller Christen« zu begegnen sei.

Der Sultan, nunmehr Oberhaupt eines mächtigen Reiches, das auch die ideologische Konfrontation mit der Res publica christiana öffentlich verkündete, wurde zum eigentlichen Herrscher Südosteuropas. Das regionale Staatensystem, das die Osmanen ursprünglich als gleichberechtigten Akteur aufgenommen hatte, war zusammengebrochen, und an seine Stelle trat die »Pax Ottomana«. Würden die christlichen Staaten in Mittel- und Südeuropa, in Skandinavien und im Westen des Kontinents anders reagieren als die Länder im Südosten? Wenn diese Herrscher nichts von der Geschichte lernen sollten, dann hätten die Osmanen gute Chancen, das Spiel erneut zu spielen, um noch weiter nach Europa vorzustoßen.

\subsubsection{Klassische Periode, 1453-1688}

Die eigentliche Schlüsselerfahrung der klassischen Periode war die Eroberung Konstantinopels 1453 durch Mehmed II. Mit einem Schlag wurde der anfangs unterschätzte Osmanenstaat zum Angstgegner des Abendlandes. Päpste, Kaiser und mächtige christliche Könige mochten zwar insgeheim die osmanische Herrschaft in Südosteuropa als die gerechte Strafe Gottes für die orthodoxen Schismatiker angesehen und gepriesen haben, doch mit dem Fall der mächtigen Christenbastion am Bosporus hatten die wenigsten gerechnet. Von den alten Stätten des Jesusglaubens blieb nur Rom in christlichen Händen - alle anderen befanden sich unter der Herrschaft der Ungläubigen. Asien und Afrika und jetzt auch Südosteuropa waren verloren, in Spanien gab es immer noch muslimische Herrscher ... War es dann verwunderlich, wenn Pius II. sich an die »Europäer« wandte, um sie zur Eintracht zu ermahnen, damit sie dem Feind widerstehen könnten, der sie in »ihrem eigenen Haus« - Europa - angriff?

Seit der zweiten Hälfte des 15. Jahrhunderts geriet der Aufruf zum Kreuzzug langsam in Vergessenheit. Stattdessen predigten Päpste, Kaiser und Kö-

5 Vgl. neuerdings zu der Reaktion der gebildeten Europäer des 15. Jahrhunderts Nancy BisAHA, Creating East and West. Renaissance Humanists and the Ottoman Turks, Philadelphia, PA 2006. 
nige den Krieg gegen die Osmanen - und das Ziel wurde auch anders definiert. Nicht mehr Palästina und der Hl. Gral, sondern Südosteuropa und Konstantinopel sollten befreit werden. Natürlich, für viele Zeitgenossen jener Epoche waren die Osmanen zugleich auch eine handliche »Vogelscheuche«, die es einzusetzen galt, um andere Ziele zu erreichen. Das Papsttum mag zwar aktiv den Krieg gegen die Osmanen unterstützt haben, aber wäre es wirklich von Vorteil für die Kurie gewesen, wenn der Sultan und sein Staat schnellstens als politisches Problem von der Bildfläche verschwunden wären? Und hätte man in Rom nicht mehr gewonnen, wenn das Osmanische Reich zwar in die Schranken gewiesen worden, aber doch in Südosteuropa präsent geblieben wäre? Und was eignete sich besser für eine europaweite Propaganda, als einen verhassten Nachbarn der »geheimen Sachen mit den Türken« zu bezichtigen?

Dennoch, die europäisch-osmanischen Beziehungen in den Jahren 14531688 können durchaus als ein »Clash of Civilizations « angesehen werden. In jener Epoche gab es keine politischen Bündnisse, keine dynastischen Verbindungen und auch die Vasallität, die bis Mitte des 15. Jahrhunderts noch auf Wechselseitigkeit beruhen konnte, wurde zu einem einseitigen osmanischen Machtinstrument. Die Osmanen führten ihren »Heiligen Krieg«, und die Christen formierten sich unter päpstlichen Auspizien zu »Heiligen Allianzen« (»Lega sacra«), um dem Feind zu widerstehen. Natürlich waren das keine europaweiten Koalitionen, die gebildet wurden, sondern es war eher das Anliegen der unmittelbaren Nachbarn der Osmanen, sich zu verteidigen. Im Gegensatz zur formativen Periode, in der das Abendland offensive Kriege gegen den Sultan führte (1396 oder 1443/44), war die nunmehrige militärische Auseinandersetzung von Seiten der Christen defensiv angelegt. Das galt sowohl für Ungarn als auch für Venedig wie auch später für die Habsburgermonarchie. Die großen Schlachten in den Jahren 1453-1688 waren das Ergebnis der osmanischen Expansion in Richtung Mitteleuropa bzw. Mittelmeer und nicht das Resultat eines christlich-europäischen südöstlichen Vorstoßes.

Es gab auch ungeschriebene Regeln, die die christlichen Herrscher in Bezug auf die Osmanen einhielten. Und dabei machte es keinen Unterschied, ob die Potentaten Katholiken waren oder Lutheraner. Der Begriff »Erbfeind des Christlichen Namens « war eine Vorstellung, die man sowohl in Wien und Rom, aber auch in Paris oder London vorfinden konnte - von Madrid ganz zu schweigen.

Die besondere Atmosphäre, die seit dem Verlust Konstantinopels im Abendland vorherrschte, die Vorstellung, dass der Sultan ein »Sohn des Satans « sei, dass die Osmanen eine »Geißel Gottes« (Luther) für die Sünden der Christen seien, dass der Kampf gegen die Osmanen keine gewöhnliche Konfrontation sei, sondern etwas Sakrales beinhalte - Krieg des Kreuzes 
gegen den Halbmond eben -, all das führte schließlich dazu, dass man sich selbst und den »ideologischen Glaubensfeind « durch einen Verteidigungsgraben voneinander abgrenzte.

Gerade deshalb sollte man ein Land, das die »Schutzmauer« gegen die Osmanen verteidigte, indem es sich gegen Angriffe ihrer Truppen wehrte, nach Möglichkeit unterstützen - sei es finanziell, sei es militärisch, oder zumindest neutral bleiben, sollten die Beziehungen zu dem betroffenen Herrscher nicht freundschaftlich sein. Diese ungeschriebene Regel, die im Rahmen des europäischen Staatensystems galt, ließ jedoch nicht zu, dass ein christliches Land, das gerade Krieg gegen die Osmanen führte, von einem anderen christlichen Herrscher angegriffen wurde - etwas, das während der formativen Periode durchaus vorkam.

Es wurde zwar sehr oft gemutmaßt, dass z.B. Frankreich und das Osmanische Reich im 16. Jahrhundert als Verbündete gegen die Habsburgermonarchie agierten - eine These, die sich sehr hartnäckig in der Historiographie festgesetzt hat, doch Belege dafür gibt es nicht. Außer man glaubt der antifranzösischen Propaganda im Alten Reich oder hält den gefälschten Allianzvertrag zwischen Heinrich II. (1547-1559) und Süleyman dem Prächtigen (1520-1566) für echt ${ }^{6}$. Die klassische Periode der europäisch-osmanischen Beziehungen kannte keine christlich-osmanischen Bündnisverträge, die sich gegen ein christliches Land richteten. Auch wenn es zahlreiche Beschuldigungen gab, die das Gegenteil behaupteten, hielten sich die Herrscher im europäischen Staatensystem an diese ungeschriebene Regel ${ }^{7}$.

Die Osmanen haben es während dieser Zeit vermocht, ihr über den Islam definiertes Verständnis des Völkerrechts ihren christlichen Widersachern aufzuzwingen. In der osmanischen Hauptstadt durften europäische Vertreter residieren, doch der Sultan erachtete es nicht als notwendig, die Hauptstädte der Christenheit mit osmanischen Residenten zu besetzen. Das war staatsideologisch nicht tragbar, weil das bedeutet hätte, dass der mächtige Sultan einen »ungläubigen Monarchen« als gleichberechtigt angesehen hätte. $\mathrm{Zu}$ dem waren die permanenten Botschafter ja eine Erfindung des christlichen Europa. Die Osmanen machten ihrerseits die Residenten für die Taten ihrer Herrscher verantwortlich, und daher wurden die Diplomaten im Falle eines Konfliktes verhaftet und eingesperrt - die Idee, dass die Person des Botschafters unantastbar ist, scheint in diesem Fall keine Anwendung gefunden

6 Vgl. Maria Glotzbach, Die Wahrnehmung der Türken in den französischen Reiseberichten aus dem Umfeld der diplomatischen Missionen des Botschafters Gabriel d'Aramon 1547 bis 1553 : Estre en Pays Infideles, fort estrangeres \& barbare: Mais le tout m'ha esté pour plaisir, München 2006, S. 21f.

7 Vgl. zu den Besonderheiten der europäisch-osmanischen Beziehungen des 16.-17. Jahrhunderts Ivan PARvev, Habsburgs and Ottoman between Vienna and Belgrade, 1683-1739, Boulder Col. 1995, S. 249-267. 
haben. Da der Heilige Krieg nicht eingestellt werden durfte, war es den muslimischen Herrschern lediglich erlaubt, einen nicht mehr als zehn Jahre dauernden Waffenstillstand mit den Staaten der Ungläubigen abzuschließen. Die Osmanen haben sich an diese Regel gehalten, und nur im 17. Jahrhundert gab es Ausnahmen ${ }^{8}$. Der Sultan machte sich auch nichts aus der Rangordnung der Monarchen, die im europäischen Staatensystem galt. Dass der Vertreter des Kaisers erst nach dem venezianischen Bailo oder nach dem Residenten der Moldau zur Audienz vorgelassen wurde, war nicht unüblich?

Dadurch wollte der Sultan beweisen, dass er mit den christlichen Herrschern nach Belieben umgehen konnte - und zugleich war er sich dessen sicher, dass weder der Kaiser noch ein anderer christlicher Potentat wegen eines solchen diplomatischen Affronts einen Krieg gegen die Osmanen riskieren würde.

Natürlich wurde dieser »Krieg der Zivilisationen« nicht allein auf dem Feld der Diplomatie und der militärischen Auseinandersetzung ausgetragen. Die Propaganda spielte ebenso eine wichtige Rolle, wobei wahrscheinlich in ihr einer der ausschlaggebenden Gründe zu suchen ist, dass die Schlachten der europäischen Türkenkriege so erbittert und erbarmungslos ausgetragen wurden - und zwar auf beiden Seiten ${ }^{10}$.

\subsubsection{Transformative Periode, $1688-1798$}

Das Ereignis, das das Ende der klassischen Periode der europäisch-osmanischen Beziehungen eingeleitet hat, ist in den großen Krieg der Heiligen Liga gegen den Sultan von 1683-1699 eingebettet. Als die kaiserliche Armee Anfang September 1688 die Donaufestung Belgrad erobert und damit der osmanischen Expansion nach Mitteleuropa das Rückgrat gebrochen hatte, war die Vision einer habsburgischen Herrschaft in Südosteuropa kein abstraktes Konstrukt mehr, sondern der Wirklichkeit ein beträchtliches Stück nähergerückt. Da es hinter Belgrad keine starken Festungen mehr gab, glaubte man in Wien, aber auch in Paris, dass in zwei oder drei Kampagnen die kaiserliche Armee Konstantinopel erobern würde. Wahrscheinlich durch den Belgrader Triumph animiert, hatte ein Berater Leopold I. eben diese Stadt als

8 Als 1664 der Frieden von Vasvár (Eisenburg) zwischen Leopold I. und den Osmanen geschlossen wurde, sollte er laut Vertragstext zwanzig Jahre gelten.

9 Vgl. zu dieser Problematik der Aufsatz von Bertold Spuler, Die europäische Diplomatie in Konstantinopel bis zum Frieden von Belgrad (1739). 2. Teil: Die diplomatischen Gebräuche. Übersicht über die türkischen Staatsbehörden, in: Jahrbücher für Kultur und Geschichte der Slaven. Zeitschrift des Osteuropa-Instituts Breslau 11 (1935), H. 2, S. 177-222.

10 Vgl. die interessante imagologische Studie von Almut HöFERT, Den Feind beschreiben. »Türkengefahr« und europäisches Wissen über das Osmanische Reich 1450-1600, Frankfurt/ Main 2004. Dazu die Rezension von Ernst D. Petritsch, in: URL: http://www.sehepunkte.de/ 2005/06/pdf/5552.pdf (eingesehen am 28.12.2008). 
Ziel des Krieges bezeichnet - sollte dies gelingen, würde sein Souverän auch zum Kaiser des Ostens werden und die Einheit der christlichen Kirche verwirklichen ${ }^{11}$.

Der Sonnenkönig, Ludwig XIV., fasste die Situation ähnlich auf, und obwohl er sich bis dahin an das Gentleman Agreement der klassischen Periode gehalten hatte ${ }^{12}$, war ihm dieses Ausgreifen der habsburgischen Macht nach Südosteuropa nicht geheuer. Man mag darüber streiten, ob die Ersetzung der osmanischen Herrschaft auf dem Balkan durch die kaiserliche tatsächlich eine so große Gefahr für Frankreich gewesen wäre, wie man in Paris damals vermutete. Tatsache ist, dass schon Ende September 1688 französische Truppen in der Pfalz einmarschierten, was für die Kaiserlichen eine zweite Front bedeutete. Dadurch musste sich der militärische Druck der Habsburger notwendigerweise vermindern, was wiederum eine indirekte Schützenhilfe für die Osmanen war.

Durch diesen Bruch der ungeschriebenen Regel der klassischen europäisch-osmanischen Beziehungen, wurde die dritte, die transformative Phase eingeleitet. Sie dauerte etwa 110 Jahre und ist durch folgende Merkmale gekennzeichnet. Zuerst galt das Gentleman Agreement aus der klassischen Periode nicht mehr. Dadurch war es möglich, dass ein europäischer Staat, der Krieg gegen die Osmanen führte, zugleich auch von einem anderen christlichen Nachbarn angegriffen werden konnte. Gleichwohl aber wurde diese faktische Allianz nicht durch formelle Bündnisverträge besiegelt - das 18 . Jahrhundert war anscheinend immer noch zu nah an der Zeit des »Clash of Civilizations «, um die europäisch-osmanische Animosität mit leichter Hand abzutun $^{13}$. Vielleicht sollte noch daran erinnert werden, dass für manche Völkerrechtler des 18. Jahrhunderts der Türkenkrieg nicht gerechtfertigt werden musste, da die Osmanen, so ihre Ansicht, Südosteuropa illegitim beherrschten. Insofern blieb das Osmanische Reich auch während der transformativen Periode ein Fremdkörper, das zwar keine unmittelbare Gefahr für das europäische Staatensystem darstellte, aber dennoch, da inzwischen als rückständig und unzivilisiert angesehen, nicht zu Europa gehörte ${ }^{14}$.

11 Gemeint ist hier das Memorandum des Grafen Johann Quintin Jörger (1624-1705) von 1689. Vgl. Parvev, Habsburgs and Ottomans between Vienna and Belgrade (1683-1739), S. 93. Zu Jörgers Leben Allgemeine Deutsche Biographie 14 (1881), S. 530f.

12 Im August 1684 wurde in Regensburg ein 20-jähriger Waffenstillstand mit dem Kaiser abgeschlossen, der die Kriegsführung der Habsburger in Südosteuropa wesentlich erleichterte.

13 Vgl. die diesbezüglichen Ausführungen bei Heinz Duchnard, Balance of Power und Pentarchie. Internationale Beziehungen 1700-1785, Paderborn u.a. 1997, S. 80. - »[...] Alteuropa brachte es aber noch nicht fertig, die Integrität des türkischen Imperiums wirklich völkerrechtlich festzuschreiben...«.

14 Bemerkenswert ist, dass auch im 18. Jahrhundert politische Projekte verfasst wurden, deren einziges Ziel es war, die Osmanen aus Europa zu vertreiben - so etwa der Plan von Kardinal 
Im 18. Jahrhundert gab es praktisch keine »Heiligen Allianzen« mehr gegen die Osmanen, obwohl die Päpste Venedig und die Habsburgermonarchie in ihren Waffengängen gegen den Sultan nach Möglichkeit unterstützten. Auch die Versuche, die Gesellschaft des Alten Reichs nach dem Muster der »Türkenangst« der klassischen Periode für die kaiserliche Sache zu sensibilisieren, schlugen im Großen und Ganzen fehl. Die europäisch-osmanischen Konflikte des 18. Jahrhunderts wurden immer mehr zu gewöhnlichen militärischen Auseinandersetzungen, in denen es um Macht und Länder ging und nicht um das ideologische Ringen zwischen »Kreuz und Halbmond $~^{15}$. Auch wenn Russland sich in der Rolle des Christenbefreiers gefiel und manche Zarinnen und Zaren auch daran geglaubt haben mögen, weder in Wien, noch in Paris sah man darin kaum mehr als einen Versuch, die russische Machtentfaltung in Südosteuropa in ein positives Licht zu stellen. Es ist auch kein Zufall, dass gerade im 18. Jahrhundert die Orientalische Frage entstanden ist - eben das Problem, was aus dem schon inzwischen totgeglaubten Osmanischen Reich werden sollte. Denn es war nunmehr kein Geheimnis, dass diejenige europäische Großmacht, die den Balkan allein für sich beanspruchen und behaupten konnte, auf dem besten Wege war, auch den Alten Kontinent politisch zu dominieren.

Während der transformativen Periode der europäisch-osmanischen Beziehungen legte der Sultan einen Großteil seiner Staatsideologie, die über den Islam definiert wurde, notgedrungen ab. Das war notwendig, um die sich gerade über die Frage der postosmanischen Zukunft Südosteuropas abzeichnende Rivalität der Großmächte für sich zu nutzen. Noch im 16. und 17. Jahrhundert zwang der Sultan seinen christlichen Widersachern seine Art von Frieden auf, und zwar in direkten bilateralen Verhandlungen. Im 18. Jahrhundert tauchten plötzlich Vermittler auf, etwa beim Abschluss der Verträge von 1699, 1718 und 1739, wobei der Großherr seinerseits vorschlug, die Rolle des Mediators zu spielen, um den Österreichischen Erbfolgekrieg in den 1740er Jahren zu beenden. Die Pforte war auch bereit, die Formel »ewigen Frieden« in die Staatsverträge aufzunehmen - der erste dieser Art wurde 1720 und zwar bemerkenswerterweise mit Russland geschlossen. Im Frieden von Karlowitz 1699, der mit Polen vereinbart wurde, willigte der Sultan in einen Gebietsverlust ein - Podolien wurde abgetreten, ohne dass der Gegner zuvor dieses Land erobert hatte ${ }^{16}$. Das war ebenfalls ein Novum für die Os-

Giulio Alberoni von 1736. Vgl. Trandafir Duuvar, Cent projets de partage de la Turquie (12811913), Paris 1914, S. 258-268.

15 Allerdings kämpften die Kaiserlichen und die Osmanen auch während der Kriege von 1716-1718 und 1737-1739 erbittert und erbarmungslos gegeneinander, was ein Beleg dafür ist, welche große Wirkung die langwierigen Erfahrungen der »Bloody border« in Südosteuropa auf die Psyche der Menschen ausüben konnten.

16 Vgl. zu den Verhandlungen in Karlowitz Rifa'at Abou-EL-HaJ, Ottoman Diplomacy at Karlo- 
manen und das widersprach auch dem muslimischen Grundsatz, dass kein Land an Ungläubige abgetreten werden sollte, das nicht vorher von ihnen erobert worden war. Anfang der 90er Jahre des 18. Jahrhunderts sah es die Pforte als opportun an, ständige Botschaften in einigen europäischen Hauptstädten zu eröffnen. Dass dadurch die bis dahin verachteten »Herrscher der Ungläubigen« als gleichberechtigt anerkannt würden, scheint die Osmanen nicht gestört zu haben.

Es drängt sich der Schluss auf, dass während der transformativen Periode die europäisch-osmanischen Beziehungen Konturen annahmen, die der ersten, der formativen Epoche der bilateralen politischen Kontakte ähnlich waren. Der Sultan und seine Ratgeber fanden anscheinend nichts Anstößiges daran, die staatsideologischen Grundsätze des Islam zugunsten einer sachlichen Realpolitik außer Kraft zu setzen. Wären die Osmanen nicht weise genug gewesen, um diese Transformation zuzulassen und auch aktiv zu betreiben, hätte ihr Reich nicht so lange existieren können.

\subsubsection{Integrative Periode, $1798-1856$}

Obwohl das Osmanische Reich im 18. Jahrhundert von den kontinentalen Großmächten nicht mehr als eine unmittelbare Gefahr für das europäische Staatensystem angesehen wurde, war man in Europa noch weit davon entfernt, den Sultan als einen gleichberechtigten politischen Partner zu akzeptieren. Man schloss weiterhin mit der Pforte Handelsverträge, egal ob als Kapitulationsabmachungen oder gesonderte Traktate, man tauschte Botschaften und inzwischen auch ständige Gesandte aus, man verhandelte auch über Allianzen mit dem Großherrn, aber wenn es an der Zeit war, formelle politische Bündnisse mit dem Sultan zu schließen, ließen die europäischen Herrscher das ganze Unternehmen fallen. Man wird das Gefühl nicht los, dass die aufgeklärten Monarchen sich bei dem Gedanken, mit den Osmanen eine offizielle und öffentlich verkündete Allianzpartnerschaft einzugehen, nicht ganz wohl fühlten. Auch wenn die Grundsätze der Realpolitik dies zuließen, sah man sich lieber nach anderen Varianten um.

Die Situation änderte sich radikal während der Epoche Napoleons, als Paris den Versuch wagte, eine französische Hegemonie in Europa unter dem Vorzeichen einer neuen Ideologie zu verwirklichen. Die alte Ständeordnung sollte aus den Angeln gehoben werden und durch »Liberté, égalité, fraternité« ersetzt werden - so zumindest der ursprüngliche Ansatz. Als Napoleon 1798 in Ägypten agierte und damit das Osmanische Reich in den Wirbel dieser Zeit hineingezogen wurde, zögerten die mächtigen Gegner Frankreichs,

witz, in: Journal of the American Oriental Society 87 (1967), S. 498-512; ders, Ottoman Attitudes Toward Peace Making. The Karlowitz Case, in: Der Islam 57 (1974), S. 131-137. 
Russland und England, nicht, dem bedrängten Selim III. (1789-1807) ihre Hilfe anzubieten. So kam es auch 1798 und 1799 zum formellen Abschluss von Allianzverträgen, die sich gegen Napoleon richteten. Wenig später fochten russische und osmanische Kriegsschiffe gegen die französische Flotte und die Engländer halfen den Osmanen bei der Verteidigung Ägyptens ${ }^{17}$.

Durch dieses Ereignis wurde die integrative Etappe der europäisch-osmanischen Beziehungen eingeleitet. Wie man dem Namen entnehmen kann, wird die besagte Zeit von 1798 bis 1856 Zeuge der osmanischen Integration in das europäische Staatensystem. Der erste Schritt in diese Richtung war der formelle Abschluss von politischen Allianzen, und ihre Existenz war der eindeutige Beweis dafür, dass die staatsideologischen Vorbehalte den Osmanen gegenüber zumindest auf der Ebene der großen Politik nicht mehr bestanden. Auch Russland, das einen so großen Wert auf seine Rolle als Befreier der Christen in Südosteuropa legte, schloss nicht nur 1799 einen Bündnisvertrag mit der Pforte - auch weitere sollten folgen (etwa 1805 oder 1833). Für Frankreich und England war es überhaupt keine Frage, dass man das Reich der Osmanen im Krimkrieg 1853-1856 gegen die Russen unterstützte, und zwar nicht nur politisch, sondern auch mit der Waffe in der Hand. Das Land des Sultans wurde zu einer Macht wie jede andere - mit der Pforte konnte man Krieg führen, aber wenn es die Staatsräson verlangte, konnte man sich mit ihr verbünden und sie aktiv militärisch unterstützen.

Das Osmanische Reich versuchte seinerseits, sich dem Rahmen des europäischen Staatensystems anzupassen, die geschriebenen und ungeschriebenen Regeln des »Europäischen Konzerts « zu befolgen. Niemand in Istanbul oder in Konstantinopel, wie die Europäer diese Stadt nannten, dachte ernstlich daran, die Grundsätze des Islam und des Heiligen Krieges in den Beziehungen zu Europa zu befolgen. Schließlich war das Machtpotenzial der modernen europäischen Großstaaten auch zu riesig, um es überwinden zu können. Es ist übrigens kein Zufall, dass gerade in der ersten Hälfte des 19. Jahrhunderts die Tanzimat-Periode im Osmanischen Reich eingeleitet wurde - ein Versuch, den Staat des Sultans nach europäischem Muster zu reformieren und zu modernisieren; vielleicht auch mit dem unausgesprochenen Wunsch, das Geheimnis der Macht Europas zu entschlüsseln und es später für osmanische Großmachtziele zu verwenden!

Natürlich gab es auch während der integrativen Periode der europäischosmanischen Beziehungen gewisse Bedenken und Berührungsängste gegenüber den Osmanen. So nahm der Sultan am Wiener Kongress 1815 nicht Teil, auch die Heilige Allianz, das Rückgrat der postnapoleonischen Ordnung auf

17 Vgl. Leften Stavros Stavrianos, The Balkans since 1453, New York 2000 (1. Ausgabe 1958), S. 201f. Das Vorwort ist von Traian Stoianovich, der einige Fragen der südosteuropäischen Geschichte kontrovers zur Diskussion stellt. 
dem Alten Kontinent, blieb ein exklusiver Klub, in dem die Osmanen keinen Platz hatten. Der einzige Grund - der Sultan war kein christlicher, sondern ein muslimischer Herrscher.

Doch als 1856 der Krimkrieg zu Ende ging und in Paris der Friedensschluss unterzeichnet wurde, wurde in den Vertragstext eine kleine, aber vielsagende Passage aufgenommen. So heißt es in Artikel 7: Die europäischen Großmächte erklären, »la Sublime Porte admise à participer aux avantages du droit public et du concert Européen « $^{18}$. Die formelle Aufnahme des Osmanischen Reiches in das Europäischen Konzert und zwar im Rahmen eines multilateralen völkerrechtlichen Vertrags, war die staatsrechtliche Bestätigung, dass das Land des Sultans inzwischen zu einem festen Bestandteil des europäischen Staatensystems geworden war. Die seit 1798 eingeleitete faktische Inkorporierung des Osmanischen Reichs in das Europa der Mächte wurde 1856 auch juristisch besiegelt.

Ist es angebracht, auch nach 1856 von der Existenz europäisch-osmanischer Beziehungen zu sprechen? An sich ist die Frage überflüssig, denn das Reich des Sultans ist nach dem 1. Weltkrieg auseinander gebrochen - also erst nach fast 70 Jahren. Dennoch scheint der Begriff »europäisch-osmanisch « für die Zeit nach 1856 weniger treffend zu sein, weil danach das Osmanische Reich, die Türkei, in seinen Kontakten zu den Staaten des europäischen Konzerts eher die Gleise der bilateralen Beziehungen beschritt - und die Pforte agierte im Rahmen dieses Staatensystems und nicht in Opposition zu ihm. Als einzige Ausnahme könnte man vielleicht die Orientalische Krise 1875-78 bezeichnen, als noch einmal der Gegensatz »Türkei - Europa« sehr deutlich zum Vorschein kam (wegen der Bulgarischen Gräuel 1876), um jedoch sehr schnell wieder von der politischen Bildfläche zu verschwinden. Eins ist jedoch offensichtlich: Das Osmanische Reich ist in den Jahrzehnten zwischen 1856 und 1918 nicht nur geographisch, sondern auch politisch zu einer europäischen Macht geworden. Was die Mentalität, die Kultur, die gesellschaftliche und wirtschaftliche Entwicklung anging, blieb jedoch das Osmanische Reich weitestgehend auf Distanz zu Europa, wobei diese Ansicht sowohl die Europäer selbst als auch sehr viele Osmanen teilten. Für die Erstgenannten blieb die Türkei trotz allem ein Sinnbild für Rückständigkeit

18 Edouard Gourdon, Histoire du Congrès de Paris, Paris 1857, S. 10. Wörtlich heißt es im Artikel 7: »Sa Majesté 1'Empereur des Français, Sa Majesté l'Empereur d'Autriche, Sa Majesté la Reine du Royaume-Uni de la Grande-Bretagne et d'Irlande, Sa Majesté le Roi de Prusse, Sa Majesté l'Empereur de toutes les Russies et Sa Majesté le Roi de Sardaigne déclarent la Sublime Porte admise à participer aux avantages du droit public et du concert Européen. Leurs Majestés s'engagent, chacune de son côté, à respecter l'indépendance et l'intégrité territoriale de l'Empire Ottoman, garantissent en commun la stricte observation de cet engagement, et considéront, en conséquence, tout acte de nature à y porter atteinte comme une question d'intérêt général«. 
und Despotismus, für die Letzteren blieb »Europa« das Land der machthungrigen Ungläubigen, die nichts weiter im Sinn führten, als die Muslime zu unterjochen.

\section{Schlussbetrachtungen}

Die europäisch-osmanischen Beziehungen in der Zeit von 1300 bis 1856 sollte man nicht allein unter dem Vorzeichen »Clash of Civilizations« betrachten. Es ist zwar richtig, dass von 1453 bis 1688, also für mehr als 230 Jahre, dieser Blickwinkel gerechtfertigt erscheint und auch historisch als Tatsachengerüst wohl belegt werden kann. Außerdem sind die übrigen gut 320 Jahre, also etwa $3 / 5$ der besagten Periode, anders beschaffen, so dass sie lediglich in Propagandaschriften als »Krieg der Welten« beschrieben werden können.

Eine solch differenzierte Betrachtung der europäisch-osmanischen Beziehungen und die Tatsache, dass der Sultan und seine christlichen Nachbarn keinen permanenten ideologischen Krieg geführt haben, sollte jedoch nicht den Schluss nahe legen, dass das Osmanische Reich von Anfang an ein Teil Europas gewesen sei, wie das etwa Daniel Goffman vor einigen Jahren postuliert hat ${ }^{19}$. Sowohl vor 1453 als auch nach 1856 waren sich die Europäer der Andersartigkeit des osmanischen Staates bewusst, und obwohl man politisch und militärisch mit dem Sultan zusammenarbeitete, konnte man sich auf beiden Seiten nur bedingt von den religiös-ideologischen Vorurteilen lösen. »Europa« und die »Osmanen« blieben letztendlich zwei getrennte Welten, auch wenn »Clash of Civilizations « und »Bloody border« nicht den ganzen Weg ihres gemeinsamen historischen Werdegangs begleitet haben.

Würde man das Problem jedoch anders formulieren und die spannende Frage stellen, wann denn das Osmanische Reich sich am weitesten von »Europa« entfernt bzw. sich in unmittelbarer Nähe von diesem befunden hat, dann wäre die logische Antwort folgende: Je mehr die Osmanen »Europa« aktiv und staatsideologisch bekämpften, je mehr sich der Sultan als Oberbefehlshaber des Heiligen Kriegs gegen die Christen verstand, desto größer wurde die europäisch-osmanische Kluft. Und umgekehrt - je weniger sich die Osmanen in die Rolle des ideologischen Gegners der »Europäer" gefielen, je weniger sie die normativen Postulate ihrer Religion in den europäisch-osmanischen Beziehungen gebrauchten, desto »europäischer « wurden sie. Dass dieser Prozess nicht zum Abschluss gekommen ist, könnte wahrscheinlich auch daran liegen, dass nach Ende des Ersten Weltkrieges, nach dem Zusammenbruch des Osmanischen Reichs kein konstruktives Umdenken im Rah-

19 Daniel Goffman, The Ottoman Empire and Early Modern Europe, Cambridge 2002. Vgl. »1. Introduction: Ottomancentrism and the West«, S. 1-26. 
men der eigenen Religion stattfand. Die Türkei unter Mustafa Kemal Atatürk hat die Modernisierung und Säkularisierung mit Gewalt vorangetrieben, hat versucht, den Islam in die Ecke des Privaten zu drängen, ihn aber nicht reformiert. Nach 1945 hat Japan den Shintoismus, wenn auch mühselig und sehr langsam, in die Epoche der Moderne gerettet. Dass die Europäer nach dem Ersten Weltkrieg wohl besser beraten gewesen wären, den Islam in der Türkei und im Nahen Osten durch einen Reformationsschub von »Europa« her in die Zivilisation der Modernität und Rationalität zu geleiten, wird man anhand der Ereignisse der vergangenen Jahre kaum verneinen können. $\mathrm{Ob}$ Chancen bestehen, das Versäumte nachzuholen, ob der inzwischen verstorbene Samuel Huntington (1927-2008) mit seinen Überlegungen zum »Clash of Civizations « Recht behalten soll, das wird, wie so oft, die Zukunft zeigen. Bis dahin lohnt es sich auf jeden Fall, über die europäisch-osmanischen Beziehungen zu reflektieren. 


\section{Der Adel Großbritanniens und Irlands zwischen insularer Isolation und europäischem Kosmopolitismus im späten 16. und frühen 17. Jahrhundert}

Wenn man von Europa und einem europäischen Bewusstsein in der Frühen Neuzeit spricht, dann liegt es nicht fern, auf jene soziale Gruppe zu blicken, die zumindest auf den ersten Blick in besonders starker Weise einen europäischen Kosmopolitismus verkörperte: den Adel, insbesondere den Hochadel ${ }^{1}$. Durch Freundschafts- und Patronagebindungen, durch Reisen, aber auch durch eine zumindest in ihren Grundzügen gemeinsame Standeskultur und im Einzelfall zudem durch Konnubien, war der höhere Adel über alle Grenzen hinweg in der Frühen Neuzeit verbunden und bildete zwar nicht unbedingt eine einheitliche soziale Gruppe, aber doch ein Konglomerat von regionalen und nationalen Eliten, die sich eben nicht nur im Kontext der fürstlichen Territorien und dynastischen Großreiche bewegten, sondern für die ganz Europa eine politische und kulturelle Heimat darstellte.

Freilich waren nicht alle europäischen Adelslandschaften im 16. und 17. Jahrhundert gleichermaßen gesamteuropäisch ausgerichtet. Gerade England scheint hier eine Ausnahme darzustellen. Von einem europäischen Kosmopolitismus kann man im Falle der Aristokratie in England anders als in Irland und Schottland im späten 16. und dem frühen 17. Jahrhundert nur in Ansätzen sprechen. Während englische Adlige des späten Mittelalters sich einer großen multi-ethnischen Monarchie zugehörig fühlten, zu der große Teile Frankreichs gehörten, neigten Aristokratie und gentry des elisabethanischen England auf den ersten Blick zu einer Weltsicht, die sehr viel insularer war, und das galt abgeschwächt auch noch für die Jahrzehnte nach 1603. Dazu trug nicht nur der mit der Abtretung von Calais abgeschlossene Verlust aller Besitzungen auf dem Kontinent bei, sondern auch die Tatsache, dass es seit der Exkommunikation Elisabeths durch den Papst 1570 riskant geworden war, die katholischen Länder in Europa zu bereisen, jedenfalls galt dies für Italien, weniger vielleicht für Frankreich. Es fehlte also vielfach der europäische Erfahrungshorizont, wie er später im Rahmen der Grand Tour gewonnen wurde. Erst im frühen 17. Jahrhundert nahm die Zahl der

1 Siehe dazu jetzt Ronald G. Asch, Europäischer Adel in der Frühen Neuzeit, Köln 2008, bes. S. 22-32. 
Reisenden zu. Schrittweise wurde die Kavalierstour ein integraler Bestandteil der Erziehung des höheren Adels ${ }^{2}$.

Ohne Zweifel wurden schon vor 1640 die Fundamente für eine stärker kosmopolitische aristokratische Kultur gelegt, dennoch, im Vergleich zu Schottland und Irland wahrte der englische Adel lange Zeit seine Distanz zum Kontinent nicht nur kulturell, sondern auch mit Blick auf transnationale politische Loyalitäten, die bei den calvinistischen Schotten ebenso stark ausgeprägt waren wie bei den katholischen Iren oder den Old English Irlands. Im Übrigen heirateten auch nur $5 \%$ der englischen peers im Jahrhundert vor 1660 eine Frau, die nicht aus England stammte, und die meisten dieser Ausländerinnen kamen aus Irland oder Schottland ${ }^{3}$.

Hier spielte sicherlich auch eine Rolle, dass nach dem Scheitern der Ehe Heinrichs VIII. mit Katharina von Aragon die Tudors, mit der Ausnahme Marias der Katholischen, Ehen mit ausländischen Partnern vermieden, wenn sie nicht sogar ganz unverheiratet blieben wie Elisabeth I. Die dynastischen Verbindungen hingegen, die die Stuarts mit Prinzessinnen vom Kontinent eingingen, hatten durchaus eine Auswirkung auf die Hofkultur, wenn auch sicherlich im Fall Henrietta Marias, der bourbonischen Gattin Karls I., stärker als im Falle Annas von Dänemark, der Frau Jakobs I ${ }^{4}$. Man findet dann auch seit den 1620er und 1630er Jahren eine Reihe von Aristokraten am Hof oder in seinem Umfeld, die den neuen Typus des kosmopolitischen Adligen, der mit der Kultur Kontinentaleuropas vertraut war, verkörperten. Das beste Beispiel dafür ist sicherlich Thomas Howard, Earl of Arundel, der das Amt des Earl Marshal innehatte, aber man könnte auch weitere Höflinge wie etwa James Marquess of Hamilton hier nennen ${ }^{5}$.

Eine solche Vertrautheit mit der Kunst und Kultur des Kontinents war jedoch in den Jahren vor dem Bürgerkrieg für den englischen Adel immer noch eher ungewöhnlich. Es waren weniger kulturelle Erfahrungen, die Verbindungen zwischen dem englischen Adel und dem Kontinent herstellten, sondern sehr viel eher konfessionelle Loyalitäten, deren Bedeutung vor allem

2 Zu den Anfängen der Grand Tour siehe Michael Brennan (Hg.), The Origins of the Grand Tour. The Travels of Robert Montagu, Lord Mandeville (1649-1654), William Hammond (1655-1658), Banaster Maynard (1660-1663), London 2004; Edward CHANEY, The Evolution of the Grand Tour. Anglo-Italian Cultural Relations since the Renaissance, London 1998; Bruce RedFord, Venice and the Grand Tour, New Haven (Conn.) 1996; John Walter Stoyle, English Travellers Abroad, 1604-1667. Their Influence in English Society and Politics, New Haven (Conn.) ${ }^{2} 1989$.

3 Siehe Lawrence Stone, The Crisis of the Aristocracy, 1558-1641, Oxford 1965, S. 626.

4 Siehe Robert Malcolm Smuts, Court Culture and the Origins of a Royalist Tradition in Early Stuart England, Philadelphia 1987.

5 Siehe David Howarth, Lord Arundel and his Circle, New Haven (Conn.) 1985; Richard Cust, Charles I. A Political Life, Harlow 2005, S. 148-161; und zu Hamilton siehe John Joseph SCALly, Art. »Hamilton, James, first duke of Hamilton (1606-1649)«, in: Oxford Dictionary of National Biography, URL: http://www.oxforddnb.com/view/article/12087 (eingesehen am 6.7.2007). 
nach der Zuspitzung der religiösen Auseinandersetzungen in Frankreich und den Niederlanden seit den 1570er Jahren zunahm und die durchaus zu einem aktiven Engagement in den Kämpfen auf dem Kontinent führen konnten.

So entschlossen sich nicht wenige englische Adlige im letzten Drittel des 16. Jahrhunderts, sich aktiv an den Religionskriegen auf dem Kontinent zu beteiligen, und dieses militärische Engagement bestimmte naturgemäß auch ihr Selbstverständnis als Aristokraten in England selbst Es handelte sich also um mehr als nur um kurzfristige kriegerische Abenteuer ${ }^{6}$.

Wilhelm von Oranien hatte schon seit 1572 Truppen in England rekrutiert, und 1585 entsandte Elizabeth I. offiziell ein Expeditionskorps in die Niederlande, dem sich neben dem Oberbefehlshaber, dem Earl of Leicester, immerhin vier englische peers anschlossen ${ }^{7}$. Aber auch zahlreiche andere Adlige folgten dem Aufruf zum Kampf gegen Spanien und das Papsttum, darunter der Dichter Philip Sidney, an dessen Beispiel die Haltung und Einstellung der kämpferischen Protestanten, die sich ebenso sehr der Sache des gesamteuropäischen Protestantismus wie ihrem eigenen Land verbunden wussten, vielleicht besonders deutlich wird. Sidney hatte Europa schon in seiner Jugend intensiv bereist, in Frankreich hatte er Hubert Languet, einen französischen Hugenotten, getroffen, der für ihn zu einem lebenslangen Freund werden sollte, obwohl er oder gerade weil er deutlich älter war als Sidney selbst. Sidney hatte sicherlich eine Tendenz, sich selbst über die Freundschaft zu anderen zu definieren, und gab sich einem Freundschaftskult hin, der sich auch an antiken Vorbildern orientierte ${ }^{8}$. Um so wichtiger war es, dass neben Languet auch eine Reihe von anderen engen Freunden Sidneys Ausländer waren, wie der Schotte George Buchanan oder Philippe Duplessis Mornay, der französische Hugenotte. Sidney dachte zeitweilig sogar daran, eine Ausländerin zu heiraten, und zwar eine Tochter Wilhelms von Oranien. Aus dieser Ehe wurde nichts, denn Elisabeth I. legte ihr Veto ein. Ihr Veto begründete sie bezeichnenderweise auch damit, dass Sidneys Vater als Statthalter von Irland ein hoher Amtsträger war, dessen Familie keine allzu engen Verbindungen ins Ausland haben sollte. Die Königin lehnte aber nicht nur solche Konnubien ab, sie intervenierte auch, wenn Engländer ausländische Orden oder Adelstitel annahmen, wie das Thomas Arundell of Wardour tat, der 1595 von

6 Siehe dazu Roger B. Manning, Swordsmen. The Martial Ethos in the Three Kingdoms, Oxford 2003; ders., An Apprenticeship in Arms. The Origins of the British Army, 1585-1702, Oxford 2006.

7 Siehe Simon Adams, A Puritan Crusade? The Composition of the Earl of Leicester's Expedition to the Netherlands 1585-1586, in: Ders., Leicester and the Court. Essays on Elizabethan Politics, Manchester 2002, S.176-195, hier: S. 179 und 186f.

8 Siehe Edward Berry, The Making of Sir Philip Sidney, Toronto 1998, S. 38-44; vgl. zu Sidney ferner Michael G. Brennan, The Sidneys of Penshurst and the Monarchy, 1500-1700, Aldershot 2006, S. 13-14, 21-22; siehe auch Blair Worden, The Sound of Virtue. Philip Sidney's »Arcadia« and Elizabethan Politics, New Haven (Conn.) 1996, S. 44f und 52-54. 
Rudolf II. in den Reichsgrafenstand erhoben wurde, wobei Arundell freilich Katholik war, so dass man an seiner Loyalität ohnehin zweifeln musste?

Anders lag der Fall Sidneys, der sich aber am englischen Hof dennoch marginalisiert fühlte. Umso stärker definierte Sidney sich immer auch als Mitglied eines europaweiten Netzwerkes gleichgesinnter militanter Calvinisten. Es ist daher nicht überraschend, dass er Ende der 1570er Jahre daran dachte, nach Deutschland auszuwandern, da die Königin sich scheinbar von der Sache des reformierten Protestantismus abgewandt hatte und sogar die Eheschließung mit einem Katholiken erwog ${ }^{10}$.

Dazu kam es nicht, aber Sidney fiel Ende 1586 in den Niederlanden im Kampf gegen Spanien und wurde damit zum Helden des bewaffneten Kampfes für den wahren Glauben, der stets auch ein Kampf für einen gesamteuropäischen reformierten Protestantismus war. Diese Tradition überlebte Sidney auch nach seinem Tod. Sein politischer Erbe war in dieser Hinsicht Robert Devereux, der zweite Earl of Essex, der 1566 geboren wurde und 1601 auf dem Schafott sterben sollte. Essex heiratete 1590 Sidneys Witwe, Frances Walsingham, obwohl sie nicht aus einer Hochadelsfamilie stammte und obwohl er damit die Missbilligung der Königin provozierte. Angeblich hatte Sidney ihm auch sein bestes Schwert vermacht. Auch sonst stilisierte er sich sehr bewusst als Erbe Sidneys, der nach seinem Tode zum Märtyrer und Helden erhoben worden war ${ }^{11}$.

Essex fand seine zweite Heimat freilich nicht wie Sidney in den Niederlanden, sondern eher im Frankreich Heinrichs IV., obwohl er dieses Land abgesehen von kurzen militärischen Expeditionen nicht aus eigener Anschauung kannte: Einer seiner engsten Jugendfreunde war ein junger französischer Adliger, Gabriel de Lorges, Comte de Montgomery, der mit ihm zusammen auch in Cambridge studierte ${ }^{12}$. Essex wollte sich schon 1587 dem Heer Heinrichs von Navarra anschließen, auch wenn ihm dies die Königin verbot, doch versicherte er dem Bourbonen, er würde sich in seiner Armee sehr viel wohler fühlen als am englischen $\operatorname{Hof}^{13}$. Essex verließ dann zwar England faktisch nur im Rahmen seiner Feldzüge, aber er etablierte auf dem Kontinent ein Netzwerk von Agenten und Kontaktleuten, die ihn mit Nachrichten versorgen, zugleich aber seinen Ruf als europäischer Staatsmann festigen sollten ${ }^{14}$.

9 Siehe Manning, Swordsmen, S. 89.

10 Siehe Worden, Sound of Virtue, S. 187f.

11 Siehe Paul E.J. Hammer, The Polarisation of Elizabethan Politics. The Political Career of Robert Devereux, 2nd Earl of Essex, 1585-1597, Cambridge 1999, S. 53f.

12 Siehe ebd., S. 18.

13 Siehe ebd., S. 93f.

14 Siehe ders., Essex and Europe. Evidence from Confidential Instructions by the Earl of Essex, 1595-96, in: The English Historical Review 111 (1996), S. 356-381. 
Essex wurde 1601 hingerichtet, seine Politik scheiterte, aber in gewisser Weise führte Henry Prince of Wales, der älteste Sohn Jakobs I., bis 1612 diese Politik fort. Ein energischer Fürsprecher einer gesamteuropäischen protestantischen Abwehrhaltung gegenüber Rom und Madrid, ließ er seinen Hof zugleich zum kulturellen Zentrum der Spätrenaissance in England werden. Dies war nur möglich, weil dieser Hof sich bewusst kulturellen Einflüssen Kontinentaleuropas öffnete ${ }^{15}$. Dabei verließ sich der Prinz trotz seines militanten Protestantismus auch auf die Mittlerfunktion englischer Katholiken, für die es einfacher als für Protestanten war, Italien, insbesondere die päpstlichen Territorien, zu bereisen ${ }^{16}$.

Heinrich vertrat dezidiert die Haltung des kosmopolitischen protestantischen Glaubenskämpfers, ein wiederbelebtes Rittertum und konfessionelle Militanz verbanden sich in seiner Entourage. Er konnte sein politisch-kulturelles Programm zwar nicht mehr umsetzen, da er 1612 starb, aber andere folgten ihm auf diesem Weg. Als 1642 der englischen Bürgerkrieg ausbrach, hatten $70 \%$ aller Hochadligen, der peers, in ihrer Jugend oder später als Soldaten und Offiziere gekämpft, und sehr viele eben in einer fremden Armee, denn England befand sich mit Ausnahme der Jahre 1625-29 im Frieden mit seinen Nachbarn ${ }^{17}$. Viele hatten in den britischen Einheiten des niederländischen Heeres gedient, die zeitweilig nach 1585 zusammen mit den Schotten $30 \%$ und mehr aller Feldtruppen der Republik gestellt hatten und auch noch im frühen 17. Jahrhundert eine englische Garnison auf dem Kontinent bildeten ${ }^{18}$.

Sich zu einer gemeinsamen protestantischen Sache, die ganz Europa umfasste, zu bekennen, war für viele englische Adlige keine bloße Theorie, sondern fand einen konkreten Ausdruck im Militärdienst im Ausland. Es überrascht nicht, dass Adlige, deren Karriere am Hof gescheitert war oder die in Ungnade gefallen waren, besonders dezidiert im Ausland Anerkennung und Ruhm suchten, wie etwa der dritte Earl of Essex, der Sohn des elisabethanischen militärischen Führers. Der dritte Earl war später Oberbefehlshaber der Truppen des Parlamentes im Bürgerkrieg und gehörte in den 1620er und

15 Siehe Roy Strong, Henry Prince of Wales and England's Lost Renaissance, London 1986. Vgl. zur Bedeutung des Hofes des Thronfolgers als Ausgangspunkt einer spezifisch politischkulturellen Tradition auch Jaroslav MilLer, The Henrician Legend Revived. The Palatine Couple and its Public Image in Early Stuart England, in: European Review of History 11 (2004), S. 305-331.

16 Siehe Michael G. Brennan (Hg.), The Travel Diary (1611-1612) of an English Catholic, Sir Charles Somerset, Leeds 1993, S. 23-28.

17 Siehe Manning, Swordsmen, S. 17-19.

18 Ders., Apprenticeship, S. 41-43, 52-55. Zu den schottischen Einheiten in den Niederlanden vgl. Matthew Glozier, Scots in the French and Dutch Armies during the Thirty Years War, in: Steve Murdoch (Hg.), Scotland and the Thirty Years' War, 1618-1648, Leiden 2001, S. 117-141, hier: bes. S. 126. Siehe auch Hugh Dunthorne, Scots in the Wars of the Low Countries, 1572-1648, in: Grant Gray Simpson (Hg.), Scotland and the Low Countries, 1124-1994, East Linton 1996, S. $104-121$. 
1630er Jahren zu den energischsten Verfechtern der Causa Palatina und des militanten Protestantismus generell in England ${ }^{19}$. Adlige wie Essex oder Robert Rich, der zweite Earl of Warwick, ebenso wie Robert Sidney, der zweite Earl of Leicester, sahen sich als Teil einer transnationalen europäischen protestantischen Elite, und in dieser Eigenschaft stellten sie sich dem König auch 1642 bei Ausbruch des Bürgerkrieges entgegen ${ }^{20}$. Europäisches Bewusstsein und innenpolitische Opposition gehörten in diesem Fall also zusammen.

Diese Tendenz, die eigene soziale Rolle nicht nur im nationalen Kontext zu definieren, sondern in einem übergreifenden europäischen Rahmen, war allerdings noch ausgeprägter bei den katholischen peers, die zwar nur eine Minderheit darstellten, aber doch immerhin eine Minderheit, der zwischen $15 \%$ und $25 \%$ aller peers angehörten, je nachdem in welchem Maße man die »church papists « hinzurechnet ${ }^{21}$.

Für die Katholiken, die ja in England bei einem offenen Bekenntnis zu ihrem Glauben von vielen, wenn nicht allen Ämtern ausgeschlossen waren, waren Verbindungen ins katholische Ausland naturgemäß besonders wichtig. Nicht selten lebte ein konsequent katholischer Verwandter eines »church papist « - also eines Katholiken, der äußerlich seinen Glauben verbarg und sogar protestantische Gottesdienste besuchte - in einem katholischen Land auf dem Kontinent oder in Irland, wo man vor 1640 eher als in England mit stillschweigender Toleranz rechnen konnte und wo überdies die landbesitzende Oberschicht überwiegend katholisch war $^{22}$. Europa und das katholische Ausland waren für Katholiken aber auch wichtig, um den eigenen Status zu definieren und zu verteidigen. Der Adel Frankreichs, Spaniens und auch der katholischen Teile des Heiligen Römischen Reiches bot ihnen die relevanten »role models«, die Vorbilder für wahrhaft adliges Verhalten waren. Wie Richard Cust geschrieben hat:

19 Siehe Vernon F. Snow, Essex the Rebel. The Life of Robert Devereux, the Third Earl of Essex, 1591-1646, Lincoln (Nebr.) 1970.

20 Siehe zur Verbindung der Causa Palatina mit der Opposition gegen den König Thomas Cogswell, The Blessed Revolution. English Politics and the Coming of War, 1621-1624, Cambridge 1989, S. 102f.; vgl. John AdAmson, The Noble Revolt. The Overthrow of Charles I, London 2007, S. 361-365.

21 Zur katholischen Peerage siehe jetzt Anna PolikovskajA, Für Glauben und Krone. Die katholische Aristokratie in England 1603-1649, ungedruckte Dissertation, Universität Freiburg 2008; und siehe auch Michael Questier, Catholicism and Community in Early Modern England. Politics, Aristocratic Patronage and Religion, c. 1550-1640, Cambridge 2006; sowie Ethan Howard Shagan, Introduction. English Catholic History in Context, in: Ders. (Hg.), Catholics and the »Protestant Nation«. Religious Politics and Identity in Early Modern England, Manchester 2005, S. 1-21.

22 Siehe David Edwards, A Haven of Popery. English Catholic Migration to Ireland in the Age of Plantations, in: Alan Ford / John MCCAFFERTY (Hg.), The Origins of Sectarianism in Early Modern Ireland, Cambridge 2005, S. 95-126, hier: S. 109. 
The implication of all this was that, ultimately, the honour of a noble was to be judged not in narrowly English or Protestant terms, but in the context of the whole nobility of western Europe, much of which was Roman Catholic ${ }^{23}$.

Trotz der relativen kulturellen Isolation Englands und der wenigen »transnationalen« Konnubien spielte die Adelswelt Kontinentaleuropas für Teile des englischen Adels also doch eine gewisse Rolle. Sehr viel stärker waren diese »transnationalen« Bindungen aber in Schottland. Der bei den Wissenschaftlern aus der Neuesten Geschichte beliebte Ausdruck »transnational«, passt für die Frühe Neuzeit nur begrenzt, da es sich bei den frühneuzeitlichen Monarchien um keine modernen Nationalstaaten handelte, und die dynastischen Großreiche können noch nicht einmal als Vorform des Nationalstaates betrachtet werden, anders als z.B. die Königreiche England oder Frankreich ${ }^{24}$. Die Frage, in welchem Maße Teile des schottischen Adels sich nach 1603 auf England hin orientierten, wird an dieser Stelle übergangen. Man kann festhalten, dass für die Mehrheit der Hof in Whitehall nur eine sehr begrenzte Anziehungskraft hatte, vor allem nach 1625, nach dem Tode Jakobs I. ${ }^{25}$. Überdies, wer sich entschied, sich dauerhafter am Hofe aufzuhalten, verlor doch oft die Verbindung zu seiner Heimat, wurde anglisiert und in Schottland selbst damit Außenseiter.

Für viele schottische Adlige war biographisch die Affinität zum Kontinent viel größer als die zu England, man ging nach Dänemark, in die Niederlande, nach Schweden oder ins protestantische Deutschland, aber gelegentlich auch nach Frankreich oder sogar in kaiserliche oder spanische Dienste, um Geld als Militärunternehmer oder auch nur als Offizier zu verdienen. Der schottische Adel war arm und das Land tendenziell überbevölkert; angesichts der zumindest bis zum Ende des 16. Jahrhunderts noch verbreiteten Neigung,

23 Richard Cust, Catholicism, Antiquarianism and Gentry Honour. The Writings of Sir Thomas Shirley, in: Midland History 23 (1998), S. 40-70, hier: S. 56.

24 Zum Begriff siehe Gunilla Budde u.a. (Hg.), Transnationale Geschichte. Themen, Tendenzen und Theorien, Göttingen 2006; Jürgen Osterhammel, Imperien, in: Ebd., S. 56-67 und ders., Transnationale Gesellschaftsgeschichte. Erweiterung oder Alternative, in: Geschichte und Gesellschaft 27 (2001), S. 464-479.

25 Siehe zu dieser Frage Neil CudDy, Anglo-Scottish Union and the Court of James I, 16031625, in: Transactions of the Royal Historical Society, 5th Ser., 39 (1989), S. 107-124; Keith M. Brown, The Scottish Aristocracy, Anglicisation and the Court, 1603-1638, in: Historical Journal 36 (1993), S. 543-576; ders., The Scottish Nobility and the British Multiple Monarchy (1603-1714), in: Ronald G. Asch (Hg.), Der europäische Adel im Ancien Régime, Köln 2001, S. 363-384, hier: S. 364-366; ders., Noble Society in Scotland. Wealth, Family and Culture from Reformation to Revolution, Edinburgh 2000; ders., The Origins of a British Aristocracy. Integration and its Limitations before the Treaty of Union, in: Steven G. ELLIS / Sarah BArber (Hg.), Conquest and Union. Fashioning a British State, 1485-1725, Harlow 1995, S. 222-249, hier: S. 232-239; sowie ders., Courtiers and Cavaliers. Service, Anglicization and Loyalty among the Royalist Nobility, in: John MorriLl (Hg.), The Scottish National Covenant in its British Context, 1638-51, Edinburgh 1990, S. 155-192. 
lokale Konflikte gewaltsam auszutragen, war es nicht schwierig, im Land gute Soldaten anzuwerben, namentlich unter den Angehörigen des eigenen Verwandtschaftsverbandes, denn die Clanstrukturen begünstigten die massenhafte Rekrutierung von Soldaten ${ }^{26}$.

Gerade im frühen 17. Jahrhundert kam diesem Phänomen eine große Bedeutung zu, und ohne Zweifel prägten die Kriegsdienste auf dem Kontinent auch die Mentalität und die politische Haltung des schottischen Adels, wie nach dem Aufstand der Covenanters 1638 deutlich werden sollte. Wie wichtig die Präsenz der Schotten auf dem Kontinent war, wird an einigen Zahlen deutlich. $22 \%$ aller Offiziere des dänischen Heeres, das in Deutschland kämpfte, waren in den späten 1620er Jahren Schotten, und zwischen 1620 und dem Ende des Dreißigjährigen Krieges fochten an die 25.000 einfache Soldaten und ca. 2.000 Offiziere in der Armee Schwedens, das ja nur einen sehr kleinen einheimischen Adel besaß, was auch für Dänemark galt ${ }^{27}$. Nicht alle diese Offiziere gehörten von Haus aus zur adligen Oberschicht Schottlands, aber nicht wenige wurden von Gustav Adolf und seinen Nachfolgern nobilitiert, so auch der spätere Oberbefehlshaber der Armee der Covenanters, der schwedische Feldmarschall schottischer Herkunft Alexander Leslie ${ }^{28}$.

Der Kriegsdienst für Dänemark, Schweden und die Niederlande war für Schotten, soweit sie nicht Katholiken waren - und selbst einige Katholiken kämpften für Christian IV. von Dänemark oder sogar Gustav Adolf ${ }^{29}-$ zumindest nach 1620 der Normalfall, wenn sie als Soldaten und Militärunternehmer ins Ausland gingen. Die wenigsten Offiziere sahen sich dabei als reine Söldner. Nicht wenige glaubten, auch im Ausland für die heimische Dynastie zu kämpfen, denn durch die Heirat Elizabeth Stuarts mit dem Kurfürsten von der Pfalz, dem späteren Winterkönig, war ja die Causa Palatina, wie es schien, eng mit den dynastischen Interessen der Stuarts verbunden ${ }^{30}$.

26 Zur Bedeutung der Verwandtschaftsverbindungen für die Rekrutierung, die innere Struktur und die Kampfesweise schottischer Einheiten siehe auch Steve Murdoch, Network North. Scottish Kin, Commercial and Covert Association in Northern Europe, 1603-1746, Leiden 2006, S. 39.

27 Siehe Allan I. Macinnes, The British Revolution, 1529-1660, Basingstoke 2005, S. 53; Steve Murdoch, Britain, Denmark-Norway and the House of Stuart, 1603-1660. A Diplomatic and Military Analysis, East Linton 2000, S. 219; und die SSNE Datenbank, Scotland, Scandinavia and Northern Europe, URL: http://www.abdn.ac.uk/history/datasets/ssne.

$28 \mathrm{Zu}$ Leslie siehe Edward M. Furgol, A Regimental History of the Covenanting Armies, 16391651, Edinburgh 1990, S. 28; Sir James B. Paul (Hg.), The Scots Peerage, 9 Bde., Edinburgh, 1904-1914, hier: Bd. 5, S. 372-378; siehe auch David Stevenson, Art. »Leslie, Alexander, first earl of Leven (c. 1580-1661)«, URL: http://www.oxforddnb.com/view/article/16482 (eingesehen am 6.7.2007). Zur Nobilitierung von Offizieren durch Gustav Adolf siehe Alexia GrosJEAN, An Unofficial Alliance. Scotland and Sweden 1569-1654, Leiden 2003, S. 148.

$29 \mathrm{Zu}$ den Katholiken siehe Murdoch, Network North, S. 100.

30 Siehe ders., The House of Stuart and the Scottish Professional Soldier 1618-40. A Conflict of Nationality and Identities, in: Bertrand TAITHE / Tim THORNTON (Hg.), War. Identities in Conflict 1300-2000, Stroud 1998, S. 37-56, hier: S. 45. 
Freilich gab es auch Schotten, die es vorzogen, auf der Gegenseite zu kämpfen, also für das Haus Habsburg. Zu dieser Gruppe gehörte etwa Walter Leslie, der, obwohl von Haus aus Protestant, in die Dienste erst Spaniens und dann des Kaisers trat. Leslie gehörte zu den Personen, die daran beteiligt waren, Wallenstein zu beseitigen. Er wurde nach seiner Konversion in den Reichsgrafenstand erhoben und heiratete 1647 Franziska Dietrichstein, eine mährische Magnatentocher aus einer der reichsten Familien der Habsburgermonarchie. Interessant ist, dass Leslie sich eine gewissermaßen transnationale Herkunft zulegte. Er behauptete, von einem Ungarn abzustammen, der 1067 im Gefolge der Braut König Malcolms III. nach Schottland gekommen war, so dass er somit in Österreich nicht ganz und gar ein Fremder gewesen wäre ${ }^{31}$. Im Übrigen bewahrte sich Leslie auch im Ausland eine gewisse Loyalität gegenüber der Dynastie der Stuarts und versuchte, in den 1630er Jahren zwischen Karl I. und Wien diplomatisch zu vermitteln; er war für Karl I. jedenfalls ein wichtiger Kontaktmann in Wien ${ }^{32}$. Ein Beispiel vielleicht für das Wechseln zwischen verschiedenen Rollen und Identitäten, das für kosmopolitische Adlige wie Leslie typisch war.

Ohne Risiko war ein solches Spiel aber nicht. Einer der größten schottischen Magnaten, der Marquess von Hamilton (geb. 1606), befehligte in den frühen 1630er Jahren ein englisch-schottisches Expeditionskorps von 6.000 Mann, das sich dem Heer Gustav Adolfs anschloss. Dieses Engagement erfolgte im Auftrag Karls I., der auch die Rekrutierung der Soldaten finanzierte, um so doch noch die Pfalz für seine deutschen Verwandten zurückzugewinnen, ohne Wien oder Madrid offen den Krieg erklären zu müssen. Hamilton war überdies Oberststallmeister und Kammerherr des Königs und ein enger Vertrauter. Aber diese Identifikation mit der Sache des gesamteuropäischen Protestantismus prägte Hamiltons Haltung offenbar dauerhaft. Nach seiner Rückkehr nach England war er eine Art inoffizieller Botschafter Schwedens in England und versuchte sogar, eine Heiratsverbindung zwischen der schwedischen Dynastie und den pfälzischen Wittelsbachern zu Stande zu bringen ${ }^{33}$. Angesichts der zunehmenden Gleichgültigkeit Karls I. gegenüber dem Schicksal der Pfalz und dem der kontinentaleuropäischen

$31 \mathrm{Zu}$ Leslie siehe David Worthington, Alternative Diplomacy? Scottish Exiles at the Courts of the Habsburgs and their Allies, 1618-1648, in: Murdoch, Scotland and the Thirty Years War, S. 51-75, hier: S. 58f. und 71f. Vgl. auch ders., Art. »Leslie, Walter, Count Leslie in the nobility of the Holy Roman empire (1606-1667)«, in: Oxford Dictionary of National Biography, URL: http://www.oxforddnb.com/view/article/16501 (eingesehen am 6.7.2007). Leslie erhielt 1665 den Orden vom Goldenen Vlies.

32 Siehe ders., Scots in Habsburg Service, 1618-1648, Leiden 2004, S. 179f., 202-205 und $222-230$.

$33 \mathrm{Zu}$ Hamiltons Karriere siehe John Joseph SCALly, The Political Career of James, third Marquis and first Duke of Hamilton, 1606-1649, to 1643, Ph. D. thesis, Cambridge 1992, S. 36-50. Siehe auch ders., Art. »Hamilton«; und Hilary L. Rubinstein, Captain Luckless. James, first Duke of Hamilton, 1606-1649, Edinburgh 1975. 
Protestanten insgesamt waren Spannungen zwischen Hamilton und dem König freilich auf diese Weise schwer zu vermeiden. Zeitweilig warf man Hamilton sogar vor, in eine Verschwörung zum Sturz des Königs verwickelt zu sein, um selbst nach der Krone zu greifen, denn er war mit den Stuarts eng verwandt. Er selbst mag zumindest bis 1640 gegenüber dem König loyal gewesen sein, aber die Männer, die in seinem Expeditionskorps in Deutschland gedient hatten, sahen in Karl I. oft genug einen Herrscher, der, anders als Gustav Adolf, allzu viel Kompromisse mit Rom und Madrid geschlossen hatte. Hamilton hatte auf dem Kontinent somit eine Klientel erworben, die auch seine eigene politische Position potentiell bestimmte und ihn in einen Gegensatz zum König brachte.

Weitaus deutlicher als Hamilton standen aber jene Schotten in Opposition zu Karl I., die die gesamten 1630er Jahre als Soldaten auf dem Kontinent verbracht hatten, jedenfalls soweit sie für Schweden fochten. Von diesen Exilschotten kehrten immerhin 302 Offiziere nach 1637 in ihre Heimat zurück, um das Heer der aufständischen Covenanters zu führen, darunter 18 Obristen und Oberstleutnants, drei Generalmajore und ein schwedischer Feldmarschall, eben Alexander Leslie ${ }^{34}$. Der Sieg der Covenanters über Karl I. in den beiden Bishops' Wars wäre ohne diese Offiziere nahezu unmöglich gewesen, obwohl es auch eine Reihe von Schotten gab, die für den König kämpften, wie etwa den General James King oder den katholischen Earl of Crawford, der in spanischen Diensten gestanden hatte ${ }^{35}$. Leslie selbst begründete gegenüber Oxenstierna, dem schwedischen Kanzler, sein Engagement für die Sache der Covenanters mit seinem Patriotismus ${ }^{36}$; die patria, für die er focht, war freilich in ihrer Identität definiert durch den Bezug auf angestammte Freiheitsrechte und den wahren Glauben, es handelte sich somit um einen konfessionellen Patriotismus, der sehr gut mit der Loyalität gegenüber einem gesamteuropäischen Protestantismus verträglich $w^{37}{ }^{37}$. Faktisch mag neben diesem konfessionellen Patriotismus für Leslies Entscheidung, sich den Covenanters anzuschließen, allerdings auch der Um-

34 Siehe Alexia Grosjean, General Alexander Leslie, the Scottish Covenanters and the Riksråd Debates, 1638-1640, in: Allan I. Macinnes / Thomas Ris / Frederik G. Pedersen (Hg.), Ships, Guns and Bibles in the North Sea and Baltic States, c. 1350-1700, East Linton 2000, S. 115-138, hier: S. 124-126.

35 Siehe Murdoch, Network North, S. 41 und 44f. Generell zu Offizieren mit ausländischer Kriegserfahrung oder auch ausländischer Herkunft im Heer des Königs (nicht notwendigerweise Schotten) siehe Barbara Donagan, War in England 1642-1649, Oxford 2008, S. 232-236.

36 Siehe Leslie an Oxenstierna, 8. Aug. 1639, Axel Oxenstierna, Rikskansleren Alex Oxenstiernas Skrifter och Brefvexling, hg. v. Kongl. Vitterhets-, Historie- och Antiqvitetsakademien Stochholm, Senare Afdelingen, vol. IX, Stockholm 1898, S. 482, wo Leslie schreibt: »De toto negotio hoc affirmare possum, id, ubivis terrarum cordatis omnibus et patriae amantibus, praesertim quibus cordi est verae religionis amor, acceptum fore«. Vgl. auch GrosJEAn, General Alexander Leslie.

37 Zur Idee den Patriotismus in der Frühen Neuzeit siehe Robert von Friedeburg (Hg.), »Patria« 
stand eine Rolle gespielt haben, dass sein Ziehvater (viele schottische Familien gaben ihre Kinder an Pflegeeltern, die damit faktisch als Blutsverwandte galten) ein Campbell war und Leslie damit in Verbindung zum Earl of Argyle, dem Chef des Clans Campbell, stand. Argyle war von Anfang an ein führender Covenanter ${ }^{38}$.

Es wäre zwar eine Zuspitzung zu sagen, dass der Aufstand der Covenanters 1638 vor allem deshalb ausbrach, weil Schottlands Bindungen an Schweden, den baltischen Raum und generell das protestantische Nordeuropa enger waren als die Bindungen an England, aber dennoch spielten solche Beziehungen für den Erfolg und den Verlauf der schottischen Revolution bis weit in die 1640er Jahre sicherlich eine wesentliche Rolle ${ }^{39}$.

Zum Abschluss soll nun ein kurzer Blick auf Irland und die unterschiedlichen Adelseliten dieses Landes geworfen werden, insbesondere die Old English $^{40}$, die katholischen Nachkommen der anglo-normannischen Adligen des Mittelalters, und die führenden gälischen Familien, aber auch auf die Protestanten. Irland war anders als Schottland kein Königreich, das nur in einer Personalunion mit England verbunden war, sondern eine abhängige Provinz, die in mancher Hinsicht schon wie eine Kolonie behandelt wurde. An diese Situation mussten sich nach dem Scheitern der Rebellion Tyrones 1604 auch die katholischen Adligen auf Dauer anpas$\operatorname{sen}^{41}$. Sie entwickelten dabei jedoch zumindest zum Teil eine erhebliche Geschicklichkeit, indem sie zwischen unterschiedlichen politischen und sozialen Rollen, aber auch unterschiedlichen kulturellen Identitäten wechselten, wie das Jane Ohlmeyer für den Earl of Antrim gezeigt hat, der seinen Stammsitz im Osten Ulsters hatte, aber einem Verwandtschaftsver-

und »Patrioten« vor dem Patriotismus. Pflichten, Rechte, Glauben und Rekonfigurierung europäischer Gemeinwesen im 17. Jahrhundert, Wiesbaden 2005.

38 Siehe Murdoch, Network North, S. 42.

39 Siehe Macinnes, Revolution, S. 123; Edward M. Furgol, Scotland turned Sweden. The Scottish Covenanters and the Military Revolution, in: John S. MorriLl (Hg.), The Scottish National Covenant in its British Context, 1638-51, Edinburgh 1990, S. 134-154.

$40 \mathrm{Zu}$ den Old English siehe Alan Ford, »Firm Catholics« or »Loyal Subjects «? Religious and Political Allegiance in Early Seventeenth-century Ireland, in: David George Boyce / Robert Eccleshall / Vincent Geoghegan (Hg.), Political Discourse in Seventeenth and EighteenthCentury Ireland, Basingstoke 2001, S. 1-31; und siehe Aidan Clarke, The Old English in Ireland, 1625-1642, London 1966.

41 Zur Lage in Irland siehe Nicholas CAnny, Making Ireland British, 1580-1650, Oxford 2001; Ciaran BRADY, The Chief Governors. The Rise and Fall of Reform Government in Tudor Ireland, 1535-1588, Cambridge 1994. Zum Scheitern der Reformation in Irland siehe Ute LotzHeumann, Die doppelte Konfessionalisierung in Irland. Konflikt und Koexistenz im 16. und in der ersten Hälfte des 17. Jahrhunderts, Tübingen 2000. Und aktueller siehe ForD / MCCAFFERTY, Origins of Sectarianism. Siehe auch Ronald G. Asch, Die Englische Herrschaft in Irland und die Krise der Stuart-Monarchie im 17. Jahrhundert, in: Historisches Jahrbuch 110 (1990), S. 370-408. Schließlich zur Ulster Plantation: Philip S. Robinson, The Plantation of Ulster. British Settlement in an Irish Landscape, 1600-1670, Belfast ${ }^{2} 1994$. 
band, den Mac Donalds oder MacDonnells entstammte, der ursprünglich in Westschottland ansässig gewesen war. Antrim, der 1609 geboren war, starb 1683 und durchlebte die Wirren der Jahrhundertmitte in Ulster. Antrim war gälischer Herkunft und Katholik und im Übrigen auch mit Tyrone verwandt, aber zugleich ein wichtiger Höfling in Whitehall, der die Witwe des ermordeten Favoriten Buckingham heiratete und damit schon fast zur Königsdynastie selbst gehörte ${ }^{42}$. Seine Vorfahren hatten sich als Vorkämpfer einer sogenannten Zivilisierung Ulsters geriert und hatten schottische Siedler ins Land gebracht. Antrims Vater war eben deshalb in die peerage erhoben worden, weil er die angeblich barbarischen einheimischen Iren zurückgedrängt hatte ${ }^{43}$. Sein Sohn verdiente sich wie andere Magnaten in Irland im Übrigen vor 1640 sein Geld, indem er Soldaten für Spanien rekrutierte. Das war durchaus legal, denn England und Spanien waren nicht im Krieg und der englische König war froh, möglichst viele junge irische Männer, besonders wenn es Katholiken waren, nach Flandern und Brabant schicken zu können ${ }^{44}$.

1650 standen dort immerhin zwölf irische Regimenter in spanischen Diensten, während acht für Frankreich fochten. Die Offiziere dieser Regimenter waren teils gälischer Herkunft, teils gehörten sie auch zu den Old English. Die Letzteren suchten auch im Ausland als loyale Untertanen der englischen Krone zu erscheinen und wurden in London auch bis zu einem gewissen Grade in dieser Rolle gesehen, trotz ihrer Konfession ${ }^{45}$. Anders die "mere" Irish, die ihr Land und ihren Status in der Heimat verloren hatten; ihre anti-englische Haltung war stärker, aber wahrscheinlich entstand erst in der Fremde das Bewusstsein einer gemeinsamen irischen Identität. Vorher hatte man sich eher dem eigenen Verwandtschaftsverband oder einer Region zugehörig gefühlt. Zudem, so ist argumentiert worden, gaben die Ideale der katholischen Reform und der Gegenreformation, für die jeder spanische Offizier immer auch kämpfte, den Exulanten ein spezifisches Ethos, das ihre

42 Siehe Jane H. Ohlmeyer, Civil War and Restoration in the Three Stuart Kingdoms. The Career of Randall MacDonnell, Marquis of Antrim, 1609-1683, Cambridge 1993.

43 Siehe George Hill, An Historical Account of the MacDonnells of Antrim. Including Notices of some other Septs, Irish and Scottish, Belfast, 1873, S. 231f. und 247-249.

44 Siehe Ohlmeyer, Antrim, S. 282.

45 Siehe Gráinne Henry, The Irish Military Community in Spanish Flanders, 1586-1621, Dublin 1992, S. 114-120. Siehe auch Robert A. Stradling, The Spanish Monarchy and Irish Mercenaries. The Wild Geese in Spain, 1618-1668, Blackrock 1994. Vgl. P. Gounier, Mercenaires irlandais au service de la France, 1635-1664, in: Revue d'histoire moderne et contemporaine 15 (1968), S. 672-690; und Éamon Ó CiosÁın, A Hundred Years of Irish Immigration to France, 1590-1688, in: Thomas O'Connor (Hg.), The Irish in Europe, 1580-1815, Dublin 2001, S. 93-106. Zur Emigration nach Kastilien auch Ciaran O'SCEA, Irish Immigration to Castile in the Opening Years of the Seventeenth Century, in: Patrick J. Duffy / Gerry Moran (Hg.), To and From Ireland. Planned Migration Schemes, c. 1600-2000, Dublin 2004, S. 17-38. 
ihre Militärkarriere erst legitimierte und über einen bloßen Söldnerdienst hinaushob ${ }^{46}$.

Für die katholischen Adligen, die in Irland zurückblieben, war es unvermeidlich, zwischen unterschiedlichen Identitätsoptionen zu wechseln. Antrim selbst, der als Beispiel schon genannt wurde, zeigt dies deutlich genug. Der Chef eines gälischen Clans, Mitglied einer gesamtbritischen aristokratischen Elite und ein Militärunternehmer, der auf der europäischen Bühne agierte, präsentierte sich wahlweise als loyaler Diener der Stuarts und als irischer Patriot. Antrim wechselte auch nach Beginn des irischen Aufstandes 1641 mehrmals die Seiten und kam am Ende sogar zu einem Arrangement mit Cromwell. Seine Biographin hat von einem Chamäleon-ähnlichen Verhalten gesprochen und von »divided loyalties, occasionally amounting almost to an identity crisis $\ll^{47}$.

Aber unter einem Identitätskonflikt litten nicht nur katholische Adlige, Ähnliches galt potentiell auch für Protestanten, die von Einwanderern abstammten, die nach der Mitte des 16. Jahrhunderts ins Land gekommen waren, oder selbst als erste in Irland Fuß gefasst hatten. Richard Boyle etwa, der erste Earl of Cork (1566-1643), ist dafür ein Beispiel. Mit erheblicher Skrupellosigkeit hatte er sich in Irland in den Besitz enormer Latifundien gesetzt, übrigens auch auf Kosten der protestantischen Kirche, war aber eigentlich ein Aufsteiger aus einer Bauernfamilie in $\mathrm{Ken}^{48}$. Er konnte sich in Irland einerseits durchaus als Erbe irischer politischer und kultureller Traditionen inszenieren, während er andererseits, obwohl oder weil er ein homo novus war, bestrebt war, zur exklusiven Aristokratie seiner englischen Heimat $\mathrm{Zu}$ gang zu finden. Seine Kinder heirateten vielfach in die englische peerage ein. Es kam auch zu Konnubien mit etablierten Familien in Irland, wobei die Ehepartner aber Protestanten waren. Eine seiner Töchter etwa heiratete den 16. Earl of Kildare, George Fitzgerald. Fitzgerald war der Nachkomme einer Familie, die einst zu den mächtigsten anglo-normannischen Geschlechtern in Irland gehört hatte, sich aber seit der Mitte des 16. Jahrhunderts im Niedergang befand. Cork war auf dieses Konnubium stolz und suchte das Prestige der finanziell ruinierten Fitzgeralds wiederherzustellen, um damit auch seine eigene Familie fester zu etablieren ${ }^{49}$. Ja, Cork war bestrebt, sich oder zumindest seinen Nachkommen in gewisser Weise eine irischen Ahnenreihe zuzulegen, ein wenig so, wie manche neue Familien, die nach den Konfiskationen in Böhmen und Mähren nach 1620 Fuß fassten, für sich eine böh-

46 Siehe Gráinne Henry, Ulster Exiles in Europe, 1605-1641, in: Brian MacCuarta SJ (Hg.), Ulster 1641. Aspects of the Rising, Belfast 1993, S. 37-60.

47 Ohlmeyer, Antrim, S. 8, vgl. ebd., S. 188-192.

48 Siehe Nicholas Canny, The Upstart Earl. A Study of the Social and Mental World of Richard Boyle, first Earl of Cork, 1566-1643, Cambridge 1982.

49 Siehe ders., Earl, S. 51. 
mische Vergangenheit zu konstruieren suchten. Dazu passt es, dass Cork sich auch bemühte, seine Kinder Gälisch lernen zu lassen ${ }^{50}$

Corks Erben und Nachfolger verstanden es tatsächlich trotz ihres Protestantismus, die Konfliktlinien der irischen Gesellschaft durch ihre vielfältigen Kontakte und Verbindungen partiell zu überwinden, sie waren dabei durchaus bereit, ihre politische Haltung mit einer Chamäleon-gleichen Flexibilität zu verändern, wie Patrick Little über Lord Broghill, Corks dritten Sohn, geschrieben hat ${ }^{51}$.

Eine solche Anpassungsfähigkeit zeichnete den mächtigsten angloirischen Adligen dieser Epoche, James Butler, den 12. Earl und ersten Herzog von Ormonde (1610-1688), in noch höherem Maße aus. Ormonde entstammte einer alten anglo-normannischen Familie, den Butlers, die lange katholisch geblieben war, während er selbst dank seiner Vormünder als Protestant aufwuchs. Ormonde betonte politisch und kulturell sehr stark seine protestantische und englische Identität, brach aber die Beziehungen zu seinen zahlreichen katholischen Verwandten und Klienten nie $\mathrm{ab}^{52}$. Er machte nie einen Versuch, seine katholischen Verwandten zu bekehren ${ }^{53}$, entscheidend war allein die politische Loyalität gegenüber der englischen Krone. Hinzu trat eine deutliche Öffnung gegenüber der Adelskultur des Kontinents. Ormonde selbst hatte in den 1650er Jahren einige Jahre im Exil im Ausland verbracht, und sein Sohn Thomas heiratete eine Niederländerin, die mit dem Hause Oranien verbunden war $^{54}$.

Ormonde war nach 1660 schon durch seinen Herzogstitel eine Ausnahmeerscheinung in Irland und bewegte sich auf der europäischen Bühne ebenso sicher wie am Hofe in Whitehall. Situativ entschied er sich für eine englische, eine eher irische oder eine kosmopolitische europäische Identität als Aristokrat, oder wie Toby Barnard es formuliert hat:

50 Siehe ebd., S. 126-128; vgl. Patrick LittLe, Lord Broghill and the Cromwellian Union with Ireland and Scotland, Woodbridge 2004, S. 14 und 17; siehe auch ders., The Geraldine Ambitions of the First Earl of Cork, in: Irish Historical Studies 33 (2002), S.151-168.

51 Siehe Little, Broghill, S. 196.

52 Siehe David Edwards, The Poisoned Chalice. The Ormond Inheritance, Sectarian Division and the Emergence of James Butler, 1614-1642, in: Toby C. Barnard / Jane Fenlon (Hg.), The Dukes of Ormonde, 1610-1745, Woodbridge 2000, S. 55-82, hier: S. 57; und Eleanor O'KeEfFE, The Family and Marriage Strategies of James Butler, First Duke of Ormonde, 1658-1688, Ph. D. thesis, Cambridge 2000, S. 140-142. Siehe auch William Pius Kelly, The Early Career of James Butler, twelfth Earl and First Duke of Ormond, 1610-1688, Ph. D. thesis, Cambridge 1997. Zu den Earls of Ormond siehe auch David Edwards, The Ormond Lordship in County Kilkenny, 1515-1642. The Rise and Fall of Butler Feudal Power, Dublin 2003.

53 Siehe Toby C. Barnard, Aristocratic Values in the Careers of the Dukes of Ormonde, in: Ders. / FENLON, Ormonde, S. 161-175, hier: S. 167.

54 Siehe ders., Introduction. The Dukes of Ormonde, in: Ders. / Fenlon, S. 1-54, hier: S. 53 und 37, und ders., Aristocratic Values, in: Ebd., S. 172. 
The Ormondes conformed themselves to and may sometimes have set, a standard, that in turn competitors and toadies copied. These standards, at first anglicised, latterly cosmopolitan, set the Ormondes apart, as they intended, from lesser nobles ${ }^{55}$.

Das heißt, die europäische Adelskultur war für Ormonde auch ein Mittel, um den Statusunterschied zu den anderen irischen Adligen zu betonen, die im Vergleich zu ihm als Provinzler erscheinen mussten. Die zunehmende Europäisierung der englischen Adelskultur nach 1660 wird es Ormonde im Übrigen aber auch erleichtert haben, zwischen den irischen Wurzeln seiner Familie und seiner neuen Zugehörigkeit zur englischen protestantischen Aristokratie einen gewissen Ausgleich und ein verbindendes Element zu finden. Man kann in seinem Fall ähnlich wie beim Marquess von Antrim von einer »hybriden Identität« sprechen. »The multiple identities between which the chamaleon-like Ormondes could shift included Irish, English, and European $\aleph^{56}$.

Wirft man einen Blick auf den Adel Englands, Schottlands und Irlands mit dem Ziel, die kosmopolitischen Elemente in der kulturellen und politischen Identität dieser Adelgruppierungen zu identifizieren, gilt es, dabei zu betonen: Die Beziehung zwischen unterschiedlichen Identitäten oder Identifikationen war nie ein Nullsummenspiel, man musste nicht wählen, man konnte sehr wohl zugleich englischer, irischer oder schottischer Patriot und zugleich ein europäischer Aristokrat sein, ja diese unterschiedlichen Identitäten konnten sich gegenseitig verstärken. Ein Adliger, der in einer zusammengesetzten Monarchie wie der der Stuarts lebte, war dabei genötigt, mehrere Rollen gleichzeitig zu spielen. Loyalität gegenüber der engeren regionalen oder nationalen politischen Herkunft trat neben die Bindungen an die Dynastie und die Gesamtmonarchie, und dies alles wurde potentiell überwölbt durch die Zugehörigkeit zu konfessionellen oder auch kulturellen Gemeinschaften, die in ihrem Zuschnitt gesamteuropäisch waren. Es galt, die Beziehungen zwischen diesen unterschiedlichen Bindungen und Loyalitäten situativ immer erneut auszuhandeln. Das galt natürlich besonders für die Adelseliten an der Peripherie, deren Status im Zentrum unklar war und die wie die katholischen Iren, aber auch ihre protestantischen Standesgenossen bei Hofe mit einem gewissen politischen und sozialen Argwohn betrachtet wurden.

Freilich konnten, wie sowohl der schottische als auch der irische Fall zeigen, ein längerer Aufenthalt im Ausland und noch mehr Kriegsdienste in fremden Armeen auch das vielleicht zuvor nur schwach entwickelte nationale Bewusstsein fördern. Der Kampf für die Sache des Protestantismus verstärkte auf diese Weise bei schottischen Adligen die Überzeugung, dass ihr eigenes Land dazu ausersehen war im Endkampf mit den Mächten der Fins-

55 Barnard, Aristocratic Values, S. 175.

56 Ders., Introduction, S. 53. 
ternis eine prominente Rolle zu spielen, und in ähnlicher Weise gewannen die irischen Offiziere in Flandern die Überzeugung, dass ihr Land Teil einer gesamteuropäischen katholischen Gemeinschaft war und es daher durchaus wagen konnte, sich von England partiell oder ganz unabhängig zu machen.

Für die Vorgeschichte des Krieges der drei Königreiche waren die transnationalen Bindungen und Loyalitäten sowohl des schottischen als auch des irischen Adels jedenfalls von großer Bedeutung. In einer zusammengesetzten Monarchie war es natürlich nicht ungewöhnlich, dass periphere Fürstentümer und Provinzen stärker in transnationale oder transdynastische Netzwerke integriert waren als das Zentrum. Das galt zum Beispiel im Mittelmeerraum für das spanische Königreich Neapel, das in vieler Hinsicht engere Bindungen an die päpstlichen Territorien besa $\beta$ als an Aragon oder gar Kastilien $^{57}$. Aber im britischen Fall wirkte der Dreißigjährige Krieg wie ein Katalysator, der die bestehenden transnationalen oder besser vielleicht transdynastischen Bindungen verstärkte oder verwandelte. Damit intensivierten sich die Beziehungen Schottlands zu Skandinavien und dem Baltikum, während umgekehrt die Bindungen zwischen dem katholischen Irland und Spanien ebenfalls vertieft wurden, jedenfalls wenn man auf die Zahl der irischen Soldaten blickt, die für Spanien kämpften. Infolgedessen wuchsen in der britischen Monarchie die zentrifugalen Tendenzen, und der Bürgerkrieg, respektive der Krieg der drei Königreiche, war auch ein Resultat dieser Entwicklung der nachhaltigen Europäisierung, wenn schon nicht des englischen, so doch des katholischen irischen und schottischen protestantischen Adels.

57 Siehe Guido Metzler, Die doppelte Peripherie. Neapel als römische Kolonie und als spanische Provinz, in: Wolfgang Reinhard (Hg.), Römische Mikropolitik unter Papst Paul V. Borghese (1605-1621) zwischen Spanien, Neapel, Mailand und Genua, Tübingen 2004, S. 179-334. 


\section{Martin Peters \\ Europa im Blick der Geschichte und Statistik (1750-1815)}

I.

Die Erforschung des Profils von Europa war seit der Mitte des 18. Jahrhunderts ein zentrales Anliegen der historischen Wissenschaften. Bislang fehlt es noch an einer systematischen Auswertung der Europavorstellungen, die in den historischen und statistischen Studien des Zeitraums 1750 bis 1815 vermittelt wurden. Dies ist erstaunlich, weil sich gerade in dieser Zeit die »Europäische Staatengeschichte« und »Statistik« als eine neue eigenständige Forschungsrichtung an den Hochschulen etablierte. Denn seit den 1770er Jahren verdichteten sich die historisch-statistischen Forschungen institutionell immer stärker, so dass es zu einer engen Verzahnung beider Fächer kam. Lehrstühle für Geschichte und Statistik wurden eingerichtet oder Professoren berufen, die entsprechende Veranstaltungen anbieten konnten. Besonders an den Universitäten in Göttingen, Leipzig, Helmstedt, Erlangen, Landshut, Berlin und Königsberg wurde erfolgreich Geschichte und Statistik gelehrt und erforscht. Ganz offensichtlich musste Geschichte, um erfolgreich zu sein, fortan mithilfe der Statistik geschrieben werden ${ }^{1}$. Nicht mehr die chronologische Behandlung von Ereignissen, sondern vielmehr die Transformation von politischen Ordnungen rückte in den Fokus des Faches. Klimabedingungen, Bevölkerungszahlen, natürliche Ressourcen, dynastische, staatliche und gesellschaftliche Entwicklungen in Religion, Verfassung, Verwaltung, Militär und Schulwesen gewannen an Bedeutung, um den jeweiligen »Zustand « eines Staates - das Kardinalthema der Statistik - aus den historischen Prozessen heraus zu beschreiben mit dem Ziel, Reformvorschläge zur Optimierung der jeweiligen Verhältnisse zu unterbreiten. Die einzelnen europäischen Staaten wurden miteinander verglichen, begrenzt, bemessen und nach ihren Verfassungen beschrieben. Mit diesen Anstrengungen sollten vor allem zwei drängende Fragen beantwortet werden, nämlich: Wie ließ sich die Zusammengehörigkeit der europäischen Staaten begründen und was konnte Europa als Einheit in Vielheit leisten?

Schon seit Hermann Conring (1606-1681) hatte sich die Statistik als Universitätsdisziplin formiert ${ }^{2}$ und seit Gottfried Achenwall (1719-1772) in den

1 Beispielhaft ist der Göttinger Historiker Johann Christoph Gatterer (1727-1799), der 1773 ein »Ideal einer allgemeinen Weltstatistik« verfasst.

2 Vgl. Harm Klueting, Die Lehre von der Macht der Staaten. Das außenpolitische Machtproblem 
1750er Jahren gleichsam als Parade- und Modewissenschaft des 18. Jahrhunderts etabliert ${ }^{3}$. Auch Johann Peter Süßmilch (1707-1767) mit seinem Werk Die göttliche Ordnung (1740) wirkte maßgeblich an diesem Prozess mit, indem er die »Politische Arithmetik« und »Demographie« zu einem Wissenschaftszweig ausbildete. August Ludwig Schlözer (1735-1809) gab mit den Briefwechseln und den StatsAnzeigen (1775-1794) gleichsam »Zentralorgane" heraus mit wertvollen historischen, politischen und statistischen Daten und Ressourcen. Impulse für die Entwicklung der Europäischen Staatengeschichte und Statistik lieferten darüber hinaus die Erforschung der »internationalen Beziehungen« sowie des »Europäischen Völkerrechts«. Der Blick über die Grenze des eigenen Reiches, Landes und Staates hinaus und die Perspektive auf die internationalen Beziehungen setzte, wie Heinz Duchhardt konstatiert, schon früh in den ersten zwei Jahrzehnten des 18. Jahrhunderts $e^{2}{ }^{4}$. Seit 1750 erarbeitete Johann Jacob Moser (1701-1785) systematisch ein Europäisches Völkerrecht ${ }^{5}$. Das Wissen um die Europäische Staatengeschichte und Statistik gehörte fortan zur Ausbildung angehender Regenten, Diplomaten und Beamten. Ohne dieses Wissen um und über Europa war politisches Handeln unmöglich geworden.

\section{II.}

Am Aufschwung der Disziplinen der Europäischen Staatengeschichte und der Statistik hatte die Universität Göttingen großen Anteil, sowohl durch Achenwall als auch vor allem durch Georg Christian Gebauer (1690-1773) ${ }^{6}$. Einen wichtigen Impuls für den Auf- und Ausbau der Schwerpunkte Geschichte und

in der "politischen Wissenschaft« und in der praktischen Politik im 18. Jahrhundert, Berlin 1986, bes. S. 39-83; Arno SeIfErt, Staatenkunde - eine neue Disziplin und ihr wissenschaftshistorischer Ort, in: Mohammed Rassem / Justin Stagl (Hg.), Statistik und Staatsbeschreibung in der Neuzeit vornehmlich im 16.-18. Jahrhundert (Bericht über ein interdisziplinäres Symposion in Wolfenbüttel, 26.-27. September 1978), Paderborn u.a. 1980, S. 217-248.

3 Klueting, Macht, S. 58. 1748 erschien Gottfried Achenwalls »Vorbereitung zur Staatswissenschaft der heutigen fürnehmsten europäischen Reiche und Staaten worinnen derselben eigentlichen Begriff und Umfang in einer bequemen Ordnung entwirft und seine Vorlesungen darüber ankündigt «.

4 Heinz Duchhardt, Die Formationsphase der Wissenschaft von den internationalen Beziehungen. Christian Gottfried Hoffmanns Entwurff einer Einleitung zu dem Erkänntniß des gegenwärtigen Zustandes von Europa von 1720, in: Sven ExternbrinK / Jörg Ulbert (Hg.), Formen internationaler Beziehungen in der Frühen Neuzeit. Frankreich und das Alte Reich im europäischen Staatensystem. Festschrift für Klaus Malettke zum 65. Geburtstag, Berlin 2001, S. 37-42.

5 Vergleiche den Beitrag von Karl-Heinz Lingens in diesem Band (Europa in der Lehre des »praktischen Völkerrechts«, S. 173-186).

6 Georg Christian Gebauer, Grund-Riss zu einer umständlichen Historie der vornehmsten europäischen Reiche und Staaten, Leipzig 1749. 
Statistik gab das weitreichende Privileg der Veröffentlichungsfreiheit, das die Göttinger Hochschullehrer genossen. Unterstützend wirkte sich zudem das europäische Gelehrtennetzwerk Göttingens und seiner Professoren aus, das vor allem nach Schweden, Frankreich, England, Russland, Österreich und Ungarn geknüpft wurde. Die Göttinger Professoren entwickelten ein Kommunikationssystem, das sie in kurzer Zeit mit vielfältigen Nachrichten und Informationen aus ganz Europa versorgte. Zu den herausragenden Vertretern dieser deutschsprachigen Europäischen Staatengeschichte und Statistik gehörten neben Gottfried Achenwall ${ }^{7}$ zudem auch Anton Friederich Büsching ${ }^{8}$, Eobald Toze $^{9}$, Johann Georg Meusel ${ }^{10}$, August Friedrich Wilhelm Crome ${ }^{11}$, Julius August Remer ${ }^{12}$ sowie Adolph Friedrich Randel ${ }^{13}$. Auch der Völkerrechtler Georg Friedrich von Martens hatte an diesem Wissenschaftsschub großen Antei $1^{14}$. Wie erfolgreich diese Autoren im Deutschen Reich waren, belegen die vielfachen Auflagen ihrer Werke, vor allem Achenwalls und Meusels ${ }^{15}$.

Den Wissenschaftsaustausch zwischen Frankreich und dem Deutschen Reich prägte in besonderem Maße der Elsässer Historiker und Staatsrechtler Christoph Wilhelm Koch ${ }^{16}$. Weitere Schnittstellen und intensiver Austausch bestanden auch mit Dänemark, z.B. über die Universität Kiel oder Gelehrtenkreise in Altona. Toze erlangte durch die Übertragung seiner Europäischen Staatskunde ins Dänische internationale Aufmerksamkeit ${ }^{17}$. Von den

7 Gottfried Achenwall, Staatsverfassung der Europäischen Reiche im Grundrisse, Göttingen 1752. Ferner: ders., Entwurf der allgemeineren europäischen Staatshändel des XVII. und XVIII.ten Jahrhunderts, Göttingen 1756.

8 Anton Friederich Büsching, Vorbereitung zur gründlichen und nützlichen Kenntniss der geographischen Beschaffenheit und Staatsverfassung der europäischen Reiche und Republiken: Welche zugleich ein allgemeiner Abriss von Europa ist, Hamburg 1761.

9 Eobald Toze, Der gegenwartige Zustand von Europa, worin die natürliche und politische Beschaffenheit der europaischen Reiche und Staaten aus bewahrten Nachrichten beschrieben wird, Bützow 1767.

10 Johann Georg Meusel, Anleitung zur Kenntnis der europäischen Staatenhistorie, Leipzig 1775.

11 August Friedrich Wilhelm Crome, Ueber die Größe und Bevölkerung der sämtlichen europäischen Staaten. Mit einer illuminirten Karte, Leipzig 1785.

12 Julius August Remer, Tabellen zur Aufbewahrung der wichtigsten statistischen Veränderungen in den vornehmsten europäischen Staaten, 12 Bände, Braunschweig 1786-94.

13 Adolph Friedrich Randel, Annalen der Staatskräfte von Europa: Nach den neuesten physischen, gewerblichen, wissenschaftlichen und politischen Verhältnissen der sämmtlichen Reiche und Staaten, in tabellarischen Übersichten, 2 Theile, Berlin 1792-1805.

14 Georg Friedrich von Martens, Grundriß einer diplomatischen Geschichte der europäischen Staatshändel [...] Zum Gebrauch academischer Vorlesungen, Berlin 1807.

151752 erschien z.B. die zweite Auflage von Achenwalls »Staatsverfassung der Europäischen Reiche im Grundrisse«, weitere Ausgaben erschienen 1756, 1762, 1768, 1785, 1790. Die erste Auflage wurde 1749 veröffentlicht unter dem Titel: »Abriss der neuesten Staatswissenschaft. Der vornehmsten Europäischen Reiche und Republicken zum Gebrauch in seinen academischen Vorlesungen«. Meusels Lehrbuch der Statistik erlebte vier Auflagen.

16 Christoph Wilhelm (von) Косн, Tableau des Revolutions de l'Europe, Lausanne 1771.

17 Eobald Toze, Indledning til den almindelige og særdeles Europæiske Statskyndighed, 1. Deel, 
oben aufgeführten Standardwerken wurde Tozes Studie Der gegenwärtige Zustand von Europa auch ins Englische übersetzt ${ }^{18}$.

Auch wenn es vermessen wäre, der Geschichte und der Statistik für diesen Zeitraum eine Deutungshoheit in den Wissenschaften zubilligen zu wollen, so gewannen diese beiden Disziplinen gegenüber der Theologie, Philologie und Philosophie immer stärker an Einfluss und stießen zunehmend auf ein immer größeres Publikum; zudem fanden jetzt historische und statistische Studien in fürstlichen und gelehrten Bibliotheken einen festen Platz. Wenn auch die Forderungen und Erwartungen vieler Gelehrter, als Ratgeber von Fürsten und ihren Regierungen fungieren zu wollen, zu hoch gesteckt waren, gelangten einige statistisch geschulte Gelehrte in die Nähe von politischen Entscheidungsträgern. Insofern kann auch formuliert werden, dass August Ludwig Schlözer, Christian von Dohm, Johann August Sack, Leopold Krug, Bernhard von Nau, Johann von Thünen der Statistik ihren beruflichen Erfolg in Wissenschaft, Diplomatie und Verwaltung verdankten.

Die Statistik erfüllte eine ganze Reihe von Anforderungen sowohl der damaligen Wissenschaften als auch der »Aufklärung«: Sie war eine politisch engagierte Wissenschaft mit einer praktischen Dimension, weil sie wichtige Informationen für die Regierungspraxis bereitstellte; sie bündelte die Erkenntnisse anderer (Teil-)Disziplinen: Geschichte, (Staats-)Recht, Geographie, Ökonomie, Policeywissenschaft, Medizin oder Demographie und strahlte zugleich - polyhistorisch - auf andere Wissenschaften aus.

Es waren besonders die Napoleonischen Kriege, die Historikern, Staatsrechtlern, Geografen und Statistikern die Wandelbarkeit Europas vor Augen führten. Gerade um die Jahrhundertwende 1800 erhielten Europäische Geschichte und Statistik erneut einen Schub. In diesem Zusammenhang wurden die Friedensschlüsse mit ihren Regelungen zu territorialen, dynastischen, zeremoniellen und auch ökonomischen Fragen als zentrale statistische und historische Quelle der Europäischen Staatengeschichte und Statistik wiederentdeckt. Gerhard Philipp Heinrich Norrmann z.B. argumentierte 1802:

Mehrere seit dem Anfange der Französischen Revolution geschlossene Verträge und Friedenschlüsse, oder im Innern mancher Staaten vorgefallene Umwandelungen haben Europens geographisch-politische Gestalt merklich verändert, manche bisherige Staaten vernichtet, mit benachbarten vereinigt, oder in neue umgeformt und auch dem Namen nach verändert u.s. $\mathrm{f}^{19}$.

Kjöbenhavn 1787.

18 Eobald Toze, The Present State of Europa. Translated from the German by Thomas Nugent, London 1770.

19 Gerhard Philipp Heinrich Norrmann (Hg.), Anton Friedrich Büschings Vorbereitung zur Europäischen Länder- und Staatenkunde nebst einer statistischen Uebersicht des jetzigen Europa, Hamburg ${ }^{6} 1802$, S. 14. 
Im gleichen Jahr zählte auch August Ludwig von Schlözer in seiner Theorie der Statistik die »GrundVerträge zwischen Herrscher und Volk« sowie »Friedens-, Grenz-, Handels- und Allianztraktate« zu den »wahren Urkunden« und ersten Quellen der - historisch orientierten - Statistik ${ }^{20}$.

\section{III.}

»Europa« spielte in den Jahren zwischen 1750 und 1815, wie gezeigt wurde, eine gewichtige Rolle in den historischen Wissenschaften des Deutschen Reiches. In dieser Zeit waren die Universitätsfächer »Europäische Staatengeschichte« und »Statistik« en vogue. Wie aber wurde europäische Geschichte geschrieben? Wie stellte sich Europa den damaligen Gelehrten dar? Dass Europa nicht nur geographisch als ein Kontinent angesehen wurde, sondern auch als ein durch gemeinsame oder wenigstens vergleichbare religiöse (Christentum) und intellektuelle Werte (Aufklärung), Lebensgewohnheiten (Ehe, Familie) und Regularien (Regierungsform, Recht) geprägtes kulturelles Ordnungsgefüge, dessen waren sich die damaligen Zeitgenossen durchaus bewusst. Es ging in den Werken zur Europäischen Staatengeschichte und Statistik daher nicht nur um eine additive Beschreibung einzelner, dem Kontinent Europa zugewiesener Staaten, sondern es wurde vielmehr der Grad der Glückseligkeit und Wohlfahrt der einzelnen Staaten gegeneinander bestimmt und bewertet. Doch wurden auch europäische Verzahnungen und Verstrickungen - Wissensaustausch, Rechtsrezeption, dynastische und zwischenstaatliche Beziehungen, Migration, grenzüberschreitender Handel - untersucht?

Dass Europa als ein »Staatskörper« beschrieben wurde, war sowohl im Völkerrecht als auch in der Europäischen Staatengeschichte und Statistik gebräuchlich. Dabei stellten Allianzen und Friedensverträge den quellenmäßig sichtbaren Beleg für binneneuropäische Beziehungen dar. Europa habe, so der Erlanger Statistiker Johann Georg Meusel (1743-1820) in seinem mehrfach aufgelegten Lehrbuch der Statistik, durch die Bemühungen, das Gleichgewicht aufrechtzuerhalten, einen solchen, durch Unterhandlungen, Verträge, Bündnisse und Gegenbündnisse erzeugten Zusammenhang bewirkt, dass Europa die Gestalt eines einzigen großen Staatskörpers erhalten habe ${ }^{21}$. Europa wird für Meusel zusammengehalten durch ein Netzwerk völkerrechtlicher Vereinbarungen.

20 August Ludwig von Schlözer, Theorie der Statistik: nebst Ideen ueber das Studium der Politik ueberhaupt, Göttingen 1804, S. 72.

21 Johann Georg Meusel, Lehrbuch der Statistik, Leipzig ${ }^{4} 1817$, S. 33. 
Europa war für die Historiker und Statistiker jener Zeit mit einem Staat oder Staatenverbund gleichzusetzen. Den Friedensverträgen kam dabei die Funktion eines Mediums zur Ausgestaltung Europas als staatliche Einheit zu. Wie bei Meusel findet sich die Metapher des Staatskörpers auch bei dem Völkerrechtler Johann Jacob Moser. Europa bildete für ihn ein Netz aus gleichen und ungleichen souveränen Staaten mit einer inneren Struktur und Rangfolge. Die Länder und Staaten waren nicht allein auf sich selbst konzentriert. Über den einzelnen Fürsten und Staaten standen, quasi als verbindende Klammer, der Kaiser, der Papst und das »Projekt der Universalmonarchie« (Moser). Darüber hinaus benannte Moser spezifische interdynastische Begründungsmetaphern, die eine europäische Dimension bezeichneten: neben der »Ruhe« vor allem das »Gleichgewicht « und die »Freiheit« Europas $^{22}$ : »Und so werden auch zwischen denen Principal-Interessenten selbst die Friedens-Schlüsse zuweilen, wenigstens dem Buchstaben nach, auf diese Freyheit und das Gleichgewicht Europens gegründet « ${ }^{23}$.

IV.

»Hegemonie«, »Gleichgewicht« und auch »Freiheit« bildeten die zentralen Kategorien der Europäischen Geschichte und Statistik. Einer der führenden Europa-Historiker des ausgehenden 18. Jahrhunderts war der oben schon erwähnte Christoph Wilhelm (von) Koch, der lange Zeit an der Universität Straßburg lehrte. In seinem Tableau des révolutions de l'Europe ordnet er die Geschichte Europas nach der Herrschaft Karls des Großen, Ottos des Großen, Heinrichs IV., des Papstes (bzw. Vatikans), Habsburgs und Ludwigs XIV. von Frankreich, bei denen es sich seiner Ansicht nach um Hegemonien mit europaweiter Ausstrahlung handelte ${ }^{24}$. Nach Kochs Perspektive existierte Europa nicht erst seit dem Friedensvertrag von Utrecht 1713 mit seiner Fixierung des Gleichgewichtsprinzips, sondern schon seit dem Untergang des Rö-

22 Vgl. Heinz Duchнardt, »Europa« als Begründungsformel in den Friedensverträgen des 18. Jahrhunderts: von der »tranquillité« zur »liberté«, in: Heinz DuchHARdT / Martin PETERs (Hg.), Instrumente des Friedens. Vielfalt und Formen von Friedensverträgen im vormodernen Europa, Mainz 2008-06-25, Abschnitt 5-11, URL: http://www.ieg-mainz.de/vieg-online-beihefte/032008.html (eingesehen am 26.1.2009); ders., The missing balance, in: Journal of the History of International Law 2 (2000), S. 67-72; ders.: Gleichgewicht der Kräfte, Convenance, Europäisches Konzert: Friedenskongresse und Friedensschlüsse vom Zeitalter Ludwigs XIV. bis zum Wiener Kongreß, Darmstadt 1976.

23 Johann Jacob Moser, Grund-Sätze des Europäischen Völcker-Rechts in Kriegs-Zeiten. Vormahl zum Gebrauch seiner Staats- und Canzley-Akademie entworfen, Tübingen 1752, S. 2 f.

24 Über die europaweite Ausstrahlung der Herrschaft einzelner Fürsten in der Frühen Neuzeit, vergleiche Christoph KAMPMANN, Universalismus und Staatenvielfalt: Zur europäischen Identität in der Frühen Neuzeit, in: Jörg A. Schlumberger / Peter SEgl (Hg.), Europa - aber was ist es? Aspekte seiner Identität in interdisziplinärer Sicht, Köln u.a. 1994, S. 45-76. 
mischen Reichs und seit Karl dem Großen, weil es stets einzelne erfolgreich agierende Dynastien gegeben habe, die ihren Einflussbereich über mehrere europäische Territorien hinaus auszudehnen vermochten. Neu war seiner Ansicht nach seit Utrecht 1713 allerdings das Bemühen, den Frieden in Europa über Vereinbarungen und Absprachen auszutarieren ${ }^{25}$.

In Kochs Geschichtsdarstellung kommt deutlich ein europäisches Paradoxon zum Vorschein: Zum einen beschreibt er ein Europa, das durch die Hegemonie einer Dynastie oder eines Regenten über weite Teile des Kontinents hergestellt wird. Zum anderen sieht er ein Europa, das durch die oppositionelle Haltung gegen diese Hegemonie charakterisiert ist. Europa besaß demnach zwei Seiten, die in einem direkten Spannungsverhältnis standen. Dabei datiert Koch den Ursprung des Gleichgewichtsprinzips nicht mit seiner schriftlichen Überlieferung ins frühe 18. Jahrhundert, sondern sieht - wie viele andere Zeitgenossen auch - seine Wurzeln schon im 16. Jahrhundert in Zusammenhang mit der Auseinandersetzung zwischen Franz I. von Frankreich und Karl V. von Habsburg. Er schreibt:

La Maison d'Autriche ne cherchoit qu'à s'aggrandir, ou du moins à se maintenir dans sa puissance; la France au contraire avoit toujours en vuë l'abbaissement de cette Maison, en établissant un certain équilibre entre des Puissances de l'Europe. Telle est l'origine de la doctrine de l'équilibre, $\&$ du lien politique qui existe aujourd'hui entre les Souverains de l'Europe. C'est ici l'époque de ces négociations \& de ces alliances sans fin, de ces guerres fréquentes \& presque toujours générales, pour empécher qu'aucune des Puissances ne s'aggrandit au point de devenir trop formidable aux autres ${ }^{26}$.

Aber nicht nur der Topos vom Gleichgewicht, den Koch als ein Instrument definiert, mit dem die Machtgelüste Habsburgs begrenzt werden sollen, ist in diesem Passus das Interessante ${ }^{27}$, sondern auch seine Wertung von Friedensverträgen und -verhandlungen. Fast abfällig bezeichnet Koch - aus seiner historischen Perspektive - die damaligen Friedensbemühungen als »endlose«. Der Völker- und Staatsrechtler Moser sieht zwar, ebenso wie Koch, dass Friedensbemühungen häufig erfolglos blieben, findet jedoch in der schriftlichen Fixierung europäischer Begründungsmetaphern wie »Ruhe« und $»$ Freiheit« in den Friedensverträgen einen gewissen Gewinn und einen Min-

25 Siehe Kampmann, Universalismus, S. 74f.

$26 \mathrm{KocH}$, Revolutions, S. 153.

27 Über die verschiedenen profranzösischen, proenglischen und prohabsburgischen Perspektiven der Ausdeutung des Gleichgewichtsprinzips vergleiche Arno Strohmeyer, Theorie der Interaktion. Das europäische Gleichgewicht der Kräfte in der frühen Neuzeit, Wien u.a. 1994. Zum Gleichgewichts- und Hegemoniebegriff bei Johann Gottfried Eichhorn, vgl. Martin Peters, Europäische Friedensverträge der Vormoderne (1500-1800), rezipiert von Johann Gottfried Eichhorn, in: Heinz Duchiardt / Martin Peters (Hg.), Kalkül-Transfer-Symbol. Europäische Friedensverträge der Vormoderne, Mainz 2006-11-02, Abschnitt 122-131, URL: http://www. ieg-mainz.de/vieg-online-beihefte/01-2006.html (eingesehen am 26.1.2009). 
desterfolg auf dem Weg zu einem friedlichen Europa. Der Statistiker Meusel nun spricht den Friedensverträgen eine bedeutende politische und rechtliche Kraft zu, die eine Ausbildung Europas zu einem Staat bewirken würden.

\section{V.}

Europa wird bereits in der historischen und statistischen Literatur des ausgehenden 18. Jahrhunderts auch über die Menschen und ihre Kultur entworfen. Von Europäern ist in der wissenschaftlichen Literatur gerade dann die Rede, wenn Vergleiche mit Kulturen außereuropäischer Völker - der Asiaten und Afrikaner - angestellt werden. In der Regel aber werden hier die Europäer nicht politisch und staatsrechtlich als Bürger, sondern ethnologisch als Volk begriffen. Doch die Selbstbeschreibung als Europäer gelingt durchaus nicht nur durch die ethnologische Gegenüberstellung mit Nicht-Europäern, sondern auch durch den statistischen Vergleich der europäischen Staaten und ihrer Beiträge zum Kulturfortschritt. Der Schlusssatz zu August Friedrich Wilhelm Cromes Werk Ueber die Größe und Bevölkerung der sämtlichen europäischen Staaten lautet:

der Schriftsteller kann wahrlich keine grössere Belohnung für seine mühsamste Arbeit einerndten, als die Hofnung: zum Flor seiner Mitbürger, zerstreut in ganz Europa, nach seinen Kräften etwas beygetragen zu haben!

Absicht seiner Studie ist - wie er im Untertitel selbst verkündet -, einen Beitrag zur Kenntniß der Staatenverhältnisse zu liefern. Dabei geht es ihm jedoch nicht, wie zu vermuten wäre, um die Verhältnisse, Beziehungen und Transfers zwischen den Staaten, sondern um die Zustände der einzelnen Staaten in Europa, die er erfasst und miteinander vergleicht. Zu diesem Zweck hat er es sich zur Aufgabe gemacht, eine neue »Größen-Karte« von Europa zu präsentieren, bei der sowohl die Fläche eines jeden europäischen Staates als auch seine Bevölkerungszahl veranschaulicht und kartiert werden. Ziel seiner kartographischen Visualisierung und statistischen Analyse ist die Bewertung der europäischen Staaten nach ihren »Stärken «, ihrem »Wohlstand « und ihrer $\gg$ Cultur $«{ }^{28}$. Dabei ist die Karte nicht so angelegt, dass Größe und Bevölkerung der europäischen Staaten präsentiert werden. Crome legt vielmehr Wert darauf, die Verhältnisse »der Größe eines Staates, gegen den andern « zu präsentieren, um, wie er ausführt, eine »sinnliche Vorstellung der Ländergrößen«, z.B. der Bevölkerungszahl, zu vermitteln. Auf diese Weise betrachtet Crome die Staaten in Europa keineswegs als Herrschaftsräume, sondern teilt Europa in bevölkerungsschwache oder -starke Regionen und

28 CRome, Größe, Vorrede. 
Flächenräume ein, woraus sich seiner Meinung nach Rückschlüsse auf den Zustand des Gewerbes, des Handels und den Grad der Kultur in diesen Gebieten ziehen lassen ${ }^{29}$. Für Crome ist Europa in letzter Konsequenz kein Staatenverbund, sondern vielmehr ein Mosaik unterschiedlich ausgeprägter und unterschiedlich zu charakterisierender Kulturräume und -regionen.

Auch Europa als Währungsraum wurde überraschenderweise bereits im letzten Viertel des 18. Jahrhunderts diskutiert. Wie konkret die Einheit Europas unter den Statistikern gedacht werden konnte, zeigt der Artikel Ueber einen in Europa einzuführenden allgemeinen Münzfu $\beta$, den der Historiker und Ökonom Dietrich Hermann Hegewisch, damals bekannt als Experte für Karl den Großen, 1787 im Historisch-politischen Magazin publizierte ${ }^{30}$. Hegewisch, in Quakenbrück im Osnabrücker Nordland geboren, hatte in Göttingen studiert, war in Hamburg als Zeitungsredakteur tätig, bevor er im damals noch dänischen Kiel Professor für Geschichte wurde und u.a. Barthold Georg Niebuhr zu seinen Schülern zählte ${ }^{31}$. Einige seiner Studien wurden sogar ins Französische und Englische übertragen ${ }^{32}$. In seinem Artikel plädiert Hegewisch für die Einführung eines einheitliches Maßes, Gewichtes sowie Münzfußes. Um dieses Ziel zu erreichen, das den Kaufleuten und Reisenden zugutekomme, müssten sich, so Hegewisch, die europäischen Nationen untereinander verabreden: »Ohne Zweifel verdiente diese Sache eben so sehr, als der von einigen vorgeschlagene ewige Friede, auf einem allgemeinen europäischen Congresse erwogen zu werden $\aleph^{33}$. Damit gehört Hegewisch zu den frühen Vordenkern einer europäischen Währungs- und Finanzunion auf der Basis völkerrechtlicher Vereinbarungen.

VI.

Die Motivation, Europa aus den verschiedensten Perspektiven heraus zu denken und zu entwerfen, war in den Disziplinen Geschichte und Statistik ab

29 Ebd., S. 13.

30 [AnONym, Ueber einen in Europa einzuführenden allgemeinen Münzfuß, in: Historisch-politisches Magazin, nebst litterarischen Nachrichten 1787, Bd. 1, S. 211-214. Der renommierte Hamburger Mathematiker Johann G. Büsch enttarnte den anonymen Autor und kommentierte den Beitrag kritisch: Ueber einen in Europa einzuführenden allgemeinen Münzfuß, in: Handlungsbibliothek 2 (1789), S. 505-513. Eine Anti-Replik veröffentlichte Hegewisch, in: Schreiben an Hrn. Professor Büsch über die Möglichkeit und Nüzlichkeit eines allgemeinen Münzfusses, in: Deutsches Magazin 4 (1792), S. 361-383.

31 Siehe Lebensnachrichten über Barthold Georg Niebuhr aus Briefen desselben und aus Erinnerungen einiger seiner nächsten Freunde, Bd. 1, Hamburg 1838, S. 33-47.

32 Z.B. Dietrich Hermann Hegewisch, Histoire de l'empereur Charlemagne. Traduction libre de l'Allemand, Paris 1805; ders., Introduction to Historical Chronology. Translated from the German by James Marsh, Burlington 1837.

33 Hegewisch, Münzfuß, S. 214. 
der Mitte des 18. Jahrhunderts enorm hoch. Europa wurde trotz vielfältiger Unterschiede zwischen den einzelnen Staaten als Einheit beschrieben. Die intensive Betonung dieser Gemeinsamkeiten resultierte nicht etwa aus einer realen militärischen Bedrohung von außen. Das Osmanische Reich z.B. war seit dem Frieden von Passarowitz von 1718 keine ernsthafte Gefahr mehr. Allerdings wurden in Europa immer mehr Nachrichten aus dem Osmanischen Reich sowie aus Amerika, Afrika, Asien, Sibirien, Australien und Neuseeland verbreitet, was zu einer intensiven Beschäftigung mit philosophischen, anthropologischen, völkerrechtlichen, ethnographischen und ethnologischen Sachverhalten führte. Insofern dienten die Studien der Europäischen Staatengeschichte und Statistik der Identifizierung des Vertrauten, und zugleich waren sie ein Gegenentwurf zum Fremden und Anderen. 


\section{Karl-Heinz Lingens}

\section{Europa in der Lehre des »praktischen Völkerrechts«}

In Art. 7 des Pariser Friedens vom 30. März $1856^{1}$ erklärten die fünf Großmächte und der König von Sardinien die Hohe Pforte »admise à participer aux avantages du droit public et du concert Européens«. Welches waren diese »Vortheile«, die Verbündete und Gegner dem Sultan nach dem Krimkrieg versprechen zu können glaubten? Vor allem: Was war dieses »europäische Völkerrecht«, auf das die Vertragspartner sich neben dem »europäischen Konzert« bezogen?

Antwort auf diese Fragen versprach den Zeitgenossen die einschlägige Wissenschaft. Ein Jahr zuvor war - in 3. Auflage - ein deutsches Lehrbuch mit eben diesem Titel erschienen: August Wilhelm Heffters Das Europäische Völkerrecht der Gegenwart ${ }^{2}$. Es galt und gilt als eines der bedeutendsten Völkerrechtskompendien des 19. Jahrhunderts. Mit der Wahl des Titels, in Folgeauflagen noch ergänzt um den Hinweis »auf den bisherigen Grundlagen«, reihte sich der Berliner Professor in die Tradition des sog. praktischen oder positiven Völkerrechts ein. Entstanden vor der Mitte des 18. Jahrhunderts, suchte diese Lehre das zwischen den Staaten geltende Recht - auf dieses hatte sich der ursprünglich weiter gefasste Begriff des »ius gentium« inzwischen meist reduziert - in erster Linie aus den Gewohnheiten und Verträgen der europäischen Mächte herauszufiltern, statt es traditionell allein aus Normen des Naturrechts herzuleiten.

Eine Literaturgattung, die das Europäische zur Kennzeichnung ihres wissenschaftlichen Ansatzes wählt, muss beim Thema Auf dem Weg nach Euro$p a$ fast zwangsläufig Interesse wecken. Um Veränderungen in den dahinter verborgenen Europavorstellungen der verschiedenen Autoren zu erfassen, ist chronologisches Vorgehen angeraten. Am Anfang steht Johann Jacob Moser, den die späteren Positivisten trotz einiger Vorgänger als den "Vater« ihrer Wissenschaft anerkannten. Deren Bild formten im späten 18. Jahrhundert vor allem Karl Gottlob Günther und Georg Friedrich von Martens; Johann Ludwig Klüber, Theodor von Schmalz und andere passten es den neuen Gegebenheiten nach der Französischen Revolution und dem Wiener Kongress

1 Clive Parry (Hg.), The Consolidated Treaty Series, Vol. 114 (1855-1856), Dobbs Ferry, New York 1969, S. 414.

2 August Wilhelm HefFTER, Das Europäische Völkerrecht der Gegenwart, Berlin ${ }^{3} 1855$ (Berlin $\left.{ }^{1} 1844\right)$. 
an. Heffter im zweiten und Franz von Holtzendorff im letzten Drittel des 19. Jahrhunderts erläuterten schließlich das im Pariser Vertrag mit den Osmanen erwähnte Völkerrecht, für dessen Kennzeichnung ihre Nachfolger auf den Zusatz »europäisch« verzichteten. Die Ausführungen zum Geltungsgebiet des »praktischen Völkerrechts « - fester Bestandteil, ja Charakteristikum aller dieser Abhandlungen - lassen erkennen, dass es nicht zuletzt die fremdartige Macht am Südostrand des Kontinents war, welche die vorwiegend deutschsprachigen Autoren zum Attribut »europäisch« als Kennzeichen des von ihnen beschriebenen Rechts greifen ließ.

I.

Hugo Grotius, dem wir die erste systematische Darstellung des Völkerrechts verdanken, hatte es 1625 gleichermaßen auf die naturrechtliche Tradition und die Selbstbindung der Staaten gegründet ${ }^{3}$. Gegen Ende des 17. Jahrhunderts setzte sich in der Wissenschaft zunächst aber Samuel Pufendorfs ${ }^{4}$ ausschließlich naturrechtliche Linie durch. Dem tendenziell universellen Anspruch des naturrechtlichen Völkerrechts entsprach eine lediglich abstrakte Definition der Völker und Staaten als Rechtssubjekte. Die deduktive Methode, durch die Natur vorgegebene unveränderliche Rechtssätze allein mittels der Vernunft zu erschließen, ließ zeitgenössische Beispiele überflüssig erscheinen.

Von dieser herrschenden Lehre wich Johann Jacob Moser radikal ab. Er präsentierte ein Völkerrecht, das auf der Rechtspraxis und dem Rechtsverständnis der europäischen Souveräne gründete.

»Ich erinnere hiebey nochmahls«, betonte er $1750, » \mathrm{da} \beta$ ich kein raisonnirtes Völcker-Recht schreibe, welches sich ein jeder Gelehrter nach seinen Begriffen und Leidenschafften selbsten zu bilden pfleget, wie er will, oder wie er es am besten zu treffen vermeinet, sondern ein Völcker-Recht, wie es unter den Europäischen Souverainen und Nationen üblich ist $\iota^{5}$. Missverständnisse über diesen Kreis konnten nicht aufkommen: Moser zählt die Mitglieder namentlich auf und gruppiert sie in verschiedene Kategorien ${ }^{6}-$ Staatsform, Würde, Rang, Religion; seine Nachfolger fügen andere Kriterien wie Größe und Machtmittel dazu. Russland findet sich in der Liste ebenso

3 Hugo Grotius, De iure belli ac pacis libri tres in quibus ius naturae \& gentium item iuris publici praecipua explicantur, Nachdruck der Ausgabe Paris 1625, 2 Bde., Hildesheim 2006.

4 Samuel Pufendorf, De Jure Naturæ Et Gentium Libri Octo, Lund 1672.

5 Johann Jacob Moser, Grund-Sätze des jetzt-üblichen Europäischen Völcker-Rechts in FridensZeiten, auch anderer unter denen Europäischen Souverainen und Nationen zu solcher Zeit fürkommender willkührlicher Handlungen, Hanau 1750, Vorrede S. 3r.

6 Moser, Grund-Sätze, »Erstes Buch. Von Europa, so ferne es einen einigen Staats-Cörper ausmacht $\ll$, S. 15-64. 
wie ohne Einschränkung die Ottomanische Pforte. Dass die Türken wirklich ihren Platz in Mosers Europa hatten, belegt die ungezwungene Erwähnung an mehreren Stellen des Buches. Nicht religiös-kulturelle Gründe bewirkten für ihn eine Abschichtung, sondern allein rechtliche: Staaten, »welche ... vile Gerechtsame besitzen, so der Souveraineté ähnlich seynd «? finde man im Reich, in Italien sowie in Polen (Kurland), den Schatten, nicht das Wesen der Souveränität in Monaco. Dem Herzog von Parma wird das erstrebte Recht nicht zugestanden, kleine Republiken wie Lucca, Ragusa und San Maríno seien aber ebenso »in würcklichem Besitz der völligen Souveraineté« wie der Malteser-Orden ${ }^{8}$.

Hinsichtlich ihrer Souveränität sind alle Staaten einander gleich - und sie sind unabhängig. Es existiert kein allgemeines Völkergesetz und kein allgemeiner Völkervertrag, nicht einmal zwischen den europäischen Völkern. »Und eben so wenig werden aus denen particular-Verträgen einiger oder mehrerer Europäischer Machten Sätze gezogen oder erwisen werden können, in denen alle Europäische Souverainen eine gleiche Meinung hegeten «?.

Die Übereinstimmung der in Kriegs- und Friedenszeiten geschlossenen Verträge in vielen Haupt- und Nebenpunkten gibt jedoch laut Moser »zwar kein vollkommenes, doch einiges, Recht, an andere Regenten oder Machten, mit denen keine dergleichen Verträge geschlossen worden seynd, eben dises zu verlangen $\aleph^{10}$. Stärker wirkt ein von europäischen Gemeinsamkeiten ausgehender Zwang bei Mosers zweiter Rechtsquelle. Weil viel mehr Sachen allein durch Herkommen geregelt sind, ist sie praktisch noch wichtiger. »Ein Herkommen heißt, wann etwas mehrmahlen, oder, nach Beschaffenheit derer Umstände, auch wohl nur einmahl, geschehen ist und andere dabey intereßierte Machten es gewußt und darzu stille geschwiegen haben ${ }^{11}$.

$\mathrm{Ob}$ eine solche auf den Kontext angewiesene Definition sachgerecht formuliert war, darf gerade angesichts ihrer Tragweite bezweifelt werden - immerhin verlangte sie von den europäischen Regenten eine Art Protest, wenn nicht an anderem Ort anderes Herkommen oder gar Gegenteiliges galt. Moser sieht konformes Verhalten als hinreichenden und unwiderleglichen Beweis praktischer Wirksamkeit: »mit einem solchen Herkommen ist an denen Europäischen Höfen und in denen Europäischen Staats-Sachen meistens weit mehr auszulangen, als mit allen nur zu ersinnenden Vernunfft- und Billigkeits-Gründen $\ll^{12}$.

7 Ebd., S. 21 (§ 20).

8 Ebd., $(\S 18)$.

9 Ebd., S. 2 (§ 9).

10 Ebd., S. 3 (§ 12).

11 Ebd., S. $4(\S 15)$.

12 Ebd., S. 4f. (§ 19). 
Die Stärke des Arguments folgt der Qualität der Gewohnheit: »Je allgemeiner solches Herkommen ist, je länger es gedauert hat, je öffter es fürgekommen ist und aus je neueren Zeiten es herrühret, um so stärcker verbindet dasselbige auch andere souveraine Regenten und Nationen « ${ }^{13}$.

Mit dem Rekurs auf die neuesten Fälle, die in den zeitgenössischen Vertragssammlungen nun auch greifbar waren, setzt sich Moser methodisch von Grotius ab. Dessen bevorzugte altehrwürdige Beispiele sind für ihn »durch die Banck ... unbrauchbar ${ }^{14}$. Mehr noch: Auch das Werk des Niederländers stammt aus einer vergangenen Epoche. Mitte des 18. Jahrhunderts interessiere die Praxis nicht mehr,

was auch in Europa selbst in älteren Zeiten Völcker-Rechtens gewesen seyn mag, sondern was ohngefähr seit denen Zeiten der Westphälischen Fridens-Tractaten darinn üblich ist, als seit welcher Zeit Europa in vilen hieher einschlagenden Materien eine gantz andere Art zu dencken und zu handlen angenommen hat, wie von vilen Staatsklugen Leuten vorlängst beobachtet worden ist ${ }^{15}$.

Das Ergebnis der jüngsten Entwicklung stellt sich Moser wie folgt dar:

Man kan zwar nicht sagen, daß die Europäische souveraine Staaten eine Art eines Systematis oder Corporis foederatarum Rerumpublicarum wären; sondern sie stehen vil mehr an und für sich ausser aller Verbindung gegen einander: Indessen hat doch ihre natürliche Lage, die den meisten gemeinschaftliche Religion und die bey denen meisten (obgleich in mehrerem oder wenigerem Grad,) befindliche Sorge für die Erhaltung ihrer eigenen und anderer Europäischer Staaten Erhaltung gegen die von einigen anderen zu machen suchende Conquêten die meiste Europäische Staaten in eine gewisse Art der Verbindung gesetzet, auch dadurch eben ein eignes Europäisches Völcker-Recht herfürgebracht, daß man also Europam in so ferne wohl, und mit ungleich grösserem Recht, als alle übrige Welt-Theile, als einen einigen grossen Staats-Cörper betrachten $\mathrm{kan}^{16}$.

So scharf und beeindruckend sich Mosers Europabild von dem seiner Vorgänger abhebt, eine Frage bleibt offen. Letztlich geht aus seinen Ausführungen nicht hervor, warum er den »Kontinent« als Bezugspunkt wählte. Noch ein halbes Jahrhundert zuvor hatte Bernhard von Zech in einer Nachbarwissenschaft mit Friedrich Leutholf von Franckenbergs Europäischer Herold oder zuverläßige Beschreibung derer europäisch-christlichen Kayserthums, Königreiche, freyer Staaten und Fürstenthümer ${ }^{17}$ enger abgegrenzt und Osmanen und auch Russen außen vor gelassen. Neben dem von Gollwitzer an-

13 Ebd., S. 4 (§ 16).

14 Ebd., S. 12 (§ 49).

15 Ebd., Vorrede, S. 3r.

16 Ebd., S. 15f. (\$ 1).

172 Bde., Leipzig 1705. 
geführten säkularisierten Zeitgeist ${ }^{18}$ ist man geneigt, die implizierende Entscheidung dem Moserschen Pragmatismus zuzuschreiben. Ob das von ihm Geschilderte zum eigentlichen Völkerrecht gehöre, »nun nach denen Göttlichen geschribenen und natürlichen auch menschlichen Rechten recht oder unrecht « oder »innerlich gut oder böse" sei - über all das will Moser nicht streiten. Ausdrücklich sieht er sich weniger als Rechtslehrer denn als »einen Beschreiber dessen, wie die Europäische Souverainen und Nationen mit einander umgehen und eben deßwegen, weil es unter ihnen so hergebracht ist, es für Recht halten und angeben $\ll^{19}$, ein Ansatz, den es angesichts der späteren Entwicklungen im Auge zu behalten gilt.

II.

Mosers Konzeption verdient ausführliche Behandlung, denn es sind dort schon fast alle künftig wichtigen Aspekte des Europabildes der praktischen Völkerrechtswissenschaft angesprochen. Die Relevanz seiner Praxisorientierung wird kurze Zeit später gewissermaßen auf höchster Ebene bestätigt. Christian August Beck, der Erzherzog Joseph im Rahmen des Unterrichts im Natur- und Völkerrecht das »allgemeine natürliche Völkerrecht« erläutert, schließt seinen 90 Druckseiten umfassenden Vortrag mit einigen knappen Bemerkungen zum positiven Völkerrecht. Er schildert es dem künftigen Kaiser als »so erdichtet eben nicht, wie es von vielen angesehen wird, um so mehr, da man in wirklichen Staatsgeschäften souveräner Mächte eher nicht zu dem natürlichen Völkerrecht schreitet, als bis keine Verträge und Observanzen vorhanden sind $\aleph^{20}$.

Aus der Gewichtung - das Kapitel umfasst nur gut eine Seite - geht jedoch schon hervor, dass Mosers Anpreisung des europäischen Völkerrechts als unverzichtbar für einen Regenten, »der mit anderen souverainen Machten zu thun hat und mit eigenen Augen sehen will $\aleph^{21}$, zunächst Wunschdenken blieb. In der wissenschaftlichen Bearbeitung dieses Rechts fand Moser jedoch schon bald Nachfolger. Wenige wollten allerdings dabei wie er auf die Einbeziehung des allgemeinen, natürlichen Völkerrechts verzichten - mit der Folge, dass Begriffe und Inhalte in die Diskussion gerieten. In seiner $\mathrm{Zu}-$ sammenstellung der »Litteratur des gesammten sowohl natürlichen als posi-

18 Heinz Gollwitzer, Europabild und Europagedanke. Beiträge zur deutschen Geistesgeschichte des 18. und 19. Jahrhunderts, München ${ }^{2} 1964$, S. 60.

19 Moser, Grund-Sätze, Vorrede S. 3r.

20 Hermann Conrad (Hg.), Recht und Verfassung des Reiches in der Zeit Maria Theresias. Die Vorträge zum Unterricht des Erzherzogs Joseph im Natur- und Völkerrecht sowie im Deutschen Staats- und Lehnrecht, Köln 1964, Kap. 13, § 2, S. 393.

21 Moser, Grund-Sätze, S. 8f. (§ 36). 
tiven Völkerrechts« verwarf Diedrich Heinrich Ludwig von Ompteda Mosers Ausdruck »europäisch« als nicht sachgemäß: Schon seit langer Zeit habe es unstreitig auch außerhalb der Grenzen Europas »gesittete Völkerschaften, wenigstens ansehnliche Theile derselben« gegeben, welche das modifiziert natürliche sowie ein Gewohnheitsrecht anwendeten; gerade »anjetzt, da in Amerika ein ansehnlicher neuer Staat aufblühet, der auf die Theilnehmung an dem Genuß des Völkerrechts ebenfalls den gerechtesten Anspruch machet«, sei »die Benennung des europäischen Völkerrechts viel zu eingeschränkt $\ll^{22}$.

Georg Friedrich von Martens erachtete diesen Einwand zwar als sachlich zutreffend, allerdings nicht für erheblich genug, die »a potiori« immer noch richtige Benennung abzuändern ${ }^{23}$. Karl Gottlob Günther hielt Ompteda indes entgegen, »daß die europäischen Nazionen das vorzüglichste Augenmerk verdienen, da sie ohnstreitig in weit genauern und häufigern Verbindungen unter einander als mit den Völkern der übrigen Welttheile stehen, deren Grundsätze mit dem europäischen Völkerrechte ohnedies oft schwer $\mathrm{zu}$ vereinbaren sind $\aleph^{24}$.

Aber nicht nur mit der Betonung einer europäischen Sonderstellung war Günther richtungweisend. Schon im Titel Europäisches Völkerrecht in Friedenszeiten nach Vernunft, Verträgen und Herkommen ist die bisherige Gleichsetzung von praktischem und europäischem Recht aufgegeben. »Europäisch« avanciert zum Oberbegriff, die Quellengattungen rücken in die zweite Reihe. Das schlug sich auch in der idealen Darstellungsform nieder, die Martens in seiner »Einleitung« so begründet:

Da die Völker Europens das Subject, die gegenseitigen Rechte aber das Object unserer Wissenschaft ausmachen, so muß, ehe letztere erörtert werden, eine Uebersicht der Völker aus welchen Europa besteht, vorangehn, und näher untersuchet werden, theils wie fern sie zusammen genommen, im Gegensatz der übrigen Völker des Erdbodens, als ein Ganzes angesehen werden können, theils wie sie unter sich in Ansehung ihrer politischen Wichtigkeit, ihrer Verfassung, ihrer Religion verschieden sind ${ }^{25}$.

Fester Bestandteil jeder Übersicht war ein sachbezogener geschichtlicher Abriss von der Antike über die mittleren Zeiten bis zur übereinstimmend im 16. Jahrhundert verorteten Ausbildung des Völkerrechts. Kaum ein Autor un-

22 Diedrich Heinrich Ludwig von OMPTEDA, Litteratur des gesammten sowohl natürlichen als positiven Völkerrechts, 2 Bde., Regensburg 1785, ND Aalen 1963, hier: Bd. 1, S. 18 (§ 5).

23 Georg Friedrich von MaRTENs, Versuch über die Existenz eines positiven Europäischen Völkerrechts und den Nutzen dieser Wissenschaft, Göttingen 1787, S. 3 Anm. *.

24 Karl Gottlob GünTHER, Europäisches Völkerrecht in Friedenszeiten nach Vernunft, Verträgen und Herkommen, mit Anwendung auf die teutschen Reichsstände entworfen, Erster Theil, Altenburg 1787, S. 27 (§ 16).

25 Georg Friedrich von MARTENs, Einleitung in das positive Europäische Völkerrecht auf Verträge und Herkommen gegründet, Göttingen 1796, S. 22 (§ 11). 
terließ den Hinweis auf den Beitrag des Christentums, ansonsten wurden gegenseitiges Interesse, Verträge, Ähnlichkeit der Sitten, Blutsverwandtschaft unter den Fürsten, Handel und vieles mehr herangezogen. Mosers Staatskörper fand keine Zustimmung, den Zustand ohne gemeinsames Oberhaupt glaubte man eher mit dem Begriff »System « beschreiben zu können. Dieses wurde als recht locker eingestuft, umfasste es doch auch Staaten, »die weder Verträge noch Verkehr mit einander haben, und sich kaum zu kennen scheinen«. Rußland war dem ursprünglich christlichen Europa erst später beigetreten, die Türkei laut Martens »nie im Ganzen $\aleph^{26}$. Auch Günther zufolge waren es die »Besitzungen in diesem Welttheile ... allein, um derentwillen die Pforte zu den europäischen Staaten gerechnet wird « ${ }^{27}$.

Europa »en détail« enthalten naturgemäß die Beschreibungen der einzelnen Rechtsgebiete, mal mehr, mal weniger. Unterscheiden sich die Ausführungen über Verträge kaum von denen naturrechtlicher Lehrwerke, weist Günthers Kapitel Von der ursprünglichen Gleichheit und dem nachher eingeführten Range der Nazionen ${ }^{28}$ schon in der Überschrift auf eine spezifisch europäische Entwicklung hin. Den wenig erfolgreichen Versuch der Bildung neuen europäischen Völkerrechts kann der Leser in den Ausführungen zur damals aktuellen »bewaffneten Neutralität $\ll^{29}$ verfolgen; Tradition und Kontinuität Europas verdeutlichten hingegen die umfangreichen diplomatischen Regeln. Ihre Darstellung erfolgte auch in eigenen Kompendien, die den europäischen Bezug ebenfalls schon im Buchtitel herausstellten ${ }^{30}$.

In der Abhandlung der Sachgebiete wurden jetzt Naturrecht und Empirie in das umfassend verstandene europäische Völkerrecht integriert. »Ich habe bey ieder Materie die natürlichen Grundsätze vorausgeschickt und deren Bestätigung oder Abänderung durch das practische Völkerrecht bemerklich zu machen gesucht«, klärt Günther in seiner Vorerinnerung über mögliche Diskrepanzen auf ${ }^{31}$. Für ihn ergänzen die Bestimmungen des willkürlichen Rechts der Völker »die oft unzulänglichen Regeln des natürlichen Rechts«; sie können letzteres näher bestimmen, erweitern oder einschränken, »wenn sie nur demselben nicht gerade zuwiderlaufen $\aleph^{32}$. In der Sache stimmte Günther völlig mit dem Naturrechtler Vattel überein, der lediglich die Kontroll-

26 Beide Zitate ebd., Einleitung, S. 27 (§ 13).

27 GÜNTHER, Europäisches Völkerrecht, S. 109 (§ 29).

28 Ebd., Erstes Buch, Drittes Kapitel, S. 198-279.

29 Etwa bei Martens, Einleitung, Achtes Buch, Siebentes Hauptstück: Von der Neutralität, S. 340-363.

30 Franz Xaver von Moshamm, Europäisches Gesandschaftsrecht, Landshut 1805, siehe auch schon Johann Jacob Moser, Beyträge zu dem neuesten Europäischen Gesandtschaffts-Recht, Frankfurt/Main 1781.

31 GüNTHER, Europäisches Völkerrecht, Vorerinnerung.

32 Ebd., S. 14 (§ 7). 
funktion des Naturrechts gegenüber den »Coutumes« stärker hervorhob ${ }^{33}$. Europäische Gewohnheiten wurden so innerrechtlich wieder einer begrenzten Kritik der Vernunft unterworfen.

III.

Die Französische Revolution und Napoleons Herrschaft, die das als wichtigste Sicherung des Völkerrechts empfundene politische Gleichgewicht bedrohte, schärften das Bewusstsein der Abhängigkeit des Rechts von den politischen Verhältnissen. Die Veränderlichkeit positiven Völkerrechts, von den Naturrechtlern kritisiert, strich Friedrich Saalfeld 1809 gerade als Vorteil des europäischen Systems heraus: »immerhin wird dennoch in jedem Zeitraume ein Völkerrecht vorhanden sein, so lange überhaupt die Verbindung der Staaten Europa's unter einander fortdauert, so lange nicht alles in Barbarei zurücksinkt « ${ }^{34}$. Kurze Zeit später standen die Völkerrechtler vor der Aufgabe, die durch den Wiener Kongress herbeigeführte grundlegende Änderung der politischen Verfassung Europas in ihre Kompendien einzuarbeiten. Das neue »europäische Föderativsystem « beschreibt Karl Heinrich Ludwig Pölitz 1825 folgendermaßen:

seit dem Wiener Congresse bildete Europa nicht mehr, wie früher, eine Masse durch ihre Zwecke und politischen Interessen vereinzelter Staaten, zwischen welchen gewöhnlich nur vorübergehend, und zunächst blos in Augenblicken der Gefahr und Noth, größere oder kleinere Bündnisse abgeschlossen wurden; Europa bildet in unsrer Zeit, namentlich nach seinen fünf Großmächten, einen Staatenverein, für welchen es - abgesehen von allen besonderen Interessen der einzelnen Staaten - gewisse allgemeine, den ganzen Erdtheil und selbst die außereuropäischen Erdtheile berücksichtigende, Zwecke und Interessen giebt, welche diese Mächte theils in ihrer eigenen politischdiplomatischen Stellung gegen einander, theils in ihren Verhältnissen zu den Mächten des zweiten und dritten politischen Ranges unsers Erdtheils geltend machen ${ }^{35}$.

33 Emer DE VATTEL, Le droit des gens ou Principes de la loi naturelle, appliqués à la conduite et aux affaires des Nations et des Souverains, ND der Ausgabe 1758, Geneva 1983, S. 14f. (§§ 25-27) erkennt verschiedene auf dem »consentement tacite « basierende Gewohnheitsrechte an, »soit entre toutes les Nations policées, soit seulement entre toutes celles d'un certain Continent, de l'Europe par exemple, ou celles qui ont ensemble un Commerce plus fréquent« (S. 14, § 26). Coutumes, die Ungerechtes oder Unerlaubtes enthalten, müssen wegen Verstoßes gegen das Naturrecht aufgegeben werden.

34 Friedrich SAALFeld, Grundriß eines Systems des europäischen Völkerrechts, zum Gebrauche akademischer Vorlesungen, Göttingen 1809, S. VII.

35 Karl Heinrich Ludwig Pölitz, Die Staatswissenschaften im Lichte unserer Zeit, Fünfter und letzter Theil: Practisches (europäisches) Völkerrecht; Diplomatie; und Staatenpraxis, Leipzig ${ }^{2} 1828$, S. 11f. (Hervorhebung im Original); siehe aber auch sein Zitat aus dem britischen Circularschreiben ebd. S. 116f., das ein solches Föderativsystem als ungeeignet verwirft. 
Die damit aufgeworfene Frage nach der Gewichtung der Interessen von Staatenverein und Einzelstaat beantwortete der spätere preußische Staatsminister Karl Albrecht von Kamptz 1821 in seiner Völkerrechtliche(n) Erörterung des Rechts der Europäischen Mächte in die Verfassung eines einzelnen Staats sich zu mischen weitgehend zugunsten der Großmächte. Zwar gebe es »keinen Zweifel, daß jeder unabhängige Staat, vermöge seiner Unabhängigkeit von anderen Staaten, in der Regel berechtigt ist, nach eigenem Gefallen, seine Verfassung festzusetzen, abzuändern und aufzuheben, ohne daß andern Staaten erlaubt ist, sich darin zu mischen ${ }^{36}$.

Das »seit Jahrhunderten« in Europa geltende Völkerrechtssystem verpflichte aber dessen Glieder, »in der Ausübung dieser Unabhängigkeit nicht blos auf die gleiche Unabhängigkeit und Selbständigkeit der übrigen Nationen, sondern auch, und zwar ganz vorzüglich, auf die Erhaltung des großen Vereins aller Nationen dieses Welttheils und der Grundlagen und Grundsätze desselben Rücksicht zu nehmen $\ll^{37}$.

Ein Interventionsrecht, gemäß von Kamptz ein »uralter, allgemein anerkannter, unbestrittener und seit Jahrhunderten befolgter, Grundsatz des europäischen Völkerrechts « ${ }^{38}$, wurde jedoch von den Autoren der Lehrbücher, worauf schon Gollwitzer unter Berufung auf den »ausgesprochenen Reaktionär« Theodor von Schmalz hingewiesen hat, nur in sehr beschränktem Maße anerkannt ${ }^{39}$.

Nicht bestritten wurde allerdings gemeinhin ein Handlungsrecht der Großmächte im europäischen Interesse, wenn die Rechte der einzelnen Staaten gewahrt blieben. Ein solcher Fall war der eingangs zitierte Pariser Friede mit der Aufnahme der Hohen Pforte in die Gemeinschaft des Europäischen öffentlichen Rechts und Staatenkreises. Grundsätzlich berechtigten und verpflichteten internationale Verträge nur die daran Beteiligten. Seit Moser war jedoch beim Herkommen schon der Rechtsgedanke anerkannt, dass in bestimmten Fällen Schweigen als Zustimmung gewertet wurde. Heffter zählt daher den Vertrag von 1856 wie den Westphälischen Frieden und die Wiener Kongressakte rückblickend zu den durch die seinerzeit tonangebenden Mächte geschlossenen Abkommen, »denen dann häufig auch die übrigen ausdrücklich oder stillschweigend sich angeschlossen haben $\aleph^{40}$. Aber: Bestä-

36 [Karl Albrecht vON KAMPTZ], Völkerrechtliche Erörterung des Rechts der Europäischen Mächte in die Verfassung eines einzelnen Staats sich zu mischen, Berlin 1821, S. 1.

37 Ebd., S. 3f.

38 Ebd., S. XVI.

39 Gollwitzer, Europabild und Europagedanke, S. 190.

40 August Wilhelm HefFter, Das Europäische Völkerrecht der Gegenwart, auf den bisherigen Grundlagen, Berlin ${ }^{6} 1873$, S. 23. 
tigte dieser Vertrag inhaltlich nicht ohnehin nur das, was die Lehre seit über hundert Jahren vertrat, die herkömmliche Zugehörigkeit der Türkei zum Europäischen Völkerrecht?

IV.

Vor einer Antwort auf diese Frage muss auf deren Relevanz für eine völkerrechtsgeschichtliche Forschungskontroverse hingewiesen werden. Das Weltvölkerrecht entstand nach traditioneller Ansicht Ende des 19. Jahrhunderts durch die Erweiterung des europäischen Völkerrechts. Gestützt auf seine Studien zum Law of Nations in the East Indies, hatte Charles Henry Alexandrowicz ${ }^{41}$ festgestellt, dass - gerade umgekehrt - sich zunächst unter dem Einfluss der Hegelschen Rechtsphilosophie und des Rechtspositivismus das universelle Naturrecht auf dieses regionale, rein europäische Völkerrecht verengt habe. Erst danach hätten die europäischen Nationen beanspruchen können, als zivilisierte Staaten über die Aufnahme eines neuen Mitglieds in ihren Kreis zu entscheiden. Dem wiederum hat Wilhelm G. Grewe entgegen gehalten, Alexandrowicz vernachlässige den »droit public de l'Europe«, indem er das Völkerrecht des 16. bis 18. Jahrhundert bereits uneingeschränkt als >universelk bezeichne:

Dem steht jedoch ein ausgeprägtes Bewußtsein aller europäischen Nationen, ihrer Regierungen sowohl wie ihrer am geistigen und politischen Leben aktiv partizipierenden Schichten gegenüber, daß das Völkerrecht in erster Linie eine Rechtsordnung der christlich-europäischen Völkerfamilie sei und im Verhältnis ihrer Mitglieder zueinander gelte ${ }^{42}$.

Ab der zweiten Hälfte des 18. Jahrhunderts habe dann im Westen »der Siegeszug des Zivilisationsgedankens« begonnen, »der in einem neuen geistigen Klima die christlich-europäischen Inhalte des völkerrechtlichen Gemeinschaftsgedankens verdrängte und ersetzte $\ll^{43}$.

Als gleichzeitig nichtchristlicher und europäischer Staat steht das Osmanische Reich im Fokus dieser Problematik, die eine längerfristige Betrachtung seines völkerrechtlichen Status erfordert. Bei Moser taucht die Pforte bereits uneingeschränkt in der Liste der europäischen Staaten auf. Günther rechnete sie nur wegen ihrer europäischen Besitzungen dazu, für Martens

41 Charles Henry Alexandrowicz, An introduction to the history of the law of nations in the East Indies (16th, 17th and 18th centuries), Oxford 1967.

42 Wilhelm G. GRewe, Vom europäischen zum universellen Völkerrecht. Zur Frage der Revision des »europazentrischen« Bildes der Völkerrechtsgeschichte, in: Zeitschrift für ausländisches öffentliches Recht und Völkerrecht 42 (1982), S. 449-479, hier: S. 451.

43 Ebd., S. 467. 
war sie dem europäischen Völkerrecht niemals als Ganzes beigetreten. Dieses Urteil wird noch in der ersten Hälfte des 19. Jahrhunderts von Julius Schmelzing und Johann Ludwig Klüber geteilt, die aber ebenfalls beide für die jüngere Vergangenheit eine immer stärkere Annäherung konstatieren ${ }^{44}$. Nach Schmalz wurden der Türkei, deren Völkerrecht er an anderer Stelle als »asiatisch und muhammedanisch« bezeichnet, bereits »fast ganz gleiche Rechte zugestanden«; für ihn bestand »kein Zweifel, daß es von ihr selbst abhängt in gänzliche Gleichheit jener Rechte zu treten « ${ }^{45}$. Auch Schmelzing stellt in einer Fußnote ausdrücklich klar, dass das Osmanische Reich mit gemeint sei, wenn er es als Aufgabe der Europäischen Völkerrechtswissenschaft ansieht, die äußeren rechtlichen Verhältnisse aller Europäischen Völker »aus den unter ihnen bestehenden besonderen Verträgen und Gewohnheiten darzustellen und pragmatisch zu entwickeln $\aleph^{46}$.

1825 versucht Pölitz jedoch, das seiner Meinung nach »beengende« Prädikat »europäisch« für die Zukunft zu streichen. Sein »practisches Völkerrecht« zielt auf das Staatensystem der christlich und gleichmäßig gesitteten europäischen und amerikanischen Völker und Staaten. Zwar suchte auch er durch eine Fußnotenbemerkung: »Man stoße sich nicht an die Aufnahme des Ausdrucks $>$ christlicher und gesitteter Völker $«{ }^{47}$ mit einem Zitat von Martens den Eindruck zu erwecken, er bewege sich in traditionellen Bahnen. Aber der von Pölitz drucktechnisch hervorgehobene Einfluss der christlichen Religion war für Martens nur ein Faktor in der historischen Entwicklung des europäischen Völkerrechts und keineswegs ein aktuelles Abgrenzungsmerkmal. Das Dilemma der Wissenschaft jedoch - hier die europäische Türkei, die sich in manchen Rechtsgewohnheiten noch von den christlichen Nachbarn unterschied, dort die überseeischen Vereinigten Staaten, die, christlich und europäischen Ursprungs, das europäische Völkerrecht ausdrücklich oder stillschweigend komplett übernommen hatten - war offenkundig.

Es sollte Heffter vorbehalten sein, 1844 unter Beibehaltung der Bezeichnung »europäisch« den Schritt zur transatlantischen Gemeinschaft zu vollziehen und damit die Gewichte entscheidend zu verlagern:

44 Julius Schmelzing, Systematischer Grundriß des praktischen Europäischen Völker-Rechtes. Für akademische Vorlesungen und zum Selbst-Studium entworfen, I, Rudolstadt 1818, S. 5f.; Johann Ludwig KLÜBER, Europäisches Völkerrecht, Schaffhausen ${ }^{2} 1851$, S. 2, Anm. d, und S. 44.

45 Theodor von Schmalz, Das europäische Völker-Recht in acht Büchern, Nachdr. der Ausg. Berlin 1817, Frankfurt/Main 1970, S. 36, Charakterisierung S. 203; zu Schmalz' Völkerrecht Hans-Christoph KRaus, Theodor Anton Heinrich Schmalz (1760-1831). Jurisprudenz, Universitätspolitik und Publizistik im Spannungsfeld von Revolution und Restauration, Frankfurt/ Main 1999, S. 560-570.

46 Schmelzing, Systematischer Grundriß. S. 4.

47 Karl Heinrich Ludwig Pölitz, Die Staatswissenschaften im Lichte unserer Zeit, Fünfter und letzter Theil: Practisches (europäisches) Völkerrecht, Diplomatie und Staatenpraxis, Leipzig ${ }^{2} 1828$, S. 5. 
So gilt denn auch das Europäische Völkerrecht seiner geschichtlichen Wurzel nach wesentlich nur unter christlichen Staaten, deren Sittlichkeit durch ein Uebereinkommen in den höchsten Gesetzen der Humanität und dem damit übereinstimmenden Charakter der Staatsgewalten verbürgt ist ${ }^{48}$.

Die Beziehungen zur Pforte beruhten nach Heffters Meinung dagegen nur auf politischer Convenienz und dem Druck der vereinigten christlichen Mächte. Damit waren die Weichen für die Zukunft gestellt: Das neue Rechts-Kriterium war gemeinschafts-, nicht mehr gebietsbezogen, europäisches Völkerrecht und Europa nicht mehr deckungsgleich.

Der Abschluss des Vertrags von 1856 führte dazu, dass die Gegensätze in der Lehre noch schärfer herausgestellt wurden. Zwar war eine wechselseitige Rechtsbindung nun nicht mehr zu bestreiten, ja das europäische Völkerrecht galt jetzt sogar für und gegen die Barbareskenstaaten, soweit sie Nebenlande der Pforte waren. Heffter erinnerte daher an deren Piratenvergangenheit und stellte insgesamt die »Tragweite der Aufnahme in das 〉Europäische Staaten-Concert«« durch einen von ihm angenommenen selbstverständlichen und stillschweigenden Vorbehalt beider Parteien hinsichtlich der Religion in Fra$\mathrm{ge}^{49}$. Schärfer noch formulierte der Wiener Professor Leopold Neumann:

die Auffassung des Koran, der ewigen Kampf gegen die Ungläubigen zur ersten Pflicht macht, Recht und Sitte der Islamiten, sind und bleiben, was man auch in jüngster Zeit sagen, schreiben, auf dem Papier decretiren mag, in vollem Gegensatze zum Völkerrechte christlicher Staaten ${ }^{50}$.

Und Franz von Liszt, der das »Europäische« aus dem Titel, nicht aber aus der Darstellung seines »Völkerrechts« gestrichen hatte, beurteilte 1898 die ausdrückliche Aufnahme rückblickend als »wohl verfrüht $\aleph^{51}$.

»Christlich-europäisch« wurde in der zweiten Jahrhunderthälfte der Maßstab, dem das Geschichtsbild angepasst wurde. Franz von Holtzendorff, der das Pariser Abkommen als »Unabhängigkeitserklärung des praktischen Völkerrechts von der religiösen Glaubensgemeinschaft der Nationen« interpretierte, formulierte 1885 die seither gängige Ansicht:

Die Terminologie des Europäischen Völkerrechts deckte sich niemals mit den Gränzen des Europäischen Festlandes und der zu ihm gehörigen Inseln. Vor dem Abschluß des Pariser Friedens im Jahre 1856 war das Europäische Gebiet der Türkei gleicherweise wie ihre außereuropäischen Besitzungen der Herrschaft allgemeiner Europäischer Völkerrechtsordnung entzogen. Andererseits hatten schon seit Jahrhunderten Europäische Rechtsgrundsätze und Vertragsbestimmungen ihre Einwanderung in die

48 Heffter, Das Europäische Völkerrecht der Gegenwart, S. 11, die Bemerkung zur Pforte in Fn. 1.

49 Ebd., S. 15-17.

50 Leopold von Neumann, Grundriss des heutigen europäischen Völkerrechts, Wien ${ }^{3} 1885$, S. 13.

51 Franz von Liszt, Das Völkerrecht systematisch dargestellt, Berlin 1898, S. 2. 
transatlantische Welt angetreten. Sprach man dennoch schon vor 1856 von den Grundsätzen des Europäischen Völkerrechts, so lag darin nicht sowohl die Andeutung einer geographischen Herrschaftsgränze, als der Hinweis auf ein geschichtliches Ursprungsverhältnis ... ${ }^{52}$.

Nach Holtzendorff sind es nun drei Gruppen, die das so genannte Europäische Völkerrecht - »in der Gegenwart das Völkerrecht schlechthin, das gemeine Weltrecht der Culturstaaten $\aleph^{53}$ - anwenden:

1. »diejenigen Staaten Europas, welche im Verlaufe ihrer geschichtlichen Entwicklung sich allmählig in die Rechtsgemeinschaft eines internationalen Verkehrs eingerichtet und eingelebt haben, was bei allen christlichen Nationen seit dem Mittelalter der Fall gewesen ist «;

2. »Gebiete, welche in der neuen Welt von Europa aus colonisirt worden sind « und

3. »solche Staaten, welche zwar auf Gebieten außerhalb des Europäischen Culturverbandes oder im Gegensatz zu den Ueberlieferungen Europäischer Cultur entstanden sind, aber durch ausdrückliche Vereinbarung in die Rechtsgemeinschaft der Europäischen Staaten (sog. Europäisches Concert) eingeführt worden sind $\aleph^{54}$.

Wie tief der Graben zwischen den ersten beiden Gruppen und der dritten nun war, soll abschließend ein weiteres Zitat Holtzendorffs verdeutlichen. Die Bezeichnung >Völkerrecht civilisirter Staaten` lehnt er unter Berufung auf das »neue« Europaverständnis ab:

Da der Begriff der >Civilisation « indessen als höchste Gesittung auch von altasiatischen Staatswesen für sich in Anspruch genommen wird, so darf die historische Bezugnahme auf Europa, als den Ursprungscontinent des modernen Völkerrechts, zum Zwecke der Gegenüberstellung zu den seiner Anwendung nicht unterliegenden Landgebieten auch noch gegenwärtig festgehalten werden. Mit Asiaten kann man sich leichter verständigen, wenn man jede Streifrage über das Wesen der Civilisation vermeidet und ihnen Grundsätze anempfiehlt, welche den Namen einer Völkermacht tragen, deren Ueberlegenheit sie anzuerkennen genöthigt sind ${ }^{55}$.

52 Franz von Holtzendorff, Grundbegriffe, Wesen und Verhältnißbestimmungen des Völkerrechts, in: Franz von HoltzendorfF (Hg.), Handbuch des Völkerrechts. Auf der Grundlage Europäischer Staatenpraxis, Erster Band: Einleitung in das Völkerrecht, Berlin 1885, S. 1-76, Zitat S. 13.

53 Ebd., S. 12f.

54 Ebd., S. 14.

55 Ebd., S. $14 f$. 
V.

Die Lehre vom europäischen Völkerrecht versucht im 18. Jahrhundert, unabhängig von religiösen Bekenntnissen in einem begrenzten Raum eine gemeinsame rechtliche Ordnung zu beschreiben. Die räumliche Ausdehnung auf den amerikanischen Kontinent schwächt die Vorstellung zunächst nicht, trägt aber ihrerseits Anfang des 19. Jahrhunderts zur stärkeren Wahrnehmung christlicher Zusammengehörigkeit bei. Der Begriff »Europäisches Völkerrecht«, einerseits als kontinentaler Ansatz aufgeweicht durch eine Marginalisierung der Türkei, andererseits historisch umgedeutet zur christlich geprägten Ursprungsbezeichnung, hält sich jedoch bis Ende des 19. Jahrhunderts. Erst im imperialistischen Zeitalter verschwindet das »beengende « Adjektiv (Pölitz schon 1825), paradoxerweise verdrängt durch einen Zivilisationsbegriff, der das Europäische überhöht - und auch die spätere Forschung geprägt hat. 


\title{
Kerstin Armborst-Weihs \\ Die zionistische Bewegung und ihr Verhältnis zu Europa
}

\author{
Visionen, Entwürfe und Wirklichkeiten von den \\ Anfängen bis zur Zwischenkriegszeit
}

Ende 1897, im Jahr des Ersten Zionistenkongresses in Basel, erschien in dem Zentralorgan der zionistischen Bewegung Die Welt ein Leitartikel mit dem Titel Die guten Europäer ${ }^{1}$, der sich mit der Frage beschäftigte, ob sich der Zionismus mit dem »Europäerthum « vereinbaren lasse, wie es vor allem von assimilierten Juden angestrebt werde. Der Autor des Artikels, der Schriftsteller und Literaturhistoriker Samuel Lublinski betrachtete das »Europäerthum« als ein »großes Culturziel«, wobei er »Europa« nicht geographisch, sondern als einen »Culturgattungsbegriff« verstand ${ }^{2}$. Ein guter Europäer könne jedoch nur sein, wer sein Vaterland liebe und es bedürfe noch vieler Schritte, um die verbreitete Auffassung vom Zwiespalt zwischen Heimatgefühl und Europäertum zu beseitigen:

[...]; die Nationen müssten gelernt haben, ihren wechselseitigen Besitzstand zu respectieren, ihre Eigenthümlichkeiten intensiv zu pflegen und ihre geistigen Werte gegeneinander auszutauschen. Und endlich, als Letztes und Höchstes, müsste in irgend einer Form der politische Zusammenschluss Europas erfolgen. Dann erst wird das Meer der europäischen Cultur überallhin so hohe Wellen schlagen, dass auch das schwächste Talent, welches im allerengsten Winkel lebt, hoch emporgetragen wird und einen freien Weltblick gewinnt ${ }^{3}$.

Vom Zionismus als der jüdischen Nationalbewegung gingen diesem Denken zufolge weniger abgrenzende Tendenzen aus, als vielmehr solche Entwicklungen, die im europäischen Kontext letztendlich integrierend wirken sollten:

Ich weiß jetzt, dass das Nationaljudenthum und ein kleines jüdisches Gemeinwesen in Palästina nur dazu dienen können, den Zusammenschluss Europas zu beschleunigen und das ist das höchste aller Ideale, die ich kenne. Ich weiß, dass gerade die Judenfrage, wie sie bisher behandelt wurde, Sprengstoffe in alle Lager trug und die Entwicklung hemmte und fälschte. Und ich weiß endlich, dass die Rückkehr zum alten

\footnotetext{
S[amuel] Lublinski, Die guten Europäer, in: Die Welt 1/27 (1897), S. 1-3.

Ebd.

Ebd., S. 2f.
} 
Stamm, die Pflege von tiefgehenden, nationalen Seeleneigenschaften mich ebensowenig zu hindern braucht, ein guter Europäer zu sein, wie irgend einen Jungwiener die Liebe zu seiner Vaterstadt ${ }^{4}$.

Lublinski maß dem Zionismus vor allem eine kulturelle Bedeutung zu und war überzeugt, dass die zionistische Bewegung die »Gesamtcultur « ${ }^{5}$ fördern werde. Mit diesem kulturellen Fokus repräsentierte er nur eine kleine Gruppe unter den Anhängern des Zionismus, die erst einige Jahre später als eigene Fraktion innerhalb der Zionistischen Weltorganisation (ZWO) an Gewicht gewann ${ }^{6}$. Doch die Frage nach der Bedeutung der zionistischen Bewegung für das jüdische Leben in Europa und für das Verhältnis der Juden zu ihren europäischen Heimatländern beschäftigte viele, insbesondere westeuropäische Zionisten, die für sich selbst keine Auswanderung nach $\mathrm{Pa}-$ lästina anstrebten. Als eine bis zum Ersten Weltkrieg vorwiegend auf den europäischen Kontinent konzentrierte Organisation stand die zionistische Bewegung in vielfacher Hinsicht vor der Herausforderung, sich zu »Europa« zu positionieren?.

Lublinskis Ausführungen geben somit Anlass zu untersuchen, wie sich die Bewegung innerhalb Europas verortete, ob der Zionismus tatsächlich integrative Elemente in Bezug auf Europa aufwies und welche faktischen Entfaltungsmöglichkeiten sich in dieser Hinsicht abzeichneten, oder ob der Zionismus - mit seiner Forderung nach einem eigenen jüdischen Staat außerhalb Europas - nicht vielmehr eine Entfremdung und Ablösung der Juden von ihren Lebenswelten in der Diaspora vorantrieb und damit innerhalb der europäischen Geschichte eher als ein Phänomen der Abgrenzung und Distanzierung betrachtet werden muss. Damit eng verknüpft sind die Fragen nach den Europabildern innerhalb der zionistischen Bewegung und den Erwartungen, die der Zionismus an eine gemeinsame europäische Politik richtete ${ }^{8}$.

Eine Annäherung an diese Fragestellungen erfordert einerseits eine nähere Betrachtung des im 19. und frühen 20. Jahrhundert überaus ambivalenten Verhältnisses der Juden zu Europa, andererseits aber auch die Berücksichtigung der Vielschichtigkeit der jüdischen Nationalbewegung. Daher gliedert sich die Untersuchung im Folgenden in drei Schritte, die jeweils unterschiedliche Ebenen der zionistischen Bewegung betrachten: die Einstel-

4 Ebd., S. 3.

5 Ebd.

6 Siehe u. Abschnitt 2.

7 Ende des 19. Jahrhunderts lag das Zentrum der jüdischen Diaspora noch eindeutig auf dem europäischen Kontinent; etwa die Hälfte der jüdischen Weltbevölkerung lebte im Zarenreich. Erst die Einwanderungswelle aus Osteuropa Ende des 19. und Anfang des 20. Jahrhunderts ließ die jüdische Bevölkerungsgruppe in den USA bedeutend anwachsen.

8 Die wichtige Frage nach den zionistischen Vorstellungen von den Grenzen Europas muss hier unberücksichtigt bleiben. Da »Europa« nur selten direkt definiert wird, wäre für eine solche Untersuchung eine eingehende Analyse der jeweiligen Kontexte erforderlich. 
lungen zu Europa vor allem in der Entstehungszeit des Zionismus, die innere Entwicklung der international organisierten, aber zunächst insbesondere auf Europa konzentrierten zionistischen Bewegung zwischen 1897 und dem Ersten Weltkrieg und die Verflechtungen von europäischer Politik und Zionismus. Ein vierter Schritt soll die Ergebnisse verknüpfen und im Gesamtkontext bewerten.

In den verschiedenen Länderorganisationen und später auch in den grenzübergreifenden Interessengruppen der zionistischen Bewegung prägten sich zahlreiche Facetten zionistischer Ideen, Programmatiken und Aktivitäten aus, die hier nur in Ansätzen Berücksichtigung finden können. Schwerpunktmäßig konzentriert sich die Untersuchung auf für die gesamte Entwicklung der zionistischen Bewegung bedeutsame Schriften, auf die Politik der Zentrale der Zionistischen Weltorganisation und deren Organ, die Wochenzeitschrift Die Welt.

\section{Zionistische Einstellungen zu Europa}

$\mathrm{Zu}$ Beginn des 19. Jahrhunderts standen die jüdischen Gemeinschaften in den europäischen Ländern weitgehend am Rande der nicht-jüdischen Gesellschaften - und zwar sowohl in geographischer als auch in sozialer Hinsicht. Der überwiegende Teil der Juden lebte in eher ländlichen Gegenden, der Prozentsatz jüdischer Bevölkerung in den großen Städten Europas war dagegen verschwindend gering. Meist ausgeschlossen von Positionen in öffentlichen Ämtern, vom Dienst in der Armee und von vielen weiteren Berufsfeldern, konnten sie insgesamt nur wenig Einfluss auf Politik, Wissenschaften und Künste nehmen. Doch Reformansätze wie das Toleranzedikt Josephs II. hatten insbesondere unter den »Maskilim«, den jüdischen Aufklärern, Hoffnungen geweckt, dass ein fortschrittliches Europa den Juden die Tore in eine neue, bessere Welt öffnen würde.

Ende des 19. Jahrhunderts hatte sich das Bild gewandelt. Im intellektuellen Leben vieler Städte zeigten die Juden Präsenz, und wenn sie auch in den Entscheidungszentren politischer Macht wenig vertreten waren, so konnte doch ein Teil von ihnen im Zuge von Aufklärung, Emanzipation und industrieller Revolution ins Zentrum der Gesellschaft rücken. Der Eintritt in die modernen Gesellschaften zog für viele Juden in Westeuropa eine Neudefinierung jüdischer Existenz auf rein konfessioneller Grundlage nach sich. In Osteuropa, wo der größte Teil der jüdischen Weltbevölkerung lebte, war der Emanzipationsprozess gescheitert. Anders als in Westeuropa blieben im Osten relativ isolierte jüdische Gemeinschaften, die ihre kollektiven Strukturen weit über den religiösen Bereich hinaus beibehielten, am Rande der Mehrheitsgesellschaften bestehen. Parallel dazu hatte sich eine kleine säkulare, 
zunächst noch weitgehend auf Integration und Emanzipation setzende Elite herausgebildet. Der Gedanke der Rückkehr nach »Eretz Israel« war unter den in der Zerstreuung lebenden Juden von jeher präsent. Er fand Ausdruck in Gebeten und war vielfach verbunden mit messianischen Vorstellungen - mit der Hoffnung auf die Vereinigung der Juden in Zion ${ }^{9}$ und auf das Erscheinen des Messias. Doch obgleich stets Juden in Palästina ansässig waren und Zion als Symbol des jüdischen Ursprungs, der jüdischen Einheit und der Erlösung eine zentrale Bedeutung hatte, gab es bis ins 19. Jahrhundert keine Masseneinwanderung oder Pläne, durch Bildung eines neuen Reiches in Palästina den Anbruch des messianischen Zeitalters vorzubereiten. Denn damit wäre nach jüdischem Glauben dem Willen Gottes in menschlicher Weise vorgegriffen und so dem religiösen Verständnis von der Rückführung und Erlösung durch Gott widersprochen worden. Im 19. Jahrhundert hatten sich die Lebenswelten der jüdischen Gemeinschaften in Europa und das Denken der Menschen jedoch soweit verändert, dass verstärkt darüber nachgedacht wurde, wie das Leid von Teilen der jüdischen Bevölkerung anders als durch die Hilfe philanthropischer Organisationen gemindert werden könnte, wie der drohende Verlust jüdischer Traditionen und Eigenständigkeit zu verhindern sei und auf welche Weise das jüdische Volk aus der Rolle des Außenstehenden und Verachteten befreit werden könnte. Mit dem Aufkommen des Nationalismus in Europa nahm nun der Zionismus als jüdische Nationalbewegung Gestalt an. Die ersten modernen, allerdings noch stark religiös geprägten Pläne für eine Rückkehrbewegung ins Gelobte Land entstanden Mitte des 19. Jahrhunderts in Regionen, die wesentlich von nationalen Konflikten geprägt waren und gleichzeitig auch Schnittstellen jüdischen Lebens zwischen Ost und West darstellten ${ }^{10}$.

Anfang der 1860er Jahre prophezeite Moses Hess in seinem Buch Rom und Jerusalem $^{11}$ das Scheitern der jüdischen Emanzipation in den europäischen Staaten und forderte die Schaffung eines jüdisch-sozialistischen Gemeinwesens in Palästina. Der Untertitel der Schrift Die letzte Nationalitätsfrage und die Anknüpfung an die italienische Nationalbewegung verdeutlichten, dass Hess die »Judenfrage« anders als die meisten seiner Zeitgenossen nicht als ein religiöses, sondern als ein rein nationales Problem betrachtete, das sich in den Kontext der nationalen Freiheitsbewegungen im Europa des 19. Jahrhun-

9 Der Name »Zion« bezeichnete zu biblischen Zeiten zunächst den Tempelberg, wurde dann auf die Stadt Jerusalem und später auf »Eretz Israel« insgesamt ausgedehnt. Vgl. Heiko HaumanN, Zionismus und die Krise jüdischen Selbstverständnisses. Tradition und Veränderung im Judentum, in: Ders. (Hg.), Der Traum von Israel: Die Ursprünge des modernen Zionismus, Weinheim 1998, S. 9-64, hier: S. 10f.

10 Vgl. Michael Brenner, Geschichte des Zionismus, München 2002, S. 10-12.

11 Moses Hess, Rom und Jerusalem. Die letzte Nationalitätsfrage, Leipzig 1862. 
derts einordnete ${ }^{12}$. In den 1860er Jahren fanden diese Gedanken unter den Juden in Europa jedoch noch keinen Widerhall.

Erst etwa zwanzig Jahre später, unter dem Eindruck der Pogromwellen im Zarenreich, stießen derartige Konzepte auf Resonanz. In vielen Städten des Zarenreiches bildeten sich Anfang der 1880er Jahre jüdische Vereine, die sich »Chowewe Zion « $^{13}$ nannten und die Selbstbefreiung und Palästina-Kolonisation propagierten. ${ }^{14}$ Als der Odessaer Arzt Leon Pinsker 1882 seine Schrift Autoemancipation $!^{15}$ veröffentlichte, wurde diese von der noch jungen zionistischen Bewegung im Zarenreich sehr positiv aufgenommen ${ }^{16}$. Pinsker, ehemals Anhänger der »Haskala« und Verfechter des Assimilationsgedankens, diagnostizierte in seiner Schrift das Ende des Traums vieler russischjüdischer Intellektueller, durch Bildung und Integration die Emanzipation zu erreichen. Die Massaker und Pogrome des Jahres 1881 galten ihm als Beweis dafür, dass eine Emanzipationsidee, die auf der Integration der Juden in die nichtjüdischen Gesellschaften Europas basierte, nicht angemessen war. Er forderte dagegen die Selbstemanzipation der Juden als Nation außerhalb des europäischen Kontinents.

In Pinskers Konzeption waren bereits zwei Elemente vorgezeichnet, die grenzübergreifende Kooperationen erforderten: einerseits die Selbstemanzipation des in der Zerstreuung lebenden jüdischen Volkes durch die Vereinigung als Nation, die Förderung einer jüdischen Kolonisation sowie die gemeinsame politische Aktivität und andererseits die Mitwirkung insbesondere der europäischen Mächte:

Das Streben der Juden nach einer national-politischen Einheit und Selbstständigkeit hat nicht allein eine innere Berechtigung wie das jedes anderen unterdrückten Volkes, es müsste auch Zustimmung finden bei den Völkern, denen wir, mit Recht oder Unrecht, unbequem sind. Dieses Streben muss eine Thatsache werden, die sich der internationalen Politik der Gegenwart unwiderstehlich aufdrängt und gewiss auch eine Zukunft haben wird. ${ }^{17}$

Die Sorge galt nicht nur der Not der Juden in Osteuropa und der dort herrschenden antisemitischen Stimmung. Vielmehr wurde die weite Verbreitung

12 Vgl. Shlomo Avineri, Profile des Zionismus. Die geistigen Ursprünge des Staates Israel. 17 Portraits, Gütersloh 1998, S. 58-61.

13 Hebr.: Zionsfreunde.

14 Vgl. Adolf Bӧнm, Die zionistische Bewegung, Bd. 1: Die zionistische Bewegung bis zum Ende des Weltkrieges, Tel Aviv ${ }^{2} 1935$, S. 96-115.

15 [Leon PINSKER], »Autoemancipation!« Mahnruf an seine Stammesgenossen von einem russischen Juden, Berlin 1882.

16 Julius H. Schoeps, Leon Pinsker und die These vom Antisemitismus als »kollektive Psychopathologie«, in: Ders. (Hg.), Palästinaliebe. Leon Pinsker, der Antisemitismus und die Anfänge der nationaljüdischen Bewegung in Deutschland, Berlin u.a. 2005, S. 21-34, hier: S. 31f.

17 Pinsker, »Autoemancipation!«, S. 20. 
des Antisemitismus in jenen Ländern, in denen Juden einen bedeutenden Bevölkerungsanteil ausmachten, insgesamt als Problem benannt, das durch den Zionismus zu mindern sei. Der Zionismus, »einer großen europäischen Gesamtstimmung entsprossen $\aleph^{18}$, sollte erreichen,

daß die jüdische Bevölkerung in den Ländern der europäischen Zivilisation durch zeitweilige Abflüsse an Zahl beständig unterhalb jenes Sättigungspunktes erhalten würde, über welchen hinaus erfahrungsgemäß die Juden nicht mehr gut vertragen werden ${ }^{19}$.

Innerhalb der entstehenden zionistischen Bewegung wurde der Antisemitismus als ein in ganz Europa verbreitetes Phänomen beklagt ${ }^{20}$. Daher richteten sich die Appelle zur Unterstützung des Zionismus in den folgenden Jahren nicht nur an einzelne Staaten, sondern an die gesamte europäische Staatengemeinschaft oder - wie der Alterspräsident Karl Lippe aus Rumänien auf dem Ersten Zionistenkongress formulierte - an »das öffentliche Gewissen in Europa $\ll^{21}$.

Die Ambivalenz des Verhältnisses der Zionisten zu Europa zeigt sich vor allem in den Ideen und programmatischen Überlegungen Theodor Herzls, die die zionistische Bewegung in den Anfangsjahren bedeutend prägten. Insbesondere der sich in Frankreich verbreitende pseudowissenschaftlich untermauerte Antisemitismus und die judenfeindliche Atmosphäre in Österreich veranlassten den Juristen und Journalisten Herzl zu seinem zionistischen Engagement ${ }^{22}$. Die antisemitisch geprägten Gesellschaften in den verschiedenen Ländern betrachtete Herzl als »äußere Feinde « ${ }^{23}$, durch die die Juden als Volk zusammengehalten würden. Während seiner Korrespondentenzeit in Paris war Herzl zu der Überzeugung gelangt, dass es nicht ausreiche, dem Antisemitismus in Europa mit Zeitungsartikeln zu begegnen, sondern dass

18 S[amuel] Lublinski, Völkereinsamkeit, in: Die Welt 2/49 (1898), S. 2f., hier: S. 3.

19 Nathan Birnbaum, Die nationale Wiedergeburt des jüdischen Volkes in seinem Lande, als Mittel zur Lösung der Judenfrage. Ein Appell an die Guten und Edlen aller Nationen (Erstdruck Wien 1893), in: Ders., Ausgewählte Schriften zur jüdischen Frage, Bd. 1, Czernowitz 1910, S. 1-21, hier: S. 9.

20 Vielfach wurde der Antisemitismus auch als eine typisch europäische Erscheinung betrachtet. So veröffentlichte »Die Welt« 1899 einen Artikel über einen Pogrom in Südafrika mit dem Titel »Europa in Afrika«, in dem es hieß: »Im halbzivilisierten Süden Afrikas hat sich dieser Tage etwas zugetragen, was sonst nur im hochcultivierten, überfeinerten Abendlande zeitweilig passiert: Eingeborene sind über jüdische Geschäftsläden hergefallen, haben die Einrichtungsstücke demoliert, die Locale verwüstet, Waren gestohlen, die Eigenthümer bedroht - kurz, sie haben sich benommen wie zivilisierte Europäer«. Erwin RosenBerger, Europa in Afrika, in: Die Welt 3/41 (1899), S. 5f., hier: S. 5.

21 Zionisten-Congress in Basel (29., 30. und 31. August 1897). Officielles Protocoll, Wien 1898, S. 4.

22 Vgl. Klaus Dethloff, Einleitung, in: Ders. (Hg.), Theodor Herzl oder der Moses des Fin de siècle, Wien u.a. 1986, S. 7-61, hier: S. 17-26.

23 Theodor HerzL, Der Judenstaat. Versuch einer modernen Lösung der Judenfrage, Neuausgabe nach dem Erstdruck Leipzig / Wien 1896, Zürich 1988, S. 19. 
es dazu einer andersgearteten Bewegung bedürfe. Die Dreyfus-Affäre, die im Frankreich der 1890er Jahre zu weitgreifenden Diskussionen und zur Polarisierung der politischen Kräfte führte, bestätigte Herzl in dieser Auffassung.

1896 erschien in Wien seine politische Programmschrift Der Judenstaat. Versuch einer modernen Lösung der Judenfrage, in der Herzl die »Judenfrage« als ein nationales Problem bezeichnete, das durch die Gründung eines Judenstaates zu lösen wäre. Zwei große Aufgaben betrachtete Herzl zunächst als vorrangig: Erstens sollte der Judenstaat von innen her durch die Schaffung politischer Organe vorbereitet und durch Erwerb von Land konstituiert werden, und zweitens sollte die Zustimmung der europäischen Mächte den Staat sichern. Aufgrund der für die europäischen Staaten durch eine jüdische Staatsgründung zu erwartenden Vorteile erschien Herzl die Unterstützung des Plans von Seiten der Regierungen in Europa realistisch. Neben wirtschaftlichen und sozialen Aspekten nannte Herzl ein weiteres Argument:

Für Europa würden wir dort [d.h. in Palästina] ein Stück des Walles gegen Asien bilden, wir würden den Vorpostendienst der Kultur gegen die Barbarei besorgen. Wir würden als neutraler Staat im Zusammenhange bleiben mit ganz Europa, das unsere Existenz garantieren müßte ${ }^{24}$.

Herzl setzte somit nicht nur auf die Mitwirkung der europäischen Mächte »Europa« stellte für ihn auch einen zentralen Bezugspunkt dar und lieferte gleichzeitig Vorbilder und Modelle für den neu zu gründenden jüdischen Staat. Anders als beim Auszug aus Ägypten sollten die Juden diesmal nicht alles hinter sich lassen und nicht alle Verbindungen abbrechen: »Wenn wir noch einmal aus Mizraim ${ }^{25}$ wandern, werden wir die Fleischtöpfe nicht vergessen ${ }^{26}{ }^{6}$. Vielmehr plädierte Herzl für einen Kultur- und Wissenstransfer: Er stellte sich den Judenstaat als Destillat sämtlicher positiver Errungenschaften der europäischen Staaten vor, in dem ein Sprachföderalismus nach dem Vorbild der Schweiz herrschen und in dem jeder seine aus dem Herkunftsland mitgebrachten Traditionen und Gebräuche pflegen sollte ${ }^{27}$.

Auch viele jüdische Kolonisten zeigten eine ambivalente Einstellung zu Europa: Zwar hatten sie Europa meist verlassen, weil sie dort keine Zukunft mehr sahen, doch nach den ersten Begegnungen mit der Wirklichkeit in Palästina entwickelten sie ein ausgeprägtes Selbstverständnis als »Europäer«, das sie veranlasste, die Siedlungen nach »europäischen Standards $\aleph^{28}$ auszu-

24 Ebd., S. 39.

25 Hebr.: Ägypten.

26 Herzl, Judenstaat, S. 87.

27 Ebd., S. 87 u. 99f. Siehe auch die Beschreibung des Judenstaates in Herzls erstmals 1902 veröffentlichten Roman »Altneuland «.

28 Die Orientierung an »europäischen Standards« geht Yaacov Shavit zufolge aus vielen Doku- 
richten. Selbst radikale Nationalisten stellten sich den jüdischen Staat als jüdisch-europäische Insel in Asien vor und bemühten sich, die Verfechter von Integration und Assimilation davon zu überzeugen, dass »Europa« eine »bewegliche Kultur« sei, die nach Asien mitgenommen werden könne ${ }^{29}$.

Jenen - meist westeuropäischen - Zionisten, die selbst akkulturiert waren und keine Auswanderung anstrebten, galten ihre jeweiligen Herkunftsländer weiterhin als Heimat und Vaterland; ihr zionistisches Engagement zielte auf die Hilfe für in Not geratene osteuropäische Juden und war verbunden mit der Hoffnung, die Existenz eines jüdischen Staates werde sich positiv auf das jüdische Leben in Europa und das Verhältnis zwischen den Juden und den jeweiligen Mehrheitsgesellschaften auswirken ${ }^{30}$. In diesem Zusammenhang wurden auch Stimmen laut, die ähnlich wie Samuel Lublinski auf eine friedens- und einheitstiftende Wirkung des Zionismus in Europa setzten. Während Theodor Herzl in dieser Hinsicht vor allem die Beschwichtigung der sozialen Unzufriedenheit und den wirtschaftlichen Frieden in den Herkunftsländern im Blick hatte ${ }^{31}$, deutete Bertha von Suttner, die sich am Rande der Ersten Haager Friedenskonferenz für den Zionismus einsetzte, die Wirkung des Zionismus umfassender und insbesondere unter rechtlichen Gesichtspunkten:

Durch das Erwachen des zionistischen Gedankens kann der Friedensgedanke nur gefördert werden, wie denn überhaupt alle Befreiungskämpfe zusammenhängen. Der Weg zur Freiheit, zur Menschenwürde, zur endlich anerkannten Unverletzlichkeit der persönlichen Güter - darunter jedes Einzelnen Ehre und Leben - dieser Weg wird jetzt von verschiedenen Pionnierstruppen ausgehauen. Eine der tapfersten darunter - weil sie ja unter Steinwürfen arbeiten muss - ist die Zionistentruppe ${ }^{32}$.

Vor allem während des Ersten Weltkriegs und in der unmittelbaren Nachkriegszeit erfuhr diese Interpretation mit unterschiedlichen Akzentsetzungen innerhalb der zionistischen Bewegung eine neue Konjunktur ${ }^{33}$.

menten der frühen Siedler hervor. Vgl. Yaacov Shavit, The 〉Glorious Century< or the `Cursed Century<: Fin-de-Siècle Europe and the Emergence of Modern Jewish Nationalism, in: Journal of Contemporary History 26/3-4 (1991), S. 553-574, hier: S. 573, Endnote 24.

29 Vgl. ebd., S. 564f.

30 Siehe z.B. die Dokumente Nr. 20 und 36 in: Jehuda Reinharz, Dokumente zur Geschichte des deutschen Zionismus 1882-1933, Tübingen 1981, S. 45-47 u. 76-79. - Weit verbreitet war die von Nathan Birnbaum 1893 formulierte Hoffnung, die Existenz eines jüdischen Staates und die Auswanderung eines Teils der jüdischen Bevölkerung dorthin werde »eben so sehr ein beträchtliches Nachlassen der antisemitischen Spannung, als eine Milderung des Daseinskampfes der jüdischen - und übrigens auch der nichtjüdischen - Volksmassen bedeuten« (BIRNBAUM, Wiedergeburt, S. 9).

31 Herzl, Judenstaat, S. 104-107.

32 Bertha von Suttner, Nach dem Haag!, in: Die Welt 3/21 (1899), S. 1f., hier: S. 2.

33 Siehe u. Abschnitt 3 u. 4. 


\section{Europa als Aktionsraum}

Die Idee der nicht nur religiös definierten Zusammengehörigkeit aller Juden als ein Volk und der Begriff der Nation stellten von Anfang an Kernelemente der zionistischen Theorien und Programmatiken dar. Zunächst erfasste die neue Nationalbewegung jedoch hauptsächlich Juden auf dem europäischen Kontinent, und ihre grenzübergreifende Zusammenarbeit prägte die Entwicklung der zionistischen Bewegung bis zum Ersten Weltkrieg. Schon bald nach dem Erscheinen seiner Schrift Der Judenstaat gelang es Theodor Herzl und seinen Mitstreitern, Anhänger des Zionismus aus verschiedenen Ländern in einer Organisation zusammenzufassen. Zum Ersten Zionistenkongress in Basel kamen 1897 über 200 Delegierte aus mindestens 17 Ländern, wobei etwa ein Drittel der Teilnehmer aus Osteuropa stammte ${ }^{34}$. Erklärtes Ziel des Baseler Programms war die »Schaffung einer öffentlich-rechtlich gesicherten Heimstätte in Palästina«, unter anderem durch die »Gliederung und Zusammenfassung der ganzen Judenschaft durch geeignete örtliche und allgemeine Veranstaltungen nach den Landesgesetzen ${ }^{35}$. Daher wurde von Beginn an daran gearbeitet, der Bewegung eine breite, international verankerte Basis zu verschaffen. Die Zionistische Weltorganisation (ZWO) setzte sich aus Landesorganisationen zusammen, deren gewählte Delegierte an den regelmäßig stattfindenden Kongressen teilnahmen; der Exekutive gehörten Vertreter mehrerer Länder an.

Die ersten Jahre der organisierten zionistischen Arbeit standen insbesondere im Zeichen des Austauschs zwischen »Ost-« und »Westjuden« sowie der Diskussion über die Situation der Juden und die Stellung des Zionismus in den einzelnen Ländern. Vielfach galt es, tief verwurzelten Vorurteilen zu begegnen. Theodor Herzl selbst äußerte nach dem Ersten Zionistenkongress seine Überraschung über die Teilnahme so vieler hoch gebildeter Delegierter aus Osteuropa, die ihr Judentum bewusst lebten:

[...] wir hatten uns nie etwas anderes vorgestellt, als daß sie auf unsere geistige Hilfe und Führung angewiesen seien. Und da tauchte vor uns auf dem Baseler Kongreß ein russisches Judentum auf, das wir in solcher Kulturstärke nicht erwartet hatten. [...] Und welche Beschämung für uns, die wir geglaubt hatten, ihnen überlegen zu sein. [...] Ich mußte daran denken, wie man mir in der ersten Zeit oft entgegengehalten hatte: Sie werden nur die russischen Juden für die Sache gewinnen. Wenn man mir das heute wieder sagte, würde ich antworten: Das genügt ${ }^{36}$

34 Nathan Michael Gelber / Oskar K. Rabinowicz, Art. »Congress, Zionist«, in: Encyclopedia of Zionism and Israel, Bd. 1 (1971), S. 205-212, hier: S. 206.

35 Zionisten-Congress 1897, S. 114 u. 119.

36 Theodor HerzL, Der Baseler Kongreß, in: Ders., Gesammelte Zionistische Werke, Bd. 1: Zionistische Schriften, Tel Aviv ${ }^{3} 1934$, S. 188-208, hier: $198 f$. 
Aus dem intensivierten Austausch zwischen Ost und West gingen einerseits enge Verbindungen und Kooperationen hervor, andererseits traten nun aber auch Differenzen und Distanzen offen zu Tage: Mit der Verdichtung der grenzübergreifenden Kommunikation und der Diskussionen über Themen, die »von der Polarität zwischen den Juden im Westen und im Osten lebten«, verbreitete sich die Kollektivbezeichnung »Ostjuden« als Zusammenfassung von Judenheiten mit sehr unterschiedlichem religiösen, politischen und kulturellen Hintergrund ${ }^{37}$. Gleichzeitig entwickelte sich aber auch eine bewusste Wahrnehmung von zwei Gruppen innerhalb des Judentums, die als »West-« bzw. »Ostjuden « unterschiedliche $»$ Kulturpersönlichkeiten $\aleph^{38}$ darstellten ${ }^{39}$.

Bis zum Ersten Weltkrieg tagte der Zionistenkongress in verschiedenen europäischen Städten - in Basel, London, Den Haag, Hamburg und Wien -, der Sitz der Exekutive war zunächst Wien, dann Köln und später während des Krieges Kopenhagen. Die 1898 gegründete Jüdische Kolonialbank, die der zionistischen Bewegung die finanzielle Förderung der Kolonisation durch Kredite in Unabhängigkeit von philanthropischer Unterstützung ermöglichen sollte, agierte von London aus. Viele der führenden Zionisten entwickelten eine intensive Reisetätigkeit innerhalb Europas ${ }^{40}$. Häufig hatten sie bereits in verschiedenen Ländern gelebt, kannten die Situation der Juden dort und konnten sich in mehreren Sprachen verständigen. Herzls Biographie als ungarischer Jude, der sich sowohl in Österreich als auch in Frankreich zu Hause fühlte, kann somit als exemplarisch für viele der Aktiven in der zionistischen Bewegung gelten.

Zwar gelang es der ZWO, hinter ihrem Ziel - der Wiedererlangung eines jüdischen Staates - Juden aus vielen Ländern zu vereinigen, jedoch taten sich auch neue Fronten auf. Einerseits rief der Zionismus vor allem in Großbritannien und im Deutschen Reich den Widerstand vieler Rabbiner, Gemeindevorstände und assimilierter Juden hervor. Andererseits zeigten sich in vielen Fragen Differenzen zwischen Zionisten in Ost- und Westeuropa: Die osteuropäischen Zionisten beharrten überwiegend auf Palästina als Zionsland; dagegen hätten viele westeuropäische Anhänger des Zionismus auch andere Territorien als Zufluchtsstätte für bedrohte und verarmte Juden akzeptiert ${ }^{41}$. Zudem plädierten die meisten Zionisten aus dem Osten dafür, die Arbeit nicht nur auf den Aufbau eines eigenen Staates zu konzentrieren, son-

37 Desanka Schwara, Unterwegs. Reiseerfahrung zwischen Heimat und Fremde in der Neuzeit, Göttingen 2007, S. 201.

38 M.A., »Polnische Juden«, in: Der Jude 1/8 (1916/17), S. 561f., hier: S. 561.

39 Sehr deutlich voneinander unterschieden werden »Westjuden« und »Ostjuden« beispielsweise bei Nathan Birnbaum, Etwas über Ost- und Westjuden, in: Ders, Schriften, S. 276-282, sowie in dem Aufsatz von Franz Oppenheimer, Stammesbewusstsein und Volksbewusstsein, in: Die Welt 14/7 (1910), S. 139-143.

40 Siehe etwa das Verzeichnis der wichtigsten Reisen Theodor Herzls in: Julius H. Schoeps, Theodor Herzl 1860-1904. Wenn Ihr wollt, ist es kein Märchen, Neu-Isenburg 2004, S. 219 f. 
dern auch »Gegenwartsarbeit« zu betreiben und sich für die Verbesserung der Lage der Juden in den Ländern, in denen sie lebten, einzusetzen ${ }^{41}$.

Während die Delegierten bei den ersten Zionistenkongressen zumeist als Repräsentanten ihrer Landsmannschaften auftraten, bildeten sich nach einigen Jahren verstärkt länderübergreifende Sonderverbände und Parteifraktionen. Damit wandelte sich die Funktion der Zionistenkongresse: Sie entwickelten sich von einer Plattform, die nationale Verbände zusammenführte, hin zu einem Forum, das auch den grenzübergreifend agierenden Fraktionen die Möglichkeit zur Präsentation und Diskussion ihrer Programme gab und damit dem Dialog jenseits der landsmannschaftlichen Bindungen weiteren Raum bot. Die neu entstehenden Gruppierungen setzten Schwerpunkte, die von dem von Theodor Herzl und Max Nordau begründeten »allgemeinen« oder auch »politischen« - Zionismus abwichen: Die »Demokratische Fraktion«, eine vom Kulturzionismus geprägte Gruppe junger Intellektueller aus verschiedenen Ländern, machte sich einerseits für die volle Durchsetzung des demokratischen Gedankens in der ZWO stark und setzte sich andererseits für eine stärkere Berücksichtigung der kulturellen Arbeit ein. Sie bewirkte unter anderem die Einberufung einer international besetzten ständigen Kulturkommission, die innerhalb der Organisation über die kulturelle Tätigkeit in den einzelnen Ländern berichten sollte ${ }^{42}$. Einige Mitglieder aus den Reihen der »Demokratischen Fraktion« gründeten 1901 in Berlin den Jüdischen Verlag, dessen Arbeit die politischen Aktionen ergänzen und eine Brücke zwischen den Juden in West und Ost schlagen sollte ${ }^{43}$.

Das Auftreten der »Demokratischen Fraktion« und die Beschäftigung der ZWO mit Kulturfragen provozierten einen weiteren grenzübergreifenden Zusammenschluss: Aus Ablehnung einer säkularen jüdisch-nationalen Erziehung gründeten religiöse Zionisten 1902 in Wilna die Gruppierung »Misrachi $\aleph^{44}$, die den »politischen Zionismus« Herzls unterstützte, darüber hinaus aber eine Förderung der religiösen Erziehung als ein zentrales Element ihrer zionistischen Arbeit betrachtete. Innerhalb kürzester Zeit gründete die Vereinigung mit Sitz im weißrussischen Lida Untergruppen in vielen

41 Siehe etwa das Programm, das die Zionisten im Zarenreich 1906 auf ihrer Konferenz in Helsingfors verabschiedeten. Darin heißt es, die 3. allrussische Zionistenkonferenz halte es für notwendig, »die nationale Vereinigung des Judentums auf dem Boden der sich vollziehenden Umwandlung des russischen Staatswesens zum Zwecke der Anerkennung der jüdischen Nationalität und der gesetzlichen Selbstverwaltung in allen Sachen des jüdischen Nationallebens durchzuführen«. Darauf folgen zahlreiche, auf eine Verbesserung der Minderheitenrechte der jüdischen Bevölkerung zielende Forderungen. Zitiert nach der deutschen Übersetzung in: Jüdische Rundschau 22 (1917), S. 190-192, hier: S. 190.

42 Vgl. Stenographisches Protokoll der Verhandlungen des V. Zionisten-Congresses in Basel, 26. 27., 28., 29. und 30. December 1901, Wien 1901, S. 430f.; David VitaL, Zionism: The Formative Years, Oxford 1982, S. 189-198.

43 Vgl. Reinharz, Dokumente, S. 60f.

44 Die Abkürzung steht für »merkas ruchani«, hebr.: geistiges Zentrum. 
Teilen des Zarenreiches sowie in Galizien, Rumänien, Österreich, Ungarn, Deutschland, England und der Schweiz ${ }^{45}$ und erhielt schon bald den Status einer selbstständigen Vereinigung innerhalb der $\mathrm{ZWO}^{46}$.

Der ebenfalls im Zarenreich entstandene sozialistische Zionismus entwickelte sich zu einer weiteren, länderübergreifend organisierten Richtung innerhalb der zionistischen Bewegung. Aus der Reihe der konkurrierenden sozialistisch-zionistischen Parteien ragte die marxistisch geprägte Partei »Poale Zion $«{ }^{47}$ heraus, deren Anhänger den »politischen Zionismus « mit einem Engagement für die Klasseninteressen des jüdischen Proletariats und die Verwirklichung des Sozialismus verbinden wollten. Die Mitglieder der $» P o-$ ale Zion « traten aus den jeweiligen Landesföderationen aus und begründeten 1907 einen Weltverband, der eigene Delegierte zu den Zionistenkongressen schickte $^{48}$.

Zwar behinderten diese Parteibildungen eine einheitliche Linie der zionistischen Bewegung, jedoch intensivierten sie grenzübergreifende Diskussionen und Kooperationen. Mit ihrem Verbleib in der Gesamtorganisation bekräftigten sie ihr Bekenntnis zur gemeinsamen Zielsetzung. Trotz vieler innerer Auseinandersetzungen gelang es der ZWO bis zum Ersten Weltkrieg, Verbindungen zwischen den verschiedenen jüdischen Gemeinschaften, insbesondere zwischen jenen in Europa, zu fördern und nicht nur den Grundstein für eine grenzüberschreitende Nationalbewegung, sondern auch Möglichkeiten für eine übergreifende jüdische Interessenvertretung zu schaffen.

\section{Europa als Verhandlungspartner}

Das europazentrierte internationale Netzwerk der zionistischen Bewegung und die Veranstaltungsorte der Zionistenkongresse waren Ausdruck dessen, dass viele der in der ZWO diskutierten Fragen im europäischen Kontext entstanden waren und der Ausgangspunkt der anvisierten Schritte zu ihrer Lösung oft ebenfalls auf dem europäischen Kontinent lag.

In den ersten Jahren wurde die Arbeit der zionistischen Bewegung vom "politischen Zionismus« dominiert, der auf einem »funktionalen Konzept des Nationalismus « ${ }^{49}$ beruhte: Die durch äußeren Druck, durch die Ablehnung und verweigerte Integration seitens der europäischen Staaten hervorge-

\footnotetext{
45 Vgl. Y. GoldschlaG, Art. »Mizrahi«, in: Encyclopedia of Zionism and Israel 2 (1971), S. 791-796, hier: S. 792.

46 BöHм, Bewegung, S. 206.

47 Hebr.: Arbeiter Zions.

48 Gideon Shimoni, The Zionist Ideology, Hannover u.a. 1995, S. 170-187; Böнм, Bewegung, S. 364

49 Shimoni, Ideology, S. 88.
} 
rufene Notlage der Juden hält diesem Konzept zufolge einerseits das jüdische Volk zusammen und erfordert andererseits eine funktionale Lösung der »Judenfrage « - eine vor allem durch politische Arbeit zu schaffende jüdische »Heimstätte«, die in der Konsequenz auch im Interesse der europäischen Staaten und Gesellschaften liegen muss und zu ihrem Nutzen wäre ${ }^{50}$.

Dem Baseler Programm entsprechend konzentrierte sich der »politische Zionismus« darauf, eine internationale Diskussion über die Forderungen der Zionisten anzustoßen und durch eine jüdische Diplomatie auf die europäischen Mächte einzuwirken, um auf diesem Weg den Judenstaat zu schaffen. Bereits der erste Kongress brachte den Zionismus ins Blickfeld der Öffentlichkeit. In der britischen Presse wurde der Ruf nach einer gesamteuropäischen Lösung der »Judenfrage« und nach einer europäischen Konferenz laut $^{51}$ - ein Vorschlag, den die zionistische Presse begeistert aufgriff. Die Zeitung Die Welt bewertete diese Idee als folgerichtig, da der Zionismus sich von Anfang an als eine Bewegung gefühlt habe,

die nicht durch geographische oder politische Grenzen einzuengen ist, als eine internationale Bewegung mit nationalen Zielen, die ihrer Natur nach ganz bestimmt an einem Punkte anlangen muß, wo internationale Auseinandersetzungen über sie erfolgen werden.

Es sei davon auszugehen,

daß ohne den Zionismus der Gedanke einer europäischen Lösung der Judenfrage niemals und nirgends lebendig geworden wäre. [...] Die Errichtung einer gesicherten Judenheimstätte ist eine europäische Frage, und deshalb versteht man, daß sie von Europa im Einverständnis mit dem Sultan gelöst werden muß $3^{52}$.

Zwar lasse eine europäische Konferenz Konflikte um Einflusssphären im Mittelmeer erwarten, jedoch könne ein neutraler Staat, der von allen Mächten verbürgt werde und keine Expansion anstrebe, zukünftig alle internationale Rivalität um die Vorherrschaft in diesem Gebiet in friedlicher Weise beseitigen ${ }^{53}$.

Auch Theodor Herzl griff den Vorschlag einer Konferenz verschiedentlich auf, jedoch richtete er seine Anstrengungen vorrangig auf bilaterale Verhandlungen. Im ersten Jahrzehnt zionistischer Politik konzentrierte er sich darauf, in Audienzen beim deutschen Kaiser, beim Sultan und bei russischen Ministern, in Verhandlungen mit der britischen Regierung sowie im persönlichen Gespräch mit Papst Pius X. um Unterstützung für den Zionismus zu

50 Ebd., S. 88-93.

51 Benjamin JAFFE, The British Press and Zionism in Herzl's Time (1895-1904), in: Transactions and miscellanies 24 (1974), S. 89-100, hier: S. 93.

52 Spectator, Die europäische Conferenz, in: Die Welt 1/21 (1897), S. 1f., hier: S. 1.

53 Ebd., S. 2. 
werben und Zusicherungen zu erwirken - allerdings mit wenig konkreten Resultaten $^{54}$.

Um seine Ideen innerhalb der europäischen Diplomatie zu verbreiten, nutzte Herzl auch seine Kontakte zu Bertha von Suttner, die dem Zionismus nach anfänglichen Bedenken sehr positiv gegenüberstand und für einen Anschluss der jüdischen Bewegung an die Friedensbewegung plädierte. In Herzls Auftrag führte Suttner am Rande des Haager Friedenskongresses mit verschiedenen Diplomaten Gespräche über den Zionismus und berichtete darüber in der zionistischen Presse ${ }^{55}$. Sie betrachtete die zionistischen Bemühungen um ein eigenes jüdisches Territorium als einen wichtigen Schritt auf dem Weg des Zusammenwachsens der Völker und vertrat damit eine im Zionismus oft geäußerte Meinung:

Der Jude, der sich heute zur Weltbürgerschaft bekennt - und die meisten vorgeschrittenen Juden stehen ja auf dieser Stufe - nützt deshalb dem Weltbürgerschaftsgedanken nur wenig, weil ihm dieser Standpunkt als Folge seiner Vaterlandslosigkeit vorgeworfen wird; besitzt er aber ein Vaterland, ein selbständiges angesehenes Heimatreich, dann kann er sagen: Ich bin über die Interessen meines Landes hinausgewachsen, ich fühle mich als Europäer, als Culturmensch. Von allen Culturen habe ich die Schätze mir zunutze gemacht, wie ja auch die Schätze der jüdischen Cultur dem Allgemeingut zugeflossen $\operatorname{sind}^{56}$.

Obwohl sich in den europäischen Ländern mehr und mehr die Überzeugung durchsetzte, dass ein jüdischer Staat außerhalb Europas den Einwanderungsdruck in den westeuropäischen Staaten mindern und in Osteuropa die Not der Juden mildern könnte, wurden keine Anstrengungen zu einer gemeinsamen und umfassenden Beschäftigung mit den zionistischen Forderungen unternommen. Vielmehr verfolgte jede Regierung in der Frage eines Judenstaates eigene Machtinteressen. Das Zarenreich, das an einer Abwanderung der Juden stark interessiert war, sah von einer Unterstützung der das Osmanische Reich betreffenden Pläne Herzls ab, da es eine Belastung der russischen Beziehungen zur Pforte befürchtete ${ }^{58}$. Auch Wilhelm II. versagte den Zionisten nach anfänglichem Interesse an den jüdischen Auswanderungsplänen seine Mitwirkung ${ }^{58}$. Lediglich die britische Regierung sah in einem

54 Vgl. DethlofF, Einleitung, S. 44-47.

55 Vgl. Brigitte Hamann, Bertha von Suttner. Ein Leben für den Frieden, München u.a. ${ }^{2} 1987$, S. 258. Siehe auch: Bertha von SutTneR, Gespräche über den Zionismus aus dem Haag, in: Die Welt 3/28 (1899), S. 1-2; dies., Gespräche über den Zionismus aus dem Haag (Mr. Léon Bourgeois), in: Die Welt 3/31 (1899), S. 1-3.

56 Dies., Nach dem Haag!, S. 2.

57 Aleksandr LoKšın, Tsarist Policy Toward Zionism in Russia at the End of the Nineteenth and the Beginning of the Twentieth Century, in: Haumann, Traum, S. 170-185, hier: S. 182f.

$58 \mathrm{Vgl}$. Schoeps, Herzl, S. 155; Walter Laqueur, A History of Zionism. From the French Revolution to the Establishment of the State of Israel, New York 2003, S. 111. 
Engagement für den Zionismus Vorteile und legte 1903 den »Uganda-Plan« zur Errichtung einer autonomen jüdischen Ansiedlung in Ostafrika unter britischer Oberhoheit vor. Kolonialminister Joseph Chamberlain hoffte, in dem nur spärlich besiedelten Gebiet mit den jüdischen Immigranten eine zu Großbritannien loyale Bevölkerungsgruppe verwurzeln zu können ${ }^{59}$. Der Plan scheiterte allerdings an dem erbitterten Widerstand von Seiten der osteuropäischen Zionisten ${ }^{60}$.

Mit Ausbruch des Ersten Weltkriegs musste die ZWO ihre Tätigkeit stark einschränken. Ihre Mitglieder gehörten nun den beiden feindlichen Machtblöcken an, die Neutralitätserklärung der Leitung und die Verlagerung ihres Sitzes nach Kopenhagen ermöglichten der Organisation aber ein Weiterarbeiten in begrenztem $\mathrm{Maße}^{61}$. Nach dem Kriegseintritt des Osmanischen Reichs maßen die Alliierten den Anliegen des Zionismus und der Palästinafrage eine besondere strategische Bedeutung bei. Dies führte sowohl auf französischer als auch auf britischer Seite zu einer verstärkten Aufmerksamkeit gegenüber Vertretern der zionistischen Organisation ${ }^{62}$.

Auch hinter der »Balfour-Deklaration«, die das britische Wohlwollen hinsichtlich der Errichtung einer nationalen jüdischen Heimstätte in Palästina ausdrückte und die Mitwirkung an deren Verwirklichung signalisierte, standen klare Machtinteressen, wie etwa die Hoffnung, durch ein jüdisches Gebiet unter britischer Oberhoheit die nordöstliche Flanke des Suez-Kanals sichern zu können ${ }^{63}$. Obwohl die Deklaration noch keine Zusicherung für eine Staatsgründung bot, wurde sie von den Zionisten als großer politischer Erfolg gefeiert, lag damit doch erstmals ein Dokument vor, das eine Unterstützung zionistischer Forderungen versprach ${ }^{64}$.

Nach dem Krieg gaben sowohl die »Balfour-Deklaration« als auch Wilsons »Vierzehn Punkte« der zionistischen Arbeit neuen Auftrieb. In weiten Kreisen der jüdischen Gemeinschaften entfaltete sich eine politische Aktivität, die in vielen Teilen Österreich-Ungarns, Deutschlands und Sowjetrusslands ihren Ausdruck in der Gründung von »Nationalräten« fand, in denen

59 Dov S. ZAKheim, The British Reaction to Zionism: 1895 to the $1990 \mathrm{~s}$, in: The Round Table 350 (1999), S. 321-332, hier: S. 322.

60 Siehe o. Anm. 41.

61 Vgl. Michael Krupp, Zionismus und Staat Israel. Ein geschichtlicher Abriss, Gütersloh ${ }^{3} 1992$, S. 66; BöHM, Bewegung, S. 626f.

62 Vgl. Zakheim, Reaction, S. 324; G. Weill, Art. »France, Relations with Zionism and Israel«, in: Encyclopedia of Zionism and Israel 1 (1971), S. 350-356, hier: S. 351f.

63 Vgl. Winfried Baumgart, Vom Europäischen Konzert bis zum Völkerbund. Friedensschlüsse und Friedenssicherung von Wien bis Versailles, Darmstadt ${ }^{2} 1987$, S. 63f. Ausführlich zum Zustandekommen der »Balfour-Deklaration« siehe Egmont ZECHLin, Die deutsche Politik und die Juden im Ersten Weltkrieg, Göttingen 1969, S. 373-412.

64 Vgl. Stenographisches Protokoll der Verhandlungen des XII. Zionisten-Kongresses in Karlsbad vom 1. bis 14. September 1921, Berlin 1922, S. 14f.; Böнм, Bewegung, S. 673-676; ZеснLIN, Politik, S. 413-416. 
die Zionisten eine entscheidende Rolle spielten ${ }^{65}$. Unterstützung kam zunehmend auch aus den USA, wo die zionistische Bewegung während des Ersten Weltkriegs stark angewachsen war $^{66}$.

Nun kam die bereits vor dem Krieg entwickelte Programmatik verstärkt zum Tragen, die neben den Zielen des Landerwerbs, der Besiedlung Palästinas und der nationalstaatlichen Konstituierung auch die Bemühungen um nationale Gleichstellung der jüdischen Minderheiten in den europäischen Vielvölkerstaaten umfasste. Alle Hoffnungen richteten sich auf die Pariser Friedenskonferenz, an der zahlreiche jüdische, meist zionistisch dominierte Delegationen teilnahmen. Diese schlossen sich mit Ausnahme der französischen und der britischen Delegation schließlich zum überstaatlichen »Comité des Délégations Juives auprès de la Conférence de la Paix « zusammen, das sich - auch als Fürsprecher anderer Minoritäten - engagiert für das Zustandekommen der Minderheitenschutzverträge einsetzte. ${ }^{67}$ Nach Abschluss der Konferenz setzte das von namhaften Zionisten geleitete »Comité« seine Arbeit fort. Es profilierte sich als vehementer Verteidiger der Schutzbestimmungen zugunsten der Juden und anderer Minderheiten und kooperierte nach 1925 auch mit dem Europäischen Nationalitätenkongress ${ }^{69}$.

65 Shmuel Ettinger, Vom 17. Jahrhundert bis zur Gegenwart. Die Neuzeit, in: Haim Hillel BenSAsson (Hg.), Geschichte des jüdischen Volkes. Von den Anfängen bis zur Gegenwart, Bd. 3, München ${ }^{3} 1995$, S. 887-1348, hier: S. 1152f.

66 Vgl. Laqueur, History, S.178-181.

67 Vgl. dazu insbesondere: Erwin VIEfHaus, Die Minderheitenfrage und die Entstehung der Minderheitenschutzverträge auf der Pariser Friedenskonferenz 1919. Eine Studie zur Geschichte des Nationalitätenproblems im 19. und 20. Jahrhunderts, Würzburg 1960. Die Frage, welchen Einfluss jüdische Gruppen letztendlich tatsächlich auf die Ausarbeitung der Verträge nehmen konnten, wird in der Forschung unterschiedlich beantwortet; vgl. Frank NesEmanN, Jüdische Diplomatie und Minderheitenrecht. Zur Wirkungsgeschichte des Comité des Délégations Juives, 1919-1936, in: Jahrbuch des Simon-Dubnow-Instituts 4 (2005), S. 567-587, hier: S. 579-583. 


\section{Der Zionismus und Europa - ein ambivalentes Verhältnis}

Die zionistische Bewegung stellte sich von Beginn an als eine Nationalbewegung mit europäischem Hintergrund dar - in Bezug auf ihre Entstehungsgeschichte, ihre Träger und zu einem wesentlichen Teil auch hinsichtlich ihres Aktionsraums und der in ihrem Umkreis entwickelten Konzepte. Europa als das »soziale und politische Lernfeld ${ }^{69}$ des Zionismus bot einerseits Erfahrungen und Handlungsmuster, die die zionistische Bewegung für ihre eigene Politik übernahm. Andererseits bildeten auch die judenfeindlichen Entwicklungen in Europa und die aus zionistischer Sicht wenig aussichtsreichen Konzepte nicht-zionistischer Gruppen zur Lösung der »jüdischen Frage« einen bedeutsamen Erfahrungskontext, in dem zionistische Entwürfe entstanden und geformt wurden ${ }^{70}$. Mit Blick auf den Beitrag des Zionismus zur innereuropäischen Kooperation und Kommunikation lassen sich sowohl integrative als auch desintegrative Elemente ausmachen, wobei zwischen ihrer beabsichtigten und faktischen Wirkung oftmals eine große Diskrepanz herrschte.

Der sich in vielen Ländern Europas ausbreitende Nationalismus und Antisemitismus setzte unter den in der Zerstreuung lebenden Juden eine Suche nach Alternativen zu Integration und Assimilation in Gang. Vielfach wandelten sich Hoffnungen auf ein fortschrittliches, die Juden integrierendes Europa zu einem Europabild, geprägt von der Vorstellung, dass auf dem europäischen Kontinent ein Leben in Gleichberechtigung und Anerkennung für ein staatenloses jüdisches Volk nicht möglich sei. Trotz der im Laufe der Jahrhunderte immer deutlicher hervorgetretenen regionalen und nationalen Unterschiede zwischen den einzelnen Judenheiten bildete sich in Teilen der jüdischen Bevölkerung ein kollektives Bewusstsein heraus, das weniger religiös als vielmehr national begründet war.

Obgleich der Zionismus auf eine Staatsgründung außerhalb des europäischen Kontinents zielte und sich die neue jüdische Bevölkerung in Palästina in Abgrenzung zu den europäischen Juden verstand, lässt sich nicht von einer vollständigen mentalen Loslösung der Zionisten von Europa sprechen. So war Europa vielfach auch Vorbild: Aus dem europäischen Kontext bekannte Strukturen und Traditionen dienten den Konzepten für einen jüdischen Staat in vielerlei Hinsicht als Orientierung und Modell. Andererseits schien die Mitwirkung Europas, ein europäisches Zusammenwirken für eine Staatsgründung unabdingbar. Mit fortschreitender Konsolidierung der zionis-

68 Vgl. Nesemann, Diplomatie, S. 570-575.

69 Karlheinz SchneIDER / Nikolaus SimON, Die europäischen Wurzeln des Zionismus. Reflexionen zum Abschluss einer Seminarreihe, in: Dies. (Hg.), Der Zionismus und seine europäischen Wurzeln. Dokumentation einer Arbeitstagung in der Evangelischen Akademie Arnoldshain, November 1986, Berlin 1987, S. 105-117, hier: S. 111.

70 Vgl. ebd., S. 111f. 
tischen Bewegung traten ihre Mitglieder zudem immer nachdrücklicher mit Forderungen nach nationaler Gleichstellung und kultureller Autonomie für Juden in ihren europäischen Heimatländern auf ${ }^{71}$. Die Hoffnung galt in dieser Hinsicht insbesondere gemeinsamen Vereinbarungen der europäischen Staaten und nach dem Ersten Weltkrieg zunehmend auch einer transatlantischen Politik ${ }^{72}$.

Entsprechend der Transterritorialität der »jüdischen Frage« entwickelte sich die ZWO zu einer Institution, die zwar auf der Basis der zionistischen Vereinigungen in den einzelnen Ländern entstand, aber bis zum Ersten Weltkrieg die Netzwerkbildung vorantrieb und trotz der großen Unterschiede zwischen den verschiedenen Judenheiten »europäisch « agierte, indem sie zahlreiche grenzübergreifende Institutionen und Kooperationen hervorbrachte. Parallel zum Anwachsen der Bewegung nahm - den Zielen der Organisation entsprechend - jedoch auch die Zahl derer zu, die den Kontinent Richtung Palästina verließen, wobei die Bindungen an die europäischen Heimatländer aber häufig erhalten blieben.

Die ZWO bemühte sich, durch die Betonung der »nationalen Einheit des jüdischen Volkes« ein gemeinsames, über das Religiöse hinausgehendes identifikatorisches Element für Juden aus unterschiedlichen Herkunftskulturen zu schaffen. Damit entfaltete der Zionismus innerhalb der jüdischen Gemeinschaften in Europa aber nicht nur Bindekräfte, sondern rief vor allem in Westeuropa Frontbildungen, insbesondere der assimilierten Juden und der jüdischen Gemeinden hervor. Trotz zahlreicher Bemühungen, Brücken zwischen den verschiedenen jüdischen Lebenswelten und ihren unterschiedlichen Gruppierungen zu schlagen, blieb der Zionismus stets eine Minderheitsbewegung.

Die von der zionistischen Bewegung angestrebte grenzübergreifende $\mathrm{Zu}$ sammenarbeit konnte kaum über den innerjüdischen Kontext hinaus wirksam werden. Zwar forderte der Zionismus die europäische Diskussion über eine Lösung der »Judenfrage« heraus, jedoch bewirkte er bis zum Ende des Ersten Weltkriegs keine multilateralen Zusammenkünfte, die sich dieses Themas angenommen hätten. Auf lange Sicht gelang es ihm aber, dass seine Vertreter auf europäischer Bühne angehört und als Fürsprecher der jüdischen Minderheiten

71 Vgl. etwa die Reden und Anträge von Nahum Sokolov, Daniel Pasmanik und Nachman Syrkin auf dem XI. Zionisten-Kongress in Wien 1913, in: Zionistisches Aktionskomitee (Hg.), Stenographisches Protokoll der Verhandlungen des XI. Zionisten-Kongresses in Wien vom 2. bis 9. September 1913, Berlin u.a. 1914.

72 Während des russischen Bürgerkriegs sah die ZWO diese Hoffnungen jedoch auf das Bitterste enttäuscht; der Präsident der Zionistischen Exekutive, Nahum Sokolov, kritisierte nicht nur das tatenlose Zusehen Europas v.a. bei den Pogromen in der Ukraine, sondern äußerte auch seine Enttäuschung über die Untätigkeit des Völkerbundes, dessen Entstehung die Zionisten »mit tiefer Genugtuung und Hoffnung « begrüßt hatten. Rede Nahum Sokolovs in: Stenographisches Protokoll der Verhandlungen des XII. Zionisten-Kongresses, S. 17-35, hier: S. 21. 
akzeptiert wurden. Die Konstituierung des »Comité des Délégations Juives« und seine Mitwirkung an der Pariser Friedenskonferenz stellte einen bedeutenden Schritt hinsichtlich einer grenzüberschreitenden - nun auch Nordamerika mit einschließenden - jüdischen Interessenartikulation im Rahmen der internationalen Diplomatie dar. Unter maßgeblicher Beteiligung der Zionisten wurde das »Comité« als Vertreter eines in der Zerstreuung lebenden Volkes ohne eigenes Territorium zum Fürsprecher einer europäischen Minderheitenpolitik auf der Grundlage einer national-kulturellen Autonomie.

Die bereits seit den Anfängen der zionistischen Bewegung häufig geäußerten Vorstellungen, das Judentum und insbesondere der Zionismus könne Vorreiter im Kampf für den Frieden in Europa sein und die europäische Integration vorantreiben, waren auch während des Ersten Weltkriegs und nach seinem Ende noch präsent. Angesichts der Ereignisse der zurückliegenden Jahre gingen die Meinungen über die tatsächlichen Möglichkeiten einer solchen völkerverbindenden Mission jedoch weit auseinander. Während die einen angesichts der gegenwärtigen Situation kapitulierten und die Verwirklichung einer friedlichen, gerechten Gesellschaft zunächst nur in Palästina für möglich hielten ${ }^{73}$, betonten andere weiterhin die große Bedeutung der europäischen Komponente des jüdischen Problems. Letztere Ansicht findet sich besonders pointiert in einem Artikel des zionistischen Publizisten Heinrich Margulies, in dem dieser mit großer Vehemenz betont, das jüdische Volk habe trotz umfangreicher Einwanderungsprojekte nach wie vor eine Aufgabe in Europa zu erfüllen: Da die Juden in Europa keine territorialen Interessen verfolgten, könnten sie mit ihrem Einsatz für die immer wichtiger werdende Frage der Minoritätenrechte eine bedeutende Rolle bei der »Entwirrung des europäischen Problems $\aleph^{74}$ spielen:

Wenn Europa nicht bei allen künftigen Auseinandersetzungen völlig ausgeschaltet werden will, wenn die Staaten Europas nicht auf das Niveau der südamerikanischen Kleinstaaten sinken wollen, muss im Laufe der nächsten 50 Jahre die kontinentale Einheit der Vereinigten Staaten von Europa geschaffen werden. Es handelt sich [...] darum, die Reibungsflächen zwischen den europäischen Völkern zu glätten. [...] Der jüdische Nationalismus steht im Dienste dieser Politik. [...] Seitdem die jüdische Politik national, d.h. jüdisch ist, geht sie nicht mehr auf Trennung und Isolierung, sondern auf Überbrückung und Zusammenfassung. Jeder föderative Zusammenschluss stärkt die Position der Minoritäten, also auch der Juden ${ }^{75}$.

73 Vgl. das Beispiel des Schriftstellers und Zionisten Arnold Zweig bei Eleonore LAPPIN, Der Jude 1916-1928: jüdische Moderne zwischen Universalismus und Partikularismus, Tübingen 2000, S. 88.

74 Heinrich Margulies, Jüdische und europäische Politik, in: Neue jüdische Monatshefte 3 $(1918 / 19)$, S. 496-502, hier: S. 500.

75 Ebd., S. $501 f$. 
Vor dem Hintergrund einer solchen Situationsanalyse konnte Margulies zu folgendem Urteil kommen, das für eine einheitliche, zionistisch dominierte jüdische Politik eine weitgreifende Perspektive im europäischen Kontext sah:

Finden sich die Juden Europas zur einmütigen jüdischen Politik zusammen, so werden sie wissen, dass sie, und zunächst fast nur sie, sich ganz in den Dienst derjenigen Prinzipien stellen können, die wie Personalautonomie, Minoritätenschutz, Nationalitätenbund und Kontinentalpolitik nicht nur Europa aus seiner Schande emporführen, sondern auch altjüdischer Hoffnung auf Völkerversöhnung und Völkerverbrüderung nahe kommen werden ${ }^{76}$.

76 Ebd., S. 502. 


\section{Europavisionen in Ostmitteleuropa in der ersten Hälfte des 20. Jahrhunderts}

Der Titel dieses Beitrags ist programmatisch: Europavisionen in Ostmitteleuropa in der ersten Hälfte des 20. Jahrhunderts - die Beschäftigung mit diesem Thema kann einem Historiker einen Gutteil seines Lebens rauben und einen Literaturhistoriker im Bann der in verschnörkeltes Wort gefassten europäischen Visionen für längere Zeit festhalten.

Als 2003 die auf dem 44. Deutschen Historikertag vorgetragenen Referate unter einem unbescheidenen Buchtitel »Vision Europa « erschienen ${ }^{1}$, war den beiden Herausgebern, Heinz Duchhardt und Małgorzata Morawiec, diese Erfahrung längst zuteil geworden, denn sie blickten beide auf einige Jahre zurück, in denen die Präsenz der »Vision« und der »Option« Europa zum Tagesgeschäft geworden war. Finanziert von der VolkswagenStiftung im Programm »Einheit in der Vielfalt«, konnte das Projekt optionsmäßig visionär die Vielfalt der europäischen Einheiten (heute würde man sagen der Identitäten) thematisieren. Die deutschen und polnischen Identitäten im 19. und frühen 20. Jahrhundert, die sich in ihren spezifischen Ausformungen auf Europa bezogen, wurden als europäische Föderationspläne verstanden und so auch definiert. Heinz Duchhardt hat sie zielstrebig als »Vision Europa « in einem Buch zusammengefügt und damit ihren - sich aus historischen Voraussetzungen ergebenden - zukunftsweisenden Charakter beschworen.

Dass dem einen Band der Vision drei Bände der »nur« Option Europa folgten ${ }^{2}$, erklärt sich durch die Erweiterung des Forschungsansatzes. Denn den als »visionär« definierten deutschen und polnischen Föderationsplänen wurden die viel mehr auf die Optionalität hin ausgerichteten ungarischen Europa-Entwürfe an die Seite gestellt, die den vielfältigen Charakter ostmitteleuropäischer Pläne zur Einigung Europas unterstreichen.

Und es ist auch kein Ergebnis der Ernüchterung gewesen, dass der Titel der dritten Publikation, die aus dieser Beschäftigung mit ostmitteleuropäischem Gedankengut erwuchs, lediglich »Der Europa-Gedanke in Ungarn

1 Heinz Duchhardt / Małgorzata Morawiec, Vision Europa. Deutsche und polnische Föderationspläne des 19. und frühen 20. Jahrhunderts, Mainz 2003.

2 Włodzimierz Borodziej [u.a.] (Hg.), Option Europa. Deutsche, polnische und ungarische Europapläne das 19. und 20. Jahrhunderts, 3 Bde., Göttingen 2005. 
und Deutschland in der Zwischenkriegszeit« lautet ${ }^{3}$. Vielmehr wird hiermit unterstrichen und adäquat beschrieben, dass sich die Europäisierungsprozesse in Ostmitteleuropa (und damit ist auch Deutschland gemeint) von der Vision über die Option zur Alltagspragmatik wandelten.

Man kann in diesem Beitrag nicht die Triade der Entwicklung anhand des gesamten Corpus der Europapläne in Ostmitteleuropa nachzeichnen. Als Beispiel dient Polen, und zwar ein Text, der in vieler Hinsicht eine Kuriosität ist: als Einzeldruck, als ein Text von wenigstens einer gewissen literarischen Qualität, als Zeitzeugnis der in Polen der Zwischenkriegszeit geführten Diskurse und als Beitrag dazu schlechthin.

1930 erschien in Warschau im Selbstverlag des Autors eine Broschüre, die als ein Versuch gewertet werden könnte, die Paneuropa-Idee in Polen zu popularisieren. Die Zeit des Erscheinens ist womöglich etwas spät dafür gewesen, ergibt sich aber aus der politischen Notwendigkeit, just zu dem Zeitpunkt erneut für ein gemeinsames europäisches Haus die Werbetrommel zu rühren.

Betitelt Paneuropa und Polen ${ }^{4}$, knüpfte der Text formal an die literarische Tradition einer in Form eines fiktiven Gesprächs gehaltenen Aufklärung über aktuelle sozial-politische oder wirtschaftliche Themen an. Den Anfang und Höhepunkt dieser Form zugleich bildete in der polnischen Literatur das bereits 1543 erschienene Werk Krótka rozprawa von Mikołaj Rej, ein zeitkritisches Gespräch zwischen den Vertretern der drei Stände: dem Feudalherren, dem Vogt und dem Pfarrer. Damit ist für einen polnischen Leser die literarische Tradition mustergültig konstruiert, und der hohe Anspruch auf gelehrte Qualität wird zusätzlich durch zwei Zitate untermauert: das erste von Adam Mickiewicz und das andere aus Sallusts Bellum Jugurthinum. Als eine zusätzliche und wohl auch entsprechend wirksame Anspielung auf die humanistische Tradition der polnischen Dichtkunst könnte die Widmung gedeutet werden: Das Werk wird dem vorzeitig verstorbenen Töchterchen Dorota gewidmet. Die Konnotation mit den Klageliedern von Jan Kochanowski liegt auf der Hand. Die Zusammensetzung der Sprechenden erinnert an die Akteure der griechischen Tragödie. Es treten auf: die Vernunft, die Vorsehung und, als Vertreter des Volkes, Lech.

Diese Figur steht in der Tradition des Urvaters des polnischen Staates. Der legendäre Lech, der polnische Part des slawischen Brüdertriumvirats, Lech, Czech und Rus, gründete, nachdem er sich während einer Wanderung durch Osteuropa von seinen Brüdern getrennt hatte, an der Warthe in Großpolen

3 Heinz DuchHardt / István Németh (Hg.), Der Europa-Gedanke in Ungarn und Deutschland in der Zwischenkriegszeit, Mainz 2005.

4 Jakób Tysczegiewski, Paneuropa a Polska skreślił [...] oraz mowa Victora Hugo z d. 2181849 roku, Warszawa 1930. Siehe BorodzieJ, Option Europa, Bd. 1, S. 95f. und Bd. 2, S. 444. 
die Stadt Gnesen und machte sie zur Hauptstadt seines Reiches und den weißen Adler zum Symbol seiner Herrschaft. Lech steht also an der Wiege der polnischen Staatlichkeit, und die ihn im Text verkörpernde Figur wird zum Inbegriff des polnischen Staatsverständnisses.

Diese Informationen sind, außer dass sie eine literarische und historische Tradition konstruieren, für das nähere Charakteristikum des Autors wichtig. Das Werk wird mit einem Pseudonym signiert: Ein Jakób Tysczegieski soll der Verfasser sein. Die Aussprache dieses Namens ist selbst für einen Polen eine Zumutung. Der Autor zeigt sich aber bereits im Vorfeld der Argumentation zugunsten einer - wie später noch gezeigt wird - sich in Polen nicht ohne Vorbehalte verbreitenden Idee als gebildeter und in der polnischen Nationalkultur versierter Mensch.

$\mathrm{Zu}$ den Anhängern und Verbreitern der Paneuropa-Idee in Polen gehörten - wie könnte es im Hinblick auf die Stammkundschaft der paneuropäischen Ideen anders sein - Adlige, Künstler, Intellektuelle, Diplomaten. Somit waren auch in Polen die Wegbereiter der paneuropäischen Bewegung eher in den Kreisen der Visionäre als in denen der Pragmatiker zu suchen $^{5}$. Die Schwäche dieser Kreise lag - in Polen vielleicht noch mehr als in den übrigen Ländern Mitteleuropas (im Vergleich zu Ungarn beispielsweise $^{6}$ ) - in ihrer sehr elitären Zusammensetzung. Bereits zu Beginn des Textes spricht die Vernunft dieses Problem an, indem sie auf die Ideengeschichte des paneuropäischen Gedankenguts verweist, vertreten von »großen und aufgeklärten Denkern« vergangener Zeiten? ${ }^{7}$ Diese Traditionslinie konstruiert der Verfasser von Alexander dem Großen über Dante, Georg von Podiebrad, Heinrich IV. bis zu Napoleon Bonaparte, Victor Hugo und - damit liefert er einen Hinweis auf seine geistige Affinität zur Russophilie Zar Nikolaus II. Die gesellschaftspolitischen Umbrüche der ersten Hälfte des 20. Jahrhunderts hätten das Interesse der Wissenschaft für diese längere Zeit als Torso bekannte - Idee eines »Paneuropa« geweckt. Neben dem Völkerbund verweist die Vernunft auf internationale Abkommen zur Regelung des europäischen Verkehrsnetzes, der Kommunikation, des Flugwesens und der Telekommunikation. Diese Instrumente könnten - in den Augen der Vernunft - als Garanten eines friedlichen Umgangs der europäischen Staaten miteinander fungieren. Den »vernünftigen« Errungenschaften der europäischen Gemeinschaft wird vom Autor die »nationale« Argumentation Lechs gegenübergestellt, der auf die gerade wiedergewonnene Souve-

5 Näheres dazu Włodzimierz Borodziej / Błażej Brzostek / Maciej GóRny, Polnische EuropaPläne des 19. und 20. Jahrhunderts, in: BorodziEj [u.a.], Option Europa, Bd. 1, S. 41-134, hier: S. 94f.

6 Siehe Andres Tuli, Die paneuropäische Sektion in Ungarn (1926-1932), in: DuchHardt / NÉmEth (Hg.), Der Europa-Gedanke, S. 47-70, passim.

7 Tysczegiewski, Paneuropa, S. 5. 
ränität des polnischen Staates pocht und die nationalen Ängste vor der Einmischung anderer Staaten in die polnische Innenpolitik sowie vor der Einschränkung der Handlungsfreiheit polnischer Außenpolitik anspricht.

In dieser Argumentation spiegelt sich die grundsätzliche Skepsis der polnischen Öffentlichkeit gegenüber Paneuropa. Paneuropa wäre nichts anderes als eine neue Koalition, die gegen eine andere - womöglich schon bewährte Koalition aufträte, um neue Ressentiments zu schüren ${ }^{8}$. Alle Argumente der Vernunft, die auf wirtschaftliche und politische Vorteile eines gemeinsamen europäischen Standortes verweisen, beantwortet Lech mit der Frage, welchen Nutzen »diese bizzare Hypothese« dem polnischen Volk bringen würde? ${ }^{9}$ Und hier ködert ihn die Vernunft mit den großen Summen, die statt für den Unterhalt der Armee und der Außenvertretung - was die Hälfte des Staatsbudges verschlinge - für wirtschaftliche Projekte ausgegeben werden könnten: für die Elektrizität, für den Wohnungsbau, für die Trockenlegung ausgedehnter Moorlandschaften in Ostpolen etc. Arbeitsplätze würden entstehen, neue Siedlungsperspektiven würden sich eröffnen, Broterwerb ermöglicht werden und die Auswanderung gestoppt. Dies alles waren wirtschaftliche Probleme, mit denen sich der neue polnische Staat konfrontiert sah und deren Lösung nur bedingt finanziert werden konnte ${ }^{10}$. Signifikant ist aber die Antwort Lechs: Das zeitgenössische Ideal seines Volkes bestehe in der Beschwörung der glorreichen piastischen und jagiellonischen Tradition des Landes, mit dem Ziel, seine Stellung innerhalb (West-)Europas zu behaupten ${ }^{11}$. Kein Argument der Vernunft - auch nicht dieses, Lechs altbackene Phantasmagorien seien längst überholt - bringt diesen symbolischen Vertreter des Volkes dazu, auf den wehrhaften Charakter der polnischen Armee zu verzichten. Und schon gar nicht wollte er den politischen Machtanspruch Polens in Europa aufgeben ${ }^{12}$. Lech wirft der Vernunft vor, die paneuropäischen Ideen seien von einem mystisch-messianischen Charakter à la Towiański. Sie versprächen eine moralische Erneuerung und mystische Verwandlung der europäischen Staaten und ließen ihren Selbsterhaltungstrieb außer Acht. Dieser Darwinismus Danilevskijs in der Argumentation eines Volksvertreters gibt einen Teil der Atmosphäre wieder, in der im Polen der Zwischenkriegszeit intellektuelle Debatten über den Platz Polens an der europäischen Sonne ge-

8 Ebd., S. 11.

9 Ebd., S.13.

10 Zur wirtschaftlichen Situation Polens in der Zwischenkriegszeit und zu den Maßnahmen der Regierung siehe Marian LeczyK, Druga Rzeczpospolita 1918-1939. Społeczeństwo, gospodarka, kultura, polityka [Die Zweite Republik 1918-1939. Die Bevölkerung, die Wirtschaft, die Kultur und die Politik], Warszawa 2006; Andrzej Jezierski, Historia gospodarcza Polski [Wirtschaftsgeschichte Polens], Warszawa 2003; Nikolaus WoLf, Economic integration in historical perspective. The case of interwar Poland, 1918-1939, Berlin 2003.

11 TyscZegiewski, Paneuropa, S. 13.

12 Ebd., S. $15 f$. 
führt wurden. Die Meinung, dass die Völker um ihr Dasein kämpfen müssten, weil nur die Stärksten sich das Recht auf internationale Anerkennung verschaffen könnten, war keineswegs unpopulär ${ }^{13}$. Die machtpolitischen Ideen eines Imperium Jagiellonicum fanden nicht ausschließlich in den politischen Kreisen um Józef Piłsudski ihre aktiven Befürworter ${ }^{14}$. Die ideengeschichtliche Verankerung dieser Debatten im Gedankengut von Danilevskij und Spengler verweist darauf, dass polnische Intellektuelle Anschluss an europäische Diskurse suchten und zahlreiche Elemente dieses Gedankenguts in den Debatten rezipierten.

Unter Berufung auf humanitäre Werte verleiht der Verfasser unseres Textes durch die Äußerung der Vorsehung der Diskussion einen klassisch-antiken Zug: Der Mensch sei zu Höherem berufen und die Natur kenne keinen niederträchtigen Kampf ums Überleben. Es seien unbestreitbar ehrbare Werte: die Heimat- und Menschenliebe. Sie könnten sich aber ohne die Verurteilung der Kriege und ihrer Todesmaschinerie nie wirklich durchsetzen. Deswegen plädiert die Vernunft für die Kraft, die »wie Ariadne Europa aus dem dunklen Labyrinth « befreie und es vor dem Untergang rette ${ }^{15}$.

Die Vernunft nennt alle aus den Programmschriften Paneuropas bekannten Argumente für den europäischen Zusammenschluss: die wirtschaftlichen Vorteile, den Zollabbau, die konkreten Ersparnisse, die damit erzielt werden könnten, um andere soziale Projekte zu fördern, den freien Warenaustausch und persönliche Mobilität der Menschen. Den Rüstungsstopp und die Friedensgarantie erwähnt sie neben dem sozialen Ausgleich als schlüssige Folge der europäischen Vereinigung. Autoritäten werden genannt, die aktuell für paneuropäische Ideen standen: Aristide Briand, Gustav Stresemann, der ehemalige polnische Premierminister Aleksander Skrzyński, Eduard Beneš, der Vorsitzende der deutschen Paneuropa-Sektion Paul Löbe und der österreichische Bundeskanzler Ignaz Seipel ${ }^{16}$. Paneuropa wird als Bollwerk gegen den Bolschewismus gepriesen ${ }^{17}$.

Aber auch damit werden die Ängste Lechs nicht gebannt. Paneuropa erscheint ihm als Brutstätte des Pangermanismus, der in Polen eine Eroberungspolitik in der Tradition des Deutschen Ostmarkenvereins fortsetzen werde. An der Frage der deutsch-polnischen Beziehungen entzündete sich tatsächlich 1927 ein Konflikt zwischen Coudenhove-Kalergi und der polnischen Paneuropa-Sektion. Grund dafür war eine ungeschickte Äußerung

13 Hier geäußert auf Seite $17 \mathrm{ff}$.

14 Vgl. dazu Małgorzata MorawIEC, »Imperium Jagiellonicum« versus »Pansarmatien«. Polnische Konzepte der Anbindung Ungarns an einen mitteleuropäischen Staatenbund in der Zwischenkriegszeit, in: Duchhardt / NÉmeth, Der Europa-Gedanke, S. 7-20, hier: S. 13f.

15 Tysczegiewski, Paneuropa, S. 19f.

16 Ebd., S. 25f.

17 Ebd., S. 28. 
des Grafen über die Danzigfrage. Coudenhove erwartete von den Polen, dass sie Danzig den Deutschen überließen. Als Gegenleistung sollten sie Teile Litauens bekommen. In einem offenen Brief distanzierte sich Aleksander Lednicki, der Vorsitzende der polnischen Sektion, von diesen Plänen und übte daran scharfe Kritik. Da er aber selbst kein unumstrittener Politiker war, der sich in den Kreisen der polnischen Nationalisten immer wieder unbeliebt machte, wurde die gesamte paneuropäische Bewegung von den polnischen Nationaldemokraten als deutschfreundlich und damit auch revisionistisch eingestuft.

Der Konflikt zwischen Lednicki und der Nationaldemokratie machte deutlich, dass die nationale Partei (ND) Coudenhove und sein Paneuropa für den Deckmantel einer deutsch-französischen Versöhnung hielten. Im März 1930 verhinderten Parteimitglieder einen Auftritt Coudenhoves in der Warschauer Universität. Das Fiasko der Paneuropabewegung in Polen konnten auch nicht seine Versuche aufhalten, den Polen ihre Aufgabe als »antemurale« in Erinnerung zu rufen. Im Herbst 1931 verurteilte das polnische Paneuropakomitee die territoriale Expansion Deutschlands als für den europäischen Frieden bedrohlich $^{18}$. In den Jahren 1933/34 äußerte sich das polnische Außenministerium mehrfach negativ über die Paneuropabewegung. Es riet davon ab, an den paneuropäischen Kongressen teilzunehmen, und drängte Lednicki, aus dem Organisationskomitee auszutreten. So weit ist es zwar nicht gekommen, aber die Aktivitäten der polnischen Paneuropasektion wurden immer rarer. Lednicki selbst nahm sich infolge einer finanziellen Affäre im August 1934 das Leben. Coudenhove bemühte sich zwar noch im Dezember 1939, General Sikorski für seine Idee zu gewinnen, erhielt jedoch eine eher abweisende Antwort ${ }^{19}$.

Vor dem Hintergrund dieser Ereignisse und der sich abzeichnenden politischen Unlösbarkeit der Konflikte ist es verständlich, dass der Verfasser unseres Beispieltextes sowohl mit den Äußerungen der Vorsehung als auch denen der Vernunft bemüht ist, die Angst der Polen vor der Germanisierung unter dem Deckel Paneuropas abzuwehren ${ }^{20}$. Er selbst stellt sich dabei als überzeugter Paneuropäer dar.

18 Es ging hauptsächlich um die Einschätzung der Korridor-Frage von Lednicki, der in einem Gespräch mit der amerikanischen Zeitung »Washington Star« mitgeteilt hatte, dass Polen den Korridor nie aufgeben werde, es sei aber bereit, mit Deutschland einen Nichtangriffspakt abzuschließen, wenn das Deutsche Reich Ostpreußen völlig entmilitarisieren würde. Vgl. Die Kabinette Brüning I/II, Nr. 578, Aufzeichnung des Oberregierungsrats Planck über den Besuch des Polnischen Gesandten beim Reichskanzler, 1. Dezember 1931, 12.30 Uhr. >Akten der Reichskanzlei. Weimarer Republikı online, URL: http://www.bundesarchiv.de/aktenreichskanzlei 1919-1933 (eingesehen am 18.12.2008).

19 Näheres dazu Borodziej / Brzostek / Górny, Polnische Europa-Pläne, S. 95f. Über Aleksander Lednicki siehe ebd., Bd. 1, S. 80, 90, 94, 96 u. Bd. 2, S. $401 \mathrm{f}$.

20 Tysczegiewski, Paneuropa, S. 30f. 
Und trotzdem ist es von der Konstruktion des Textes und vom gesamten Ablauf der Argumentationsdebatte her nicht zwingend schlüssig, wenn Lech am Ende seine Vorbehalte gegen Paneuropa fallen lässt und fast enthusiastisch als Anhänger der paneuropäischen Bewegung ins Horn der Vernunft bläst. Auch der Jubel der Vorsehung: »Es lebe Paneuropa! Es lebe Polen!« wirkt zum Schluss etwas aufgezwungen. Dass der Verfasser von der Idee überzeugt ist, scheint bewiesen. Ob die Protagonisten im Text ihre gegenseitigen Argumente als überzeugend empfanden, dürfte dem Leser nach der Lektüre keineswegs klar genug gewesen sein. Darüber, ob der implizite oder auch nur intendierte Leser mit der Argumentation des Textes einig gewesen ist, kann man überhaupt nichts sagen. Es fehlt an jeglicher rezeptionsgeschichtlicher Überlieferung, an der sich das untersuchen lassen würde.

Somit bleibt der Text eine Ephemeride. Das entspricht jedoch dem Befund, dass auch die paneuropäische Bewegung im Polen der Zwischenkriegszeit eine Vision geblieben ist. Sie war zwar im Vergleich zu anderen polnischen Einigungs- oder Föderationsentwürfen dieser Zeit das eigentliche Europaprojekt, das bemüht war, den sich neu formierenden polnischen Nationalismus und das alte Misstrauen gegenüber den Nachbarn bei Seite zu lassen und tatsächlich eine neue Option im polnischen Föderationsdenken zu eröffnen, indem es über die regionalen osteuropäischen Unionen hinweg eine kontinentale Perspektive in die Debatte einbrachte. Die alten Ängste und eingefahrenen Phobien waren jedoch sowohl in der polnischen Öffentlichkeit als auch in den politischen Kreisen zu groß, um dieser Initiative auch nur annähernd gerecht zu werden und ihr breiten Widerhall zu verschaffen. 
Irene Dingel

\title{
Der Abendlandgedanke im konfessionellen Spannungsfeld
}

\author{
Katholische und evangelische Verlautbarungen (um 1950/60)
}

Die Rede vom »Abendland « und mehr noch vom »Christlichen Abendland « hat eine lange Tradition. Entstanden im Zeitalter der Französischen Revolution und der Napoleonischen Kriege ${ }^{1}$, trifft man sie in zahlreichen Veröffentlichungen insbesondere seit dem Ende des 19. Jahrhunderts an. Sie diente bekanntlich zur Bezeichnung eines sich vom Orient abgrenzenden Okzident oder auch einfach nur als Synonym für den westlichen Kulturkreis des geographischen Erdteils Europa. Zahlreiche historisch ausgerichtete Untersuchungen, die sich mit der Entstehung und Entwicklung des Europagedankens beschäftigen, haben dies in den Blick genommen und vor allem die politische Dimension des Abendlandgedankens analysiert ${ }^{2}$. Dass das »Christliche Abendland « aber nicht nur in politischen und in politisch-kulturellen Gemengelagen zur Debatte stand, wie dies etwa an den Zeitschriften Abendland und Neues Abendland ablesbar ist, ist offensichtlich. Auch die Funktions- und Entscheidungsträger der christlichen Konfessionen bedienten sich der Rede vom »Christlichen Abendland « und machten diese Vision zum Gegenstand von Reflexionen und Veröffentlichungen, die auf ein breites Publikum zielten. Dabei war es keineswegs eindeutig, was man mit der Qualifizierung als »christlich « überhaupt meinte und welche unter Umständen wiederzubelebenden historischen Vorstellungen man eben mit dem »Christlichen Abendland « verband. Im Rahmen dieser kleinen Untersuchung soll deshalb eine Perspektive gewählt werden, die bisher kaum eine Rolle gespielt hat,

1 Hier ist in erster Linie zu denken an Novalis' Rede in Jena vor Friedrich Schlegel und Ludwig Tieck aus dem Jahre 1799, die später auch gedruckt erschien: »Die Christenheit oder Europa«. Auch wenn der Begriff des »Christlichen Abendlands« hier nicht vorkam, sondern die Rede von einem christlichen Europa war, so ging es im Grunde um dasselbe. Vgl. Novalis, Schriften. Die Werke Friedrich von Hardenbergs, Bd. 3: Das philosophische Werk II, hg. v. Richard SAmuel in Zusammenarbeit mit Hans-Joachim MäHL und Gerhard Schulz, Darmstadt 1968, S. $495-524$.

2 So hatte Axel Schildt z.B. geltend gemacht: »Die Abendland-Ideologie rekurrierte zwar immer wieder auf theologische Argumentationsfiguren, aber es handelte sich doch um eine politische Ideologie; [...] «. Axel ScнiLdt, Zwischen Abendland und Amerika. Studien zur westdeutschen Ideenlandschaft der 50er Jahre, München 1999, S. 22f. Von theologischer Seite liegen bisher leider keine Analysen des Abendland-Gedankens vor. 
wenn es um die Analyse des Abendlandgedankens ging, nämlich die historisch-theologische. Sie soll ein Schlaglicht auf verschiedene, in theologischen Kreisen zu erhebende Verständnishorizonte werfen, die die Rede von einem »Christlichen Abendland« bestimmten und die man als gesellschaftlich zukunftsträchtig zu vermitteln versuchte. Es soll - an einigen ausgewählten Beispielen - darum gehen, aufzuzeigen, welches kulturelle Bewusstsein hinter der Rede von einem »Christlichen Abendland« stand, auf welches Europabild sie ausgerichtet war oder aber welches Leitbild zukunftsperspektivisch entworfen und mit Blick auf ein zu bauendes Europa konstruiert wurde. Dabei wird nicht nur die Variationsbreite im konfessionell gebundenen Umgang mit dieser Vision von einem »Christlichen Abendland« angerissen, sondern auch deutlich werden, dass die gezielte Anwendung dieser Formel und ihr Leitbildcharakter, den sie nach dem Zweiten Weltkrieg erhielt, nur unter Berücksichtigung der jeweiligen theologischen bzw. konfessionellen Hintergründe und Einbindungen adäquat erfasst wird. Dies kann zugleich als Problemanzeige für weitere, zu vertiefende Forschungen dienen. Denn es versteht sich von selbst, dass an dieser Stelle keine erschöpfende Aufarbeitung des konfessionell bestimmten Umgangs mit dem Abendlandgedanken geleistet werden kann, die offenbar noch an keiner Stelle auch nur ansatzweise erfolgt ist, während in historischen Abhandlungen das Thema »Abendland« und »Abendlandbewegung « gern aufgegriffen wird ${ }^{3}$. Dieser Beitrag wird also lediglich fünf Beispiele herausgreifen, die deshalb als aussagekräftig und vielleicht sogar als exemplarisch angesehen werden können, weil sie die Stellungnahmen herausragender kirchlicher Persönlichkeiten oder theologischer Gelehrter sowohl im Katholizismus als auch im Protestantismus repräsentieren. Dabei muss sich die Darstellung im Großen und Ganzen auf die fünfziger Jahre des 20. Jahrhunderts beschränken. Nur in einem Fall wird sie darüber hinausgreifen. Es ist naheliegend, die Erhebung des konfessionell eingebundenen Abendlandgedankens am Quellenbefund zu orientieren und in entsprechenden schlaglichtartigen, einander kontrastierenden Skizzen zu entfalten. Nach einer kurzen historischen Situierung der Thematik erfolgt ein Blick auf die päpstliche Direktive für das Verständnis des »Christlichen Abendlands«. Sodann wird es um die Abendland-Nostalgie und den Versuch einer Synthese von Abendland und Sozialismus im katholischen Milieu gehen. Den Abschluss bildet ein Blick auf die evangelischen Gegenentwürfe und deren politisch-appellativen Charakter.

3 Vgl. dazu die informative Studie von Vanessa Conze, Das Europa der Deutschen. Ideen von Europa in Deutschland zwischen Reichstradition und Westorientierung (1920-1970), München 2005 , bes. S. $25-206$. 


\section{Historische Situierung}

Seit Novalis und mit ihm die jungen Romantiker als Reaktion auf die Ideen der Französischen Revolution und die Abschaffung der christlichen Religion durch den Pariser Konventsbeschluss vom 7. November 1793 das »Christliche Europa« wiederentdeckten und so, ungefähr zeitgleich mit Friedrich Schleiermachers »Reden über die Religion an die Gebildeten unter ihren Verächtern $\aleph^{4}$, der Religion als Kulturfaktor und ästhetisches Movens eine Renaissance bescherten, hatte die Rede von einem »Christlichen Abendland « - denn dies meinte Novalis im Grunde, wenn er von einem christlichen Europa sprach ${ }^{5}$ - immer dann Hochkonjunktur, wenn eine politisch-gesellschaftliche Krise die Rückbesinnung auf traditionelle Werte nahelegte. Dies war insbesondere nach dem Ersten Weltkrieg und mehr noch nach der Katastrophe des Zweiten Weltkriegs im Zuge der dann einsetzenden Europäischen Einigungsbemühungen der Fall. In diesen Zusammenhängen wurde deutlich, dass die beiden großen Konfessionen, der Katholizismus und der Protestantismus, einen unterschiedlichen Zugang zum Abendlandgedanken entwickelten und pflegten. Die Grundlagen für eine sowohl typisch katholische als auch für eine charakteristisch evangelische Aneignung des Abendlandgedankens hatte allerdings schon Novalis gelegt, auch wenn er selbst in seiner EuropaSchrift nicht in konfessionellen Mustern argumentiert hatte. Ihm war es vielmehr um das Christentum überhaupt gegangen, das er in einem romantisch überhöhten und idealisierten Mittelalter verankerte und für seine Zukunftsvision in Dienst nahm: »ein« christliches Abendland mit »einer« Kirche, in der das Christentum als Religion des Geistes »alle Menschen « in echter Freiheit integrierte ${ }^{6}$. Während sich hier religiöses Einheitspathos jenseits konfessioneller Identitäten ausdrückte, setzten Katholizismus und Protestantismus

4 Vgl. Friedrich Daniel Ernst Schleiermacher, Über die Religion. Reden an die Gebildeten unter ihren Verächtern (1799), in: Ders., Kritische Gesamtausgabe, 1. Abt., Bd. 2: Schriften aus der Berliner Zeit. 1796-1799, hg. v. Günter MeскENSTock, Berlin / New York 1984, S. 185-326.

5 Vgl. dazu Paul E. HüBInger, Abendland, Christenheit, Europa. Eine Klärung der Begriffe in geschichtlicher Sicht, in: Aus Politik und Zeitgeschichte 14 (1954), S. 37-43. Christoph Schneider weist, angesichts der historischen Verortung der Schrift, darauf hin, dass es Novalis in seinem Europa-Verständnis um den »einheitlich-christlich geprägten Kulturraum« gegangen sei. So schon im Titel seiner Veröffentlichung: Europa als einheitlich-christlicher Kulturraum. Novalis' Schrift »Die Christenheit oder Europa« von 1799, in: Dominic EgGeL / Brunhilde WehiNGER (Hg.), Europavorstellungen des 18. Jahrhunderts. Imagining Europe in the 18th century, o.O. [Hannover] 2009, S. 169-185, das Zitat S. 185.

6 Bei Novalis wird dieser Gedanke gleich eingangs entfaltet, bevor er auch mit Blick auf die durch die Reformation entstandene Spaltung durchgeführt wird: »Es waren schöne glänzende Zeiten, wo Europa ein christliches Land war, wo Eine Christenheit diesen menschlich gestalteten Welttheil bewohnte; Ein großes gemeinschaftliches Interesse verband die entlegensten Provinzen dieses weiten geistlichen Reichs. - Ohne große weltliche Besitzthümer lenkte und vereinigte Ein Oberhaupt, die großen politischen Kräfte« [Kursivierung im Original]. NovaLIS, Die Christenheit oder Europa, S. 507. 
in der Rezeption dessen jeweils charakteristische Akzente. Auf katholischer Seite standen das Mittelalter und die damals angeblich noch gegebene und jetzt wieder zu erstrebende Einheit der Christenheit im Vordergrund; auf protestantischer Seite wurde im Allgemeinen die Freiheit von Amtsautoritäten sowie die Freiheit zur Bejahung der vielfältigen Realisationsformen des Christentums stark gemacht? ${ }^{7}$ Je deutlicher aber in der Ausformulierung und Anwendung des Gedankens von einem christlichen Europa bzw. vom »Christlichen Abendland« die katholische Aneignung hörbar wurde, umso mehr nahm zunächst der protestantische Umgang mit der Formel »Christliches Abendland« ab. Dies blieb auch in der Zwischenkriegszeit noch so, in der nicht wenige katholische Stimmen mit der Zeitschrift Abendland versuchten, ein Gegengewicht gegen einen sich breit machenden, von Oswald Spengler und seiner Veröffentlichung Untergang des Abendlandes (1918) beflügelten Kulturpessimismus zu bilden ${ }^{8}$. Aber vorerst noch erzielte dies weder im katholischen noch im evangelischen Bereich wirkliche Breitenwirkung. Als verlässliche Indikatoren können dafür vor allem die großen Enzyklopädien gelten. Weder das von protestantischer Seite erstellte Handwörterbuch für Theologie und Religionswissenschaft Die Religion in Geschichte und Gegenwart (RGG) von 1929, noch das katholische Lexikon für Theologie und Kirche (LThK) von 1930 führten das Lemma »Abendland«; anders die Neuauflagen der fünfziger Jahre $-R G G^{3}$ von 1957 und $L T h K^{2}$ von 1957 -, die beide den Entwicklungen nach dem Zweiten Weltkrieg Rechnung trugen und bereits den konfessionell differierenden Zugang zum Abendlandbegriff widerspiegeln ${ }^{9}$. Denn tatsächlich erlebte die Argumentation mit der Vorstellung

7 Dass das »Abendland « nach dem Zweiten Weltkrieg sowohl bei Katholiken als auch bei Protestanten zu »einem zentralen Topos« wurde, stellt auch Schildt fest, leider ohne entsprechende, aus der konfessionellen Perspektive argumentierende Autoren bzw. Quellen zu benennen, anhand derer man die spezifische Aneignung und Ausdeutung dieses Gedankens würde nachvollziehen können. Vgl. Schildt, Zwischen Abendland und Amerika, S. 23.

8 Vgl. dazu auch Conze, Das Europa der Deutschen, S. 27-32.

9 Vgl. Ernst Wolf, Art. Abendland, Christliches, in: Die Religion in Geschichte und Gegenwart 1 ( 31957$)$, Sp. 9f, der den Begriff »Abendland« wegen mangelnder Eindeutigkeit für nicht brauchbar hielt. Auch die Qualifizierung des Abendlands als »christlich« bzw. seine Identifizierung mit dem Christlichen stellte er in Frage: »Auf keinen Fall ist \A.২ die alleinige Form der Gestaltung des Christlichen im europäischen Raum, noch das Christliche die alleinige und maßgebliche Bestimmung des Abendländischen« (Sp. 10). Dagegen entwarf Karl Rahner eine »Theologie des Abendlandes «, nachdem Alois Halder in seinen voraufgegangenen Ausführungen über den Begriff »Abendland « konstatiert hatte: »Die letzte Deutung des Phänomens 〉A. ist deshalb, soweit überhaupt, nur in einer Geschichts th e o l o g i e möglich. Von da aus ist nur zu sagen, in welcher Weise das A. noch existiert u. wie es sich verhält zu modernen realpolit. od. ideolog. Bestrebungen seiner Erneuerung u. Verteidigung (Europagedanke, Paneuropa, neues Abendland usw.)«. Vgl. Alois Halder / Karl Rahner, Art. Abendland I. A. Begriff, II. Zur Theologie des A., in: Lexikon für Theologie und Kirche 1 ( $\left.{ }^{2} 1957\right)$, S. 15-21. Auch die neuesten Auflagen beider Nachschlagewerke bieten jeweils einen Artikel »Abendland«. Mehlhausen nahm in der Religion in Geschichte und Gegenwart ${ }^{4}$ die bereits von Wolf formulierte Kritik am Abendlandbegriff auf. Vgl. Joachim Menlhausen, Art. Abendland, Christliches, in: Religion in Geschichte und Ge- 
von einem »Christlichen Abendland « nach dem Zusammenbruch von 1945 einen deutlichen Aufschwung. Für die aus Deutschland kommenden Stimmen spielten die Erfahrungen des Kirchenkampfs eine große Rolle sowie die in diesem Zusammenhang nach dem Krieg einsetzende Wiederbesinnung auf ein von politischer Ideologisierung und erzwungener Gleichschaltung freies Christentum. Dies schwang mit, wann immer jetzt im kirchlichen oder theologisch geprägten Raum vom »Christlichen Abendland « die Rede war. Aber dahinein mischten sich auch konfessionelle Untertöne, aus denen ersichtlich wird, dass die Konfessionskirchen durchaus verschiedene Europa-Konzepte favorisieren konnten. A priori liegt die Vermutung nahe, dass diese Konzepte fest zu konturieren und den jeweiligen konfessionellen Lagern zuzuordnen seien. Aber Stichproben zeigen, dass die Variationsbreite dessen, was man mit der Formel vom »Christlichen Abendland« als Leitbild für Europa propagieren wollte, erstaunlich groß ist. Die hier ausgewählten Beispiele sollen dies deutlich machen, wobei es weniger um die politische Einbindung und Anwendung des Begriffs gehen soll, als vielmehr darum, unter theologischer Perspektive der spezifisch konfessionellen Semantik nachzuspüren, wie sie in Verlautbarungen herausragender, theologisch gebildeter Persönlichkeiten des öffentlichen Lebens Eingang gefunden hat ${ }^{10}$.

\section{Der Abendlandgedanke im Katholizismus der späten vierziger und fünfziger Jahre - Die päpstliche Direktive}

Da die protestantische Aneignung des Abendlandgedankens weitgehend als Reaktion auf die katholische angesehen werden kann, liegt es nahe, zunächst im katholischen Milieu auf Spurensuche zu gehen und den Blick auf die lehramtliche Autorität im Katholizismus zu richten. Von 1939 bis 1958 hatte Eugenio Pacelli als Papst Pius XII. den Pontifikat inne. Seine umstrittene Stellung zum Nationalsozialismus ist bis heute Gegenstand von Untersuchungen, zumal er 1933 als Kardinalstaatssekretär an dem Abschluss des

genwart $1\left({ }^{4} 1998\right)$, Sp. 9f. Harald Dickerhoff dagegen erkannte ihm entwicklungsfähiges Potenzial zu: »Entlastet v. einer einseitig am MA-Bild der Romantik orientierten ideolog. Engführung des Begriffs, könnte die Erforschung abendländ. Merkmale die kulturphilos. Suche nach den Wurzeln abendländ.-eur. Humanität, Rationalität u. weltgestaltender Dynamik aber durchaus befruchten«. Und sein Mitautor Wolfgang Kluxen betonte die Aufgabe der lateinischen Kirche - d.h. des Katholizismus -, bei aller Einbindung in das Lateinisch-Abendländische die Einheit der Weltkirche zu gewährleisten. So Harald Dickerhoff / Wolfgang Kluxen, Art. Abendland I. Begriffsgeschichte, II. Aktuelle Diskussion, in: Lexikon für Theologie und Kirche 1 ( $\left.{ }^{3} 1993\right)$, Sp. 22-24, das Zitat Sp. 23.

10 Außer Acht bleibt daher die sich schon in den zwanziger Jahren formierende katholisch geprägte Abendlandbewegung mit der Zeitschrift »Abendland«, ebenso wie das im Jahr 1946 neu gegründete Organ »Neues Abendland«. 
Reichskonkordats beteiligt gewesen war $^{11}$. Aber auch in lehramtlicher Hinsicht trat er hervor. Mit der Dogmatisierung der leiblichen Himmelfahrt Marias im Jahre 1950 hatte er zum zweiten und bislang letzten Mal in der Geschichte des Papsttums von der Infallibilität einer Ex-Cathedra-Entscheidung Gebrauch gemacht ${ }^{12}$. Sowohl sein politisches als auch sein kirchliches Engagement machten Pius XII. zu einem der bemerkenswertesten Päpste der Neuzeit. Man darf davon ausgehen, dass auch seine Äußerungen zum »Christlichen Abendland« nicht ungehört verhallten. Am 11. November 1948 sprach er vor einer Delegation des Zweiten Internationalen Kongresses der Europäischen Union der Föderalisten und betonte:

Niemand, glauben Wir, wird sich weigern können, der Behauptung zuzustimmen, daß ein geeintes Europa, um sich im Gleichgewicht zu halten und die Verschiedenheit auf seinem eigenen Kontinent auszugleichen - ganz zu schweigen von seinem Einfluß auf die Sicherheit des universellen Friedens - einer unerschütterlichen sittlichen Grundlage bedarf, auf der es ruhen kann. Wo soll es diese Grundlage finden? Lassen wir die Geschichte antworten: es gab eine Zeit, in der Europa in seiner Gesamtheit ein kompaktes Ganzes darstellte, und inmitten all seiner Schwächen und trotz alles menschlichen Versagens war das für es eine Kraft; es vollbrachte dank dieser Einheit große Dinge. Die Seele dieser Einheit war die Religion, die die ganze Gesellschaft bis zum Grund mit christlichem Glauben durchtränkte ${ }^{13}$.

Damit hatte er das Zusammengehen von politischer und religiös-sittlicher Einheit im Sinne des Christentums als Leitbild für eine europäische Eini-

11 Seine Haltung ist durchaus umstritten und wird unterschiedlich bewertet. Vgl. Alessandro Angelo Persico, Il caso Pio XII: mezzo secolo di dibattito su Eugenio Pacelli, Milano 2008. Allgemeine Informationen finden sich bei Hubert KIRCHNER, Das Papsttum und der deutsche Katholizismus 1870-1958, Leipzig 1992 (KGE III/9), S. 89-119; außerdem in Jean-Marie MAYEUR (Hg.), Geschichte des Christentums, Bd. 12: Erster und zweiter Weltkrieg, Demokratien und totalitäre Systeme (1914-1958), dt. Ausg. bearb. u. hg. v. Kurt MeIER, Freiburg/Br. u.a. 1992, S. $378-383$.

12 Die erste Entscheidung dieser Art war die Dogmatisierung der Immaculata Conceptio, d.h. der unbefleckten Empfängnis Marias im Zuge der ultramontanistischen Bestrebungen des Papsttums. Pius IX. hatte dies im Jahre 1854 mit der Verlesung der Bulle »Ineffabilis Deus« in St. Peter in Rom vollzogen, ohne sich dafür auf eine Konzilsentscheidung stützen zu können. Vgl. Leif Grane, Die Kirche im 19. Jahrhundert: europäische Perspektiven, Göttingen 1987, S. 135f. Die Bulle »Ineffabilis Deus« in: Heinrich Denzinger / Peter Hünermann, Kompendium der Glaubensbekenntnisse und kirchlichen Lehrentscheidungen, Freiburg/Br. u.a. ${ }^{37} 1991$, Nr. 2800-2804, S. 774-776 [im Folgenden: D + Nr.]. - Die Dogmatisierung der Unfehlbarkeit fand erst auf dem ersten Vatikanischen Konzil von 1870 statt. Vgl. die erste dogmatische Konstitution »Pastor aeternus « über die Kirche Christi, 4. Sitzung, 18.7.1879, in: D 3050-3075, bes. Cap. 4: De Romani Pontificis infallibili magisterio, D 3065ff., hier: D 3074. Dazu Giuseppe Alberigo (Hg.), Geschichte der Konzilien. Vom Nicaenum bis zum Vaticanum II, Düsseldorf 1993, S. 385-412.

13 Der Papst über die Einheit Europas und die christliche Religion, in: Herder-Korrespondenz 3 (1948/49), S. 167. Die Herder-Korrespondenz bietet eine Übersetzung der in französischer Sprache gehaltenen Papst-Rede. 
gung angesprochen. Dass er das Vorbild dafür vor allem im Hochmittelalter fand, wird aus anderen Zusammenhängen deutlich. So konnte er z.B. mit Blick auf das zu allen Zeiten erstrebenswerte Ideal der religiösen Einheit im Rahmen des Christentums offen für die Legitimität der mittelalterlichen Verfolgungen von Ketzern eintreten, hatten sich diese doch wider besseres Wissen vom wahren, d.h. vom katholischen, Christentum abgewandt. Dies geht deutlich aus seiner Rede anlässlich eines päpstlichen Empfangs für die Teilnehmer des Zehnten Internationalen Historiker-Kongresses am 7. September 1955 hervor:

Die Kirche betrachtete und betrachtet die freiwillige Abkehr vom wahren Glauben als eine Schuld. Wenn diese Abkehr etwa seit dem Jahre 1200 eine Strafverfolgung seitens der geistlichen und weltlichen Gewalt nach sich zog, so geschah dies, um die Zerreißung der religiösen und kirchlichen Einheit des Abendlandes zu vermeiden. Gegenüber den Nichtkatholiken [d.h. Nicht-Christen: I.D.] wendet die Kirche den im Kodex des Kanonischen Rechts enthaltenen Grundsatz an: ^Ad amplexandam fidem catholicam nemo invitus cogatur (Niemand soll gegen seinen Willen gezwungen werden, den katholischen Glauben anzunehmen; Can. 1351), und vertritt die Auffassung, daß die Überzeugung dieser Menschen einen Grund, freilich nicht den Hauptgrund, zur Toleranz darstellt ${ }^{14}$.

Dass diese nachträgliche Legitimierung von blutigen Verfolgungen und mittelalterlichen Ketzerkreuzzügen in protestantischer Sicht dem Abendlandgedanken nur abträglich sein konnte, liegt klar auf der Hand, zumal Papst Pius XII. die Reformation mit dafür verantwortlich machte, dass Europa in der Folgezeit das mittelalterliche Ideal einer »Symphonie« von Kirche und Staat und damit die Konturen des »Christlichen Abendlandes« eingebüßt hatte. In derselben Rede führte er aus:

Das, was man Abendland oder westliche Welt nennt, war seit dem Mittelalter starken Veränderungen unterworfen. Die Religionsspaltung im 16. Jahrhundert, der Rationalismus und Liberalismus führten zum Staat des 19. Jahrhunderts, zu seiner Politik der Stärke und seiner säkularisierten Zivilisation. Es konnte daher nicht vermieden werden, daß in den Beziehungen der katholischen Kirche zum Abendland eine Verschiebung eintrat ${ }^{15}$.

Religionsspaltung, Rationalismus und Liberalismus waren demnach die Faktoren, die das im Mittelalter noch intakte »Christliche Abendland « allmählich ausgehöhlt hatten. Gelegentlich konnten außerdem Kommunismus bzw.

\footnotetext{
14 Die Stimme des Papstes. Das geschichtliche Selbstverständnis der Kirche, in: Herder-Korrespondenz 10 (1955/56), S. 77. Die Herder-Korrespondenz bringt eine nichtamtliche Übersetzung der wohl ursprünglich auf Italienisch gehaltenen Rede.

15 Ebd., S. 77f.
} 
Sozialismus als antikirchliche bzw. antichristliche Faktoren in der Verfallsgeschichte des mittelalterlichen Abendlands, die man nun zu revidieren die Chance hatte, hinzutreten. Diese oder ähnliche Analysen, wie wir sie bei Pius XII. antreffen, waren nicht singulär, sondern wurden auch in anderen Publikationen von katholischen Autoren geäußert. Besonders signifikant war die Verlautbarung Papst Pius' XII. in einem Brief an den Bischof von Augsburg aus Anlass der 1000-Jahr-Feier der Schlacht auf dem Lechfeld ebenfalls im Jahre 1955, in der es hieß:

Denn Wir können nicht umhin, für das Abendland zu wiederholen, was Wir vor gerade drei Jahren von der europäischen Kultur erklärten, daß sie nämlich >unverfälscht christlich und katholisch sein oder aber verzehrt werden wird von dem Steppenbrand jener anderen materialistischen, der nur die Masse und die rein physische Gewalt etwas gelten ${ }^{16}$.

Die protestantische Seite, die im selben Jahr das 400. Jubiläum des Augsburger Religionsfriedens beging, war also mit einem Abendlandgedanken konfrontiert, der den seit der zweiten Hälfte des 16. Jahrhunderts fast überall in Europa eingeschlagenen Weg der konfessionellen Toleranz schien wieder rückgängig machen zu wollen und den Gedanken einer Ökumene dezidiert ausschloss ${ }^{17}$, zumal der Papst in derselben Botschaft unmissverständlich deutlich gemacht hatte, dass er die mit dem Religionsfrieden rechtlich besiegelte Glaubensspaltung für das »schwerste Verhängnis« hielt, »welches das christliche Abendland und seine Kultur treffen konnte $\ll^{18}$.

\section{Katholische Abendland-Nostalgie - Theodor Steinbüchel zum Domjubiläum in Köln}

Ähnlich wie Pacelli äußerte sich auch der Philosoph, Moraltheologe und Sozialethiker Theodor Steinbüchel (1888-1949). Er hatte in Bonn und Straßburg Philosophie, katholische Theologie und Nationalökonomie studiert und Lehrstühle in Gießen, München und Tübingen innegehabt $t^{19}$. Am 21. August 1948 hielt er aus Anlass des 700. Jahrestags der Grundsteinlegung des Köl-

16 Die Botschaft des Papstes [= aus dem Brief Papst Pius' XII. an Bischof Joseph Freundorfer zur Feier der St. Ulrichs-Woche in Augsburg], in: Herder-Korrespondenz 9 (1954/55), S. 525. Denselben Gedanken hatte Pius im Jahre 1952 in einem Brief an die Vorsitzende des Katholischen Deutschen Frauenbundes geäußert. Vgl. Herder-Korrespondenz 6 (1951/52), S. 567.

17 Vgl. dazu auch Irene DingEL, Protestantische Stellungnahmen zu Europa und zur Europäischen Integration. Eine Problemanzeige, in: Jahrbuch für Europäische Geschichte 9 (2008), S. 42f.

18 Die Botschaft des Papstes, in: Herder-Korrespondenz 9 (1954/55), S. 525.

19 Im Jahre 1926 wurde er Professor für Philosophie in Gießen, von 1935 bis zur Schließung der durch die Nationalsozialisten war er Professor für Moraltheologie an der Katholisch-Theologischen Fakultät in München. Ab 1941 lehrte er in Tübingen, wo er von 1946-1948 auch das 
ner Doms im Rahmen der Vortragsreihe »Europa und die Christenheit« in der Aula der Universität Köln einen Vortrag unter dem Titel »Europa als Idee und geistige Verwirklichung $\ll^{20}$, der den über antiken Resten erbauten mittelalterlichen Kölner Dom als »Denkmal«, »Mahnmal« und Symbol eines geeinten Europa stilisierte ${ }^{21}$.

Um den $D$ o $m$ aber 1 ä $\beta \mathrm{t}$ sich die Idee Europa wirklich zentrieren. Denn sie entspringt h e i $1 \mathrm{ig}$ e $\mathrm{m}$ Bezirk. Europa ist durch Jahrhunderte $\mathrm{ch} \mathrm{h}$ i s t l i che s $\mathrm{A}$ b e n d l a nd, und was zu diesem zählt, nimmt von Europa seinen Ausgang. Wo Europa diesen Heimatbereich christlicher Glaubensgemeinschaft verläßt, liegt die große Zäsur in seiner Geschichte ${ }^{22}$,

so Steinbüchel. Die Einheit von Antike und Christentum, die Einheit des Glaubens und Einheit der Bildung - wie sie in Steinbüchels Analyse noch bis ins Spätmittelalter hinein wenigstens annähernd gewährleistet waren, aber durch Konziliarismus und Schisma bereits zu bröckeln begannen - waren für ihn signifikante Merkmale des »Christlichen Abendlandes $\aleph^{23}$. Sie funktionierten wie eine Klammer, die den »g e i s t i g - abendländische[n] Kulturraum ${ }^{24}$ in all seiner politischen, kulturellen und geistesgeschichtlichen Pluralität und trotz aller Spannungen zusammenhielt und ihm feste Konturen verlieh. Den Höhepunkt dessen sah er im 13. Jahrhundert, das in seinem Geschichtsbild trotz aller kirchengeschichtlichen Tiefen makellos dastand. So führte er z.B. aus, dass die Ketzerkreuzzüge jener Epoche nicht primär auf politische Macht und wirtschaftlichen Nutzen gezielt hätten, sondern im Grunde das im Blick hatten, was das »Christliche Abendland « als sein Fundament und als sein Bestand sicherndes Charakteristikum schlechthin nicht aufgeben konnte: die Einheit im Glauben.

In diesem geistigen Europa eint sich alle Gegensätzlichkeit noch in dem allverbindenden Glauben: Scholastik und Mystik, Ethik und Physik, Philosophie und Theologie, intellectus und fides, und der neue Aristotelismus des Thomas gibt sich selbst die alte augustinische Krönung in der lex aeterna, dem ewigen Schöpferplan, in dem Gott das principium und das finis von allem ist, was Sein hat $\mathrm{d} \mathrm{u} \mathrm{r} \mathrm{ch} \mathrm{ihn} \mathrm{und} \mathrm{zu} \mathrm{ihm} \mathrm{h}$ i $\mathrm{n}^{25}$.

Dies änderte sich mit dem 16. Jahrhundert. Die jetzt eingetretene Glaubensspaltung habe zwar die Idee Europas als abendländischer Christenheit nicht

Amt des Rektors versah. Vgl. Andreas Lienkamp, Art. Steinbüchel, Theodor, in: Religion in Geschichte und Gegenwart 7 ( $\left.{ }^{4} 2004\right)$, Sp. 1701f.

20 Theodor Steinbüchel, EVROPA als Idee und geistige Verwirklichung, Köln [um 1953].

21 »Der Dom ist ein Denkmal Europas und ein M a h n mal an Europa zugleich«: STEINBÜCHEL, Europa, S. 5. [Die Sperrungen finden sich so im Original].

22 Ebd., S. 5f.

23 Vgl. ebd., S. 7-10.

24 Ebd., S. 13. Ebenso konnte er von einer »kirchlich-abendländischen Kultur« sprechen, ebd.

25 Ebd., S. 15. 
ausgelöscht, aber eben doch »Grad und Innigkeit der Einheit« entscheidend gemindert ${ }^{26}$. Damit sah Steinbüchel die Umformung, ja vielmehr die Entleerung der Europa-Idee einhergehen, die sodann einer radikalen Säkularisierung anheimgefallen sei. Nicht mehr die Gemeinschaft, sondern der Zweck war seiner Sicht nach fortan ausschlaggebend, nicht mehr der inhärente »Sinn«, sondern das zu erreichende »Ziel« bestimmte nunmehr die EuropaIdee:

Seit dem 16. Jahrhundert gibt es die bisherige Einheit abendländischer Christenheit als einheitliche Glaubensgemeinschaft, wie sie bisher im regnum und sacerdotium rechtlich verbunden war, nicht mehr. Zwischen Europa und der Christenheit steht kein Gleichheitszeichen mehr. Eine politische $Z$ w e c k idee tritt an die Stelle der bisherigen Gemeinschaftsidee Europa, die mehr war als ınur eine Idee`, mehr als subjektiver Gedanke, Idee im platonischen Ursinn: formgebende Wirklichkeit gewurzelt im Glauben der abendländischen Menschheit. Und diese neue Idee ist wirklich `nur eine Idee`, ein politisches Bestreben: das `Gleichgewicht〈 der europäischen Nationen ${ }^{27}$.

Die hier zwischen den Zeilen mitschwingende Klage über eine sich durch die Jahrhunderte hindurch verstärkende Abkehr von einem - philosophisch $\mathrm{zu}$ verstehenden - platonischen Realismus, der auch Europa einen höheren Sinn verlieh, macht deutlich, welchen Abendlandgedanken Steinbüchel selbst zu retten und zu propagieren hoffte. Dessen dem Katholizismus näher als dem Protestantismus stehende Renaissance machte er denn auch folgerichtig bei Novalis' Europarede von $1799 \mathrm{fest}^{28}$. In der rückblickenden Lektüre seiner Rede gewinnt man den Eindruck, dass sein auf die symbolische Kraft des Kölner Doms ausgerichteter historischer Durchgang durch die Entwicklung des »Christlichen Abendlandes « unterschwellig darauf zulief, der protestantischen Seite eine Europa-Idee überhaupt abzusprechen, und ihr deren Pervertierung durch das Aufkommen von Nation und Imperialismus, Materie und Technik vorzuhalten, ja sogar anzulasten ${ }^{29}$. Und so gipfelten seine Ausführungen in dem Ruf: »Europa will seine abendländische Tradition noch $\mathrm{n} \mathrm{i} \mathrm{h} \mathrm{t}$ verlassen! Will sich auf's neue verwirklichen aus $i r^{30} \ll$ !

26 Vgl. ebd., S. 18f.; das Zitat S. 19.

27 Ebd., S. 22f.

28 Vgl. ebd., S. 27f.; das folgende Zitat S. 28. »Aus dem Geist der deutschen Romantik und des deutschen Idealismus hat sich so die abendländische Europa-Idee noch einmal erneuert. In ihrer romantisch-gläubigen Gestalt, die dem Katholizismus näher steht als der bei Hegel aus spezifisch protestantischer Geistigkeit entworfene Idealismus, spiegelt sich die Europa-Idee noch einmal wider in die Geschichte des Kölner Domes«.

29 Vgl. ebd., S. 35.

30 Ebd., S. 42. 


\section{Katholischer Nonkonformismus -}

\section{Johannes Hollnsteiners Synthese von Abendland und Sozialismus}

Während Steinbüchel den Gedanken des »Christlichen Abendlands« retrospektiv entfaltete und insofern im Grunde eine Rückkehr zu vormodernen Zuständen erhoffte, wenn er dem christlichen, d.h. katholischen, Glauben zutraute, aufs neue »Einheit in der Vielheit « ${ }^{31}$ für Europa zu stiften, entwarf der österreichische katholische Theologe und Kirchenhistoriker Johannes Hollnsteiner (1895-1971) einen Abendlandgedanken, der von der Zukunftsperspektive her seinen Zuschnitt erhielt. Dies mag nicht zuletzt auch durch eigene Lebenserfahrungen mit bedingt gewesen sein. Hollnsteiners Biographie ist alles andere als geradlinig verlaufen ${ }^{32}$. Im Jahre 1914 war er in das Augustiner Chorherrenstift St. Florian eingetreten, studierte dort und an der Universität Wien katholische Theologie, empfing die Priesterweihe (1919) und schloss ein Geschichtsstudium, ebenfalls in Wien und in Freiburg/Br. an. In beiden Fächern promovierte er und lehrte später Kirchengeschichte und Kirchenrecht an der Universität Wien. Eine Zeitlang war er auch Vizepräsident des Metropolitangerichts. Im März 1938 wurde er von der Gestapo verhaftet und seines Amtes als Universitätsprofessor enthoben. Nur durch Intervention Franz Werfels, mit dessen Frau er als Seelsorger in engem Kontakt gestanden hatte, kam er aus dem Konzentrationslager Dachau nach elf Monaten Haft wieder frei. Im Oktober 1945 erfolgte die Verhaftung durch die Alliierten und seine Internierung im amerikanischen Lager Salzburg-Glasenbach für ehemalige Nationalsozialisten und Kriegsverbrecher, das er aber im April 1947 ohne Verurteilung wieder verlassen konnte. Damit stand auch seiner Rückkehr in die Universitätsprofessur nichts mehr im Wege, aber einen Lehrstuhl erhielt Hollnsteiner dennoch nicht. Grund dafür waren sein Austritt aus dem Orden und seine Eheschließung. Das bedeutete die Versetzung in den Ruhestand mit nur 53 Jahren. Er gründete daraufhin im Jahre 1948 den Pilgram-Verlag, in dem als erstes Werk sein Buch Das Abendland. Aufstieg / Krise / Zukunft erschien ${ }^{33}$. Es handelte sich dabei um eine historische Darstellung, die Spenglers Untergang des Abendlandes zum Anlass für einen am Ende der Studie vorgelegten Gegenentwurf, nämlich für die Skizzierung eines sich erneuernden »Christlichen Abendlandes« nahm. Auf den

31 Ebd., S. 16 u.ö.

32 Eine biographische Studie zu Hollnsteiner hat Friedrich BuchmaYr vorgelegt unter dem Titel: Der Priester in Almas Salon. Johannes Hollnsteiners Weg von der Elite des Ständestaats zum NS-Bibliothekar, Weltra 2003.

33 Johannes Hollnsteiner, Das Abendland. Aufstieg / Krise / Zukunft, Wien / Linz / Zürich 1948. Zur Biographie Hollnsteiners und seinen Werken vgl. Friedrich BuchmaYR, Art. Hollnsteiner, Johannes, in: Biographisch-Bibliographisches Kirchenlexikon 15 (1998), Sp. 726-732, mit Literaturergänzung unter URL: http://www.bautz.de/bbkl/h/hollnsteiner.shtml (eingesehen am 18.10.2008). 
Argumentationsverlauf kann hier nicht im Einzelnen eingegangen werden, zumal im Zusammenhang unserer Fragestellung lediglich von Interesse ist, was Hollnsteiners Entfaltung seiner Abendland-Vision charakteristisch von anderen Entwürfen abhob. Dass er überhaupt eine Zukunft für ein - sich in seinen geschichtlichen Phasen stets unterschiedlich charakterisierendes und definierendes - 》Christliches Abendland « gegeben sah, wurzelt in seiner Gegenwartsanalyse. Er beobachtete nach dem Zusammenbruch des Nationalsozialismus eine neue Hinwendung zum Christentum, die durch entschiedene Initiativen der Kirchenleitungen gestützt waren. Sowohl die Aktivitäten Pius' XII., der z.B. das Kardinalskollegium aus seiner nationalen Zentrierung auf Kandidaten italienischer Herkunft befreit und auf die Weltkirche hin ausgerichtet hatte ${ }^{34}$, als auch die ökumenischen Vorstöße der evangelischen Kirchenleitungen galten ihm als Belege für diese Renaissance christlicher Impulse. Ja, Hollnsteiner meinte sogar, eine ökumenische Annäherung der beiden großen Konfessionskirchen zu erkennen, grundgelegt in der Lehre von der Universalität der Kirche, zu welcher letzten Endes auch diejenigen gehören sollten, die sich gegenwärtig nicht zur sichtbaren katholischen Bekenntniskirche hielten ${ }^{35}$. Ob diese ökumenische Ausweitung, wie er sie von katholischer Seite aus in die Wege geleitet sah, allerdings tatsächlich auch von Pius XII. in der Weise mitgetragen wurde, wie Hollnsteiner ausführ$t^{36}$, mag man bezweifeln. Tatsache ist jedenfalls, dass er vor dieser Folie in der Lage war, eine Abendlandvision zu entwerfen, die sich nicht, wie sonst, am mittelalterlichen Ideal einer homogenen abendländischen Christenheit orientierte. Das »Christliche Abendland« der Zukunft basierte für ihn auf

34 Und zwar durch gezielte Integration anderer Nationalitäten. Vgl. Hollnsteiner, Abendland, S. 220. Hollnsteiner bilanziert, dass »24 italienischen Kardinälen 37 Nichtitaliener« gegenübergestanden hätten.

35 Vgl. ebd., S. 217: »Diese Annäherung der beiden großen abendländischen Kirchengemeinschaften, der römisch-katholischen und der protestantischen, worunter alle aus derselben Wurzel entsprossenen Kirchengemeinschaften gemeint sind, erfolgt in einem noch höheren Ausmaß dadurch, daß die L e hre von der Universali tät der Ki r c h e überden Rahmen der Bekenntniskirche hinaus von Seite der katholischen Kirche stärker betont wird. Es war immer theologisches Lehrgut, daß zur Kirche Christi nicht nur die gehören, die sich bekenntnismäßig angeschlossen haben, sondern darüber hinaus alle, die nach Erkenntnis der Heilswahrheit streben und sich bemühen, nach der erkannten Wahrheit zu leben« [Sperrungen im Original].

$36 »$ Mit der Zurückhaltung hinsichtlich dieser Lehre ist aber nun gebrochen. Papst Pius XII. hat sie mit aller nur wünschenswerten Klarheit bei verschiedenen Anlässen herausgestellt. Er betont in der Enzyklika über den mystischen Leib Christi, daß sauch sie, die nicht zur sichtbaren Gemeinschaft der katholischen Kirche gehören [...] aus einem unbewußten Sehnen und Wünschen heraus schon in einer Beziehung stehen zum mystischen Leib des Erlösers $<$. Und noch deutlicher sagt er in seiner Ansprache an das Kardinalskollegium am 20. Februar 1946: >So betrachtet, kann die Kirche die Gemeinschaft derer genannt werden, die unter dem übernatürlichen Einfluß der Gnade in der Vollkommenheit ihrer persönlichen Würde als Gotteskinder in der ebenmäßigen Entfaltung aller menschlichen Anlagen und Kräfte den mächtigen Bau des menschlichen Zusammenlebens errichten««. Hollnsteiner, Abendland, S. 218. 
einem christlich-ethischen Sozialismus und verwirklichte sich gerade in dieser Synthese von Christentum und Sozialismus. Darin sah er nicht nur die Überwindung des »Zeitalters des Individualismus«, welcher das Abendland in die zurückliegende schwere Krise geführt hatte, sondern dies war seiner Ansicht nach auch der entscheidende Hebel, um einen dauerhaften Spannungsausgleich zwischen Ost und West herbeizuführen.

Ein Sozialismus - nicht aus Nützlichkeitserwägungen, sondern - aus tiefster menschlicher und christlicher Verantwortung, wird dann auch jene Form finden, die Menschenwürde und Menschenrechte achtet und zur Geltung bringt, ohne andere in ihren ehrlichen Rechten zu kränken. Je reibungsloser und harmonischer der Aufbau eines sozialistischen Gemeinwesens und der Umbau der Wirtschaft von einer privaten Profitwirtschaft zu einer gemeinschaftsbewußten Planwirtschaft erfolgt, umso rascher wird der Gesundungsprozeß des Abendlandes vor sich gehen. Je enger die Christen und Sozialisten der verschiedenen Richtungen und Länder zusammen arbeiten, umso sicherer wird das Ziel einer klassenlosen abendländischen Volks- und Völkergemeinschaft erreicht werden ${ }^{37}$.

Es war der christliche Sozialismus, der nach dem Entwurf Hollnsteiners zum Kennzeichen des zukünftigen, europäisch geeinten »Christlichen Abendlands« werden sollte.

\section{Der evangelische Gegenentwurf - Walther von Loewenich und Erwin Mülhaupt}

Die evangelischen Kreise begegneten dem katholisch aufgeladenen Abendlandgedanken mit großer Skepsis. Sie lässt sich paradigmatisch an den Veröffentlichungen der beiden Theologen und Kirchenhistoriker Walther von Loewenich (1903-1992) und Erwin Mülhaupt (1905-1996) ablesen, die 1955, respektive 1965 gedruckt erschienen ${ }^{38}$. Loewenich war von 1946-1971 Professor für Kirchen- und Dogmengeschichte, Konfessionskunde und christliche Kunst in Erlangen, wo er 1956/57 auch als Rektor der Universität amtiert hatte. Bleibende Bedeutung erlangte er durch sein konsequentes Eintreten für die Historisierung des traditionellen Dogmen- und Lehrbestands sowie insbesondere durch seine Lutherforschung ${ }^{39}$. Letzteres verband ihn auch

37 Vgl. ebd., S. 328-332; das Zitat auf S. 330f.

38 Walther von LoEwenich, Europa oder christliches Abendland?, in: Europa und das Christentum. Drei Vorträge von Walther von Loewenich, Fedor Stepun und Joseph Lortz, Wiesbaden 1959, S. 15-32. - Erwin Mülhaupt, Evangelische Besinnung über das Christliche Abendland, Stuttgart 1965.

39 Vgl. Carsten Nicolaisen, Art. Loewenich, Walther v., in: Religion in Geschichte und Gegenwart 5 ( $\left.{ }^{4} 2002\right)$, Sp. 528f. 
mit Erwin Mülhaupt. Mülhaupt hatte nach Wehrdienst und Kriegsgefangenschaft (1943-46) im Jahre 1951 eine Professur für Kirchengeschichte an der Kirchlichen Hochschule Wuppertal übernommen und trat als Reformationshistoriker durch zahlreiche Veröffentlichungen hervor ${ }^{40}$.

Walther von Loewenich beschäftigte sich im Rahmen einer durch Josef Lortz ausgesprochenen Vortragseinladung an das Institut für Europäische Geschichte in Mainz mit dem Abendlandbegriff ${ }^{41}$, den er seit der Romantik durch eine $»$ Begeisterung für diese mittelalterliche Einheitskultur $\aleph^{42}$ geprägt und zu Recht vor allem in katholischen Kreisen beheimatet sah. Er warnte nachdrücklich vor einer »falschen ungeschichtlichen Idealisierung « ${ }^{43}$, zumal die mittelalterlich religiöse Einheit des »Christlichen Abendlands« wie er ausführte - ja nur um den Preis der Trennung von der Ostkirche im Schisma von 1054 zustande gekommen sei $^{44}$. Sein gesamter Vortrag zielte auf eine Entmythologisierung des »Christlichen Abendlands« mit Hilfe historischer Klarstellungen. So spürte er die von katholischer Seite mit der Kirchenspaltung angesetzten, das »Christliche Abendland« vorgeblich schwächenden Säkularisierungsprozesse bereits im Zeitalter Karls des Großen auf $f^{45}$. Die im Sinne christlicher Einheitskultur angeführte Aufeinanderbezogenheit von Kaisertum und Papsttum entlarvte er als unerbittliche Rivalität. Verweltlichung vor allem des Renaissance-Papsttums und Auseinanderfallen des Corpus Christianum längst vor dem Zeitalter der Glaubensspaltung - all dies thematisierte er als historische Anfragen an den nostalgischen Abendlandgedanken, dem er damit ausdrücklich eine Absage erteilte. Seiner Ansicht nach hatte man den im Zuge historischer Entwicklungen entstandenen konfessionellen Flickenteppich in Europa als nicht revidierbare Tatsache $\mathrm{zu}$ akzeptieren. Gegen wesensmäßige Zuschreibungen erklärte Walther von Loewenich die konfessionellen Disparitäten als »geschichtliche Festsetzungen, denen von heute aus gesehen eine gewisse Zufälligkeit anhaftet«, was den Protestantismus, wie er betonte, aber keineswegs anti-europäisch mache. »Man kann sagen«, so Loewenich, »daß Genf ebenso europäisch wurde wie Rom und bis in die Gegenwart herein diese europäische Bedeutung behalten hat als einen säkularen Nachklang aus der Zeit Calvins $\aleph^{46}$.

40 Vgl. den Eintrag unter seinem Namen im Mitarbeiterverzeichnis in: Die Religion in Geschichte und Gegenwart Registerbd. ('1965), Sp. 167f. Außerdem Hans-Ludwig SlupinA, In memoriam Erwin Mülhaupt, in: Luther-Jahrbuch 65 (1998), S. 15-18.

41 Vgl. dazu Dingel, Protestantische Stellungnahmen, S. 41-45.

42 LOEWENICH, Europa oder christliches Abendland?, S. 21.

43 Ebd., S. 22.

44 Vgl. ebd., S. 20.

45 Schon die Entwicklung von Karl I. zu Karl V. sei ein Säkularisierungsprozess gewesen; vgl. ebd., S. 23.

46 Ebd., S. 26. 
Nichtsdestoweniger konnte er durchaus einräumen, dass »aufs Ganze gesehen [...] die Glaubensspaltung eine Schwächung des europäischen Gedankens gewesen « $\mathrm{sei}^{47}$, dessen gegenwärtige Renaissance nun aber eine Herausforderung an beide Konfessionen darstelle. Diese Analyse verknüpfte er mit einer Zukunftsperspektive, die forderte, im »Wiedererwecken des christianum« für Europa das restaurative Denken zu überwinden und zu einer ernsten Beschäftigung mit den Entwicklungen der Moderne und ihren Problemen zu gelangen ${ }^{48}$. Und dies bedeutete für ihn konkret eine wirkliche, überhaupt noch zu leistende Auseinandersetzung des Christentums mit der modernen Wissenschaft, d.h. mit den Naturwissenschaften und den modernen historischen Fragen sowie mit den sozialen und sozialethischen Problemen der Zeit.

Mülhaupts Kritik am katholischen Abendlandbegriff zog ebenfalls primär dessen historische Fundamente in Frage. Aber die Akzente, die er setzte, gingen doch in eine andere Richtung. Sie sind nicht zuletzt interessant durch die zwischen Katholizismus und Protestantismus konfessionell unterschiedlichen Geschichtsbilder, die dabei zutage traten. Hier kann nur ein analysierendes Resümee in groben Stichworten erfolgen, ohne auf die durchaus differenzierten Argumentationsstrukturen genauer einzugehen. Sein erster Punkt betraf die vorbildhaft für das »Christliche Abendland« idealisierte Periode von 1050 bis 1300. Sie sei in Wahrheit eine der blutigsten Zeitabschnitte in der Geschichte der Kirche gewesen. Auch - zweitens - die unter der plenitudo potestatis des Papstes stehende mittelalterliche Glaubenseinheit und die sich daran festmachende Einheitsidee sei für die Evangelischen das krasse Gegenteil von einem Ideal. Und schließlich - drittens - gehöre die Reformation (in der katholischen Begrifflichkeit: die »Glaubensspaltung «) keineswegs zu den Faktoren, die zu dem Zerfall des »Christlichen Abendlands« geführt hätten und deshalb als Negativkriterium zu brandmarken sei. Mülhaupt sah hierin eine krasse Simplifizierung in der Beurteilung der von dort aus in Gang gesetzten Entwicklungen und forderte Offenheit und Bereitschaft für eine positive Beschreibung der vom Zeitalter der Reformation an sich allmäh-

47 Ebd.

48 Loewenich führte in seinem Vortrag aus: »Ich glaube, man kann bei ruhiger Überlegung gar keinen anderen Weg für Europa sehen, als das Wiedererwecken des christianum. Aber wenn ich das ausspreche, dann darf ich doch umgekehrt nicht die Bedenken verschweigen, die - ich muß schon sagen - zentnerschwer auf einem lasten. Dieses christianum äußert sich kirchlich in beiden Konfessionen allzu sehr restaurativ. Und so stelle ich die Frage, die uns nun zum Schluß beschäftigen muß: Ist das Christentum in seiner überlieferten Gestalt wirklich fähig, zur tragenden Idee des kommenden Europa zu werden? Ich sehe in beiden Konfessionen [...] keine wirkliche Überwindung der Aufklärung, keine wirklich durchschlagende Auseinandersetzung mit der sogenannten Moderne, sondern im wesentlichen nur ein Zurück hinter sie. Das gilt von beiden Konfessionen. Aber dieses Zurück hinter die Moderne ist einfach eine geistige Unmöglichkeit.« Ebd., S. 28. 
lich etablierenden »Freiheit der religiösen Überzeugung, Toleranz, Gleichberechtigung der Konfessionen, Entklerikalisierung der Politik, Selbstverantwortung der Staaten und Völker « ${ }^{49}$. Er konstatierte in nicht zu überbietender Deutlichkeit:

Solange diese drei Stücke, die Verklärung des beschämendsten Zeitalters der christlichen Kirchengeschichte zwischen 1050 und 1300, das hochmittelalterliche Zwangseinheitsidol und die pauschale Ausschließung des Protestantismus und der modernen Welt integrierende Bestandteile des Begriffs vom Christlichen Abendland sind, ist er nicht zu gebrauchen und auch durch keine `Theologie des Abendlands`, wie sie Karl Rahner im Lexikon für Theologie und Kirche vorschlägt, ohne dabei diese drei Tabus zu berühren, schmackhaft zu machen ${ }^{50}$.

Dem setzte er einen evangelischen Begriff des »Christlichen Abendlands« entgegen, der zum Teil spiegelbildlich an den Hauptpunkten seiner Kritik entlang ging. Mülhaupt plädierte für eine Ausrichtung des Abendlandgedankens nicht am Hochmittelalter, sondern vielmehr am Frühmittelalter, u.a. um die Ostkirche und das byzantinische Christentum in die Abendlandidee zu integrieren. Den ostkirchlichen Anteil an der Prägung des »Christlichen Abendlands « wollte er neben dem der römischen Kirche keineswegs ignoriert wissen $^{51}$. Darüber hinaus trat er für eine Einbeziehung protestantischer Kultur und ihrer Repräsentanten in den Abendlandbegriff ein, selbst wenn diese seit der Aufklärung in nur noch loser Verbindung zum evangelischen Kir-

49 Mülhaupt, Evangelische Besinnung, S. 28. Aussagekräftig ist der Zusammenhang des oben nur ausschnitthaft wiedergegebenen Zitats: »Vor allem aber müssen wir Evangelischen, doch wieder wahrhaftig nicht wir allein, die negativen Bestimmungen ablehnen, mit denen, wie wir sahen, das katholische Ideal des Christlichen Abendlands immer wieder verbunden wird, d.h. die These, als ob mit der Reformation der Zerfall des Abendlands begonnen und immer weiter um sich gegriffen hätte. [...] Denn wir sind der Meinung: was die Päpste, katholische Schriftsteller und Theologen so pauschal abschätzig Individualismus, Liberalismus, Säkularismus, Nationalismus nennen, das hat für uns und auch weithin für die Welt durchaus auch positive Seiten und kann auch mit anderen weniger heruntersetzenden Begriffen beschrieben werden, z.B. mit Freiheit der religiösen Überzeugung [...]«, S. 27f.

50 Ebd., S. 28. Vgl. dazu Karl Rahner, Art. Abendland II. Zur Theologie des A., in: Lexikon für Theologie und Kirche 1 (21957), Sp. 18-21.

51 Vgl. dazu Mülhaupt, Evangelische Besinnung, S. 34: »Dieser protestantische Begriff vom Christlichen Abendland, soweit er das Mittelalter betrifft, hat schließlich - und dies könnte vielleicht aktuellere Bedeutung haben, als man auf den ersten Blick meint - den Vorteil, daß er das christliche Byzanz oder das morgenländische Christentum nicht einfach ausschließt, wie dies beim extrem katholischen Begriff der Fall ist. Denn genau am Beginn des hochmittelalterlichen Zeitraums, an dem der extrem katholische Begriff vom Abendland so sehr interessiert ist, steht bekanntlich das Datum 1054, an dem sich die östliche und westliche christliche Kirche feierlich, richtiger: unfeierlich, nämlich mit gegenseitigen Flüchen voneinander getrennt haben; sie sind bekanntlich bis zum heutigen Tage noch nicht wieder zusammengekommen, und das kurze Zusammentreffen Papst Pauls VI. mit dem Patriarchen Athenagoras in Jerusalem im Januar 1964 war trotz aller Aufmachung in der Presse nicht dazu angetan, die 600jährige Trennung zu überwinden«. 
chentum gestanden hatten bzw. standen ${ }^{52}$. Zugleich aber insistierte er darauf: Christliches Abendland heißt für uns Evangelische aber vor allem auch, daß wir die Selbstbeschränkung des Protestantismus auf die Verkündigung der biblischen Botschaft und seine seit langem geübte rein geistige Auseinandersetzung mit einer frei gelassenen mündigen Welt ohne klerikale Ansprüche und Ideologien als einen unendlichen Segen ansehen und bejahen ${ }^{53}$

Die von Mülhaupt vorgeschlagene Alternative $\mathrm{zu}$ dem katholischen Abendlandbegriff lief also auf eine neue Semantik hinaus, die katholisches und evangelisches Erbe miteinander zu verbinden suchte und auf diese Weise außerdem den ökumenischen Horizont einbrachte. Dazu gehörte nicht nur die Offenheit gegenüber dem östlich-orthodoxen Christentum, sondern auch die Einbeziehung der mit der Missionskonferenz in Edinburgh im Jahr 1910 vielversprechend begonnenen ökumenischen Bewegung. In all diese Ausführungen mischte sich bei Mülhaupt, zehn bis fünfzehn Jahre nach den bisher betrachteten Verlautbarungen, aber nun bereits die Wahrnehmung einer religiösen Pluralität in Europa, die die so ausgeweitete Semantik des Begriffs des »Christlichen Abendlands « aufs neue auf die Probe stellte. Denn anders als in der unmittelbaren Nachkriegszeit gelte es wahrzunehmen, dass es in Europa Millionen von Nicht-Christen gebe, die bei aller notwendigen Beachtung und gerechtfertigten Bewahrung des christlichen Erbes des Abendlands nicht einfach vereinnahmt werden könnten und dürften ${ }^{54}$.

52 Interessant ist die Liste der von ihm durch die Epochen hindurchgehend genannten Kulturträger: »[...] sowenig wir Evangelischen aus dem Erbe des Christlichen Abendlands die Namen Augustin, Bonifatius, Karl den Großen, Bernhard von Clairvaux und aus späteren Zeiten Namen wie Friedrich Spee, Pascal, Eichendorff, Kolping, von Baader, Reinhold Schneider, Graf von Galen und manchen andern streichen wollen, ebenso wenig wollen wir im Christlichen Abendland jemals auf das Erbe von Luther, Paul Gerhardt, Spener, Zinzendorf, Schleiermacher, v. Bodelschwingh und Albert Schweitzer verzichten. Aber auch das protestantische Erbe in Leibniz, Lessing, Goethe, Kant, Kierkegaard, Bismarck wollen wir nicht verleugnen und nicht bestreiten lassen, weil sie trotz all ihrem freieren Protestantismus dennoch zu ihm gehören und das Gesicht des Abendlands mitbestimmt haben [...]«. Mülhaupt, Evangelische Besinnung, S. 35f.

53 Ebd., S. 36.

54 Mülhaupt plädierte in diesem Zusammenhang für Bescheidenheit im Umgang mit dem Begriff des »Christlichen Abendlands«. Er führte aus: »Ich meine dies so: wir halten es [...] wahrhaftig für berechtigt, auch der heutigen Welt und unseren heutigen Zeitgenossen das beste christliche Erbe des Abendlands zur Beachtung und Bewahrung, aber auch zur Weiterentwicklung zu empfehlen; aber wir sollen und dürfen dabei nicht vergessen, daß wir Christen nicht allein auf der Welt und auch in Europa nicht allein unter uns sind. Wir leben in einer pluralistischen Gesellschaft, in der es Millionen von Nicht-Christen gibt. Und Christus hat uns verboten, die Leute mit Gewalt und mit den Mitteln dieser Welt zu Christen zu 


\section{Politische Mobilisierung der evangelischen Kreise - \\ Der appellative Charakter des Abendlandgedankens bei Eugen Gerstenmaier}

Wenn man als Zwischenfazit festhält, dass die Rede vom »Christlichen Abendland « auf evangelischer Seite eher auf Zurückhaltung stieß und bei allen Umdeutungsversuchen keineswegs selbstverständlich übernommen wurde, erstaunt es, dass der Politiker und evangelische Theologe Eugen Gerstenmaier ${ }^{55}$ (1906-1986) sich überhaupt der Abendland-Begrifflichkeit bediente. Auffällig ist aber, dass er dies - als Angehöriger der dem Katholizismus zuneigenden CDU - keineswegs in politischen Zusammenhängen tat. Soweit eine erste Einsichtnahme zeigt, kommt z.B. in seinen Reden vor dem Deutschen Bundestag der Abendlandbegriff nicht vor. Hier ist die Rede von »Europa«, nicht vom »Christlichen Abendland«. Anders jedoch verhält es sich in Veröffentlichungen und Verlautbarungen, die theologisch ausgerichtet waren oder sich zumindest an eine theologisch gebildete Öffentlichkeit wandten. Damit wird etwas von dem greifbar, was er meinte, wenn er in seiner Autobiographie ausführte, dass er sein Leben in zwei Reichen gelebt habe ${ }^{56}$, nämlich auf der einen Seite als Realpolitiker auf dem Feld innerweltlich motivierter Entscheidungen, Diplomatie und Politik, auf der anderen Seite in dem Bereich theologisch-ethischer Reflexion. Dass er den Gedanken des »Christlichen Abendlands« im Sinne eines Appells an die evangelischen Kreise aufarbeitete, hängt wohl mit seiner Vergangenheit unter den Nationalsozialisten zusammen. 1934 war er wegen eines von ihm in Gang gesetzten Protests der Rostocker Studenten gegen die Wahl des deutsch-christlichen Reichsbischofs Ludwig Müller zum ersten Mal verhaftet worden. Damit war eine akademische Laufbahn unmöglich geworden. Gerstenmaier begann, sich auf den Feldern der Ökumene zu engagieren ${ }^{57}$; 1942 hatte er sich dem Kreisauer Kreis angeschlossen, wurde nach dem gescheiterten Attentat auf Hitler verhaftet und zu sieben Jahren Zuchthaus verurteilt. Sein weiterer Lebenslauf, sein Weg in die Politik und auch sei-

machen«. Ebd., S. 41. Mülhaupts Mahnung zur Bescheidenheit erinnerte im gleichen Zuge auch daran, dass es letzten Endes nicht die Kirchen gewesen seien, die das Hitler-Regime beseitigt hätten. Nicht zuletzt habe auch das atheistische Russland zur Besiegung des Dritten Reiches entscheidend beigetragen. Vgl. ebd., S. 42.

55 Zur Biographie Gerstenmaiers vgl. Andreas MeIer, Eugen Gerstenmaier, in: Wolf-Dieter Hauschild (Hg.), Profile des Luthertums. Biographien zum 20. Jahrhundert, Gütersloh 1998, S. 185-201; Jochen Christoph KaISER, Art. Gerstenmaier, Eugen Karl Albrecht, in: Religion in Geschichte und Gegenwart 3 ( $\left.{ }^{4} 2000\right)$, Sp. 760; Matthias STICKLER, Art. Gerstenmaier, Eugen Karl Albrecht, in: Biographisch-bibliographisches Lexikon 19 (2001), Sp. 550-559.

$56 \mathrm{Vgl}$. Eugen Gerstenmaier, Streit und Friede hat seine Zeit. Ein Lebensbericht, Frankfurt/ Main ${ }^{2} 1982$, S. 13.

571937 hatte er z.B. die Weltkirchenkonferenz in Oxford mit vorbereitet, vgl. STickLer, Art. Gerstenmaier, Eugen, in: Biographisch-bibliographisches Lexikon 19 (2001), Sp. 552. 
ne zum Teil umstrittenen Haltungen sind bekannt ${ }^{58}$ und brauchen hier nicht rekapituliert zu werden. Wichtig ist an dieser Stelle lediglich, dass er vor dem Hintergrund seiner zurückliegenden Erfahrungen mit den Deutschen Christen einerseits und in der Bekennenden Kirche andererseits sowie im Widerstand gegen das totalitäre Hitler-Regime nun in dem Neuaufbau von Kirchenstrukturen und einer wieder zu belebenden ökumenischen Vernetzung die Chance und den Zeitpunkt erblickte, solche Werte zu etablieren, die einen erneuten Totalitarismus unmöglich machten und die die sittliche Autorität außerhalb des Staats und der politischen Ideologie seiner Machthaber ansiedelte bzw. an Grenzen metaphysischer Art zurückband. Dafür wurden ihm Geist und Tradition des »Christlichen Abendlands« zum Maßstab.

Gerstenmaier benutzte den Begriff des »Christlichen Abendlands« konfessionell völlig wertfrei. Zu greifen ist er z.B. in seinem Beitrag zu der Festschrift für den evangelischen Bischof von Berlin-Brandenburg Otto Dibelius, den er unter dem Titel »Die Christenheit in der Europapolitik der Gegenwart« veröffentlichte ${ }^{59}$. Hier entfaltete Gerstenmaier eine Europavision, die in den Kontexten der Politik, in denen er sich sonst bewegte, so nicht von ihm zur Sprache gebracht wurde. Deutlich korrigierte er die katholische Sicht, die die Glaubensspaltung für das Zerbrechen der Einheit Europas verantwortlich machte.

Weder die Reformation noch der Dreißigjährige Krieg haben die Einheit Europas und der Christenheit aufgehoben. Dieser Prozeß von grundstürzender Bedeutung wurde - auf das geschichtliche Ereignis gesehen - eingeleitet von der Französischen Revolution. Und er hat sich vollendet in unserer Generation in der Schaffung großer totalitärer Staatsgebilde mit erklärtermaßen un-, ja gegenchristlichen Staatsinhalten. An die Stelle der christlichen Einheit Europas ist die Vielfalt der einander oft schnurstracks zuwiderlaufenden Staatsideen und >Weltanschauungen getreten $^{60}$.

Dieses Geschichtsbild ermöglichte es ihm, das »Christliche Abendland« nicht im Sinne einer Mittelalter-Nostalgie zu definieren, sondern als Gegenbild zum totalitären Staat und als Matrix für sittliche Werte zu entwerfen. Mehrheitsentscheidungen bedurften seiner Ansicht nach einer sittlichen Rückbindung, um die Gefahr abzuwenden, dass sie - sich selbst legitimierend - totalitär missbraucht würden ${ }^{61}$. In diesem Zusammenhang konnte er durchaus

58 Vgl. dazu insgesamt Stickler, Art. Gerstenmaier, Sp. 550-559; außerdem Jochen-Christoph KAISER, Eugen Gerstenmaier in Kirche und Gesellschaft nach 1945, in: Wolfgang Huber (Hg.), Protestanten in der Demokratie. Positionen und Profile im Nachkriegsdeutschland, München 1990, S. 69-92.

59 Eugen Gerstenmaier, Die Christenheit in der Europapolitik der Gegenwart, in: Robert StuPPERICH (Hg.), Verantwortung und Zuversicht. Eine Festgabe für Bischof D. Dr. Otto Dibelius DD zum 70. Geburtstag am 15. Mai 1950, Gütersloh 1950, S. 157-178.

60 Ebd., S. 157

61 Vgl. ebd., S. 162. 
von der $»$ Begrenzung der Majestät der Zahl durch die Gebote Gottes ${ }^{62}{ }^{2}$ sprechen. Es ging ihm um die gerechte Eingrenzung von »Eigenwilligkeiten und Absolutheitsansprüche[n] mehr oder weniger zufälliger parlamentarischer Mehrheiten ${ }^{63}$. Und so erinnerte er daran, »daß die Verfassungen aller großen Demokratien der Welt bis heute von den Grundanschauungen bestimmt und geprägt sind, die vom Christentum auf dem Boden des Abendlands entwickelt und zur Geltung gebracht worden sind $\aleph^{64}$.

An dieser Grundstruktur kulturellen Lebens, Denkens und Handelns änderte seiner Ansicht nach auch die inzwischen eingetretene Abwendung vom Christentum und die Säkularisierung der christlichen Werte nichts ${ }^{65}$. Eine solche, aus der Tradition des Abendlandes sich herleitende »formale« Demokratie bedurfte nach Gerstenmaier aber der inhaltlichen Füllung durch die christlichen Kirchen. Und so richtete er die Aufforderung an die Christenheit Europas, den Grundsatz der »formalen« Rechtsgleichheit »material« im Sinne des Wichernschen Erbes durch ihr Eintreten für soziale Gerechtigkeit zu füllen, nicht zuletzt, um Europa über einen puren Interessenverband hinauszuheben ${ }^{66}$. Aber auch Kritik an den christlichen Kirchen, besonders in Deutschland, meldete er an, die ihm viel zu sehr in die Weltdistanz abgedriftet waren. Damit gab er dem Abendlandgedanken einen appellativen Charakter und nahm ihn im Sinne einer Mahnung an die kirchlichen und theologischen Kreise in Dienst, nämlich sich aktiv für die Konstruktion Europas einzusetzen. Dazu gehörte Mithilfe bei der Lösung dringender sozialer Aufgaben in Konzentration auf die Diakonie und unter Verzicht auf eigene Machtinteressen ebenso, wie die Revision überkommener theologischer Ordnungsbilder. Gerstenmaier forderte darüber hinaus eine ökumenische Tatgemeinschaft der christlichen Kirchen sozusagen als konkrete Realisierung des »Christlichen Abendlands«, zumal er ausdrücklich beide Konfessionen als Träger der abendländischen Tradition veranschlagte. Auf puren Verbalismus und in ein »frommes Biedermeiertum « dürfe sich auch der Protestantismus nicht zurückziehen, selbst wenn er sich primär als »Kirche des Wortes« verstehe. Denn, so Gerstenmaier:

So einfach ist die Welt des alten Abendlandes wiederum nicht, daß es im wesentlichen damit getan wäre, wohlgemeinte, von Sachkenntnis zuweilen nicht sehr getrübte Empfehlungen oder Forderungen in den Äther zu senden oder zu Papier zu bringen. Das nur intellektuelle oder bloß verbale Sichverhalten gegenüber harten, mühseligen, uns alle täglich beanspruchenden Aufgaben unseres öffentlichen Daseins kann nicht als

\footnotetext{
62 Ebd.

63 Ebd., S. 163.

64 Ebd.

65 Vgl. ebd., S. 167.

66 Vgl. ebd., S. 165-168.
} 
ausreichender Beitrag gewertet werden. Der Staat und die Staatsmänner sollten allenthalben dankbar sein für jeden guten Rat und sie sollten ihr Ohr willig den Ermahnungen der Kirche darbieten, sich zu den Geboten Gottes und seinen Ordnungen zu halten. Aber die Kirchen können nicht erwarten, daß einem bloß verbalen Verhalten ein Erfolg beschieden ist ${ }^{67}$.

Gerstenmaier hatte damit das »Christliche Abendland « als Identifikationsmuster für den Protestantismus stark gemacht und als Aufgabe der Kirchen in Korrelation zu einem politisch zu bauenden Europa gesetzt.

\section{Conclusio}

Unser Blick hat deutlich gemacht, wie inhomogen die Vision von einem »Christlichen Abendland" sowohl innerkonfessionell als auch im konfessionellen Spannungsfeld zwischen Katholizismus und Protestantismus ausfiel. Jede abschließende Zusammenfassung der divergierenden Positionen würde die Bandbreite der Deutungsmöglichkeiten wieder einebnen und dem schillernden Bild seine Farbigkeit nehmen. Dennoch lassen sich einige Konstanten erheben, selbst wenn die Gefahr unzulässiger Vergröberung naheliegt.

So ist z.B. auffällig, dass die protestantische Haltung zum Abendlandgedanken, angesichts von dessen katholischer Überformung, durchgehend eine zurückhaltende und eher kritische war. Nur zögerlich kam es zu einer Aneignung und zugleich inhaltlichen Transformation des Abendlandgedankens, den man von seiner Zentrierung auf eine religiös-kirchliche Einheit ablösen und auf eine religiös-konfessionelle Pluralität hin öffnen wollte. Dabei trat auch das unterschiedliche Geschichtsbewusstsein der beiden großen christlichen Konfessionen deutlich zu Tage. Der katholischen Seite diente das für eine europäische Einigung fruchtbar zu machende Leitbild eines "Christlichen Abendlands « der Revision eines konfessionellen status quo, den man seit der sogenannten Glaubensspaltung des 16. Jahrhunderts als Fehlentwicklung einstufte. Repräsentanten des Protestantismus postulierten demgegenüber eine bereits in der mittelalterlichen Kirche angelegte Tendenz zu religiöser Pluralität und werteten die in ihrer Perspektive bereits früh eingeleitete Säkularisierung von Politik, Gesellschaft und Wissenschaft als historische Errungenschaft. Das hatte zur Folge, dass der Einsatz für ein »Christliches Abendland « konfessionell unterschiedliche Stoßrichtungen entwickeln konnte. Dem katholischen Bemühen um eine wiederherzustellende »unitas ecclesiae« in den europäischen Gesellschaften traten im evangelischen Lager Reflexionen zur Seite, die diese »unitas « auf die Ebene ethischer Werte und sozialethischer Fragen hoben. Dieses Bild scheint sich

67 Vgl. ebd., S. 170-176, das Zitat S. 176. 
jedenfalls in den fünfziger Jahren des 20. Jahrhunderts zunächst abzuzeichnen. Dennoch ist Zurückhaltung in der Verallgemeinerung dessen geboten. Erst eine bei weitem flächendeckendere Aufarbeitung der konfessionell eingebundenen Stellungnahmen zum »Christlichen Abendland « vermag letzten Endes sichere Auskunft zu geben. 


\title{
Europa als Vorstellung und Arbeitsgebiet der westdeutschen Staatsrechtslehre nach 1945
}

\author{
»Ich bin in Europa« \\ (Jean Paul, 1796)
}

I.

Im Kanon der an juristischen Fachbereichen oder Fakultäten gelehrten Fächer, die mehr oder weniger überzeugend unter der großen Überschrift »Öffentliches Recht« versammelt werden, gehört »Europarecht« heute zu den gängigen Teilsdisziplinen. Europarecht wird gelernt und geprüft, entsprechend reich ist der Buchmarkt ${ }^{1}$. Habilitationen im Staats- und Verwaltungsrecht werden häufig mit der zusätzlichen Venia legendi für »Europarecht« ausgestattet. Man kann fast sagen, Europarecht gehöre zur Grundausstattung der heutigen Staatsrechtslehre. Angesichts der Verankerung der europäischen Integration im Grundgesetz, der praktischen Auswirkungen des Europarechts im Alltag sowie der hohen Bedeutung der Rechtsprechung des Europäischen Gerichtshofs in Luxemburg ist das auch nicht weiter verwunderlich. Wir sind »in Europa«, wenn auch in anderem Sinne als es sich Jean Paul in seinem Jugendwerk imaginierte 2 .

Die Etablierung des Europarechts im Kanon ist jedoch erst jüngeren Datums. In der geschilderten Breite hat sie sich erst in den letzten vierzig Jahren, ab etwa 1965, vollzogen. Gewiss hat es seit den frühen fünfziger Jahren

1 Hans-Wolfgang ARndt, Europarecht, Heidelberg ${ }^{8}$ 2006; Albert Bleckmann u.a., Europarecht, Köln ${ }^{6}$ 1997; Bengt Beutler / Roland Bieber / Jörn Pipkorn / Jochen Streil, Die Europäische Gemeinschaft. Rechtsordnung und Politik, Baden-Baden ${ }^{5} 2001$; Hans Georg Fischer, Europarecht, München 2005; Peter Fischer / Heribert Franz KöcK / Margit Maria Karollus, Europarecht. Recht der EU/EG, des Europarates und der wichtigsten anderen europäischen Organisationen, Wien ${ }^{4} 2002$; Waltraud HAKENBERG, Grundzüge des Europäischen Gemeinschaftsrechts, München ${ }^{3} 2003$; Matthias Herdegen, Europarecht, München ${ }^{10} 2008$; Peter M. Huber, Recht der europäischen Integration, München 22002; Christian KoENIG / Andreas Haratsch / Matthias Pechstein, Europarecht, Tübingen 52006; Helmut Lecheler, Einführung in das Europarecht, München 22003; Gert Nicolaysen, Europarecht I, Baden-Baden 22002; ders., Europarecht II, Baden-Baden 1996; Thomas Oppermann, Europarecht, München ${ }^{32005}$; Michael Schweitzer / Waldemar Hummer, Europarecht, Neuwied u.a. '2007; Rudolf Streinz, Europarecht, Heidelberg ${ }^{7} 2005$; Frank EMmERT, Europarecht, München 1996.

2 In der Fragment gebliebenen Satire »Biographische Belustigungen unter der Gehirnschale einer Riesin«, gedruckt 1796, lässt Jean Paul einen Duodez-Fürsten eine gewaltige »Jungfer Europa« aus Blei gießen, in deren Kopf der Dichter selbst seine Wohnung bekommt. Insofern war er »in Europa«. 
zahlreiche juristische Beiträge zur Montanunion, zum Europarat, zur Europäischen Verteidigungsgemeinschaft und zu der aus den römischen Verträgen von 1957 entstandenen Europäischen Wirtschaftsgemeinschaft gegeben. Aber ein breites akademisches Lehr- und Prüfungsfach »Europarecht " gab es damals nicht. Lange schien Europarecht ein Spezialgebiet zu bleiben, das man - wenn überhaupt - in der Praxis lernen konnte, wenn einen der berufliche Zufall an eine der europäischen Institutionen verschlug.

Insofern ist der Befund, dass man in der Juristenausbildung bis um 1965 zwar Rechts- und Verfassungsgeschichte, Rechtsvergleichung und Völkerrecht gründlich erlernen konnte, kaum aber Europarecht, erklärungsbedürftig. Warum, so könnte man fragen, erreichte die Materie so spät den Zustand wissenschaftlicher Professionalisierung?

Die Rechts- und Verfassungsgeschichte der frühen und mittleren Bundesrepublik konnte (jedenfalls theoretisch) hinreichend informieren über die Europa-Idee des Mittelalters, über die Fülle der verschiedenen Friedens- und Unionspläne in der Frühen Neuzeit, von den Träumen einer Universalmonarchie, den Vorschlägen des böhmischen Königs Georg Podiebrad, den französischen Ideen eines »Grand dessin« von Sully (1617), des Abbé de SaintPierre, von Rousseau und Saint-Simon ${ }^{3}$, der englischen Quäker William Penn und John Bellers ${ }^{4}$ bis zu Jeremy Benthams Plan for an Universal and Perpetual Peace (erstmals 1853), zu Kants Schrift über den Ewigen Frieden (1795), Krauses Entwurf eines europäischen Staatenbundes von 18145, also bis zum Wiener Kongress. Was in der Folgezeit an Versuchen, Europa zu einen, verzeichnet wird, gehört zur Ideengeschichte, Diplomatie- und Völkerrechtsgeschichte des 19. Jahrhunderts. Erinnert sei an die zahlreichen, meist etwas im Schatten des Interesses stehenden völkerrechtlichen Verwaltungsabkommen zur Flußschifffahrt, zum Fernmelde- und Postwesen, zum geistigen Eigentum und gewerblichen Rechtsschutz, zur Bekämpfung des Menschenhandels und der Prostitution, aber auch der internationale Pazifismus, die Frie-

3 Abbé De SAint-Pierre, Mémoire pour rendre la paix perpétuelle en Europe, o.O. 1712 (während der Utrechter Friedensverhandlungen); Henri DE SAINT-Simon / Augustin THIERRY, De la réorganisation de la société européenne ou de la necessité et des moyens de rassembler les peuples de l'Europe en un seul corps politique en conservant à chacun son indépendance nationale, Paris 1814; Jean-Jacques Rousseau, Project pour la paix perpétuelle, o.O. 1760.

4 William Penn, An Essay towards the Present and Future Peace of Europe, o.O. 1693 und ebenfalls Quäker John BelLers, Some reasons for a European State, o.O. 1710. Nachweise u.a. bei Kurt von Raumer, Ewiger Friede. Friedensrufe und Friedenspläne seit der Renaissance, München 1953 sowie in der Quellensammlung von Hans-Jürgen Schlochauer, Die Idee des ewigen Friedens. Ein Überblick über Entwicklung und Gestaltung des Friedenssicherungsgedankens, Bonn 1953.

5 Karl Christian Friedrich Krause, Entwurf eines europäischen Staatenbundes als Basis des allgemeinen Friedens und als rechtliches Mittel gegen jeden Angriff wider die innere und äußere Freiheit Europas, o.O. 1814 (Neuausgabe Leipzig 1920). 
densbewegung sowie die Entstehung und das Scheitern der im Wesentlichen europäischen Institution des Völkerbundes.

Die Linie führt dann in der Rechts- und Verfassungs- sowie in der allgemeinen Geschichte der Weimarer Zeit und des Nationalsozialismus auf ein Gebiet, das voller Europa-Ideen und Europa-Sehnsüchte steckt. Wie auf vielen anderen Gebieten der Geistesgeschichte führte auch hier der Zusammenbruch der alten Ordnungen des 19. Jahrhunderts im Ersten Weltkrieg zu einer Suche nach neuen Ordnungen. Die Frage, was nun Europa zusammenhalten könne, stellte sich in aller Schärfe. Die alten Klammern hielten nicht mehr, etwa die europäische Klammer des Hochadels und der Monarchien. Die ideologisierten Massen- und Technikkriege zerstörten die Bindungskraft des alten Völkerrechts, das gerade noch einmal in Den Haag kodifiziert worden war. Die großen Reiche, die sich gegenseitig befehdeten, aber auch stützten, brachen zusammen (Osmanisches Reich, Habsburg, Romanow) und entlieBen die vom »Selbstbestimmungsrecht« (Woodrow Wilson) beflügelten Nationalismen der kleinen Völker. Schließlich war auch die soziale Ordnung der bürgerlichen Welt des 19. Jahrhunderts am Ende. Das Zeitalter der Massen zog herauf. In dieser Situation schwärmte man in Deutschland viel von einem übernationalen kommenden »Reich«, das als neuer europäischer Hegemon wirken könne. Andere setzten auf ein Ende des Staates im internationalen Klassenkampf. Wieder andere hofften auf ein postnationales Europa.

Aus den vielen nationalistischen, nationalrevolutionären und sozialistischen Bewegungen jener Jahre wird als zukunftweisend stets die Paneuropa-Bewegung des Grafen Richard Nikolaus Coudenhove-Kalergi hervorgehoben $^{6}$. Daneben stehen die vielen Versuche der Zwischenkriegszeit, den erneut drohenden Zusammenbruch Europas politisch zu verhindern, etwa durch das Locarno-Abkommen 1925, den Briand-Kellog-Pakt 1928 und den Briand-Plan für eine europäische Föderation von 1929. Es ist bekannt, dass es zahlreiche zukunftsgerichtete Aktivitäten, Kongresse und schriftliche Appelle gab, die allesamt eine Vision von einer Art von Vereinigten Staaten von Europa hatten. Insgesamt werden 182 Einigungspläne bis 1945 gezählt $^{7}$. An sie hoffte man nach dem Ende des Kriegs anzuknüpfen ${ }^{8}$. Alles dies war jedoch noch wesentlich eine menschenfreundliche Idee, politische Überzeu-

6 Richard Nikolaus Graf Coudenhove-Kalergi, Pan-Europa, Wien 1923 warb für die »Vereinigten Staaten von Europa« (ohne England und Russland) und war in dieser Richtung auch nach 1945 aktiv.

7 Rolf Hellmut Foerster (Hg.), Die Idee Europa 1300-1946, München 1963; ders., Europa. Geschichte einer politischen Idee, München 1967 mit Bibliographie; weitere Nachweise bei Heinz Duchiardt / Małgorzata Morawiec / Wolfgang Schmale / Winfried Schulze (Hg.), EuropaHistoriker, 3 Bde, Göttingen 2006/2007.

8 Vgl. Hans Wehberg, Ideen und Projekte betreffend die Vereinigten Staaten von Europa in den letzten 100 Jahren, in: Die Friedenswarte 41 (1941), S. 49-120, ein wichtiges Kompendium von der Mitte des 19. Jahrhunderts bis in den Zweiten Weltkrieg. 
gungsarbeit sowie - am Rande - etwas Völkerrecht, das jedoch in den damaligen Juristischen Fakultäten zwar wegen seiner Weltläufigkeit bewundert, wegen des fehlenden Zwangscharakters aber auch als »Rechtsgebiet« nicht recht ernst genommen wurde. Von »Europarecht« konnte keine Rede sein.

1. Auch nach dem Zusammenbruch des NS-Staates gab es zunächst noch kein »Europarecht«, wohl aber intensive Bemühungen, Europa zu schaffen. Herausragend war Churchills Züricher Rede vom 19. September 1946, in der nun mit großem Widerhall zur Schaffung der Vereinigten Staaten von Europa aufgerufen wurde, auf der Basis einer Aussöhnung von Frankreich und Deutschland, aber ohne Russland und England. Ebenso wichtig wurde die Rede von Staatssekretär George Marshall an der Harvard Universität vom 5. Juni 1947, die 1948 zur Organisation für wirtschaftliche Zusammenarbeit (OEEC) führte. Gewiss nahmen auch Juristen an den zahlreichen privaten und halböffentlichen Aktivitäten zugunsten des Europagedankens teil ${ }^{9}$, etwa der Europa-Union ${ }^{10}$ oder dem von Churchill präsidierten Europa-Kongress in Den Haag von 1948, der 1949 den Straßburger Europarat hervorbrachte ${ }^{11}$. Aber diese Teilnahme von Juristen war immer noch schmal und nur an wenigen Punkten professioneller Juristenarbeit verankert. Europarecht gab es noch nicht, Europa war immer noch eine Idee, aber sie war auf dem Höhepunkt des Kalten Krieges längst im Kalkül der Macht angekommen ${ }^{12}$.

Mustert man die Bücher und Aufsätze der Besatzungszeit und etwa der ersten beiden Jahre der Bundesrepublik, dann sieht man, wie fern Europa in

9 Wilhelm CoRnides, Die Anfänge des europäischen föderalistischen Gedankens in Deutschland 1945-1949, in: Europa-Archiv 6 (1951), S. 4243-4258; Ellinor von PutTKamer, Historische Pläne europäischer Verfassungsbildung, in: Völkerrechtliche und Staatsrechtliche Abhandlungen Carl Bilfinger zum 75. Geburtstag am 21. Januar 1954, Köln / Berlin 1954, S. 345-369.

10 Auf der Vorarbeit vieler einzelner Gruppen in Italien, Frankreich, Schweiz und England 1946 gegründet als Union Europäischer Föderalisten (UEF), Europa-Union. Vorsitzender in Deutschland war der Landrat Wilhelm Heide, Geschäftsführer der Fabrikant Wilhelm Hermes (eingehend hierzu CoRnIDEs, Die Anfänge des europäischen föderalistischen Gedankens in Deutschland, S. 4243-4258). Auf Heide folgten zahlreiche bekannte Persönlichkeiten, so 1949 zunächst Eugen Kogon, dann in den letzten Jahrzehnten Walter Scheel, Egon A. Klepsch, Hans-Gert Pöttering sowie ab 1999 Elmar Brok.

11 Karl Carstens, Europarat, in: Karl Strupp / Hans Jürgen Schlochauer (Hg.), Wörterbuch des Völkerrechts, Bd. I, Berlin 1960, S. 494-497. Der Europarat begann mit 10 Mitgliedern, zu denen 1950/51 die Bundesrepublik hinzukam. Seine »Verfassung« ist die Europäische Konvention zum Schutz der Menschenrechte (EMRK) von 1950, seine Organe sind die Europäische Kommission für Menschenrechte und der Europäische Gerichtshof für Menschenrechte.

12 Volkmar Gessner / David Nelken (Hg.), Cold War Law: Legal Entrepreneurs and the Emergence of a European Legal Field, Oxford / Portland, Oregon 2007. 
diesen Jahren noch lag. Die Perspektive des deutschen Staatsrechts erlaubte nur die Wahrnehmung der nächsten und dringendsten Probleme. Beginnt man mit dem Privaten, dann ging es zunächst um Ernährung und Wohnung, um das einfache Überleben ${ }^{13}$. Professoren hatten wie alle anderen das Entnazifizierungsverfahren zu durchlaufen und kamen durchweg mit den Noten »nicht belastet« oder »Mitläufer« durch ${ }^{14}$. Von etwa 80 Personen waren nur zwei im aktiven Widerstand oder in dessen unmittelbarer Nähe (Hans Peters, Christian-Friedrich Menger). Eine nicht kleine Zahl hatte sich vom Nationalsozialismus ferngehalten, etwa Rudolf Smend, Richard Thoma, Friedrich Giese, Rudolf von Laun, Ernst Friesenhahn oder Otto Bachof. Von den NS-Opfern kehrten einige wieder an die Universitäten zurück (Erich Kaufmann, Walter Jellinek, Hans Nawiasky, Gerhard Leibholz, Erwin Jacobi), andere bildeten eine eindrucksvolle erste Besetzung des Bundesverfassungsgerichts.

Was diese Juristen zunächst beschäftigte, war aber keineswegs Europa. Es ging um die dringendsten Sorgen der Reorganisation des öffentlichen und privaten Lebens. Deutschland war internationaler Paria - aus Gründen, die den meisten erst jetzt voll deutlich wurden. Das Land war besetzt und nicht souverän. Die Wirtschaft lag am Boden, die Infrastruktur weitgehend zerstört. Die Heimatvertriebenen und Flüchtlinge waren zu integrieren. Die juristischen Probleme des Tages lagen auf der Hand: Wie war die Gesetzgebung des Kontrollrats bis 1948 einzuordnen? Nach welchem Muster war die Rechtspflege in den Besatzungszonen und den dort entstehenden Bundesländern aufzubauen? ${ }^{15}$ Auf welchen Rechtsgrundlagen beruhte die Wohnraumund Lebensmittelbewirtschaftung der ersten Nachkriegsjahre? Wie stand es um den Wiederaufbau der Verwaltungs-, Finanz-, Sozial- und Arbeitsgerichtsbarkeit? Relativ wenig beachtet werden die Nürnberger Prozesse.

Die Völkerrechtler erörterten auf ihren ersten Sitzungen im Hamburger Institut von Rudolf von Laun »Deutschlands Rechtslage «16. Man fragte nach dem Untergang oder Fortbestand des Reichs, nach der Beendigung des Kriegszustands und der Anwendbarkeit der Haager Landkriegsordnung,

13 CoRnidEs, Die Anfänge des europäischen föderalistischen Gedankens in Deutschland, S. 42434258, bestätigt dies durch den Hinweis auf die Untersuchung eines amerikanischen Anthropologen, David Rodnick, der zur Jahreswende 1945/46 1500 Deutsche nach ihrem Interesse an »Europa« befragt hatte. Das Interesse war äußerst gering, während es drei Jahre später schon breite Schichten erfasst hatte.

14 Walter Pauly, Die Entnazifizierung. Leitideen und Praxis, in: Bernhard Diestelkamp / Zentarô Kitagawa u.a. (Hg.), Zwischen Kontinuität und Fremdbestimmung. Zum Einfluß der Besatzungsmächte auf die deutsche und japanische Rechtsordnung 1945 bis 1950. Deutsch-japanisches Symposion in Tokio vom 6.-9. April 1994, Tübingen 1996, S. 329-348.

15 Michael Stolleis, Rechtsordnung und Justizpolitik 1945-1949, in: Festschrift für Helmut Coing, Bd. 1, München 1982, S. 383-407.

16 Rolf STÖDTER, Deutschlands Rechtslage, Hamburg 1948. 
nach dem Rechtscharakter der alliierten Okkupationsgewalt und deren Überführung in ein beiderseits akzeptiertes Besatzungsstatut. Hinter diesen Themen verbarg sich eine Fülle praktischer Probleme, etwa die Regelung der Auslandsschulden, die Restitution von Vermögen und Gütern aller Art, die Anfänge der sog. Wiedergutmachung, schrittweise Rückkehr in den Kreis der europäischen Nationen. Nur aus dieser Perspektive war Europa eine Art Hoffnungshorizont, den man zu erreichen hoffte. Natürlich war Europa das »westliche Europa«. In der Hochphase des Kalten Kriegs zwischen dem Ende des Kontrollrats 1948, dem Korea-Krieg 1952, Stalins Tod 1953 bis zu den ersten Lockerungen durch Chruschtschow auf dem XX. Parteitag der KPdSU kam das »ganze Europa« nicht mehr in den Blick. Europa war scheinbar definitiv geteilt, sowohl ökonomisch als auch militärisch. Alte europäische Kulturlandschaften wie diejenigen Polens, Ungarns und Böhmens gerieten mehr und mehr in Vergessenheit. Im Westen erinnerten nur die Vertriebenenverbände daran, die aber selbst zu politischen Hypotheken wurden, soweit sie sich der Akzeptierung der Ergebnisse des Weltkriegs verweigerten.

Zwei weitere Faktoren können zur Erklärung dieser anfänglichen staatsrechtlichen Blindheit gegenüber Europa dienen. Zunächst die einfache Tatsache, dass die Generation derjenigen, die in den fünfziger Jahren aktiv waren, in ihrer Mehrzahl kaum Chancen gehabt hatten, sich Sprachen anzueignen und zu reisen. Die dreißiger und vierziger Jahre mit Inflation, Weltwirtschaftskrise und Abriegelung durch die NS-Zeit standen dem entgegen. Viele wissenschaftliche Verbindungen waren abgerissen. Man fühlte sich unsicher auf internationalem Parkett, zumal bei individueller NS-Belastung, die auch bei den Völkerrechtlern nicht selten war ${ }^{17}$. Der zweite hemmende Faktor, sich alsbald Europa zuzuwenden, liegt in der professionellen Einstellung von Juristen, sich einer Sache erst zu widmen, wenn sie verbindlichen normativen Charakter angenommen hat. Dann kann der Jurist tun, was er gelernt hat: Die Normen in eine Hierarchie bringen und sie zum Teil eines Systems machen, sie auslegen - sei es generell, sei es im Hinblick auf einen konkreten Fall -, ihre Vereinbarkeit mit höherrangigem Recht prüfen und Normkollisionen lösen. Mit anderen Worten: »Juristen als solche« befinden erst auf ihrem eigentlichen Terrain, wenn Normen vorhanden sind. Die in den ersten Jahren nach 1945 sich ausbreitende sogenannte Naturrechtsrenaissance widerspricht diesem Befund nicht. Sie war eher eine Frage rechtsphilosophischer Grundlagendiskussionen. Sie erweckte vordergründig den Eindruck eines prinzipiellen wertphilosophischen Neubeginns, diente aber eher der Camouflage methodischer Kontinuitäten und der Neubenennung eines Antipositivismus,

17 Michael Stolleis, Against Universalism. German International Law under the Swastika: Some Contributions to the History of Jurisprudence 1933-1945, in: German Yearbook of International Law 50 (2007), Berlin 2008, S. 91-110. 
der besonders intensiv gerade nach 1933 ausgerufen worden war. Konkretere Spuren hat sie nur in einigen Gerichtsentscheidungen zum Familienrecht und Strafrecht hinterlassen, kaum jedoch im Staats- und Verwaltungsrecht ${ }^{18}$.

Trotz aller Bekenntnisse, der Positivismus sei »überwunden«, setzte dieser sich faktisch wieder in der Weise durch, dass das Besatzungsrecht, das Recht der neuen Bundesländer und der gerade gegründeten Bundesrepublik ihre Anerkennung forderten und bekamen. Die Legitimität dieses Rechts stand außer Zweifel. Es bestand kein Anlass, es durch Berufung auf Naturrecht zu schwächen. Bald kam auch die Rechtsprechung des Bundesverfassungsgerichts hinzu, die kontinuierlich und verbindlich Normwidersprüche auflöste, also diejenige kritische Funktion wahrnahm, die bis zum 19. Jahrhundert dem Naturrecht zukam. Trotz aller Kritik im Detail war die Akzeptanz dieser Rechtsprechung so stark, dass man von »Verfassungsgerichtspositivismus « sprach und die sukzessive Unterordnung der Rechtswissenschaft unter das Bundesverfassungsgericht beobachtete. Tatsächlich konzentrierten sich die Kräfte der Wissenschaft immer mehr darauf, die Entscheidungen zu kommentieren und systematisch zu verorten. Am Ende konnte dann rückblickend von der »Entthronung der Staatsrechtswissenschaft« gesprochen werden ${ }^{19}$. Das war die praktische Seite. Erst als die Ächtung des Positivismus seit den sechziger Jahren des 20. Jahrhunderts wieder nachließ und die ersten Arbeiten über Kelsen Gehör fanden, setzte sich allmählich auch theoretisch die Einsicht durch, dass der Positivismus die der Demokratie angemessene Rechtstheorie sein könnte ${ }^{20}$.

2. Man kann deshalb - im Anschluss an Ophüls - sagen, dass die wissenschaftliche Arbeit der westdeutschen Staats- und Völkerrechtler am werdenden Europarecht zunächst vom politisch gelenkten Werden dieses Europarechts selbst bestimmt wurde ${ }^{21}$. Zeichnete sich eine neue Stufe der westeuropäischen Integration ab, waren auch die Juristen in diplomatischen und administrativen Funktionen sofort zur Stelle, um sich der neuen Normen an-

18 Siehe aber Art. 1 Abs. 3 der Verfassung von Rheinland-Pfalz v. 18. Mai 1947: »Die Rechte und Pflichten der öffentlichen Gewalt werden durch die naturrechtlich bestimmten Erfordernisse des Gemeinwohls begründet und begrenzt«. Zum »Vater« dieser Verfassung siehe Winfried Baumgart / Adolf Süsterhenn (1905-1974), in: Jürgen Aretz / Rudolf Morsey / Anton RauSCHER (Hg.), Zeitgeschichte in Lebensbildern, Bd. 6, Mainz 1984; Helmut MATHY, Das Porträt Adolf Süsterhenn (1905-1974), in: Geschichte im Westen 3 (1988), S. III. Siehe etwa Adolf SüsterhENN / Vinzenz RÜFNER, Wir Christen und die Erneuerung des staatlichen Lebens, Bamberg 1948; Adolf SüsterhenN, Die naturrechtlichen Grundlagen der internationalen Zusammenarbeit, Wiesbaden 1949; ders., Christlicher Geist in der Europäischen Gemeinschaft, Köln 1953.

19 Bernhard Schlink, Die Entthronung der Staatsrechtswissenschaft durch die Verfassungsgerichtsbarkeit, in: Der Staat 11 (1989), S. 161-172.

20 Horst Dreier, Rezeption und Rolle der Reinen Rechtslehre, Wien 2001, S. 27-34.

21 Carl Friedrich OpHüls, Staatshoheit und Gemeinschaftshoheit. Wandlungen des Souveränitätsbegriffs, in: Recht im Wandel. Festschrift Heymanns Verlag, Köln 1965, S. 519-590, hier: S. 541 mit Aufzählung der wichtigsten Autoren. 
zunehmen. Die Architekten des Neubaus waren seine ersten Kommentatoren. In diesem Sinne wurden die Ingangsetzung des Marshall-Plans 1947, die Gründung der OEEC 194822, die regionalen Zusammenschlüsse (Benelux, Nordischer Rat, RGW bzw. Comecon), der verfrühte und deshalb gescheiterte Versuch einer europäischen Verteidigungsgemeinschaft (EVG 19521954) ${ }^{23}$, die schrittweise Erweiterung der NATO, insbesondere der Beitritt der Bundesrepublik 1955, vor allem aber die Gründung der Montan-Union ${ }^{24}$ von juristischen Experten des Kanzleramts, Auswärtigen Amtes und des Wirtschaftsministeriums begleitet, etwa von Erich Kaufmann und Hermann Mosler, Walter Hallstein, Franz Etzel, Carl Friedrich Ophüls, Hans von der Groeben, Karl Carstens, Paul Barandon, Wilhelm G. Grewe, Heinz Haedrich, Hugo J. Hahn, Hans-Jürgen Schlochauer, Ulrich Everling und vielen anderen ${ }^{25}$. Unter ihnen waren besonders viele Völkerrechtler. Sie verstanden, aus der damaligen Sicht ganz überzeugend, das primäre Gemeinschaftsrecht als zwischenstaatliches Völkerrecht ${ }^{26}$. Völkerrechtliche Verträge aber mussten, auch wenn sie innereuropäischer Natur waren, über Art. 59 Abs. 2 GG

22 Raymond Poidevin (Hg.), Histoire des Débuts de la construction Européenne (mars 1948-mai 1950), Brüssel 1986.

23 Heinz Haedrich, Europäische Verteidigungsgemeinschaft, in: Strupp / Schlochauer, Wörterbuch des Völkerrechts, Bd. I, S. 477-479.

24 Dietmar Petzina, The Origin of the European Coal and Steel Community: Econonomic Forces and Political Interests, in: Zeitschrift für die gesamte Staatswissenschaft 137 (1981), S. 450468 mit ausführlicher Bibliographie.

25 Hermann Mosler, Die europäische Integration aus der Sicht der Gründungsphase, in : Ole Due / Marcus LutTer / Jürgen Schwarze (Hg.), Festschrift für Ulrich Everling, Bd. II, Baden-Baden 1995, S. 911-924. Die zahlreichen und wichtigen Publikationen von Ulrich Everling, (siehe Festschrift, Bd. II, S. 1729-1742) dokumentieren die für die Entstehung des Europarechts besonders fruchtbare Kombination von politischem Beamten (1970 bis 1980 als Leiter der Europaabteilung in Bonn), Richter am Europäischen Gerichtshof sowie Universitätslehrer in Mainz, Münster und Bonn. Gleiches gilt für die Beamten- und Diplomatenkarriere von Carl Friedrich Ophüls (Abteilungsleiter für Europafragen, Auswärtiges Amt, Honorarprofessor in Frankfurt, Botschafter).

26 Siehe etwa den inhaltsreichen Überblick über den gesamten Weg der Integration bis zur Montan-Union Hans Jürgen Schlochauer, Von der Association zur Integration Europas, in: Die Friedens-Warte 52 (1953/55), S. 1-18; ders., Der übernationale Charakter der Europäischen Gemeinschaft für Kohle und Stahl, in: JuristenZeitung 6 (1951), S. 289-290, hier: S. 289; Josef Laurenz Kunz, Supra-National-Organs, in: American Journal of International Law 46 (1952), S. 690-698, hier: S. 697; Herman Mosler, Die Wendung zum supranationalen Gedanken im Schumann-Plan, in: Recht, Staat, Wirtschaft 3 (1951), S. 245-259, der die wachsende Distanz zu staats- und völkerrechtlichen Kategorien genau beobachtete; Carl Friedrich OphÜLs, Europäischer Bundesstaat, in: Die Gegenwart 135 (1951), S. 25-29; Ernst SteindorfF, SchumannPlan und Europäischer Bundesstaat, in: Europa Archiv 6 (1951), S. 3955-3960; Helmut RidDER, Der Entwurf einer Satzung der Europäischen Gemeinschaft, in: JuristenZeitung 8 (1953), S. 289; Günther JAENICKE, Die Europäische Gemeinschaft für Kohle und Stahl, in: Zeitschrift für ausländisches Öffentliches Recht und Völkerrecht 14 (1951/52), S. 727-788; ders., Bundesstaat oder Staatenbund. Zur Rechtsform einer europäischen Staatengemeinschaft, in: Festschrift für Carl Bilfinger, o.O. 1954, S. 71-109; Rudolf L. BindschedLER, Rechtsfragen der Europäischen Einigung. Ein Beitrag zu der Lehre von den Staatenverbindungen, Basel 1954. 
in Staatsrecht transformiert werden. Erst allmählich wurde Art. 24 Abs. 1 GG (Übertragung von Hoheitsrechten) als der für den Bau des europäischen Hauses beste Weg anerkannt - eine These, die unter den Akteuren des Integrationsprozesses schon früh vertreten worden ist ${ }^{27}$.

Gegenstände des enormen Interesses der Völkerrechtler, die gewissermaßen mit den werdenden Gemeinschaften zu Europarechtlern wurden, waren der »Europarat« (1949) als erster Zusammenschluss zur Sicherung der Menschenrechte und Grundfreiheiten ${ }^{28}$, dann aber vor allem die SechserGemeinschaft der »Montan-Union« von 1951 (Europäische Gemeinschaft für Kohle und Stahl ${ }^{29}$, an welcher der Bundesrepublik viel gelegen war, weil sie in einem Teilbereich das Besatzungsstatut und das Ruhrstatut ablösen und Deutschland den Weg zu einer gleichberechtigten Stellung ebnen sollte. Ebenso lag Frankreich an einer Einbindung Deutschlands in ein europäisches Konzept. »Das Ergebnis war ein neuartiges völkerrechtliches Gebilde mit Institutionen, die dem Staatsrecht entlehnt waren $\ll^{30}$. Zugleich dachten aber Robert Schumann mit seinem legendären »Schumann-Plan«, Alcide de Gasperi, Paul Henri Spaak, Jean Monnet, Konrad Adenauer und Walter Hallstein schon an eine erste Etappe der Europäischen Föderation ${ }^{31}$. Trotz der Nichtbeteiligung Englands an der Montan-Union und trotz des spektakulären Scheiterns der Europäischen Verteidigungsgemeinschaft 1954 woll-

27 Carl Friedrich OphüLs, Juristische Grundgedanken des Schumannplans, in: Neue Juristische Wochenschrift 4 (1951), S. 289-291, der von der »Europäischen Gemeinschaft« als einem supranationalen »bundesstaatsähnlichen Gebilde« mit eigenen Hoheitsrechten spricht. Es sei etwas geschaffen worden, »das auch in seiner juristischen Formung aus dem Rahmen des Bisherigen hinaustritt«. Auch Hans-Jürgen SCHLOCHAUER, Rechtsformen der europäischen Ordnung, in: Archiv des Völkerrechts 5 (1955/56), S. 40-62 spricht von einer »Strukturwandlung des Völkerrechts«, das sich in der »Organization for European Economic Cooperation« (OEEC), der Europäischen Zahlungsunion (EZU) und der Gemeinschaft für Kohle und Stahl (Montanunion) ausdrücke. Letztere stelle »einen Übergang vom internationalen Funktionalismus zum verfassungsrechtlichen Institutionalismus dar und zeigt übernationalen Charakter« (S. 61). Zu letzterem Punkt ders., Der übernationale Charakter der Europäischen Gemeinschaft für Kohle und Stahl, in: JuristenZeitung 6 (1951), S. 289-290.

28 Hierzu Herman MosLer, Kritische Bemerkungen zum Rechtsschutzsystem der Europäischen Menschenrechts-Konvention, in: Karl Carstens / Hans Peters (Hg.), Festschrift Hermann Jahrreiss, Köln 1964, S. 289-317; Ulrich Scheuner, Die Grundrechte der Europäischen Menschenrechts-Konvention in ihrer Anwendung durch die Organe der Konvention, in: ebd., S. 355-384.

29 Gerhard BeBr, The European Coal and Steel Community: A Political and Legal Innovation, in: The Yale Law Journal 63 (1953), S. 1-43; Paul Reuter, La Communauté Européenne de Charbon et de l'Acier, Paris 1953; Ernst SteindorfF, Europäische Gemeinschaft für Kohle und Stahl, in: Strupp / Schlochauer, Wörterbuch des Völkerrechts, Bd. I, S. 458-466. - Die Bibliographie zum Schumann-Plan für die Jahre 1950-52 (Frankfurt, Institut für europäische Politik und Wirtschaft, 1953) wies 1303 Titel auf.

30 Mosler, Die europäische Integration aus der Sicht der Gründungsphase, S. 923.

31 Klaus Schwabe (Hg.), Die Anfänge des Schumann-Plans, Baden-Baden 1988; Pascal Fondaine, Eine neue Ordnung für Europa. 40 Jahre Schumann-Plan, Luxemburg 1990; Hans vON DER Groeben, Deutschland und Europa in einem unruhigen Jahrhundert. Erlebnisse und Betrachtungen, Baden-Baden 1995. 
te man die Integration weiter voranbringen. Paul Henri Spaak war der eigentliche Anreger eines Memorandums der Beneluxstaaten, das dann zur Konferenz von Messina am 1. Juni 1955 führte $^{32}$. Der wiederum hieraus entstandene Spaak-Bericht von 1956 bildete die Grundlage für die Vorarbeiten zu den Römischen Verträgen von 1957. Die Einzelheiten dieses zentralen politischen Ereignisses, einschließlich der Lösung der Saarfrage, sind vielfach geschildert worden ${ }^{33}$. Nicht nur den Beteiligten, sondern auch der europäischen Öffentlichkeit war klar, dass »Europa« von nun an eine neue Qualität besitzen würde. Für die deutsche Staatsrechtslehre war die Bundesrepublik mit dem Ende des Besatzungsregimes durch die Pariser Verträge von 1955 souverän geworden, mit den Römischen Verträgen von 1957 wurde sie endgültig im westlichen Europa verankert. Entsprechend breit war die Akzeptanz des Vertragswerks im Bundestag ${ }^{34}$. Von nun an gab es mit Kommission, Ministerrat, Parlament und Gerichtshof neue Institutionen, an deren staats- oder völkerrechtlicher Qualifikation man sich noch lange abmühen sollte, bis sich allmählich Europarecht als eigene Kategorie durchsetzte ${ }^{35}$.

Die folgenden Jahre waren von europäischem Optimismus und einem Willen zur Ausfüllung der Verträge bestimmt. Man erwartete eine gegenseitige Stimulierung des freien Warenverkehrs, der Freizügigkeit und des Agrarmarkts, so dass an ein Zurück in voreuropäische Nationalismen nicht mehr möglich schien. Wesentliches Bauelement war das »Recht«, sowohl in der Politik der Kommission als auch in der Rechtsprechung des Europäischen Gerichtshofs, der den Vorrang des europäischen Rechts bei Kollisionen mit staatlichem Recht durchsetzte. Die EWG, wie sie damals noch hieß, sollte laut Walter Hallstein ${ }^{36}-»$ Rechtsgemeinschaft« werden . Auch die »europäische Rechtsgeschichte« entdeckte hier erstmals eine Chance $^{37}$. Dieser Op-

32 Paul-Henri SpaAk, The Integration of Europe. Dreams and Realities, in: Foreign Affairs 29 (1950/51), S. 94-100.

33 Grundlegend Hans-Jürgen KüsTERs, Die Gründung der Europäischen Wirtschaftsgemeinschaft, Baden-Baden 1982; Hans von der Groeben, Aufbaujahre der EG, o.O. 1982; ders., Deutschland und Europa, S. 251-292.

34 Die Annahme erfolgte am 5. Juli 1957 mit den Stimmen von CDU/CSU, DP und SPD, während FDP und BHE dagegen stimmten.

35 Die Texte zu diesen Vorgängen finden sich nun in den Bänden Rainer Schulze / Thomas HoeREN (Hg.), Dokumente zum Europäischen Recht, Bd. 1: Gründungsverträge, Berlin u.a. 1999; dies. (Hg.), Dokumente zum Europäischen Recht, Bd. 2: Justiz (bis 1957), Berlin u.a. 2000; dies. (Hg.), Dokumente zum Europäischen Recht, Bd. 3: Kartellrecht, Berlin u.a. 1999. Eine neue zusammenfassende Darstellung bei Antonio GriLli, Le origini del diritto dell'Unione europea, Bologna 2009.

36 Walter HallsteIn, Der unvollendete Bundesstaat. Europäische Erfahrungen und Erkenntnisse, Düsseldorf 1969; siehe auch Manfred ZuleEg, Die Europäische Gemeinschaft als Rechtsgemeinschaft, in: Neue Juristische Wochenschrift 9 (1994), S. 545-547.

37 Die Gründung des Max-Planck-Instituts für europäische Rechtsgeschichte im Jahr 1964 ist dem Rechtshistoriker und Privatrechtler Helmut Coing (1912-2000) zu verdanken. Seine Grundidee 
timismus wurde aber durch De Gaulles sowohl antienglische als auch antiintegrative Politik eines »Europa der Vaterländer« für mehr als ein Jahrzehnt gebremst. Frankreich gebrauchte dreimal sein Veto gegen eine Einbeziehung Englands $(1958,1963,1967)$ und es verhinderte eine Wiederwahl Hallsteins. Erst 1969 gelang es, den (1973 vollzogenen) Beitritt Englands, Dänemarks und Irlands durchzusetzen, und von da an gewann die Integrationspolitik neue Dynamik. Fasst man alle diese Entwicklungen zusammen und sieht sie als Geschichte einer werdenden europäischen Verfassung, dann kann man in der Tat von »Ansätzen zu einer Verfassungsgeschichte der Europäischen Union« sprechen $^{38}$.

III.

An diese bekannten Vorgänge bis zum Ende der sechziger Jahre wird hier nur erinnert, um zu unterstreichen, dass sich die Juristischen Fakultäten in dem Jahrzehnt nach Abschluss der Römischen Verträge schrittweise und zunehmend für eine Aufnahme des Europarechts in ihr Curriculum öffneten, und zwar, wenn man den Kennern der Szene, Ophüls, Mosler und Ipsen folgt, ziemlich genau ab $1963^{39} .1964$ drängte Hans Peter Ipsen in seinem Schlussvortrag Der deutsche Jurist und das Europäische Gemeinschaftsrecht auf dem 45. Deutschen Juristentag, die Juristen sollten sich der Materie intensiver annehmen. Die »Vereinigung der Deutschen Staatsrechtslehrer«, die bis dahin über die Rechtslage Deutschlands, den Rechts- und Sozialstaat, die auswärtige Gewalt, die Verfassungsgerichtsbarkeit und vieles andere aus dem klassischen Kanon des Staats- und Verwaltungsrechts diskutiert hatte, hatte das Europa-Thema erstmals 1959 auf einer Tagung in Erlangen umge-

lag darin, das mittelalterliche und frühneuzeitliche »ius commune« als ein verbindendes Element Europas wieder ins Bewusstsein zu heben, weniger um der europäischen Rechtsvereinheitlichung zuzuarbeiten als um die Breite und Tiefe der europäischen Rechtskultur zu erforschen.

38 Manfred ZuleEg, Ansätze zu einer Verfassungsgeschichte der Europäischen Union, in: Zeitschrift für Neuere Rechtsgeschichte 19 (1997), S. 270-280.

39 Hans Peter IPSEN, Europäisches Gemeinschaftsrecht im Hochschulstudium, in: Neue Juristische Wochenschrift 25 (1964), S. 961-964 berichtet über die institutionellen Voraussetzungen, Europarecht an deutschen Universitäten sowie im Ausland zu studieren, empfiehlt eine intensivere Beschäftigung erst nach Erlangung der juristischen Grundlagen und sieht das Schwergewicht eher im Referendardienst, in den Wahlstationen und/oder in einer entsprechenden Dissertation. Abschließend hält er fest, dass die Westdeutsche Rektorenkonferenz »hinhaltenden Widerstand « gegen die Schaffung der Europa-Universität in Florenz/Fiesole geleistet habe. Auch Ophüls (Staatshoheit und Gemeinschaftshoheit, S. 543 Anm. 71) weist auf die Tagungen in Köln und Den Haag von 1963 hin, weiter auf die Kolloquien in Bensheim 1964 sowie in Brüssel 1965, S. 543 Anm. 71. 
hend nach Abschluss der Römischen Verträge behandel $t^{40}$. Die Referate blieben jedoch in den Bahnen des Staats- und Völkerrechts, indem sie fragten, welche Grenzen das deutsche Verfassungsrecht der Übertragung von Hoheitsrechten auf supranationale Einrichtungen gezogen habe. 1964, also relativ rasch, kam dann die Vereinigung in Kiel nochmals darauf zurück und konnte nun schon auf einem erheblich breiteren Fundament von Literatur und mit einer für Europa offeneren Perspektive diskutieren ${ }^{41}$. Hans Peter Ipsen registrierte hierbei einen »bedeutenden Erkenntnissprung $«{ }^{42}$ und stellte im Rückblick fest:

Von Erlangen (18 - 1959) bis Kiel (23 - 1964) schlägt sich schon in der Fragestellung, vornehmlich aber in der grundsätzlichen Einlassung zur Integration ein Wandlungsprozess nieder, der vom Scheitern der EVG über die Römischen Verträge zu ihrem Stufenvollzug reicht und das ursprüngliche Postulat struktureller Homogenität zwischen Staats- und Gemeinschaftsverfassung in der Kieler Formulierung in Frage stellt: ob sich demokratische und rechtsstaatliche Verfassungsstruktur in den internationalen Gemeinschaften bewahren lasse oder Veränderungen erfahre, erfahren müsse, erfahren dürfe $\mathrm{e}^{43}$.

Im engeren Sinn europarechtliche Tagungen der Staatsrechtslehrer gab es dann in den folgenden beiden Jahrzehnten nur noch zweimal ${ }^{44}$. Auf ihnen zeigten sich in Referaten und Diskussionen gewisse Eigentümlichkeiten gerade des deutschen Umgangs mit dem Europarecht, etwa die starke Betonung der Grundrechtsproblematik ${ }^{45}$. Wie anstelle des Patriotismus nun der »Verfassungspatriotismus« breite Akzeptanz fand, so trat an die Stelle des »Nationalstaats« der »Verfassungsstaat«, von dem ausgehend man nun die Konsequenzen der voranschreitenden europäischen Integration auszumessen suchte. Im Gefolge dieser allmählichen semantischen Umstellung fragte man nach dem Grundprinzipien des Verfassungsstaats und ihrer Realisierung in Brüssel, Luxemburg und Straßburg (Souveränität und Souveränitätsverluste, Gewaltenteilung und Balance zwischen starker Exekutive, schwachem Parlament und zunehmend starker Judikative). Auch wenn der europäische In-

40 Erlangen 1959: Georg ErLeR / Werner Thieme (Hg.), Das Grundgesetz und die öffentliche Gewalt internationaler Staatengemeinschaften, Berlin 1960, S. 7-80.

41 Kiel 1964: Joseph H. KaISER (Hg.), Bewahrung und Veränderung demokratischer und rechtsstaatlicher Verfassungsstruktur in den internationalen Gemeinschaften, Berlin 1966, S. 1-104.

42 Hans Peter IPSEN, Europäisches Gemeinschaftsrecht, Tübingen 1972, S. 978.

43 Ders., Staatsrechtslehrer unter dem Grundgesetz, Tübingen 1993, S. 9 [zuerst erschienen in: Archiv für/des öffentliche(n) Rechts 97 (1972), S. 375-417].

44 Christian Tomuschat / Rainer Sснмidt, Der Verfassungsstaat im Geflecht der internationalen Beziehungen, Berlin 1977 sowie SteInBerger / KLein / ThüRER, Der Verfassungsstaat als Glied einer europäischen Gemeinschaft, Berlin 1990. Hierzu Hans Peter IpsEN, Die europäische Integration in der deutschen Staatsrechtslehre, in: Europarecht - Energierecht - Wirtschaftsrecht. Festschrift für Bodo Börner, Köln u.a. 1992, S. 163-177.

45 IPSEN, Europäisches Gemeinschaftsrecht, S. 717-720. 
tegrationsprozess als unumkehrbar angesehen wird, so haben sich doch im Laufe der Zeit gewisse nationalstaatliche Vorbehalte wieder verstärkt, unterstützt vor allem durch das Bundesverfassungsgericht ${ }^{46}$. Auffällig ist auch die aus der frühen Bundesrepublik überkommene und nun auch auf Europa ausgedehnte Orientierung auf Grundrechtsfragen ${ }^{47}$, eine am Ideal der parlamentarischen Gesetzgebung orientierte kritische Haltung gegenüber der ausufernden Rechtsetzung durch die Brüsseler Exekutive, eine oft wiederholte Rüge der zu geringen parlamentarischen Legitimation des Europarechts, ohne dass wirklich ernsthaft geprüft würde, wie eine Bevölkerung von rund 500 Millionen angemessen in einem arbeitsfähigen Parlament repräsentiert werden könne. So sind auch in der deutschen Staatsrechtslehre, parallel zu den anderen europäischen Mitgliedsländern, die skeptischen Stimmen gegen eine zu weit gehende »Verstaatlichung« der Europäischen Union samt ihrer Überwölbung durch eine echte Verfassung mit Grundrechts- und Organisationsteil in den letzten zwanzig Jahren lauter geworden.

Im Hintergrund dieser Debatte stehen die Spannungen zwischen »geschlossener« und »offener« Staatlichkeit, die sich in den Anfangsjahren der Republik noch an den Namen Schmitt und Smend festmachen ließen ${ }^{48}$, nun sich aber längst davon abgelöst haben. Während die einen unverändert am Staat logisch vorrangig vor seiner Formgebung durch die Verfassung festhalten und in ihm die Garantie von Freiheit und Sicherheit sehen und deshalb nicht selten die »Staatsvergessenheit» der Staatsrechtslehre rügen ${ }^{49}$, halten die anderen eher den Prozess der europäischen Integration, die Partizipation der EU-Bürger und das langsame Hineinwachsen in einen europäischen Verfassungsstaat für die modernere Perspektive. Die einen reklamieren Nüchternheit und Skepsis, die anderen Offenheit und Optimismus. Diese Optionen spiegeln sich auch in den unterschiedlichen wissenschaftlichen Akzenten: Betonung des Staatsrechts und Völkerrechts, verbunden mit einer die Staatssubstanz nicht gefährdenden Erweiterung durch Europarecht ei-

46 Ingo Winkelmann (Hg.), Das Maastricht-Urteil des Bundesverfassungsgerichts vom 12. Oktober 1993. Dokumentation des Verfahrens mit Einführung, Berlin 1994; Peter Hommelhoff / Paul KirchHof (Hg.), Der Staatenverbund der Europäischen Union, Heidelberg 1994.

47 IPSEN, Europäisches Gemeinschaftsrecht, S. 111.

48 Frieder GüNTHER, Denken vom Staat her. Die bundesdeutsche Staatsrechtslehre zwischen Dezision und Integration 1949-1970, München 2004.

49 Hierzu Helmut Schulze-Fielitz, Grundsatzkontroversen in der deutschen Staatsrechtslehre nach 50 Jahren Grundgesetz - in der Beleuchtung des Handbuchs des Staatsrechts -, in: Die Verwaltung 32 (1999), S. 241-282; zur angeblichen »Staatsvergessenheit« siehe etwa Josef IsENSEe / Paul KirchHof (Hg.), Handbuch des Staatsrechts, Bd. 2, Heidelberg ${ }^{32004, ~ § ~ 15, ~ R d N r . ~}$ 6-11; ders., Die Verfassung als Vaterland. Zur Staatsverdrängung der Deutschen, in: Armin Mohler (Hg.), Wirklichkeit als Tabu, München 1986, S. 11-35; Udo Di FABıo, Die Staatsrechtslehre und der Staat, Paderborn 2003; besonders grell derzeit Otto DePENHEUER, Selbstbehauptung des Rechtsstaates, Paderborn 2007. 
nerseits ${ }^{50}$, langfristige Verschmelzung der nationalen Rechtsordnungen in eine europäische Ordnung neuer Qualität andererseits ${ }^{51}$. Letzteres mag eine Auswanderung traditioneller Souveränitätselemente und damit langfristig auch Auflösung der herkömmlichen »Staatsrechtslehre« bedeuten, bevor die „Vereinigten Staaten von Europa« zu einem Verfassungsstaat herangereift sind und eine entsprechende europäisch-konstitutionelle Dogmatik entwickelt werden konnte. Die Fragen, wie ein Verfassungsstaat ohne homogenen »Demos« hinreichend demokratische Substanz gewinnen und eine verbindliche Rechtsordnung legitimieren, wie das Gleichgewicht zwischen den Staatsfunktionen, zwischen Zentralismus und Regionalismus erreicht werden kann, wie schließlich die Grundrechte wirksam geschützt werden können, seien der Zukunft überlassen ${ }^{52}$.

Nun sind allerdings die Tagungen der Staatsrechtslehrer kein genauer Indikator wissenschaftsgeschichtlicher Entwicklungen; die Thematik der Tagungen wird von Fall zu Fall beschlossen und hängt von den Präferenzen des jeweiligen Vorstands ab. Man muss deshalb, um ein Bild vom Werden des Europarechts im Kontext deutschen Staats- und Verwaltungsrechts zu gewinnen, die Lehrbücher, die Kommentare und vor allem die Zeitschriftengründungen in die Betrachtung einbeziehen.

Beginnt man mit den Lehrbüchern, dann ragt Hans Peter Ipsens monumentales, über 1000 Seiten umfassendes »Europäisches Gemeinschaftsrecht « von 1972 heraus $^{53}$. Auch wenn es kein Lehrbuch im strikten Sinn war, wie der Autor selbst betonte, war es jedenfalls die erste zusammenfassende Darstellung und Deutung des Rechtsgebiets in deutscher Sprache ${ }^{54}$, dicht gefolgt von dem ebenfalls umfassenden Lehrbuch von Léontin-Jean Constantinesco ${ }^{55}$. Im Aufbau folgte Ipsens Buch den juristisch einleuchtenden Schritten von den nationalen Verfassungs- und den zwischenstaatlichen Vertrags-

50 Prägnant Josef IsenseE, Staat und Verfassung, in: Handbuch, Bd. 2, Heidelberg ${ }^{3} 1994$, Rdnr. 13: »Der Staat gibt in der Integration seine Souveränität nicht preis.... Der Staat löst sich damit nicht auf, sondern passt sich den Herausforderungen der Gegenwart an «.

51 Peter HäBERLE, Europäische Verfassungslehre, Baden-Baden ${ }^{5}$ 2008; ders., Europäische Rechtskultur. Versuch einer Annäherung in zwölf Schritten, Baden-Baden 1994.

52 Michael StolleIs, Was kommt nach dem souveränen Nationalstaat? Und was kann die Rechtsgeschichte dazu sagen?, in: Adrienne Héritier / Michael Stolleis / Fritz Scharpf (Hg.), European and International Regulation after the Nation State, Baden-Baden 2004, S. 17-30; Michael Stolleis / Wolfgang Streeck (Hg.), Aktuelle Fragen zu politischer und rechtlicher Steuerung im Kontext der Globalisierung, Baden-Baden 2007.

53 IPSEn, Europäisches Gemeinschaftsrecht; hierzu die eingehende Besprechung von Ulrich EvERLING, Europäisches Gemeinschaftsrecht, in: Der Staat 13 (1974), S. 73-90.

54 Hans Peter Ipsen selbst spricht auf der ersten Seite seiner Darstellung (Europäisches Gemeinschaftsrecht) von der »Neuartigkeit der Materie und der Tatsache, daß sie in deutscher Sprache und aus einer Feder bisher nicht systematisch behandelt worden ist«. »Seine (sc. des Europarechts) Stellung in Forschung und Lehre ist angesichts dieser Neuartigkeit zu bestimmen« $(1 / 1)$.

55 Léontin-Jean Constantineso, Das Recht der Europäischen Gemeinschaften, Tübingen 1977. 
grundlagen und erörterte dabei die Kernfrage der Abgrenzung der Geltungsbereiche von Gemeinschaftsrecht und nationalem Recht - im Ergebnis mit der Annahme des klaren Vorrangs des Gemeinschaftsrechts auch vor nationalem Verfassungsrecht, allerdings begrenzt auf den Sektor der wirtschaftlichen Integration, wie sie damals angenommen wurde. Ipsen verstand die europäische Gemeinschaft noch als »Zweckverband«, der einer eigenen demokratischen Legitimation nicht bedurfte, gleichwohl aber eine eigene Rechtsordnung aus sich erzeugen konnte. Die vereinigten Regierungen bringen das neue Gebilde, ähnlich wie bei der Reichsgründung von 1870/71, in einem »Gesamtakt« hervor. Das Gebilde wird zwar kein Staat, ähnelt aber doch dem traditionellen Bundesstaat, der durch Souveränitätsverzichte der Einzelstaaten zustande kommt.

Dem folgte die Darstellung des institutionellen Aufbaus, einschließlich des Personals und der Finanzierung. Von da aus konnten die rechtlich relevanten Handlungen der Organe beschrieben werden, weiter der Aufbau der gesamten europäischen Rechtsordnung mit ihren grundlegenden Prinzipien des offenen Wettbewerbs, der Freizügigkeit, der Niederlassungs- und Dienstleistungsfreiheit, der Freiheit des Kapital- und Zahlungsverkehrs. Es folgen (Grund-)Rechte und Pflichten des »Marktbürgers«, schließlich die bis dahin erkennbaren zehn Tätigkeitsfelder des europäischen Marktes sowie ein rechtspolitischer Ausblick (§ 54).

Ipsens Lehrbuch blieb zunächst allein, während die Kommentare zu den Römischen Verträgen, den Bedürfnissen der Praxis folgend, sich ab 1960 kontinuierlich vermehrten ${ }^{56}$. Viele von ihnen waren Loseblattwerke ${ }^{57}$, die dem Rhythmus der Rechtsetzung rasch folgen konnten, aber auch entspre-

56 Ernst Wohlfarth / Ulrich Everling / Hans-Joachim Glaesner / Rudolf Sprung, Die Europäische Wirtschaftsgemeinschaft, Kommentar zum Vertrag, Berlin 1960; Hans vON DER GROEBen / Jochen Thiesing / Claus Dieter Ehlermann, Kommentar zum EU-/EG-Vertrag, 4 Bde, Baden-Baden ${ }^{6} 2003$ (Bd. 1-3) und 2004 (Bd. 4); Claus Dieter Ehlermann / Hans von Boeckh / Hans von DER Groeben, Handbuch des Europäischen Rechts, Baden-Baden (Loseblatt); Jürgen Schwarze, EU-Kommentar, Baden-Baden 2000; Carl Otto Lenz / Klaus Dieter BorchardT (Hg.), EU- und EG-Vertrag. Kommentar, Köln ${ }^{32003}$; Kay Hailbronner / Heinrich WiLms, Recht der Europäischen Union, Kommentar, Stuttgart (Loseblatt); Rudolf STreinz (Hg.), EUV/ EGV, Vertrag über die Europäische Union und Vertrag zur Gründung der Europäischen Gemeinschaft, München 2003; Eberhard Grabitz / Meinhard Hilf (Hg.), Das Recht der Europäischen Union, Kommentar, München (Loseblatt) 1983ff.; Rudolf Geiger, Kommentar zum EG-Vertrag, EUV, EGV: Vertrag über die Europäische Union und Vertrag zur Gründung der Europäischen Gemeinschaft, München ${ }^{4} 2004$; Christian CAlliess / Matthias Ruffert, Kommentar zu EU-Vertrag und EG-Vertrag, Neuwied 22002; Christian CALlies / Matthias Ruffert, EUV / EGV, Das Verfassungsrecht der Europäischen Union mit Europäischer Grundrechtscharta, Kommentar, Neuwied ${ }^{3} 2007$.

57 Eberhard Grabitz, EWG-Vertrag Kommentar (Loseblatt), München 1983ff. Vgl. dazu Ulrich Everling, Literaturbericht: Neue Kommentare zum EWG-Vertrag, in: Der Staat 24 (1985), S. 423-431. 
chend instabil und geschichtslos waren. Was nicht mehr gilt, wird entsorgt ${ }^{58}$. Die für den Praktiker unentbehrliche Aktualität, deren Vorzug es gerade ist, nicht mehr verarbeiten zu müssen, was nicht mehr gilt, erzeugt freilich auch methodisch einen angepassten Positivismus, der zwar horizontal-vergleichend, aber kaum jemals vertikal-historisch vertiefend arbeiten kann ${ }^{59}$. Das gleiche gilt für die ganz der Aktualität verschriebenen Case-Books der Rechtsprechung des EuGH ${ }^{60}$.

An den Universitäten und Fachhochschulen wuchs nun seit etwa 1970 ein großes Bedürfnis an Einführungslehrbüchern. Seit der Schaffung der »Wahlfachgruppen« in den Ausbildungsordnungen der Länder zur Juristenausbildung um 1971/72 gehörte Europarecht in den Kanon, und zwar in einer Wahlfachgruppe, die fast überall »Allgemeine Staatslehre, Völkerrecht, Europarecht « enthielt ${ }^{61}$. Bald begannen die Verlage flächendeckend Grundrisse, Kurzlehrbücher, »Lernbücher« und Fallsammlungen zum Europarecht anzubieten $^{62}$. Das Dutzend war rasch erreicht. Einige dieser Lehrbücher sind originell und von wissenschaftlichem Interesse ${ }^{63}$, andere führen lediglich in den positivrechtlichen Rahmen der europäischen Rechtsordnung ein und verzichten sowohl auf eine historische Einbettung des Einigungsprozesses wie auf rechtspolitische Empfehlungen ${ }^{64}$. Inzwischen gehört Europarecht zum Pflichtstoff des ersten juristischen Staatsexamens und die Studierenden werden ermahnt, nationales und europäisches Recht als Einheit aufzufassen. »Es

58 Michael Stolleis, Vom Verschwinden verbrauchten Rechts, in: Rainer Maria Kiesow / Regina Ogorek / Spiros Simitis (Hg.), Summa. Dieter Simon zum 70. Geburtstag, Frankfurt/Main 2005, S. 539-558.

$59 \mathrm{Zu}$ den späteren Kommentaren [auch zum eigenen: Christian CALliess / Matthias Ruffert (Hg.), Kommentar zum EU-Vertrag und EG-Vertrag, Neuwied 1999, München ${ }^{32006}$ ] nunmehr Christian CALliEss, Europarecht, in: Rechtswissenschaft und Rechtsliteratur im 20. Jahrhundert. Mit Beiträgen zur Entwicklung des Verlages C. H. Beck, München 2007, S. 1061-1096, etwa zu den Kommentaren von Jürgen Schwarze (Baden-Baden 2000) und Rudolf Streinz (München 2003).

60 Waldemar Hummer / Bruno Simma / Christopf Vedder, Case-Books der Rechtsprechung des EuGH, Baden-Baden 1984; Ute Mager / Danielle Herrmann, Höchstrichterliche Rechtsprechung zum Europarecht, München 2004; Hans Joachim SchüTz / Thomas BRuHA / Doris KöNIG, Casebook Europarecht, München 2004.

61 Neufassungen der VO über die Ausbildung und Prüfung der Juristen (JAPO bzw. JAO, JAG) in Württemberg v. 18.5.1971, Bayern v. 24.5.1972, Berlin v. 9.6.1972, Hamburg v. 10.7.1972, Niedersachsen v. 7.6.1972, Nordrhein-Westfalen v. 6.7.1972, Rheinland-Pfalz v. 21.6.1972, Schleswig-Holstein v. 25.5.1972. Die Bundesländer Bremen, Hessen und Saarland folgten kurz darauf. - Die Kombination mit der Allgemeinen Staatslehre, die eher zur Verfassungsgeschichte gepasst hätte, wurde allgemein als »nicht unbedingt glücklich« angesehen (so M. SCHRÖDER, JA-Sonderheft $11 »$ Wahlfachgruppen«, Berlin 1972, S. 69).

62 Ein Vorläufer war Christian Runge, Einführung in das Recht der Europäischen Gemeinschaften, München 1972, ${ }^{2} 1975$, eine Zusammenfassung von einführenden Aufsätzen in der Juristischen Schulung, später Helmut LECHELER, Einführung in das Europarecht, München ${ }^{2} 2003$.

63 Dies gilt besonders für Thomas Oppermann, Europarecht, München ${ }^{3} 2005$.

64 Vgl. Anm. 1. 
hilft nichts«, sagt heute ein jüngerer Europarechtler, Ulrich Haltern, in der Einleitung seiner europarechtlichen Vorlesung.

Zugleich mit den Vorlesungen und Grundrissen begannen auch die Qualifikationsschriften der Dissertationen und Habilitationen sich auf Europarecht auszurichten. Nachdem zwischen 1965 und 1969 die ersten Habilitationen erschienen waren (Wagner, Sattler, Zuleeg) ${ }^{65}$, ist die Zahl derartiger Arbeiten kontinuierlich angewachsen. Zahlreiche europarechtliche Schriftenreihen nehmen sie auf. In der Karlsruher Juristischen Bibliographie (KJB) haben sie eine eigene, gut gefüllte Rubrik. Tatsächlich ist das Europarecht »zu einem Motor der Rechtsentwicklung und damit auch des juristischen Büchermarktes geworden ${ }^{66}{ }^{6}$.

Ein zuverlässiger Indikator für die Neugründung eines »Fachs« ist seit dem 19. Jahrhundert das Erscheinen neuer Zeitschriften. Wenn das wissenschaftliche und (oder) juristisch-praktische Interesse stark genug und der Markt dafür »reif« ist, werden Zeitschriften gegründet - Pressefreiheit vorausgesetzt ${ }^{67}$. Was das Europarecht angeht, so bestätigt sich die nun schon mehrfach beobachtete Gründungsphase im Jahrzehnt zwischen 1960 und 1970. Zuvor hatte es nur das ab 1946 in Frankfurt erscheinende und von Wilhelm Cornides gegründete Europa Archiv gegeben ${ }^{68}$, die erste außenpolitische Zeitschrift, die später zum Organ der 1955 gegründeten Deutschen Gesellschaft für Auswärtige Politik wurde. Das Europa Archiv war und ist eine Fundgrube für den Integrationsprozess der Nachkriegszeit, gerade wegen seines Charakters als $» A r c h i v «{ }^{69}$. Eine juristische Fachzeitschrift im engeren Sinn wollte es jedoch nicht sein.

Dann richtete die Neue Juristische Wochenschrift ab 1963 eine bis heute regelmäßig wiederkehrende Rubrik zum Europarecht ein, beginnend mit

65 Helmut Wagner, Beschlussverfahren im Gemeinschaftsrecht, Köln 1965; Andreas SATtLer, Prinzip der »funktionellen« Integration, Göttingen 1967; Manfred ZuLEEG, Das Recht der Europäischen Gemeinschaften im innerstaatlichen Bereich, Köln u.a. 1969; siehe auch ders., Der Aufbau der Europäischen Gemeinschaften, die Rechtsakte ihrer Organe und die Souveränität der Mitgliedstaaten, in: Gustav-Stresemann-Institut (Hg.), Einführung in die Rechtsfragen der Europäischen Integration, Köln 1969, S. 33-41.

66 Christian Callies, Europarecht, S. 1070.

67 Michael Stolleis (Hg.), Juristische Zeitschriften. Die neuen Medien des 18.-20. Jahrhunderts, Frankfurt 1999; Michael Stolleis / Thomas Simon (Hg.), Juristische Zeitschriften in Europa, Frankfurt/Main 2006, beide Bände mit reichen nationalen und internationalen Literaturhinweisen. - Über ein »Zeitschriftenimperium« und aus ihm heraus nunmehr Herman WEBER, Juristische Zeitschriften des Verlages C.H. Beck, München 2007.

68 Zu Wilhelm Cornides (1920-1966) siehe Daniel Eisermann, Außenpolitik und Strategiediskussion. Die Deutsche Gesellschaft für Auswärtige Politik 1955 bis 1972, München 1999, S. 11-13. Heute: Internationale Politik - Europa Archiv, hg. v. Werner Weidenfeld, als Organ der Deutschen Gesellschaft für Auswärtige Politik e.V.

69 Siehe Philippe Alexandre, in: Michel Grunewald / Hans Manfred Bock (Hg.), Der Europadiskurs in den deutschen Zeitschriften (1945-1955), Bern 2001. 
einem Aufsatz von Ophüls ${ }^{70}$. Er schildert das Europarecht als ein »neuartiges Rechtsgebiet«, das ungeachtet seiner Aufteilung auf drei Verträge eine innere Einheit bilde. Er charakterisiert die Europäische Gemeinschaft als supranationales Gebilde, vergleichbar einem werdenden Bundesstaat, dessen Recht in Konkurrenzfällen dem nationalen Recht vorgehe. Auch für die nationale Gesetzgebung gelte - wie im Bundesstaat - der Grundsatz des gemeinschaftsfreundlichen Verhaltens ${ }^{71}$.

Bald darauf, 1966, begann die spezielle Pflege des Europarechts, und zwar mit der im Verlag C.H. Beck erscheinenden Vierteljahresschrift Europarecht (EuR). Sie erschien »in Verbindung mit der Wissenschaftlichen Gesellschaft für Europarecht « und wurde bis 1997 in Hamburg redigiert ${ }^{72}$. Die Liste der Herausgeber enthielt die bekanntesten Namen der Zeit ${ }^{73}$, neben Ipsen auch Konrad Zweigert, der im Geleitwort schrieb, die Zeit sei reif, »um in einer Zeitschrift von hohem wissenschaftlichen Niveau durch gezielte Programme die Diskussion bisher vernachlässigter Probleme zu fördern und die bereits erarbeiteten Ergebnisse zusammenzufassen und zu vertiefen ${ }^{74}$. Der Verlag verkaufte sie zwar 1978 an den Nomos-Verlag Baden-Baden, erwarb aber 1999 den Nomos-Verlag und mit ihm auch wieder die inzwischen vergrößerte und im Zweimonatsrhythmus erscheinende Zeitschrift ${ }^{75}$.

1974 trat ihr dann die Europäische Grundrechte-Zeitschrift (EuGRZ) zur Seite, eine alle zwei Wochen erscheinende Zeitschrift für rasche Informationsvermittlung aus dem Bereich der Grundrechte. Herausgegeben und redaktionell betreut wird sie von Norbert Paul und Erika Engel. Niveauvolle wissenschaftliche Beiträge, Urteilsabdrucke und -kommentare stehen nebeneinander. Die Zeitschrift hat sich, nicht zuletzt aufgrund ihrer Mehrsprachigkeit und ihres Sitzes in der Nähe von Straßburg, hohes Ansehen verschafft.

Erst 1990 trat in Deutschland noch eine weitere, auf das europäische Wirtschaftsrecht spezialisierte Zeitschrift auf, die Europäische Zeitschrift für Wirtschaftsrecht (EuZW), wohl auch um innerhalb des Verlagsangebots

70 Carl Friedrich OphüLs, Quellen und Aufbau des Europäischen Gemeinschaftsrechts, in: Neue Juristische Wochenschrift 37 (1963), S. 1697-1701 sowie den ersten Bericht der Wissenschaftlichen Gesellschaft für Europarecht, in: Neue Juristische Wochenschrift 37 (1963), S. 1713-1721.

71 So auch sehr früh Carl Friedrich OpHüLs, Juristische Grundgedanken des Schumannplans, in: Neue Juristische Wochenschrift 7 (1951), S. 289-292. Hierzu auch Friedrich August Frhr. von DeR Heydte, Schumann-Plan und Völkerrecht, in: Festschrift für Rudolf Laun, Hamburg 1953, S. 111.

72 Ihre Gründung wurde 1961 in Hamburg vorbereitet. Siehe Gert NICOLAYSEN / Hans Peter IPSEN, in: Jan Albers u.a. (Hg.), Recht und Juristen in Hamburg, Bd. II, Köln u.a. 1994, S. 417-433, hier: S. 431.

73 Bodo Börner, Hans Peter Ipsen, Joseph H. Kaiser, Walter Much, Carl Friedrich Ophüls, Walter Roemer, Reimer Schmidt, Walter Strauss, Konrad Zweigert.

74 Konrad Zweigert, Zum Geleit, in: Europarecht 1966, S. 1f.

75 Weber, Juristische Zeitschriften, S. 73f. Siehe auch Hans Peter Ipsen, Europarecht - 25 Jahrgänge 1966-1990, S. 324. 
eine Lücke zu schließen, die vor allem die europäischen Unternehmen und die Anwaltschaft, also die Praxis im weitesten Sinn betraf ${ }^{76}$. Sie konkurriert mit der seit 1989 erscheinenden Zeitschrift Europäisches Wirtschafts- und Steuerrecht (EWS), die im Verlag des »Betriebs-Berater« erscheint und eine vergleichbare Funktion auf europäischer Ebene erfüllt.

Auf der Seite der Wissenschaft kam 1994 noch ein von führenden Vertretern der Privatrechtsvergleichung in Verbindung mit Rechtsgeschichte herausgegebenes Organ hinzu, die Zeitschrift für Europäisches Privatrecht $(Z E u P)^{77}$. Rechtsgeschichte tritt in ihr wesentlich als Hintergrund der aktuellen Probleme europäischer Rechtsvereinheitlichung auf, gewissermaßen als Brücke zwischen dem kontinentalen »ius commune « und dem englischen »common law«. Die Zeitschrift kombiniert auf ansprechende Weise aktuelle Kolumnen, Aufsätze und Kommentare zum Stand des europäischen Privatrechts.

Die Zeitschrift für Europarechtliche Studien (ZEuS), seit 1998 an die Stelle des hauseigenen Organs des Europa-Instituts an der Universität des Saarlandes getreten, publiziert mehrsprachig und versucht, Wissenschaft und Praxis gleichermaßen zu erfassen, vor allem im Bereich des Medienrechts, der Menschenrechte und des Wirtschaftsrechts. Schließlich sei die seit 1966 erscheinende Vierteljahreszeitschrift integration des in Berlin ansässigen Instituts für Europäische Politik in Verbindung mit dem Arbeitskreises Europäische Integration e.V. erwähnt. Sie wird von dem Wiener Europarechtler Heinrich Schneider herausgegeben und von einem europäisch zusammengesetzten Redaktionskollegium betreut. Der Arbeitskreis, dem heute Rudolf Hrbek (Tübingen) vorsteht, vereint führende Europarechtler mit Vertretern anderer Disziplinen der Europawissenschaften.

Wie gerade die zuletzt genannten Beispiele zeigen, hängen die Gründungsvorgänge von Zeitschriften und europarechtlich engagierte Institutionen eng zusammen. So wuchs das Europa Archiv (1946 ff.) ab 1955 mit der Deutschen Gesellschaft für Auswärtige Politik (DGAP) zusammen ${ }^{78}$. An den beiden Zentren des Völkerrechts, dem Schücking-Institut in Kiel und dem Max-Planck-Institut in Heidelberg, nahmen die dort betriebenen Zeitschriften in wachsendem Umfang europarechtliche Themen auf, blieben aber im

76 Siehe Europäische Zeitschrift für Wirtschaftsrecht, in: Neue Juristische Wohenschrift 15 (1990), S. 965; Geleitwort, in: Europäische Zeitschrift für Wirtschaftsrecht 1 (1990) sowie WEBER, Juristische Zeitschriften, S. 148f.

77 Herausgeber sind Jürgen Basedow, Uwe Blaurock, Axel Flessner, Reiner Schulze, Reinhard Zimmermann.

78 Vorläufer der Deutschen Gesellschaft für Auswärtige Politik mit ihrem heute in Berlin residierenden Forschungsinstitut war das von Theodor Steltzer (1885-1967) 1952 in Frankfurt gegründete Institut für Politik und Wirtschaft, getragen von einer gleichnamigen Gesellschaft. Vgl. Theodor STeltzer, Sechzig Jahre Zeitgenosse, München 1966. 
Kern völkerrechtliche Institute. Klar fokussiert auf Europarecht war dann ab 1964 die Wissenschaftliche Gesellschaft für Europarecht ${ }^{79}$. Seit der Mitte der sechziger Jahre entstanden Universitätsinstitute für Europarecht, wie sie heute in vielfältigen Kombinationen und Benennungen an nahezu jeder Juristischen Fakultät bestehen ${ }^{80}$. Sie dokumentierten ihre Arbeit häufig durch Jahresberichte, Jahrbücher oder Schriftenreihen. Letztere nehmen die in Deutschland traditionell häufigen Dissertationen und Habilitationen auf. Unter den juristischen Fachverlagen sind es besonders die Häuser Heymanns, Nomos, C.H. Beck, Deutscher Fachverlag, Berliner Wissenschaftsverlag und Duncker \& Humblot, die sich des Europarechts annehmen.

Vergegenwärtigt man sich die Gründungsgeschichte aller dieser Institute und der dazugehörigen Publikationen, dann kommt immer wieder die Mitte der sechziger Jahre in den Blick, also die Phase des politisch gewollten Voranschreitens der europäischen Integration, maßgeblich betrieben von Walter Hallstein ${ }^{81}$, aber getragen von der Überzeugung der meisten verantwortlichen Staatsmänner, dass die wirtschaftliche Integration die Vorstufe einer weiter reichenden politischen Integration sein könne. Die französische »Politik des leeren Stuhls« unter De Gaulle hat zwar die Erweiterung der EWG verzögern können, wirkte sich aber nicht auf die in Gang gekommenen wissenschaftlichen Anstrengungen aus. Gerade in den Jahren 1969 bis etwa 1980 verzeichnet die Geschichte der Rechtswissenschaft die Etablierung des Europarechts. Man mag dies als Ausdruck einer gewissen »Pfadabhängigkeit«, eines wissenschaftlichen »Eigensinns« oder einer relativen Autonomie wissenschaftlicher Arbeit interpretieren. Für jüngere Autoren jener Jahre war ein Ausweis in Europarecht ausgesprochen karrierefördernd; das Fach wurde ohne weitere Begründung als »wichtig« angesehen, die Materie erforderte schon bald eine starke Spezialisierung und sie eröffnete internationale Kontakte, wie sie der älteren Generation in den fünfziger Jahren noch nicht zur Verfügung gestanden hatten.

Bei dieser Umorientierung der Rechtswissenschaft war es keineswegs ausgemacht, dass Europarecht eine Domäne des öffentlichen Rechts wer-

79 Tagung am 10./11.7.1964 (Referenten Ipsen, Bülow) - Siehe auch Ipsen, Haager Kongreß für Europarecht, in: Neue Juristische Wochenschrift 7 (1964), S. 342 mit Anm. 4.

80 Beispielsweise: Berlin (Humboldt-Universität: Walter-Hallstein-Institut für Europäisches Verfassungsrecht, Institut für Völker- und Europarecht; Freie Universität: Institut für Völkerrecht, Europarecht und ausl. Öff. Recht); Freiburg (Institut für öffentliches Recht, Abt. Europa- und Völkerrecht); Hamburg (Abt. Europäisches Gemeinschaftsrecht), Köln (Institut für das Recht der Europäischen Gemeinschaften); Leipzig (Institut für Völkerrecht, Europarecht und ausländisches öffentliches Recht); München (Forschungsstelle für das Recht der Europäischen Integration); Saarbrücken (Europa-Institut, seit 1951); Tübingen (Zentrum für europäisches Recht).

81 Walter Hallstein, Zu den Grundlagen und Verfassungsprinzipien der Europäischen Gemeinschaften, in: Festschrift für Ophüls, Karlsruhe 1965, S. 1-8; ders., Die Europäische Gemeinschaft, Düsseldorf / Wien 1965, S. 21-23. 
den sollte ${ }^{82}$. Die Anfänge der europäischen Integration waren gleichermaßen vom Völkerrecht, vom Außenhandelsrecht oder internationalen Wirtschaftsrecht $^{83}$, vom nationalen Kartell- und Wettbewerbsrecht sowie vom Staatsund Verwaltungsrecht bestimmt ${ }^{84}$. Betrachtet man etwa die mit Frankfurt in Beziehung stehenden Akteure (Hallstein, Böhm, Coing, Kronstein) mit ihren Schülern (Biedenkopf, Steindorff, Mestmäcker), dann stand die Herstellung eines geordneten freiheitlichen Marktes der Waren und Dienstleistungen im Vordergrund. Europarecht erschien als $»$ Mutation des Wirtschaftsrechts $«^{85}$. Die Staats- und Völkerrechtler betrachteten das neue Gebilde dagegen über die Rechtsformen des internationalen Rechts und die Kompetenzverlagerungen des Nationalstaats nach außen (Art. 59 Abs. 2, 24 Abs. 1 GG). Die Verwaltungsrechtler interessierten sich für die Rechtsformen der Intervention, etwa für die Konstruktion des europäischen Subventionsrechts. Dabei erwiesen sich die Bindungen an das Völkerrecht zunächst als zäher, was die Gründungsvorgänge durch Verträge, also das primäre Gemeinschaftsrecht, anging. Bei den Problemen der Binnengliederung und des institutionellen Ausbaus waren dagegen die Parallelen zum Staatsrecht deutlicher ${ }^{86}$. Schon bald stand aber fest, dass das von den europäischen Institutionen geschaffene (sekundäre) Recht eine Materie sui generis sein müsse. Je mehr dann die Europäische Wirtschaftsgemeinschaft Züge eines über den gemeinsamen Markt hinausgehenden politischen Zusammenschlusses annahm - zeichenhaft auch im Wandel der Titulaturen von der EWG bis zur EU -, desto deutlicher dominierte wieder das öffentliche Recht, und man begann mit Analogien zum Bundesstaat und seiner »Mehrebenenpolitik« zu arbeiten. Auch die von der nationalen Verfassungsgerichtsbarkeit ausgehenden Bremsungen, sei es mit Rücksicht auf die Grundrechte, sei es aus Sorge vor einer Aushöhlung der Substanz der nationalen Identität und Souveränität, waren im Kern staatsrechtlich gedacht.

Hinter diesen Zuordnungsschwierigkeiten standen sowohl wissenschaftsgeschichtliche »Pfadabhängigkeiten« als auch Schwierigkeiten in der Sache, ein völlig neuartiges inter- und transnationales Gebilde mit den hergebrachten juristischen Kategorien $\mathrm{zu}$ »begreifen«, also denkerisch zu fassen und über die begriffliche Zuordnung auch dogmatische Konsequenzen zu ziehen. Die Schwierigkeiten milderten sich, je deutlicher das Schwergewicht der In-

82 Hans Peter IPSEN, Die europäische Integration in der deutschen Staatsrechtslehre, in: Festschrift Bodo Börner, S. 163-177.

83 Georg ERLER, Grundprobleme des internationalen Wirtschaftsrechts, Göttingen 1956. Siehe auch ders., Internationales Wirtschaftsrecht, in: Strupp / Schlochauer, Wörterbuch des Völkerrechts, Bd. III, S. 862-874.

84 Eingehend hierzu Ipsen, Europäisches Gemeinschaftsrecht, S. 4f.

85 Ebd., S. 9.

86 Ebd., S. 7. 
stitutionen und des neu gesetzten europäischen Rechts wurden; denn nun waren die prinzipiellen Zweifel überwunden. Die Akteure verhielten sich zunehmend »positivistisch «, indem sie Auslegung von sekundärem Europarecht und von Entscheidungen des Europäischen Gerichtshofs betrieben sowie immanente Korrekturvorschläge vorlegten. An die Stelle des juristisch ausgebildeten politischen Beamten trat nun seit den siebziger Jahren mehr und mehr der Exeget an den Universitäten. Das Fach formte sich, bildete Einführungsliteratur, Lehrbücher und Fallsammlungen aus ${ }^{87}$ und es wurde vor allem Prüfungsfach. Letzteres ist erfahrungsgemäß das entscheidende Nadelöhr auf dem langen Weg von den ersten Pionierveranstaltungen bis zu einem anerkannten $» \mathrm{Fach} \ll^{88}$.

IV.

Ein »Fach«, so könnte man sagen, ist eine kommunikative Vereinbarung auf Zeit. Es ist ein Netzwerk herrschender Ansichten. Indem es von den durch Politik, Wirtschaft, Gesellschaft und Wissenschaft gemeinsam gesteuerten Prüfungsordnungen verbindlich gemacht oder wenigstens als Chance eröffnet wird, ist es präsent. Prüfungsämter, Lehrende und Lernende lenken die knappe Zeit des Studiums in Richtungen, von denen man annimmt, sie würden von international agierenden Anwälten »gebraucht«, seien im Kontakt der Behörden auf EU-Ebene »unverzichtbar« oder gehörten einfach deshalb auf die Agenda, weil die Zeit isolierter Nationalstaaten endgültig vorbei sei. Insofern gibt es Motivationsdruck aus verschiedenen Richtungen, sich der Materie anzunehmen. In der Geschichte der Rechtswissenschaft ist ein »Fach «, bei dessen Beschreibung man sich gerne des Wortes »Entwicklung « oder biologischer Metaphern bedient (Keim, Wachstum, Blüte, Frucht und Verfall), nicht nur ein Kopfprodukt der Gelehrten und es folgt auch weder system- noch evolutionstheoretischen Vorgaben. Zwar wird, was Europarecht bedeutet, permanent durch unzählige Sprechakte »weich« vermittelt, aber die harten treibenden Kräfte sind die Europapolitik der Mitgliedsländer einschließlich der ausgehandelten Vertragsdokumente, die normativen Setzungen der europäischen Exekutive und die Entscheidungen des Europä-

87 Siehe heute etwa Hans-Wolfgang ARNDT / Kristian FISCHER, Europarecht - 20 Fälle mit Lösungen, Heidelberg ${ }^{4}$ 2004; Astrid EPINEY, Europarecht: Fälle und Lösungen, Bern 2001; Matthias Pechstein / Christian Koenig, Entscheidungen des EuGH. Studienauswahl, Tübingen 22003; Stefan Pieper / Andreas Schollmeier / Dieter Krimphove, Europarecht - Ein Casebook, Köln 22000; SchÜTZ / BRUHA / KöNIG, Casebook Europarecht; Albrecht Weber / Tonio GAs, Fälle zum Europarecht, München ${ }^{2} 2003$.

88 Michael Stolleis, Wie entsteht ein Wissenschaftszweig? Wirtschaftsrecht und Wirtschaftsverwaltungsrecht nach dem Ersten Weltkrieg, in: Bauer / Czybulka / Kahl / Vosskuhle, Umwelt, Wirtschaft und Recht, S. 1-13. 
ischen Gerichtshofs sowie des Straßburger Gerichtshofs für Menschenrechte. Sie bieten das reale Material, indem sie in den Grenzen richterlicher Tätigkeit auslegen und verbindlich machen.

An der Herausbildung des »Feldes«, das weit über den Universitätsbetrieb hinausreicht, sind gerade im Europarecht nicht nur die Hochschullehrer, die Doktoranden und Studierenden beteiligt. Von Anfang an waren es »politische Professoren«, hohe Beamte der Ministerien des Äußeren, der Wirtschaft und der Finanzen, zunehmend auch der europäischen Institutionen, Richter und Anwälte, die das Terrain beherrschten. Diese Periode reicht etwa bis zum Abschluss der Römischen Verträge von 1957. Die Professoren kamen einige Jahre später, zwischen 1960 und 1965, und meist waren es Professoren mit einer besonderen Nähe zur Politik, also solche des öffentlichen Rechts, des Wirtschafts- und Finanzrechts sowie der Wirtschaftswissenschaften. Auffällig ist die lang andauernde Abstinenz der politischen Wissenschaft. Sie steckte freilich in den Gründerjahren des Europarechts selbst in einer Orientierungskrise und drohte sich zu spalten ${ }^{89}$.

Europarecht war also seit seinen Anfängen ein stark politikabhängiges Recht. Ohne Europarat, Montan-Union, Euratom, Europäische Wirtschaftsgemeinschaft samt Agrarmarkt, ohne deren Fortentwicklung in der Währungspolitik, Sozialpolitik, Asyl-, Flüchtlings- und Einwanderungspolitik, auf den Gebieten des Polizeirechts, der Strafverfolgung und des Rechtsschutzes, der Entwicklungspolitik und der gemeinsamen Außen- und Sicherheitspolitik wäre es nicht existent. Europarecht kann freilich nicht gänzlich auf seine instrumentelle Funktion reduziert werden. Schon seit den Römischen Verträgen war jeder Zuwachs an positivem Recht auch ein Ergebnis der kommunikativen Verständigung europäischer Juristen ${ }^{90}$. Sie alle brachten ihre historisch gewachsenen Standards der eigenen Rechtskultur, die dazugehörigen sprachlichen Eigentümlichkeiten sowie implizit auch die Vorstellungen über gerichtliche Kontrollen ein. Vertragstexte fallen bekanntlich sehr unterschiedlich aus, wenn der eine Partner ihn vor dem Hintergrund einer geschlossenen Kodifikation, der andere aber im Kontext eines flexiblen Case-Law formuliert. Trotz dieser Unterschiede bildeten sich jedoch historische und systematische Standards, denen sich eine okkasionell verfahrende Politik oder ein neues Mitglied der Europäischen Union letztlich fügen mussten. Es waren und sind dies die Mindeststandards des europäischen Rechtsstaats und Rechtsschutzes, der Vorrang grundrechtlicher oder grundrechtsartiger Verbürgungen vor einfachem Recht, das Prinzip der Öffentlichkeit bei

89 Wilhelm BLEEK, Geschichte der Politikwissenschaft in Deutschland, München 2001, S. 308-370.

90 Ingolf Pernice, Europawissenschaft oder Staatsrechtslehre? Eigenarten und Eigenständigkeit der Europarechtslehre?, in: Helmut Schulze-Fielitz (Hg.), Staatsrechtslehre als Wissenschaft. Die Verwaltung 7 (2007), S. 225-251. 
Normerlass und Normhandhabung sowie die legitimierende Rückbindung an die der Gemeinschaft zugrunde liegenden Verträge, die dem Ganzen eine »Verfassung " geben ${ }^{91}$. Für die Gründergeneration der Schumann, Monnet, de Gasperi, Adenauer, Hallstein, Mosler, Etzel, Ophüls, Groeben, Carstens, Everling, Ipsen und andere gab es über diese Mindeststandards hinaus einen idealistischen Überschuss. Es war die Generation, die zwei Weltkriege im Bewusstsein hatte und Frieden und Freiheit in einem geeinten Europa schaffen wollte. Europa lag am Boden, nun sollte es wirtschaftlich und politisch geeint werden. Westdeutschland strebte zum Westen, es wollte wieder als Teil der zivilisierten Menschheit anerkannt werden, und der Westen hatte ein Interesse daran, Deutschland wirtschaftlich und militärisch so einzubinden, dass es keine Bedrohung mehr darstellte. Diese doppelte Bindung hielt - trotz aller Krisen - bis zum Jahr 1989, mit dem aus Westeuropa schrittweise das ganze Europa wurde. Erst seither können wir mit vollem Recht sagen, wir sind »in Europa«.

91 Ingolf Pernice, The Treaty of Lisbon: Multilevel Constitutionalism in Action, in: The Columbia Journal of European Law 15 (2009), S. 349-407. 


\section{Autorenverzeichnis}

Dr. Kerstin Armborst-Weihs, Institut für Europäische Geschichte, Abteilung für Universalgeschichte, Alte Universitätsstraße 19, 55116 Mainz, Deutschland

Prof. Dr. Johannes Arndt, Westfälische Wilhelms-Universität Münster, Historisches Seminar, Domplatz 20-22, 48143 Münster, Deutschland

Prof. Dr. Ronald G. Asch, Albert-Ludwigs-Universität Freiburg, Historisches Seminar, Rempartstraße 15 - KG IV, 79085 Freiburg, Deutschland

Dr. Joachim Berger, Institut für Europäische Geschichte, Alte Universitätsstraße 19, 55116 Mainz, Deutschland

Prof. Dr. Irene Dingel, Institut für Europäische Geschichte, Abteilung für Abendländische Religionsgeschichte, Alte Universitätsstraße 19, 55116 Mainz, Deutschland

Prof. Dr. Wolfgang Harms, Ludwig-Maximilians-Universität München, Department I - Germanistik, Komparatistik, Nordistik, Deutsch als Fremdsprache, Schellingstraße 3 / RG, 80799 München, Deutschland

Dr. Karl-Heinz Lingens, Max-Planck-Institut für Europäische Rechtsgeschichte, Hausener Weg 120, 60489 Frankfurt/Main, Deutschland

Dr. Małgorzata Morawiec, Graduiertenkolleg »Die christlichen Kirchen vor der Herausforderung 〉Europa««, Staudingerweg 9, 55128 Mainz, Deutschland

Prof. Dr. Elisabeth Oy-Marra, Johannes Gutenberg-Universität Mainz, Institut für Kunstgeschichte, Binger Straße 26, 55122 Mainz, Deutschland

Dr. Ivan Parvev, Universität Sofia, Historische Fakultät, Sv. Kliment Ohridsky 15, Tzar Osvoboditel Blvd., 1504 Sofia, Bulgarien

Dr. Martin Peters, Institut für Europäische Geschichte, Alte Universitätsstraße 19, 55116 Mainz, Deutschland 
Prof. Dr. Matthias Schnettger, Johannes Gutenberg-Universität Mainz, Historisches Seminar, Abt. I: Neuere Geschichte, Saarstr. 21, 55122 Mainz, Deutschland

Prof. Dr. Michael Stolleis, Max-Planck-Institut für Europäische Rechtsgeschichte, Hausener Weg 120, 60489 Frankfurt/Main, Deutschland

Dr. Martin Wrede, Justus-Liebig-Universität Gießen, Historisches Institut, Otto-Behaghel-Str. 10, 35394 Gießen, Deutschland 


\section{Register}

Kursiv gesetzte Seitenangaben verweisen auf Anmerkungen, recte gesetzte auf den laufenden Text.

\section{Ortsregister $^{1}$}

\begin{tabular}{|c|c|}
\hline Afrika $19,43,105,135,172$ & Bern 12 \\
\hline Ägypten 141f., 193, 193 & Blenheim 37 \\
\hline Altdorf 43,43 & Böhmen 13f., 159, 242 \\
\hline Altona 165 & Bonn 222 \\
\hline $\begin{array}{l}\text { Amerika, Nordamerika, Vereinigte Staaten } \\
\quad \text { von Amerika 10,43,172,178, 183, } \\
\quad \text { 188, 202, } 205\end{array}$ & $\begin{array}{l}\text { Brabant } 158 \\
\text { Brest } 10 \\
\text { Britannien } \quad 59\end{array}$ \\
\hline Andalusien 105 & Brüssel $35,247,248 f$. \\
\hline Antwerpen $27,29,47$ & Budapest 12 \\
\hline $\begin{array}{l}\text { Aragon } 162 \\
\text { Arelat } 13\end{array}$ & $\begin{array}{l}\text { Bundesrepublik Deutschland 238, 240, } \\
\quad 240,243-246,249 \rightarrow \text { Deutschland }\end{array}$ \\
\hline Asien $\quad 43,67,74,135,172,193 f$. & Burgund 14,89 \\
\hline Augsburg $32,45,47,222$ & Byzanz 133f., 134, 230 \\
\hline Auschwitz 81 & \\
\hline Australien 172 & Cádiz 90, 105 \\
\hline Avignon 96 & Calais 147 \\
\hline & Cambridge 150 \\
\hline Baden-Baden 254 & China 13 \\
\hline Balkan $10,27,67,139 f$. & \\
\hline Baltikum $\quad 157,162$ & Dachau 225 \\
\hline Bamberg 107 & Dänemark $\quad 46,58,153 f ., 165,247$ \\
\hline Basel 12, 43, 187, 195f., 199 & Danzig 212 \\
\hline Bayern $90 \rightarrow$ Kurbayern & Den Haag $30,47,194,196,200,239-241,247$ \\
\hline Bayreuth $10,13,19$ & Deutsches Reich, Deutschland $8-10,14$, \\
\hline Belgrad 66,138 & $18,27-29,51,61,63,67,77,87,150$, \\
\hline Beneluxstaaten 244,246 & $\begin{array}{l}\text { 153f., 156, 167, 196, 198, 202, 208, } \\
212,212,219,234,239 \text { f., } 240,241,245\end{array}$ \\
\hline Bensheim 247 & $247,254,256,260 \rightarrow$ Bundesrepublik \\
\hline Berlin 255,255 & Deutschland \\
\hline
\end{tabular}

1 Das Lemma »Europa« wird wegen der häufigen Erwähnung im gesamten Band hier nicht geführt. 
Dresden 96

Edinburgh 231

Eisenburg $138 \rightarrow$ Vasvár

England 15, 27f., 35-37, 46, 59, 63, 70, 70, $71,75,89,95,142,147-153,155,157 \mathrm{f}$., 161f., 165, 198, 239, 240, 240, 245, 247

Erlangen $163,227,247 f ., 248$

Ferrara 89, 95

Fiesole 247

Finnland 13

Flandern 158, 162

Florenz 12, 85, 88f., 100, 247

Frankfurt 14, 32, 32, 45, 52, 94, 253, 255, 257

Frankreich 10-12, 14f., 18, 27f., 30, 33-35, $46,57,59,60,62,67 f ., 70-75,81,87,89$, 91, 95, 137, 139, 141f., 147, 149f., 152f., 158, 165, 192f., 196, 240, 240, 245, 247

Freiburg/Br. 225, 256

Galizien 198

Gallipoli 143

Genf 228

Genua 27

Gießen 222, 222

Gnesen 209

Göttingen 7, 163-165, 171

Großbritannien 15, 28, 36, 147-162, 196, 201

Großpolen 208

Haarlem 30

Habsburg 239

Hamburg 32f., 94, 171, 196, 241, 254, 254, 256

Heiliges Römisches Reich deutscher Nation, Altes Reich 19, 28, 73, 90, 152, $165,167,175 \rightarrow$ Deutsches Reich

Helmstedt 163

Helsingfors / Helsinki 197
Höchstädt $36 f$.

Irland 147-162, 247

Israel 59, 70, 190, 190

Istanbul 142

Italien $13-15,27 f ., 36,46,87-89,114,147$, $151,175,240$

Jankau 45

Jerusalem $16,48,190,190,230$

Karlowitz 140,140

Kastilien 46, 158, 162

Kent 159

Kiel $165,171,248,248,255$

Köln 7, 32, 46f., 196, 222-224, 247, 256

Königsberg 163

Konstantinopel 107, 131, 133f., 134, 135f., 138,142

Kopenhagen 196, 201

Kreisau 232

Kurbayern 37

Kurland 175

Kurpfalz 34, 36

Kursachsen $36,42,90$

Landshut 90, 93, 163

Lauenburg 58

Leiden 30

Leipzig 26, 32, 49, 51f., 163, 256

Lida 198

Litauen 212

London 26f., 35f., 36, 47, 79, 94, 136, 158, 196

Lotharingien 13

Lucca 175

Luxemburg 12, 237, 248

Lyon $11,47,89$

Maastricht 10

Madrid 57, 59, 79, 136, 151, 155f.

Magdeburg 49

Mähren 159 


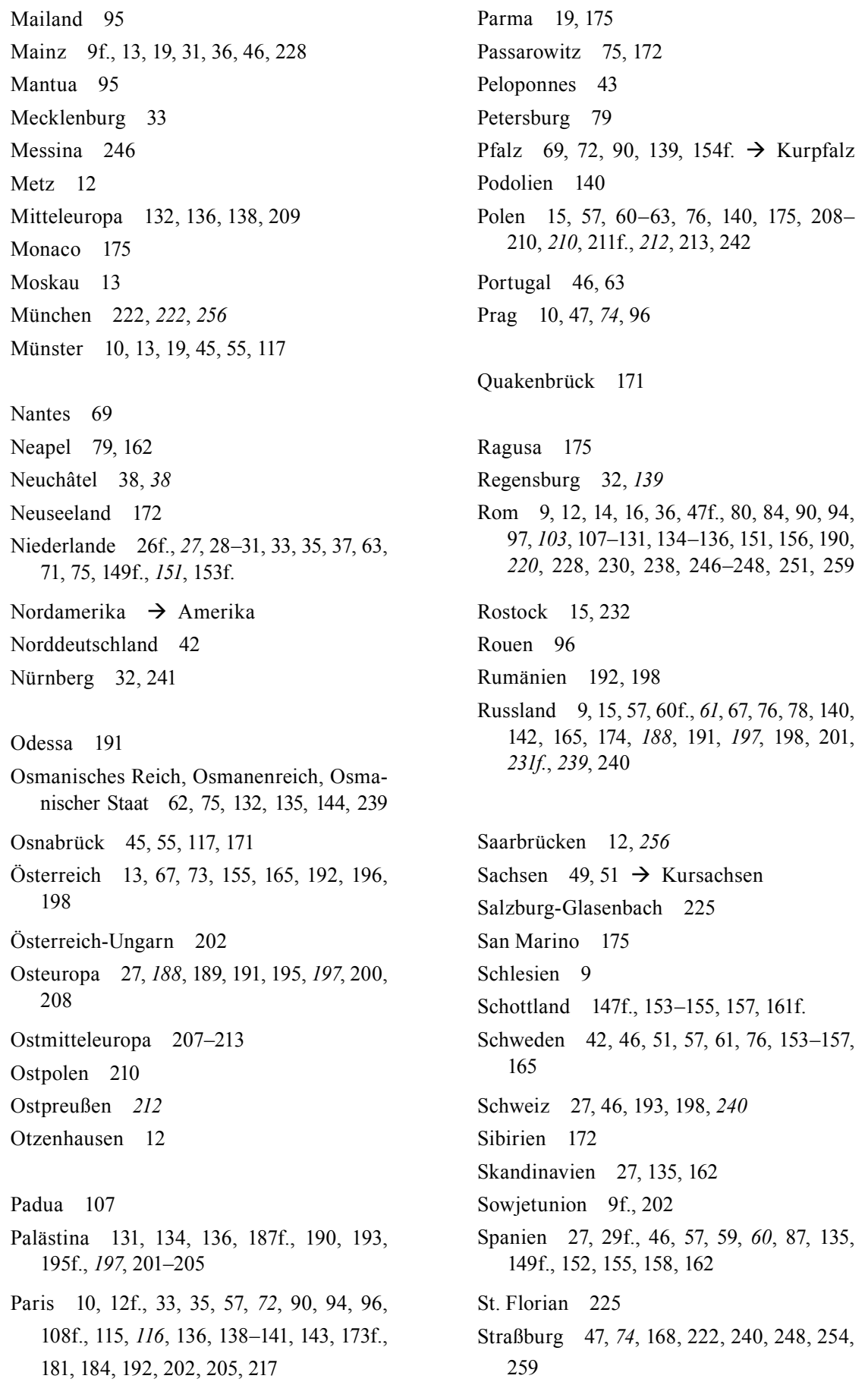


Südafrika 192

Südosteuropa 27, 131, 134-136, 138f., 139, $140,140,142,142$

Trier 12,14

Troja 109-111, 114

Tschechien 15

Tübingen 222, 222, 255, 256

Türkei 66f., 67, 143, 145, 179, 182-184, 186

Uganda 201

Ukraine 204

Ulster $157 f$.

Ungarn 27, 64, 89, 136, 165, 196, 198, 207, 209, 242

USA $\rightarrow$ Amerika

Utrecht 168f.
Vasvár $138 \rightarrow$ Eisenburg

Venedig 36, 47, 62, 134, 136, 140

Vereinigte Staaten von Amerika $\rightarrow$ Amerika

Versailles $63,80,90 \mathrm{f}$.

Westdeutschland 9,260

Whitehall $153,158,160$

Wien 12, 108f., 116, 136, 138, 140, 142, 155, 173, 180f., 184, 193, 196, 204, 225, 238,255

Wilna 198

Wittgenstein 9

Wolfenbüttel 47

Wuppertal 228

Württemberg 90

Zürich 240

\section{Personenregister $^{2}$}

Achenwall, Gottfried 163f., 164, 165, 165

Adenauer, Konrad 9, 245, 260

Aeneas 107-130

Alberoni, Giulio (Kardinal) $139 f$.

Albrecht VII. (Erzherzog von Österreich, Herzog von Burgund) 97

Aldegrever, Heinrich 93

Alençon, Duc d' $\rightarrow$ François-Hercule de Valois-Angoulême

Alexander VII. Chigi (Papst) 107

Alexander der Große 84, 209

Alkmene 83

Altrichter, Helmut 15

Anchises 110f.

Anna von Dänemark 148

Anne de Bretagne 96
Anne Stuart (Königin von Großbritannien) 36

Annius von Viterbo 87

Antaeus 98

Antrim, Earl of (der erste) $\rightarrow$ MacDonnell, Randall

Apollo 96

Argyle, Earl of $\rightarrow$ Campbell, Archibald

Arundell of Wardour, Thomas 149

Ascanius 111

Assmann, Aleida $\quad 81,101,103$

Atatürk, Mustafa Kemal 145

Athene 91

Atlas 96, 111

Augustin 231

Baader, Franz Xaver von 231

2 Autoren zeitgenössischer Literatur sind nur dann in das Register aufgenommen worden, wenn sie im Argumentationsverlauf eines Beitrags eine Rolle spielen. 


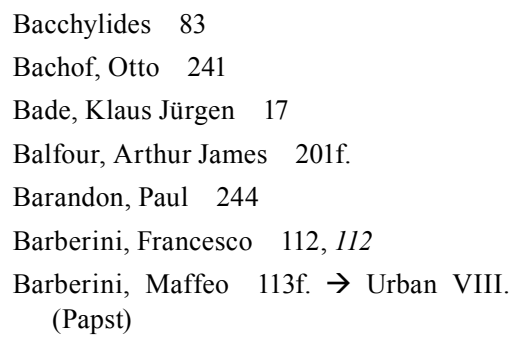

Brun, Charles le 91

Buchanan, George 149

Buckingham, Duke of $\rightarrow$ Villiers, George

Bülow, Arthur 256

Büsch, Johann Georg 171

Büsching, Anton Friedrich 165

Bulst, Neithard 11

Butler, James, Earl of Ormonde (der zwölfte) $160 \mathrm{f}$.

Butler, Thomas, Earl of Ossory (der sechste) 160

Calvin, Johannes 228

Campbell, Archibald, Earl of Argyle 157

Carl August (Herzog von Sachsen-Weimar) 99

Carstens, Karl 244, 260

Cartari, Vincenzo 94

Castelli, Francesco $\rightarrow$ Borromini, Francesco

Chamberlain, Joseph 201

Christian II. (Kurfürst von Sachsen) 90

Christian IV. (König von Dänemark und Norwegen) 154

Christina (Königin von Schweden) 91

Christus 84, 231

Chrobry, Boleslaw 14

Chruschtschow, Nikita Sergejewitsch 242

Churchill, John, Duke of Marlborough (der erste) 36

Churchill, Winston 240

Clairvaux, Bernhard von 231

Clemenceau, Georges Benjamin 77

Coing, Helmut 246, 257

Conring, Hermann 163

Constantinesco, Léontin-Jean 250

Conti, Natale 94

Cork, Earl of (der erste) $\rightarrow$ Boyle, Richard

Cornides, Wilhelm 253, 253

Cortona, Pietro da 112-116, 116

Corvinus, Matthias 89 
Cosimo I. de' Medici (Großherzog von Toskana) 89

Coudenhove-Kalergi, Richard Nikolaus Graf 211f., 239

Crawford, Earl of 156

Crome, August Friedrich Wilhelm 165, $170 f$.

Cromwell, Oliver 159

Danilevskij, Nikolaj Jakovlevic $210 \mathrm{f}$.

Dante Alighieri 84, 209

David (König von Juda und Israel) 84

David, Jacques Louis 100

Devereux, Robert, Earl of Essex (der zweite) $150 f$.

Devereux, Robert, Earl of Essex (der dritte) $151 f$.

Dibelius, Otto 233

Dickerhoff, Harald $218 f$.

Dietrichstein, Franziska 155

Dingel, Irene 21

Dipper, Christof 15

Doering-Manteuffel, Anselm 15

Dohm, Christian von 166

Dormeier, Heinrich 14

Duchhardt, Heinz 7, 7, 8-10, 12f., 18-21, 25, 55, 79f., 101, 104, 164, 207

Dudley, Robert, Earl of Leicester (der erste) 149

Dürer, Albrecht 93

Duplessis-Mornay, Philippe 149

Eichendorff, Joseph von 231

Elisabeth I. (Königin von England) 147-150

Elisabeth Stuart 154

Elsevier (Verleger- und Buchhandelsgeschlecht) 29

Engel, Erika 254

Ercole I. (Herzog von Ferrara) 89

Ercole II. (Herzog von Ferrara) 89

Essex, Earl of (der zweite) $\rightarrow$ Devereux, Robert
Essex, Earl of (der dritte) $\rightarrow$ Devereux, Robert

Etzel, Franz 244, 260

Eugen von Savoyen 36, 66

Euripides $83 \mathrm{f}$.

Europa 48-51

Eurystheus 83

Everling, Ulrich $244,244,260$

Farnese, Alessandro $\rightarrow$ Paul III.

Farnese, Pietro (Feldhauptmann) 110

Farnese, Ranuccio (Feldhauptmann) 110

Felten, Franz Josef 14

Ferdinand I. (römisch-deutscher Kaiser) 96

Ferdinand II. (römisch-deutscher Kaiser) 49

Ferdinand II. (Erzherzog von Österreich) 96

Ferro, Giovanni $111,113 \mathrm{f}$.

Feyel, Gilles 33

Ficino, Marsilio 89

Fitzgerald, George, Earl of Kildare (der 16.) 159

Flessner, Axel 255

Floris, Frans 93

Franckenberg, Friedrich Leutholf von 176

François-Hercule de Valois-Angoulême, Duc d'Alençon 89

Franz I. (König von Frankreich) 89, 95f., 169

Franz Wilhelm von Wartenberg (Fürstbischof von Osnabrück) 92

Freundorfer, Joseph (Bischof) 222

Fried, Johannes 14

Friedrich I. (Kurfürst von der Pfalz) 90

Friedrich II. (der Große, König von Preußen) 38

Friedrich III. (römisch-deutscher Kaiser) 90

Friedrich V. (Kurfürst von der Pfalz) 154 
Friedrich August I. (Kurfürst von Sachsen) 97

Friedrich Heinrich von Oranien (Statthalter der Niederlande) $\quad 46$

Friedrich Karl (Herzog von Württemberg) 90

Friedrich Wilhelm I. (Kurfürst von Brandenburg) 46

Friesenhahn, Ernst 241

Galen, Clemens August Graf von 231

Galerius Valerius Maximianus (römischer Kaiser) 84

Gasperi, Alcide de $\quad 245,260$

Gaulles, Charles de 10, 247, 256

Gebauer, Georg Christian 164

Georg Podiebrad (König von Böhmen) 209, 238

Georg I. (Fürst von Siebenbürgen) 46

Georg II. (König von Großbritannien) 73

Georg Ludwig (Kurfürst von Hannover) = Georg I. von Großbritannien 34

Georg Wilhelm (Herzog von BraunschweigLüneburg-Celle) 58

Gerhardt, Paul 231

Germania 50f.

Gerstenmaier, Eugen $\quad 232-235$

Giese, Friedrich 241

Giraldis, Giglio Gregorio 93

Goethe, Johann Wolfgang von 66, 231

Goffman, Daniel 144

Gonzaga, Anna Caterina 96

Grewe, Wilhelm Georg 182, 244

Grimmelshausen, Johann Jakob Christoph von 42

Groeben, Hans von der 244, 260

Grotius, Hugo $\quad$ 174, 176

Gruner, Wolf D. 15

Guadagnino $\rightarrow$ Valvassori,GiovanniAndrea

Günther, Karl Gottlob 173, 178f., 182,

Gustav II. Adolf (König von Schweden) 44-46, 91f., 154, 154, $155 f$.
Habermas, Jürgen 31

Häberlin, Franz Dominikus 73

Haedrich, Heinz 244

Hahn, Hans Henning 15

Hahn, Hugo J. 244

Haiminsfeld, Goldast von 31

Halder, Alois 218

Hallstein, Walter 244-247, 256f., 260

Haltern, Ulrich 253

Hamilton, James, Marquess of Hamilton (der zweite) 148, 148, 155, 155, 156

Hammer-Purgstall, Joseph von 66

Hardtwig, Wolfgang 11

Haupt, Heinz-Gerhard 15

Hebe (Göttin der ewigen Jugend) 83

Heffter, August Wilhelm 173f., 181, 183f.

Hegel, Georg Wilhelm Friedrich 182, 224

Hegewisch, Dietrich Hermann 171,171

Heide, Wilhelm 240

Heinrich II. (König von Frankreich) 89, 96, 137

Heinrich III. (König von Frankreich) 89

Heinrich IV. (König von Frankreich) 89, 92, 150f., 168, 209

Heinrich VII. (König von England) 89

Heinrich VIII. (König von England) 89, 148

Heinrich (König von Navarra) $\rightarrow$ Heinrich IV.

Henrietta Maria von Frankreich 148

Henry (Prince of Wales) 151

Herakles $\rightarrow$ Herkules

Hering, Loy (Thoman) 93

Herkules 79, 81-101, 103-105, 111

Hermes, Wilhelm 240

Herzl, Theodor 192f., 193, 194-196, 196, 197, 197, 198, $200 \mathrm{f}$.

Hess, Moses 190

Hildebrand, Klaus 14

Hildermeier, Manfred 17

Hoffman, Johann Jacob 43

Holbein, Hans 92 
Hollnsteiner, Johannes 225-227

Holtzendorff, Franz von $\quad 174,184 f$.

Howard, Thomas 148

Hoy, Nikolaus 116

Hrbek, Rudolf 255

Hudemann, Rainer 12

Hugo, Victor 209

Huntington, Samuel 132, 145

Hymnaeus 96

Ibrahim (osmanischer Sultan) 46

Ignatius von Loyola 92

Innozenz X. (Papst) 115-117

Ipsen, Hans Peter $\quad$ 247f., 250, 250, 251, 254, 254, 256, 260

Irsigler, Franz 14

Isabella Clara Eugenia von Spanien und Portugal (Statthalterin der span. Niederlande, Gemahlin Albrechts VII. von Österreich) 97

Isokrates 84

Jacobi, Erwin 241

Jakob I. (König von England) 148, 151, 153

Jean Paul 237, 237

Jellinek, Walter 241

Jesus Christus $\rightarrow$ Christus

Johann Georg I. (Kurfürst von Sachsen) $44,46,49$

Jörger, Johann Quintin 139

Joseph II. (römisch-deutscher Kaiser) 66, 189

Joseph August (Erzherzog von Österreich) 177

Julius II. (Papst) 108

Jupiter 96

Kaelble, Hartmut 17

Kamptz, Karl Albrecht von 181

Kant, Immanuel 231, 238

Kara Mustafa $65 f$.
Karl (Landgraf von Hessen-Kassel) 97

Karl I. (der Große, Kaiser) 168f., 171, 228, 228, 231

Karl I. (der Kühne, Herzog von Burgund) 89

Karl I. (König von England) 148, $155 f$.

Karl I. (der Kühne, Herzog von Burgund) 89

Karl V. (römisch-deutscher Kaiser) 90, 228, 131, 169

Karl VI. (römisch-deutscher Kaiser) 66, 90

Karl VII. (römisch-deutscher Kaiser) 73

Karl VIII. (König von Frankreich) 96

Karl XII. (König von Schweden) 91

Katharina von Aragon 148

Katharina von Medici $\quad 89,95$

Kaufmann, Erich 241, 244

Kelsen, Hans 243

Kessel, Jan van 48

Kierkegaard, Søren 231

Kildare, Earl of (der 16.) $\rightarrow$ Fitzgerald, George

Kilian, Bartholomäus 116

King, James 156

Klepsch, Egon Alfred 240

Klüber, Johann Ludwig $\quad$ 173, 183

Kluxen, Wolfgang $218 f$.

Knipping, Franz 18, 20

Koch, Christoph Wilhelm von 165, $168 f$.

Kochanowski, Jan 208

Kocka, Jürgen 17

Kogon, Eugen 240

Kolping, Adolph 231

Krause, Karl Christian Friedrich 238

Kronstein, Heinrich 257

Krug, Leopold 166

Krumeich, Gerd $\quad 15,76$

Labrot, Gérard 107

Langewiesche, Dieter 18

Languet, Hubert 149 
Laun, Rudolf von 241

Lednicki, Aleksander 212,212

le Fèvre, Raoul 84

Leibholz, Gerhard 241

Leibniz, Gottfried Wilhelm 231

Leicester, Earl of (der erste) $\rightarrow$ Dudley, Robert

Leicester, Earl of (der zweite) $\rightarrow$ Sidney, Robert

Lemoyne, François 91

Leo IV. (Papst) 110

Leo X. (Papst) 89, 110, $117 \rightarrow$ Medici, Giovanni de'

Leopold I. (römisch-deutscher Kaiser) 75, 138,138

Leslie, Alexander $154,154,156,156,157$

Leslie, Walter 155,155

Lessing, Gotthold Ephraim 231

Lippe, Karl 192

Lisola, Franz Paul von 57

Liszt, Franz von 184

Löbe, Paul 211

Loewenich, Walther von 227-231

Lorges, Gabriel de, Comte de Montgomery 150

Lortz, Josef 228

Loth, Wilfried 15

Lublinski, Samuel 187f., 194

Luder, Peter 90

Ludwig XIII. (König von Frankreich) 89

Ludwig XIV. (König von Frankreich) 19, $30,36,46,57,60,63,67-69,70,71-76$, 91, 139, 168

Ludwig XV. (König von Frankreich) 76, 91

Lünig, Johann Christian 32

Lukian von Samosata 89

Lundorp, Michael Caspar 31

Luther, Martin 56, 66, 77, 92, 136, 231

MacDonnell, Randall, Earl of Antrim 157159,161
Maderno, Carlo 112

Mahmud II. (osmanischer Sultan) 142

Malcolm III. (König von Schottland) 155

Margulies, Heinrich $205 f$.

Maria von Medici 96

Marlborough, Duke of (der erste) $\rightarrow$ Churchill, John

Marshall, George 240

Martens, Georg Friedrich von 165, 173, 178f., $182 \mathrm{f}$.

Max II. Emanuel (Kurfürst von Bayern) 34

Maximilian I. (römisch-deutscher Kaiser) 90, 92, 97

Maximilian II. (römisch-deutscher Kaiser) 96

Medici, Giovanni de’ $89 \rightarrow$ Leo X.

Megara 83

Mehlhausen, Joachim 218

Mehmed II. (osmanischer Sultan) 131, 135

Mehmed IV. (osmanischer Sultan) 66

Menger, Christian Friedrich 241

Merkur 94

Mestmäcker, Ernst-Joachim 257

Meusel, Johann Georg 165, 165, 167f., 170

Mickiewicz, Adam 208

Minerva 91

Monnet, Jean 15, 245, 260

Montgomery, Comtede $\rightarrow$ Lorges, Gabriel de

Morawiec, Małgorzata 13, 79, 80, 207

Moser, Johann Jacob 72, 164, 168f., 173$179,181 \mathrm{f}$

Mosler, Hermann $\quad 244,247,260$

Mülhaupt, Erwin 227-231, 232f.

Müller, Heribert 14

Müller, Ludwig 232

Mustafa II. (osmanischer Sultan) 140

Nanni, Giovanni da Viterbo $\rightarrow$ Annius von Viterbo

Napoleon I. Bonaparte (Kaiser der Franzosen) $56,141 \mathrm{f} ., 180,209$ 
Nau, Bernhard von 166

Nawiasky, Hans 241

Nebukadnezar (König von Babylon) 43

Neumann, Leopold 184

Niebuhr, Barthold Georg $\quad$ 171, 171

Nikolaus II. (russischer Zar) 209

Nora, Pierre 81,83

Nordau, Max 197

Novalis $215,217,217,224$

Omphale (lydische Königin) 85

Ompteda, Heinrich Ludwig von 178

O’Neill, Hugh, Earl of Tyrone (der zweite) $157 f$.

Ophüls, Carl Friedrich 243f., 244, 247, 247, 254, 254, 260

Ormonde, Earl of (der zwölfte) $\rightarrow$ Butler, James

Ossory, Earl of (der sechste) $\rightarrow$ Butler, Thomas

Ottheinrich (Kurfürst von der Pfalz) 90

Otto I. (der Große, römisch-deutscher Kaiser) 168

Otto III. (römisch-deutscher Kaiser) 14

Oxenstierna, Axel 156

Pacelli, Eugenio $219,222 \rightarrow$ Pius XII.

Pascal, Blaise 231

Pasmanik, Daniel 204

Patschovsky, Alexander 14

Paul III. (Papst) 107f., $110 \rightarrow$ Farnese, Alessandro

Paul V. (Papst) $110 \rightarrow$ Borghese, Camillo

Paul VI. (Papst) 230

Paul, Norbert 254

Penn, William 238

Peters, Hans 241

Petrarca, Francesco 85

Petrus 111, 114, 117

Petry, Ludwig 19

Philipp II. (König von Makedonien) 84

Philipp II. (König von Spanien) 29, 60
Piłsudski, Józef 211

Pindar 83

Pinsker, Leon 191

Pius II. (Papst) 131, 135

Pius V. (Papst) 147

Pius IX. (Papst) 220

Pius X. (Papst) 200

Pius XII. (Papst) 219-222, 222, 226, 226

$\rightarrow$ Pacelli, Eugenio

Plantin, Christopher 29

Plessis du, Armand-Jean, Duc de Richelieu (Kardinal) $\rightarrow$ Richelieu

Pölitz, Karl Heinrich Ludwig 180, 183, 186

Pöttering, Hans-Gert 240

Preziger, Ulrich 90

Prinzing, Günther 16

Prodikos von Keos 79, 83, 86

Pufendorf, Samuel 174

Raffael 109f.

Rahner, Karl 218, 230

Rakoczy, Georg (Fürst von Siebenbürgen) $\rightarrow$ Georg I.

Randel, Adolph Friedrich 165

Rassow, Peter 7

Recker, Marie Luise 15

Reinhard, Wolfgang 55, 108

Rej, Mikołaj 208

Remer, Julius August 165

Renaudot, Theophraste 33

Rich, Robert, Earl of Warwick (der zweite) 152

Richelieu, Kardinal de 33

Ripa, Cesare 48, 94, 98

Rist, Johann 50

Rodnick, David 241

Rösener, Werner 17

Romanow (russisches Adelsgeschlecht) 239

Rousseau, Jean-Jacques 238

Rudel, Elias 49, 49, 50

Rudolf II. (römisch-deutscher Kaiser) 43, 150 
Rückert, Friedrich 45

Saalfeld, Friedrich 180

Sabbatai Zwi 43

Sacchis, Andrea 112

Sack, Johann August 166

Saint-Pierre, Charles Irénée Castel de (Abbé de Saint-Pierre) 238

Saint-Simon, Henri de 238

Sallust 208

Salutati, Coluccio 85

Salviati, Francesco 110

Samson (Richter im Alten Israel) 84

Sandrart, Joachim von 97

Sattler, Andreas 253

Scheel, Walter 240

Schieffer, Rudolf 14

Schildt, Axel 215,218

Schiller, Friedrich 77

Schilling, Heinz 18

Schlegel, Friedrich 215

Schleiermacher, Friedrich Daniel Ernst 217, 231

Schlochauer, Hans-Jürgen 244

Schlözer, August Ludwig von $\quad$ 164, 166f.

Schmalz, Theodor von 173, 181, 183, 183

Schmelzing, Julius 183

Schmid, Günter 17

Schmidt, Georg 41

Schmidt, Patrick $81 f$.

Schmitt, Carl 249

Schneider, Christoph 217

Schneider, Heinrich 255

Schneider, Reinhold 231

Schneidmüller, Bernd $\quad 14,16$

Schubert, Friedrich Hermann 13

Schulze, Reiner 255

Schulze, Winfried 7,19

Schumann, Robert 245, 260

Schweitzer, Albert 231

Seipel, Ignaz 211

Selim II. (osmanischer Sultan) 43
Selim III. (osmanischer Sultan) 142

Seneca 84

Sidney, Philip 149, 149, 150

Sidney, Robert, Earl of Leicester (der zweite) 152

Sigismund (III.) Wasa (König von Polen und Schweden) 76

Sikorski, Władysław 212

Simson $\rightarrow$ Samson

Skrzyński, Aleksander 211

Smend, Rudolf 241, 249

Sokolov, Nahum 204

Spaak, Paul Henri 245f.

Spee, Friedrich 231

Spener, Philipp Jacob 231

Spengler, Oswald 211, 218, 225

Spieß, Karl-Heinz 14

Stalin, Josef 242

Stambolis, Barbara $\quad 8-10,12$

Steinbüchel, Theodor $\quad 222-225$

Steindorff, Ernst 257

Steltzer, Theodor 255

Stresemann, Gustav 211

Süleyman (Osmanenherrscher) 134

Süleyman I. (der Prächtige, osmanischer Sultan) $\quad 61,137$

Sully, Duc de $\rightarrow$ Béthune, Maximilien de

Sundhaussen, Holm 17

Süßmilch, Johann Peter 164

Suttner, Bertha von 194, 200

Syrkin, Nachman 204

Teti, Girolamo 113

Thamer, Hans-Ulrich 15

Thoma, Richard 241

Thünen, Johann von 166

Tieck, Ludwig 215

Tilly, Johann t'Serclaes von 45

Torstenson, Lennart 45

Towiański, Andrzej 210

Toze, Eobald $165 f$.

Turmair, Johannes (Aventinus) 90 
Turnus 115f.

Tyrone, Earl of (der zweite) $\rightarrow$ O'Neill, Hugh

Tysczegieski, Jakób 209

Urban VIII. (Papst) 111, 111, 113, 113, 114f., $117 \rightarrow$ Barberini, Maffeo

Valvassori, Giovanni Andrea 93

Vattel, Emer de 179

Vergil 109f., 113f., 117

Viktor Emanuel II. (König von Sardinien) 173

Villiers, George, Duke of Buckingham 158

Wagner, Helmut 253

Wallenstein, Albrecht Wenzel Eusebius von 155

Wallerstein, Immanuel 27

Walsingham, Francis 150

Warwick, Earl of (der zweite) $\rightarrow$ Rich, Robert
Weber, Hermann $\quad$ 10, 19

Weinfurter, Stefan 14

Weisbrod, Bernd 15

Werfel, Franz 225

Wichern, Johann Hinrich 234

Wieland, Christoph Martin 99

Wilhelm I. (Fürst von Oranien) 149

Wilhelm II. (deutscher Kaiser) 201

Wilhelm III. (König von England) 35, 149

Wilson, Woodrow 202, 239

Wolf, Ernst 218

Zech, Bernhard von 176

Zeus 83

Zimmermann, Reinhard 255

Zinzendorf, Nikolaus Ludwig Graf von 231

Zuleeg, Manfred 253

Zweig, Arnold 205

Zweigert, Konrad 254, 254

Zwingli, Huldrych 92 